DEPARTMENT OF THE INTERIOR

U. S. GEOLOGICAL SURVEY

\title{
Geotechnical description of \\ Yellow Sea sediments \\ with some preliminary geological interpretations
}

by

James S. Booth ${ }^{1}$ and William J. Winters ${ }^{1}$

Open-File Report 89-149

This report is preliminary and has not been reviewed for conformity with U.S. Geological Survey editorial standards and stratigraphic nomenclature. Any use of trade names is for descriptive purposes only and does not imply endorsement by the USGS.

${ }^{1}$ Woods Hole, Massachusetts 02543 


\section{GEOTECHNICAL DESCRIPTION OF YELLOW SEA SEDIMENTS}

with some preliminary geological interpretations

James S. Booth and William J. Winters

\section{INTRODUCTION}

In August 1985, core samples and high-resolution seismic reflection data were collected in the Yellow Sea near and south of the Shandong Peninsula (Figure 1). As one part of this study, a geotechnical investigation was conducted to establish the basic engineering properties of the sediment, to help identify and analyze potential geohazards, and to supply additional data pertinent to the investigation of geologic processes in the study area. The following is a preliminary report on that work; it provides a general summary of the results of the geotechnical laboratory tests, a brief engineering description of the Yellow Sea sediments, and initial interpretations of the geologic environment as inferred from the geotechnical data.

This investigation received its primary support from the National Science Foundation and the Academia Sinica of the Peoples Republic of China through the Woods Hole Oceanographic Institution (John D. Milliman, Principal Investigator) and the Institute of Oceanology at Qingdao (Professor Yun-shan Qin, Chief Scientist).

We most gratefully acknowledge the invitation, support and cooperation of John Milliman. We also acknowledge the assistance and cooperation of Charles A. Nittrouer and David J. DeMaster of North Carolina State University, also Principal Investigators in the research program, and of their students, Clark Alexander and Ross Elliott, whose help during the field work was invaluable.

\section{METHODS}

\section{Field}

The sampling program was carried-out August 12-18, 1985 aboard the R/V Science 1 , a research vessel operated by the Institute of Oceanology for Academia Sinica. Eleven Kasten cores and eight box cores were recovered from a total of 9 stations (Figure 1). The Kasten cores were tested for vane shear strength at sea and subsampled for later, onshore laboratory index property testing (i.e., water content, liquid limit, plastic limit, and grain specific gravity); the box cores were subcored with 10-cm I.D. poly-vinyl-chloride (PVC) pipe and stored for later triaxial and consolidation testing. Core and site information are provided in Table 1. 


\section{CONTENTS}

Introduction 1

Methods 1

field 1

laboratory 3

Results and Interpretations 3

shear strength 3

sensitivity 4

index properties $\quad 5$

consolidation states and properties $\quad 6$

$\begin{array}{ll}\text { strength parameters } & 8\end{array}$

Summary $\quad 8$

geological $\quad 8$

geotechnical $\quad 9$

$\begin{array}{ll}\text { References } & 9\end{array}$

$\begin{array}{ll}\text { Appendices } & 17\end{array}$

$\begin{array}{ll}\text { A: nomenclature and symbols } & 17\end{array}$

B: results of vane shear and index property tests 20

tabular data 21

vane shear strength profiles $\quad 27$

liquid limit, plastic limit, and water content profiles 38

water content, bulk density, porosity, and grain specific gravity profiles $\quad 58$

C: results of constant-rate-of-strain consolidation tests 78 $\begin{array}{ll}\text { tabular data } & 79\end{array}$

unedited test plots $\quad 81$

D: results of consolidated-isotropic-undrained triaxial tests 237

tabular data 238

unedited individual test plots $\quad 240$

unedited multiple test plots $\quad 260$ 
Table I

Core listing and station data

\begin{tabular}{|c|c|c|c|c|}
\hline Core & Length (m) & Latitude & Longitude & Water Depth (m) \\
\hline $\begin{array}{l}K C-1 A \\
K C-1 B\end{array}$ & $\begin{array}{l}1.05 \\
2.25\end{array}$ & $\begin{array}{c}34^{\circ} 27.95^{\circ} \mathrm{N} \\
"\end{array}$ & $122^{\circ} 29.98^{\circ} \mathrm{E}$ & 59 \\
\hline $\begin{array}{l}\mathrm{BC}-4 \\
\mathrm{KC}-4\end{array}$ & $\begin{array}{l}0.50 \\
2.53\end{array}$ & $\begin{array}{c}35^{\circ} 05.51^{\circ} \mathrm{N} \\
\end{array}$ & $123^{\circ} 33.41^{\circ} \mathrm{E}$ & $\begin{array}{l}72 \\
"\end{array}$ \\
\hline $\begin{array}{l}\mathrm{BC}-5 \\
\mathrm{KC}-5\end{array}$ & $\begin{array}{l}0.67 \\
1.99\end{array}$ & ${ }^{35^{\circ}} 30.00^{\circ} \mathrm{N}$ & $123^{\circ} 53.00^{\circ} \mathrm{E}$ & $\begin{array}{l}79 \\
"\end{array}$ \\
\hline $\begin{array}{l}\mathrm{BC}-6 \\
\mathrm{KC}-6\end{array}$ & $\begin{array}{l}0.67 \\
2.92\end{array}$ & $\underset{n}{35^{\circ}} \underset{43.00^{\circ} \mathrm{N}}{ }$ & $\begin{array}{c}123^{\circ} 11.37^{\circ} \mathrm{E} \\
\mathrm{n}\end{array}$ & $\begin{array}{l}73 \\
"\end{array}$ \\
\hline $\begin{array}{l}\mathrm{BC}-7 \\
\mathrm{KC}-7 \mathrm{~A} \\
\mathrm{KC}-7 \mathrm{~B}\end{array}$ & $\begin{array}{l}0.65 \\
1.63 \\
3.04\end{array}$ & $\begin{array}{c}36^{\circ} 56.20^{\circ} \mathrm{N} \\
" \\
"\end{array}$ & $\begin{array}{c}123^{\circ} 00.80^{\circ} \mathrm{E} \\
" \\
"\end{array}$ & $\begin{array}{l}28 \\
" \\
"\end{array}$ \\
\hline $\begin{array}{l}B C-8 \\
K C-8\end{array}$ & $\begin{array}{l}0.68 \\
3.02\end{array}$ & $\begin{array}{c}36^{\circ} 43.32^{\prime} N \\
\end{array}$ & $\underbrace{123^{\circ}} 00.00^{\circ} \mathrm{E}$ & $\begin{array}{c}34 \\
"\end{array}$ \\
\hline $\begin{array}{l}\mathrm{BC}-9 \\
\mathrm{KC}-9\end{array}$ & $\begin{array}{l}0.65 \\
1.93\end{array}$ & ${ }^{36^{\circ}} \underset{1}{25.00} \mathrm{~N}$ & $\begin{array}{c}123^{\circ} 00.00^{\circ} \mathrm{E} \\
\end{array}$ & $\begin{array}{l}66 \\
"\end{array}$ \\
\hline $\begin{array}{l}B C-10 \\
K C-10\end{array}$ & $\begin{array}{l}0.65 \\
2.32\end{array}$ & $\begin{array}{c}37^{\circ} 31.33^{\prime} \mathrm{N} \\
\end{array}$ & 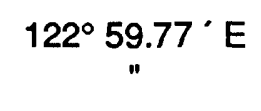 & $\begin{array}{c}54 \\
"\end{array}$ \\
\hline $\begin{array}{l}\mathrm{BC}-11 \\
\mathrm{KC}-11\end{array}$ & $\begin{array}{l}0.65 \\
1.27\end{array}$ & $\begin{array}{c}36^{\circ} 07.61^{\prime} \mathrm{N} \\
\end{array}$ & $\begin{array}{c}121^{\circ} 49.08^{\circ} E \\
\end{array}$ & $\begin{array}{c}38 \\
"\end{array}$ \\
\hline
\end{tabular}

Undrained shear strength $\left(S_{u}\right)$ was measured at sea with a motorized vane shear device. The four-bladed, $12.7-\mathrm{mm}$-square vane was inserted normal to the long direction of the core and rotated at approximately $84 \% \mathrm{~min}$. Measurements were made at $25 \mathrm{~cm}$ intervals beginning at $50 \mathrm{~cm}$ below the top of the core (the upper $50 \mathrm{~cm}$ was removed for radiometric dating). Although the North Carolina State University Kasten corer (Kuehl and others, 1985) minimizes mechanical disturbance, some disturbance probably took place during coring due to the general softness of the sediment. Thus, because the sediments are fine-grained, the strength values reported herein are probably less than the in-situ values. The inserted vane was rotated $360^{\circ}$ after the initial failure and the remolded strength, $S_{u r}$, was measured. The third vane shear strength parameter, sensitivity $\left(S_{t}\right)$, which is the "natural" shear strength to remolded shear strength ratio, was also calculated. Subsamples were taken from the location of the vane measurement for later index property testing. The subsamples were placed in plastic bags, sealed, and stored in capped core liner sections. 


\section{Laboratory}

The geotechnical index property tests were conducted as indicated:

1) Water content ( $w$ ) was measured in accordance with standard test method D2216-80 of the American Society for Testing and Materials (ASTM, 1985), except that the samples were dried at $50^{\circ} \mathrm{C}$.

2) Liquid limit $\left(w_{L}\right)$ values were determined by the cone penetrometer method (standard test BS 1377 of the British Standards Institution).

3) Plastic limit $\left(w_{P}\right)$ was measured in accordance with standard test method D4318-84 (ASTM, 1985).

4) Grain specific gravity $\left(G_{S}\right)$ measurements were made with an air-comparison pycnometer. The sample chamber was put under a vacuum, then purged with helium.

From these parameters, Plasticity Index $\left(I_{P}\right)$, Liquidity Index $\left(I_{L}\right)$, bulk density $\left(\rho_{t}\right)$, void ratio $(e)$, and porosity $(n)$ were calculated. All index property data were salt-corrected using a salinity of $35^{\circ} \% 0$.

Constant-rate-of-strain consolidation tests were performed at the top, middle, and bottom of each subcore. Standard test method D4186-82 (ASTM, 1985) was used. The maximum past stress experienced by the sample $\left(\sigma_{v m}^{\prime}\right)$, compression index $\left(C_{c}\right)$, coefficient of consolidation $\left(c_{v}\right)$, and coefficient of permeability $(k)$ were derived from the test data.

Consolidated, undrained triaxial tests were conducted on selected subcores. Because these PVC cores were relatively short, it was necessary to use small specimens ( $35 \mathrm{~mm}$ diam. $\times 70 \mathrm{~mm}$ length) in the triaxial testing. The method used was based on the ASTM (1985) standard test for unconsolidated, undrained compressive strength (D2850-82). The consolidation stress levels used were (1) assumed in situ stress, (2) $70 \mathrm{kPa}$, (3) $140 \mathrm{kPa}$, and (4) $210 \mathrm{kPa}$. Shearing was accomplished at a rate of $0.15 \mathrm{~mm} / \mathrm{min}$. During the tests, data were collected automatically by an HP-85 computer-scanner system. From the basic data set, the angle of internal friction with respect to effective stress $\left(\sigma^{\prime}\right)$, effective stress cohesion $\left(c^{\prime}\right)$, percent strain at failure, undrained shear strength ( $q_{\max }$ ), and other strength, stress, and strain parameters were determined.

Details of all testing procedures are given in Winters (1988).

\section{RESULTS AND INTERPRETATIONS}

\section{Shear Strength}

The sediments are extremely weak. The highest undrained vane shear strength $\left(S_{u}\right)$ measured was $6.6 \mathrm{kPa}$ (Table 2, Appendix B)) and about one-fifth of the 68 samples possessed strengths below the threshold of measurement of the vane shear apparatus 
(i.e., $0.2 \mathrm{kPa}$ ). Similarly, four-fifths of the attempts to measure remolded strength were unsuccessful. The down-core strength profiles (Figure 2) show a tendency for $S_{u}$ to increase with subbottom depth. The predicted strength profile (prediction based on the assumption that the sediments are normally consolidated, and therefore have an $\mathrm{S}_{\mathrm{u}} / \sigma^{\prime} \mathrm{v}$ value of approximately 0.24 ) for each of the selected cores is plotted along with the measured profile. The agreement between the two plots is reasonable in each case, which, again, implies a depositional environment (i.e., net sediment accumulation) or, at least, an environment of nonerosion.

Table 2

Vane shear strength and index property data summary

\begin{tabular}{|c|c|c|c|c|}
\hline$\underset{\text { natural shear strength }\left(S_{u}\right)[\mathrm{kPa}]}{\text { Property }}$ & $\frac{\text { Measurements }}{54^{*}}$ & $\frac{\text { Minimum }}{<0.2^{\star \star}}$ & $\frac{\text { Average }}{<3.0^{\star \star *}}$ & $\frac{\text { Maximum }}{6.6}$ \\
\hline sensitivity $\left(S_{t}\right)$ & $14 \dagger$ & 1.6 & $>3.6+t$ & $>6.3 \mathrm{t \dagger}$ \\
\hline $\begin{array}{l}\text { natural water content }(w)[\%] \\
\text { grain specific gravity }\left(G_{S}\right)\end{array}$ & $\begin{array}{l}100 \\
100\end{array}$ & $\begin{array}{r}32 \\
2.65\end{array}$ & $\begin{array}{r}68 \\
2.68\end{array}$ & $\begin{array}{r}144 \\
2.73\end{array}$ \\
\hline bulk density $\left(\rho_{t}\right)\left[\mathrm{g} / \mathrm{cm}^{3}\right]$ & 100 & 1.35 & 1.64 & 1.93 \\
\hline porosity $(n)[\%]$ & 100 & 45 & 62 & 79 \\
\hline liquid limit $\left(w_{L}\right)[\%]$ & 100 & 32 & 58 & 102 \\
\hline plastic limit $\left(w_{P}\right)[\%]$ & 100 & 18 & 25 & 36 \\
\hline plasticity index $\left(I_{p}\right)[\%]$ & 100 & 11 & 33 & 71 \\
\hline liquidity index $\left(I_{L}\right)$ & 100 & 0.67 & 1.26 & 2.03 \\
\hline
\end{tabular}

* In 14 of 68 tests the sediment was too weak for accurate strength determination with the vane shear apparatus

** $0.2 \mathrm{kPa}$ is the assumed limit of accurate measurement

*** Values below threshold were not used in the calculation. Therefore average is actually less than 3.0 † strength below measurement threshold in 54 of 68 tests

t† Values below threshold were not used, so numbers represent minima

From a geotechnical perspective, the strength data indicate that these sediments are "very soft" $\left(S_{u} \leq 12.2 \mathrm{kPa}\right)$ according to classification of Terzaghi and Peck (1967).

\section{Sensitivity}

The ratio of "natural" undrained shear strength to remolded shear strength is termed sensitivity $\left(S_{t}\right)$; it is a measure of the strength lost by a sediment when its basic structure has been destroyed. In the majority of cases, remolded shear strength was too low to be measured accurately: only 14 sensitivity determinations were possible, and most of these came from three cores (Table 2). For this reason, and because not even an approximate value can be assigned to the mean or range, sensitivity will not be discussed. 


\section{Index Properties}

Natural water content $(w)$, grain specific gravity $\left(G_{S}\right)$, liquid limit $\left(w_{L}\right)$, and plastic limit $\left(w_{P}\right)$, and related properties (bulk density $\left(\rho_{t}\right)$, porosity $(n)$, plasticity index $\left(I_{P}\right)$ and liquidity index $\left(I_{L}\right)$ ) constitute the suite of index properties for this study. With the exception of grain specific gravity, all of these properties vary over a considerable range (Table 2, Appendix B). In general, this implies a highly variable texture and (or) mineralogy within this basically fine-grained sediment.

Variation in the natural water content of these sediments (32\% to $144 \%)$ is particularly conspicuous. Because vane shear strengths are uniformly low throughout the cores, and because all cores represent only the upper few meters of sediment, variable degrees of compaction are apparently not responsible for the wide range in water contents. Thus, an environment characterized by a broad range in sediment texture is indicated. Moreover, the average $w$ of $68 \%$ suggests that silt is a prominent size class because clay-dominated fine-grained sediment ususally has a much higher water content. Spatially, as shown in Figure 3, the higher water content values are associated with the deeper, more distal core sites (with respect to presumed primary point source: the mouth of the Yellow River (Huanghe)). This implies that the sediment texture becomes finer in the offshore direction. The sediment grain-size distribution map of Milliman and others (1985) and the water content isopleth map of this study (Figure 3) are, in fact, similar in the patterns they show. The higher water contents are associated with the finer grain sizes.

There is a tendency for water content to decrease down core, which is the expected trend in any accumulating sediment column below the level of mobil (current-worked) sediment and (or) zone of bioturbation. This gradual dewatering is a response to the ever-increasing degree of compaction upon burial. The index properties that are related to water content in a fully water-saturated sediment (i.e., no gas), specifically bulk density and porosity, display similar variability and trends (see Appendix A), and at average values of 1.64 and $62 \%$, respectively, also suggest that silt is an important size class.

The same basic implications with regard to sediment grain size are present in the Atterberg limits data. Both liquid and plastic limit vary over a wide range (Table 2) and thus suggest a wide range in texture and, possibly, mineralogy. As shown on the composite plasticity chart (Figure 4), however, all the sediments can be basically classified as clays of medium to high compressibility (engineering classification: $\mathrm{CL}, \mathrm{CH}$ ) where, in the engineering sense, "clays" refers to any fine-grained sediment whose behavior is affected by clay minerals. The exact percentages of silt and clay in the textural sense is not known. As with the water contents and related data, plasticity is highest in the samples from the sites in deeper water and probably reflects the sediment grain size distribution.

Liquid limit, which is a fairly sensitive index of changes in texture and composition, is generally invariant down core. Figure 5 shows this consistency as well as the aforementioned spatial trend. Thus, assuming a consistent composition, texture is probably relatively consistent down core, indicating that the same or similar local depositional environments have been sustained during recent geologic time. However, as shown in 
Figure 6, there are exceptions. The bottom of core KC-4 is apparently much coarser than the top. Accordingly, the fine-grained sediment may be only a veneer over parts of the region.

Liquidity indices are characteristically greater than one, which is typical of surface sediments, but also indicates a lack of recent, significant erosion.

Changes in grain specific gravity indicate changes in composition. The relatively narrow range shown in these data (2.65-2.73), however, is characteristic of mineral assemblages dominated by marine terrigenous clastics and does not portend significant compositional changes. We believe that the $G_{s}$ data are consistent with the notion that the sediment in the study area is basically fine-grained and is fairly uniform in composition (mineralogy, organic content, and other components).

\section{Consolidation states and properties}

The results of the consolidation tests, along with the strength and index property tests, indicate that the seafloor off the Shandong Peninsula is fundamentally a depositional surface and is compacting normally. This is shown by the values of maximum past vertical stress, $\sigma_{v m}^{\prime}$ (Table 3, Appendix $C$ ), which are very low but generally increase gradually down the cores. This indicates a normal increase in overburden stress with subbottom depth. OCR $\left(\sigma_{\mathrm{vm}}^{\prime} / \sigma_{\mathrm{vo}}{ }_{\mathrm{v}}\right)$ values are high (10-85) at the surface, which is in agreement with values typically reported for marine sediment. However, they decrease rapidly within the upper 50 centimeters and approach a value of 1 below that level (Figure 7). This implies that the seafloor is not an erosional surface.

Compression indices, $C_{c}$ 's, range from 0.23 to 1.26 and average 0.74 . This indicates that these Yellow Sea sediments are of medium to high compressibility; most finegrained sediments have $C_{C}$ values less than 1 and the majority are less than 0.5 (Mitchell, 1976). Values of the coefficient of consolidation, $c_{v}$, are generally in the $10^{-3}$ $10^{-4} \mathrm{~cm}^{2} / \mathrm{sec}$ range. These values are, again, consistent with the fine-grained nature of the sediment, as are the permeabilities. The coefficient of permeability, $k$, has a mean value of about $10^{-7}-10^{-8} \mathrm{~cm} / \mathrm{sec}$. The permeability of these sediments is thus classified as "very low" to "practically impermeable" (Lambe and Whitman, 1969). The same areal trends manifested by the index property data are shown by $C_{c}, c_{v}$, and $k$ : values typical of finer sediment are associated with the deepest part of the study area. Consolidation test results are tabulated and plots of the data are presented in Appendix C. 
Table 3

Summary of consolidation test results

\begin{tabular}{|c|c|c|c|c|c|c|c|c|}
\hline core & $\begin{array}{l}\text { depth in } \\
\text { core } \\
\text { (m) }\end{array}$ & $\begin{array}{l}\sigma_{\text {vo }}^{\circ} \\
(\mathrm{kPa})\end{array}$ & $\begin{array}{l}\sigma_{v m}^{\circ} \\
(\mathrm{kPa})\end{array}$ & $\begin{array}{c}\sigma_{\mathrm{e}}^{\circ} \\
(\mathrm{kPa})\end{array}$ & OCR & $c_{c}$ & $\begin{array}{c}c_{v} \\
\left(\mathrm{~cm}^{2} / \mathrm{s}\right)\end{array}$ & $(\mathrm{cm} / \mathrm{s})$ \\
\hline \multirow[t]{3}{*}{$K C-1 A$} & 0.08 & 0.42 & 4.0 & 3.6 & 9.5 & 0.53 & $6 \times 10^{-4}$ & $3 \times 10^{-8}$ \\
\hline & 0.25 & 1.50 & 5.4 & 3.9 & 3.6 & 0.44 & $9 \times 10^{-4}$ & $4 \times 10^{-8}$ \\
\hline & 0.55 & 3.42 & 10.9 & 7.5 & 3.2 & 0.43 & $8 \times 10^{-4}$ & $4 \times 10^{-8}$ \\
\hline \multirow[t]{3}{*}{$B C-4$} & 0.04 & 0.10 & 2.3 & 2.2 & 23 & 0.92 & $6 \times 10^{-4}$ & $3 \times 10^{-8}$ \\
\hline & 0.21 & 0.67 & 4.3 & 3.6 & 6.4 & 1.26 & $4 \times 10^{-4}$ & $5 \times 10^{-8}$ \\
\hline & 0.42 & 1.41 & 9.3 & 7.9 & 6.6 & 0.94 & $4 \times 10^{-4}$ & $2 \times 10^{-8}$ \\
\hline \multirow[t]{3}{*}{$\mathrm{BC}-5$} & 0.02 & 0.07 & 3.0 & 2.9 & 43 & 1.07 & $2 \times 10^{-4}$ & $1 \times 10^{-8}$ \\
\hline & 0.20 & 0.74 & 5.7 & 5.0 & 7.7 & 1.00 & $3 \times 10^{-4}$ & $2 \times 10^{-8}$ \\
\hline & 0.49 & 1.82 & 8.7 & 6.9 & 4.8 & 0.91 & $3 \times 10^{-4}$ & $1 \times 10^{-8}$ \\
\hline \multirow[t]{3}{*}{$B C-6$} & 0.02 & 0.06 & 2.6 & 2.5 & 43 & 1.06 & $3 \times 10^{-4}$ & $5 \times 10^{-8}$ \\
\hline & 0.18 & 0.60 & 5.7 & 5.1 & 9.5 & 1.19 & $3 \times 10^{-4}$ & $3 \times 10^{-8}$ \\
\hline & 0.45 & 1.53 & 5.2 & 3.7 & 3.4 & 0.96 & $3 \times 10^{-4}$ & $3 \times 10^{-8}$ \\
\hline \multirow[t]{3}{*}{ BC-7 } & 0.04 & 0.23 & 4.2 & 4.0 & 18 & 0.34 & $9 \times 10^{-3}$ & $4 \times 10^{-7}$ \\
\hline & 0.20 & 1.27 & 8.0 & 6.7 & 6.3 & 0.29 & $3 \times 10^{-3}$ & $8 \times 10^{-8}$ \\
\hline & 0.46 & 3.05 & 22 & 19 & 7.2 & 0.26 & $2 \times 10^{-3}$ & $6 \times 10^{-8}$ \\
\hline \multirow[t]{3}{*}{$B C-8$} & 0.02 & 0.11 & 8.1 & 8.0 & 74 & 0.44 & $2 \times 10^{-3}$ & $8 \times 10^{-8}$ \\
\hline & 0.18 & 1.18 & 15 & 14 & 13 & 0.30 & $2 \times 10^{-3}$ & $5 \times 10^{-8}$ \\
\hline & 0.51 & 3.45 & 20 & 17 & 5.8 & 0.23 & $8 \times 10^{-3}$ & $2 \times 10^{-7}$ \\
\hline \multirow[t]{3}{*}{$B C-9$} & 0.02 & 0.07 & 4.7 & 4.6 & 67 & 1.04 & $2 \times 10^{-4}$ & $3 \times 10^{-8}$ \\
\hline & 0.20 & 0.74 & 5.6 & 4.9 & 7.6 & 1.12 & $3 \times 10^{-4}$ & $4 \times 10^{-8}$ \\
\hline & 0.49 & 1.82 & 4.6 & 2.8 & 2.5 & 0.84 & $3 \times 10^{-4}$ & $4 \times 10^{-8}$ \\
\hline \multirow[t]{3}{*}{$B C-10$} & 0.02 & 0.11 & 9.3 & 9.2 & 85 & 0.28 & $2 \times 10^{-2}$ & $6 \times 10^{-7}$ \\
\hline & 0.18 & 1.15 & 12 & 11 & 10 & 0.37 & $5 \times 10^{-3}$ & $1 \times 10^{-7}$ \\
\hline & 0.53 & 3.52 & 17 & 14 & 4.8 & 0.31 & $5 \times 10^{-3}$ & $1 \times 10^{-7}$ \\
\hline \multirow[t]{3}{*}{$B C-11$} & 0.02 & 0.07 & 2.7 & 2.6 & 38 & 0.54 & $7 \times 10^{-4}$ & $2 \times 10^{-7}$ \\
\hline & 0.19 & 1.02 & 5.4 & 4.4 & 5.3 & 0.55 & $7 \times 10^{-4}$ & $4 \times 10^{-8}$ \\
\hline & 0.51 & 2.88 & 10.4 & 7.5 & 3.6 & 0.41 & $1 \times 10^{-3}$ & $4 \times 10^{-8}$ \\
\hline
\end{tabular}

symbols:

$\sigma_{\text {vo }}^{\prime}$ : in situ effective overburden stress

$\sigma_{\mathrm{vm}}^{\prime}$ : maximum past effective vertical stress

$\sigma_{\mathrm{e}}^{\prime}$ : excess vertical effective stress $\left(\sigma_{\mathrm{vm}}^{\prime} \sigma_{\mathrm{vo}}^{\prime}\right)$

OCR : overconsolidation ratio $\left(\sigma_{\mathrm{vm}}^{\prime} / \sigma_{\mathrm{vo}}^{\prime}\right)$

$\mathrm{C}_{\mathrm{c}}$ : compression index

$c_{v}$ : coefficient of consolidation

k : coefficient of permeability 


\section{Strength parameters}

The mode of failure and the percentage strain at failure in the CIU triaxial tests are presented in Table 4 and Appendix D. Plastic deformation occurs, rather than failure along discrete planes, and considerable strain is accumulated before peak strength is reached. The amount of strain shown in Table 4 is relatively high, but not unusual, for fine-grained sediments. Also, these strain percentages imply that cements, which lead to brittle failure, are not present in these sediments.

Table 4

Summary of $\mathrm{ClU}$ triaxial test results

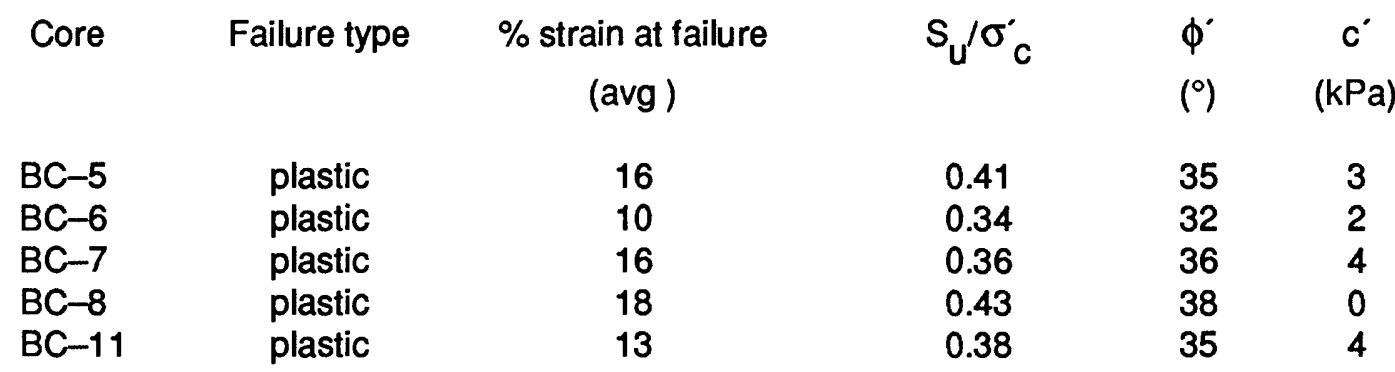

symbols: $S_{\mathrm{u}}$ : undrained shear strength

$\phi^{\prime}$ : effective friction angle $\sigma_{c}^{\prime}$ : consolidation stress on triaxial sample prior to shear $c^{\prime}$ : cohesion intercept in terms of effective stress

The strength-overburden ratio, $S_{\mathrm{u}} / \sigma_{C^{\prime}}$, which averages about 0.40 , is slightly higher than the values of 0.2 to 0.3 that are typically reported for terrestrial soils. We are uncertain, with so few samples, if the difference is significant.

Cohesion, c', and internal friction angle, $\varnothing^{\prime}$, are the basic strength parameters with respect to effective stress. The values shown in Table 4 for $c^{\prime}$ are typical for marine muds; the $\emptyset^{\prime}$ values are, in contrast, generally higher than the norm. For most finegrained marine sediments composed of common clay minerals, ClU-derived values of $\varnothing^{\prime}$ are less than $34^{\circ}$ and frequently less than $30^{\circ}$ (e.g., see Booth and others, 1985). The reason for the apparently anomalous values cannot be determined without textural and mineralogical analyses. Triaxial test results are tabulated and plots of the data are presented in Appendix D.

\section{SUMMARY}

\section{Geological}

The surface sediments near and south of the Shandong Peninsula are composed primarily of silts and clays; silts are apparently an important textural component throughout the study area and may be the dominant size class at many sites. The sediments be- 
come finer toward the deeper part of the study area. No vertical trends are present in the sediment texture, as inferred from the index property data; however, the silt-clay sediment may only be a veneer over at least part of the region. The surface is depositional: the extremely low shear strengths and high liquidity indices coupled with a lack of evidence for erosion indicate that there is net sediment accumulation throughout most of the study area.

\section{Geotechnical}

The Yellow Sea sediments are very soft and composed of silts and clays of medium to high plasticity (classification: $\mathrm{CL}$ and $\mathrm{CH}$ ). The sediments are of medium to high compressibility and have a permeabilty that ranges from "very low" to "practically impermeable". They exhibit overconsolidated behavior, although they trend toward a state of normal consolidation down core. The $S_{u} / \sigma_{v}^{\prime}$ values are slightly higher than those for normally consolidated terrestrial soil. The values of $\emptyset^{\prime}$, compared to data reported for many other marine sediments, are also slightly higher than the norm.

\section{REFERENCES}

American Society for Testing and Materials, 1985, 1985 Annual book of ASTM standards, v. 4.08: Soil and rock; building stones: Philadelphia, ASTM, 1078 p.

Booth, J. S., Sangrey, D. A., and Fugate, J. K., 1985, A nomogram for interpreting slope stability of fine-grained deposits in modern and ancient marine environments: Journal of Sedimentary Petrology, v. 55, p. 29-36.

British Standards Institution, 1975, Standard test for liquid limit-cone penetrometer method: London.

Keuhl, S. A., Nittrouer, C. A., DeMaster, D. J., and Curtin, T. B., 1985, A long, squarebarrel gravity corer for sedimentological and geochemical investigation of finegrained sediments: Marine Geology, v. 62, p. 365-370.

Milliman, J. D., Qin, Y. S., and Butenko, J., 1985, Geohazards in the Yellow Sea and East China Sea: Proceedings Offshore Technology Conference, 17th, p. 73-81.

Mitchell, J. K., 1976, Fundamentals of soil behavior: New York, John Wiley, 422 p.

Lambe, T. W., and Whitman, R. V., 1969, Soil mechanics: New York, John Wiley, $553 \mathrm{p}$.

Terzaghi, K., and Peck, R. B., 1967, Soil mechanics in engineering practice: New York, John Wiley, $729 \mathrm{p}$.

Winters, W. J., 1988, Geotechnical testing of marine sediment: U. S. Geological Survey Open-File Report 88-36, 52 p. 


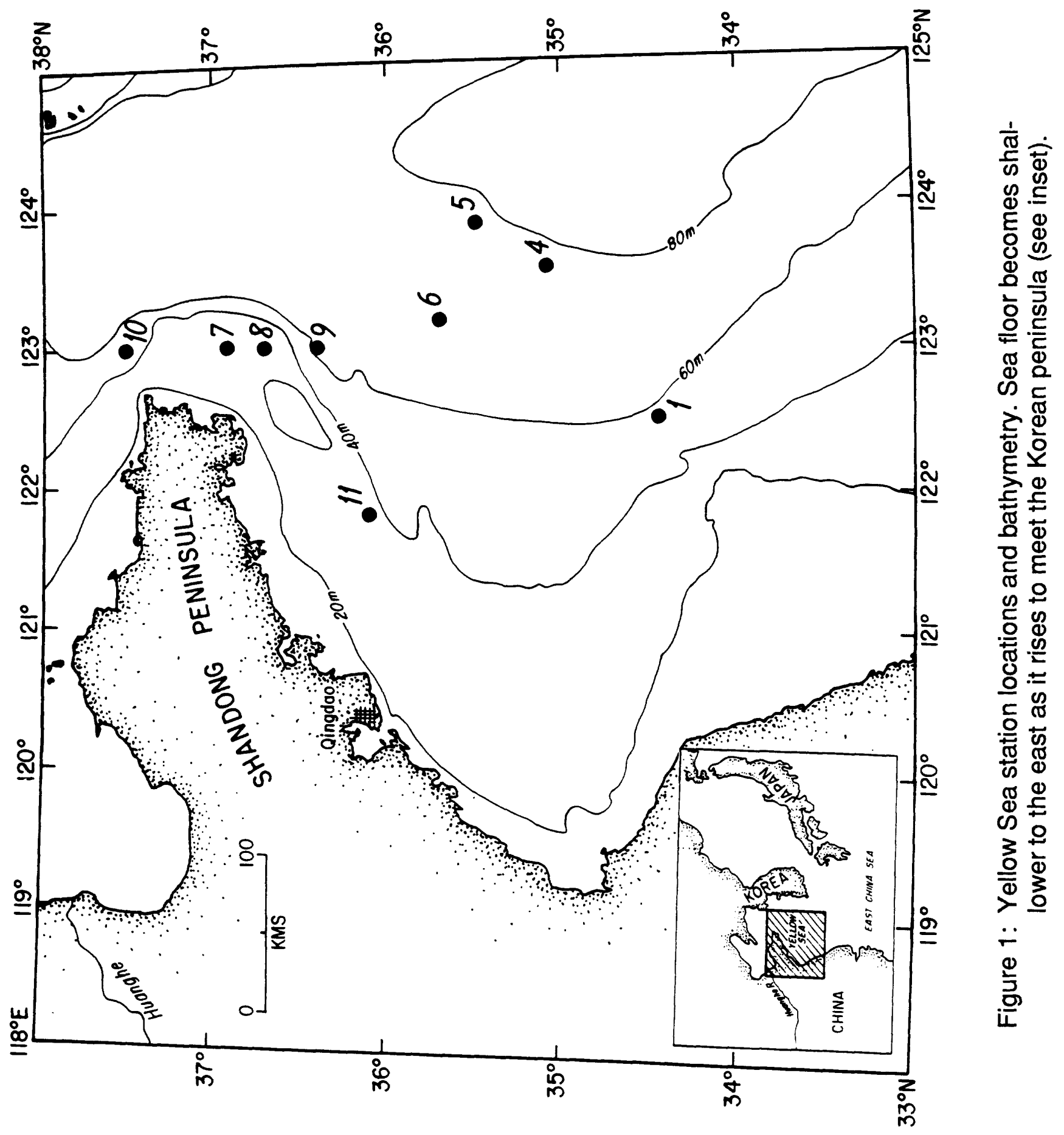


$S_{u}(k P a)$
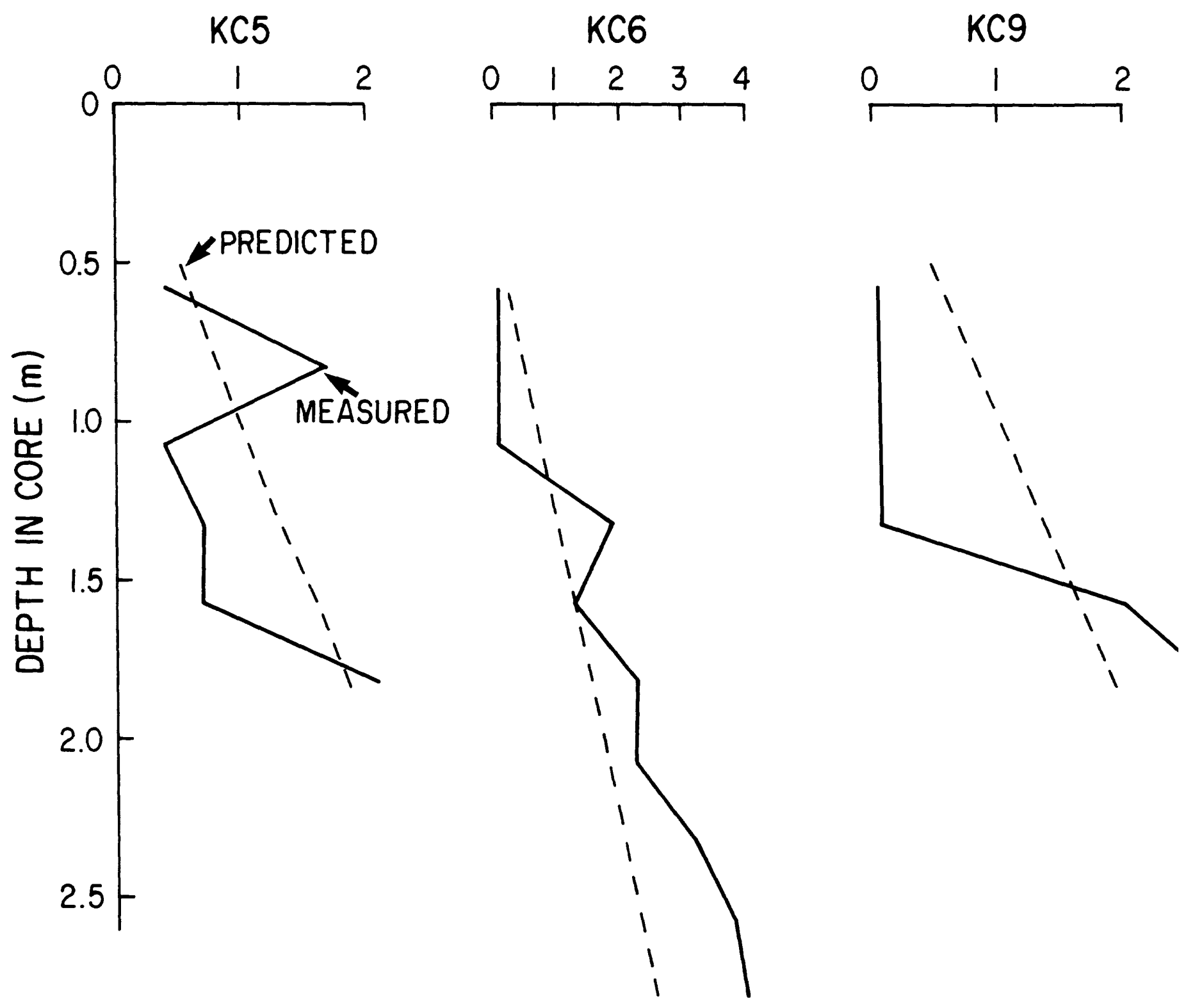

Figure 2: Selected vane shear strength profiles. Dashed lines are strength profiles predicted for each core by assuming that the sediment is normally consolidated (i.e., $S_{U} / \sigma_{V}^{\prime}=0.24$ ) 


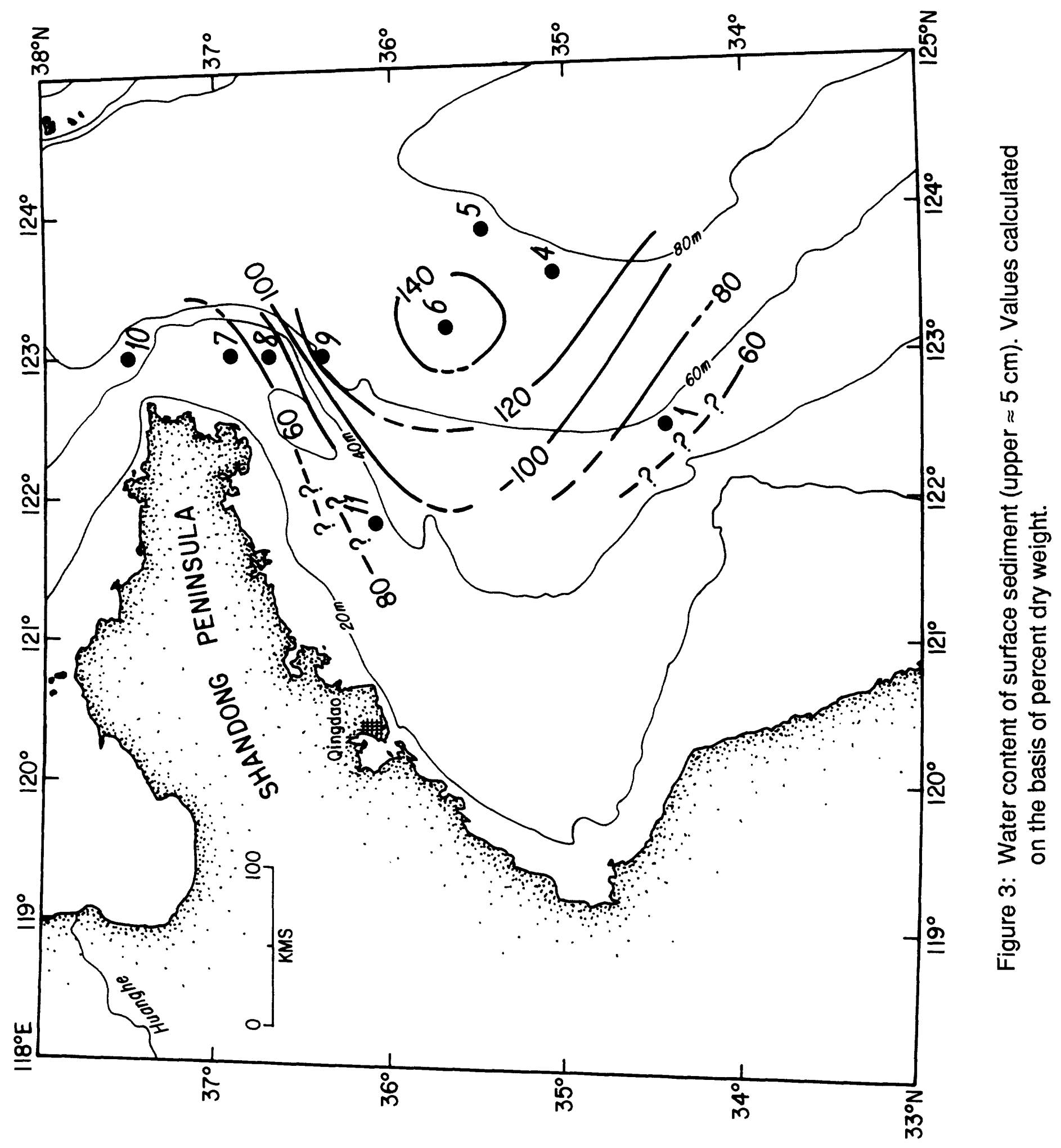




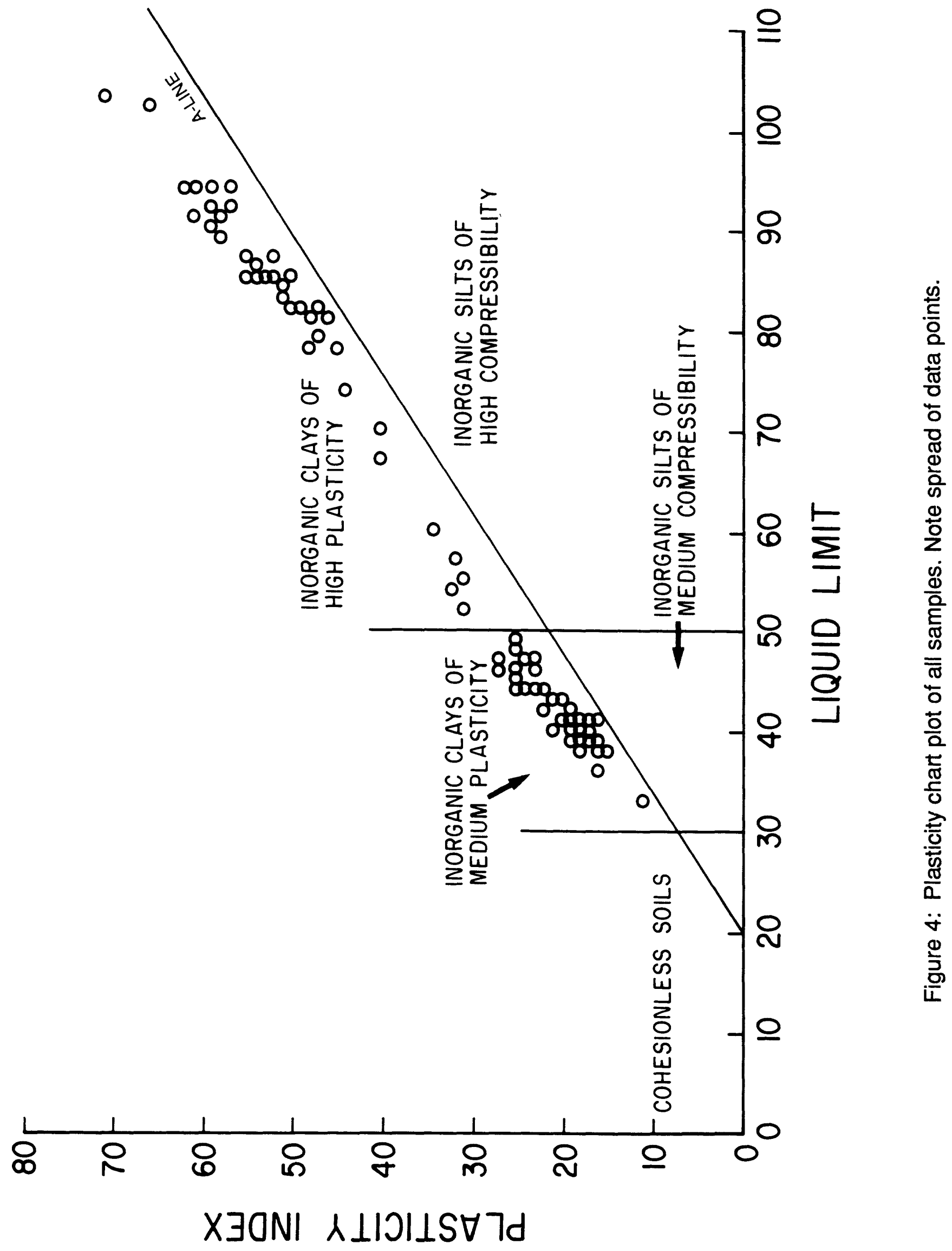




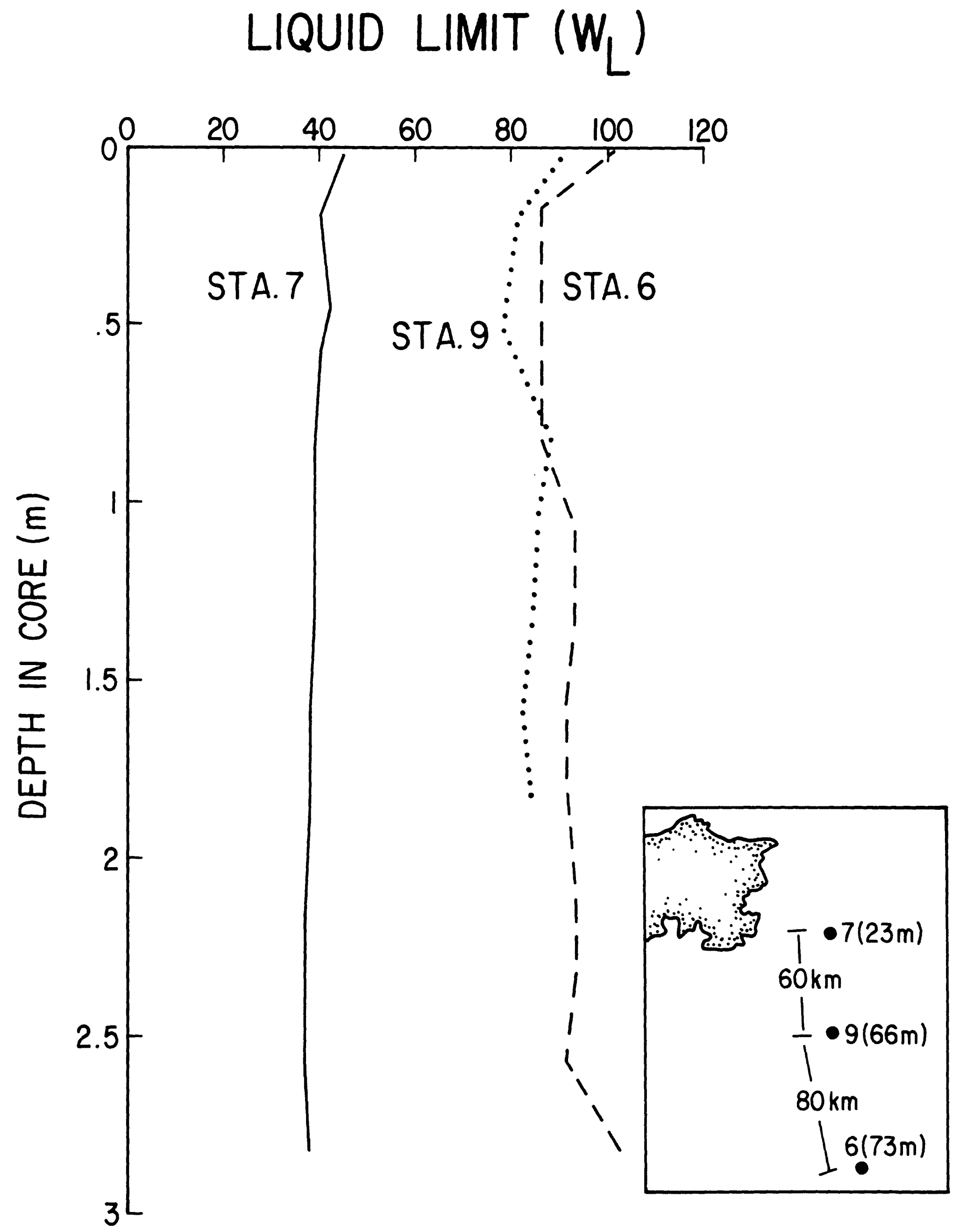

Figure 5: Liquid limit profiles of sites 6, 7, and 9. Inset shows core locations and water depths. The down-core uniformity is evident in the profiles. The offshore trend toward increasing liquid limit values is evident in the inset. 


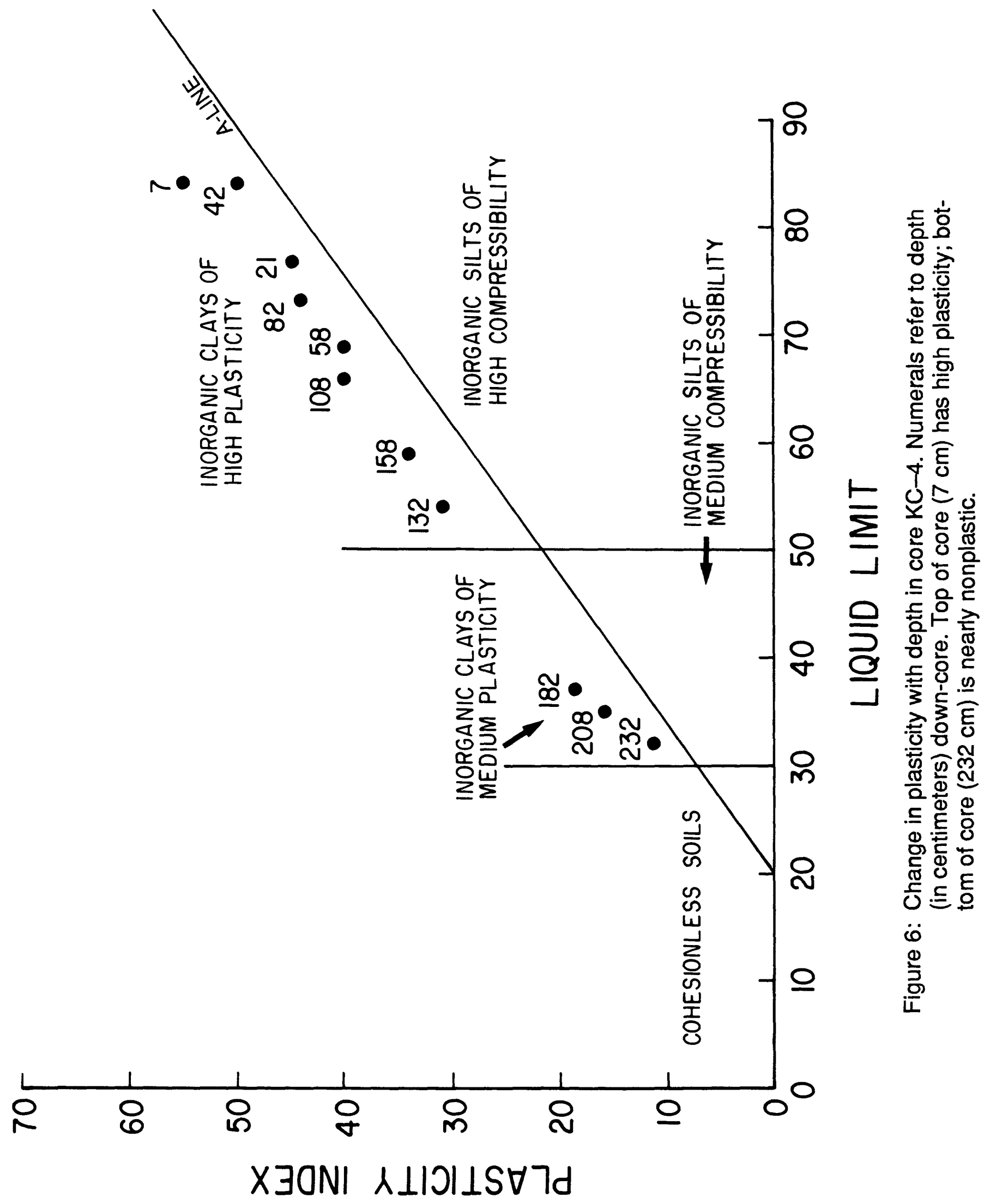




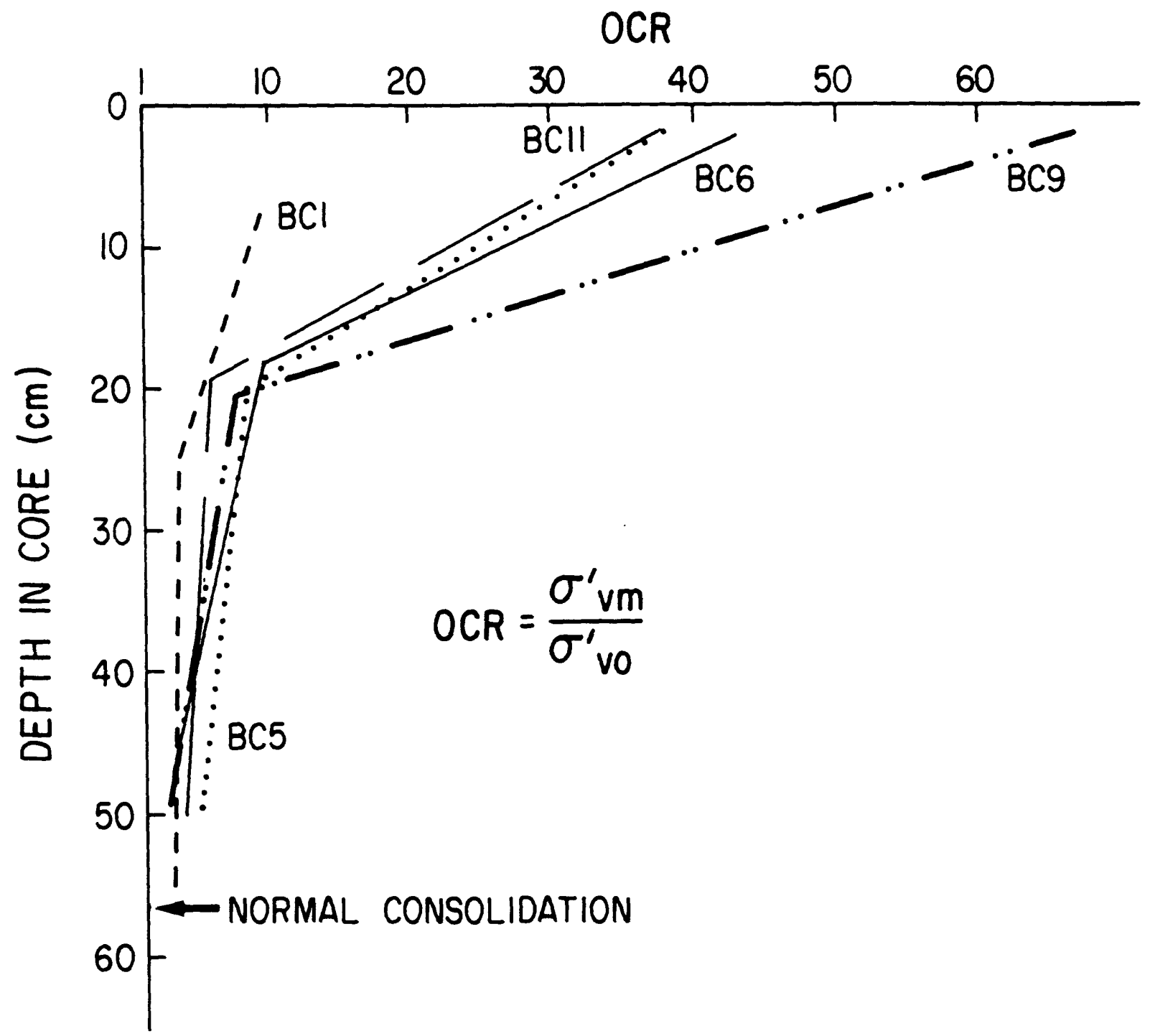

Figure 7: Consolidation state of sediments vs. depth in core. An OCR value of 1 implies that sediment is normally consolidated, values greater than 1 imply a state of overconsolidation. 


\section{Appendix A}

Nomenclature and Symbols 
Nomenclature and Symbols

$A_{f} \quad$ coefficient of pore pressure response at failure during a triaxial compression test (change in pore pressure at failure/change in deviator stress)

ASTM American Society for Testing and Materials

BC box core

C $\quad$ cohesion intercept expressed in terms of effective stress

$\mathrm{C}_{\mathrm{c}}$ compression index (change in e/change in log of vertical effective stress from consolidation test)

$\mathrm{C}_{\mathrm{cf}} \quad$ corrected field compression index (Schmertmann method)

$\mathrm{C}_{\mathrm{r}} \quad$ rebound-recompression index

$c_{v} \quad$ coefficient of consolidation

$c_{v}\left(\sigma_{v o}^{\prime}\right)$ coefficient of consolidation at the in situ effective overburden stress

$c_{v}\left(\sigma_{v m}^{\prime}\right)$ coefficient of consolidation at the maximum past vertical effective stress

$c_{v}($ avg) average coefficient of consolidation for virgin compression

DELTA u change in pore water pressure (also equals delta PORP)

e

$\mathrm{G}_{\mathrm{S}}$

ID

IL

IP

$\mathrm{k}$

$k\left(\sigma_{v o}^{\prime}\right)$

$k\left(\sigma_{v m}^{\prime}\right)$

k(avg)

$\mathrm{KC}$

$\mathrm{n}$

OCR

$p^{\prime}$

q

$S_{n}$ void ratio (volume voids/volume solids)

grain specific gravity

disturbance index (Silva method)

liquidity index

plasticity index

coefficient of permeability

coefficient of permeability at the in situ effective overburden stress

coefficient of permeability at the maximum past vertical effective

stress

average coefficient of permeability for virgin compression

Kasten core

porosity (volume voids/total volume)

overconsolidation ratio $\left(\sigma^{\prime} \mathrm{vm} / \sigma_{\mathrm{vo}}\right)$

normal effective stress acting on a plane inclined at $45^{\circ}$ in a triaxial test $\left(\sigma^{\prime}+\sigma^{\prime}{ }^{\prime}\right) / 2$

shear stress acting on a plane inclined at $45^{\circ}$ in a triaxial test $\left(\sigma_{1}-\sigma_{3}\right) / 2$ undrained vane shear strength determined on remolded sediment 
Nomenclature and symbols (cont.)

$\begin{array}{ll}S_{t} & \text { sensitivity }\left(s_{u v} / s_{r v}\right) \\ s_{u} & \text { undrained shear strength } \\ s_{u r} & \text { remolded shear strength (vane measurement) } \\ s_{u v} & \text { undrained shear strength (vane measurement) } \\ w_{w} & \text { natural water content (weight water/weight solids) } \\ w_{L} & \text { liquid limit } \\ w_{P} & \text { plastic limit } \\ w_{S} & \text { water content of a triaxial sample during undrained shear }\end{array}$

$\rho_{\mathrm{t}} \quad$ bulk density

$\sigma_{c}^{\prime} \quad$ consolidation stress exerted on a triaxial test sample prior to shear

$\sigma_{e}^{\prime} \quad$ excess vertical effective stress $\left(\sigma_{v m}^{\prime}-\sigma_{v o}^{\prime}\right)$

$\sigma_{\text {vo }} \quad$ in situ effective overburden stress

$\sigma_{v m} \quad$ maximum past vertical effective stress

$\sigma_{1}^{*} \quad$ vertical effective principal stress

$\sigma_{3}^{\prime} \quad$ horizontal effective principal stress

$\phi^{\prime} \quad$ friction angle in terms of effective stress

$\phi^{\prime}(c=0) \quad$ friction angle in terms of effective stress determined from an individual triaxial test assuming no cohesion intercept

$\phi^{\prime}(c \neq 0) \quad$ friction angle in terms of effective stress determined from a number of triaxial tests performed on similar sediment 


\section{Appendix B}

Results of Vane Shear and Index Property Tests

tabular data

profiles 
TABULAR DATA 


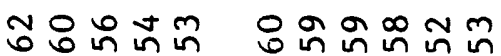

กำ กำํํㅇํำ

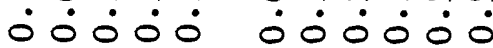

○ं0 $\dot{0} \dot{0} \dot{0} \dot{0} \dot{0} \dot{0} \dot{0}$

ติกิกิับ

$\dot{-} \dot{-} \dot{-} \dot{-} \dot{-} \dot{-} \dot{-} \dot{-} \dot{-}$

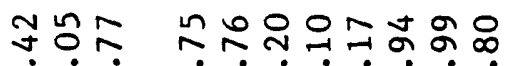
लिं $\dot{N} \dot{N} \dot{N} \dot{N} \dot{0}$

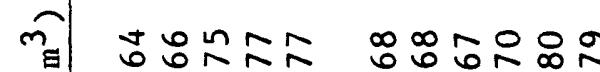

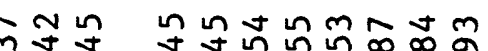

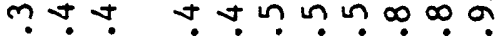
-

$\rightarrow-\dot{A} \rightarrow-\dot{A} \rightarrow \dot{A}$

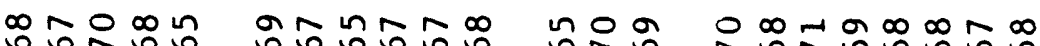
b $\dot{N} \dot{N} \dot{N} \dot{N} \dot{N} \dot{N} \dot{N} \dot{v} \dot{N} \dot{v} \dot{N} \dot{N} \dot{N} \dot{N}$

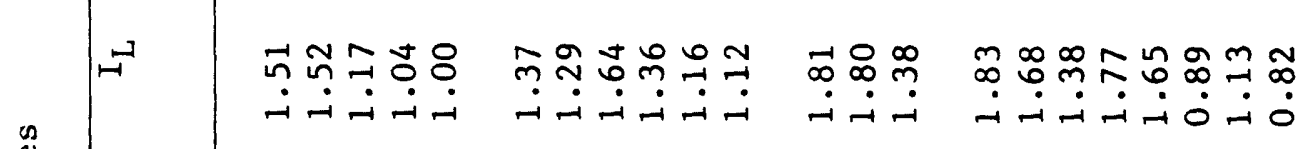

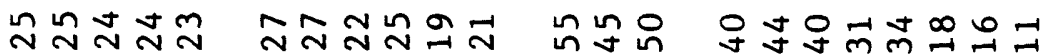

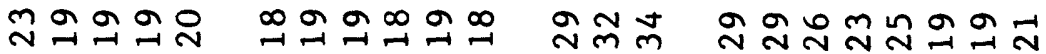

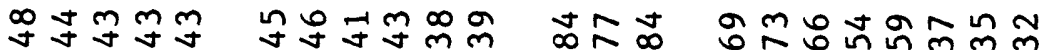

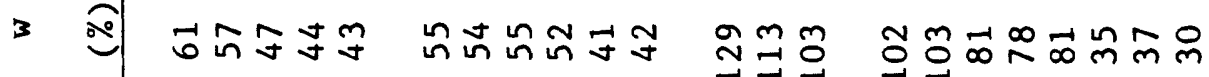

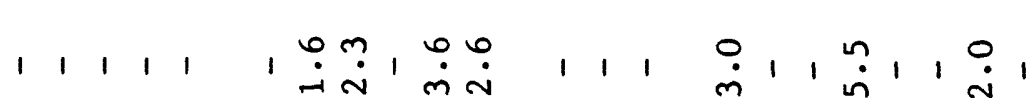
$\cos ^{2}$ -

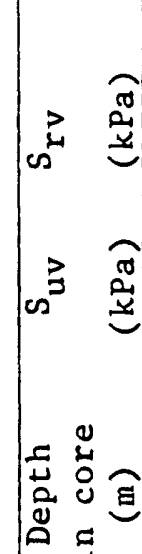
$\exists \cong$ กิ 이우 00 i. $m m$ nn $0 \stackrel{\text { in }}{n} \frac{0}{0}$

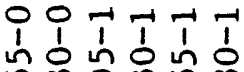
$\dot{0} \dot{0} \cdot$ ! $\infty$.

ต $ข m \rightarrow a$ من

$1,1 ? \% m n \pi \omega m$ -i் $\dot{0} \dot{m} \dot{0} \dot{0}$

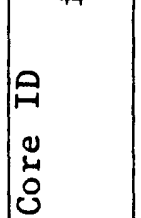
$\dot{0} \dot{0} \dot{-} \dot{-} \dot{\sim}$

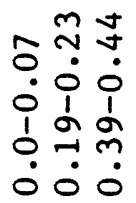

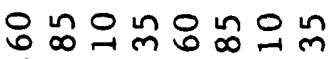
$\dot{0} \dot{0} \dot{i} \dot{i}+\dot{i}$

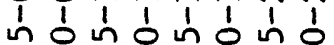
nิ $\dot{0} \dot{0} \dot{-} \dot{\mu} \dot{\sim} \dot{N}$<smiles>[SiH3][Hg][TeH]</smiles> 


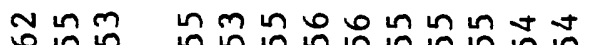

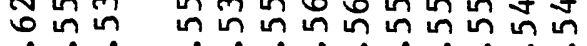

$\sqrt{\operatorname{Nan}}$

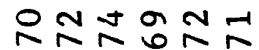
$0 \dot{00} \dot{000} \dot{0} \dot{0} \dot{0} \dot{0} \dot{0} \dot{0} \dot{0} \dot{0} \dot{0} \dot{0}$

ำ

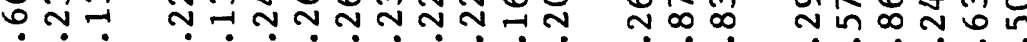
$\dot{-1}-\dot{-} \dot{-} \dot{-} \dot{-} \dot{-} \dot{-} \dot{\sim} \dot{N} \dot{N} \dot{N} \dot{N} \dot{N}$

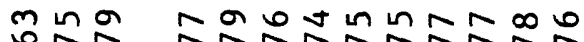

?.?

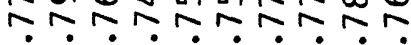

an $m$

O $m$ m 0 -

•.

$\rightarrow-1-1-1-1$

:

$\dot{v} \dot{v} \dot{v} \dot{v} \dot{v} \dot{v} \dot{v}$

$\sim \infty$

$\mathfrak{0}: 0$

응유용요

N $\sim \sim \sim \sim N$

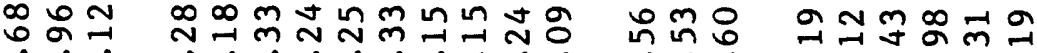

-ீ口்

ำ ชำ กำ

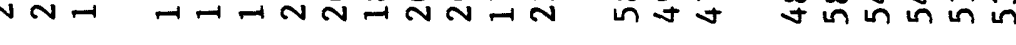

ฉ

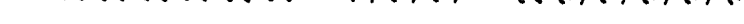

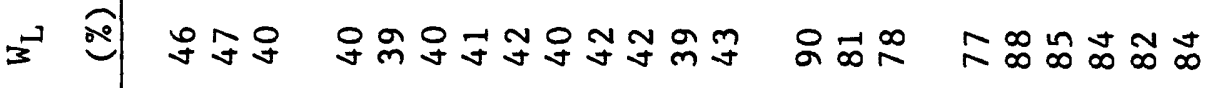

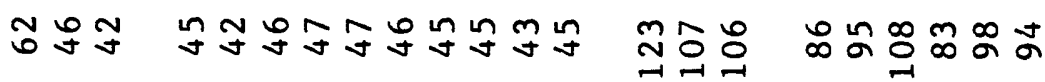

$\begin{array}{llllllllllllllllllllll}1 & 1 & 1 & 1 & 1 & 1 & 1 & 1 & 1 & 1 & 0 & 1 & 1 & 1 & 1 & 1 & 1 & 1 & 1 & 1 & 1 & 1\end{array}$

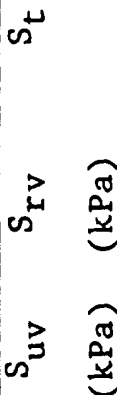

造

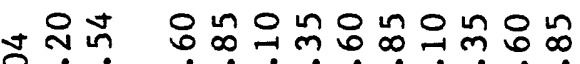

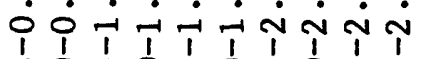

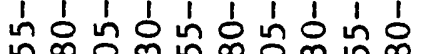

0.

$\dot{0} \dot{0} \dot{0}$

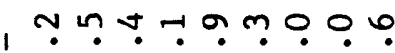

$111,11,09$

$\mid \begin{array}{ll}-1 \\ 0 \\ 0 \\ 0 \\ 0\end{array}$

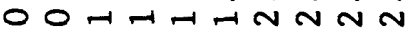

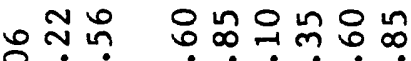

- $\dot{0} \dot{1} \quad \dot{0} \dot{1} \dot{1} \dot{1} \dot{1}$

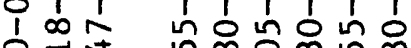

$0 \leadsto$ กี้

$\dot{0} \dot{0} \dot{0} \dot{0} \dot{-} \dot{-i} \dot{A}$

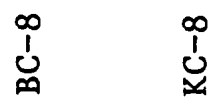

$\begin{array}{ll}i & i \\ 0 & u \\ 0 & y\end{array}$ 


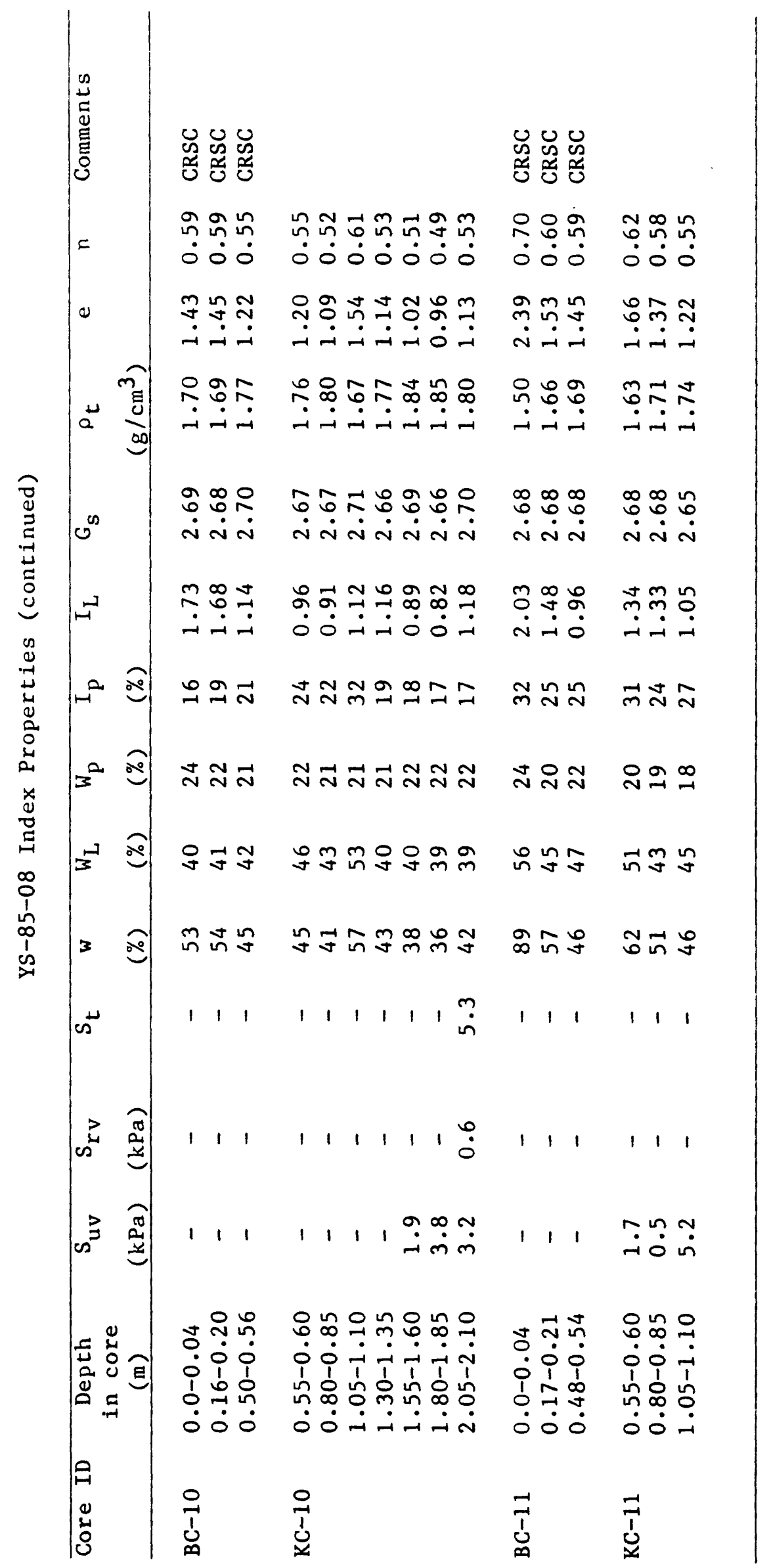




\section{PROFILES \\ Vane shear strength}




\section{VANE SHEAR STRENGTH (kPa)}

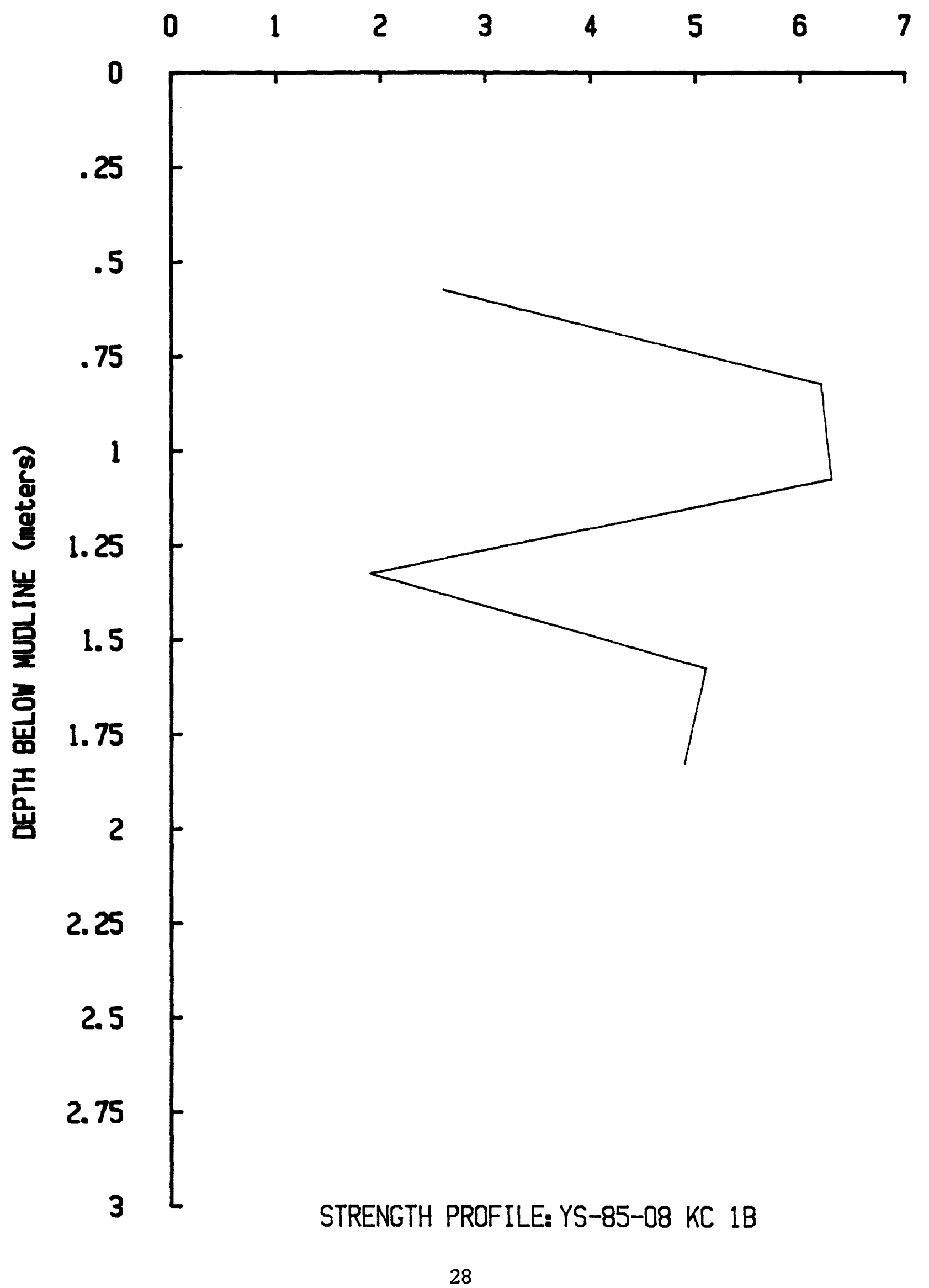




\section{VANE SHEAR STRENGTH (kPa)}

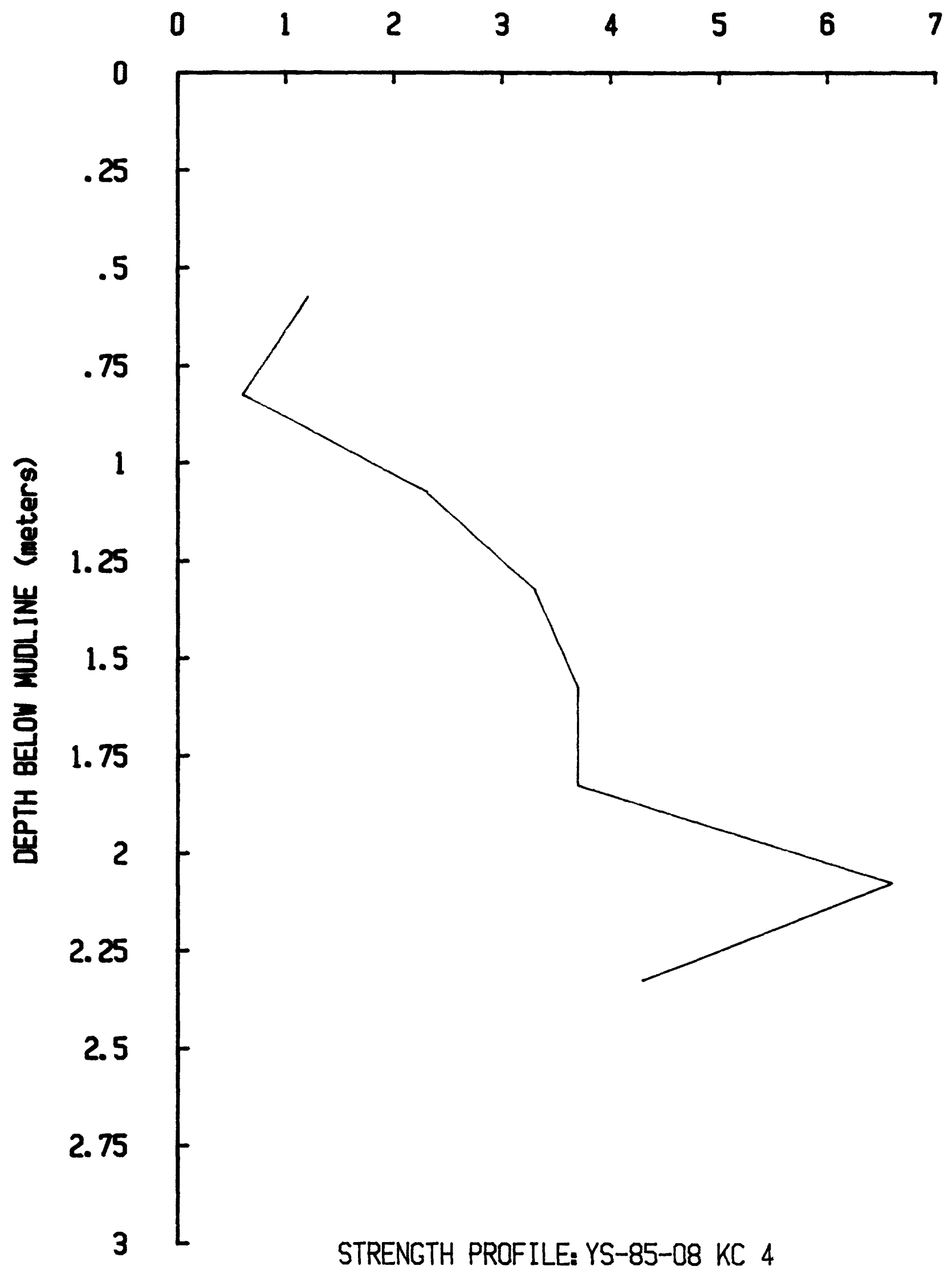


VANE SHEAR STRENGTH (KPa)

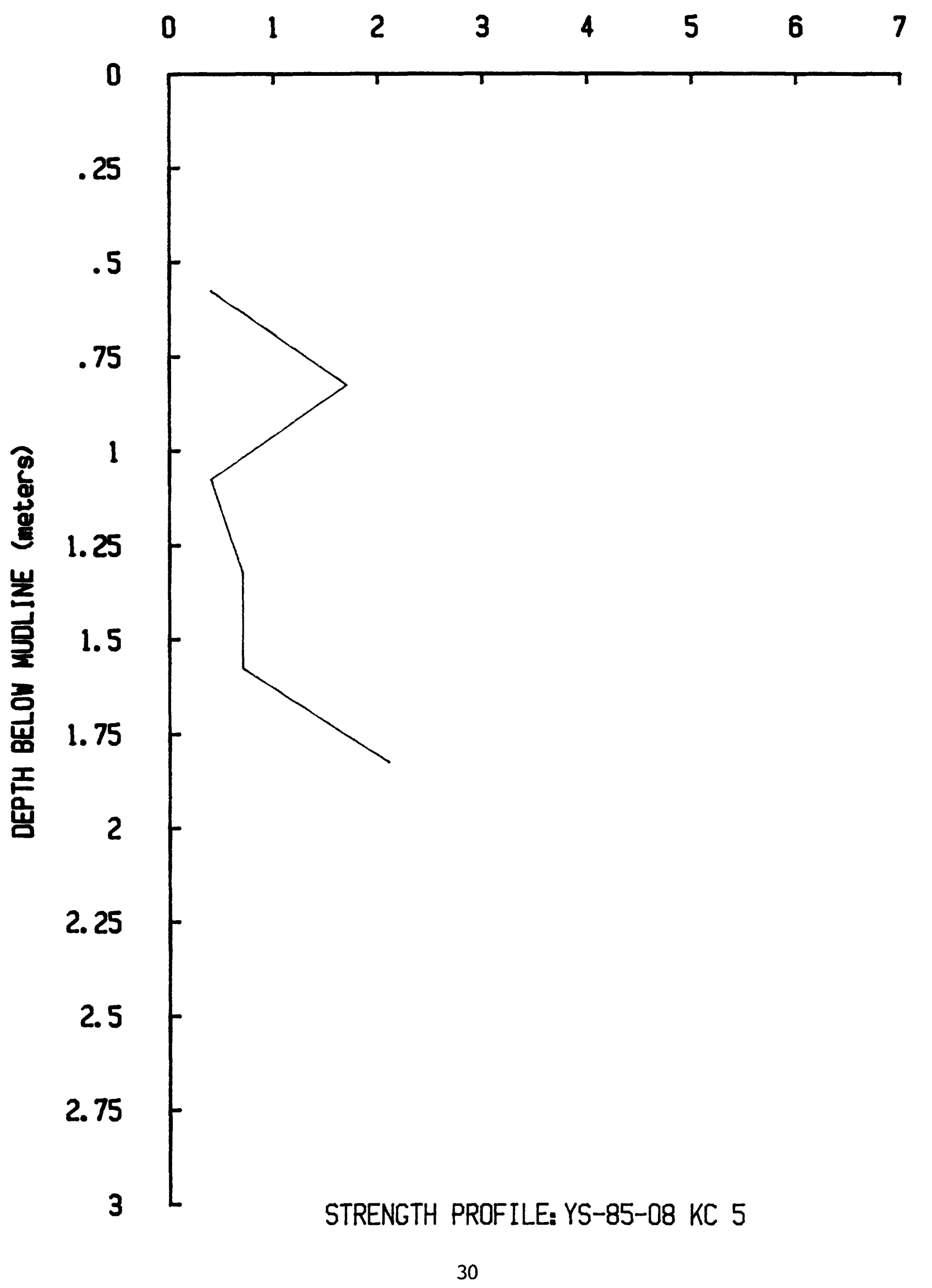




\section{VANE SHEAR STRENGTH (kPa)}

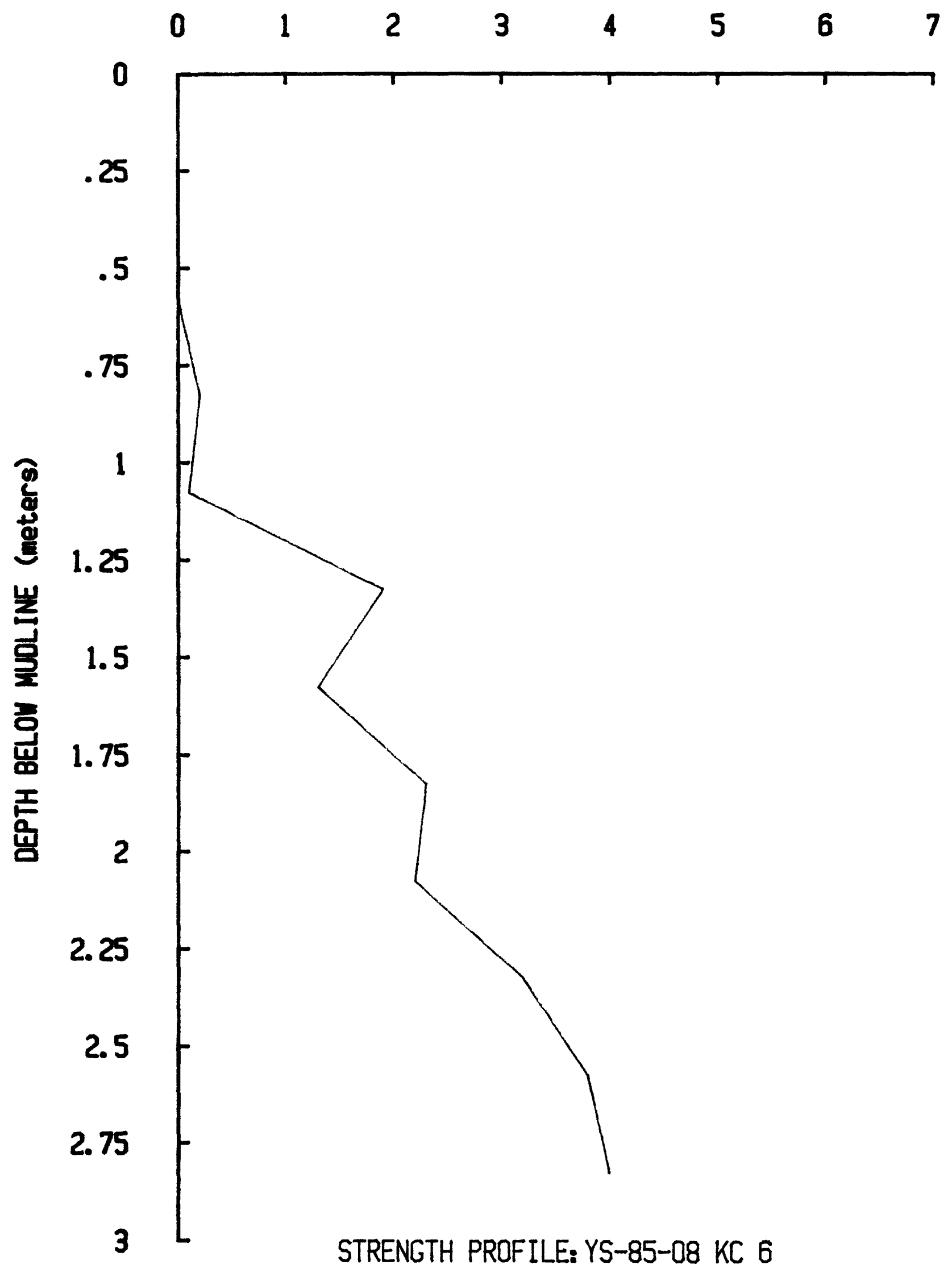




\section{VANE SHEAR STRENGTH (kPa)}

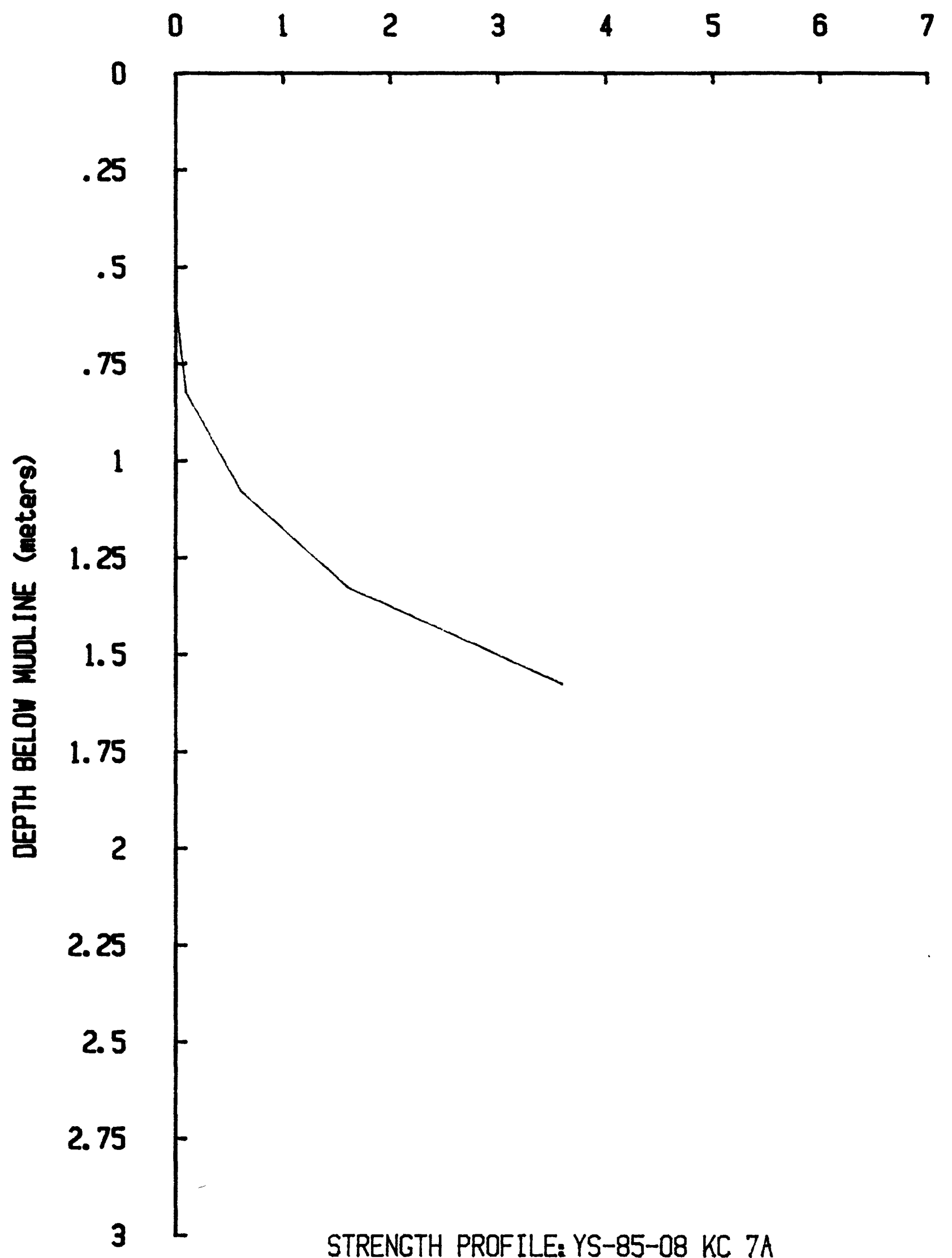


VANE SHEAR STRENGTH (KPa)

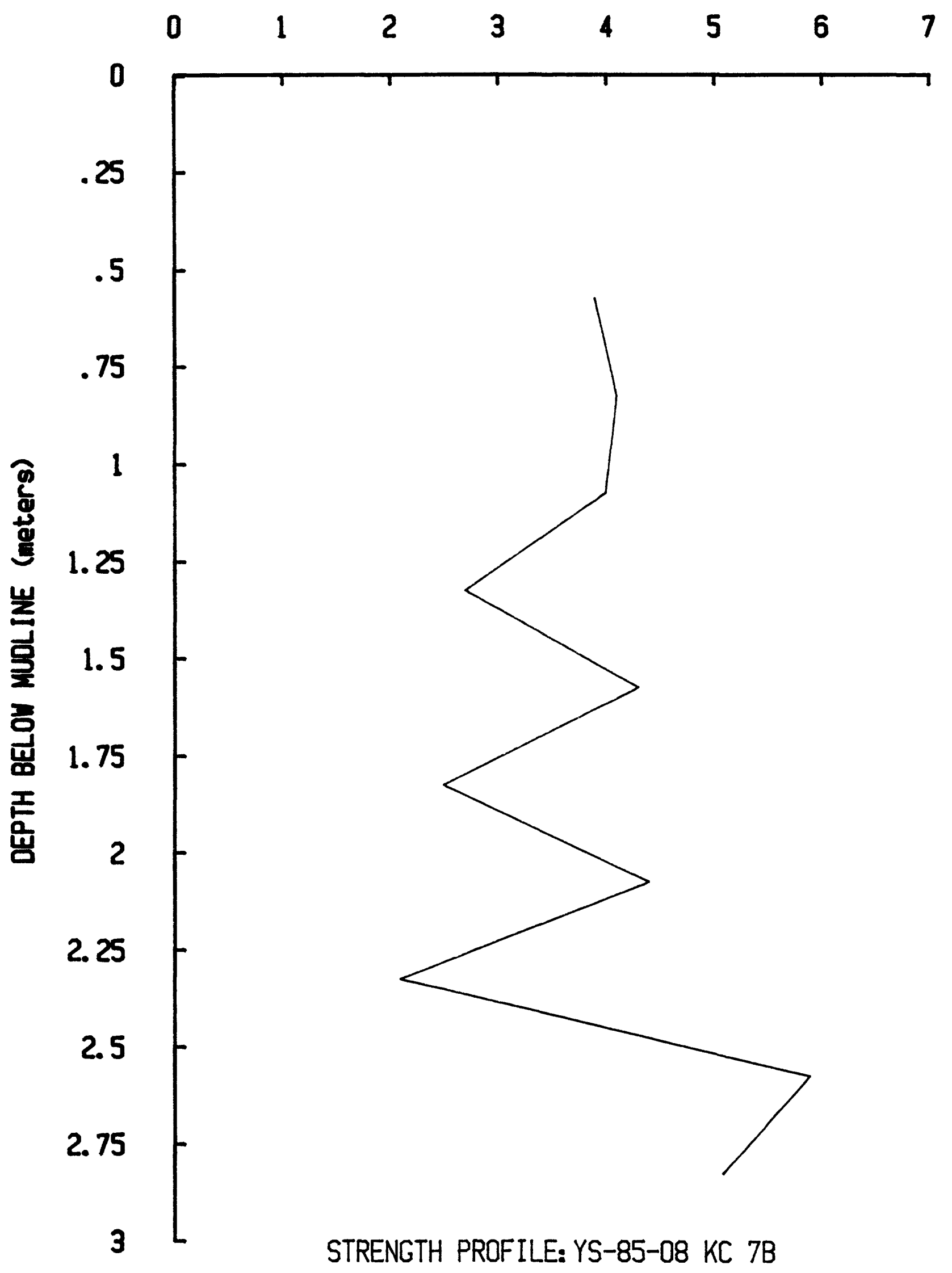


VANE SHEAR STRENGTH (KPa)

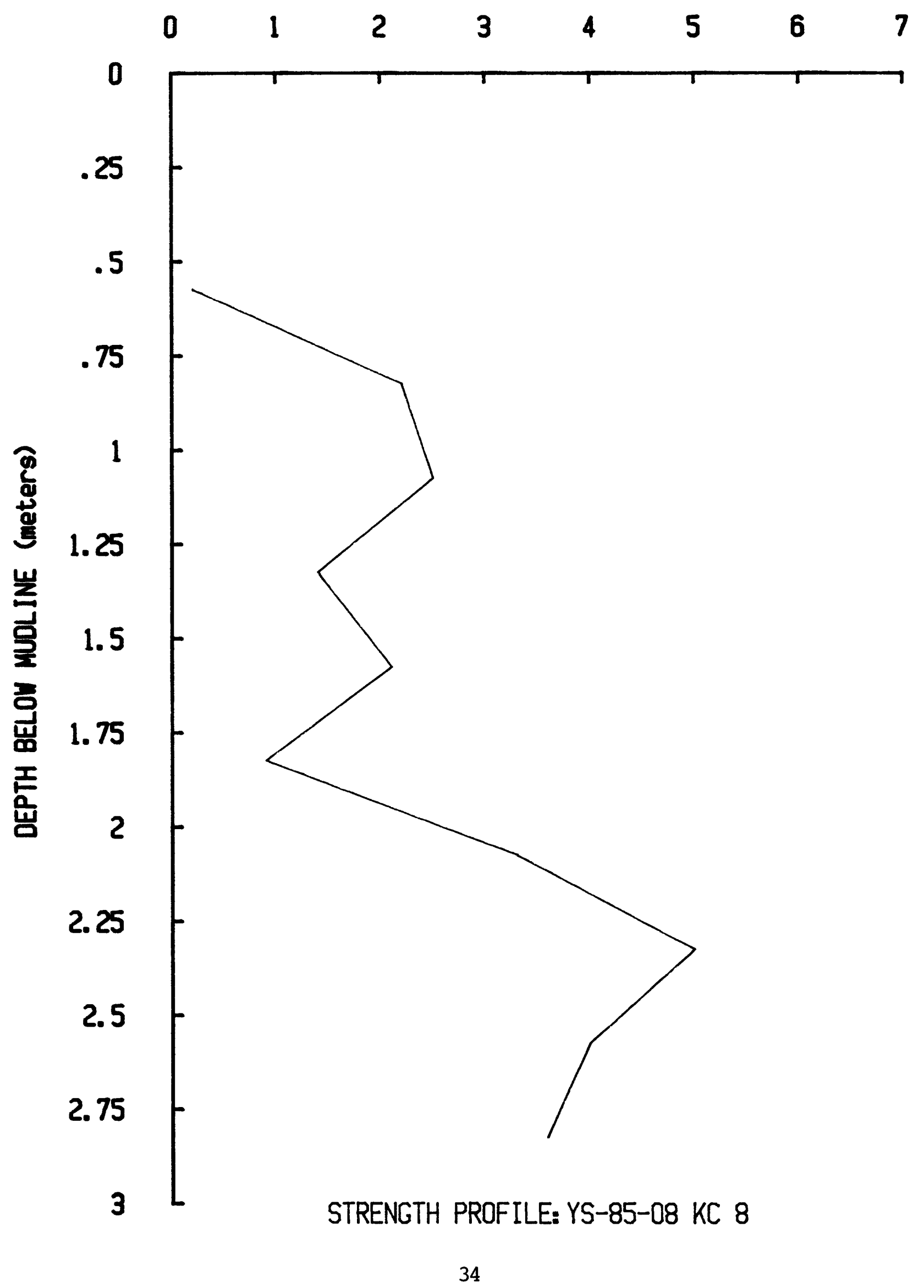




\section{VANE SHEAR STRENGTH (kPa)}

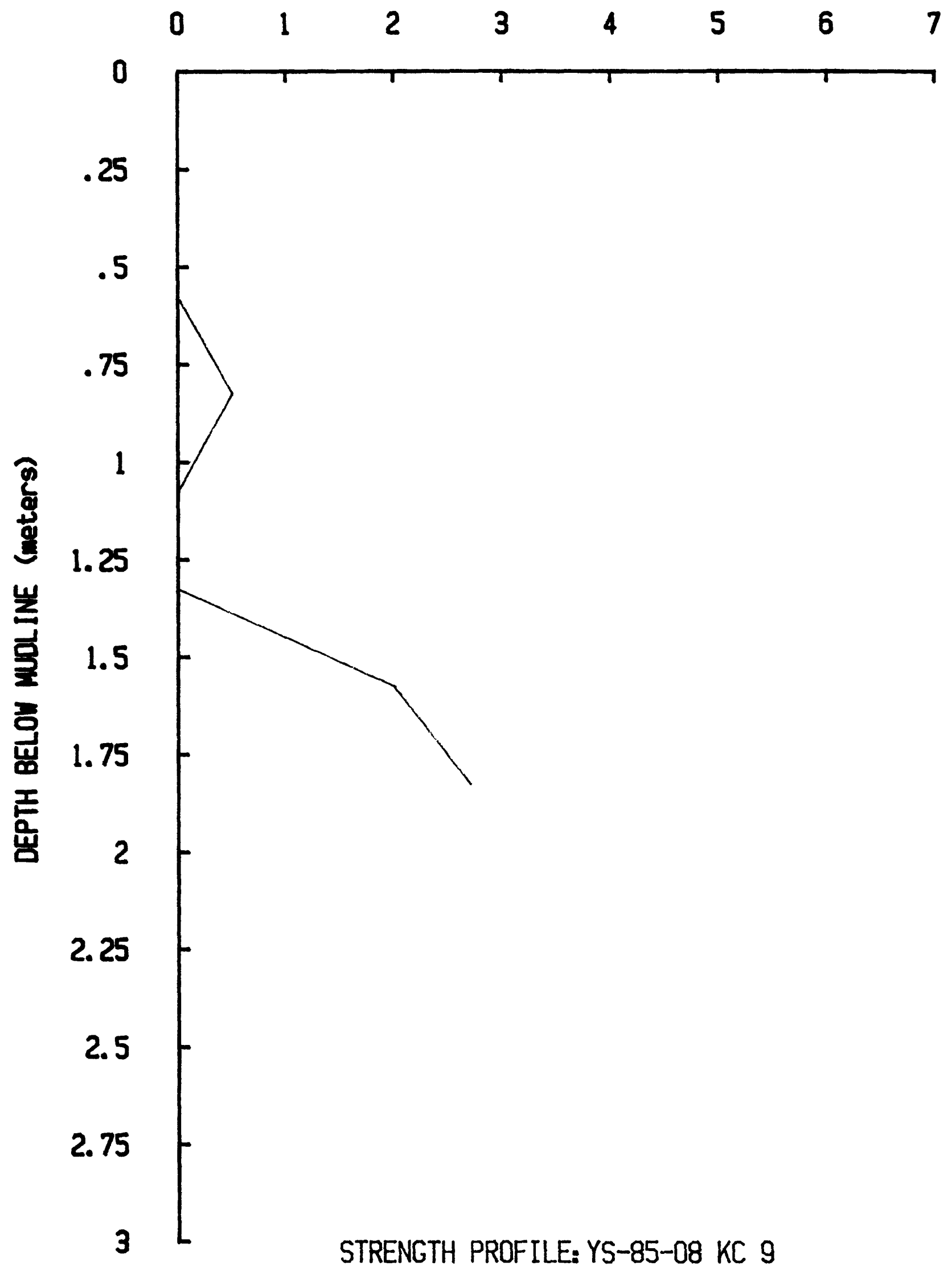


VANE SHEAR STRENGTH (kPa)

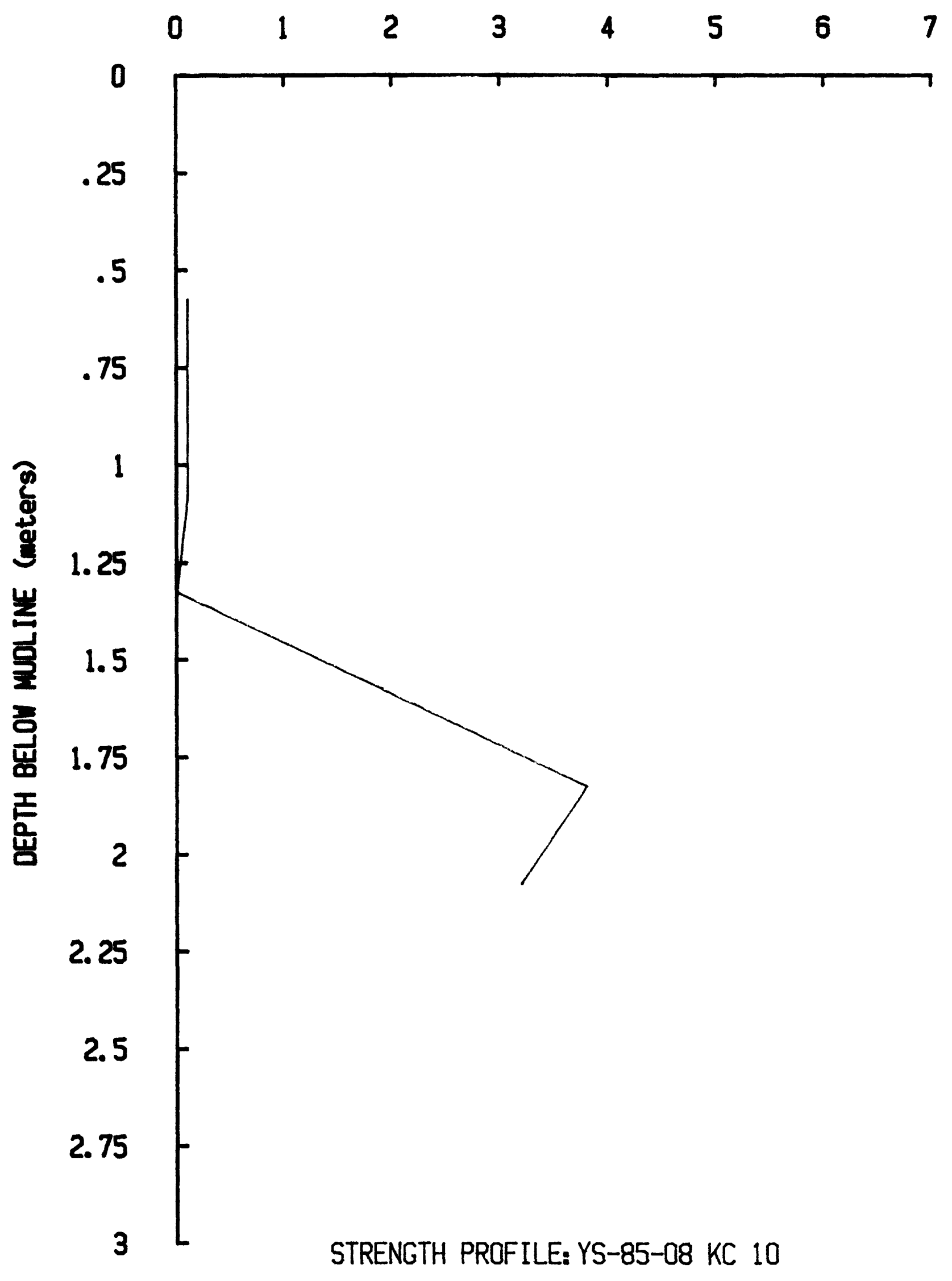


VANE SHEAR STRENGTH (KPa)

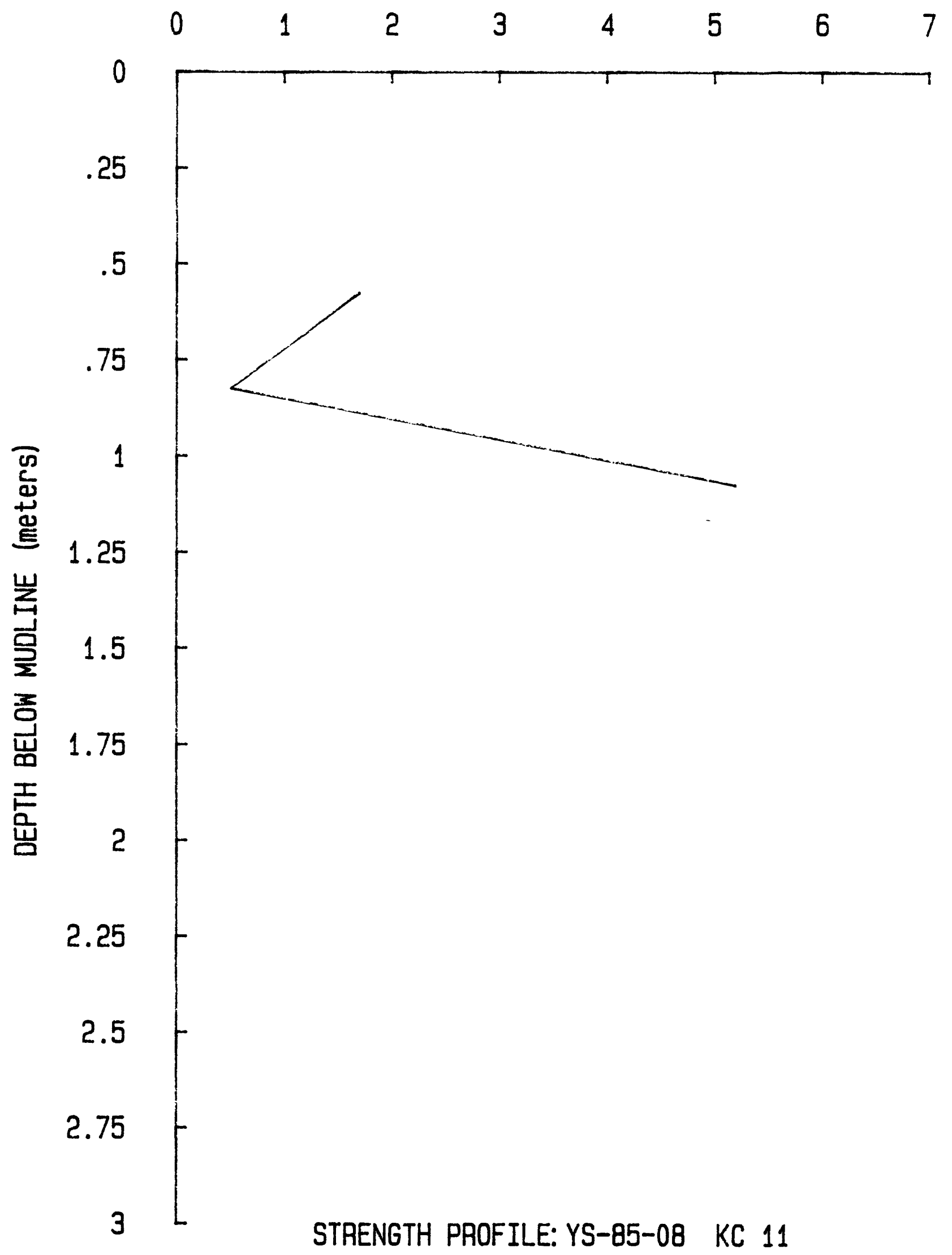




\section{PROFILES \\ Liquid limit \\ Plastic limit \\ Water content}




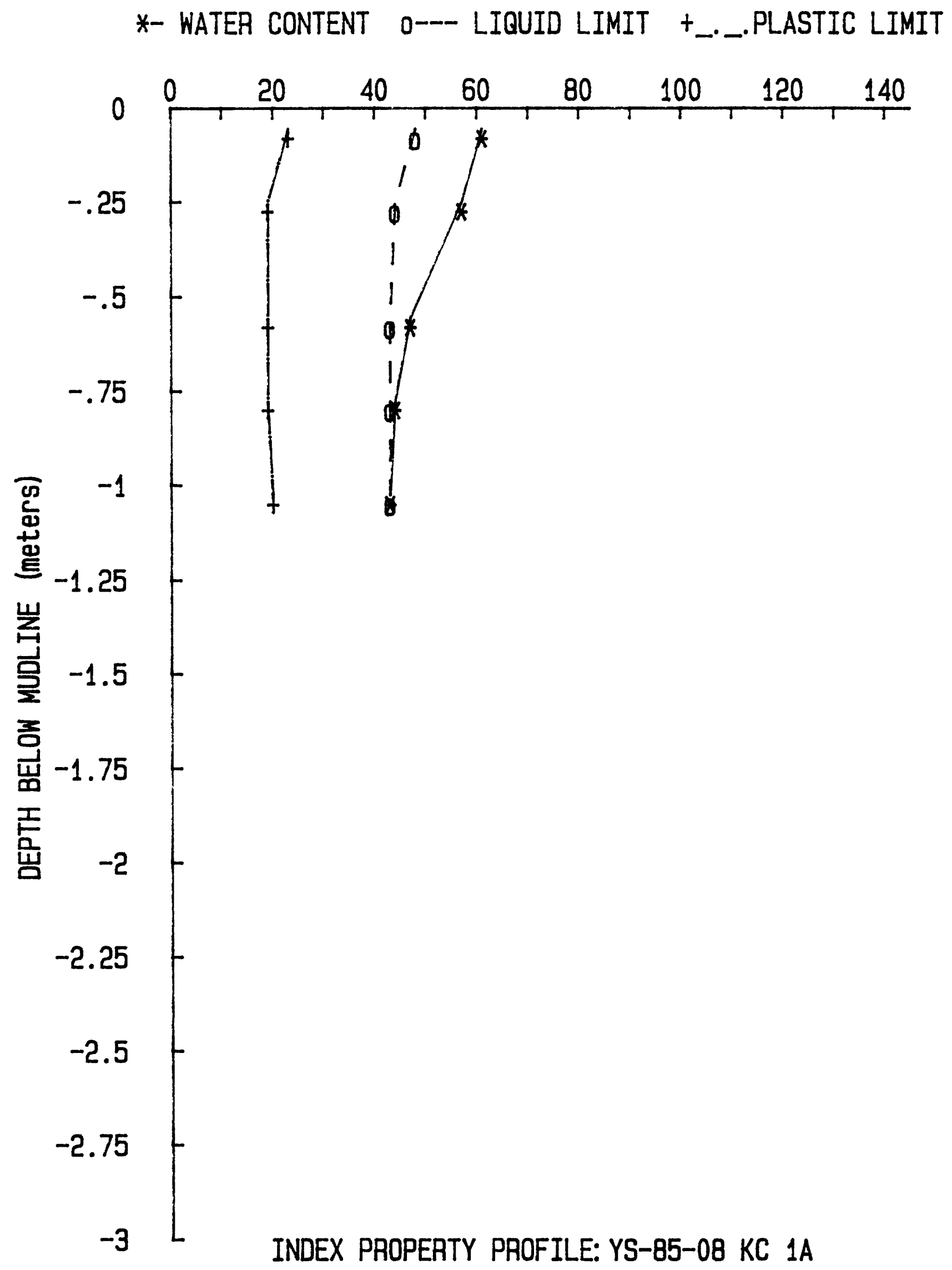




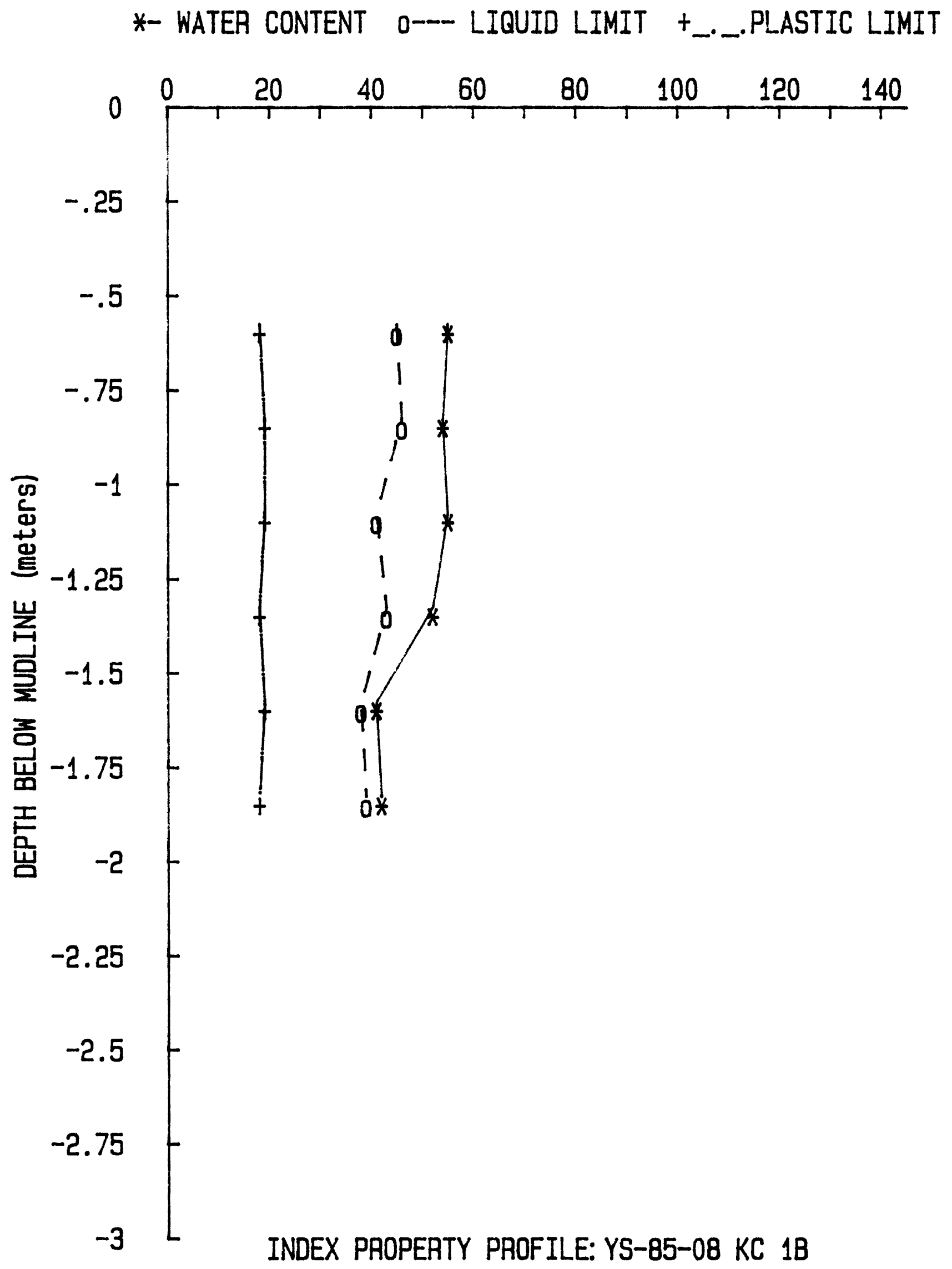




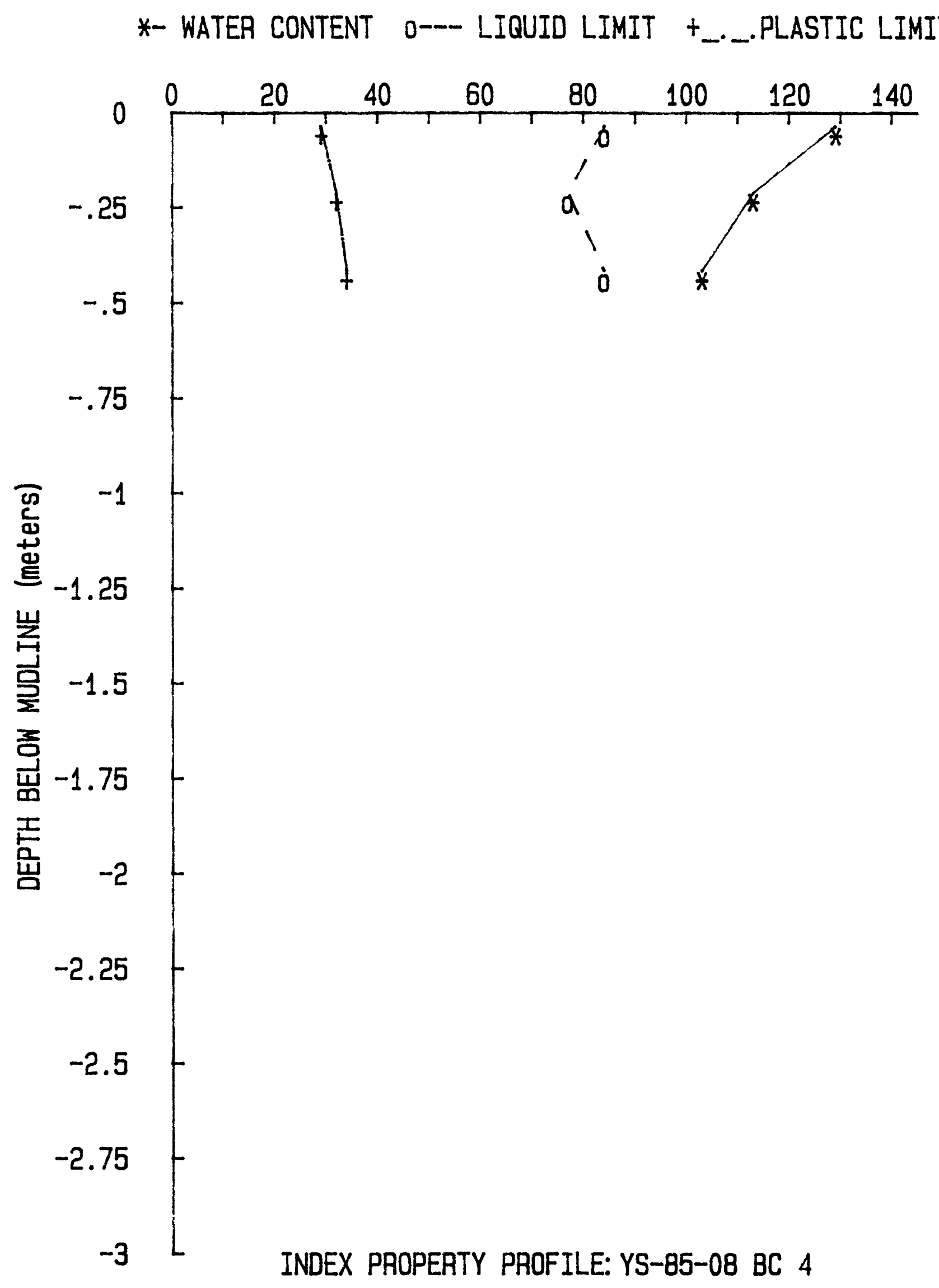




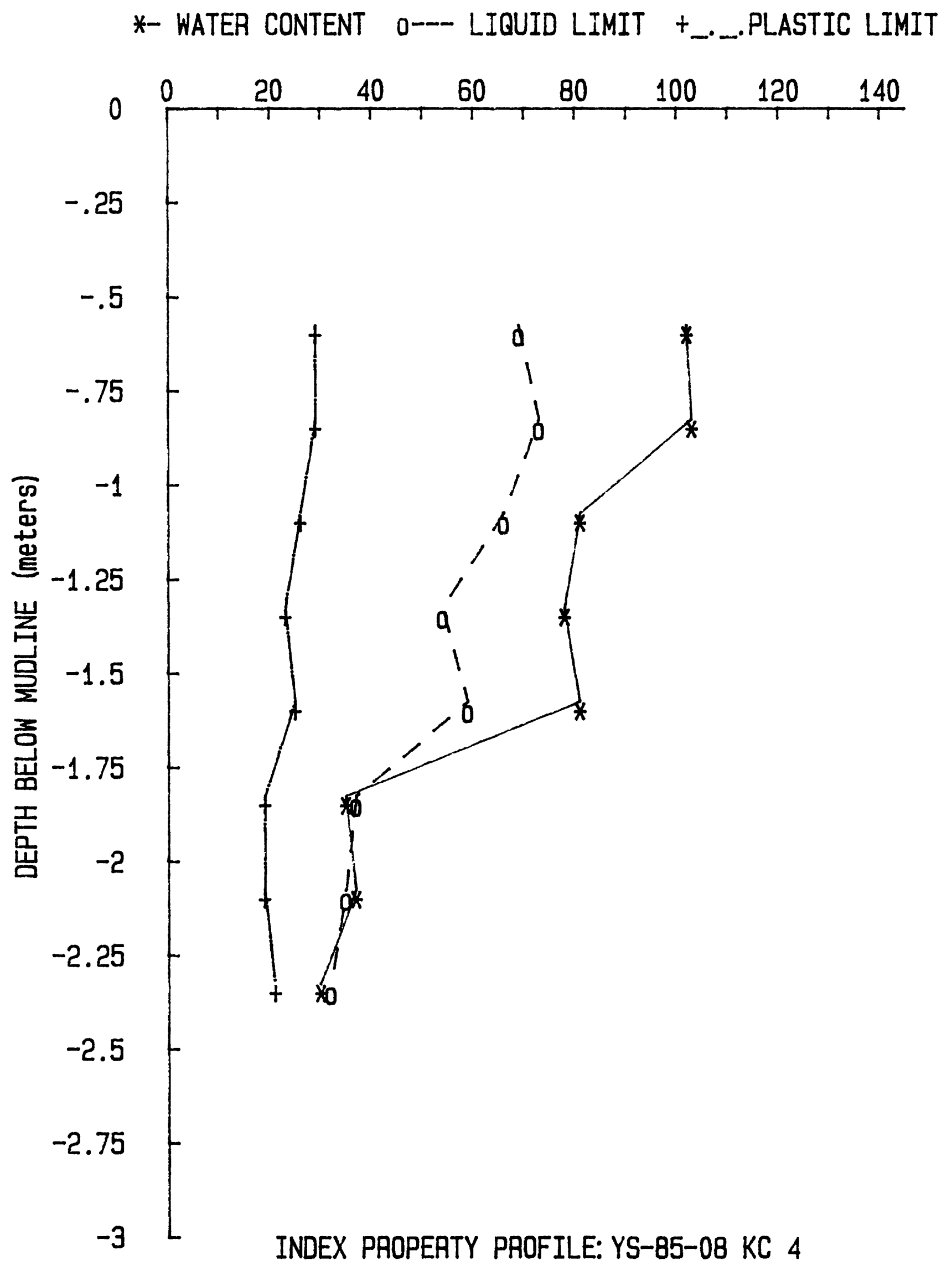




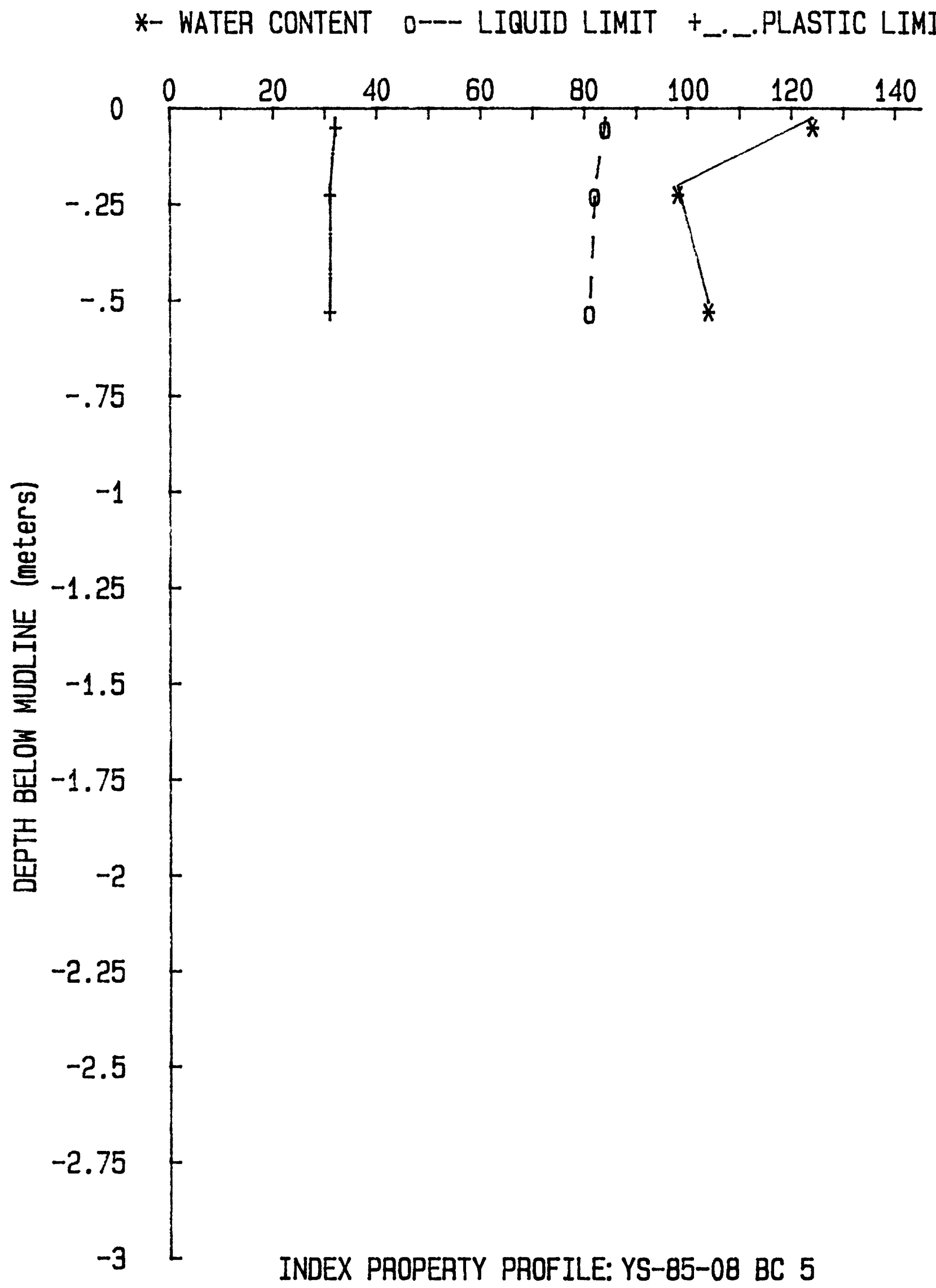




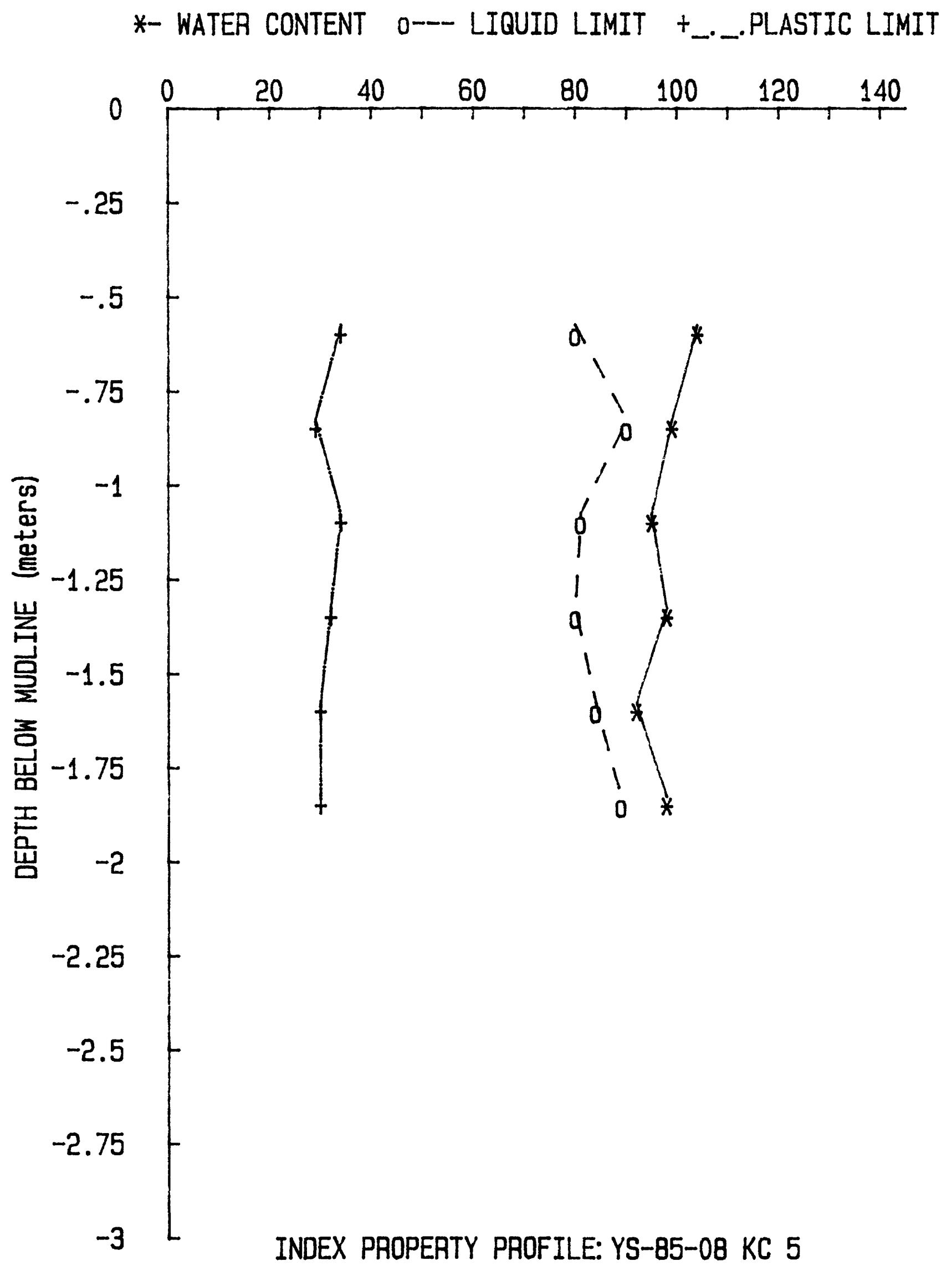




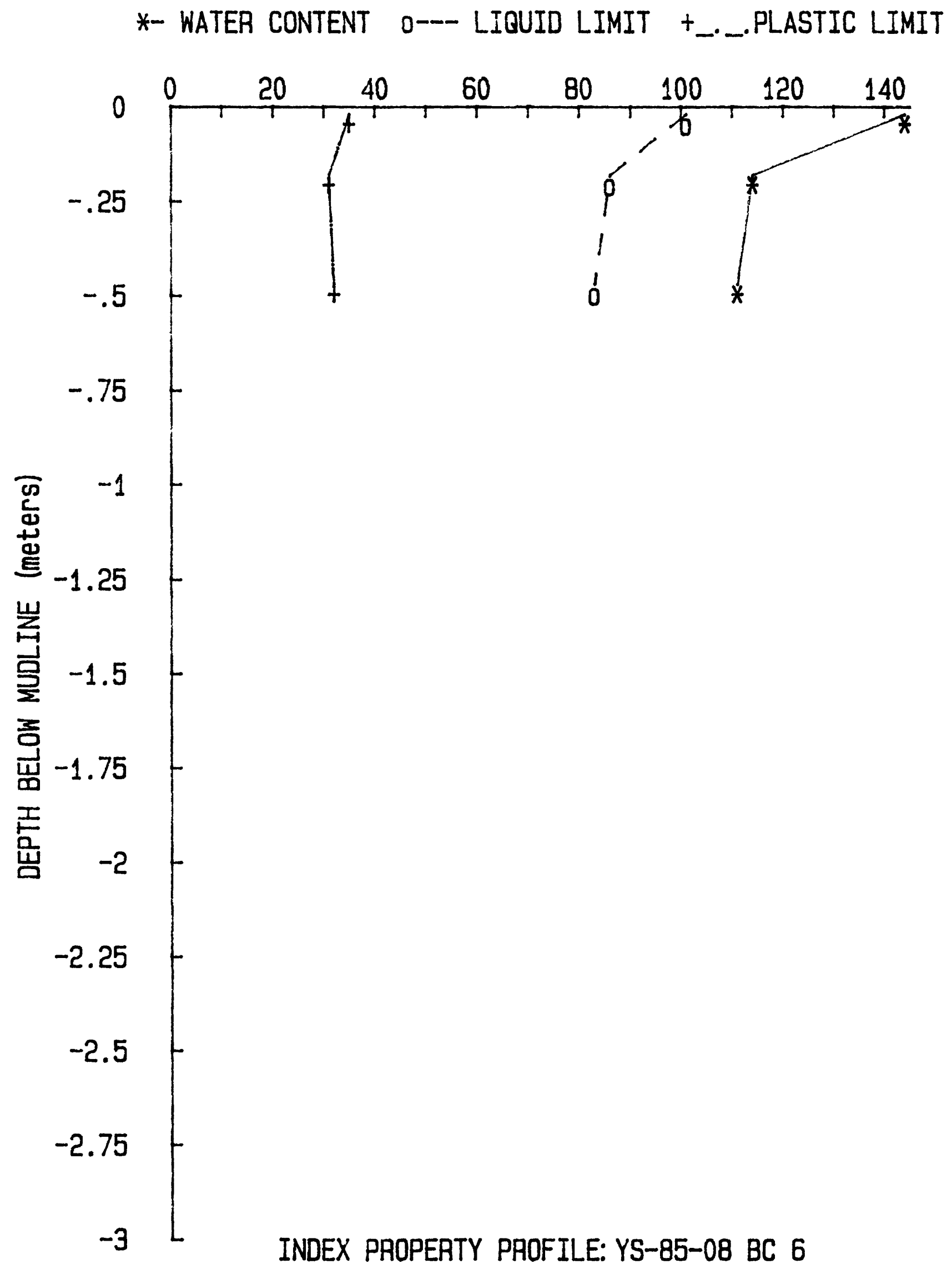




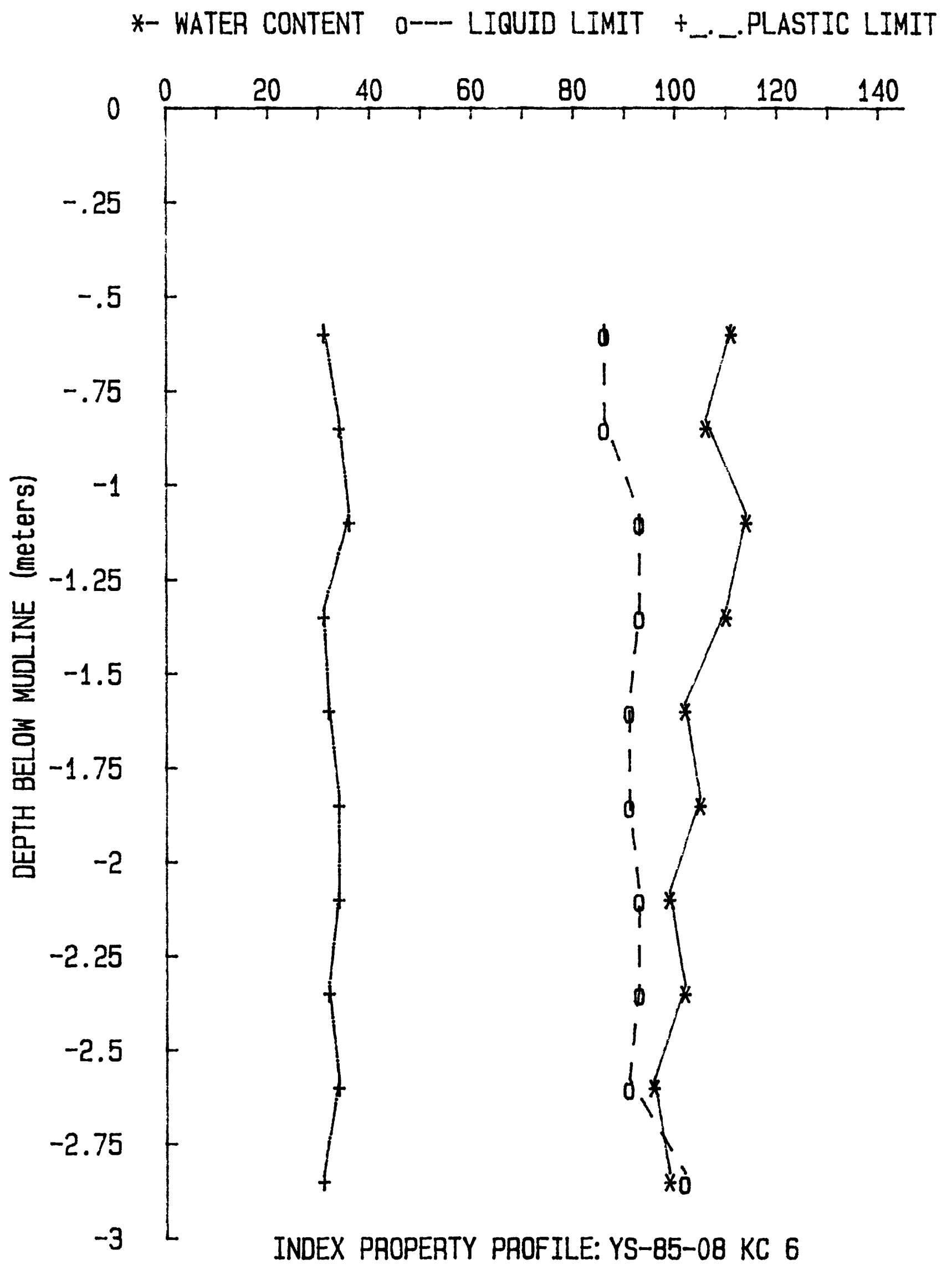




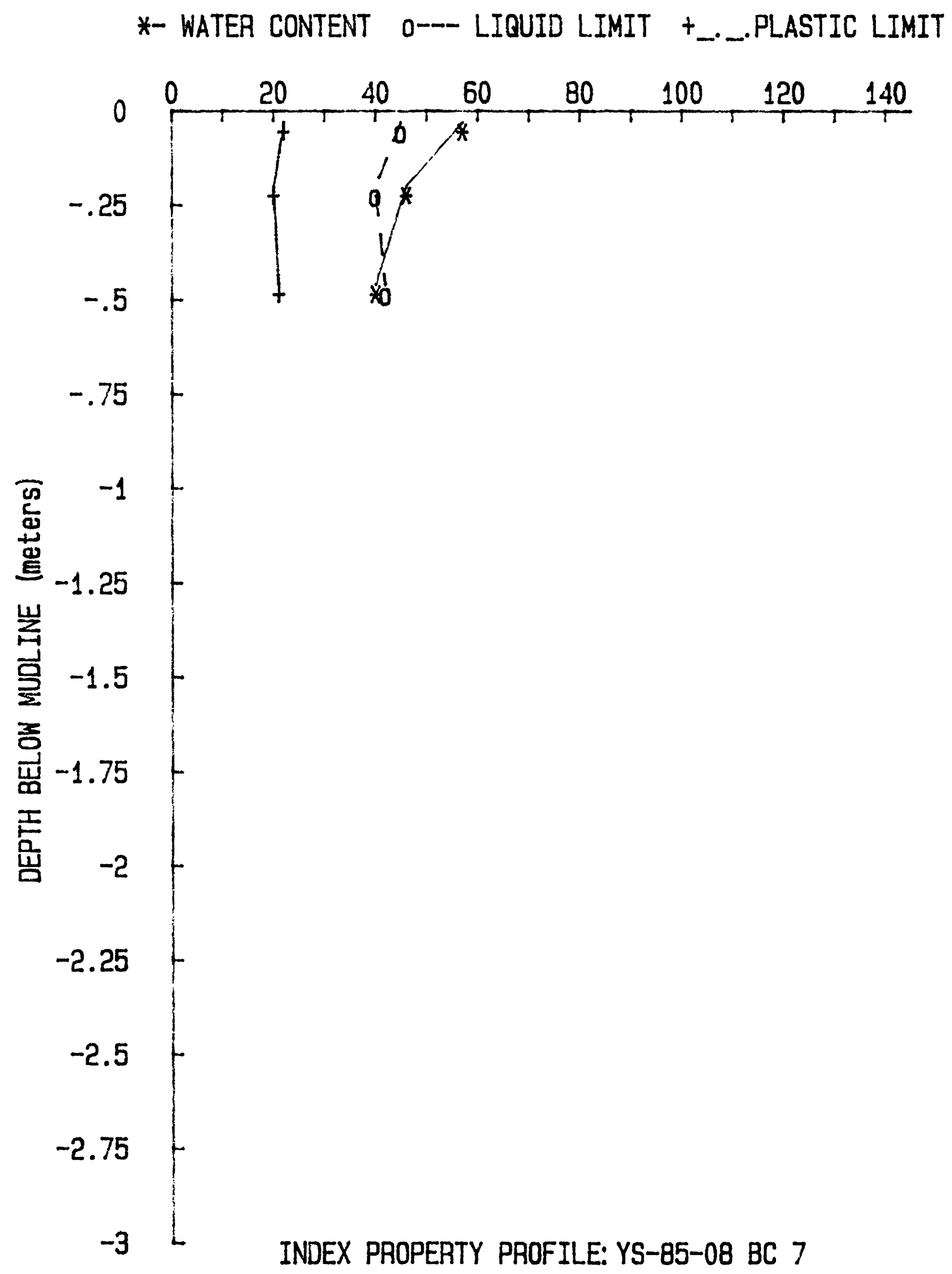




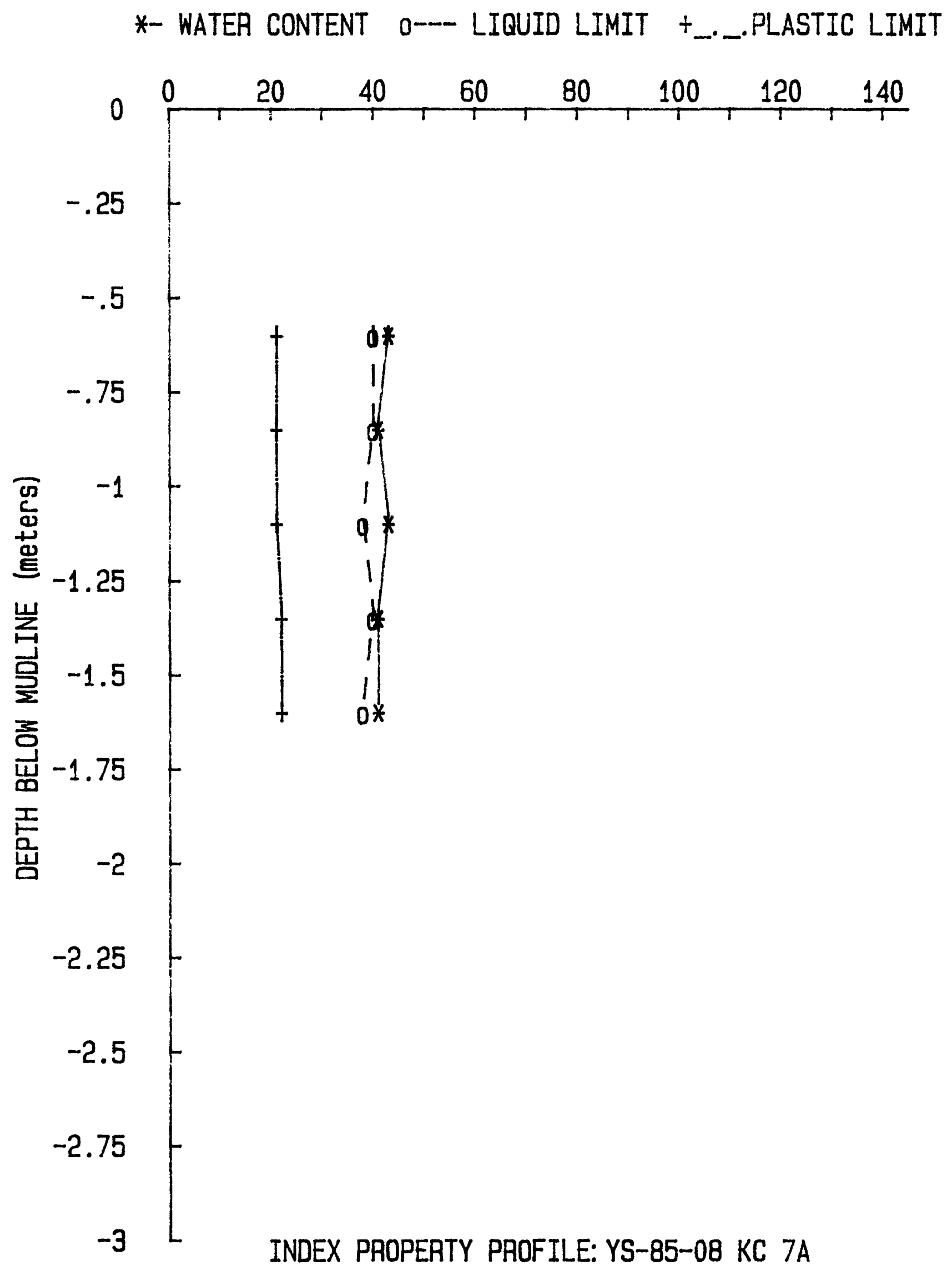




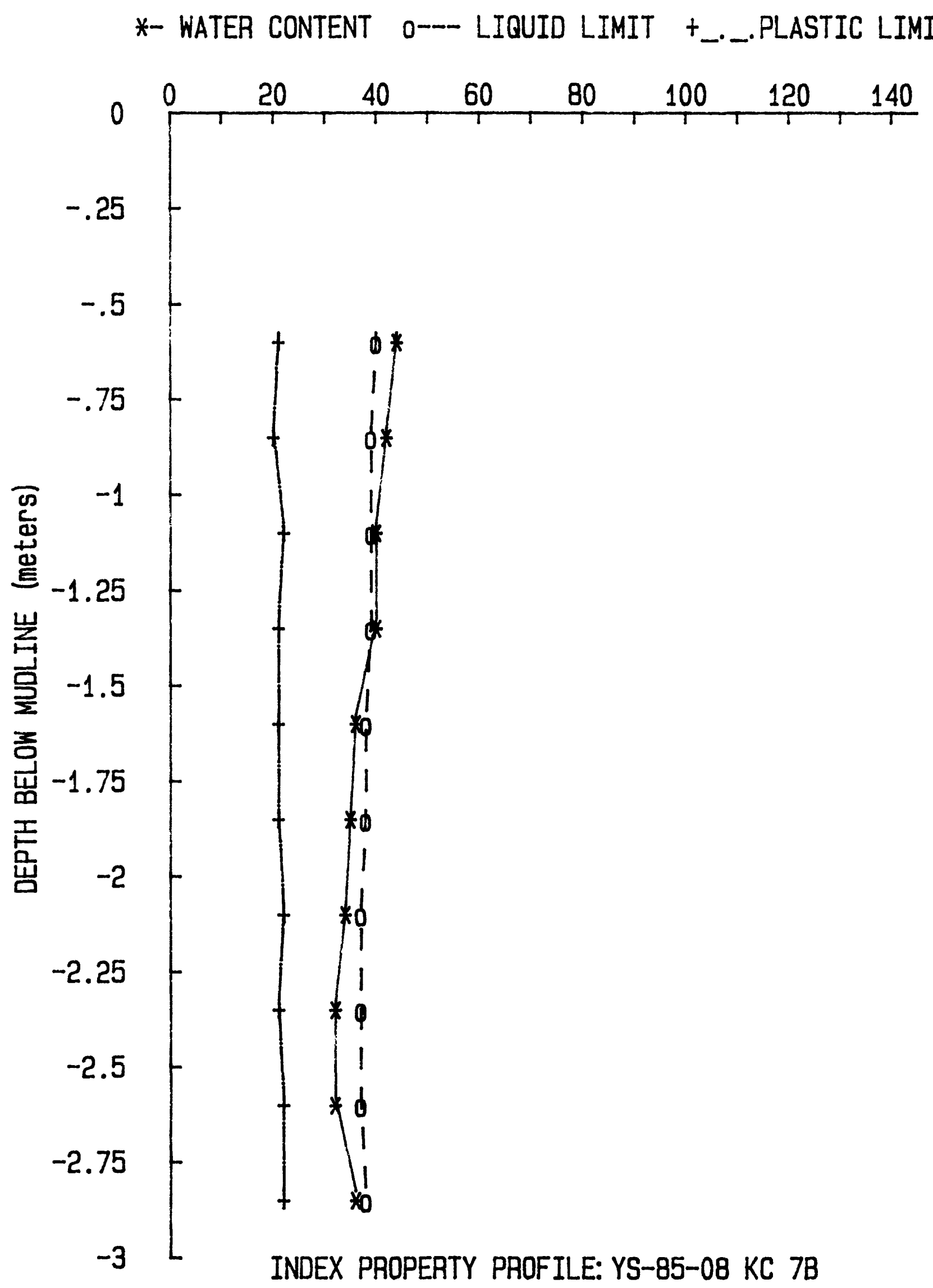




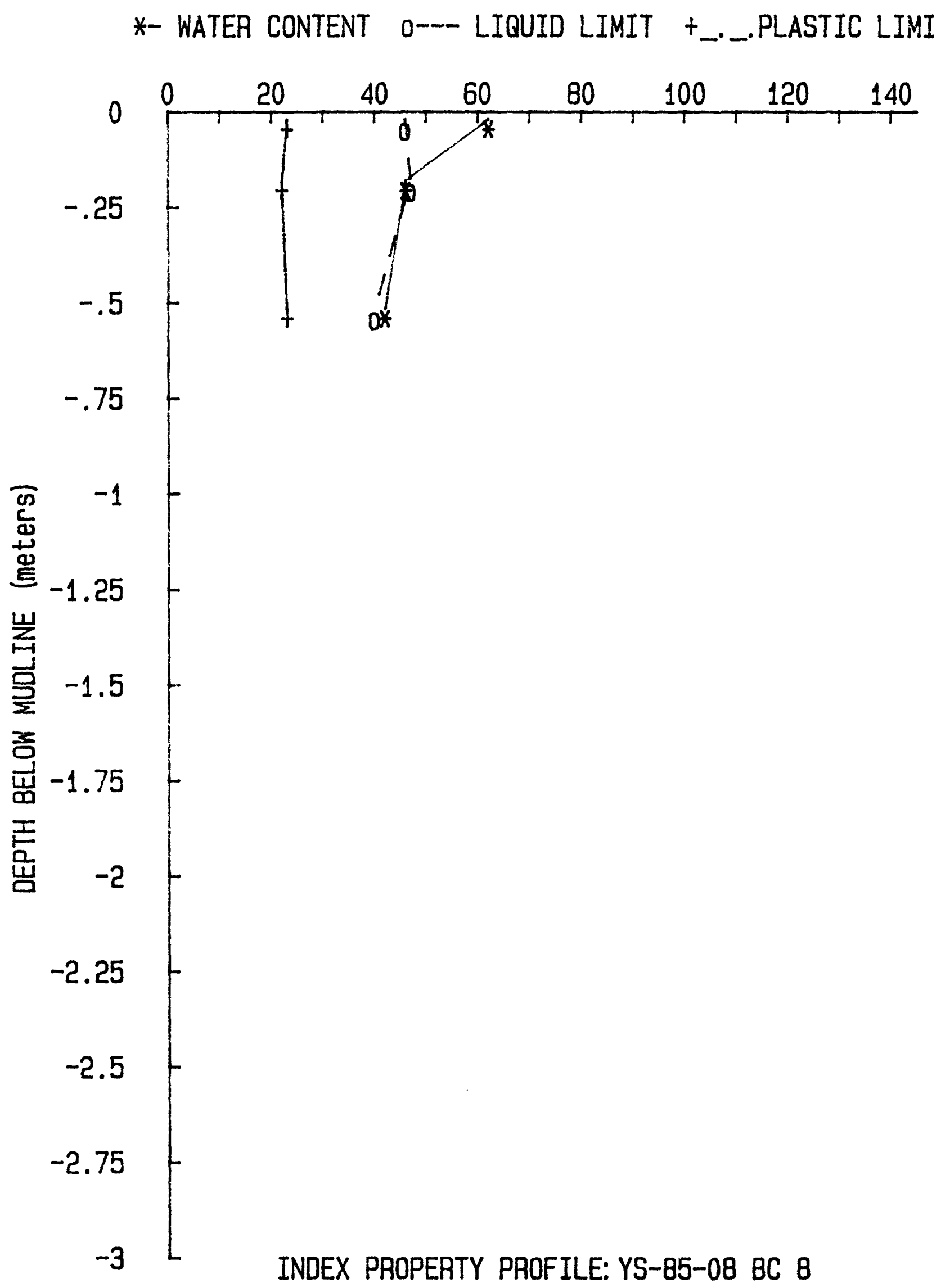




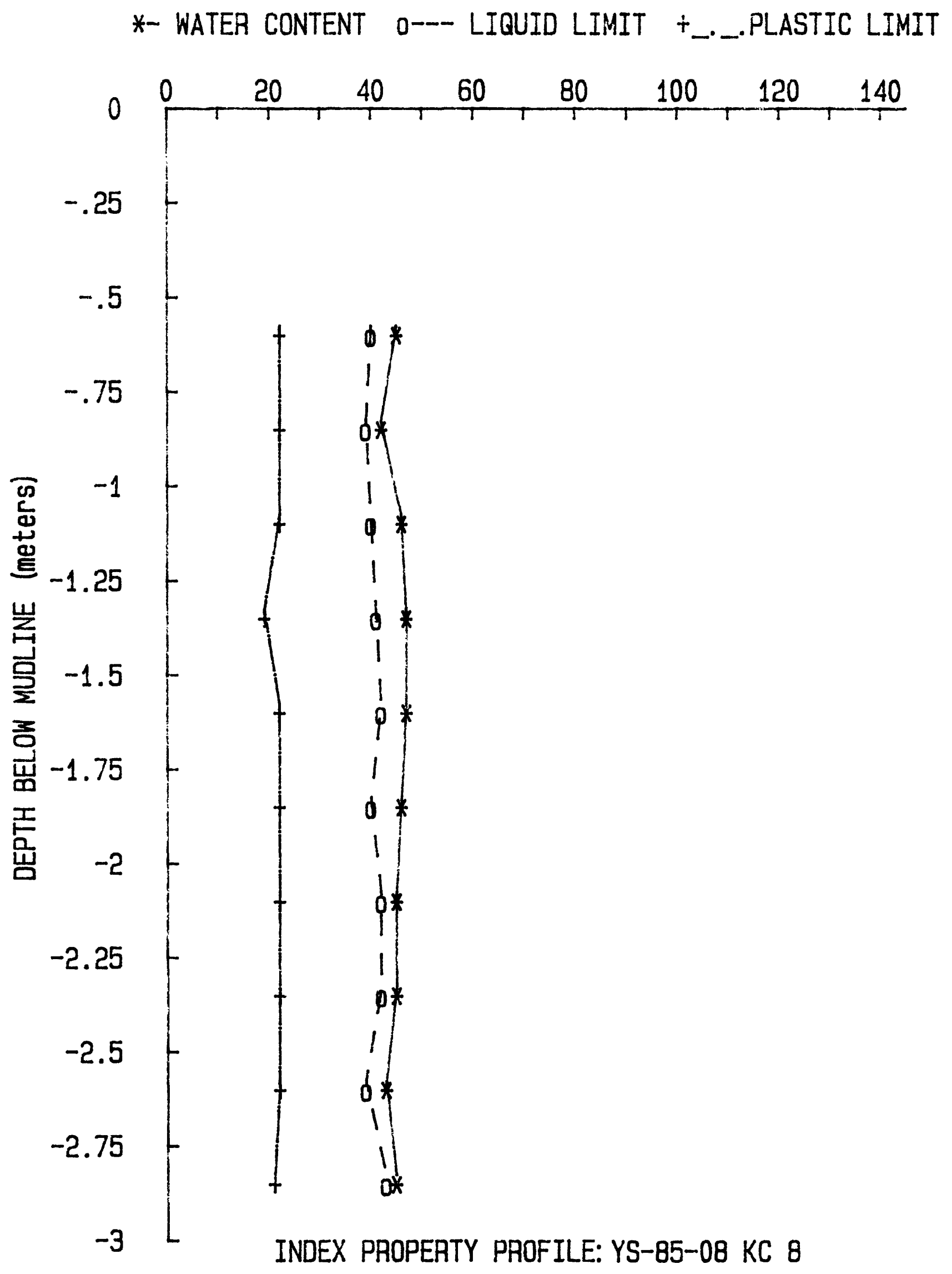




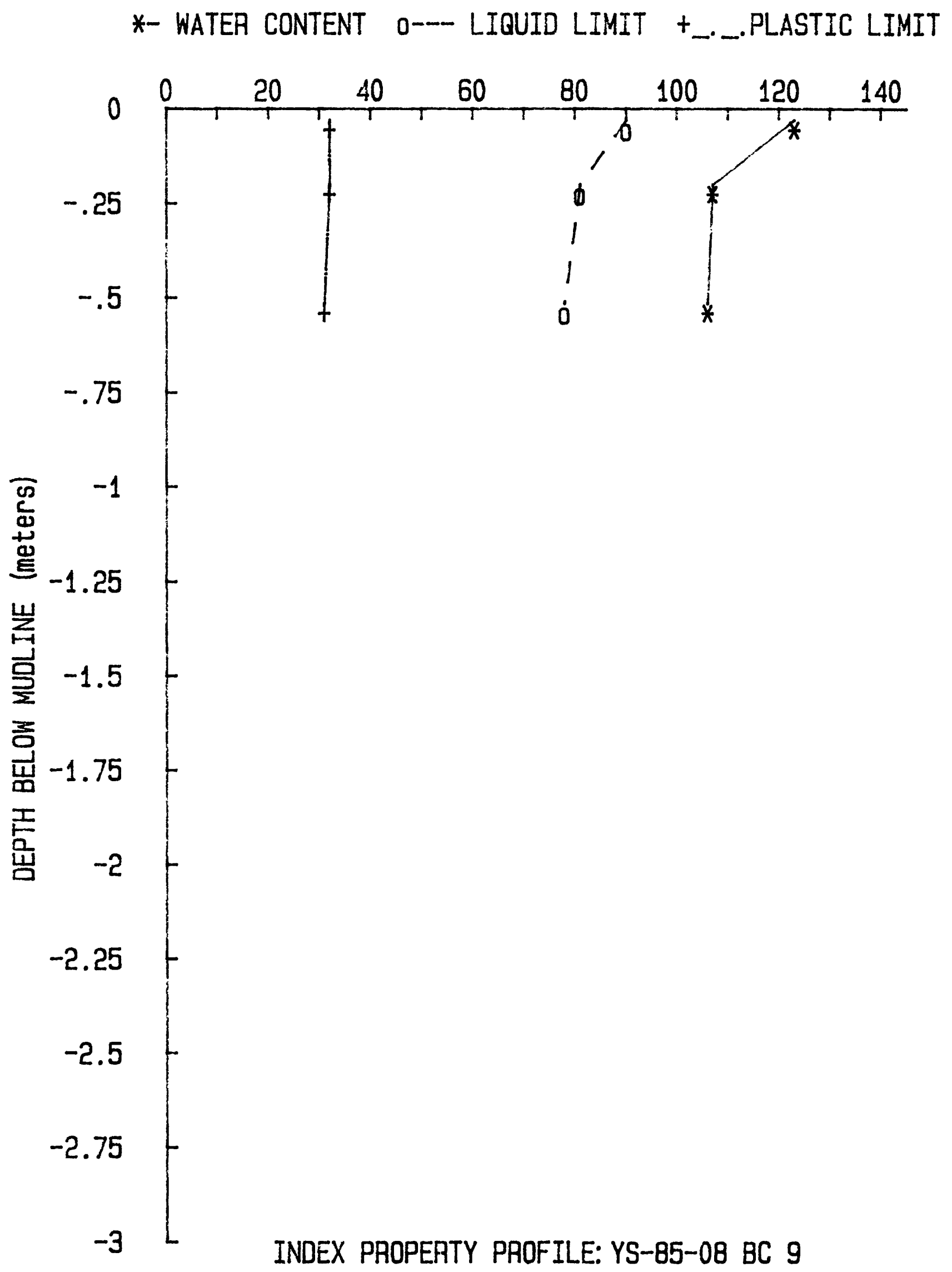




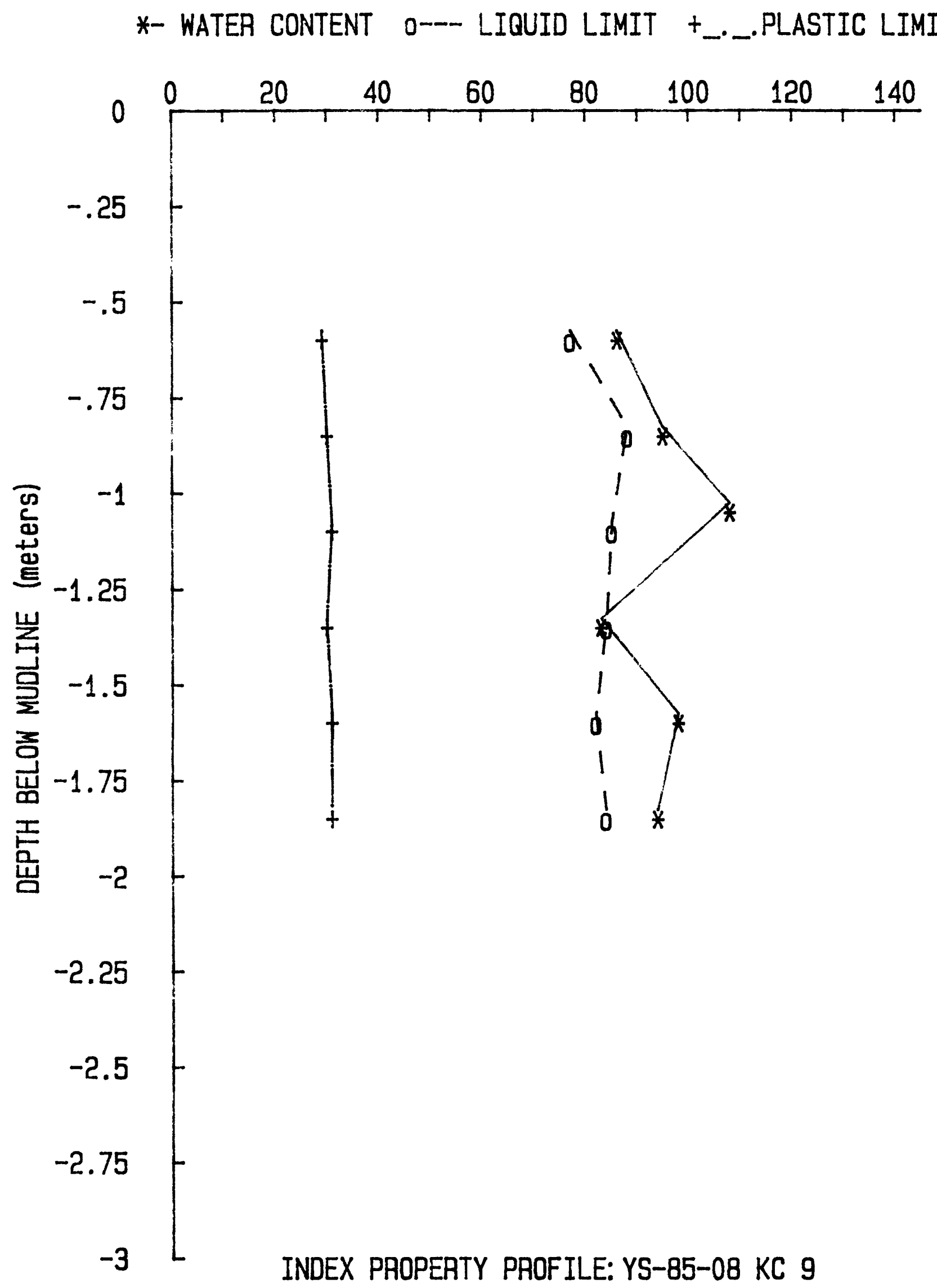




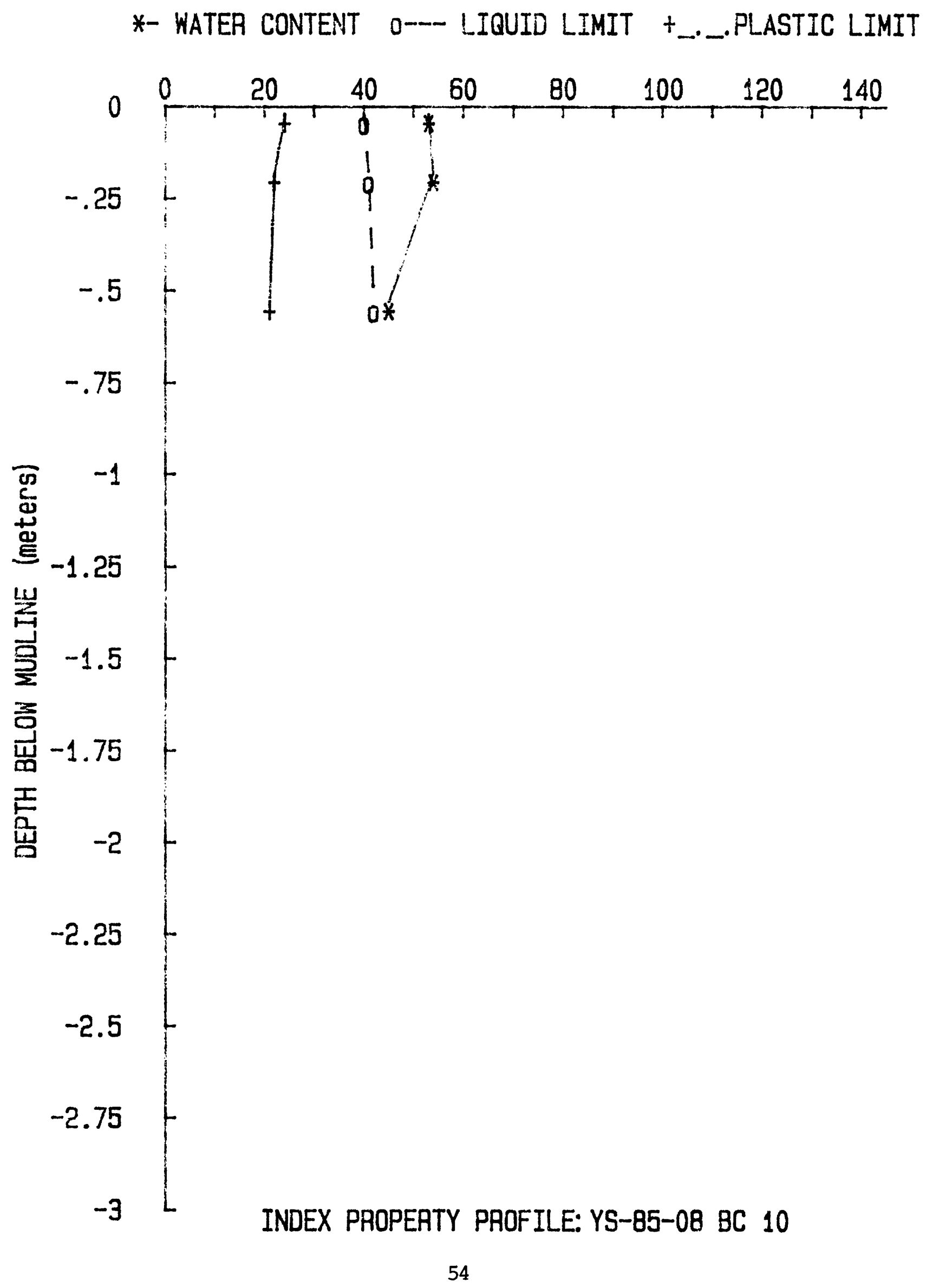




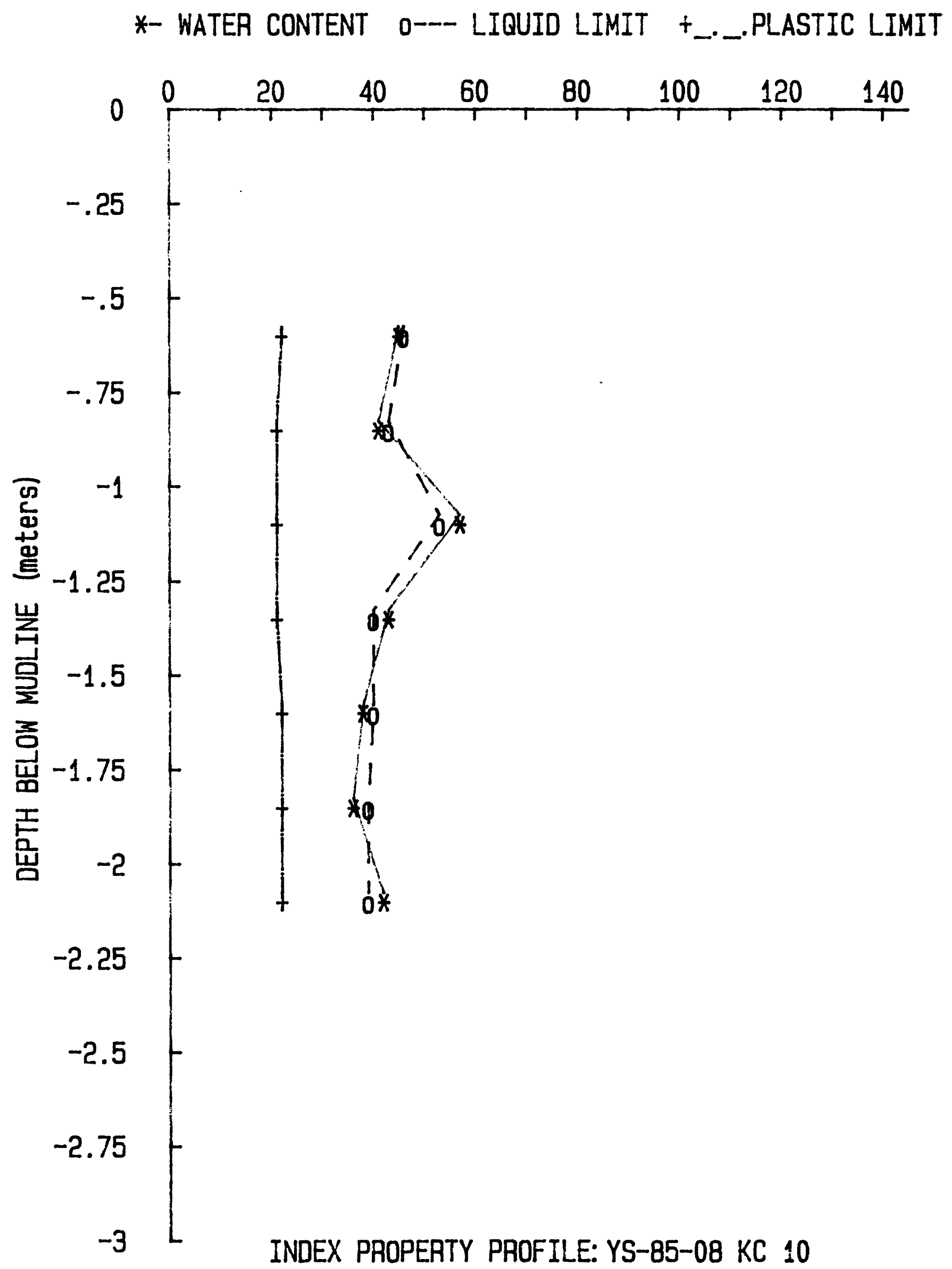




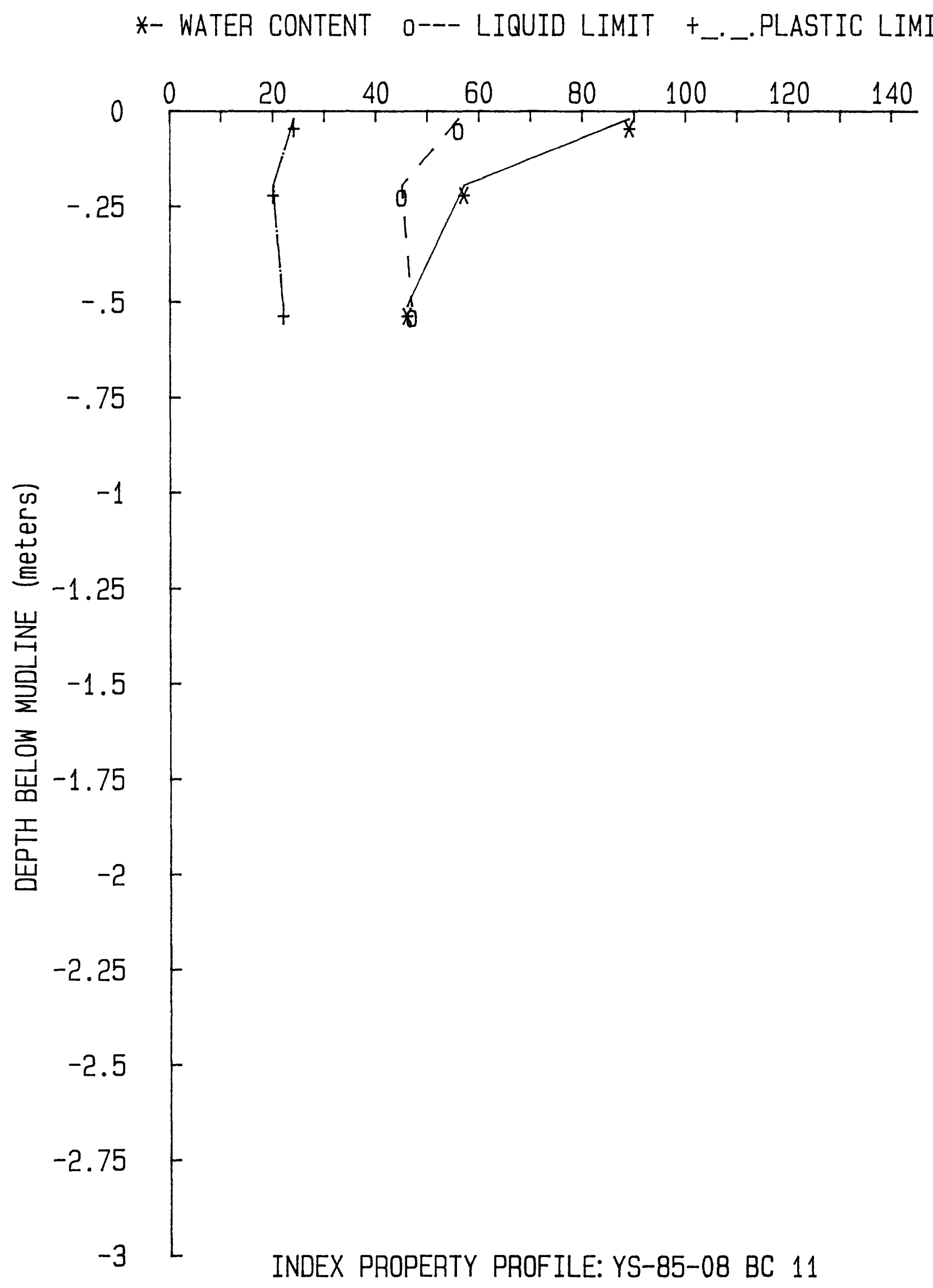




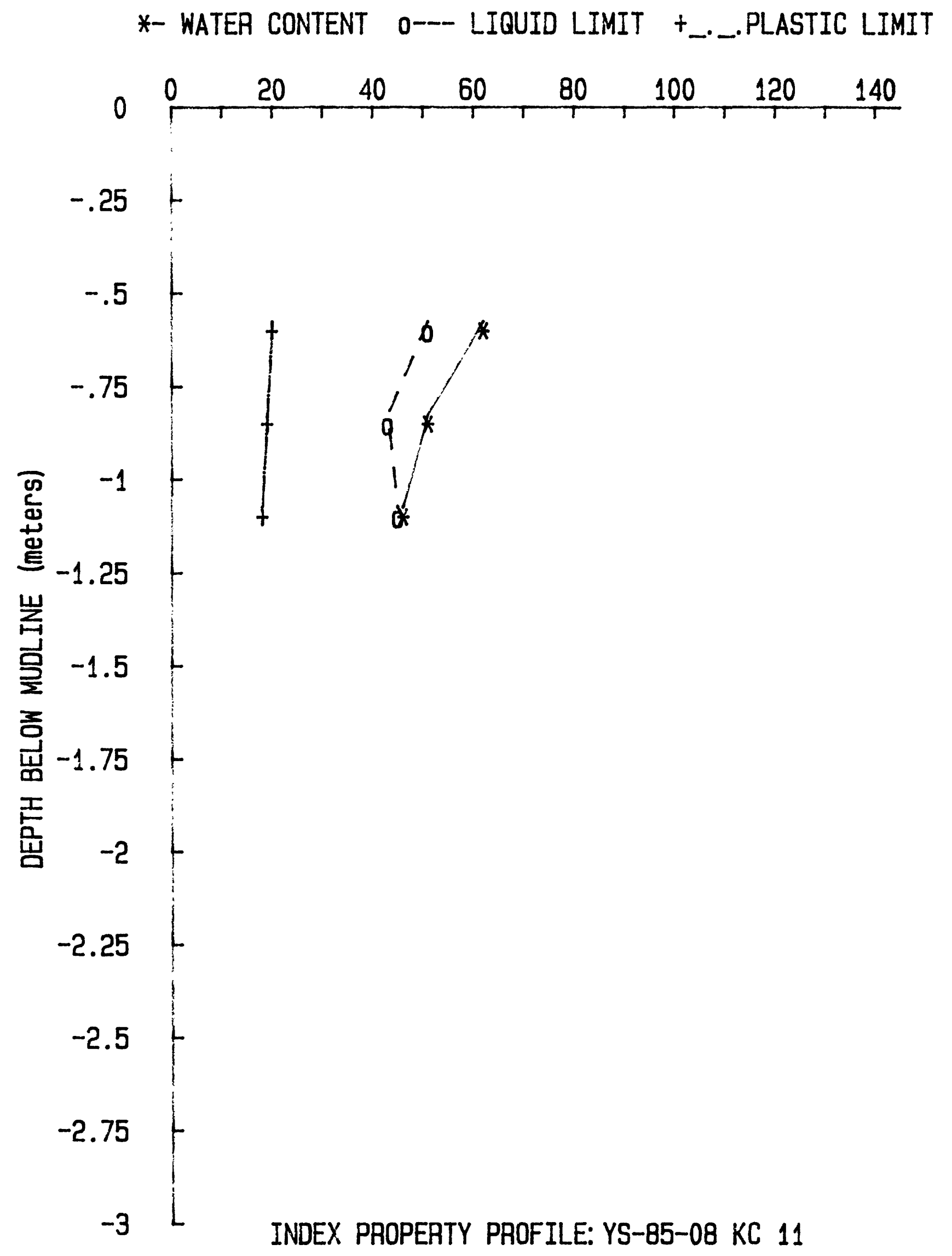




\section{PROFILES \\ Water content \\ Bulk density \\ Porosity \\ Grain specific gravity}




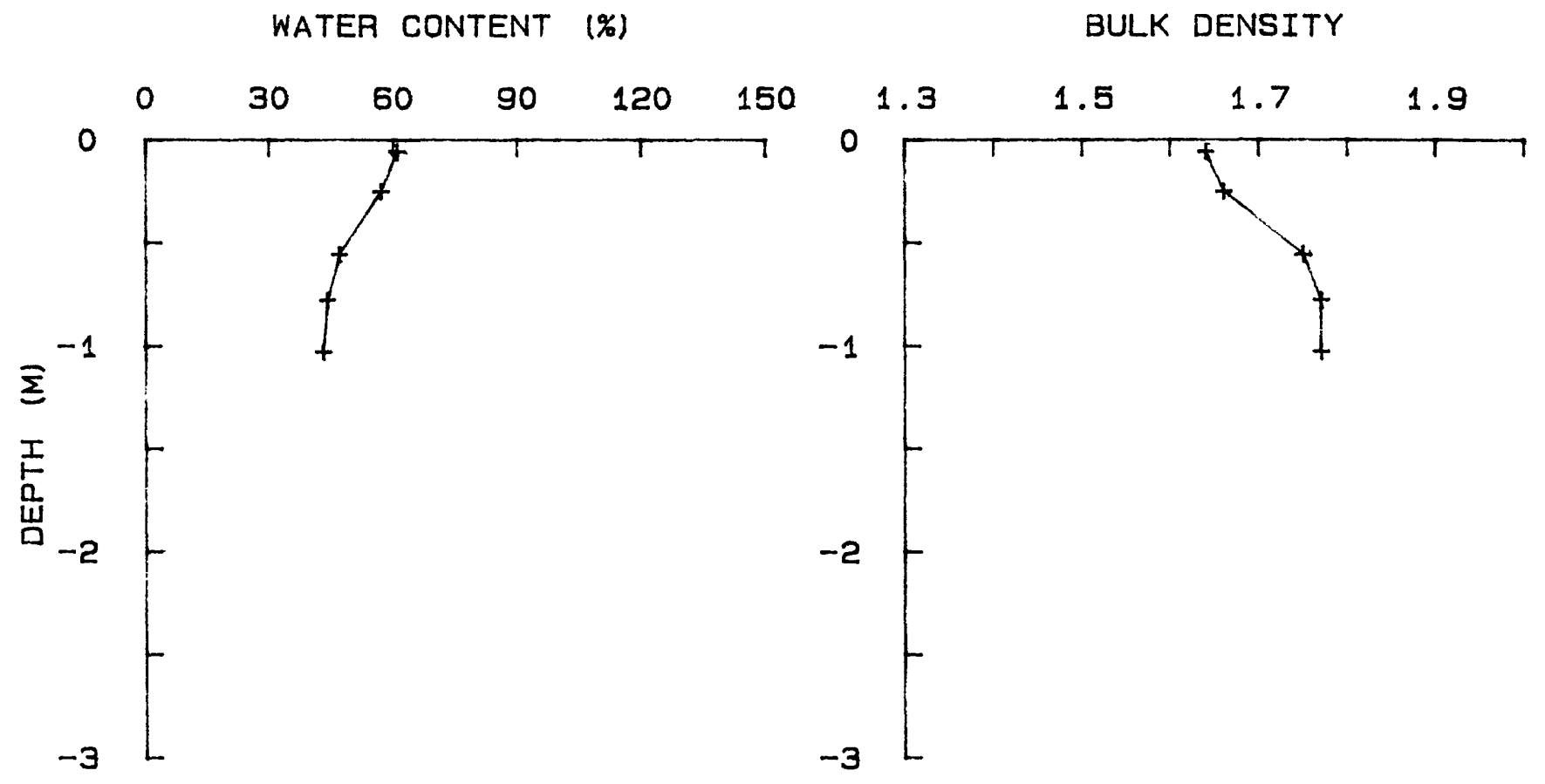

$$
\text { YS-85-08 KC } 1 \mathrm{~A}
$$

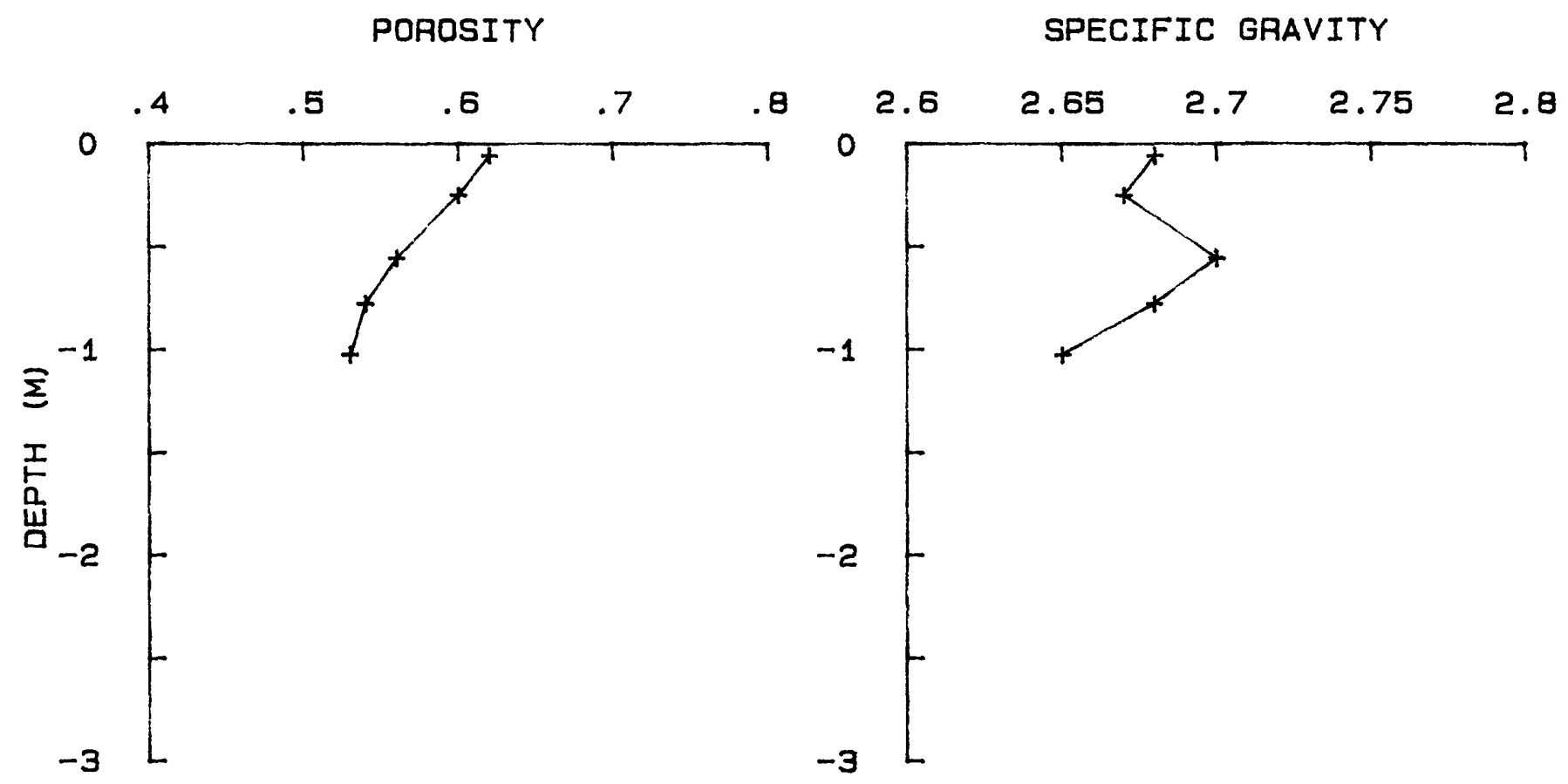




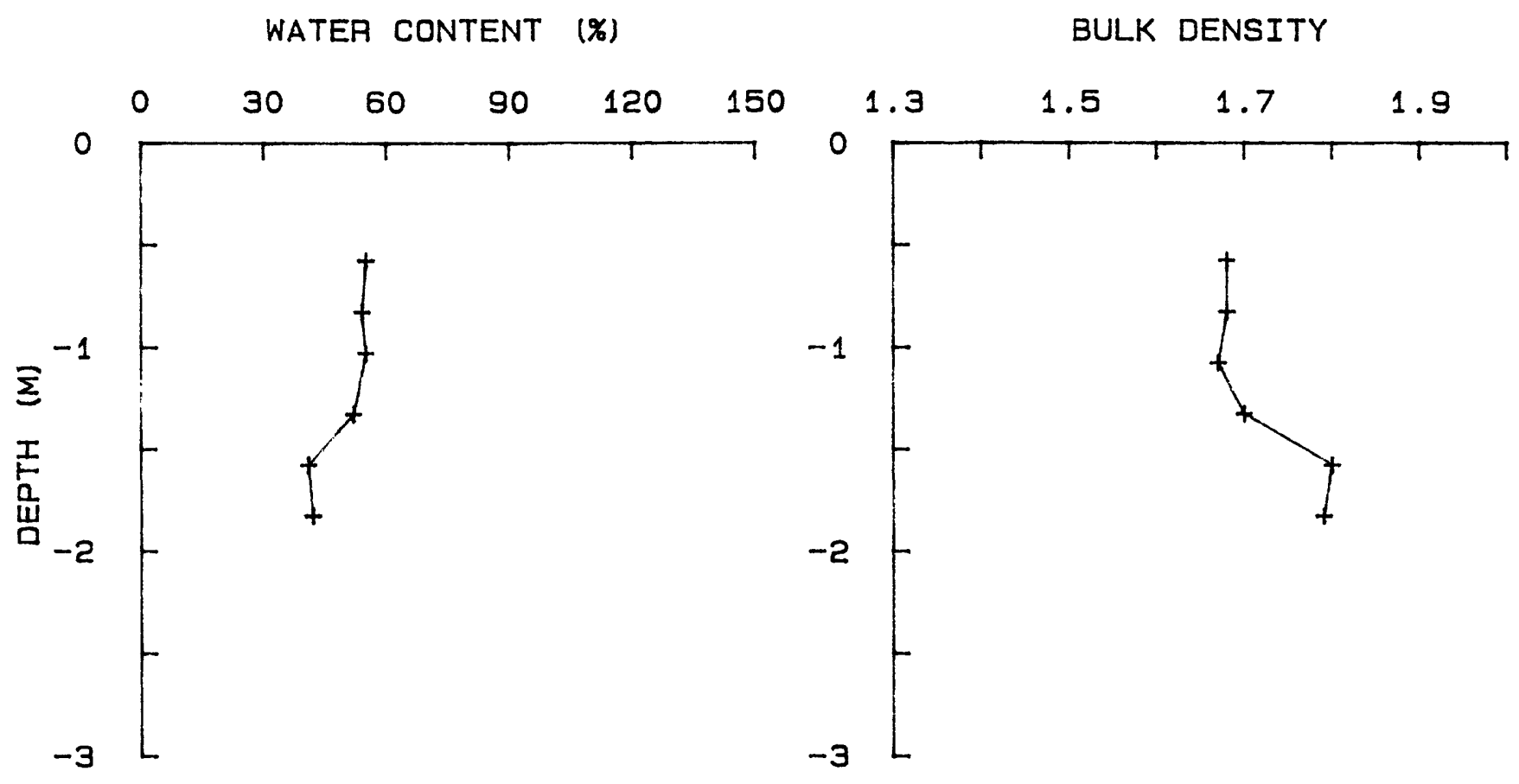

$Y S-85-08 \quad K C \quad 1 B$

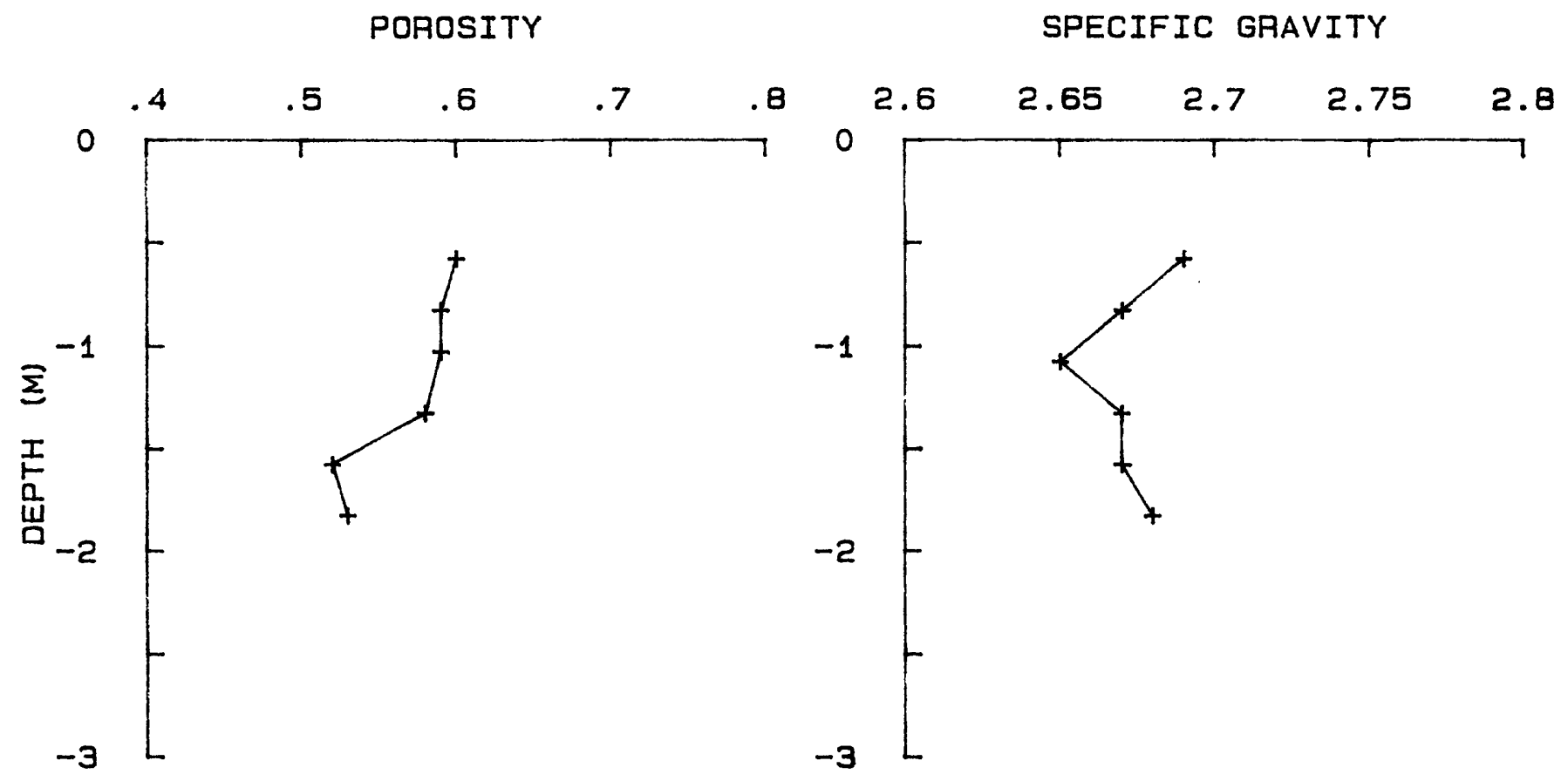




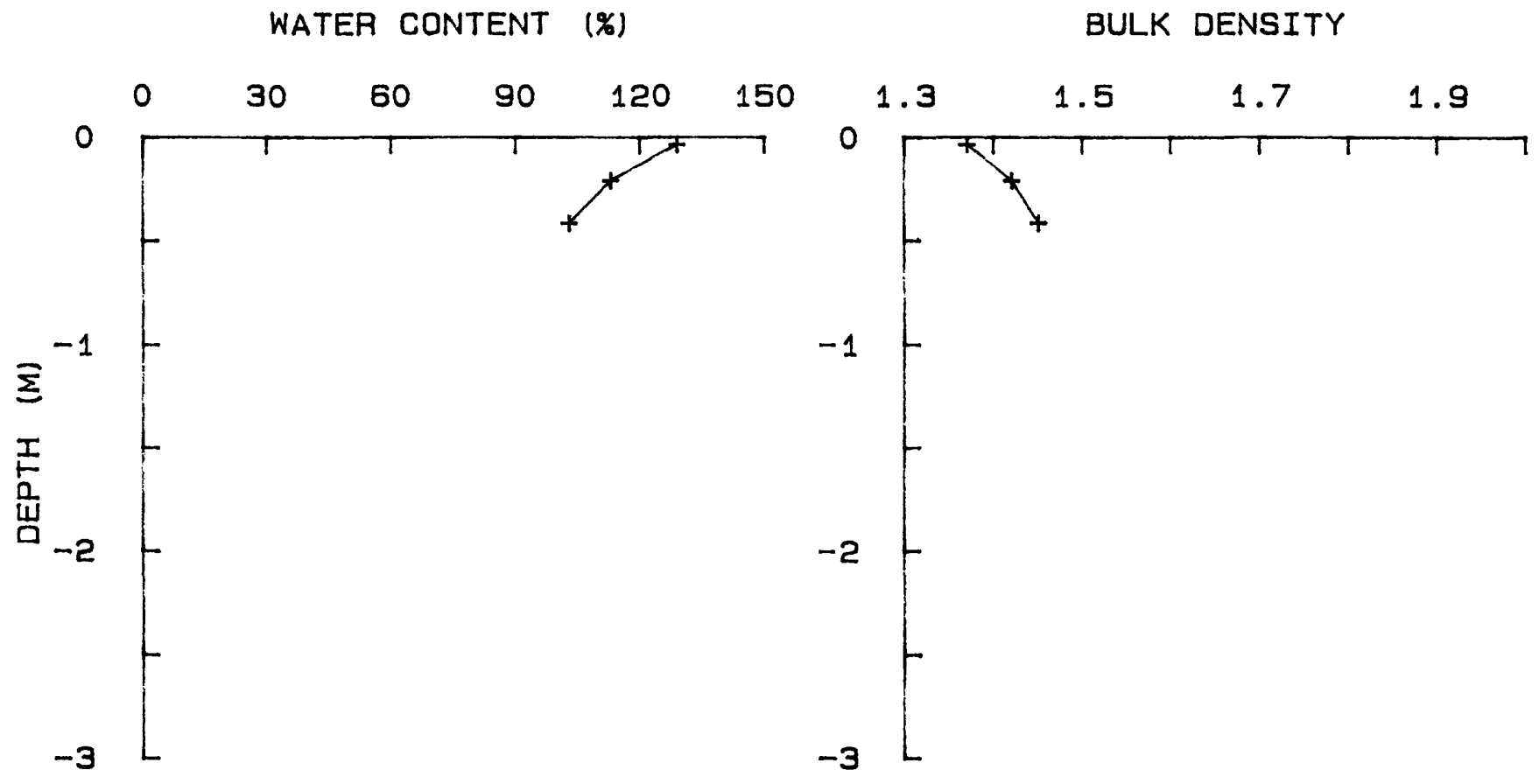

YS-85-08 BC 4

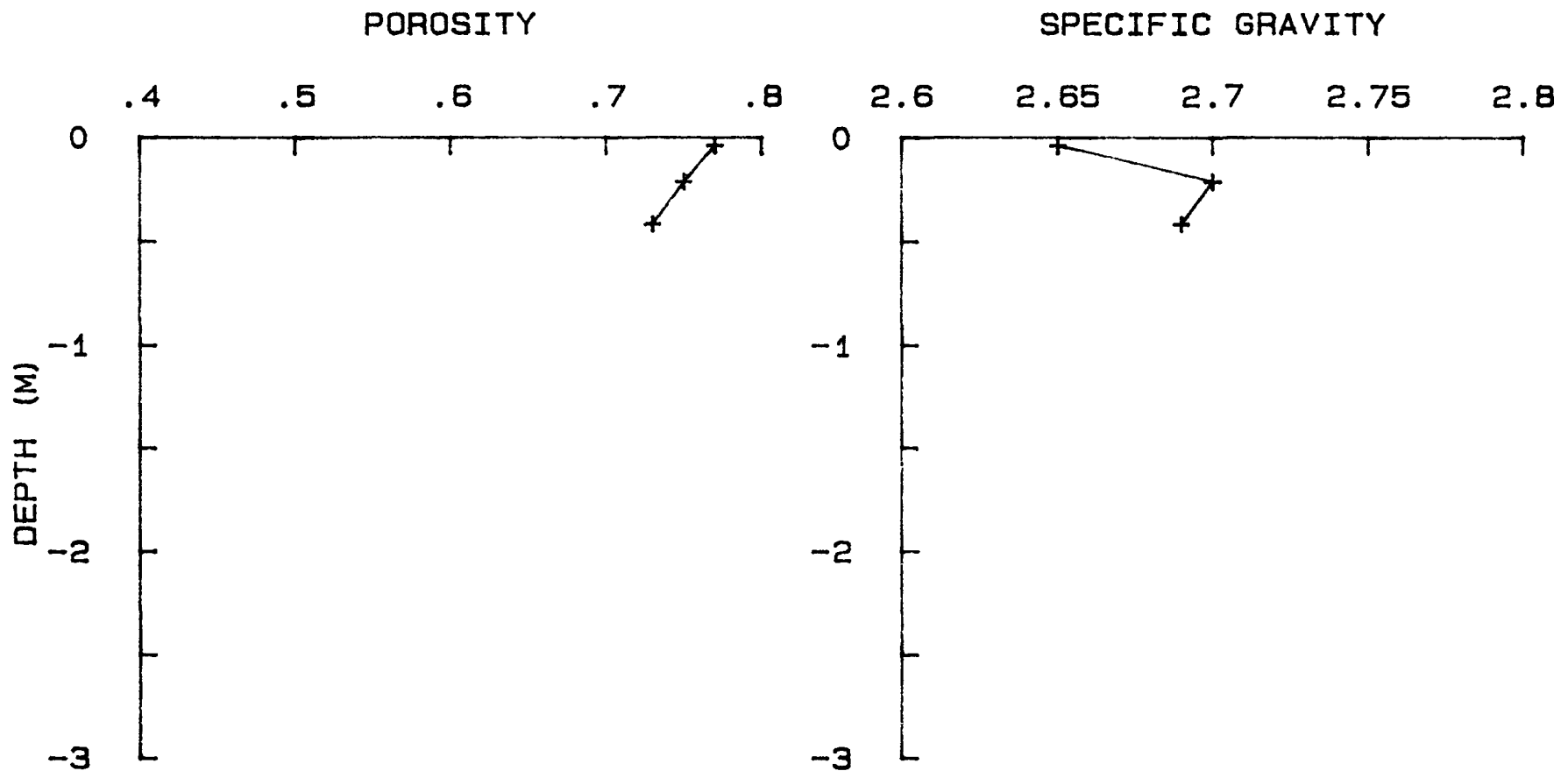




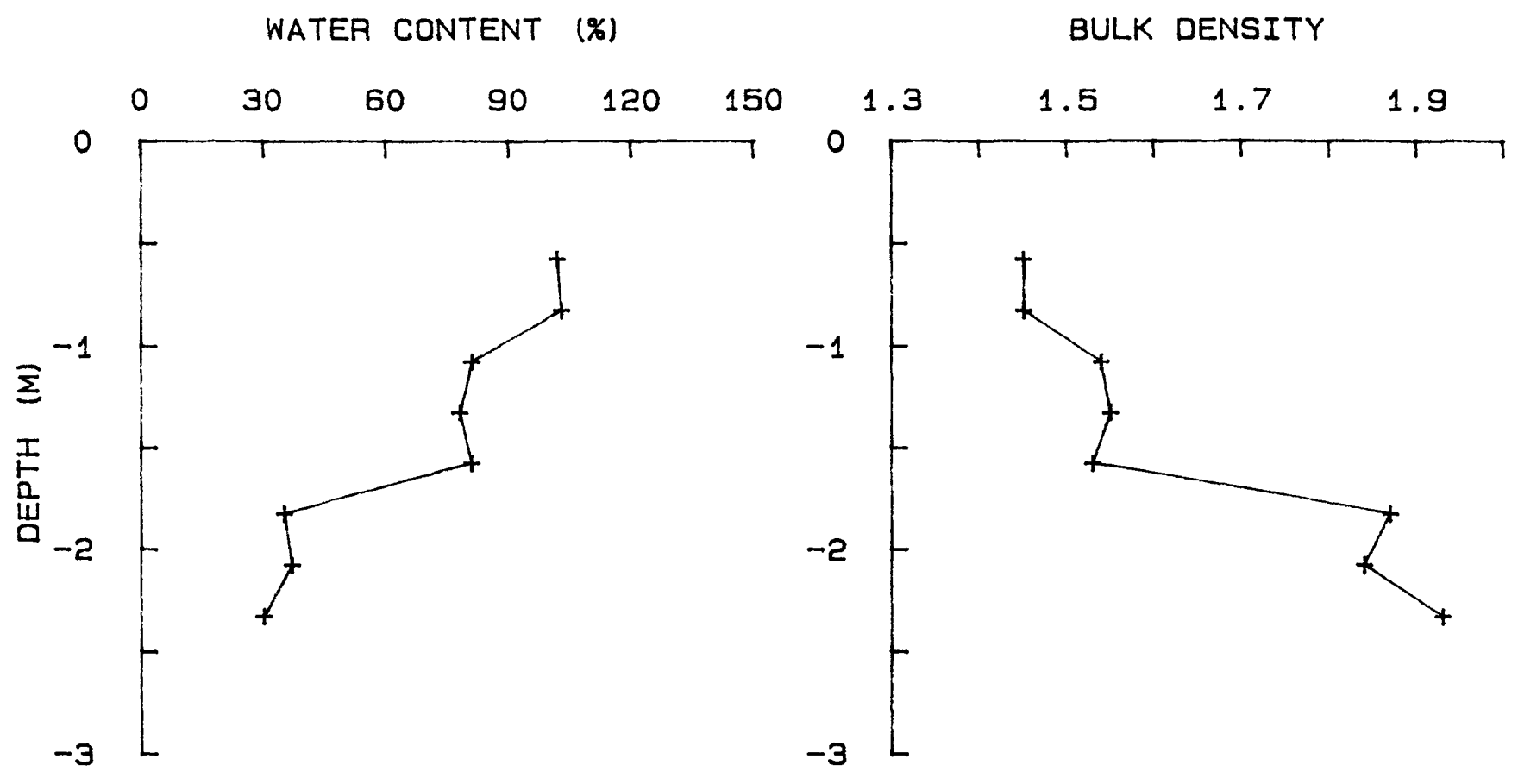

$$
\text { YS-85-08 KC } 4
$$

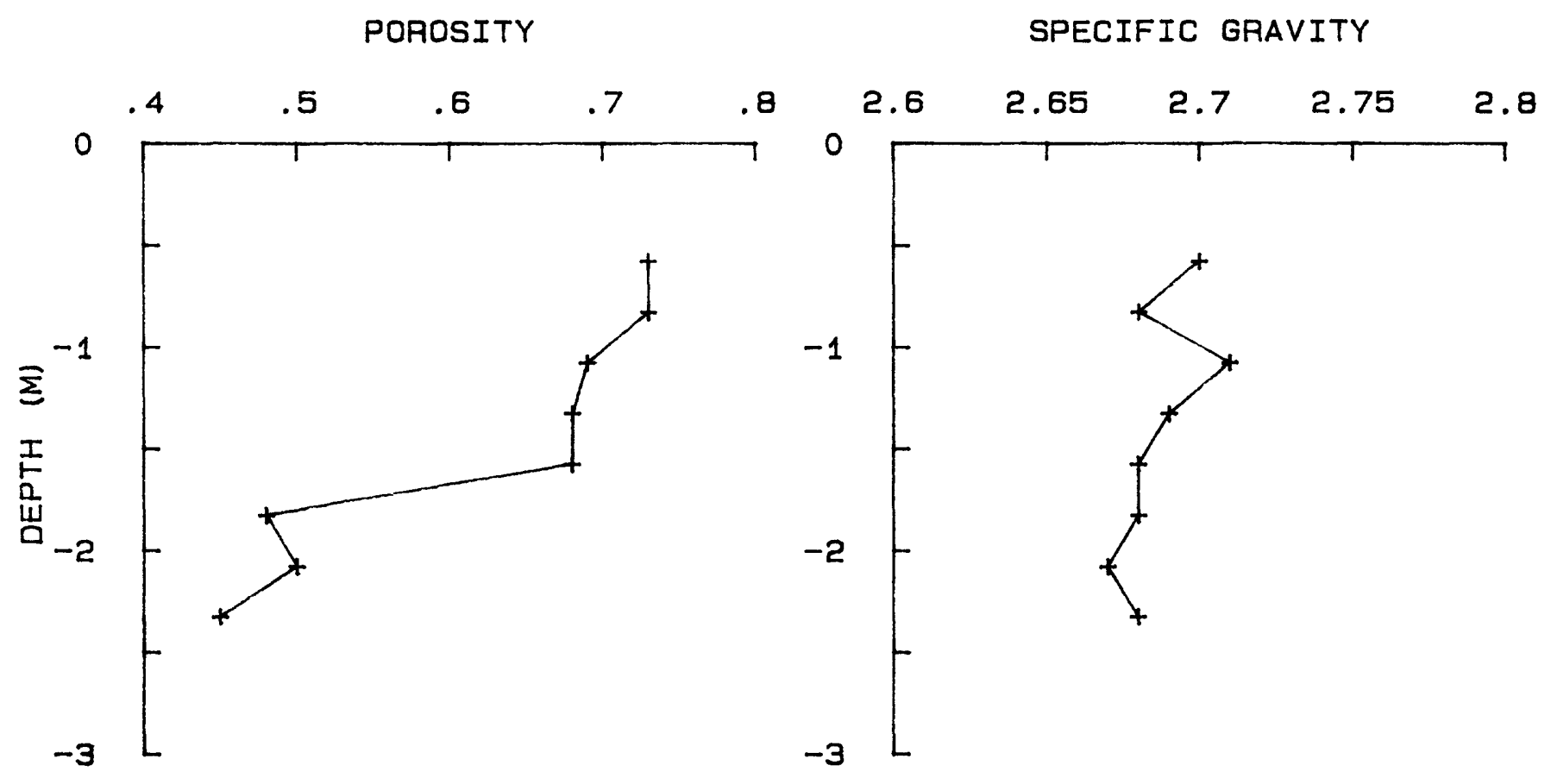




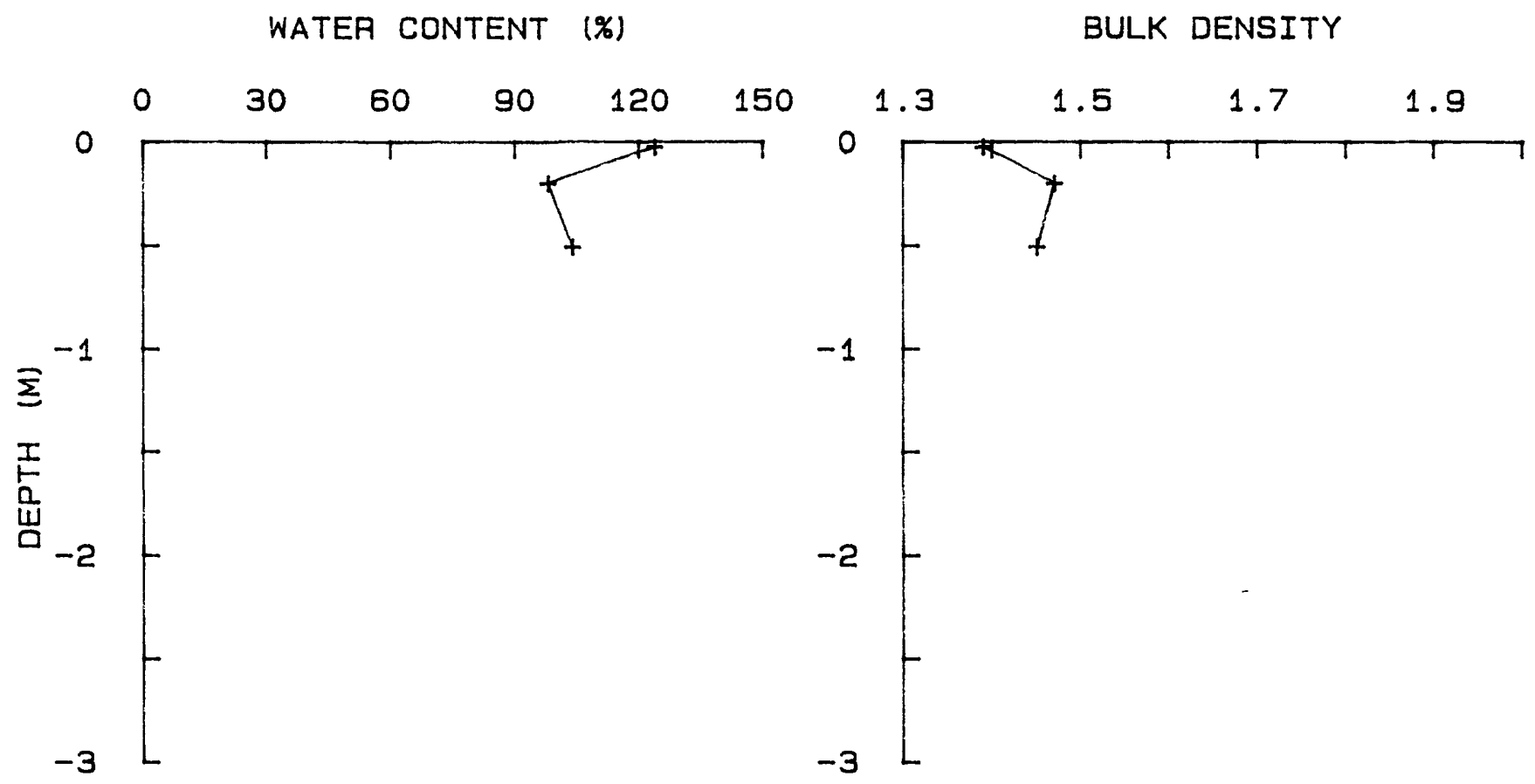

$$
\text { YS-85-08 BC } 5
$$

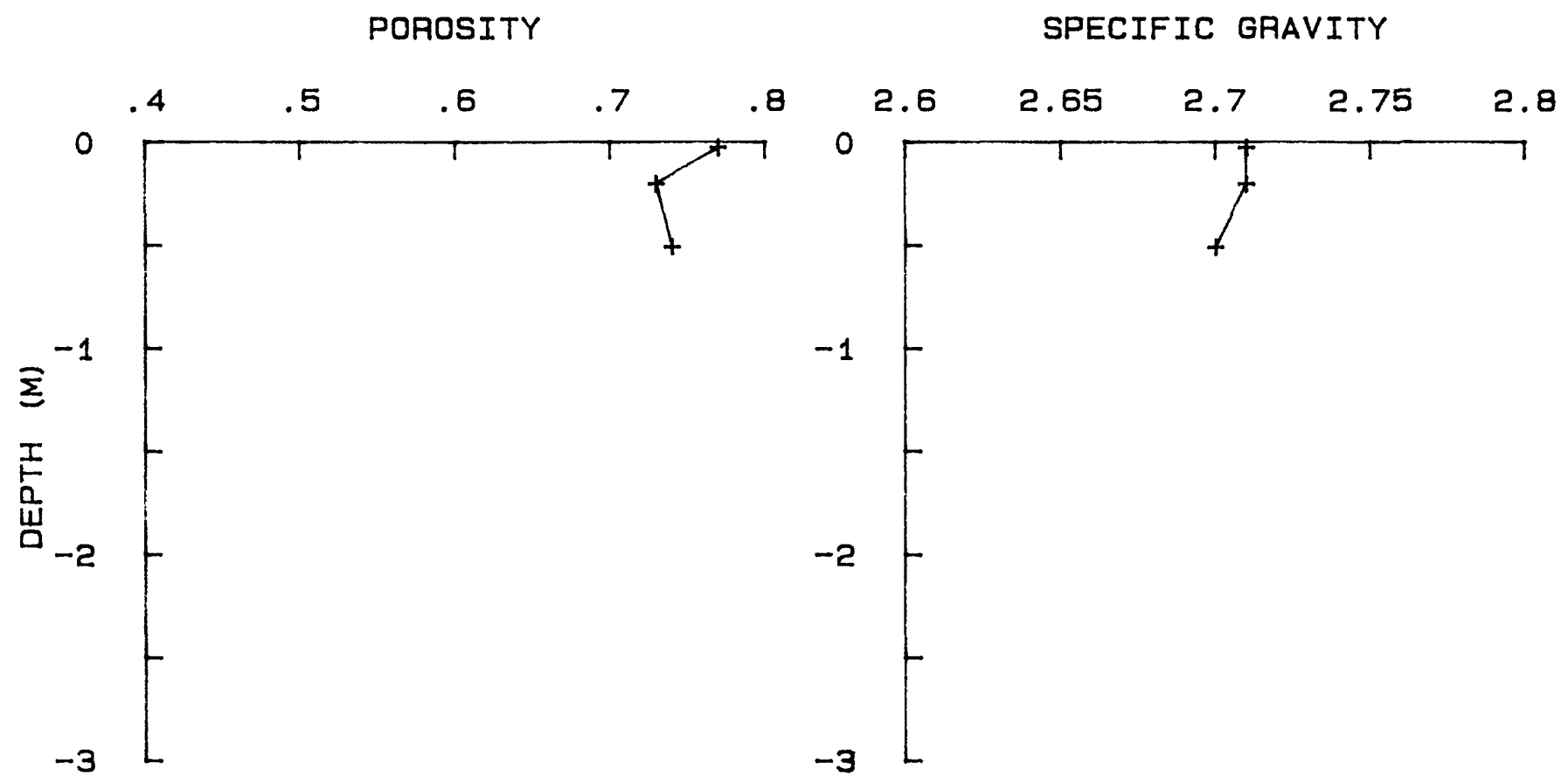




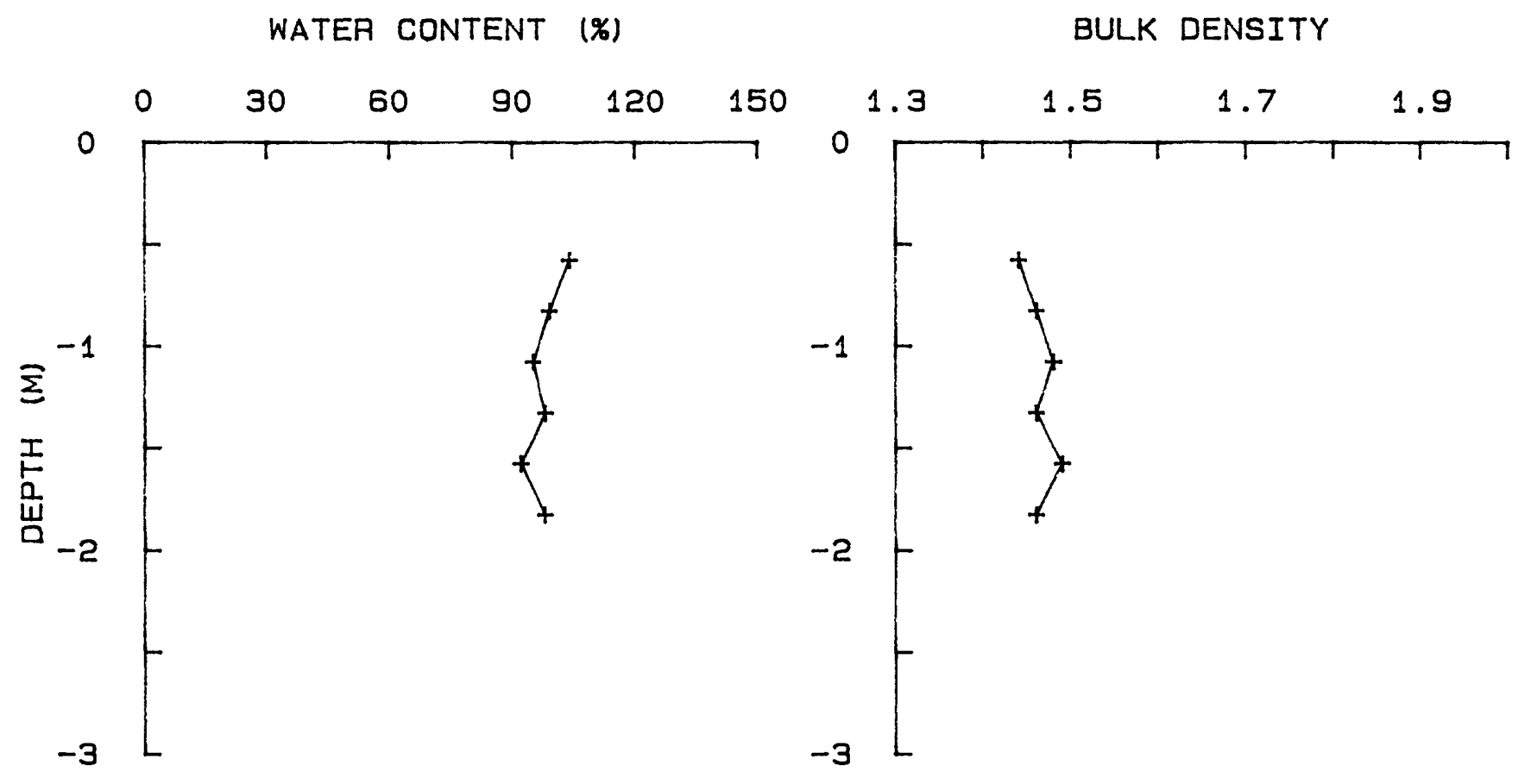

YS-85-08 KC 5

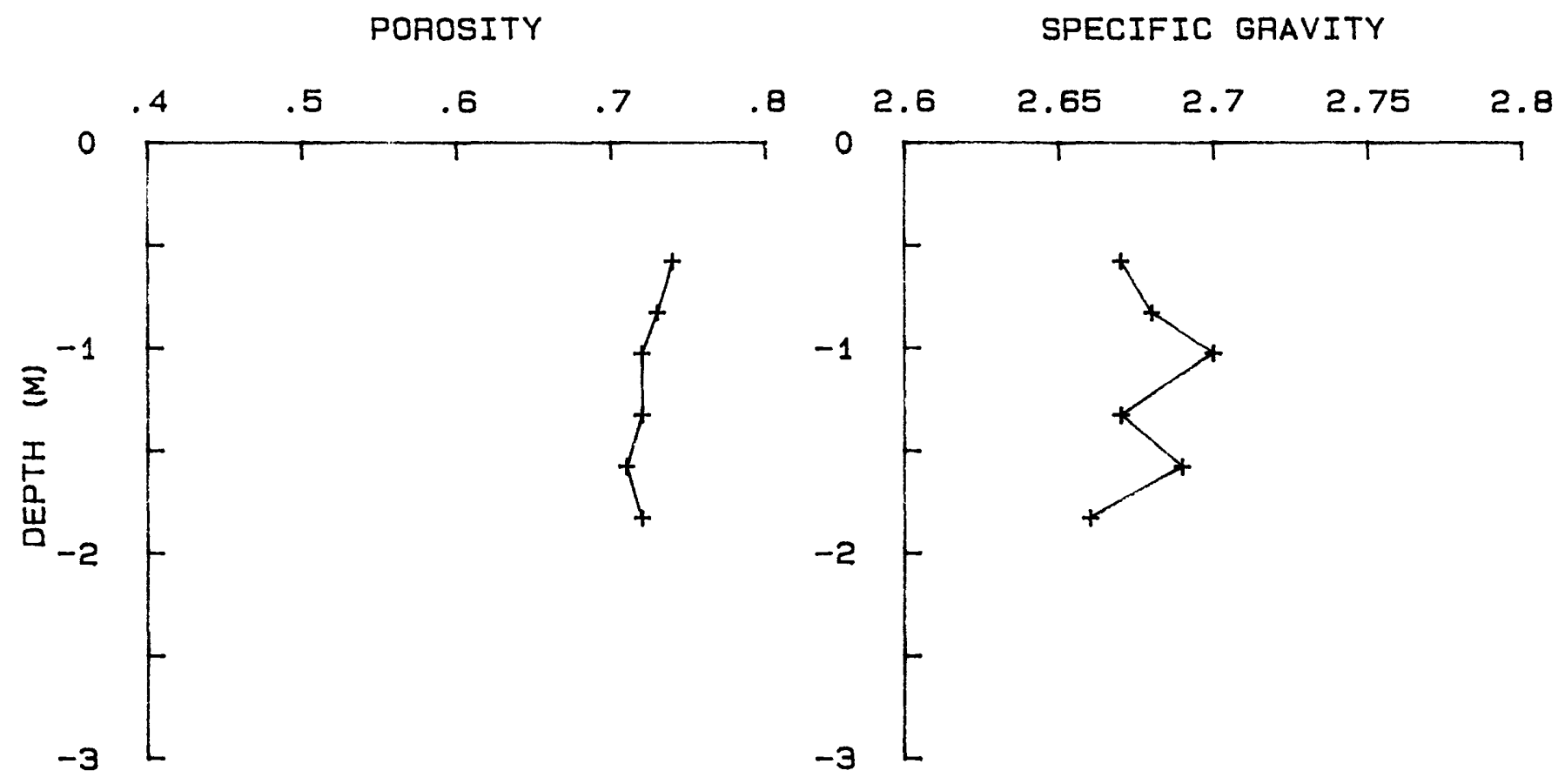




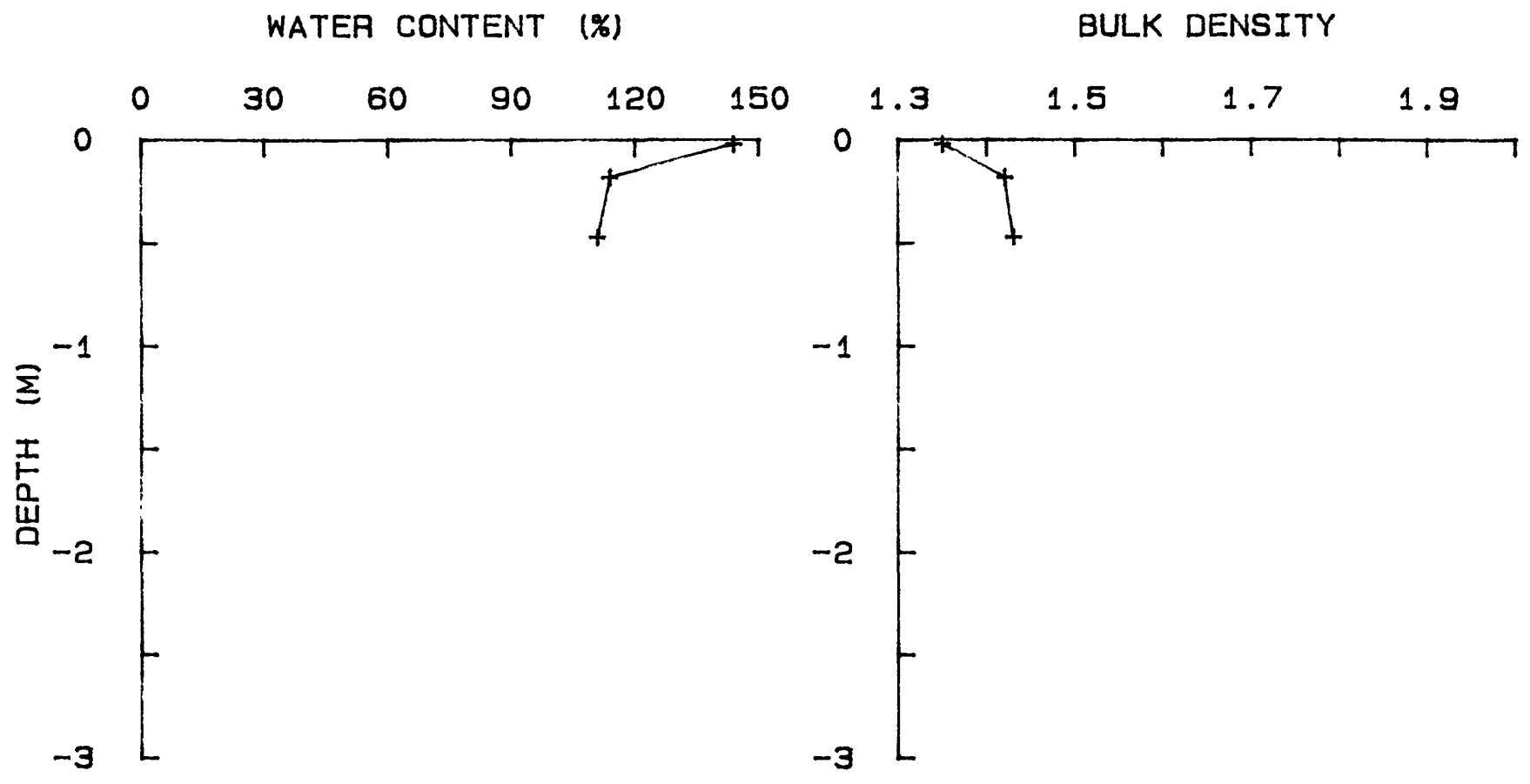

YS-85-08 BC 6

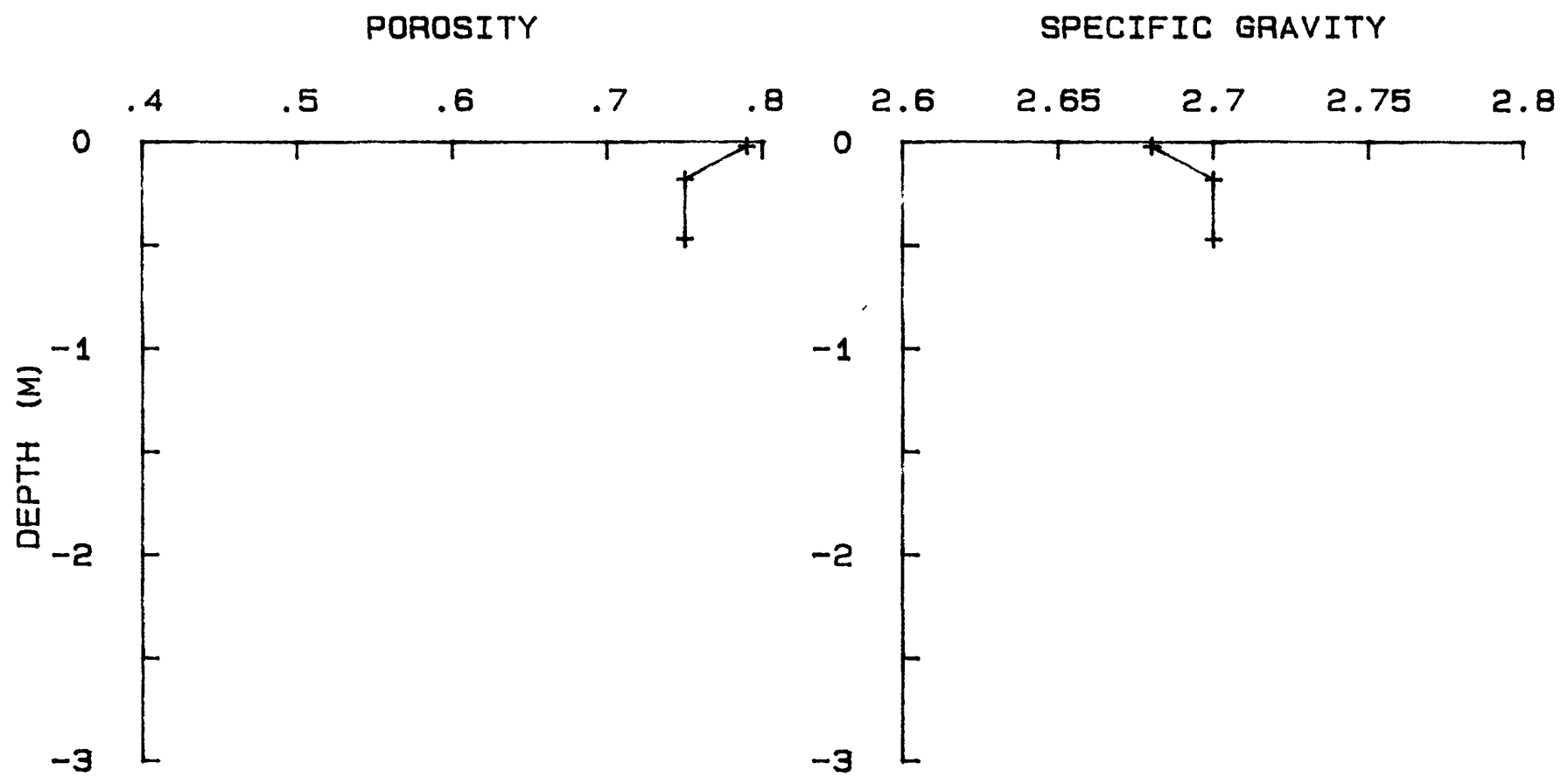




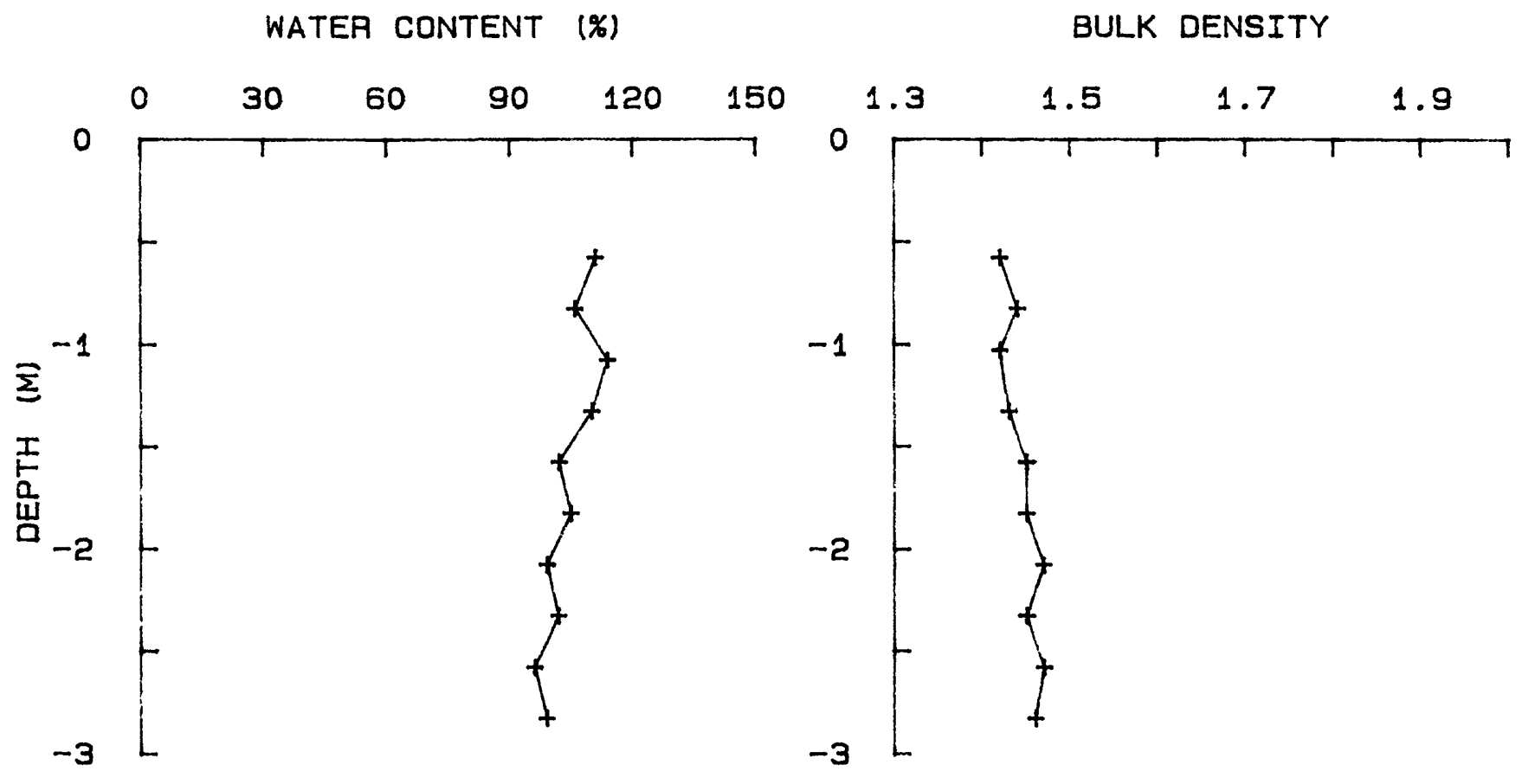

YS-85-08 KC 6

POROSITY

SPECIFIC GRAVITY

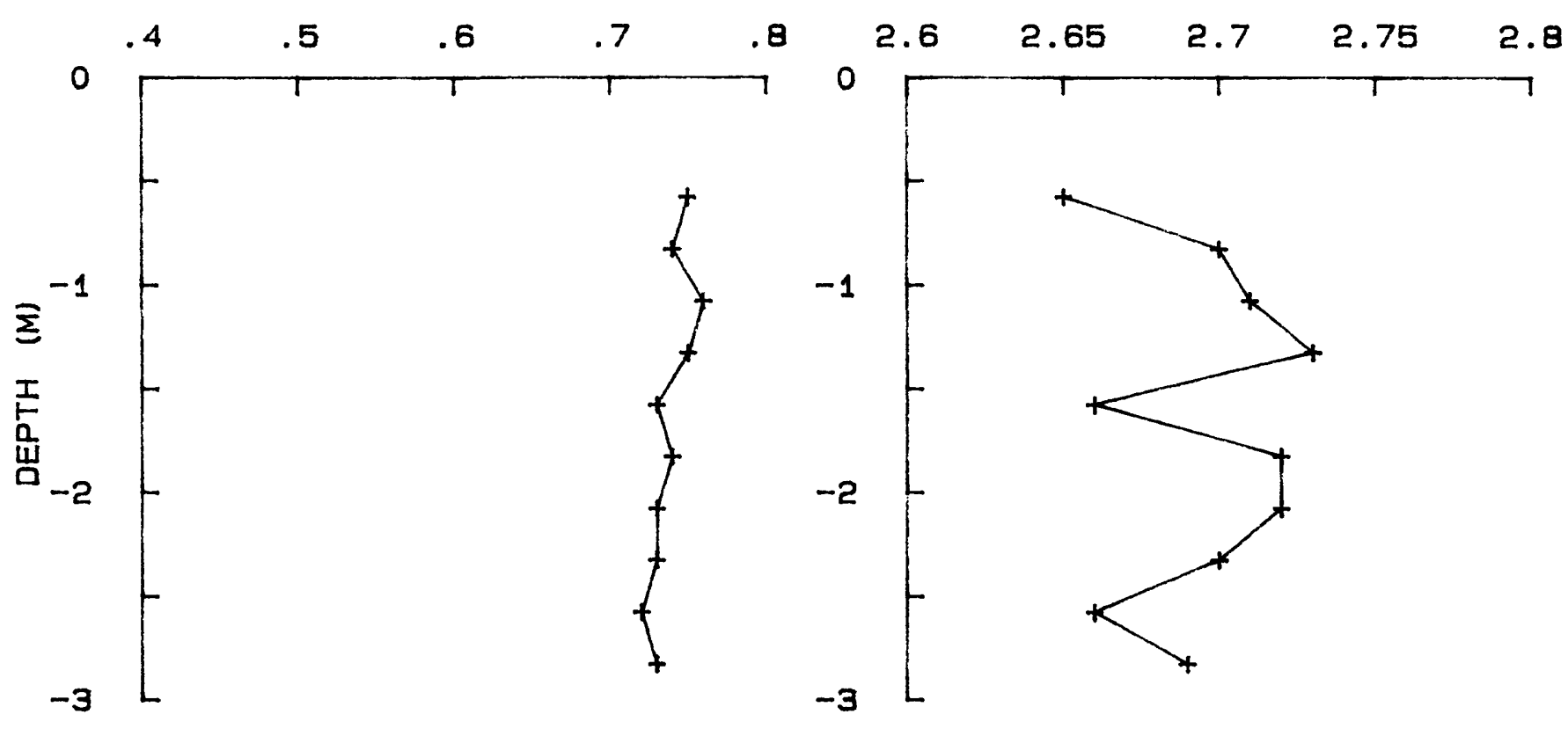




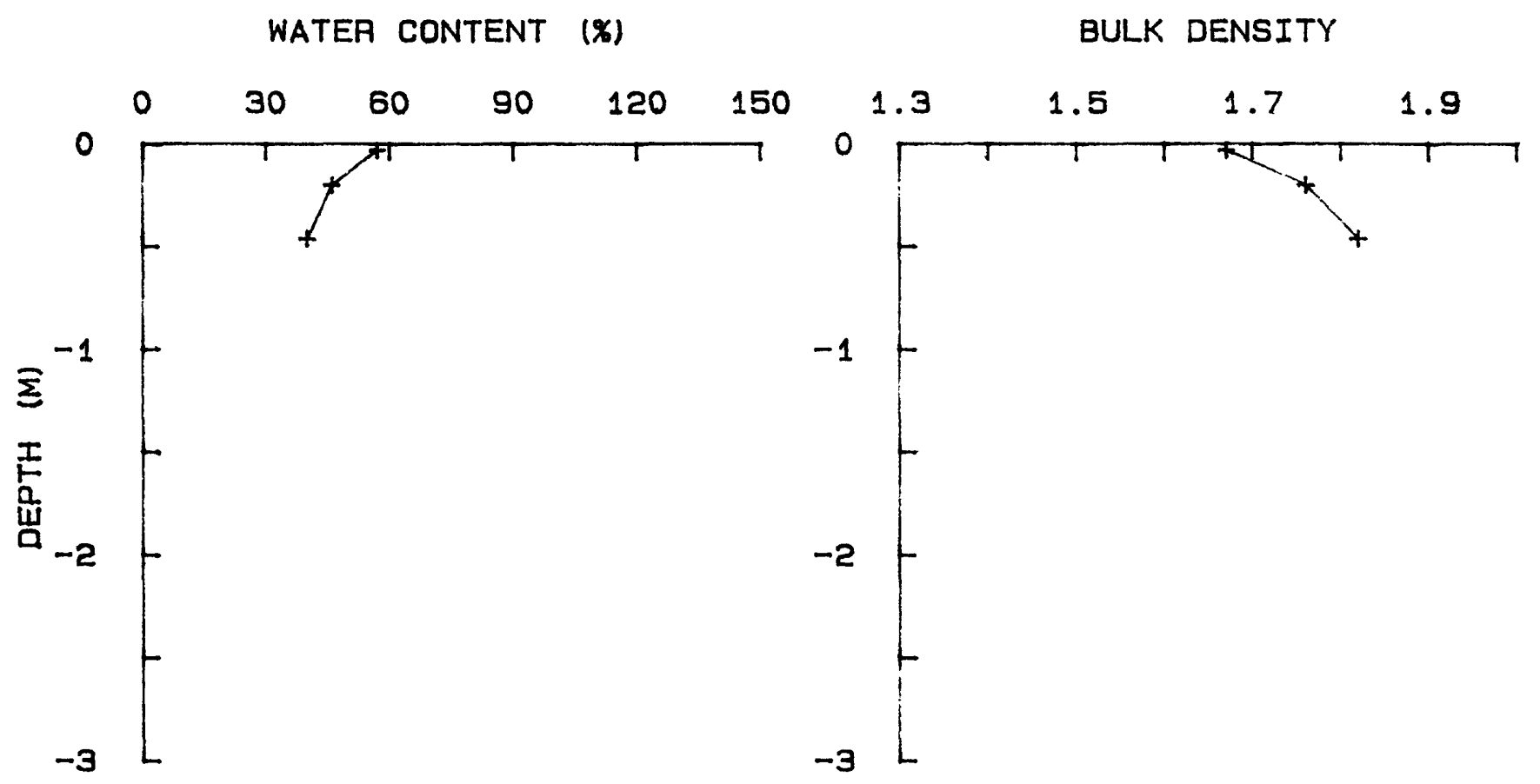

YS-85-08 BC 7

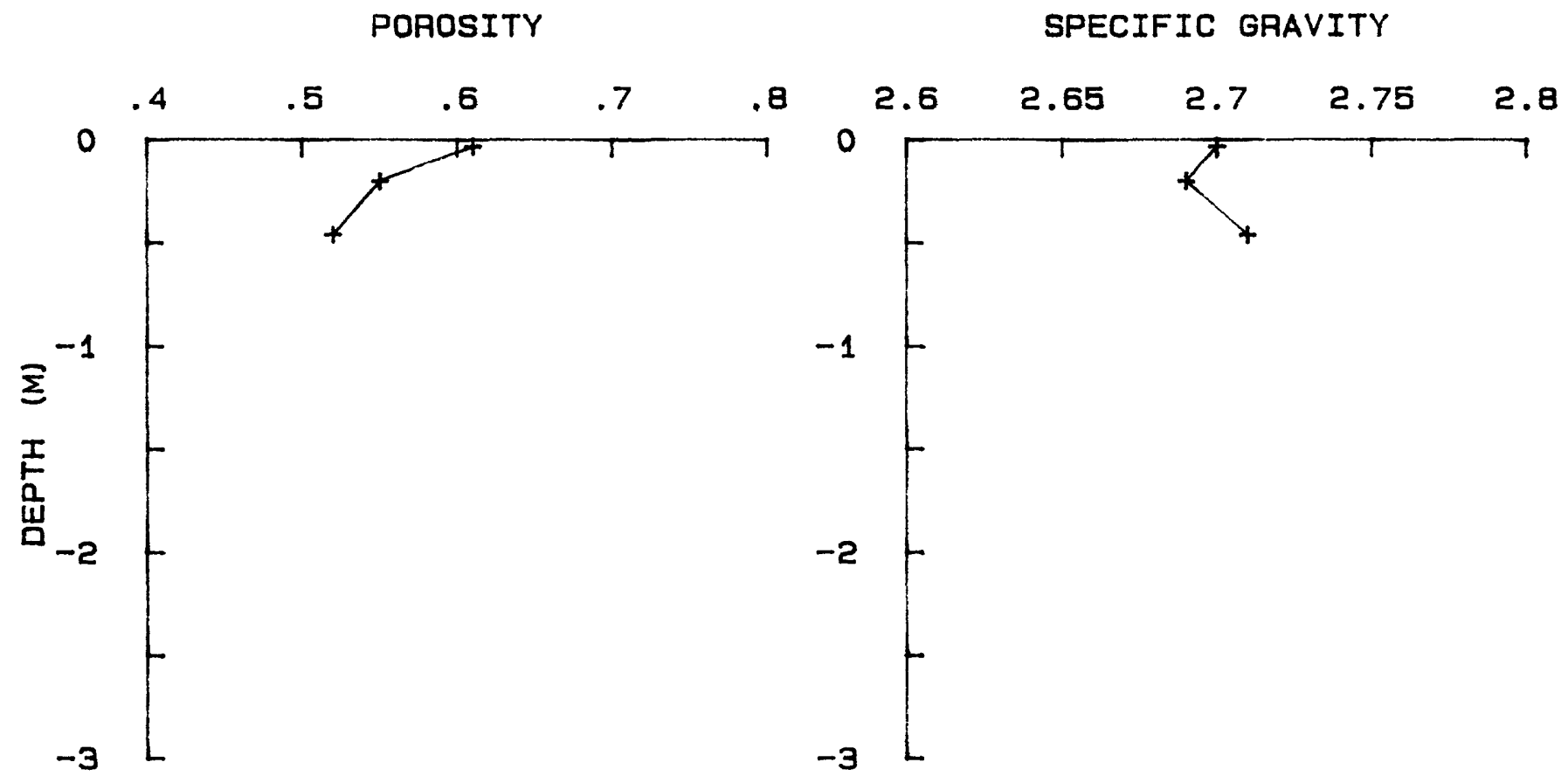


WATER CONTENT (\%)

BULK DENSITY

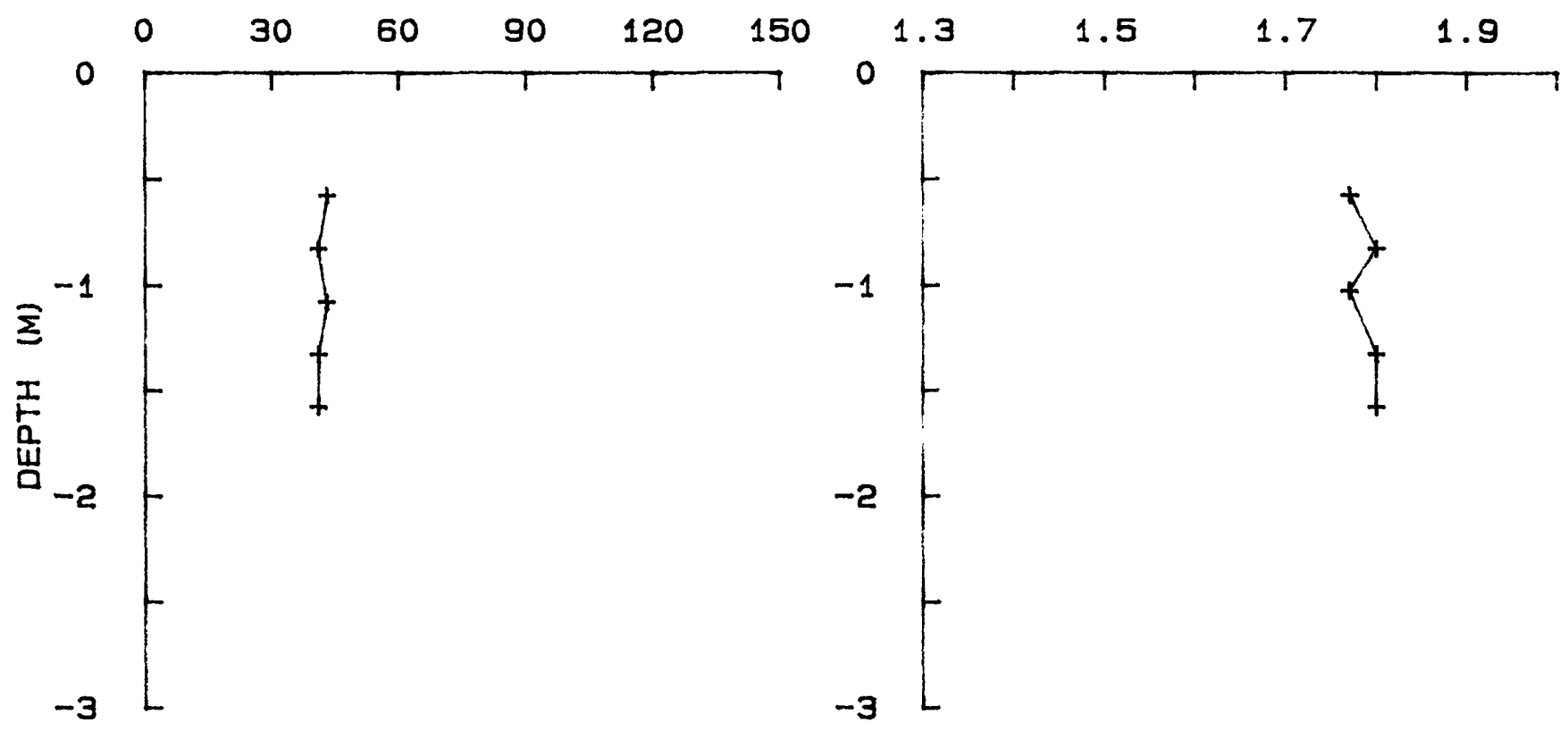

$$
\text { YS-85-08 KC 7A }
$$

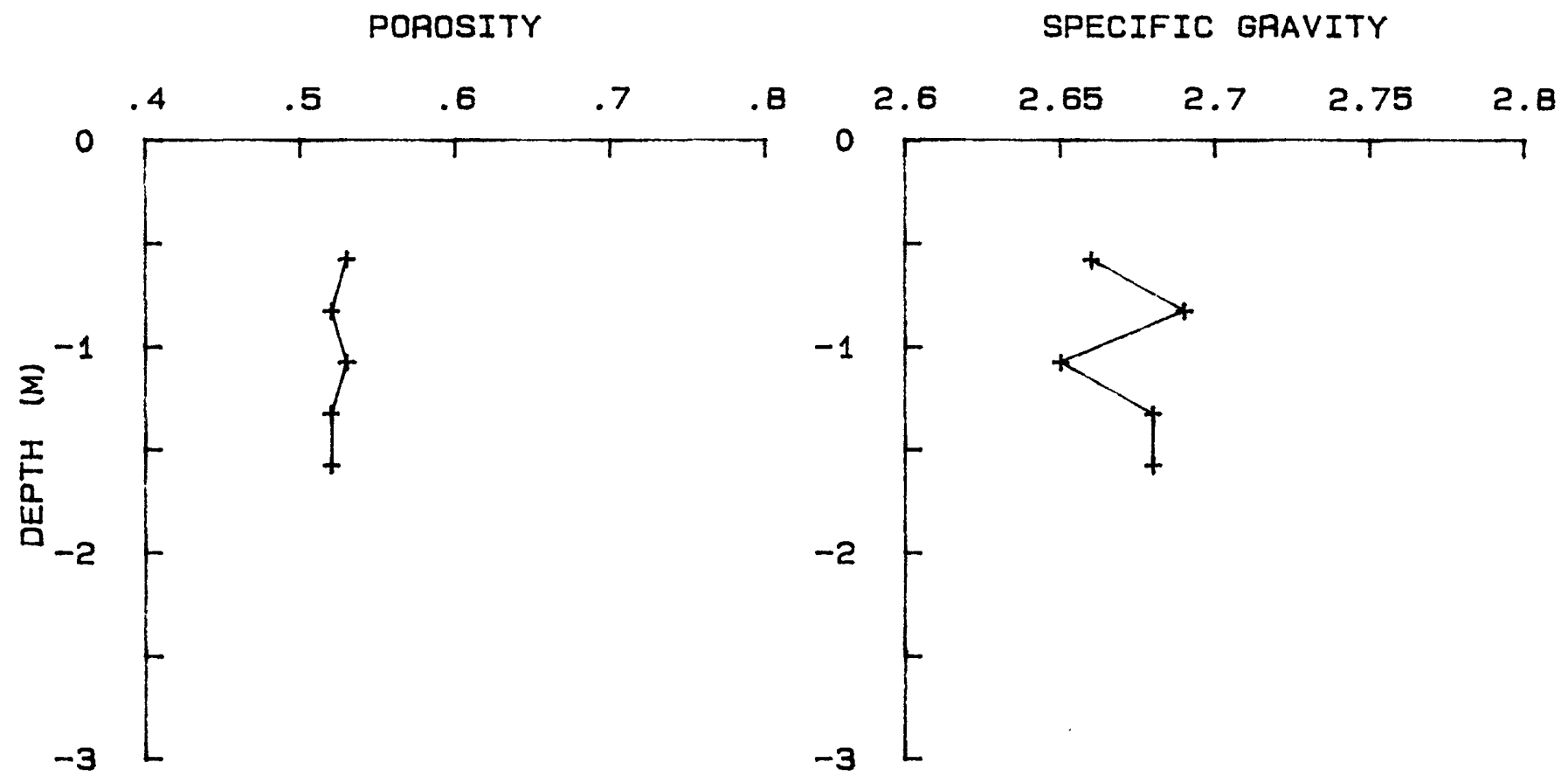


WATER CONTENT (\%)

BULK DENSITY

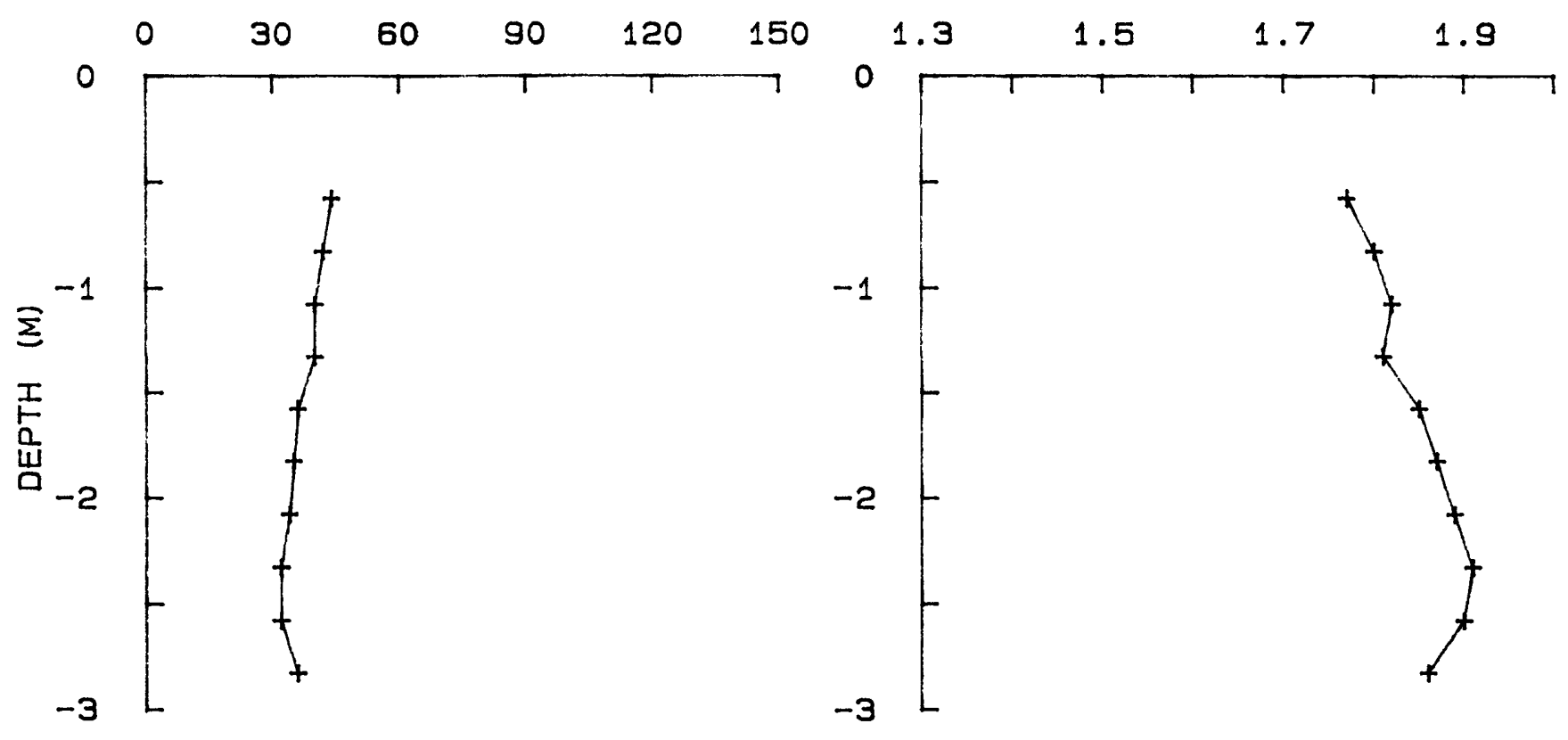

YS-85-08 KC 7B

POAOSITY

SPECIFIC GRAVITY

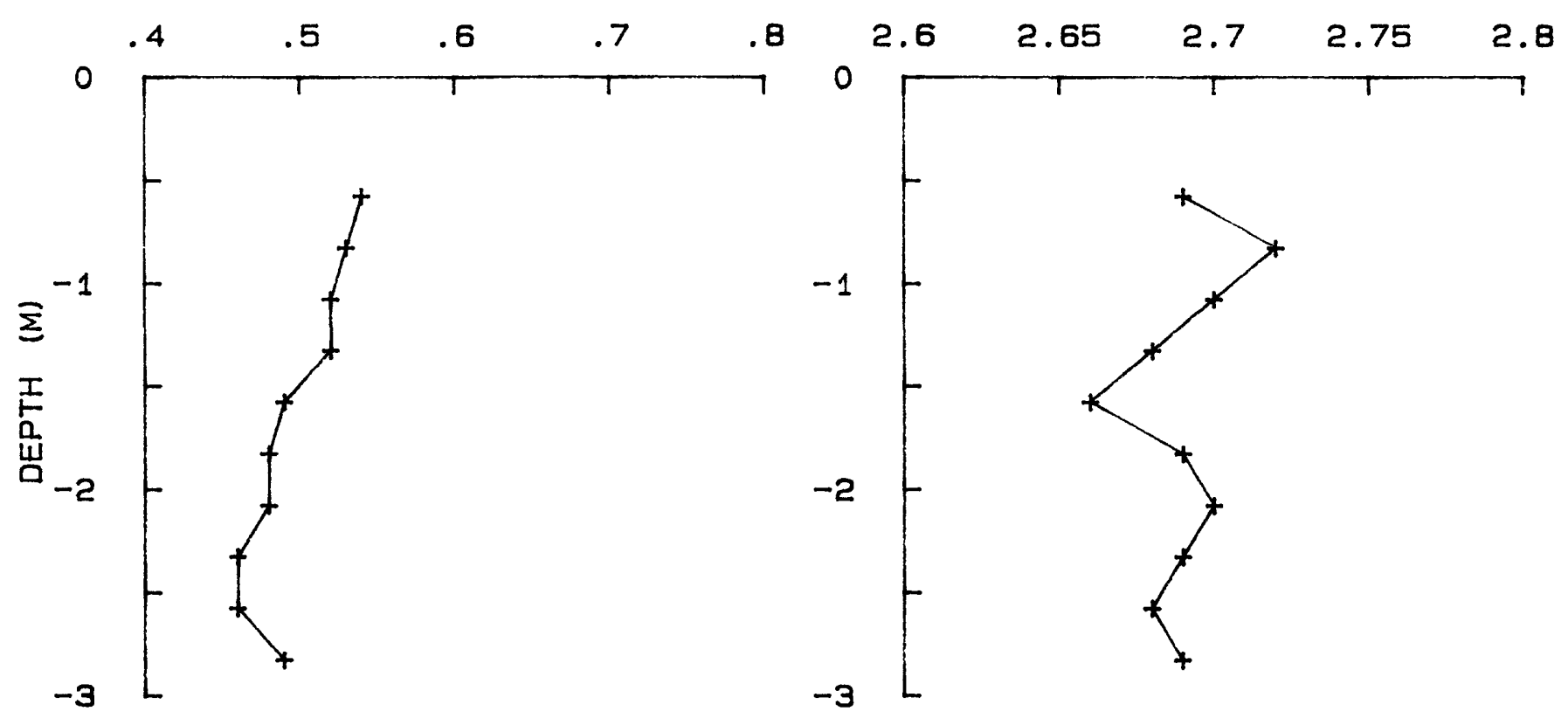




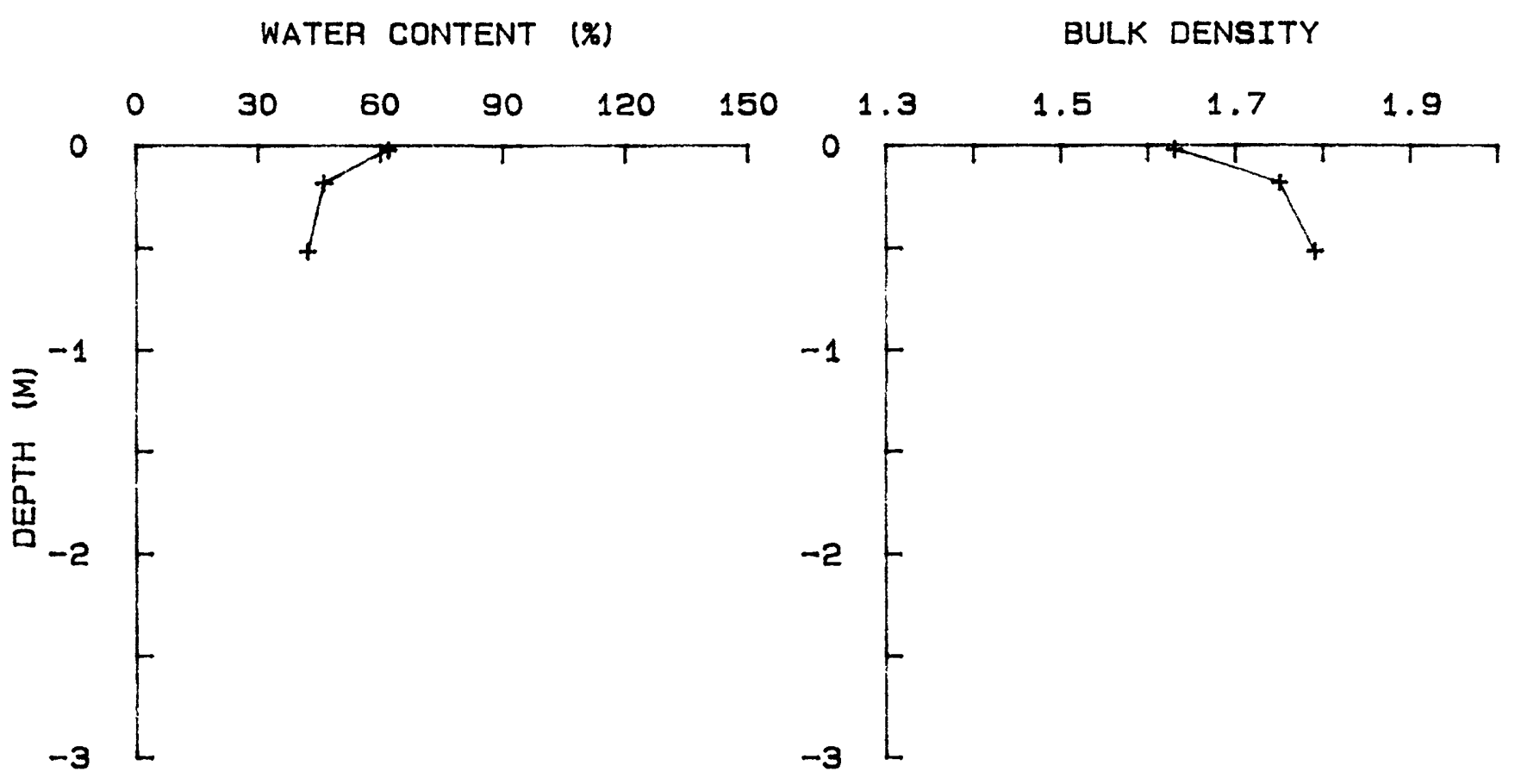

\section{YS-85-08 BC 8}

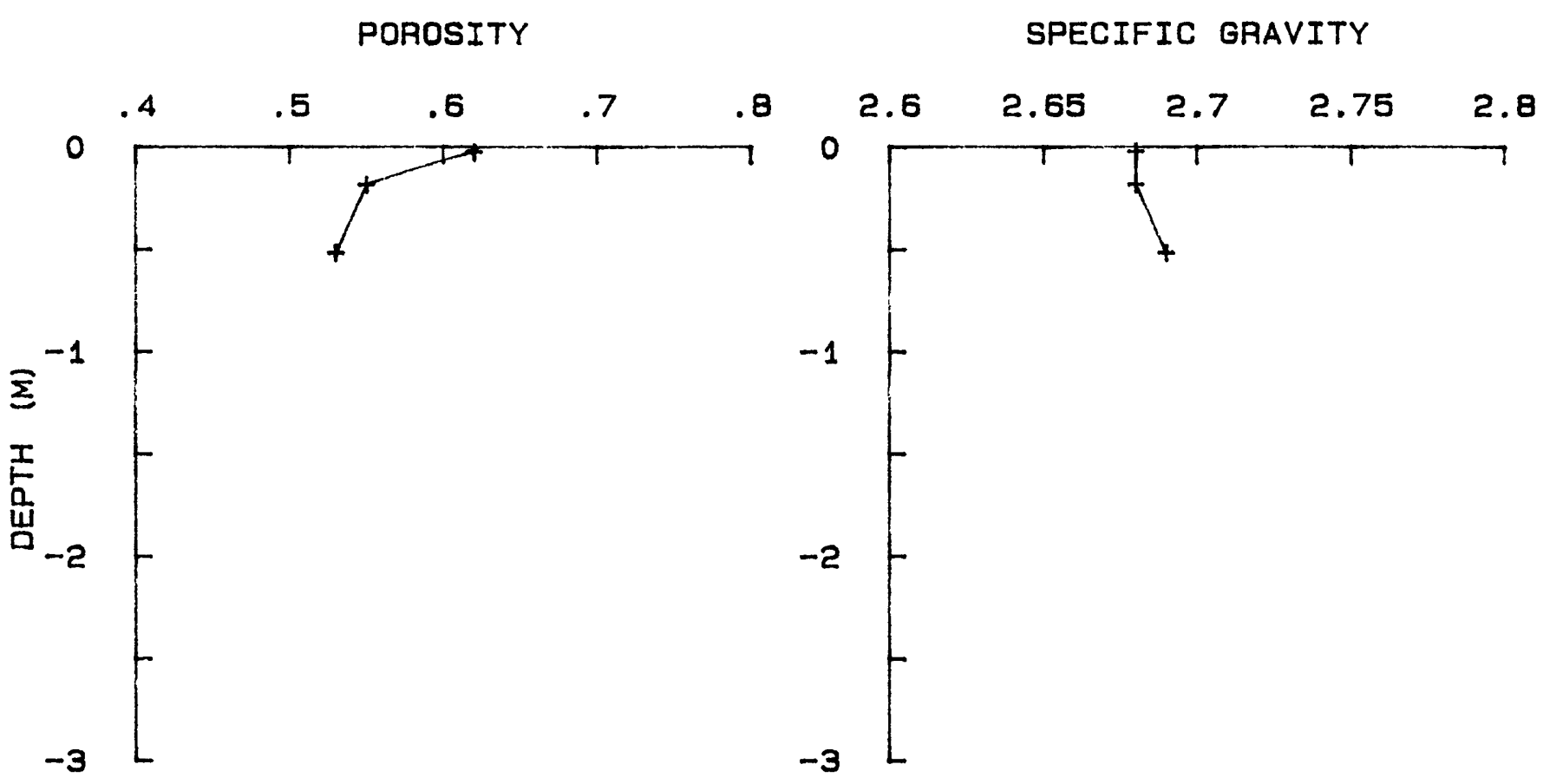


WATER CONTENT

(\%)

BULK DENSITY

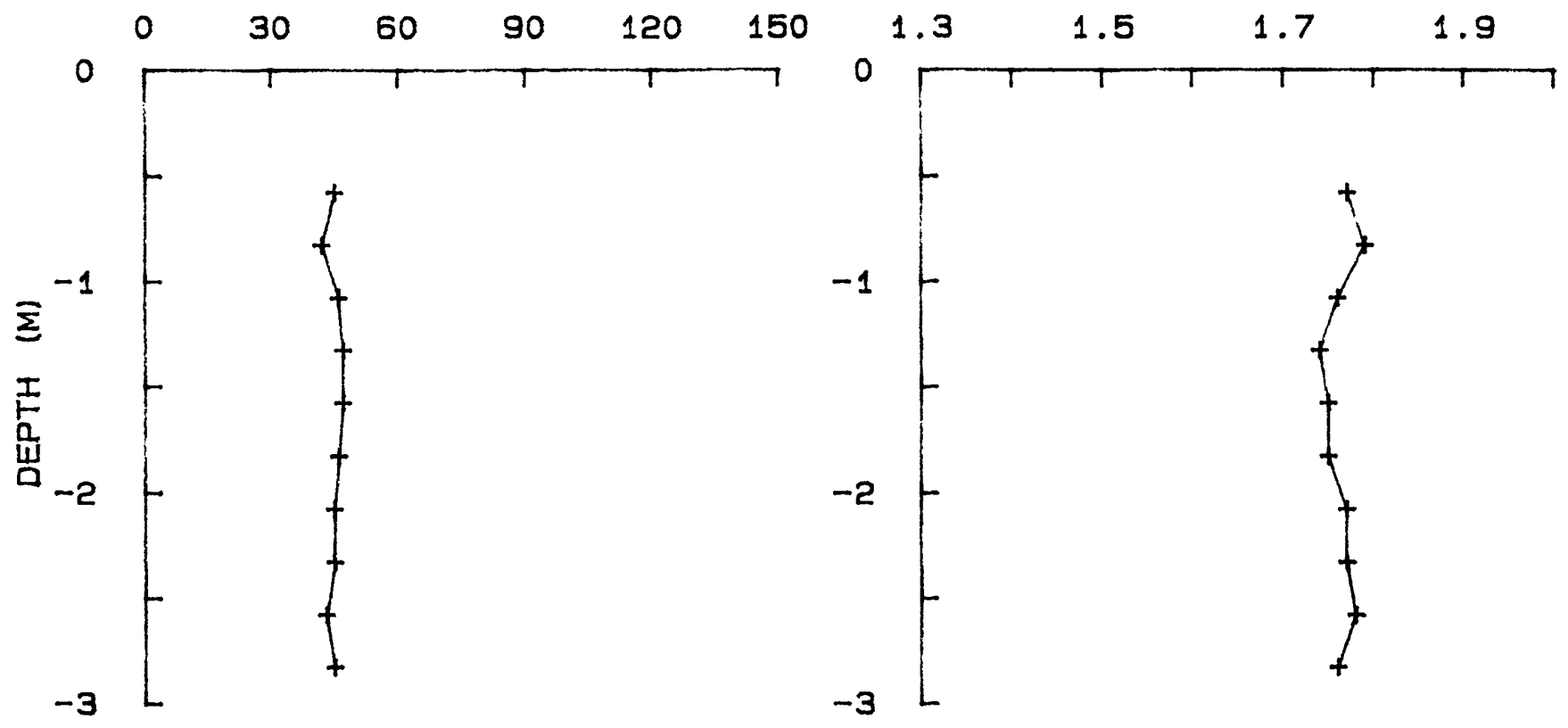

YS-85-08 KC 8

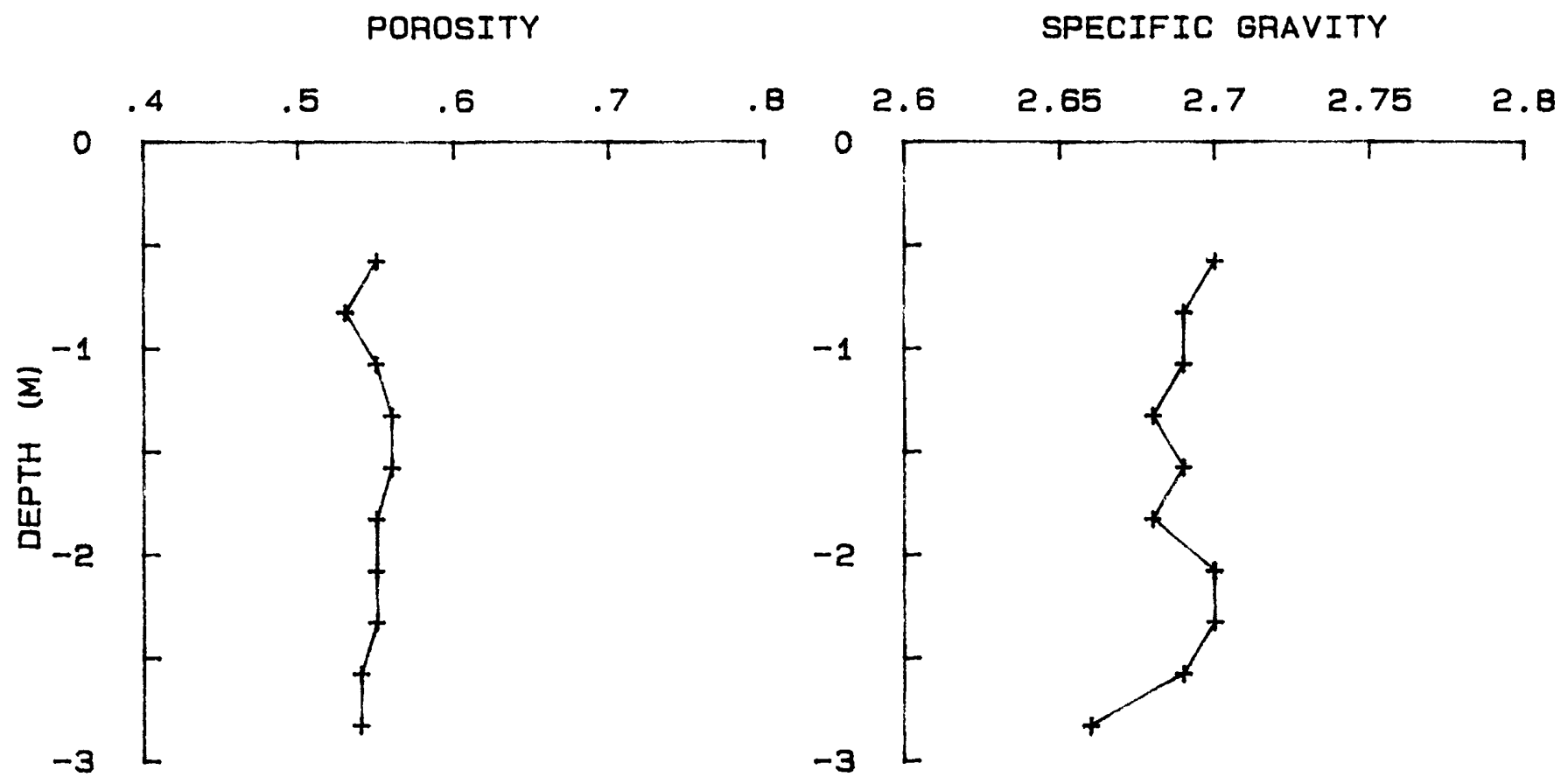




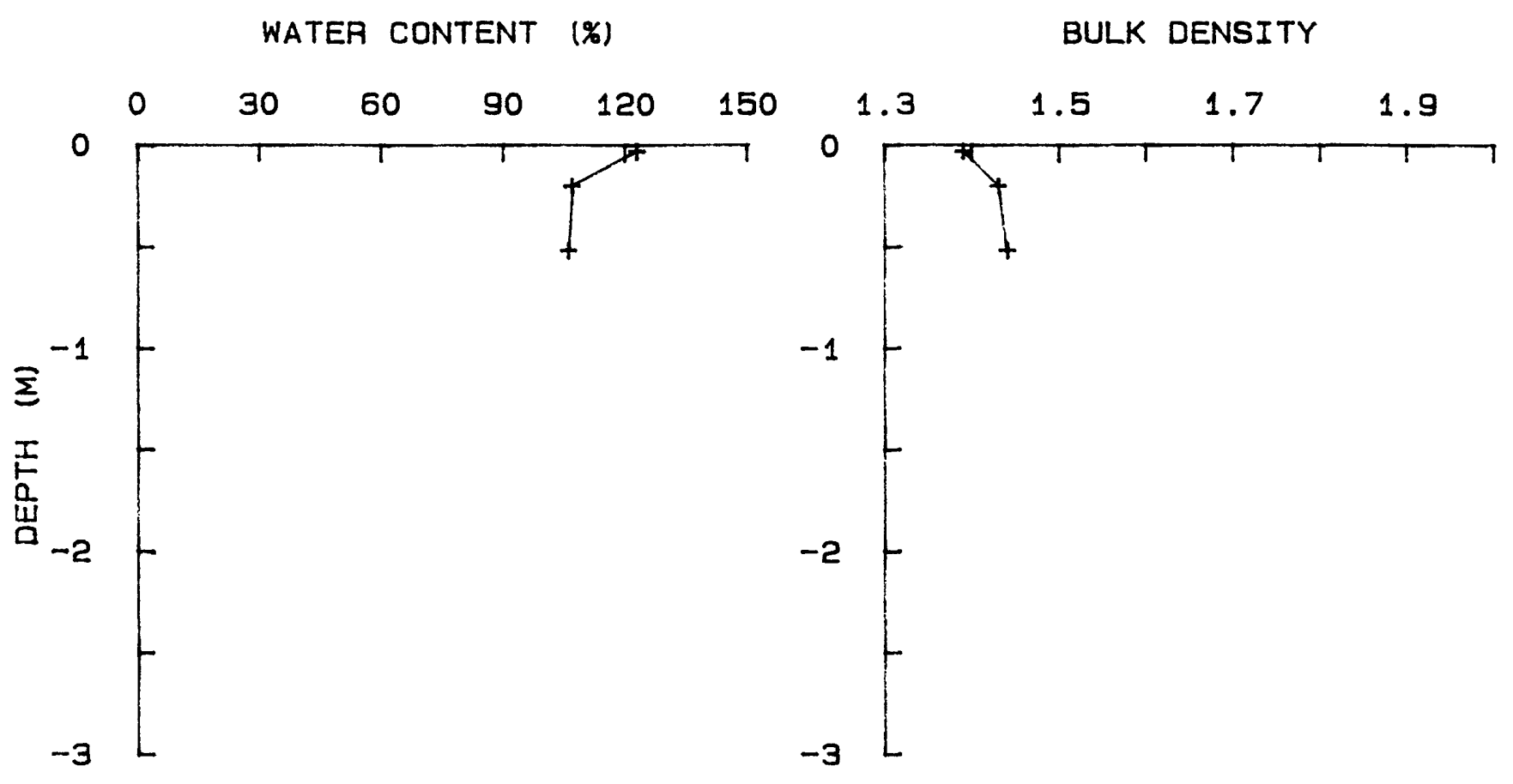

\section{YS-85-08 BC 9}

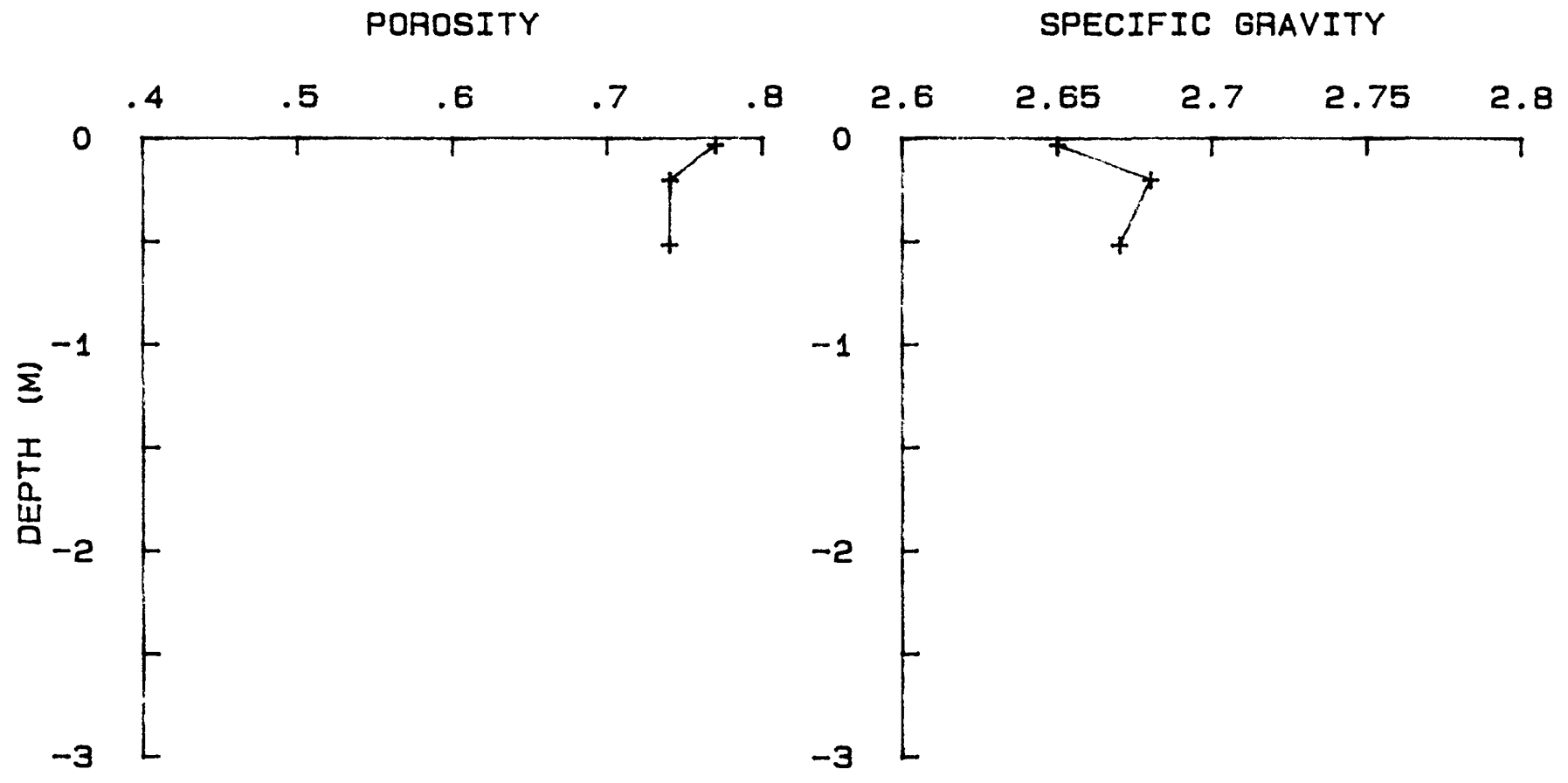




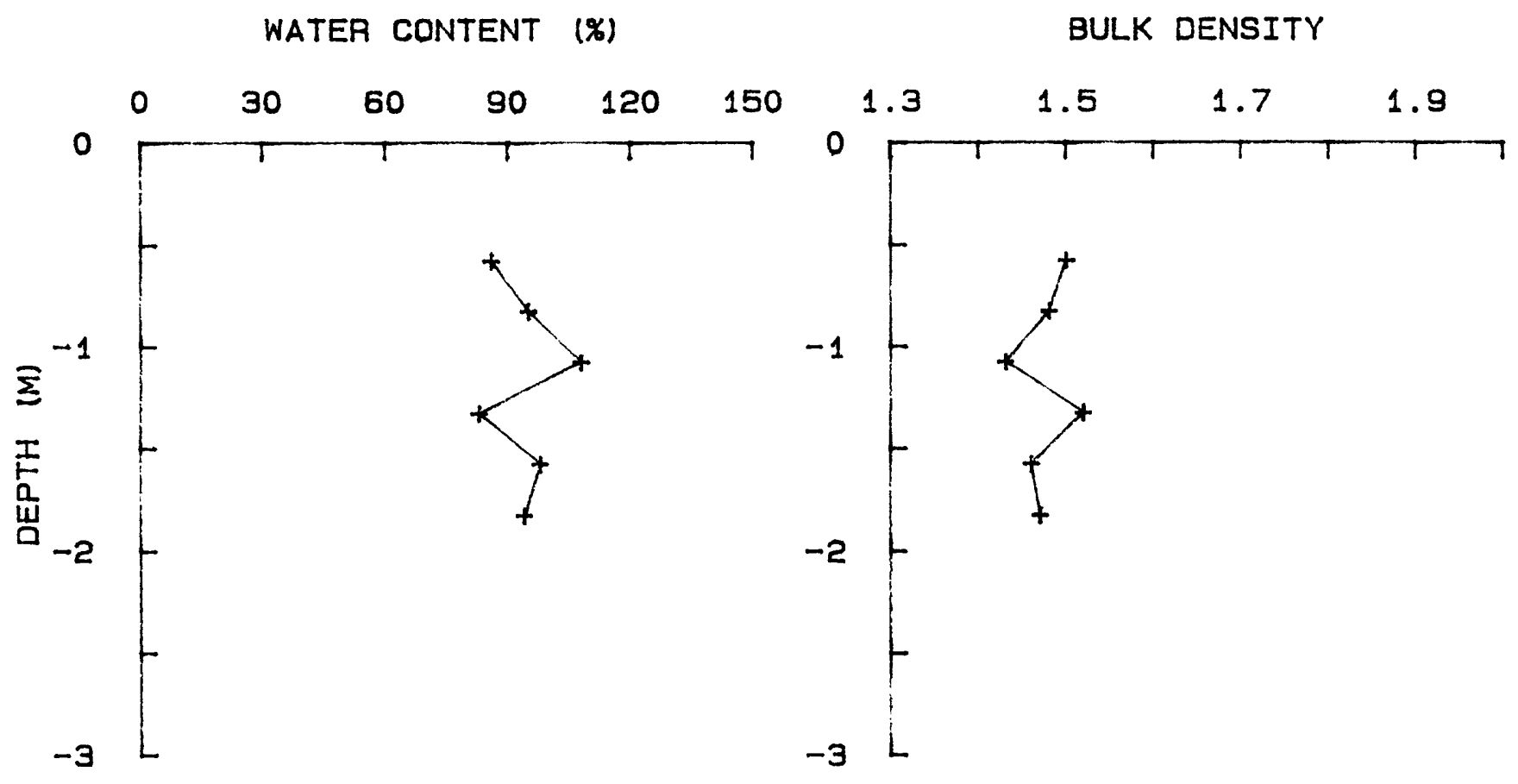

$$
\text { YS-85-08 KC } 9
$$

POROSITY

SPECIFIC GAAVITY

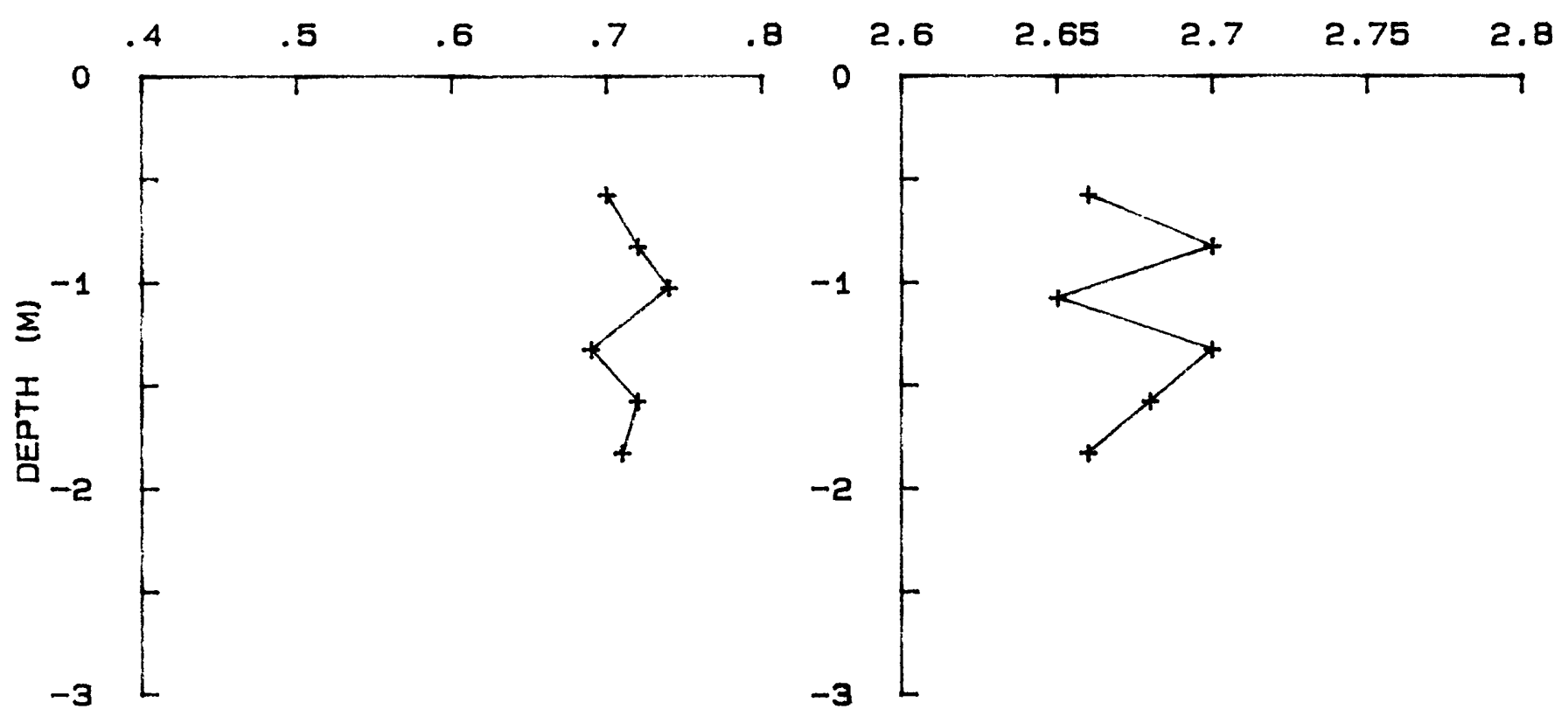


WATER CONTENT (\%)

BULK DENSITY

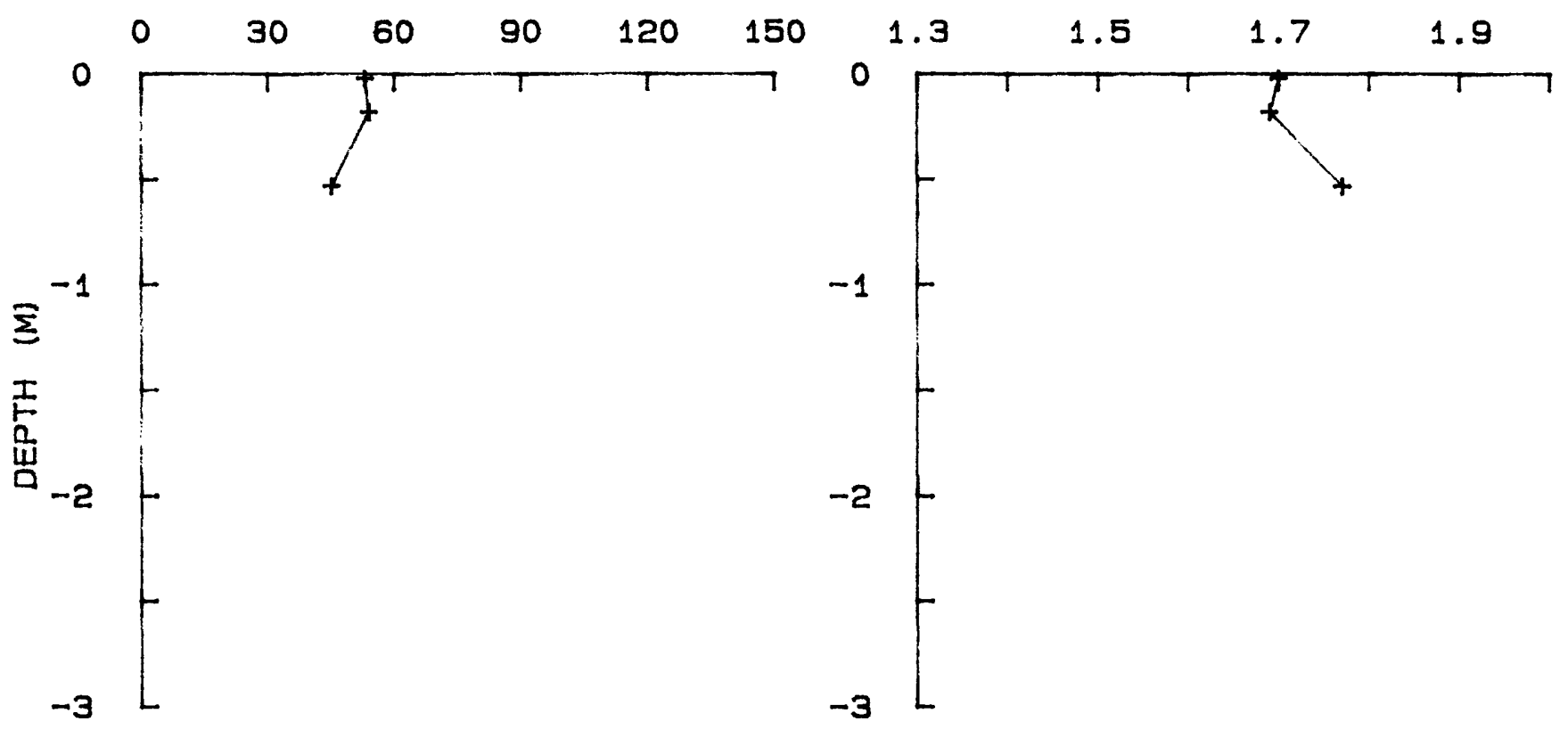

YS-85-OB BC 10

POROSITY

SPECIFIC GRAVITY

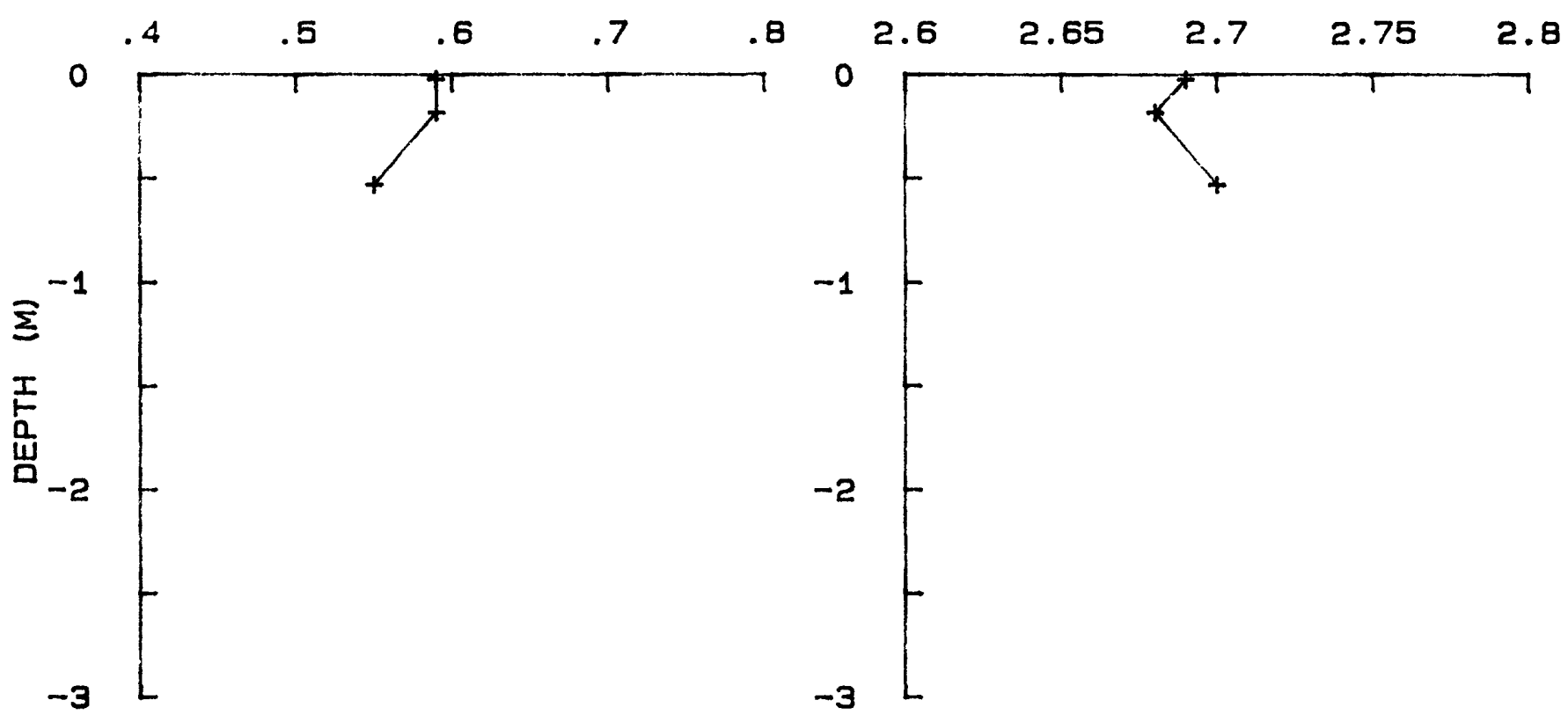




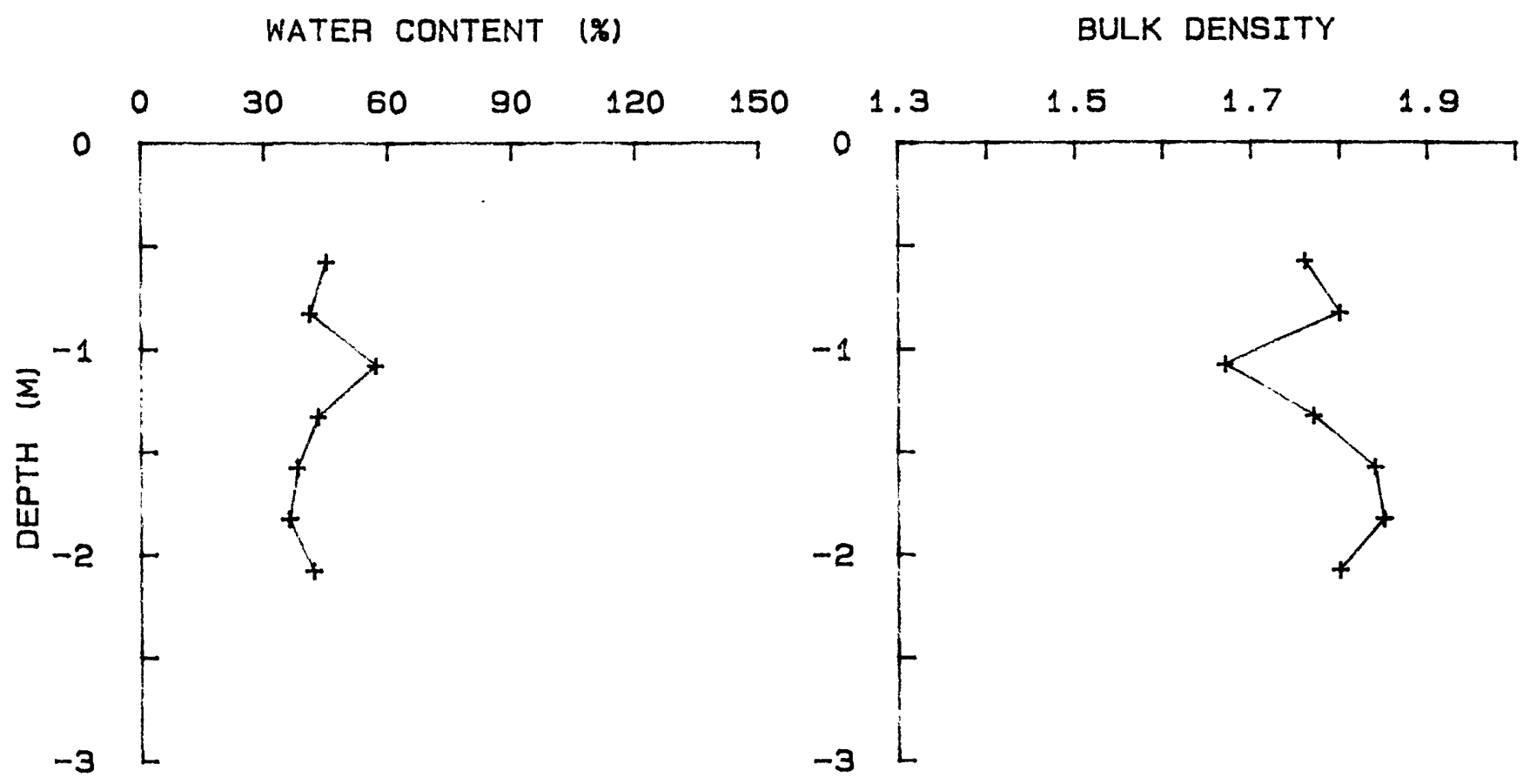

$$
\text { YS-85-08 KC } 10
$$

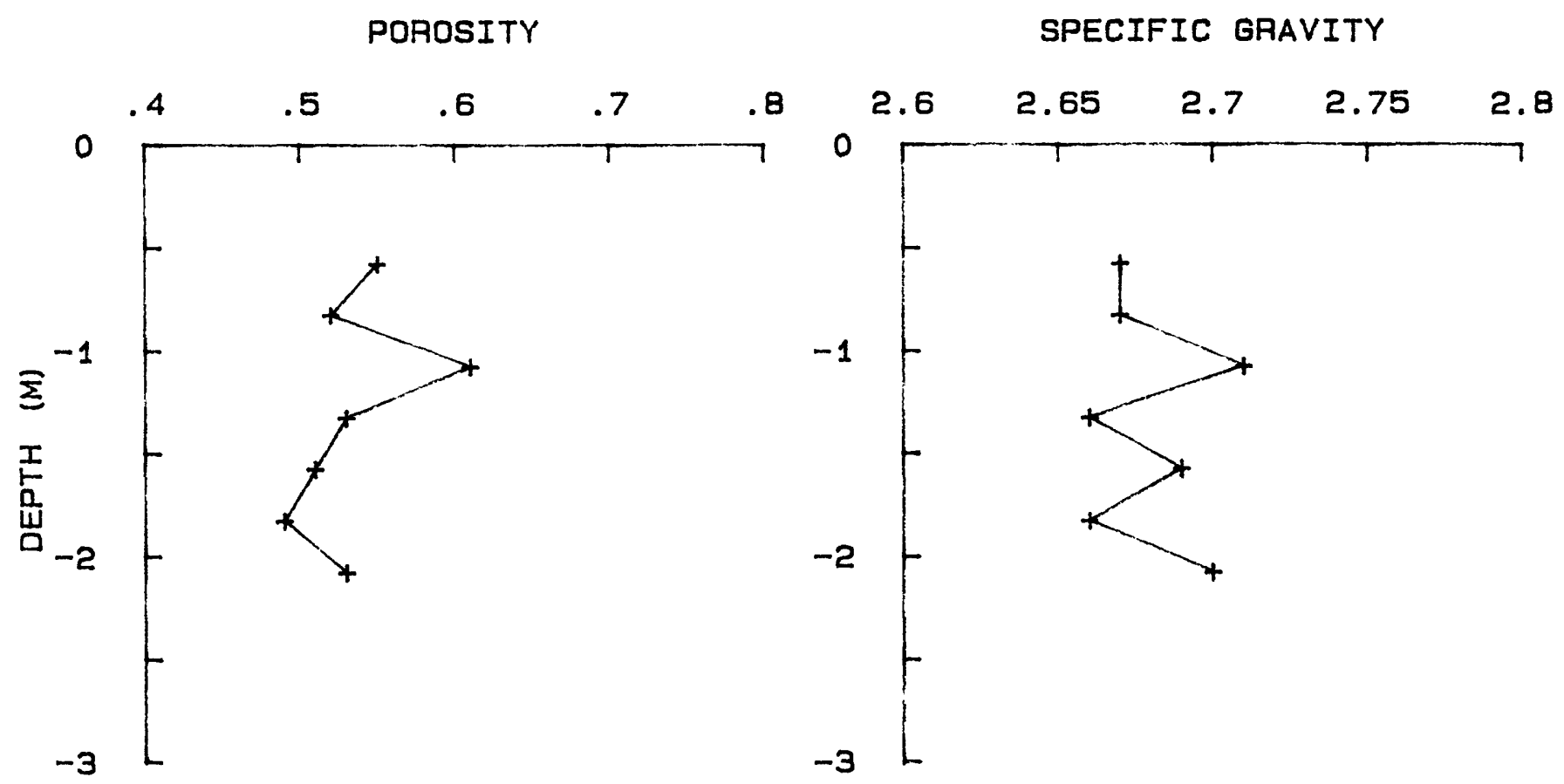




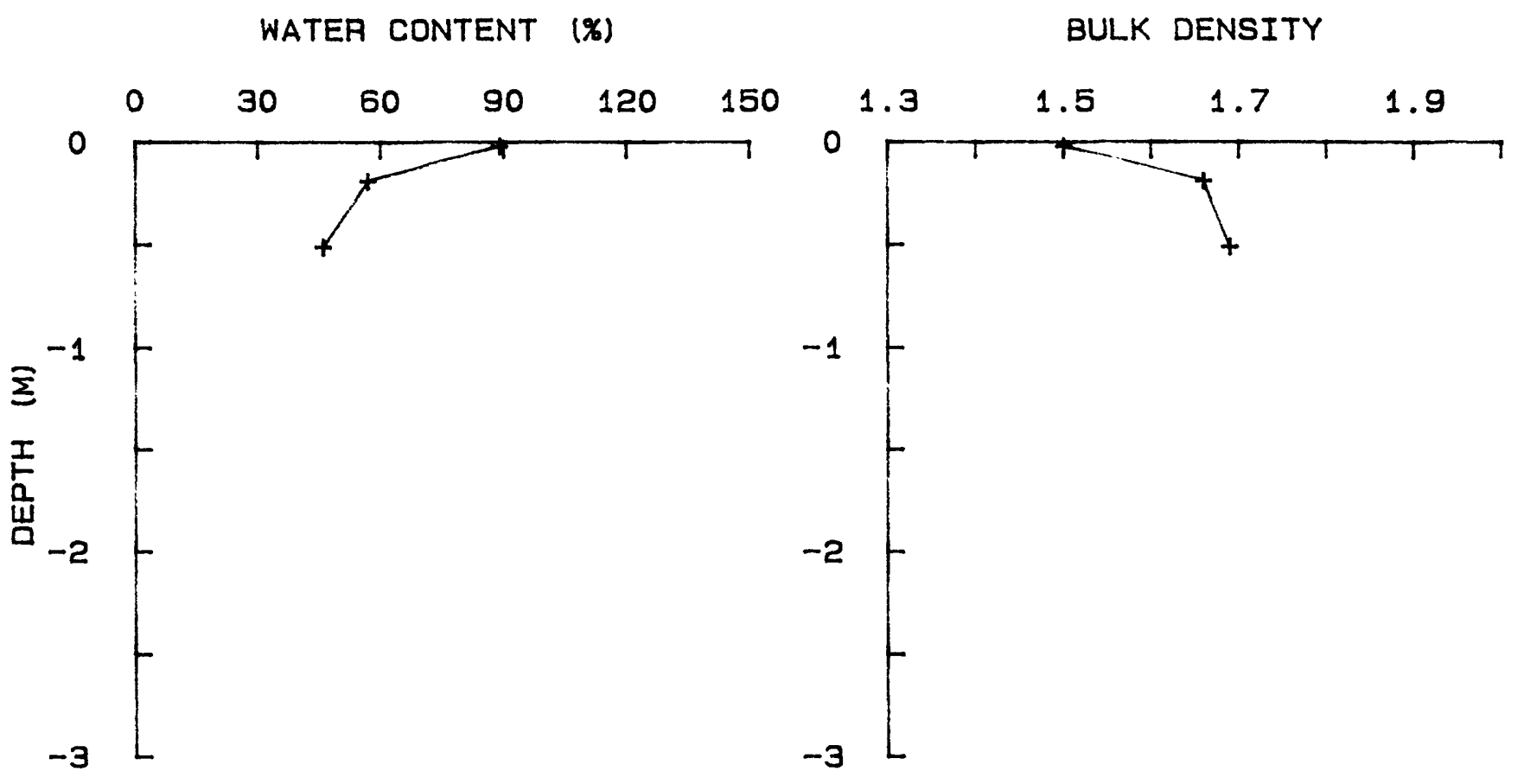

YS-85-08 BC 11

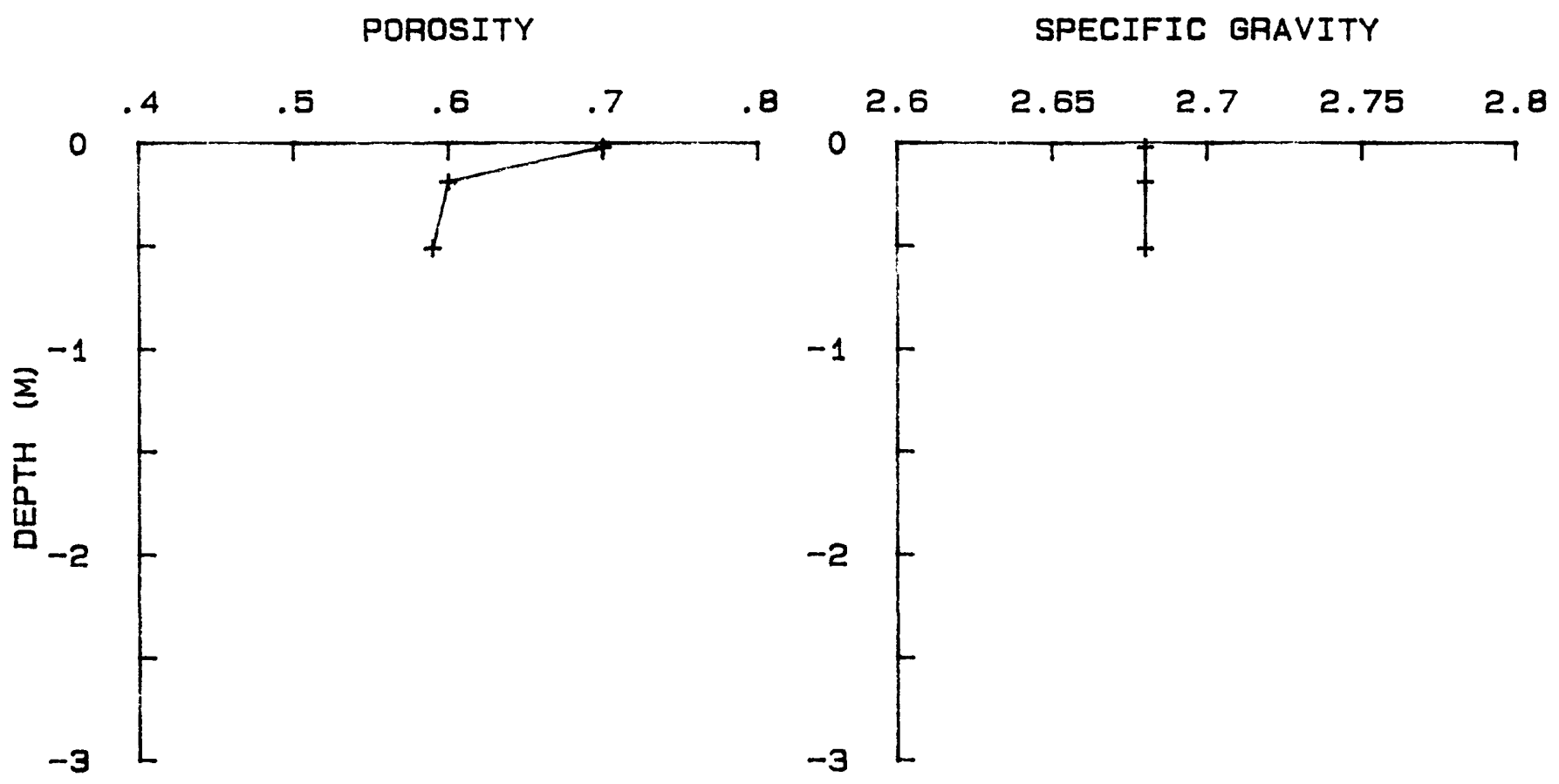




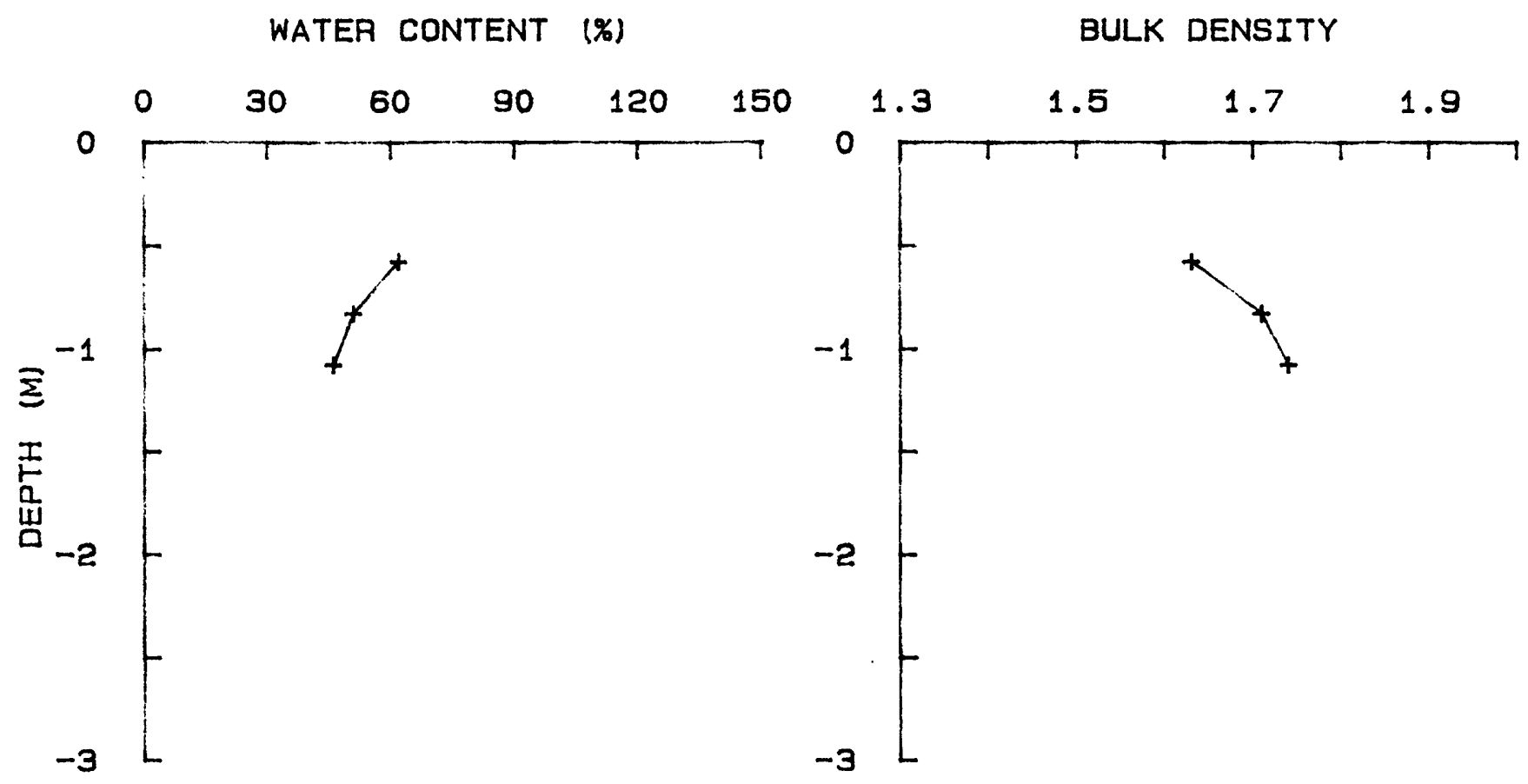

\section{YS-85-08 KC 11}

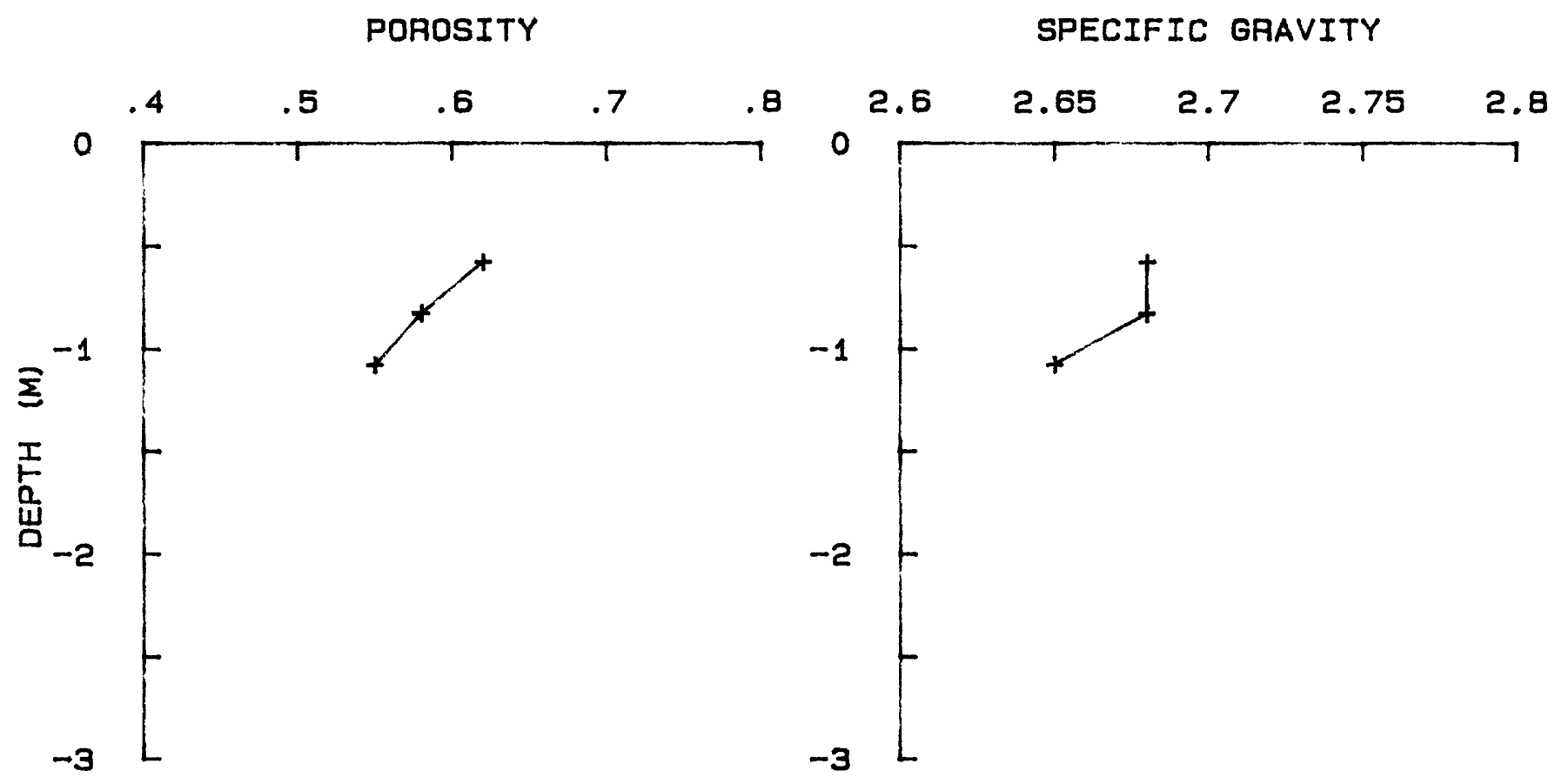




\section{Appendix C}

Results of Constant-Rate-of-Strain Consolidation Tests

tabular data

unedited test plots 
TABULAR DATA 
总

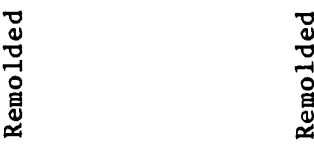

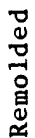

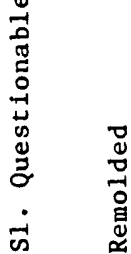

$\stackrel{20}{n}$

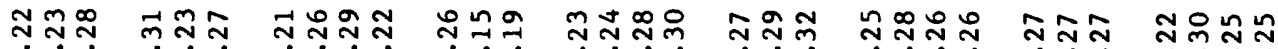
ర்0

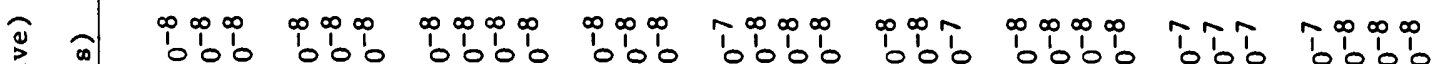
包

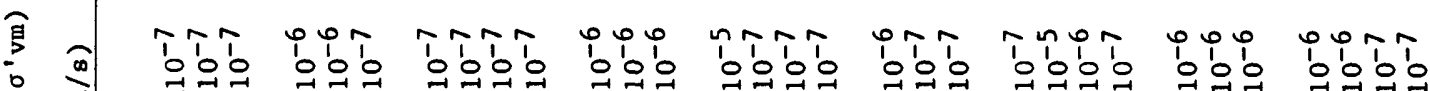
我

包 親

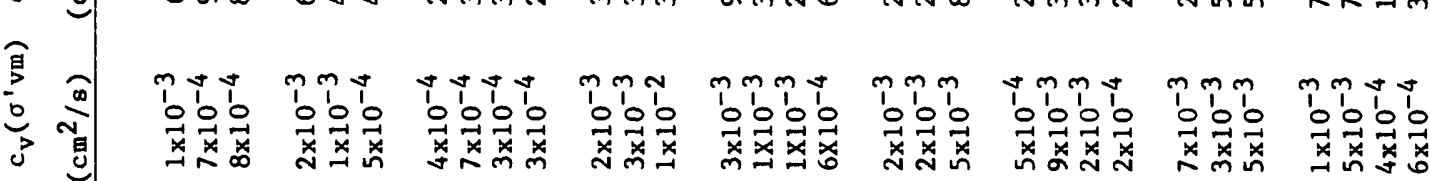

,

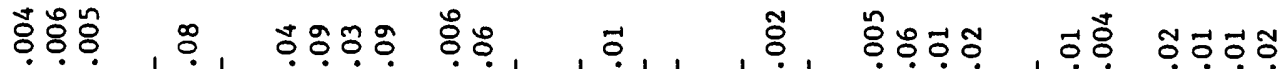
$\dot{0} \dot{0}$ $1 \dot{0}$

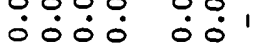
$\dot{0} 1$ $\dot{0} \dot{0} \dot{0} \dot{0} 1 \dot{0} \dot{0} \dot{0} \dot{0} \dot{0} \dot{0}$

岁

กิง

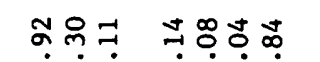

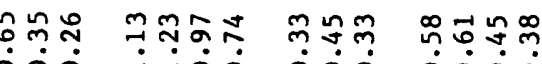

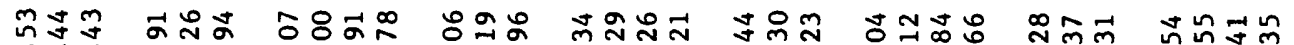
U $\dot{0} \dot{0}$ व்

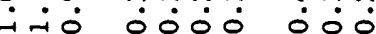

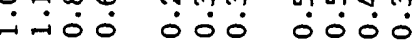
땡

- 7

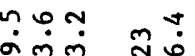

mก⿻ mit mam 000

$\dot{m} \dot{m}$ ஸִ̣

a oa จัल

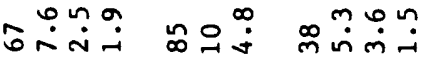

ำด m?

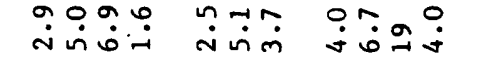

$\dot{0}=$

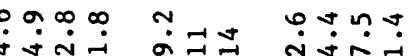
i

궁

กัง b.T.

noon m notom

$\dot{0}-\dot{m}$

ㅇำ

o 0

$\cos$

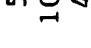
ธิตี $0 \dot{0}$ $\dot{0} \dot{0} \stackrel{\sim}{-1}$ 0ั0்

ฟิกับั

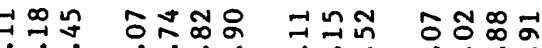

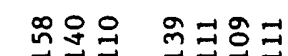
นุำำำ

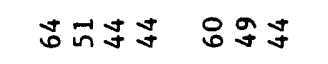

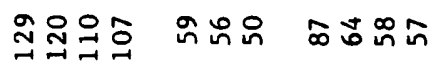
㝴苍圆 กิำก ผnก (a) Nom

$+000$

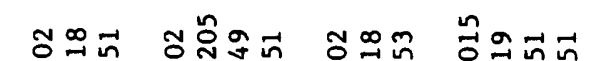


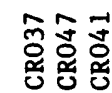
象守

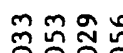
$\dot{0}: 0$ ○்:0 $\therefore \circ 0^{\circ}$

ํํㅇํํ웡

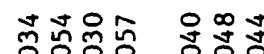

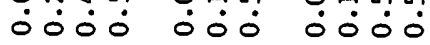
$\stackrel{\infty}{\stackrel{\infty}{*} \dot{0}}$

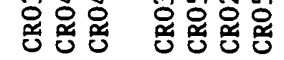

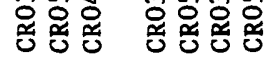

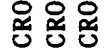

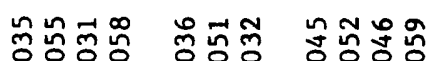

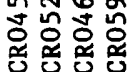
A ป $\frac{\pi}{d}$ J 总 $\begin{array}{ll}0 & i \\ i & \vdots \\ 0\end{array}$ 咅 
TEST PLOTS 


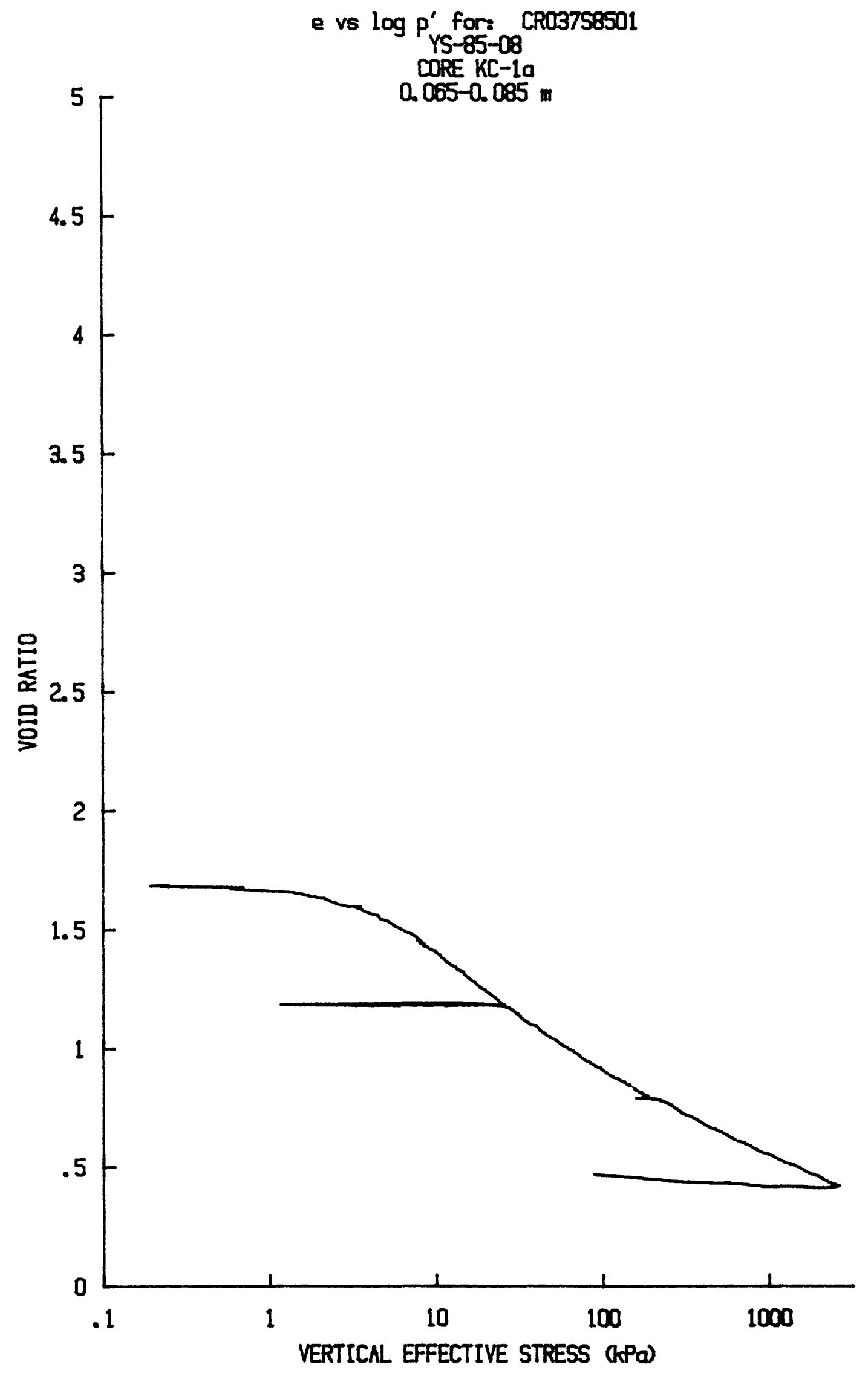




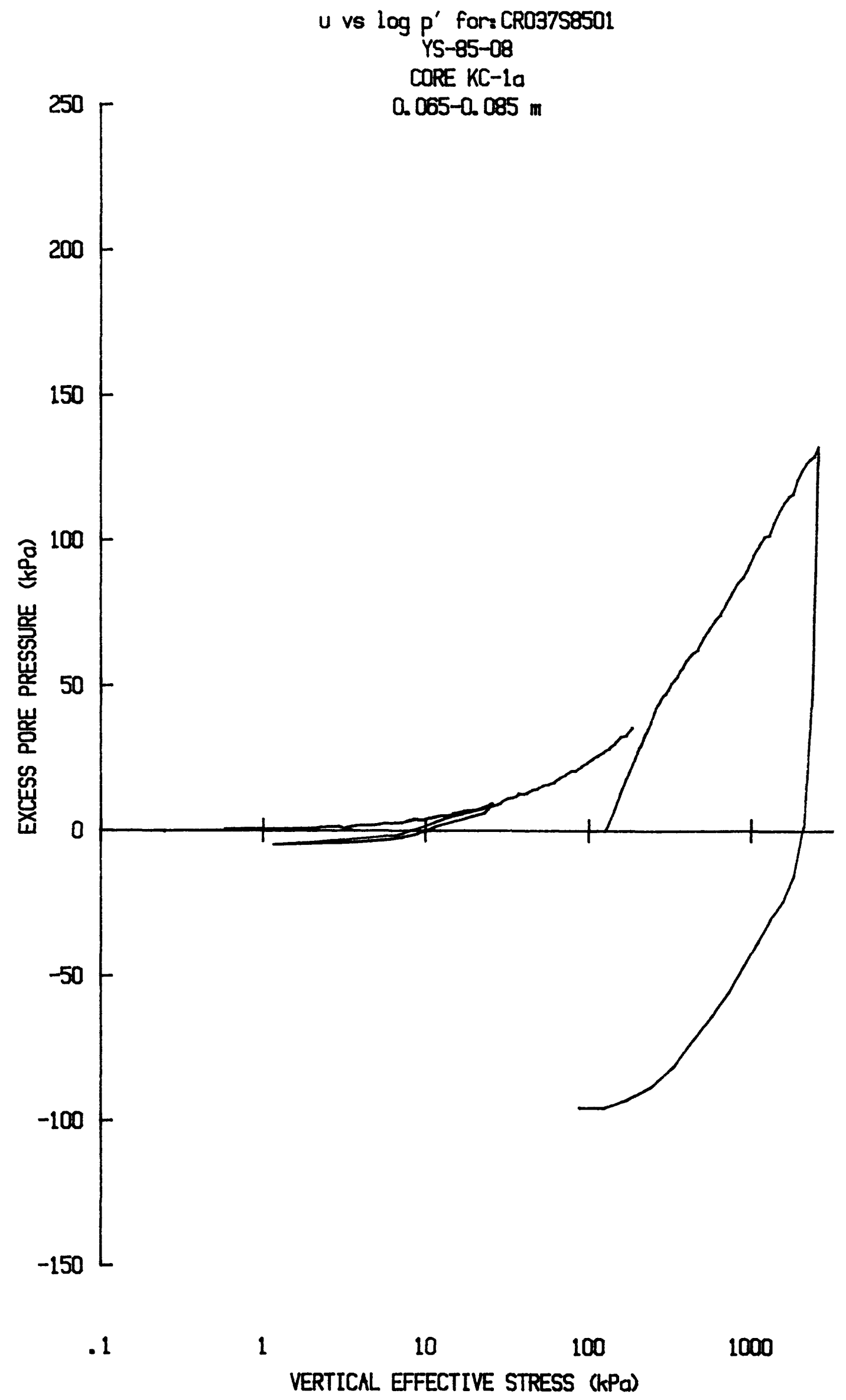




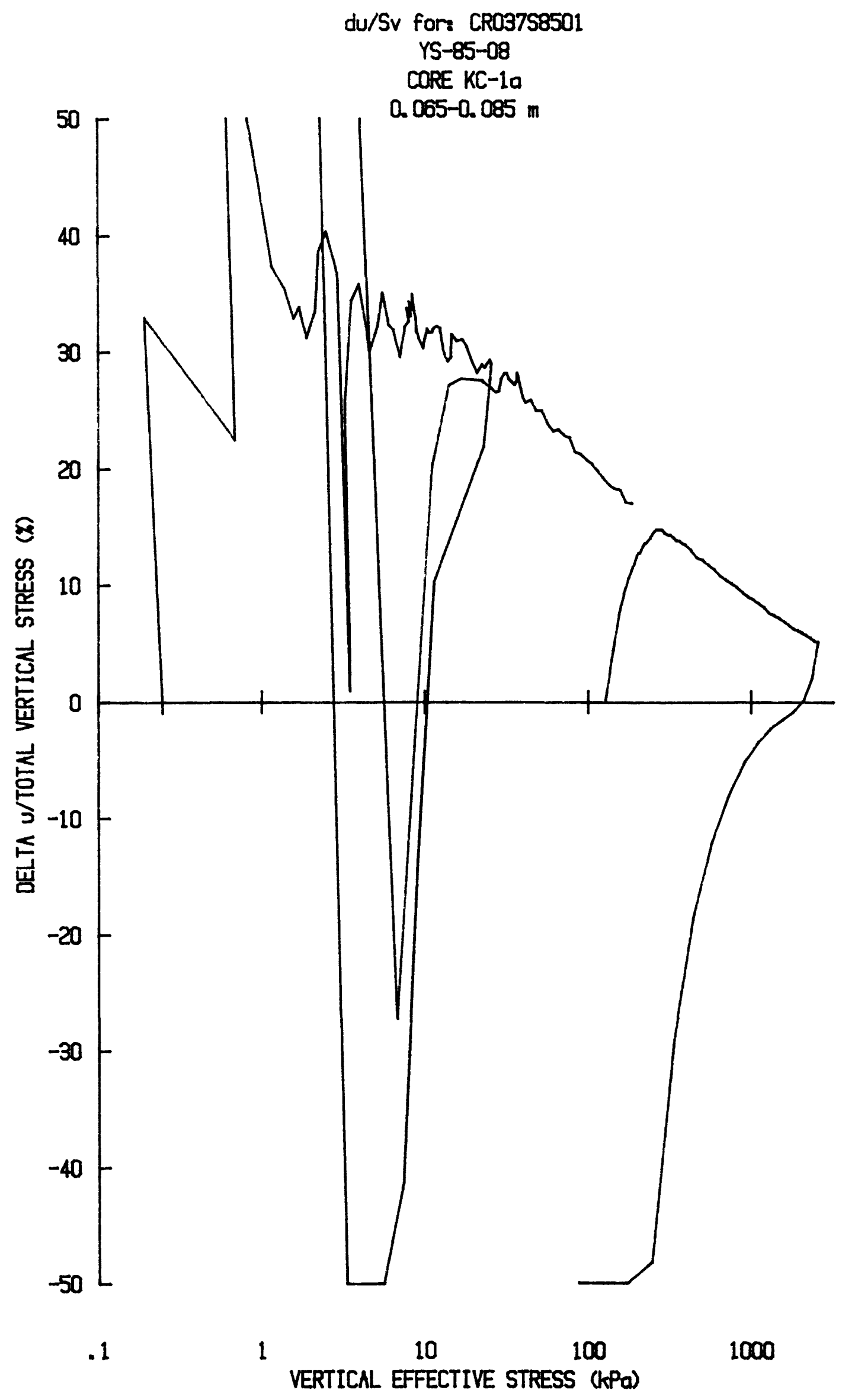




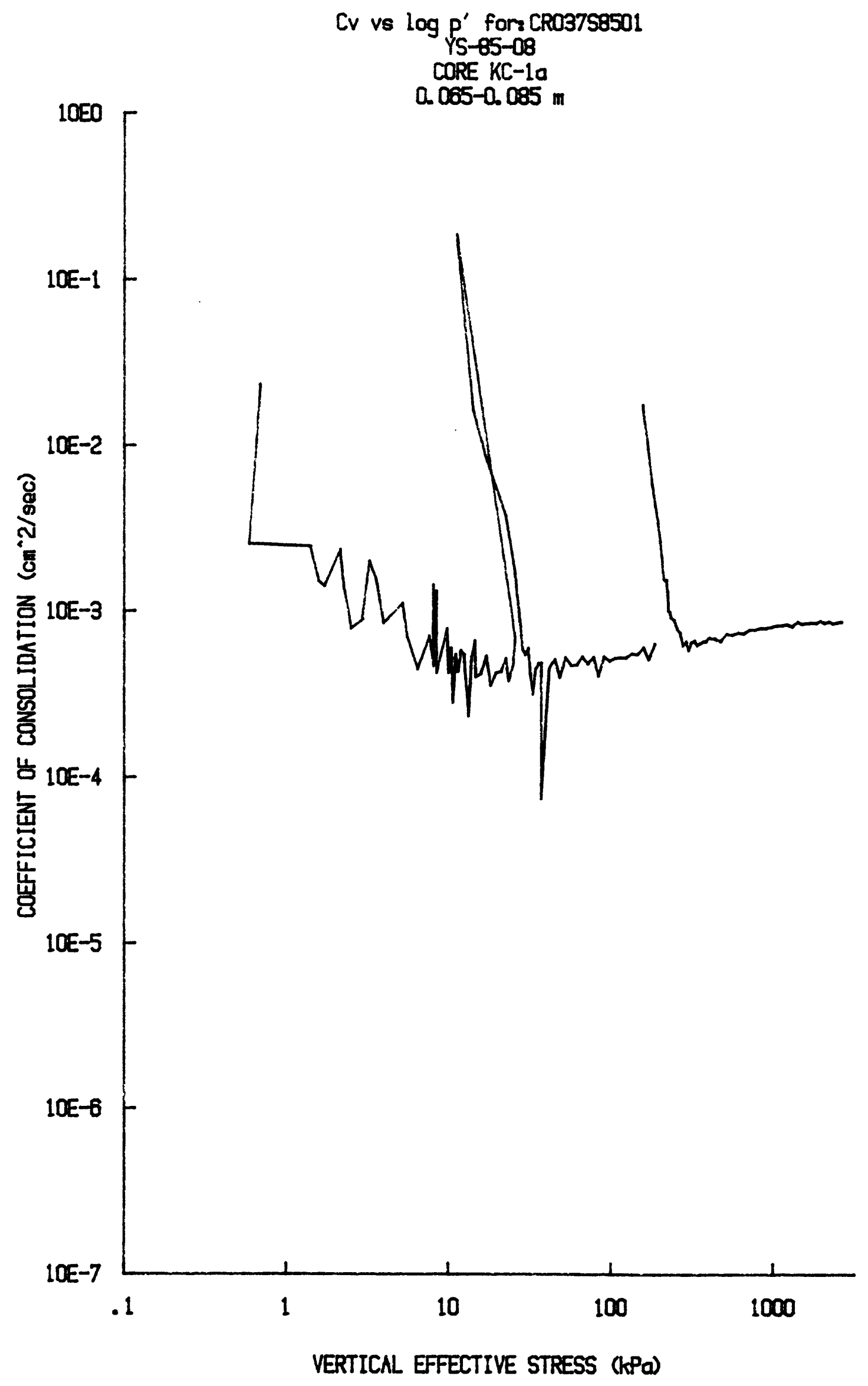




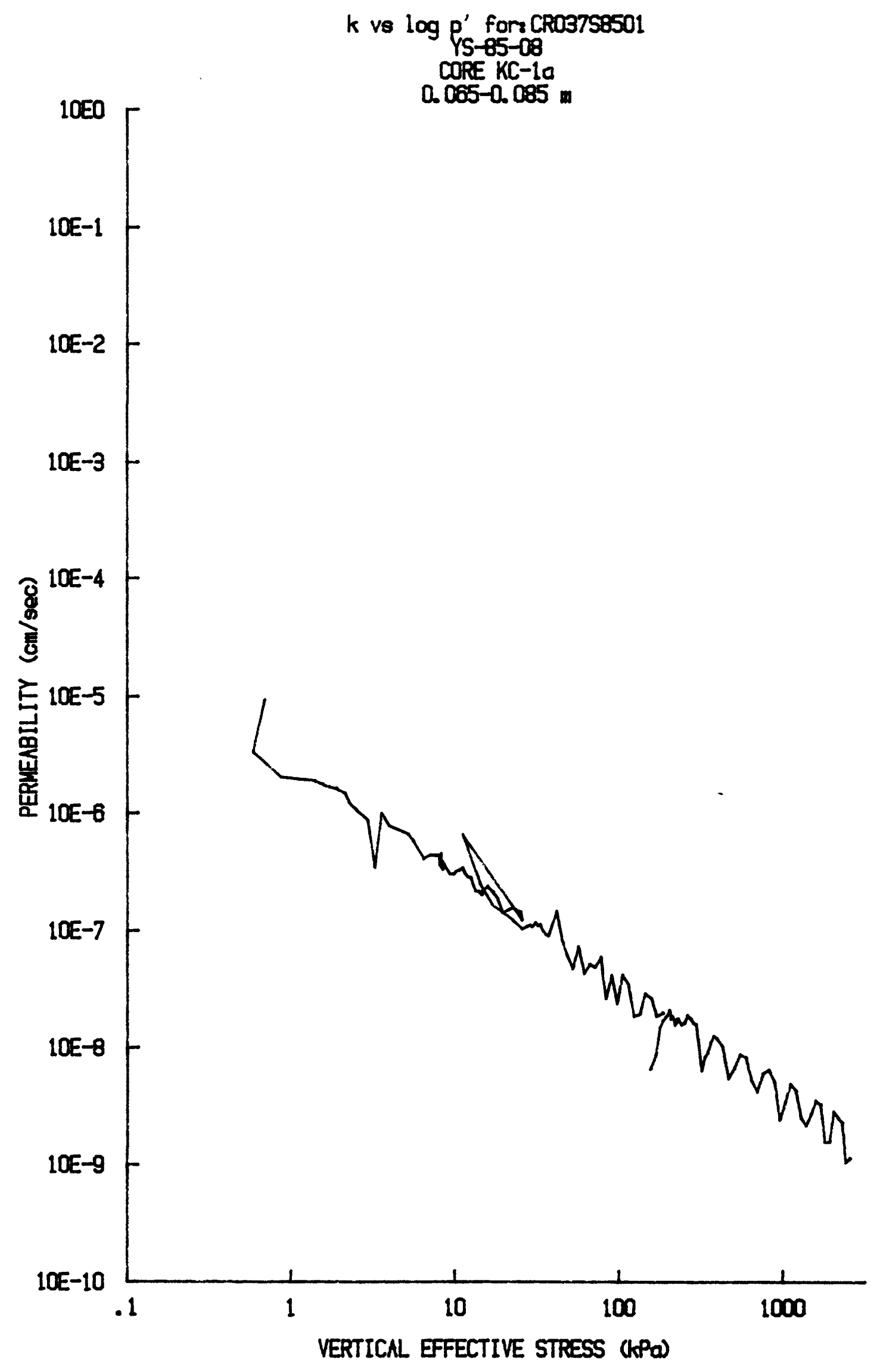




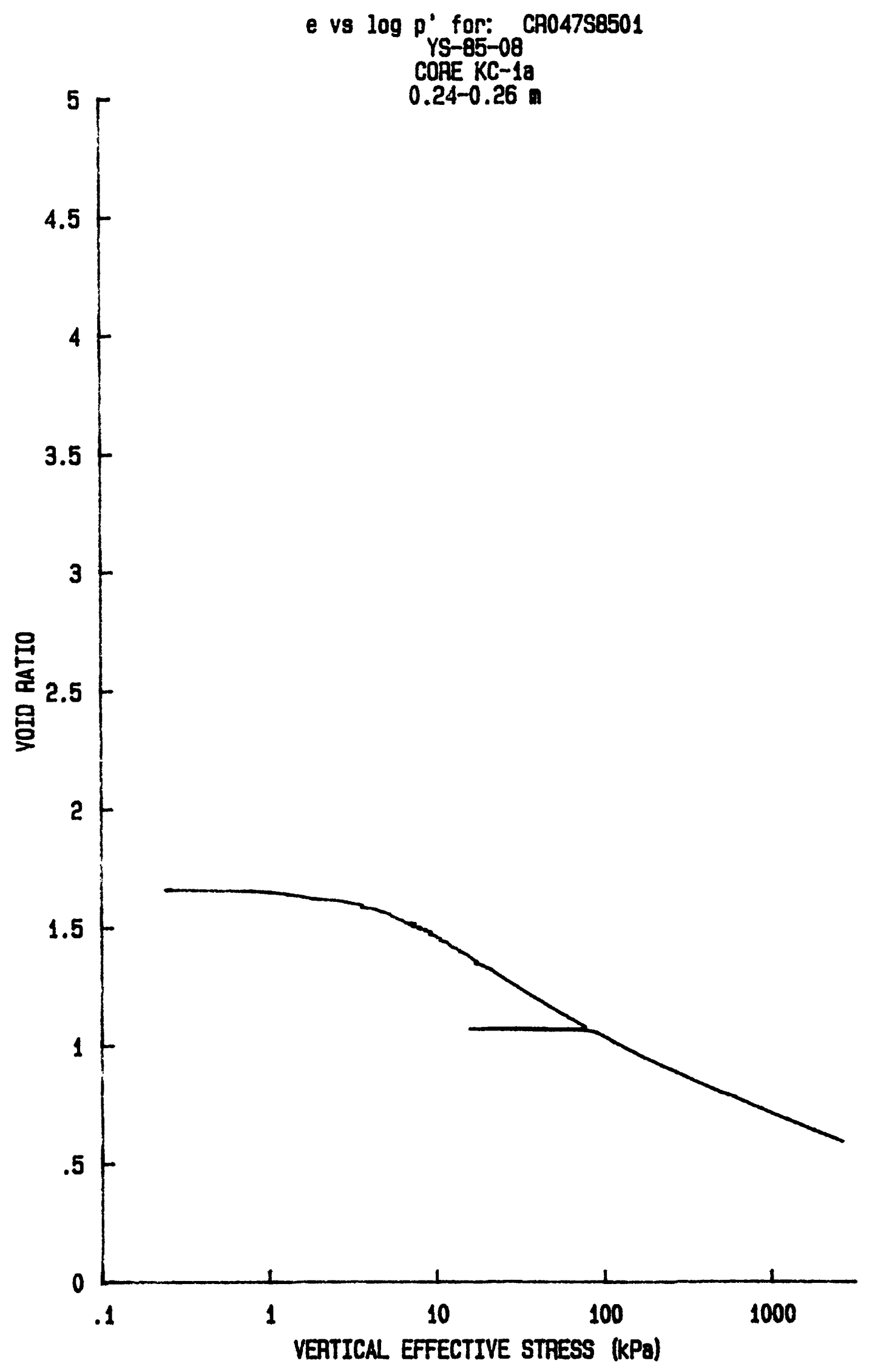




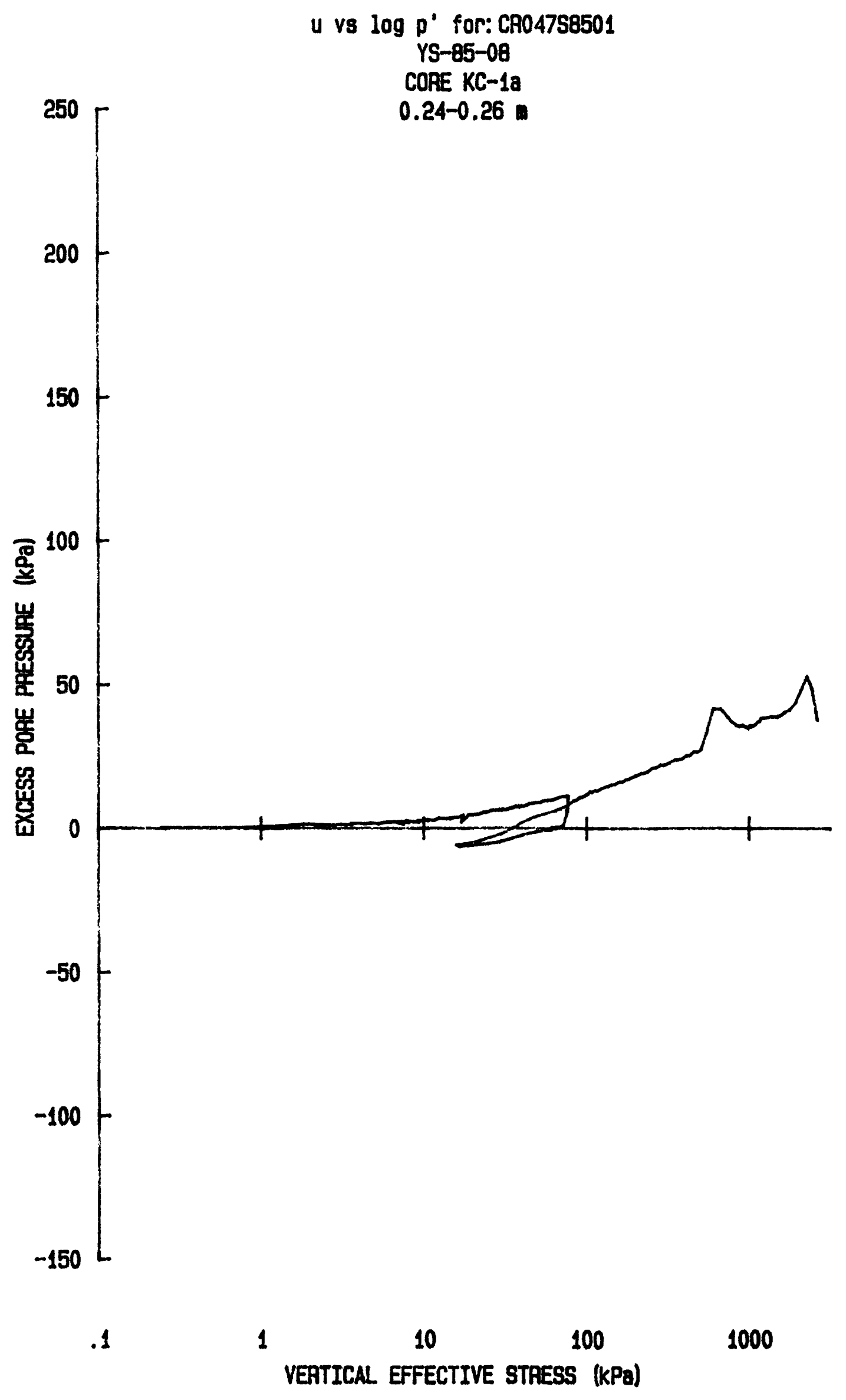




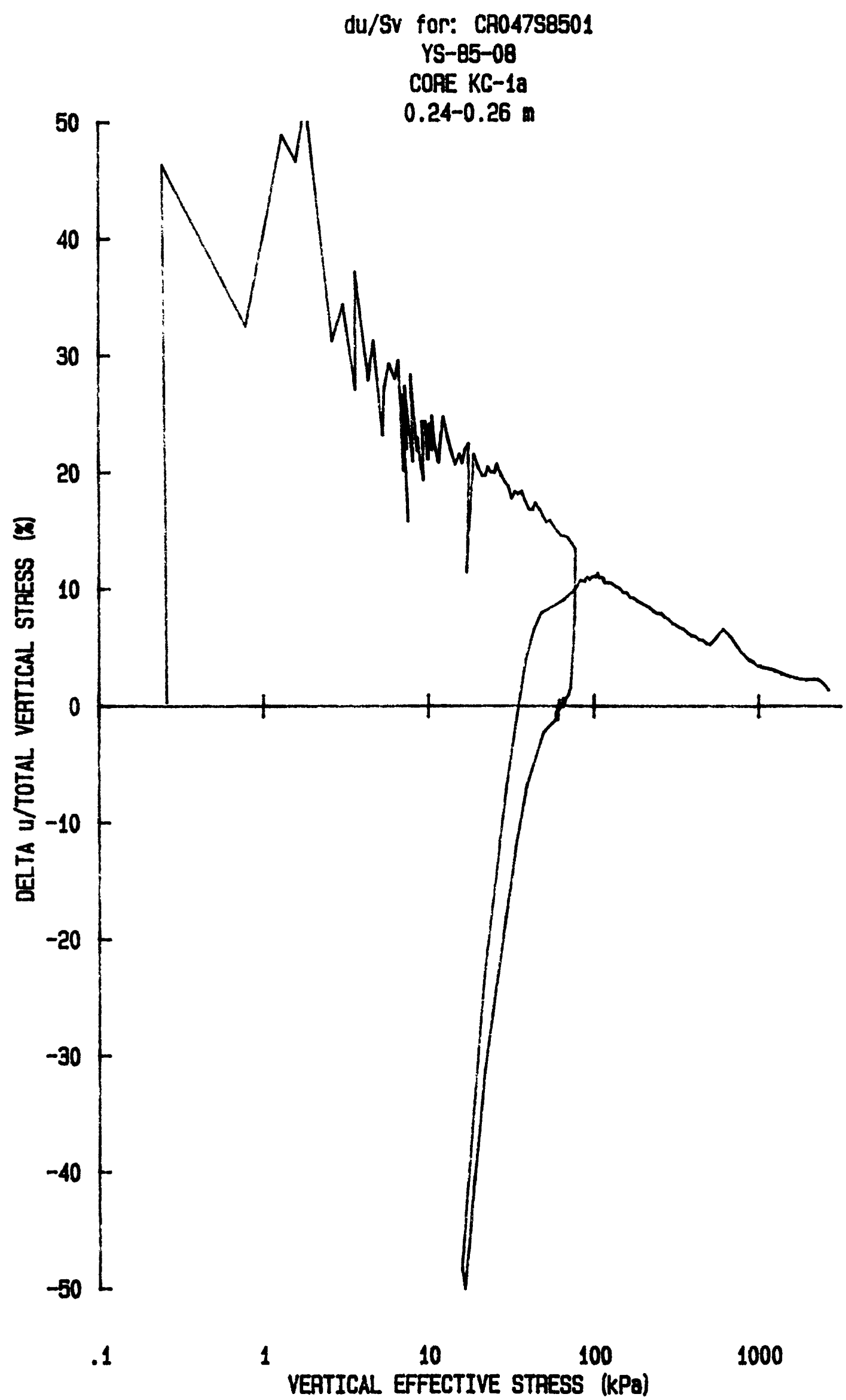

89 


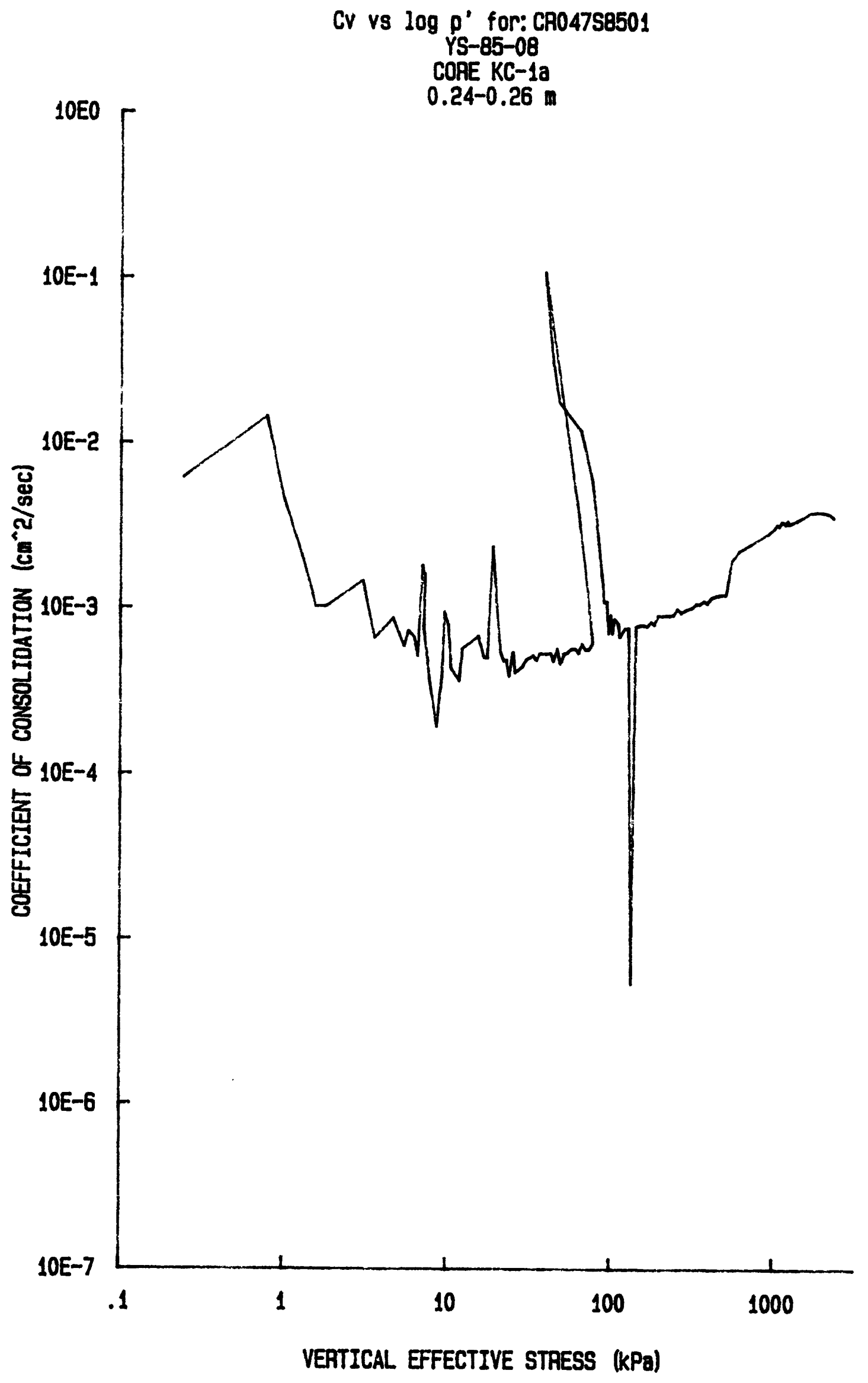




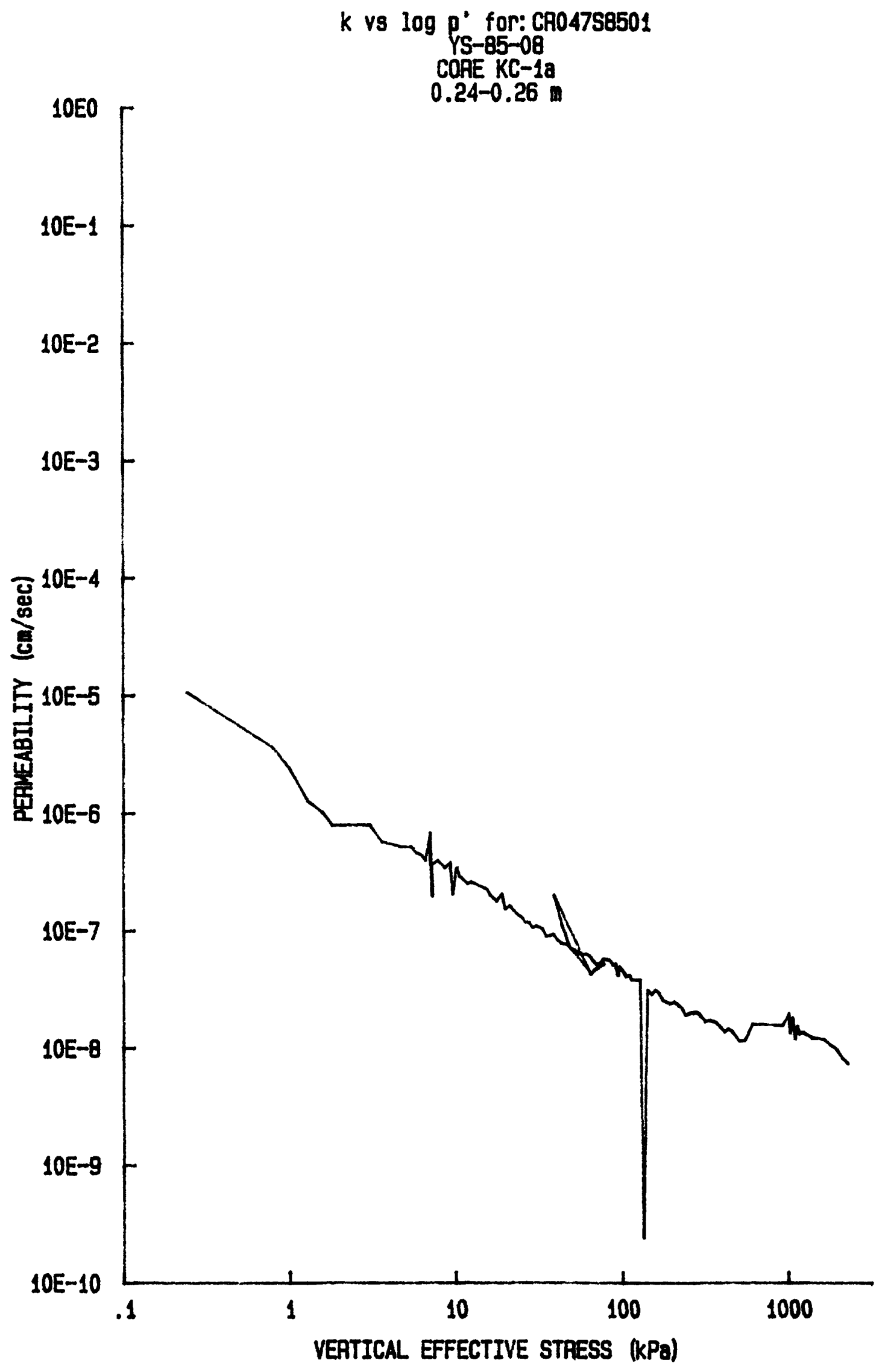




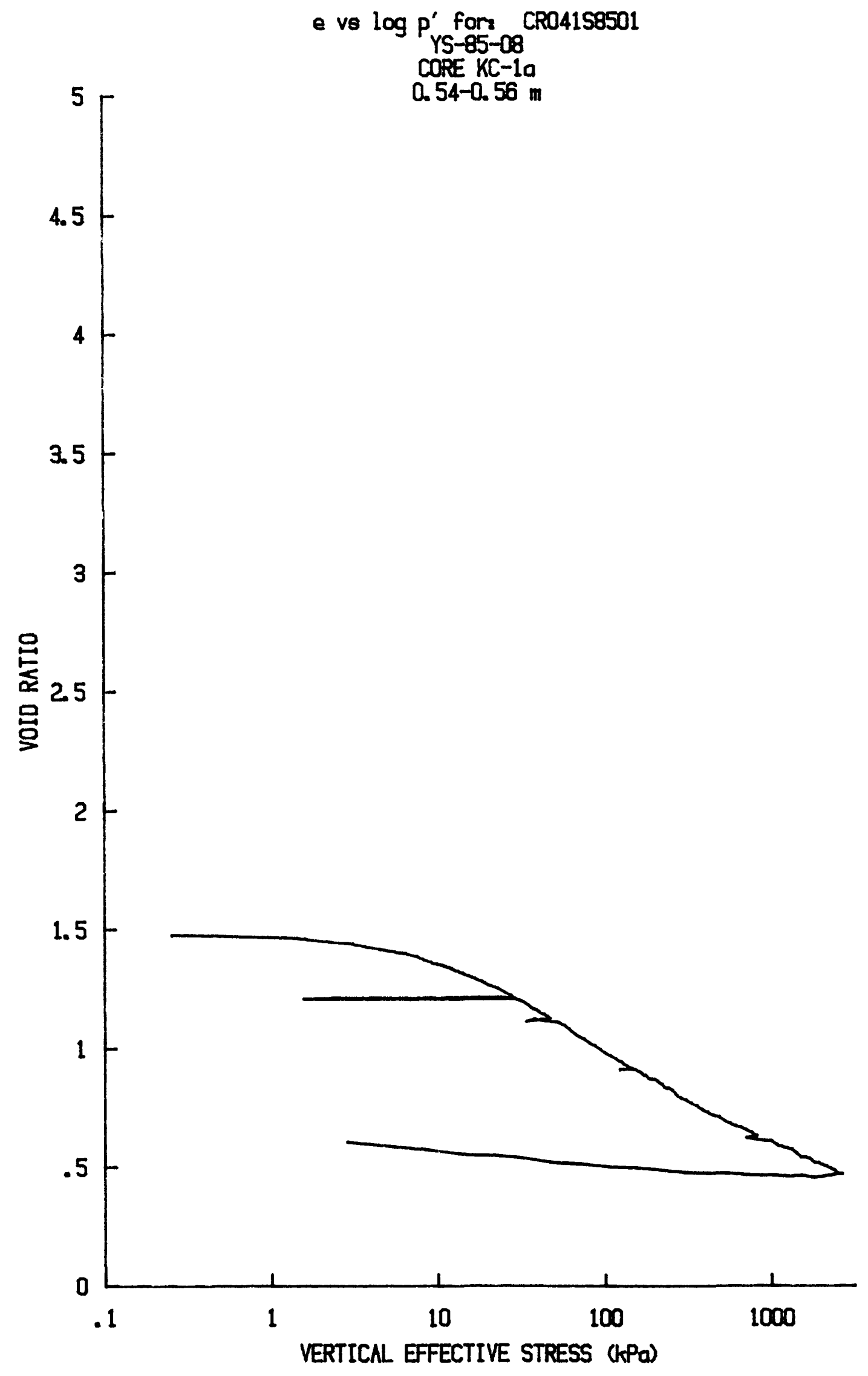




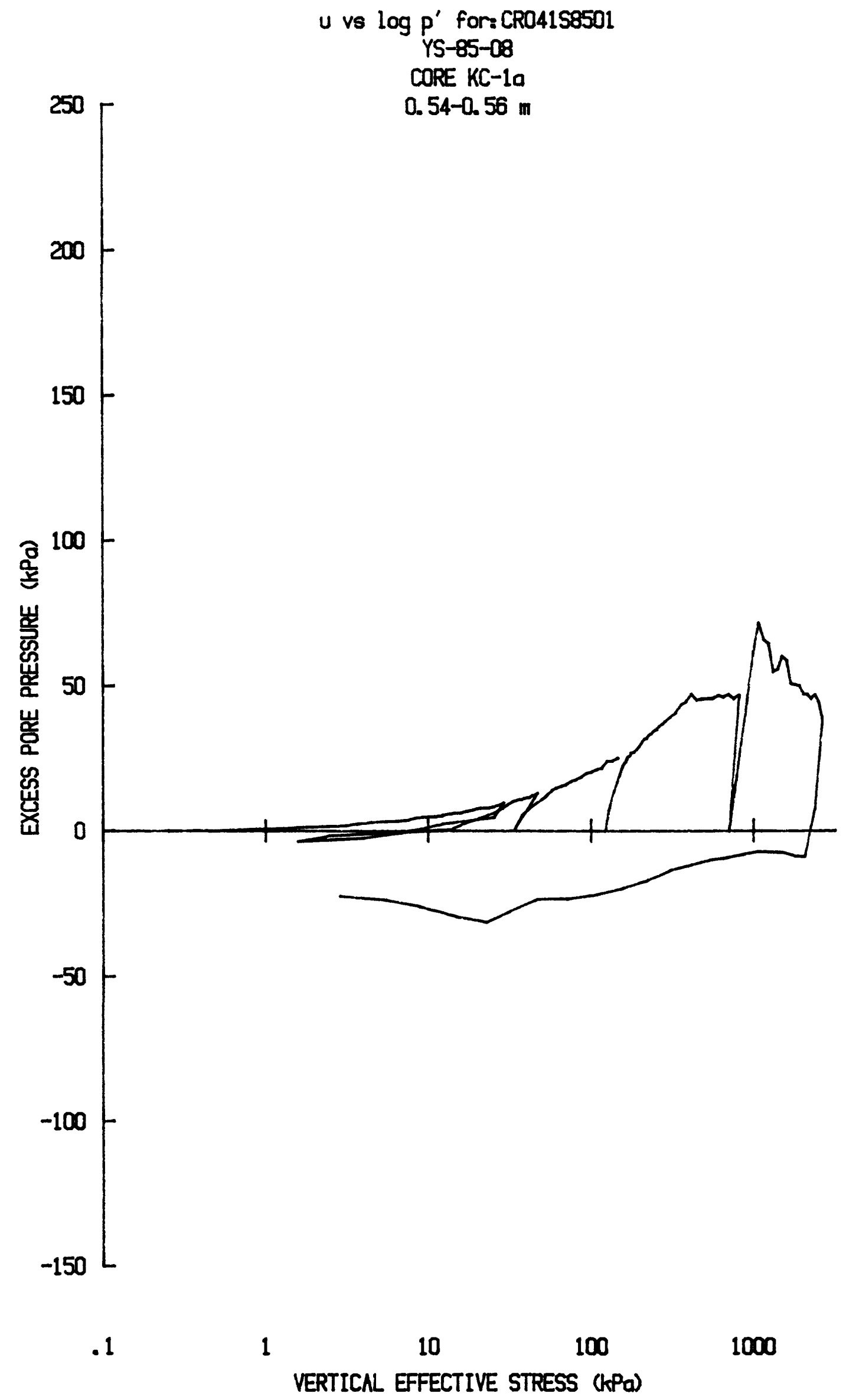




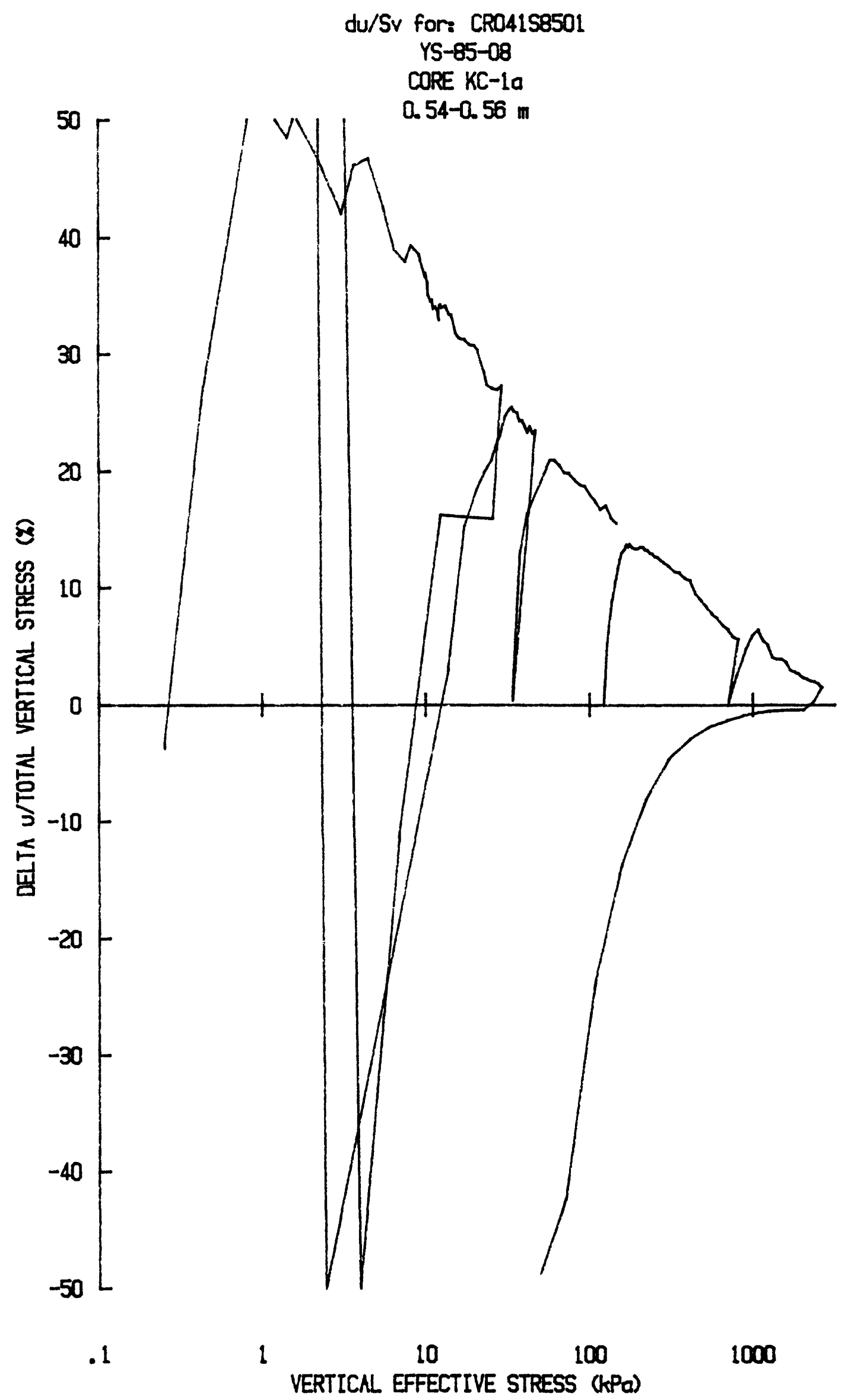




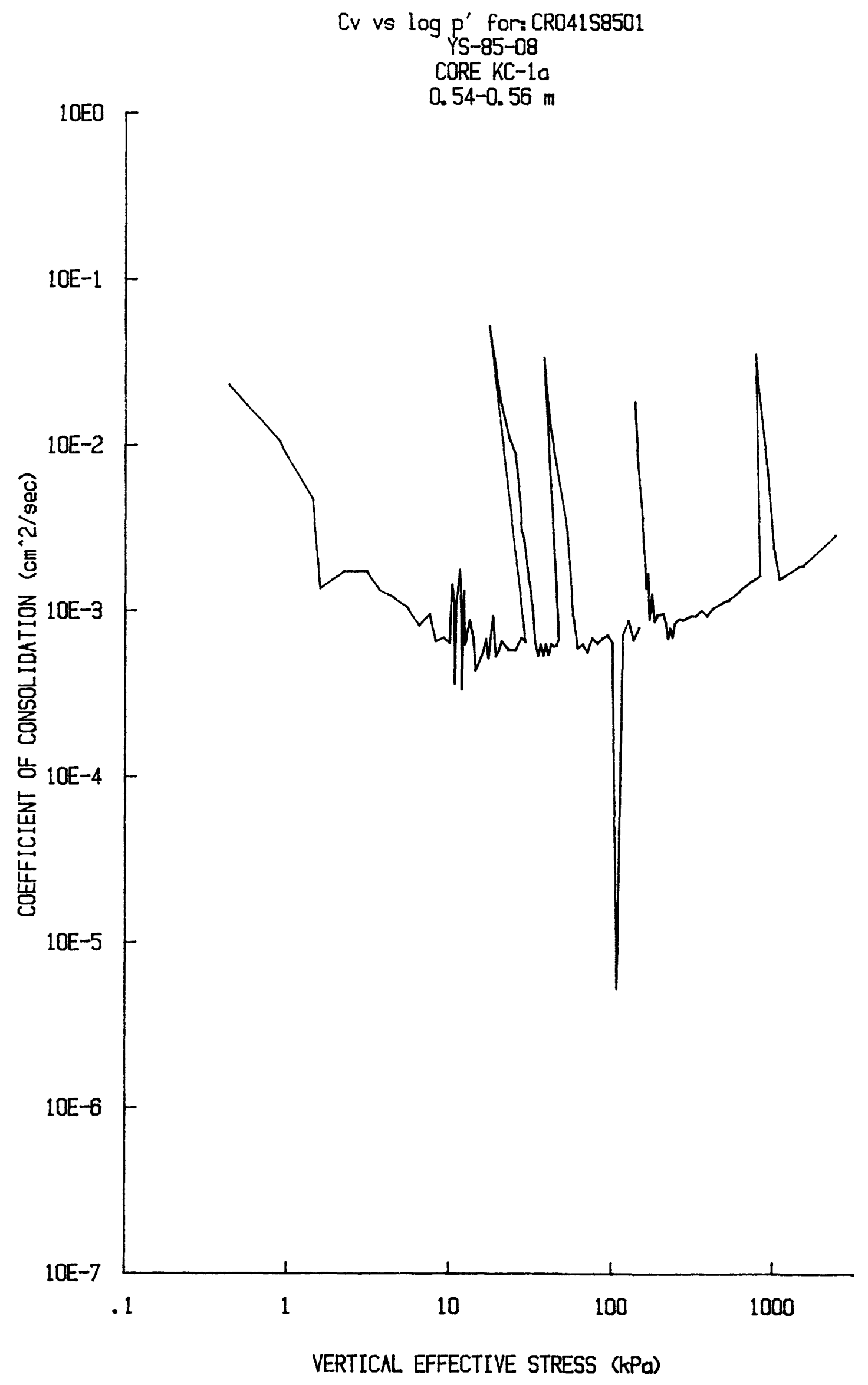




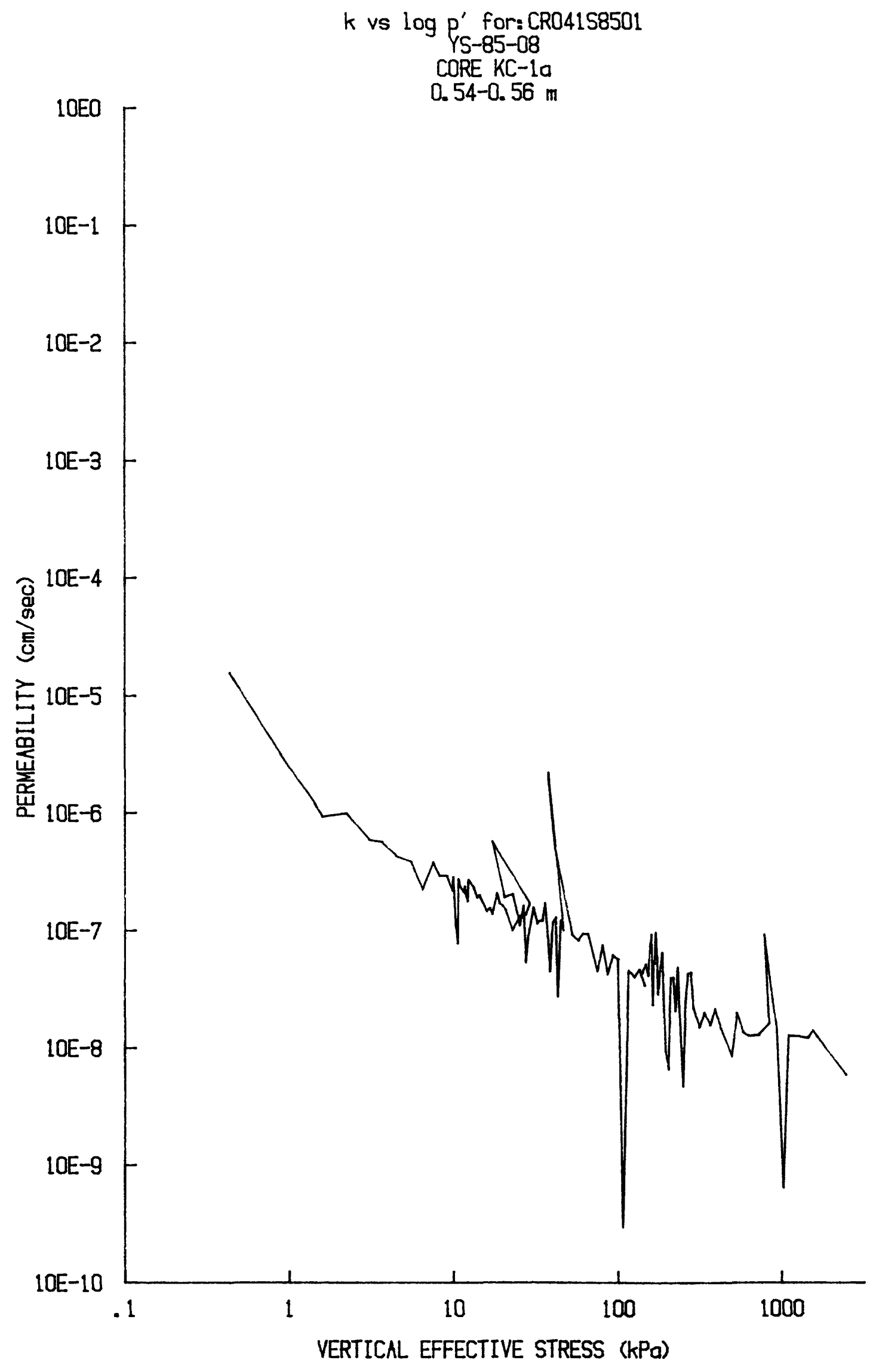




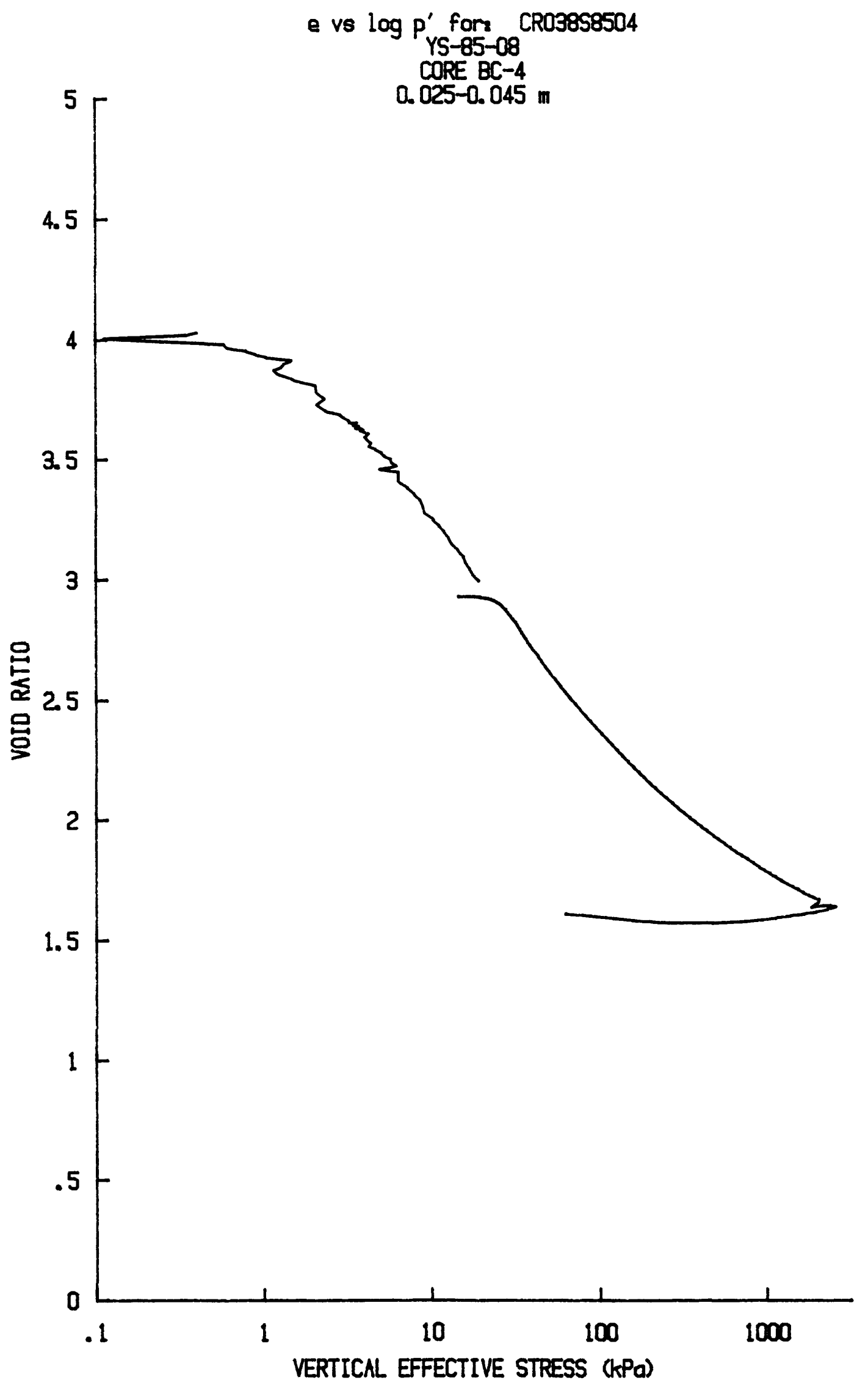




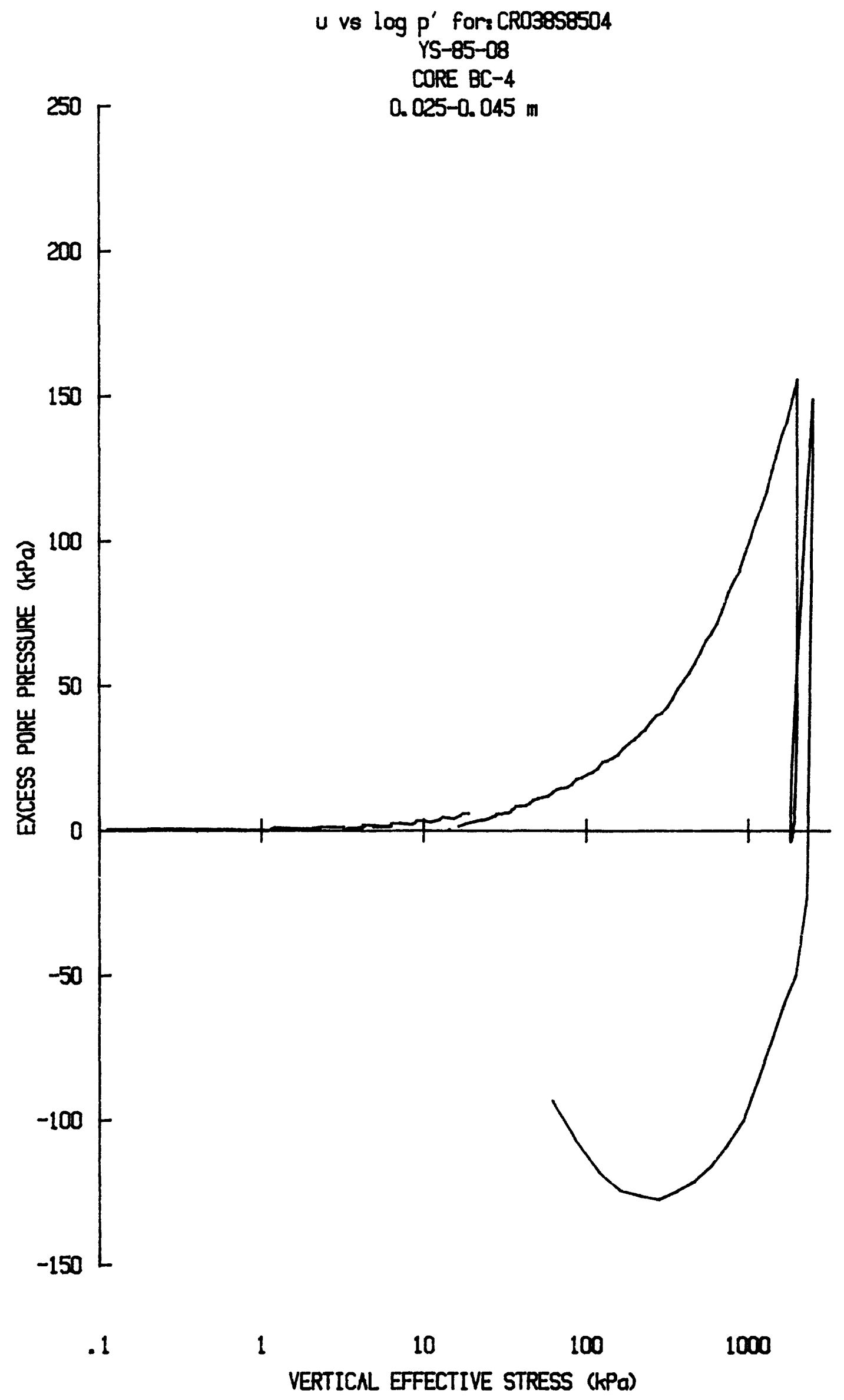




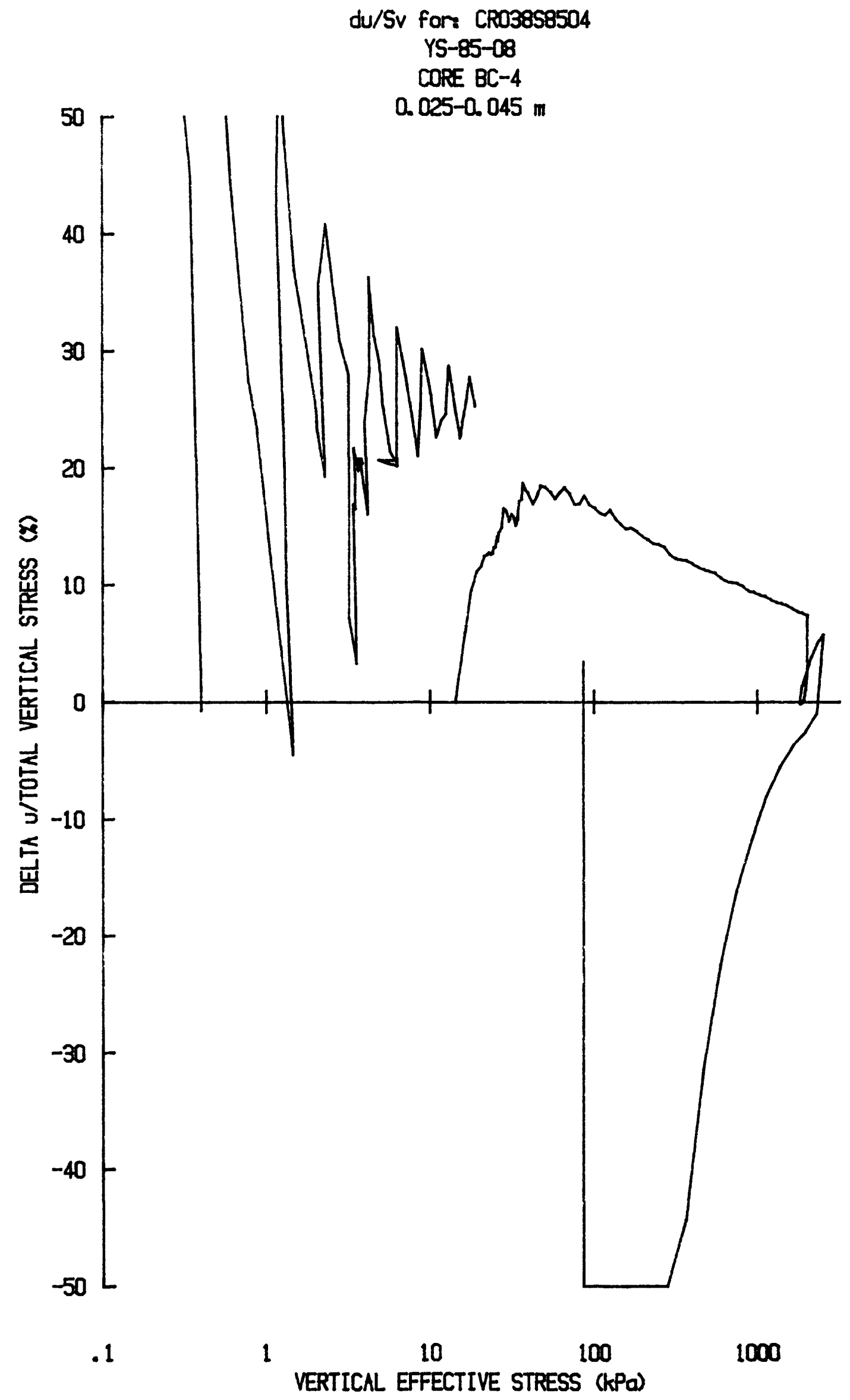




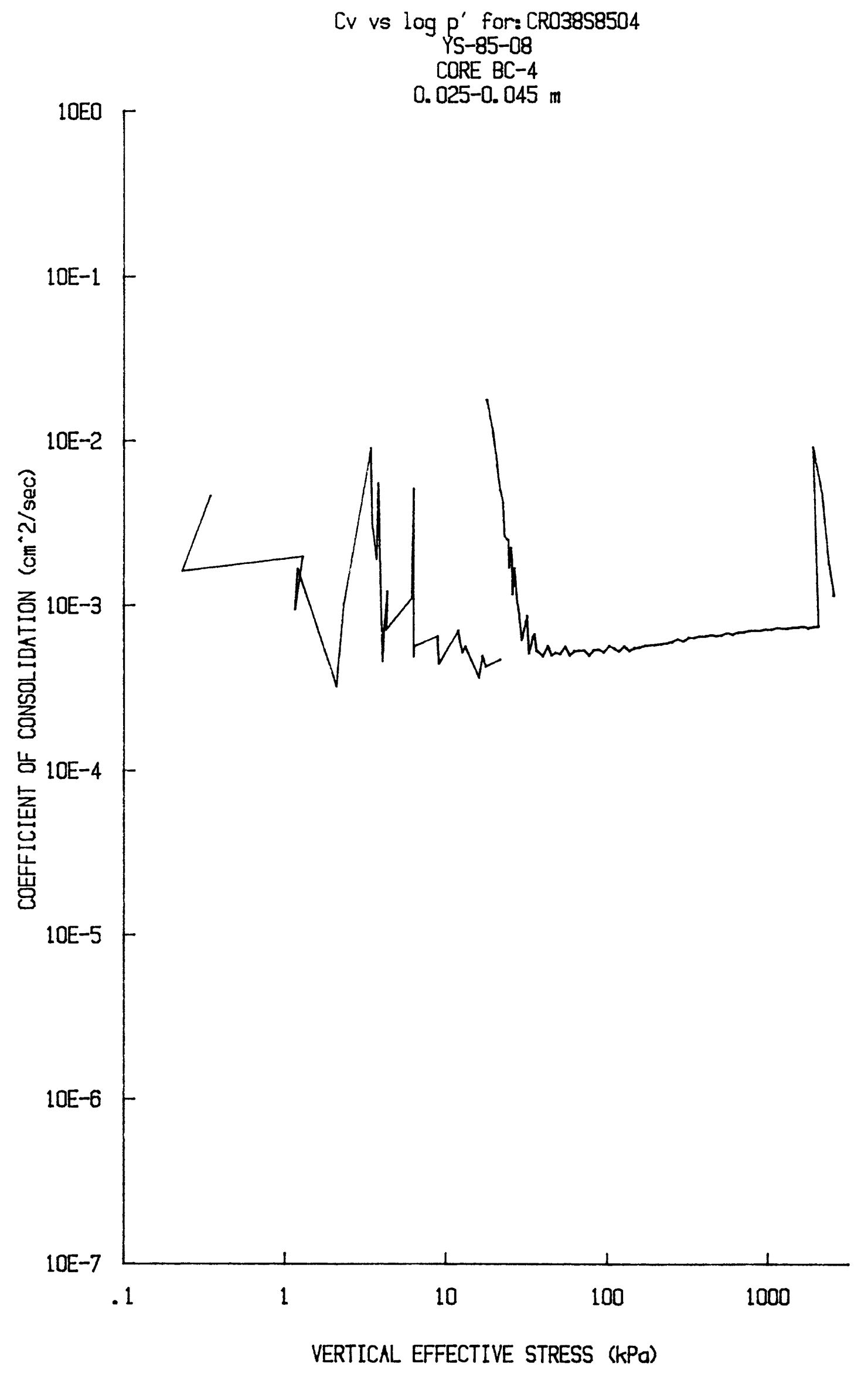




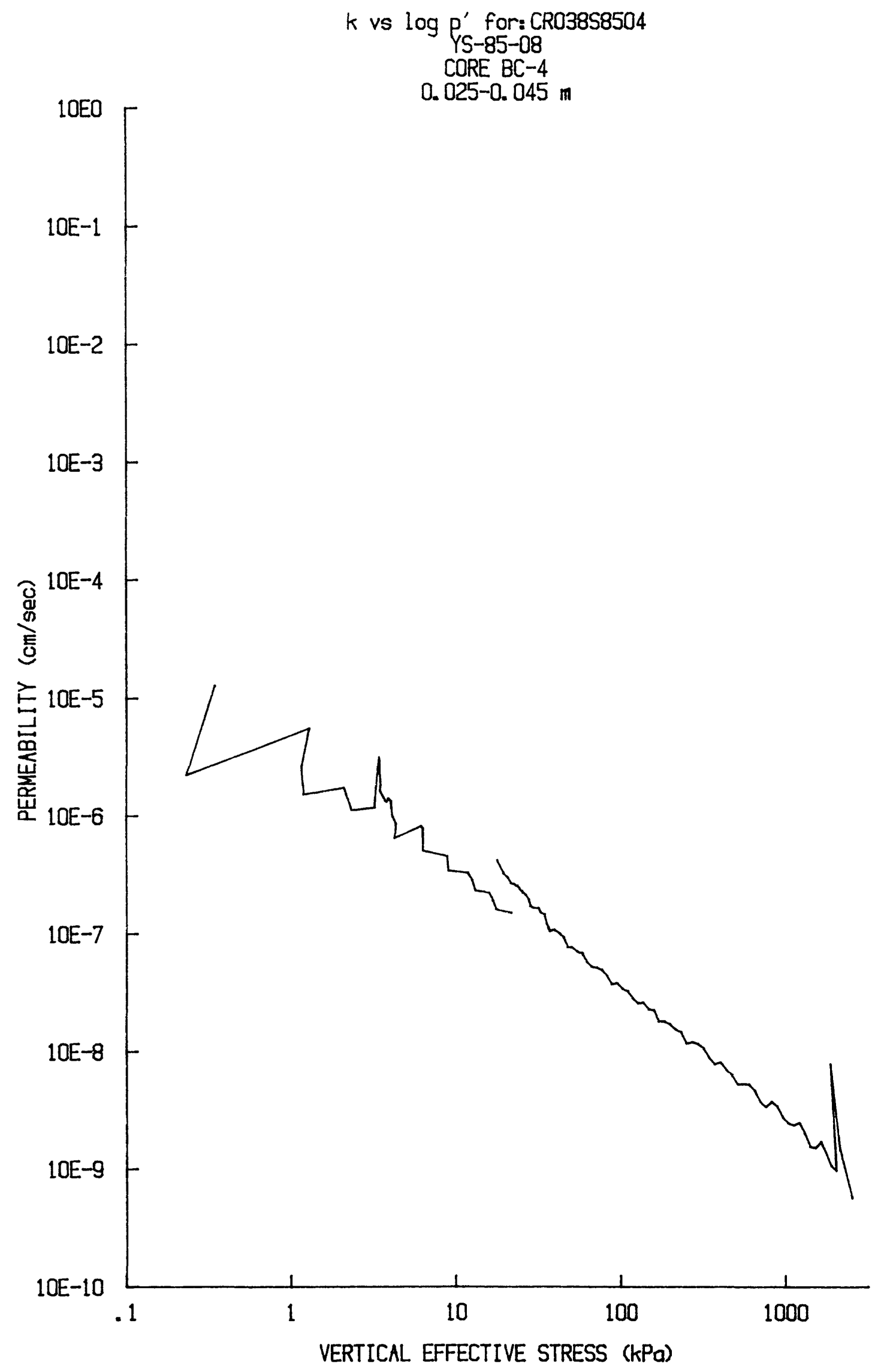




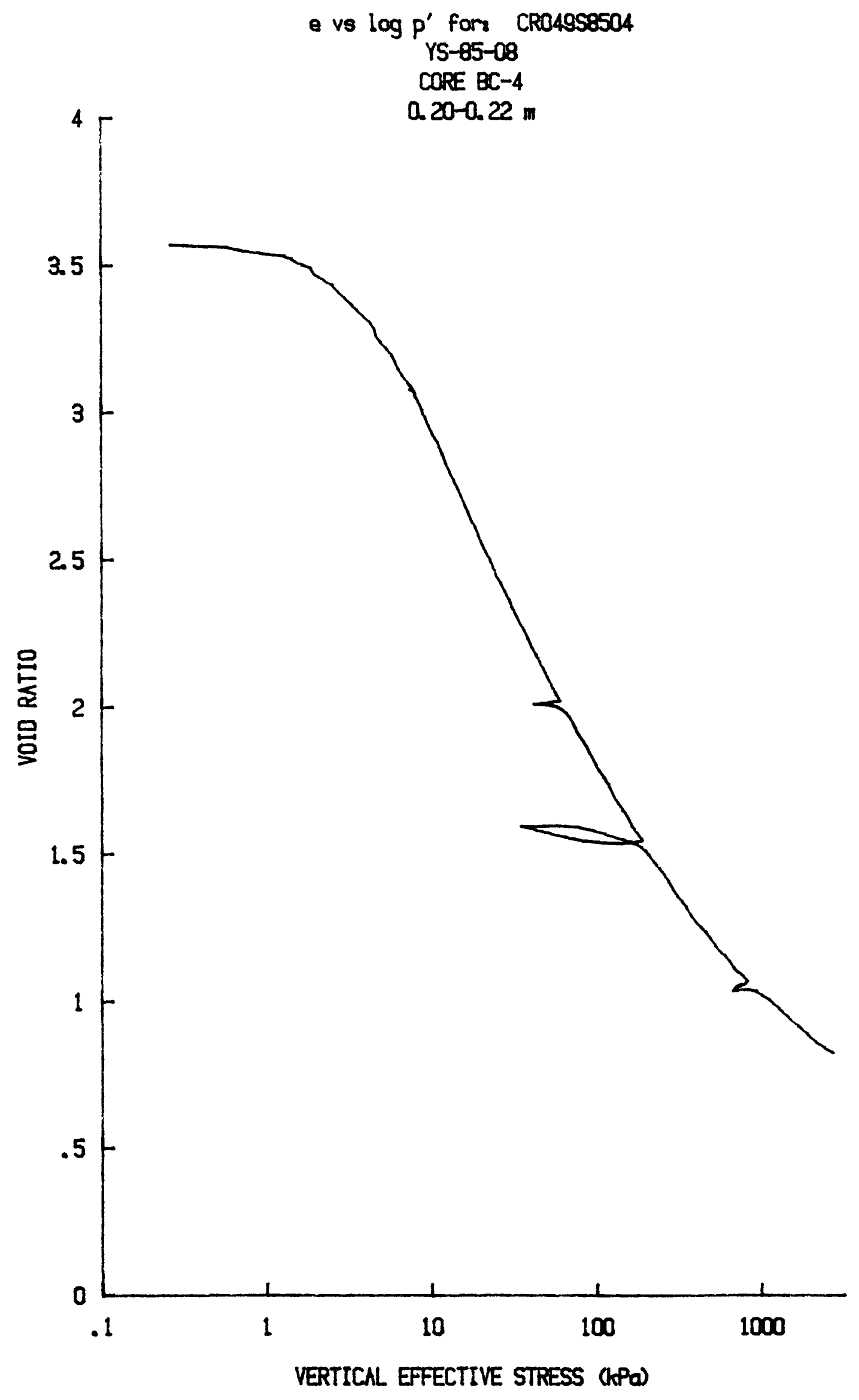




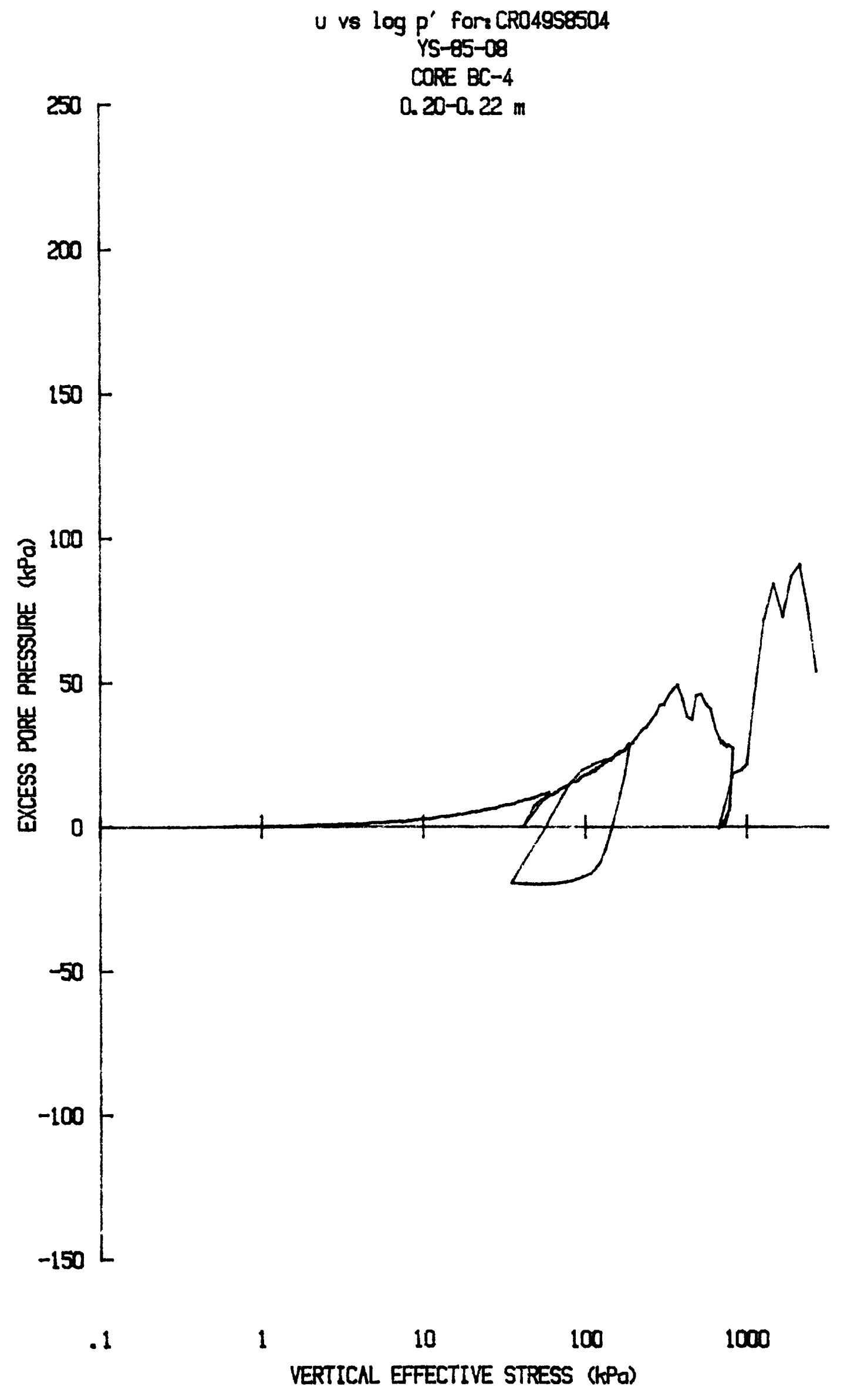




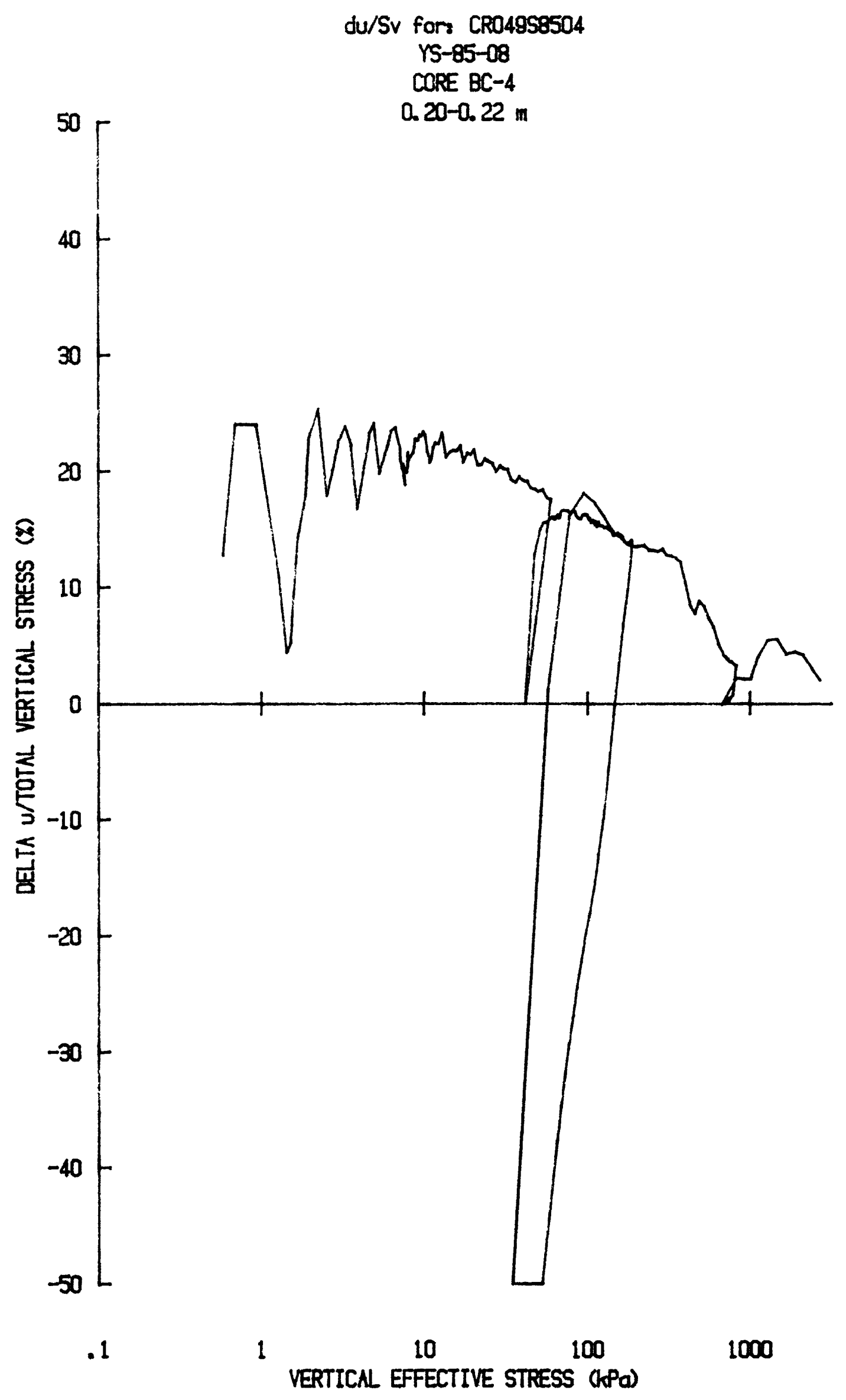




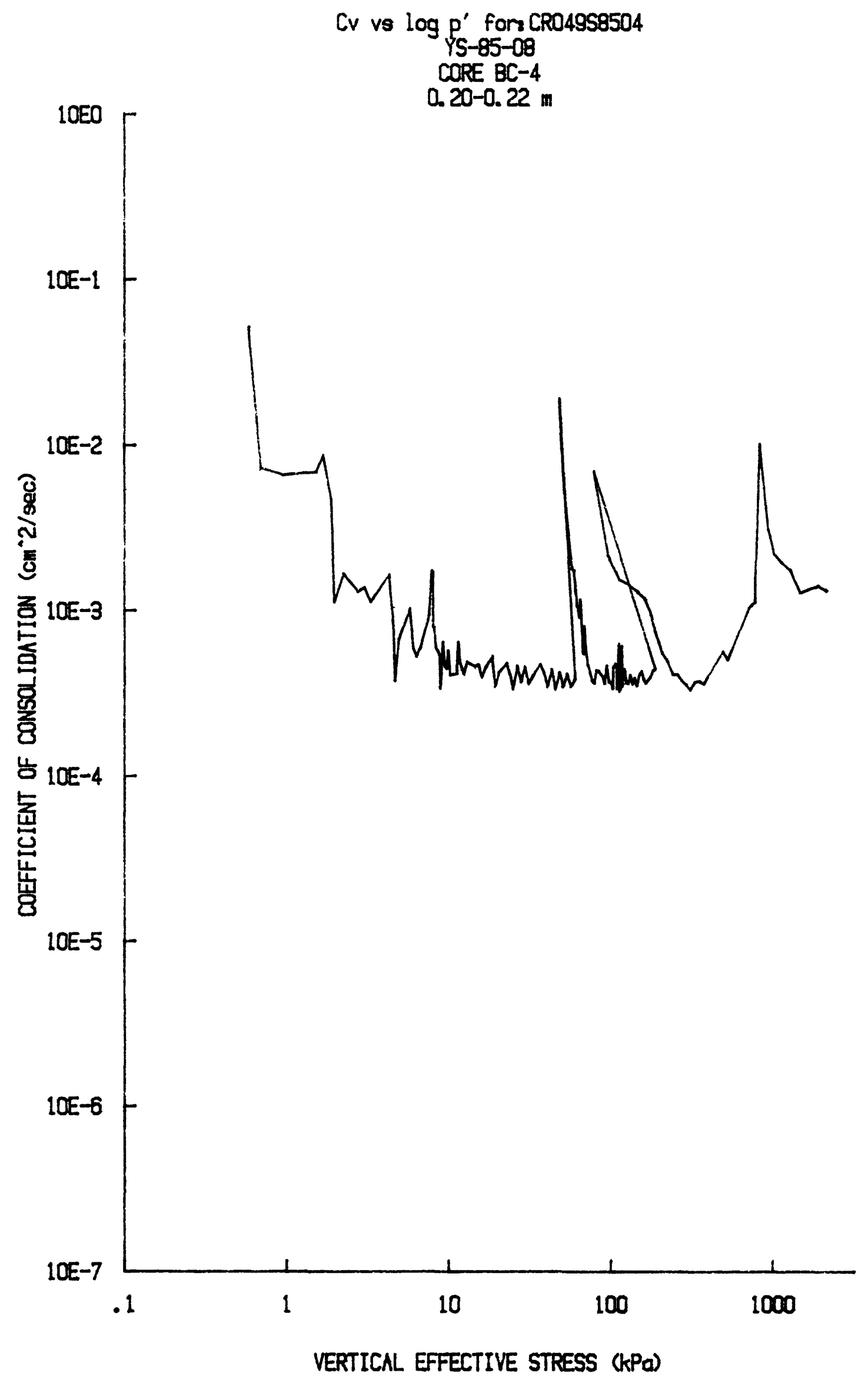




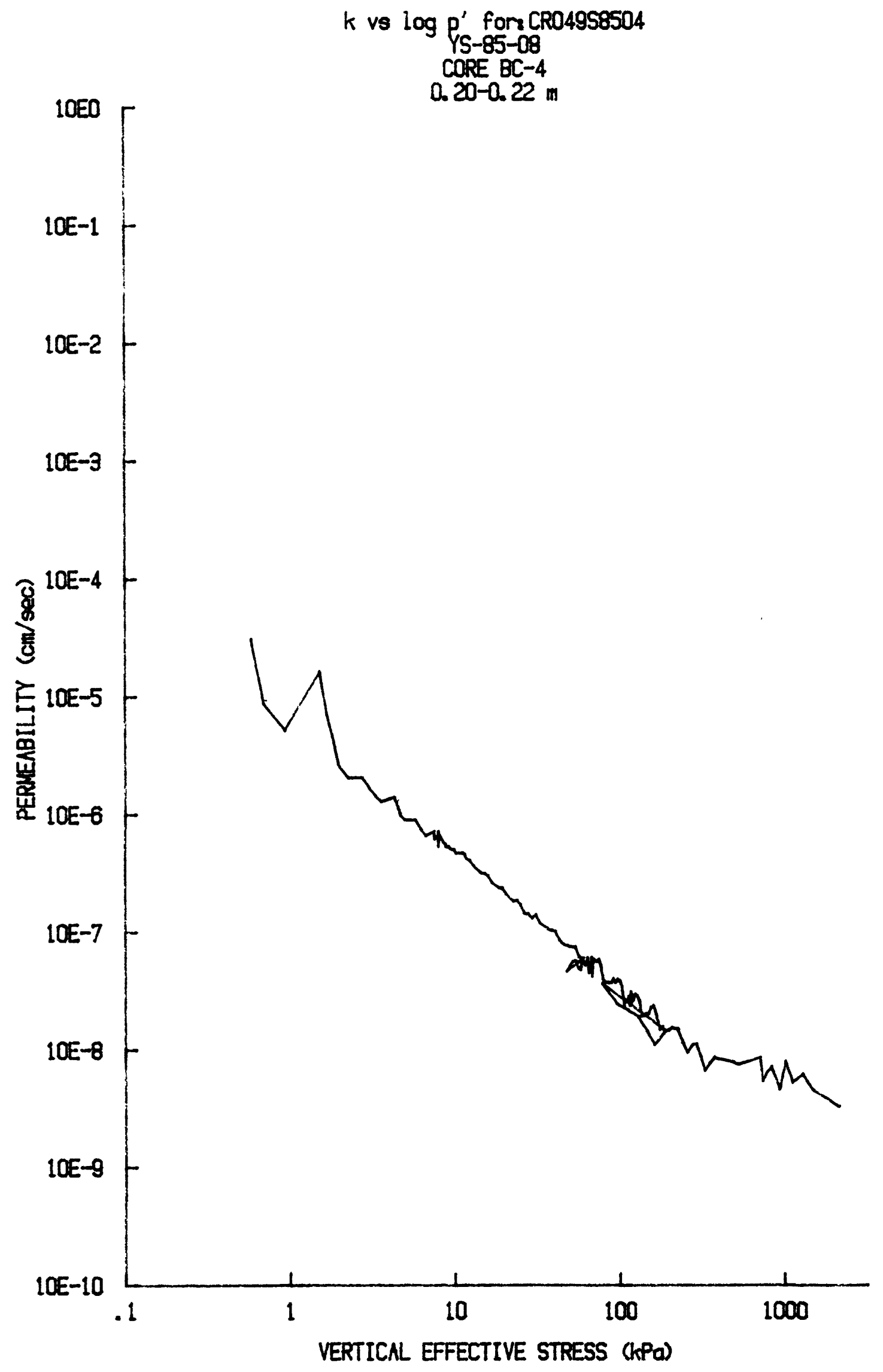




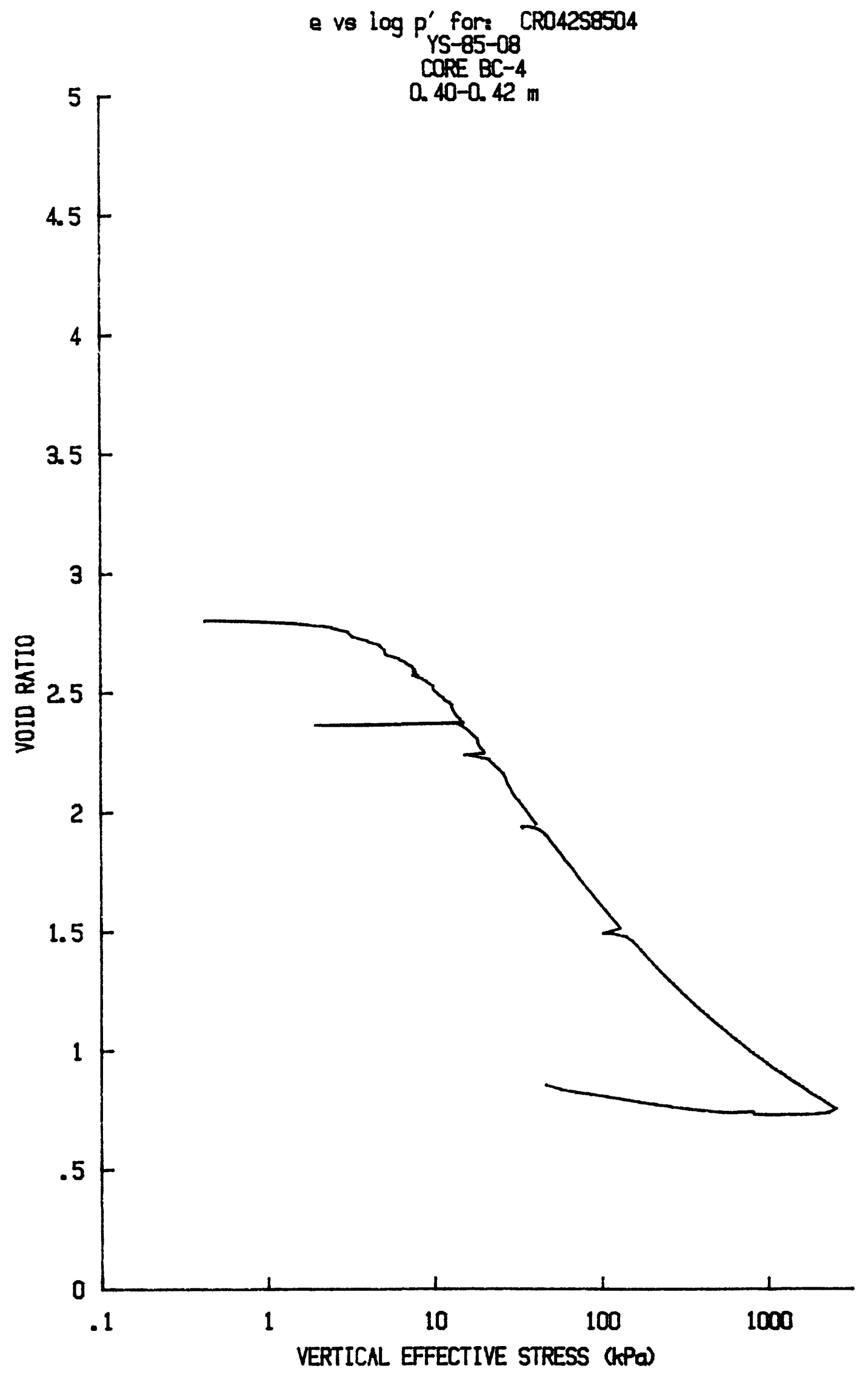




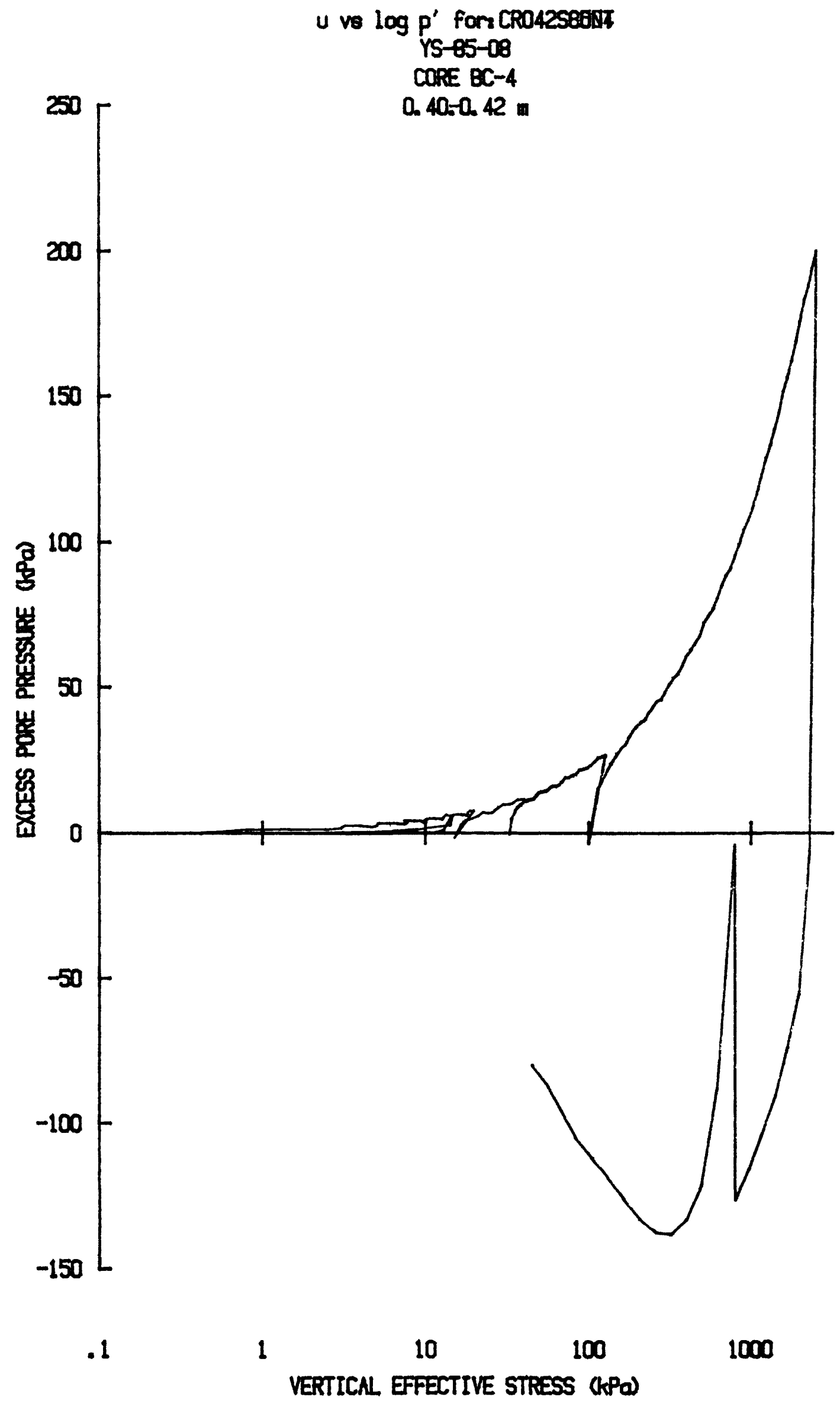




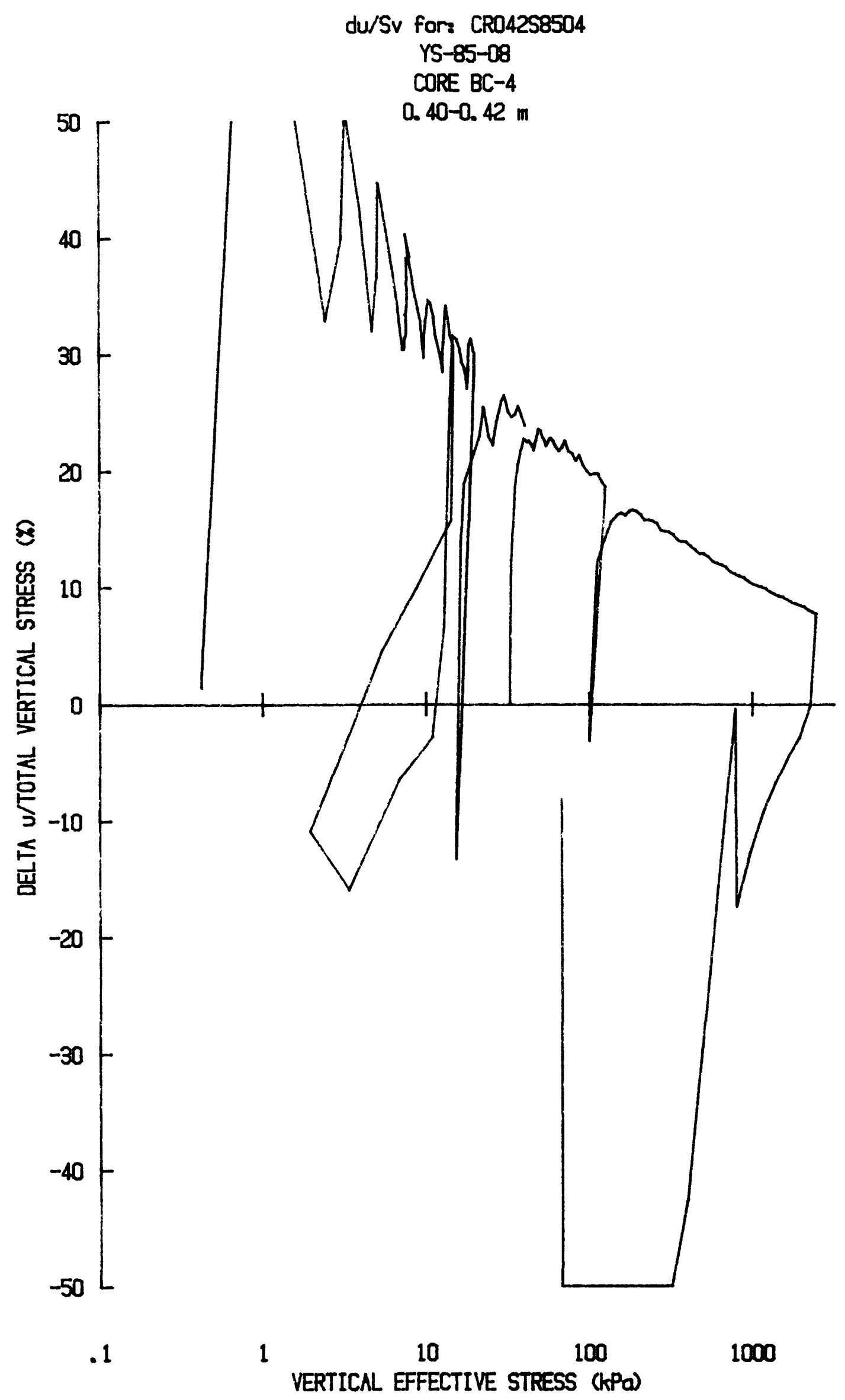




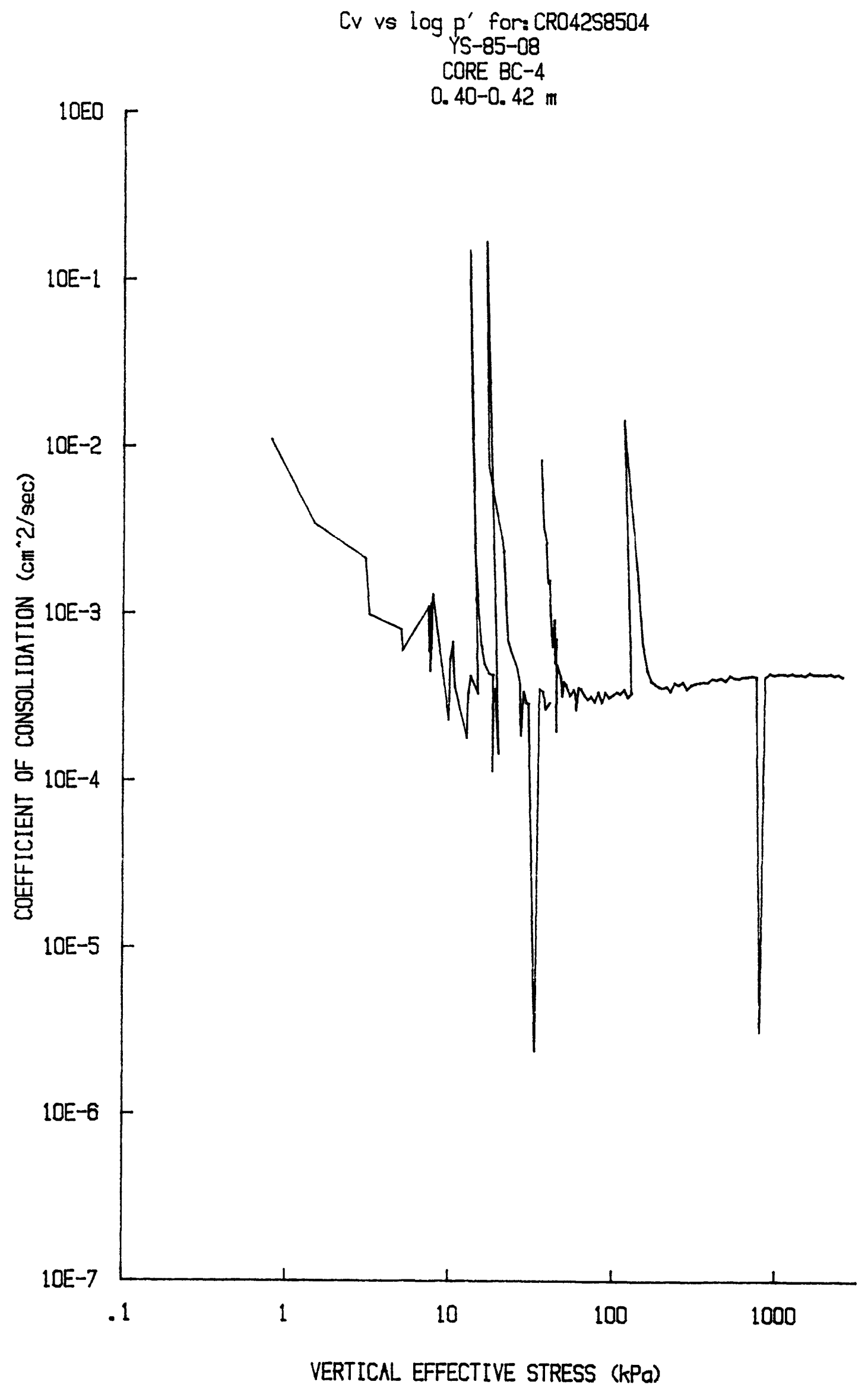




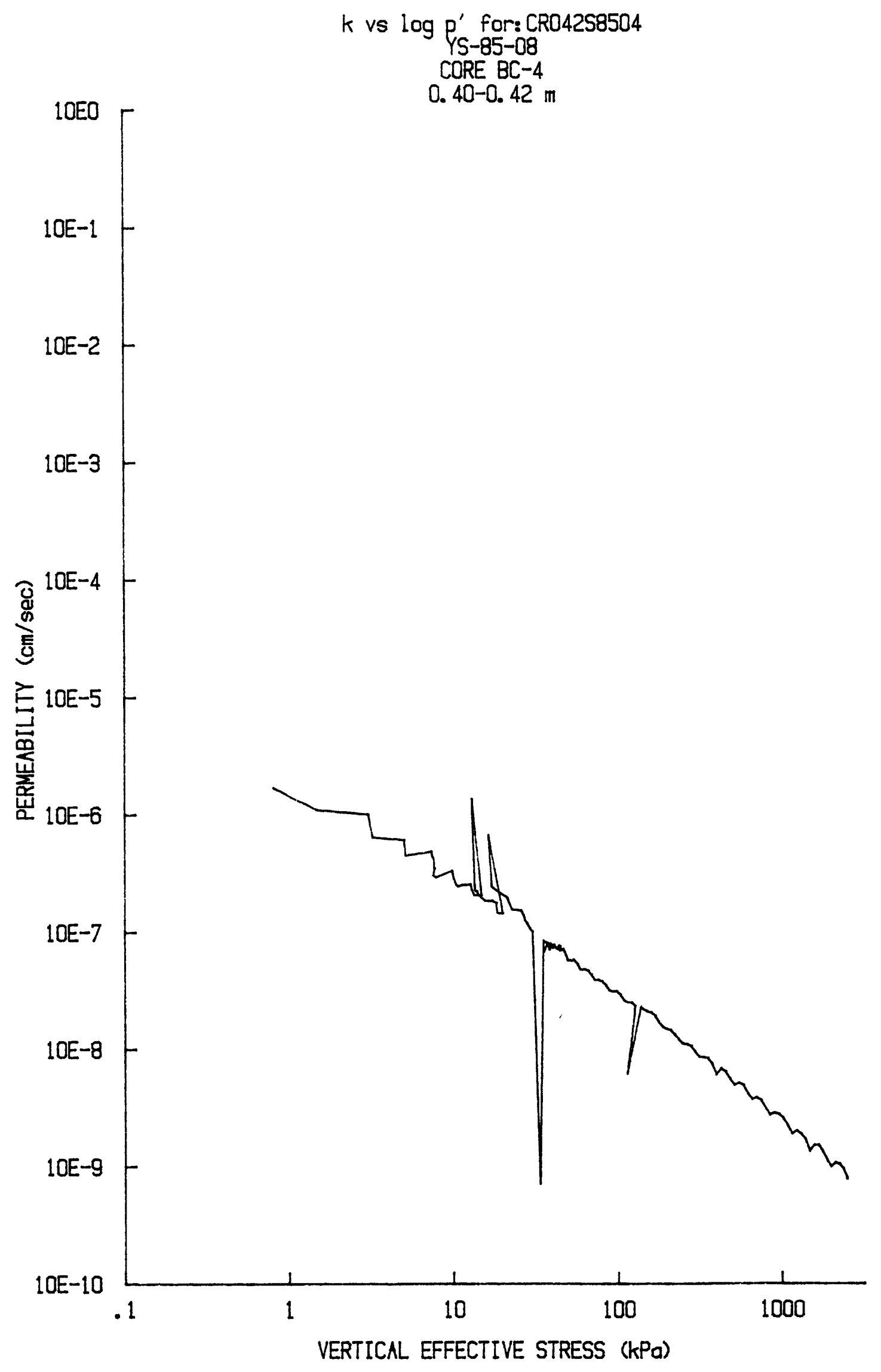




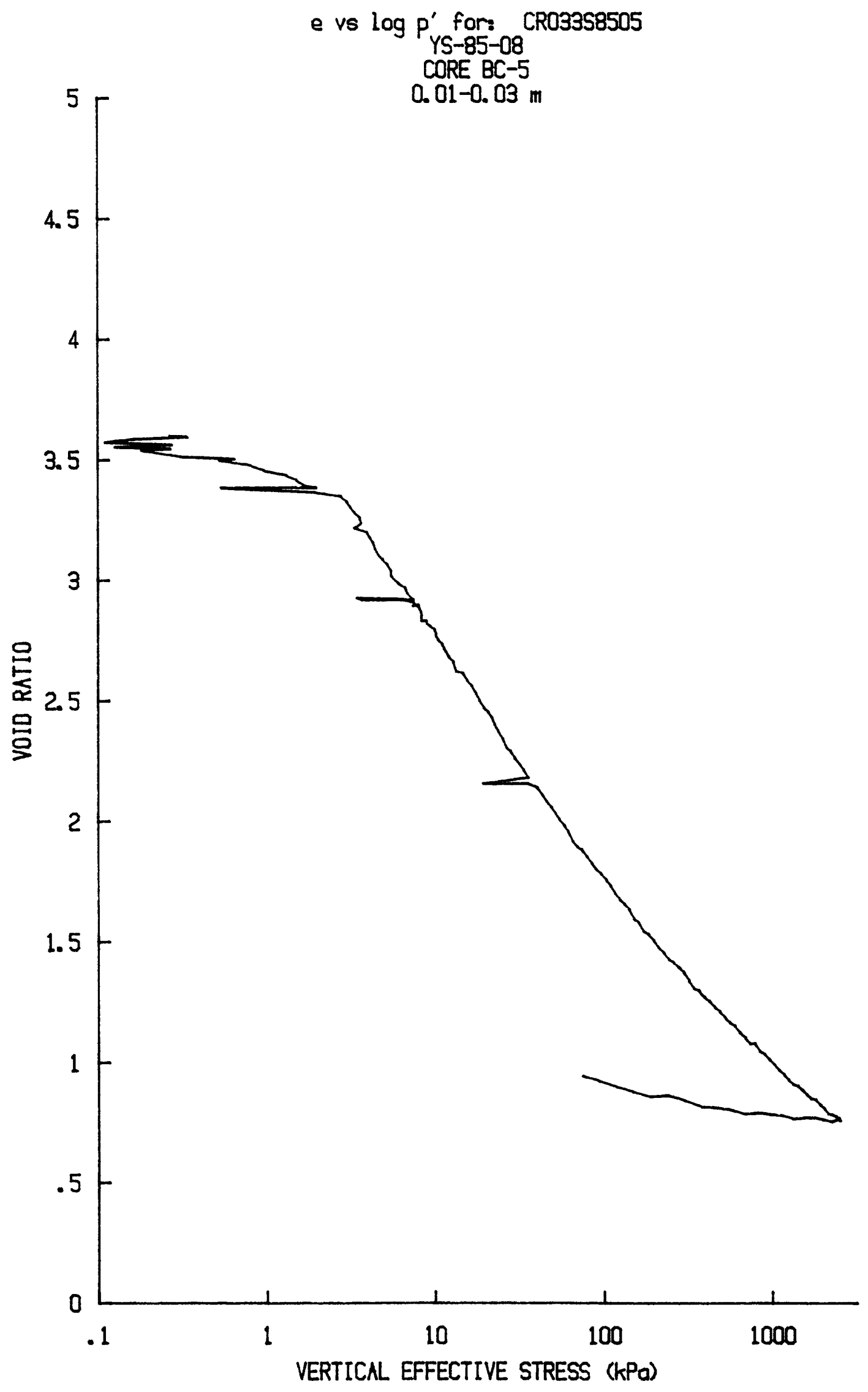




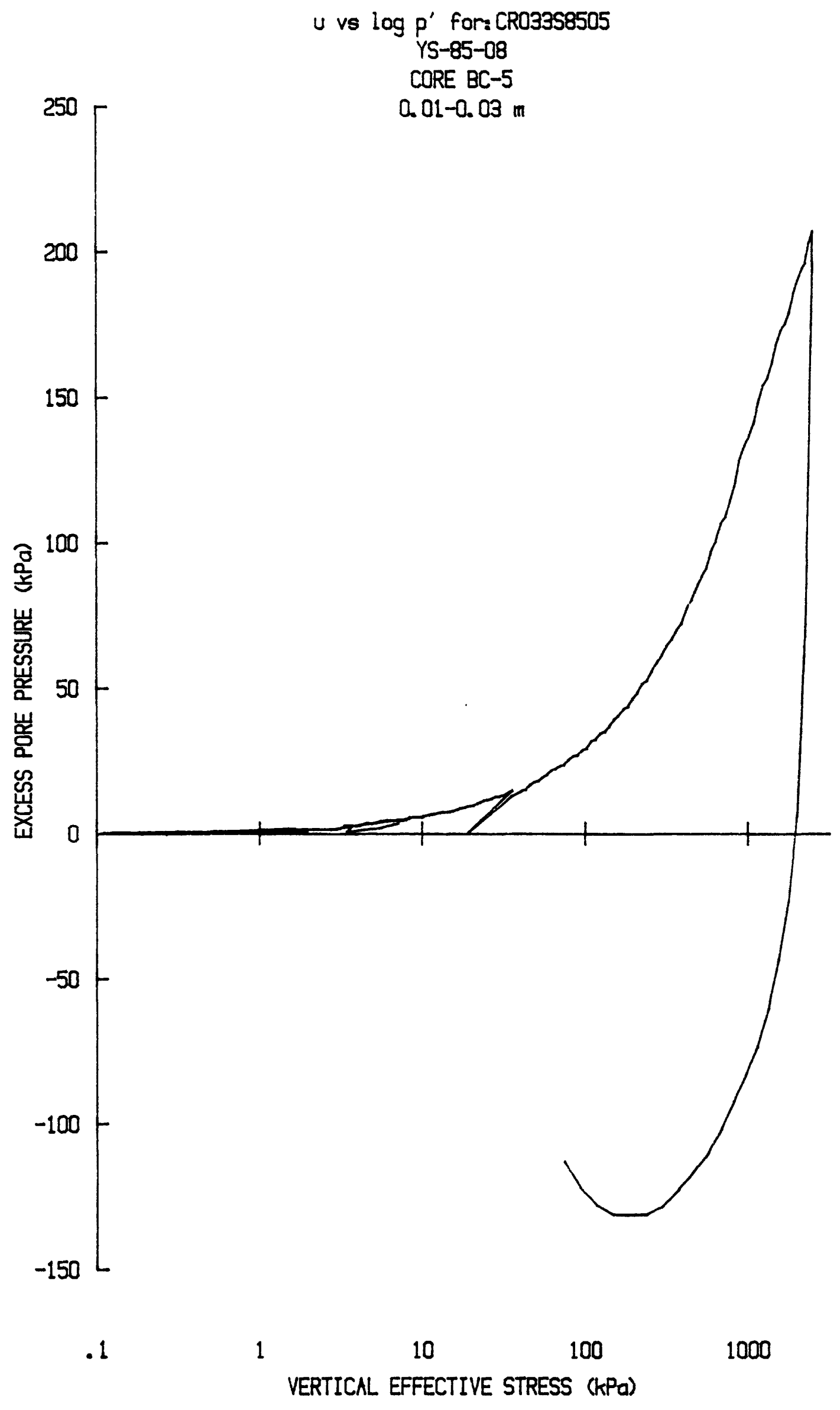




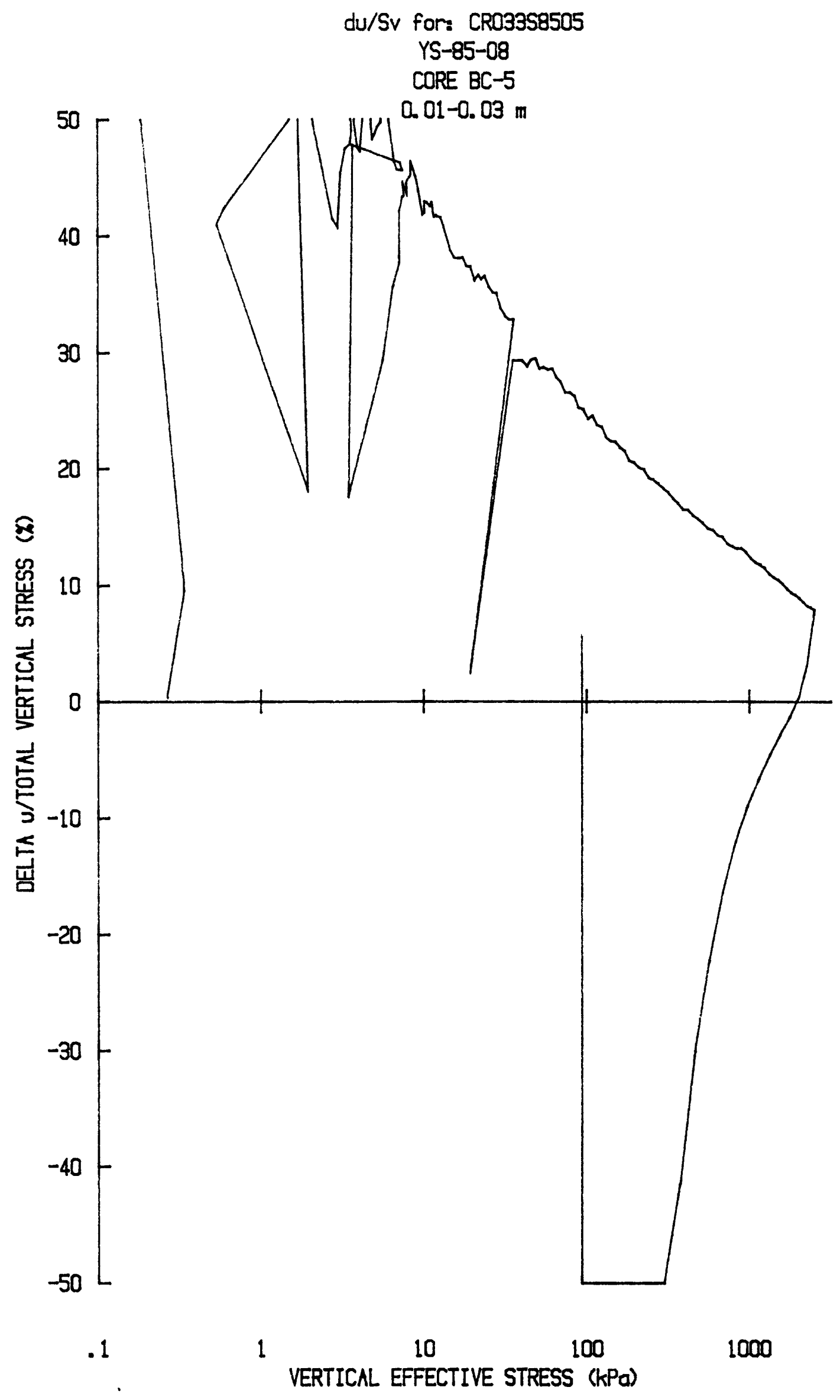




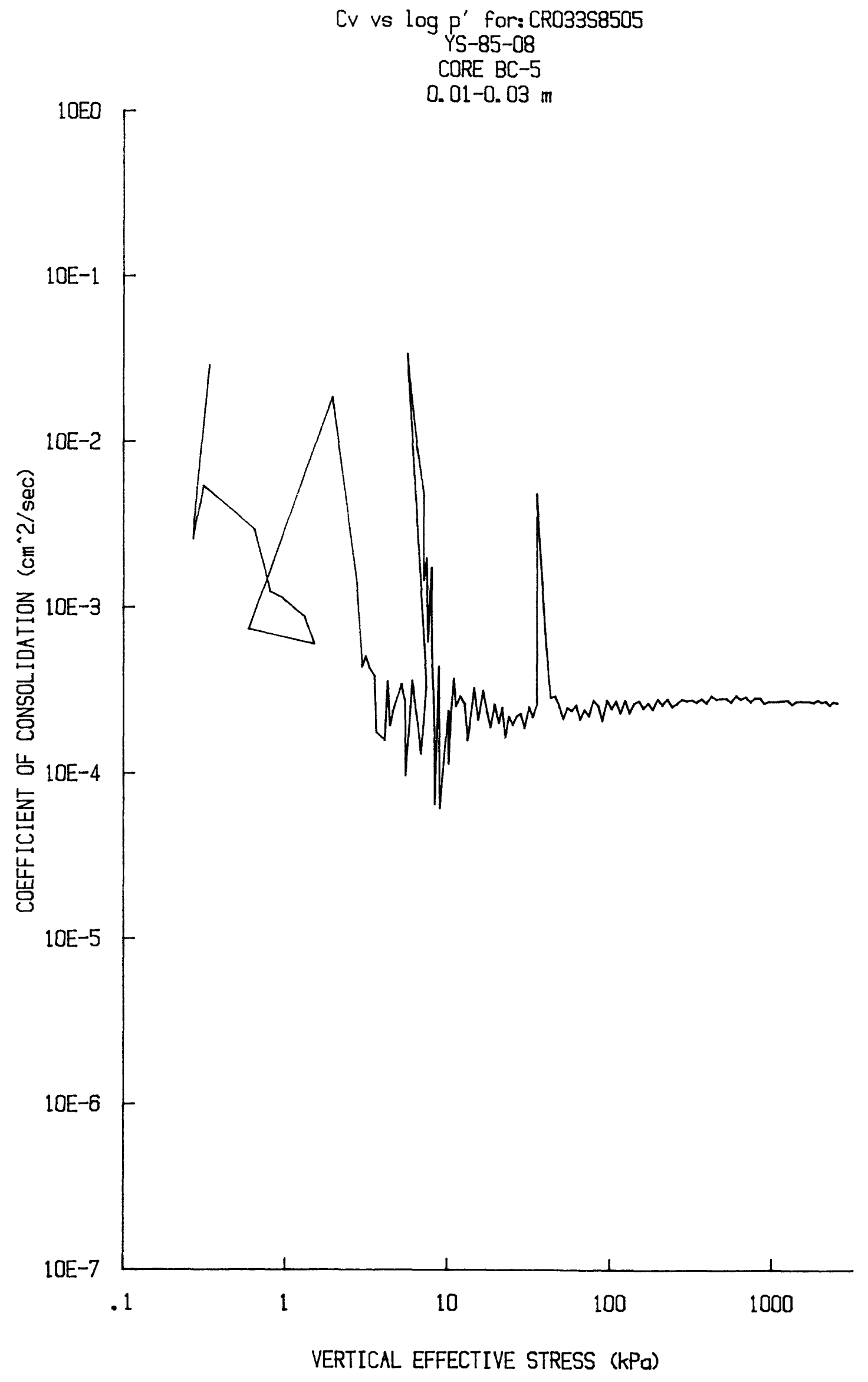




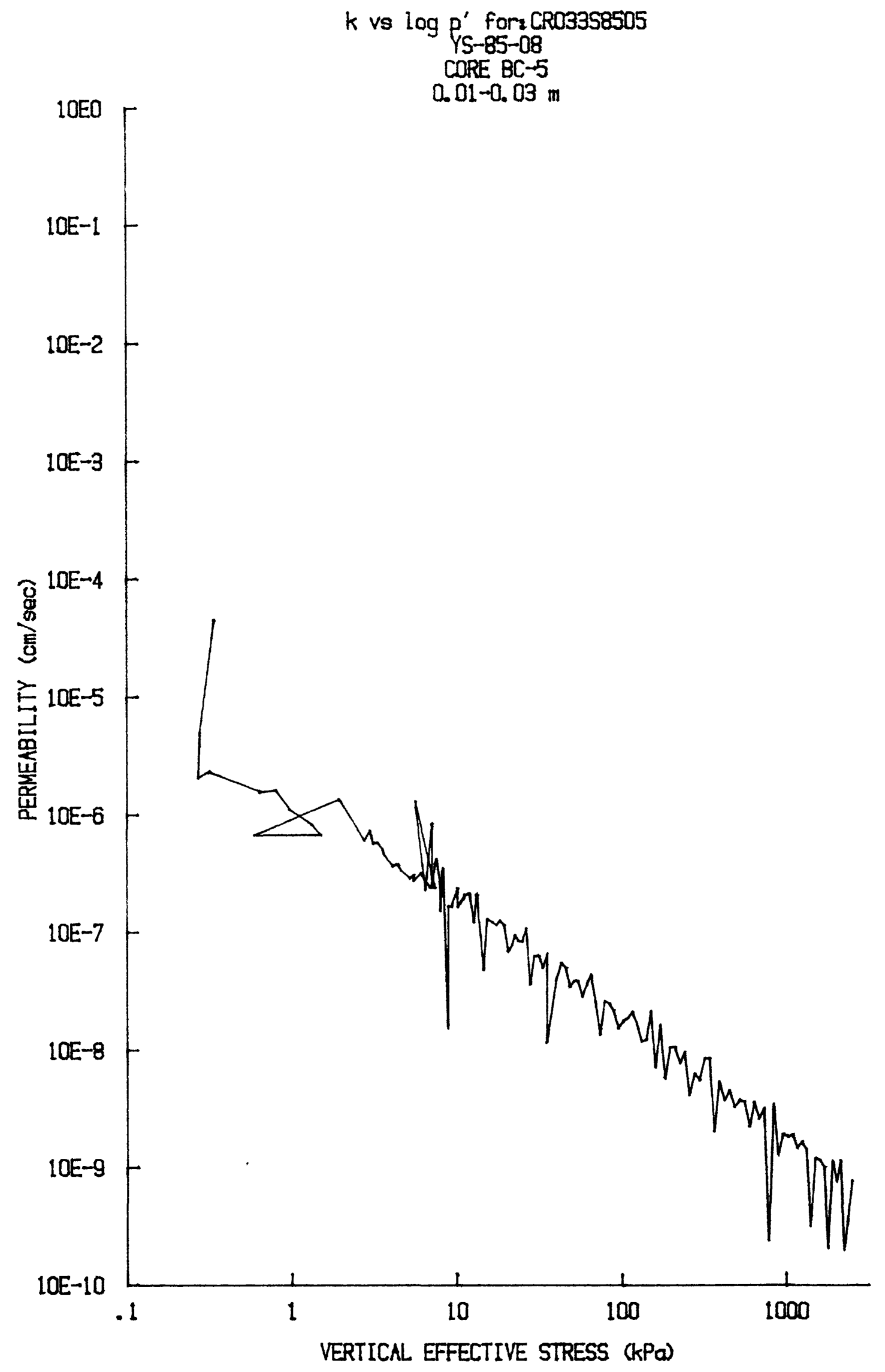




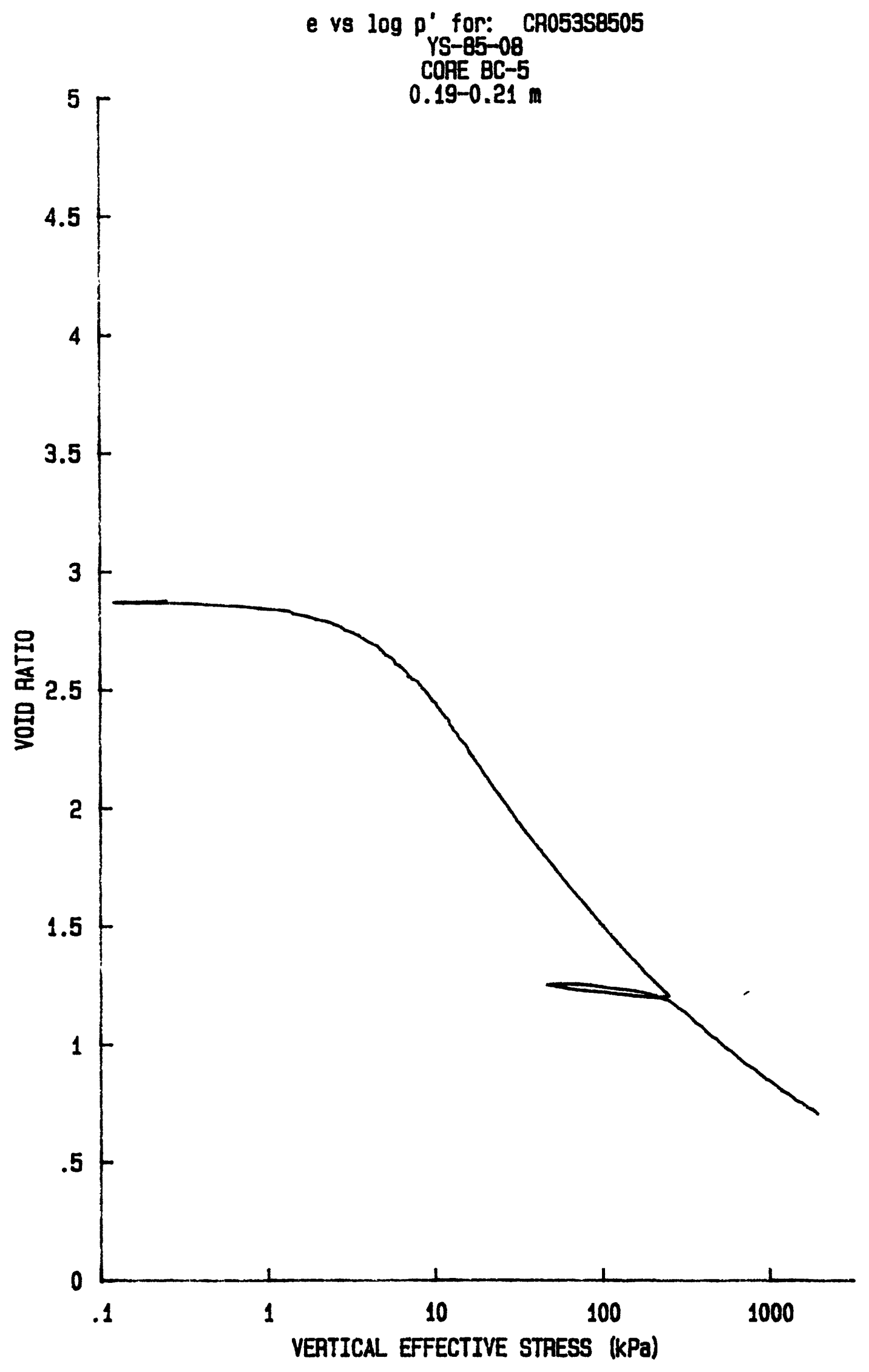




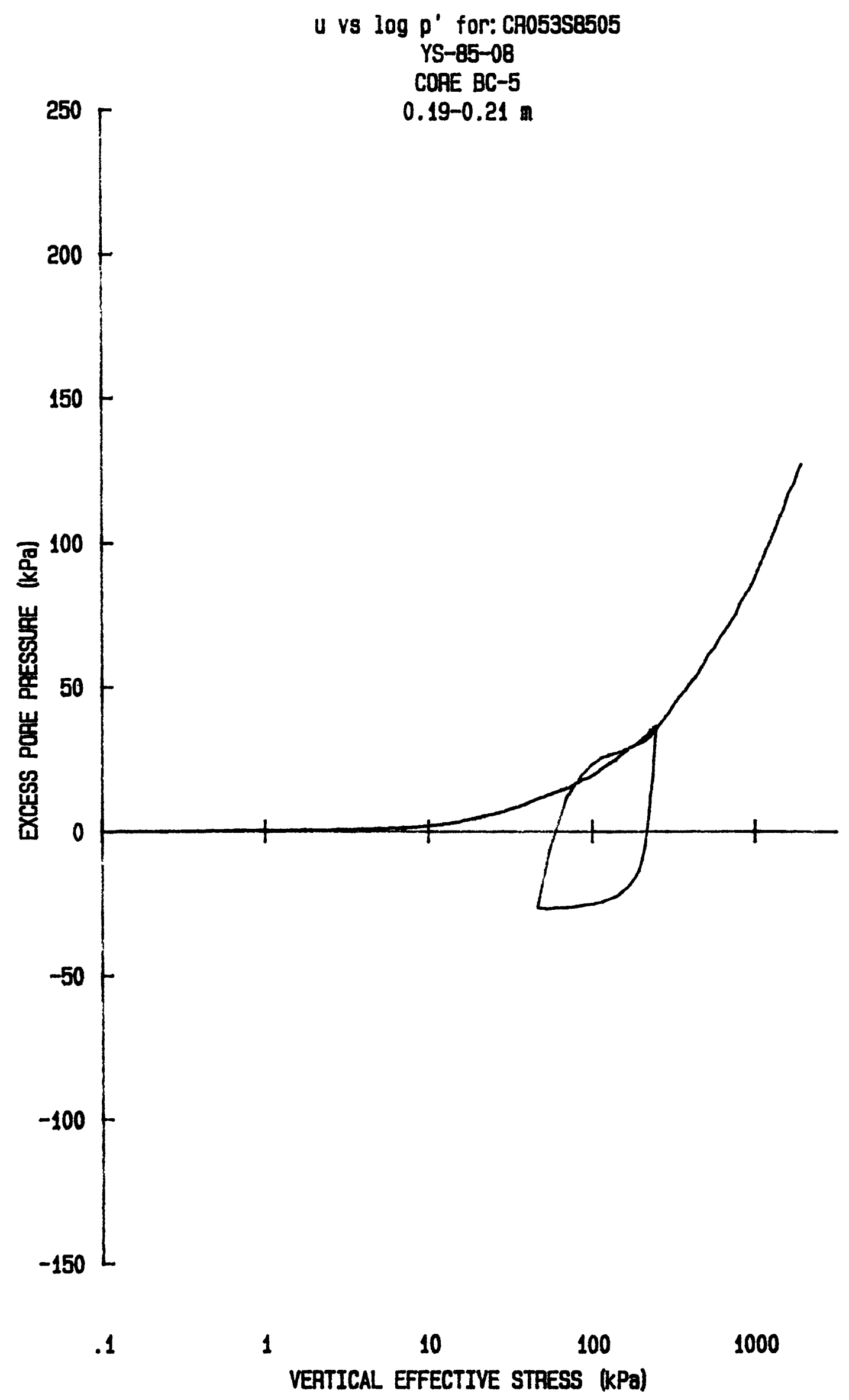




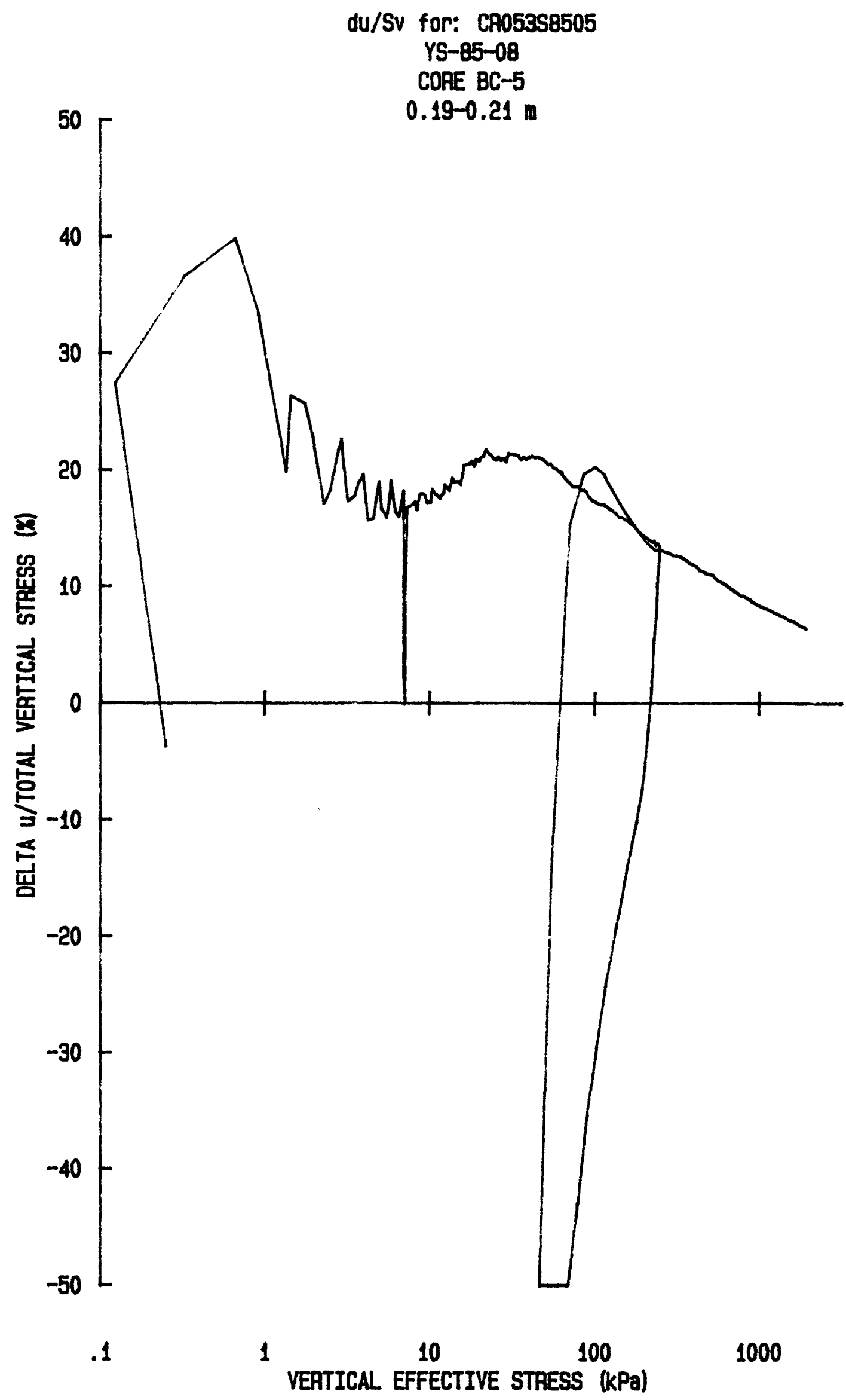




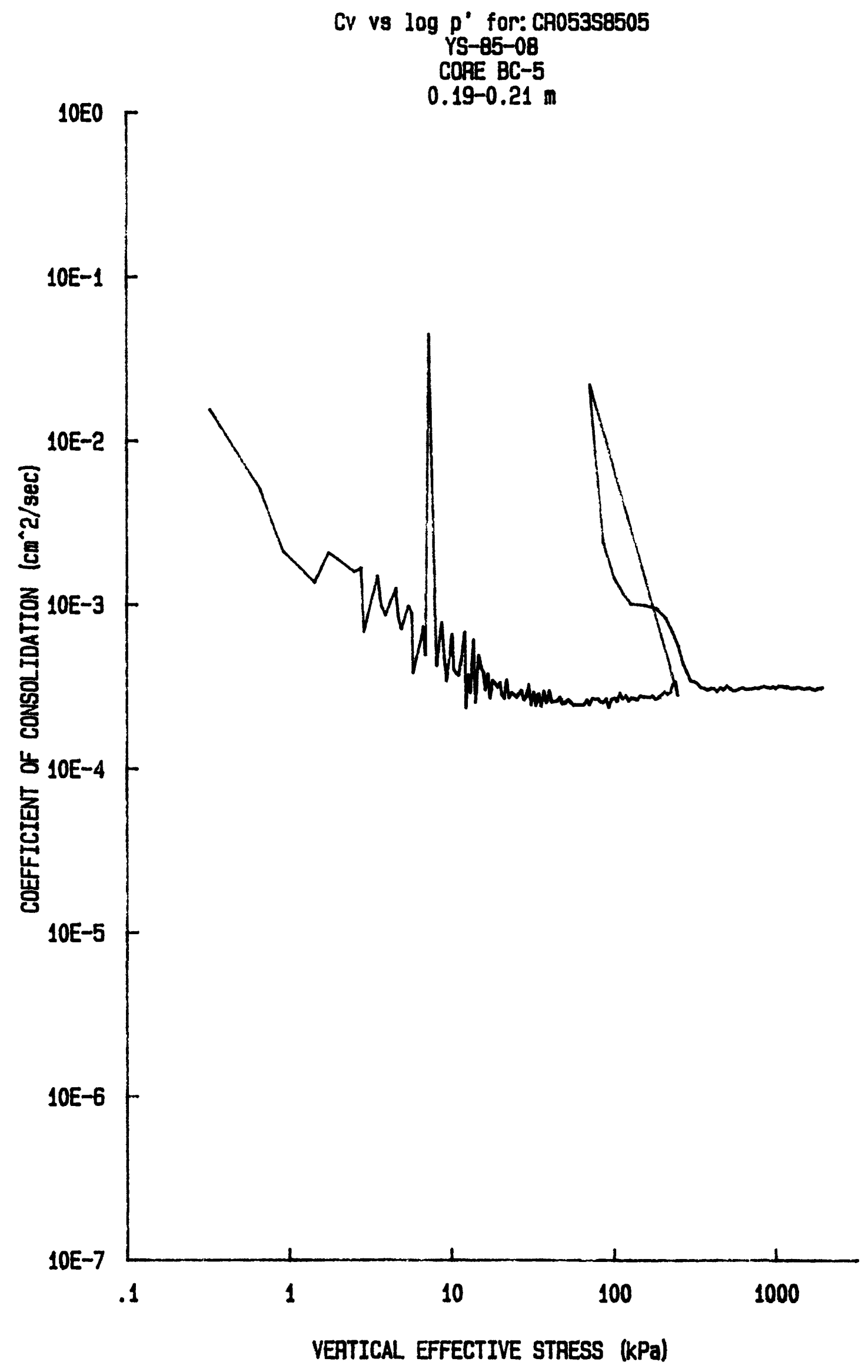




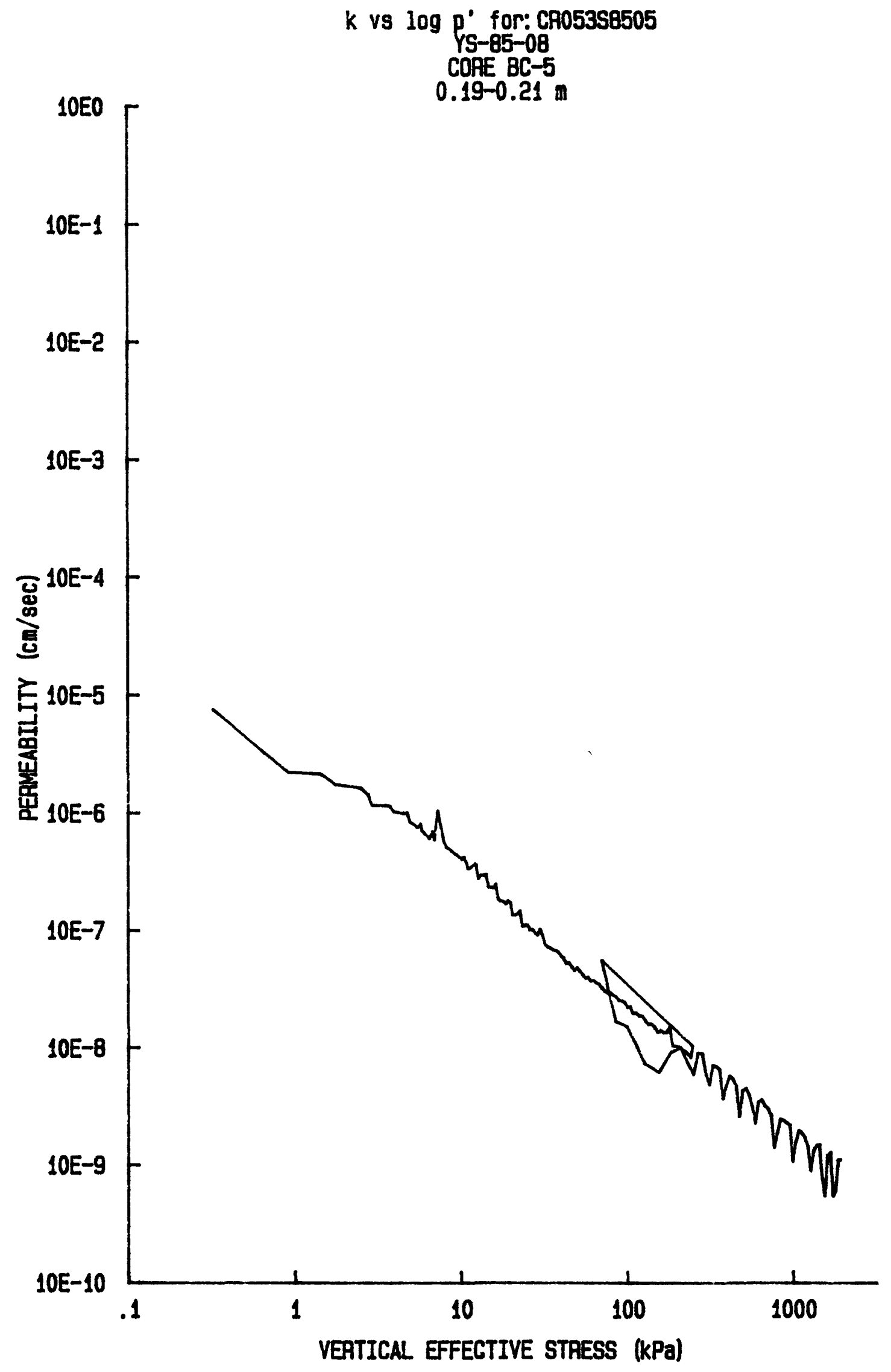




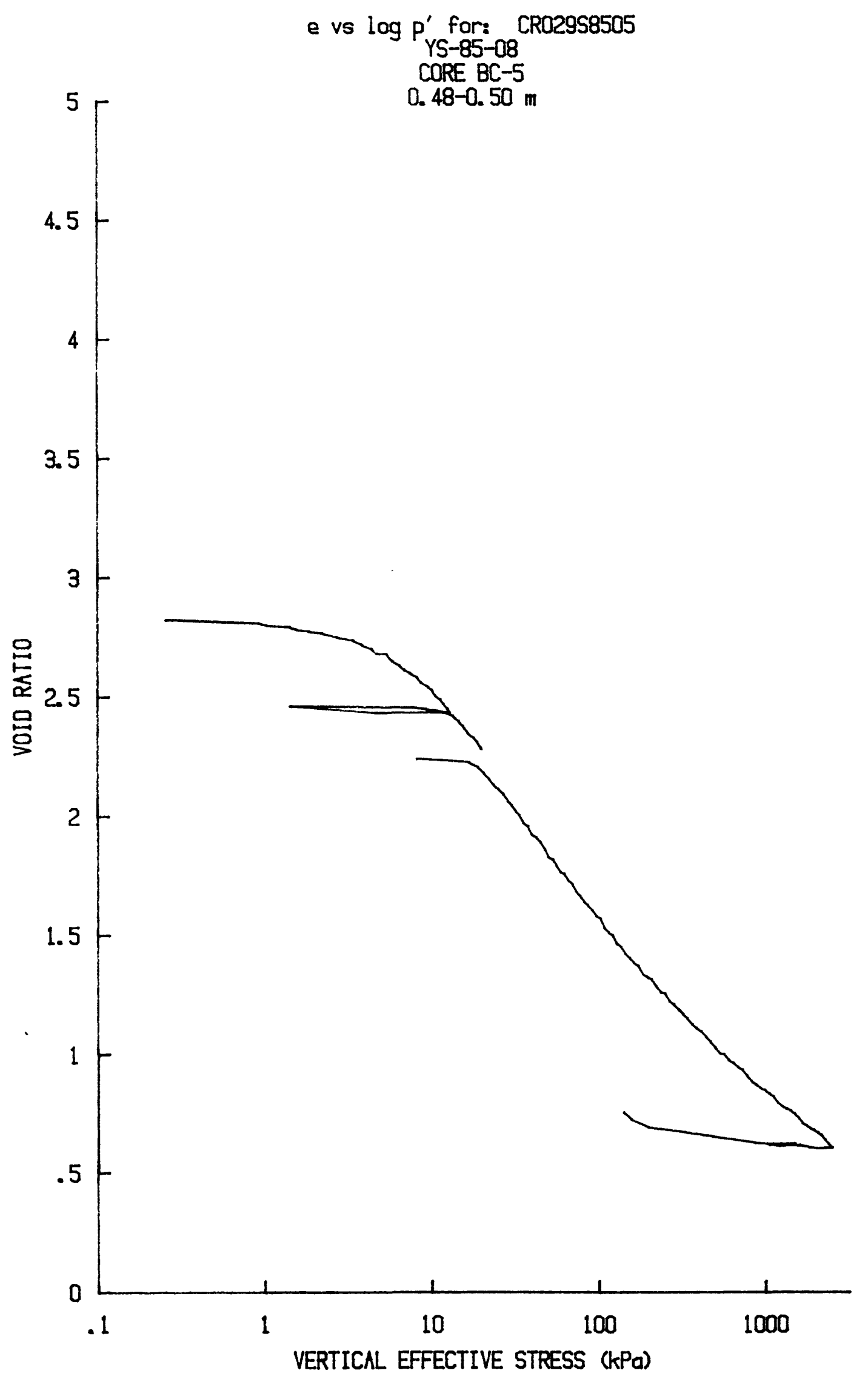




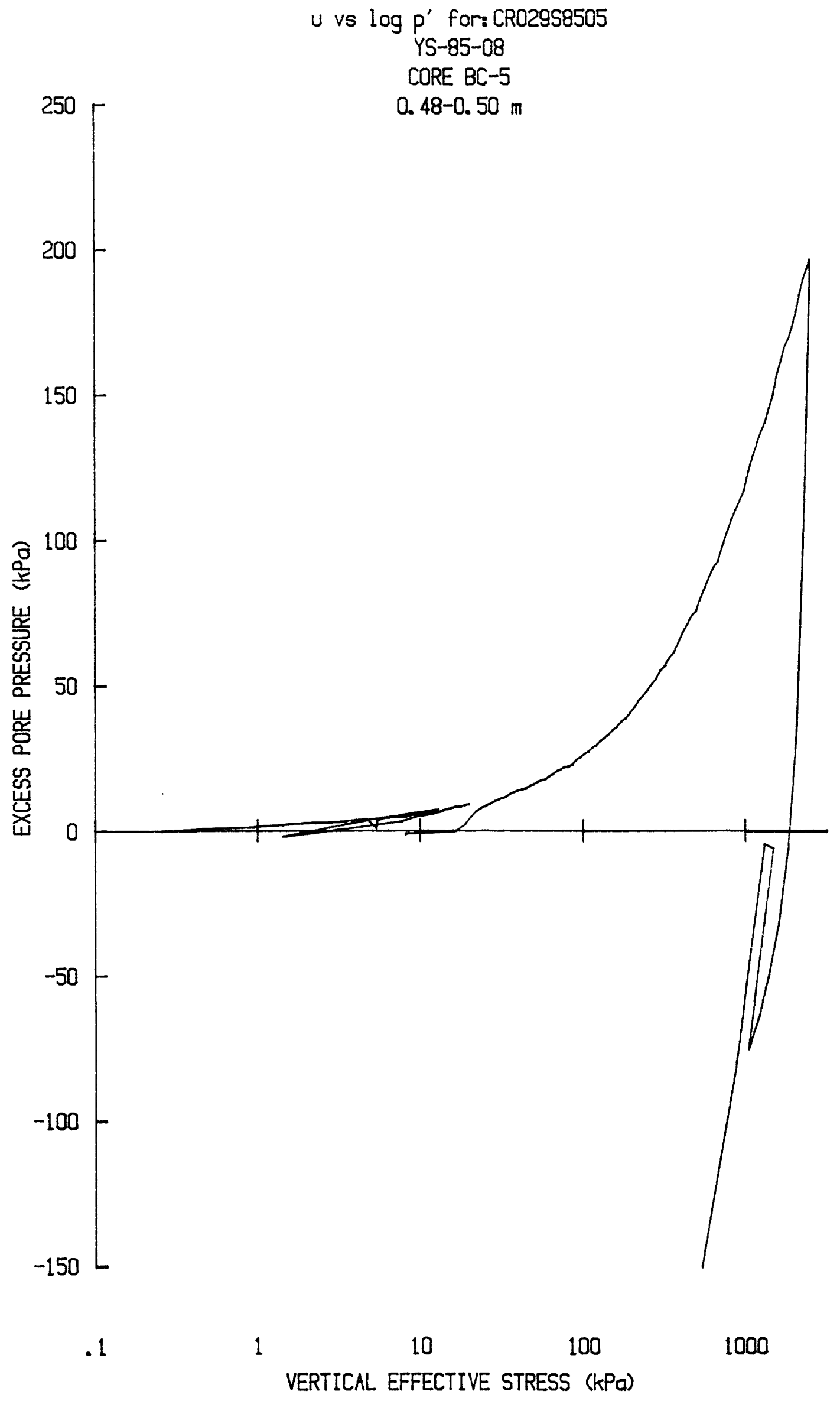




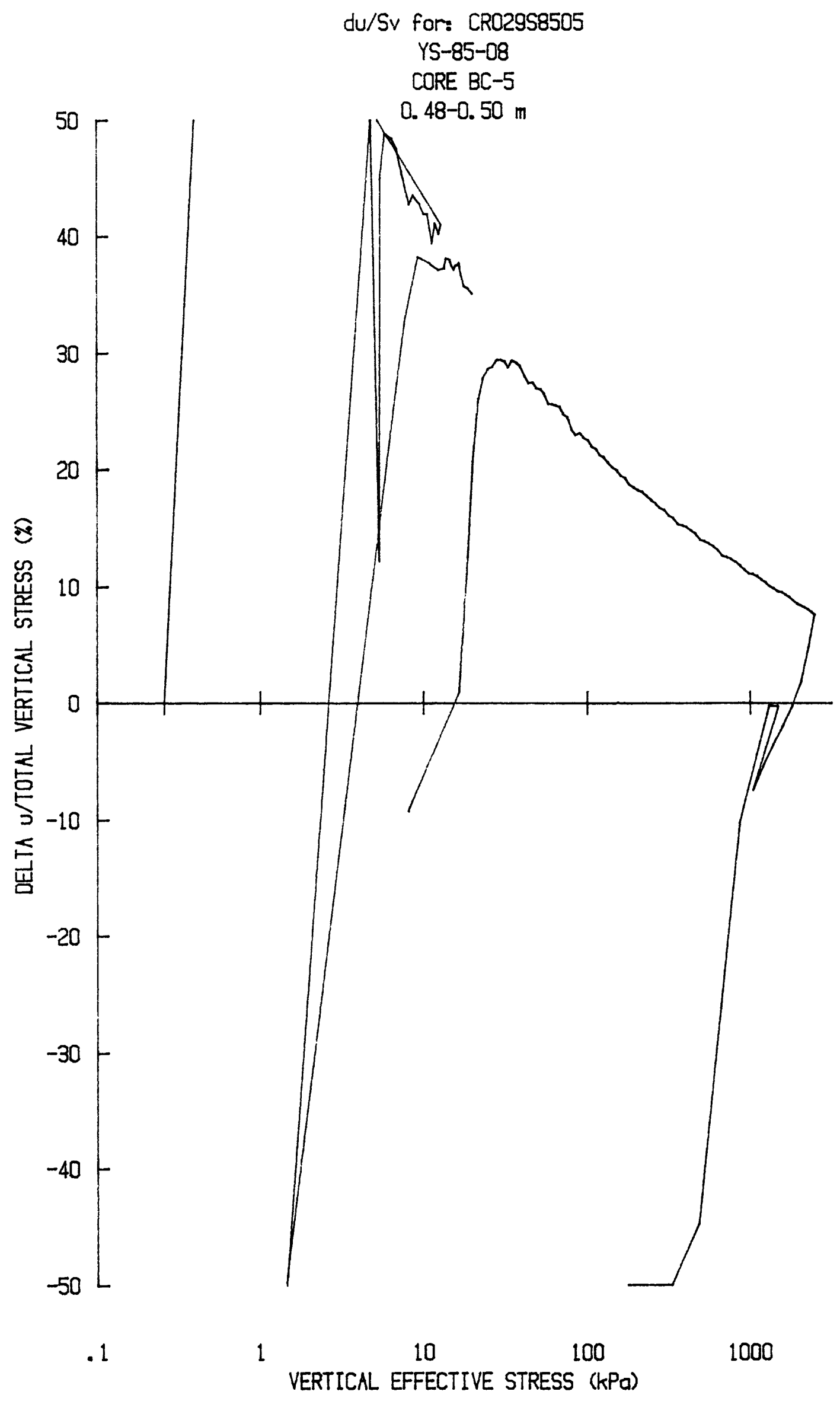




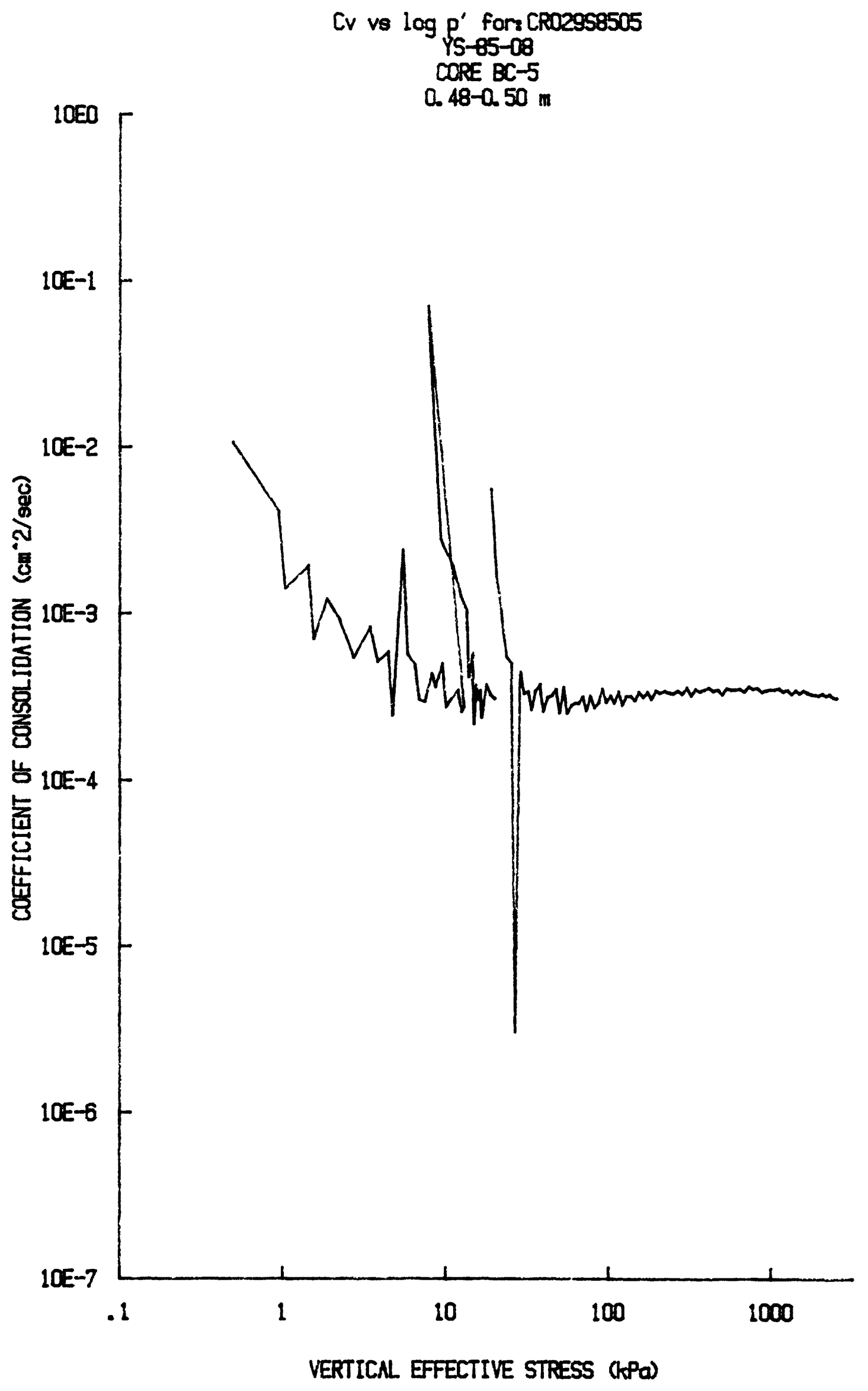




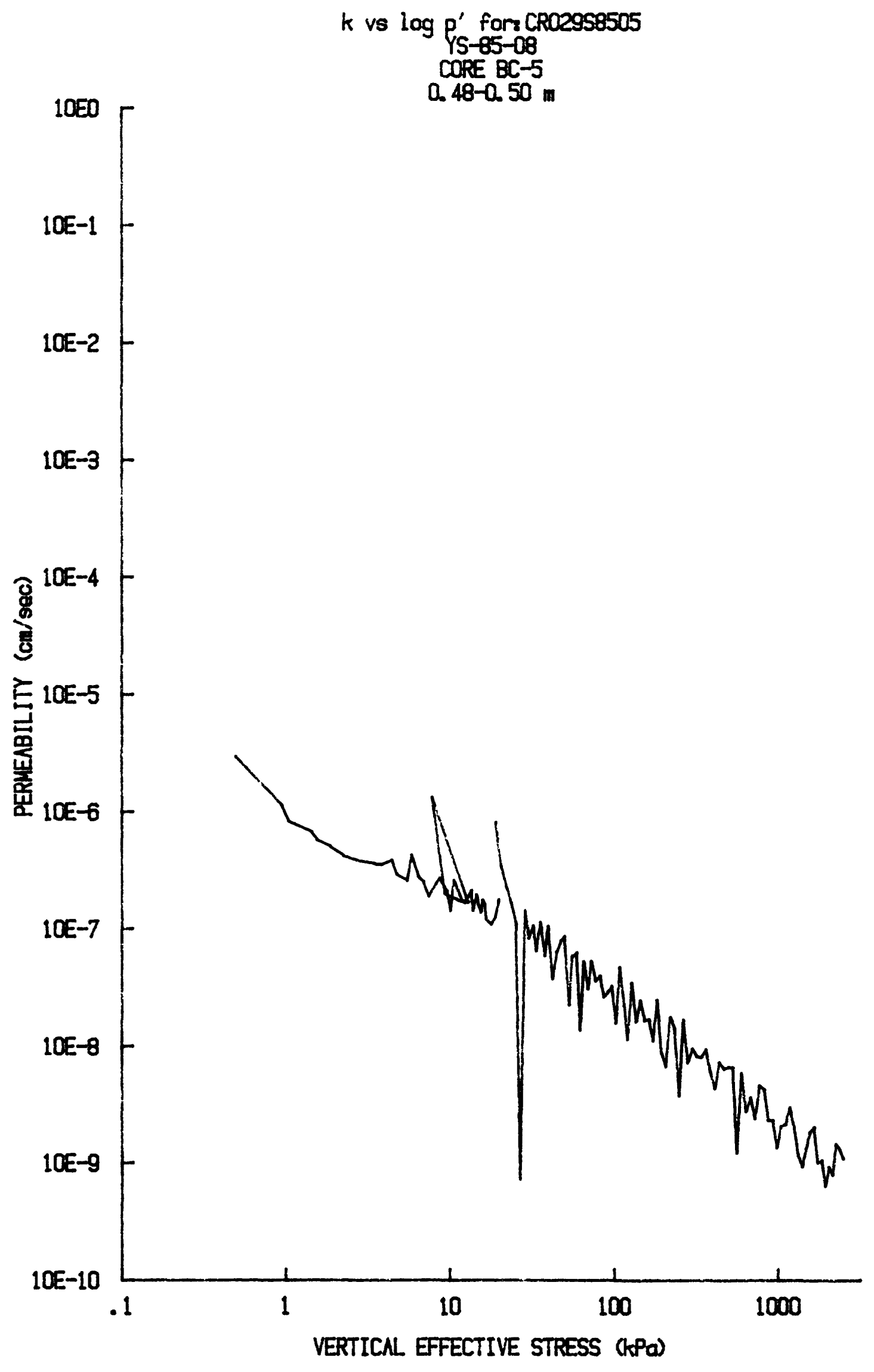




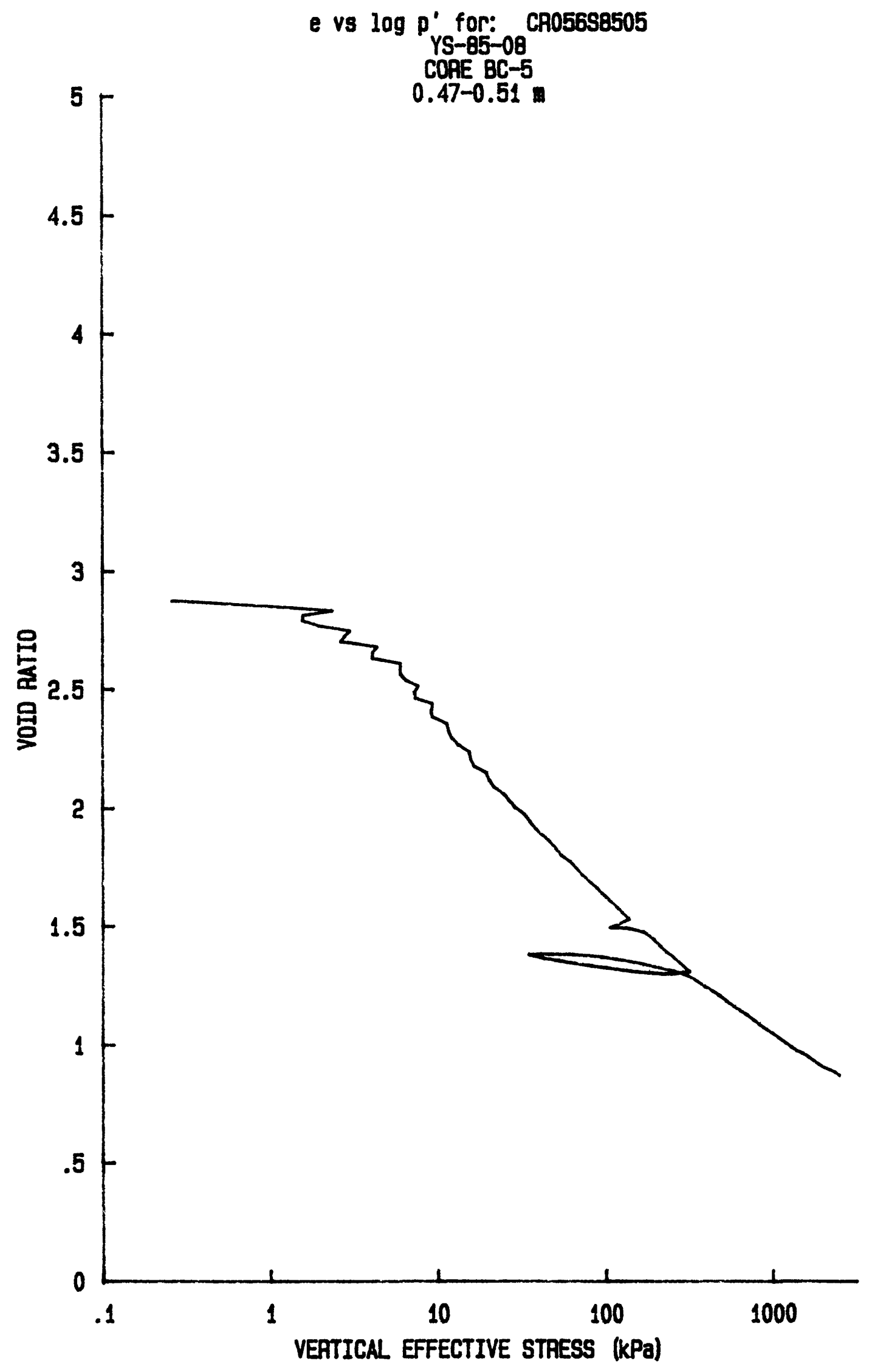




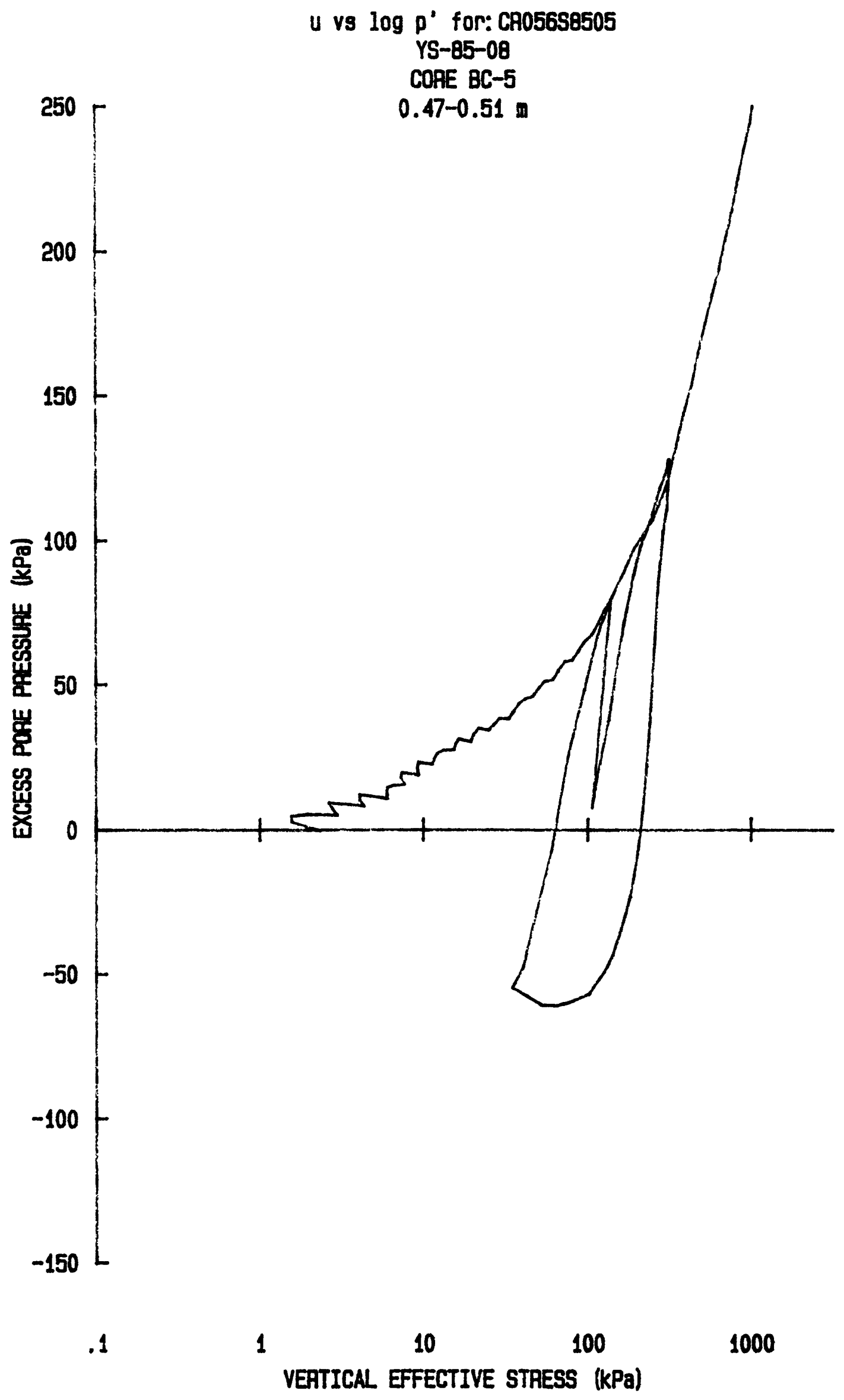




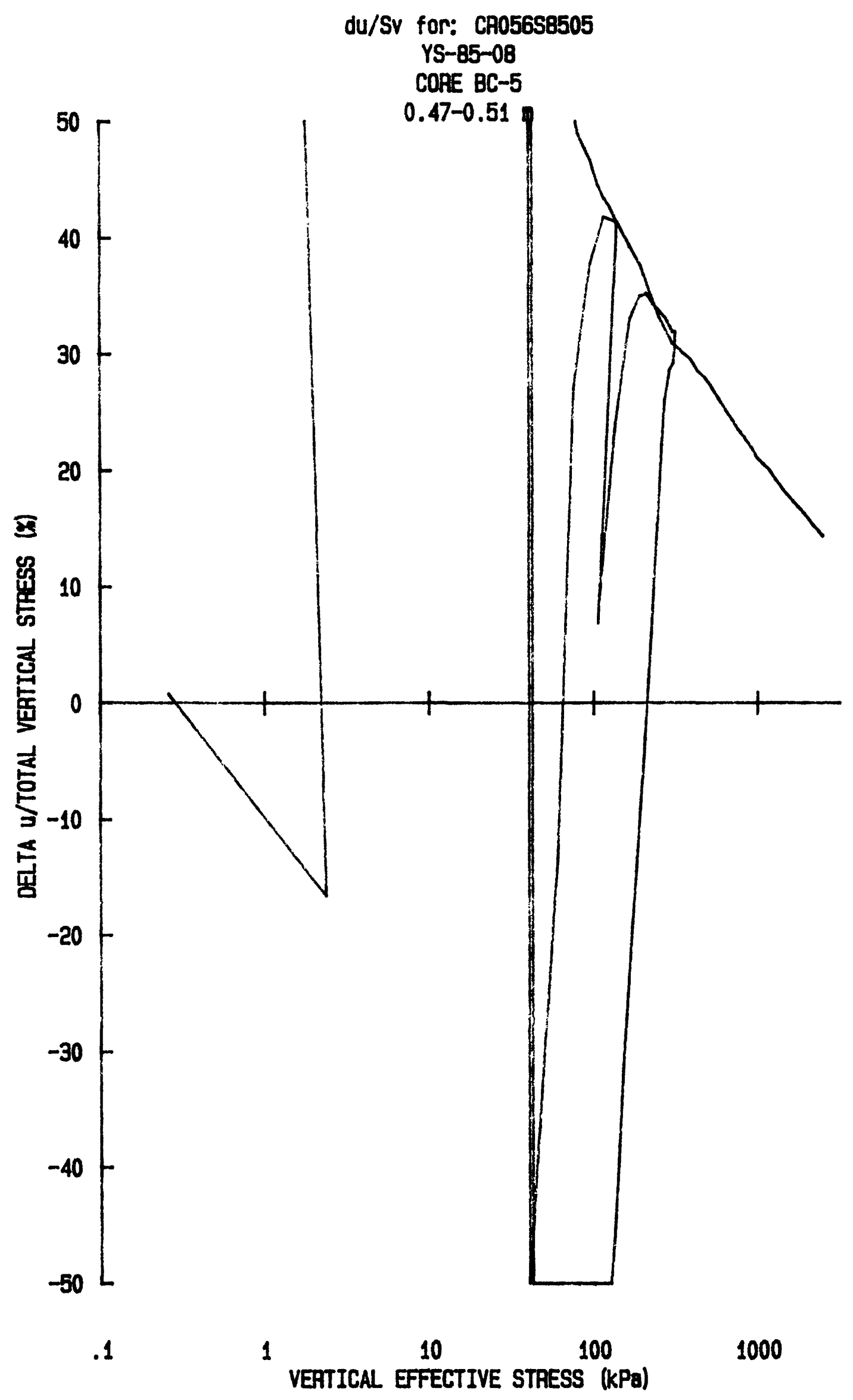




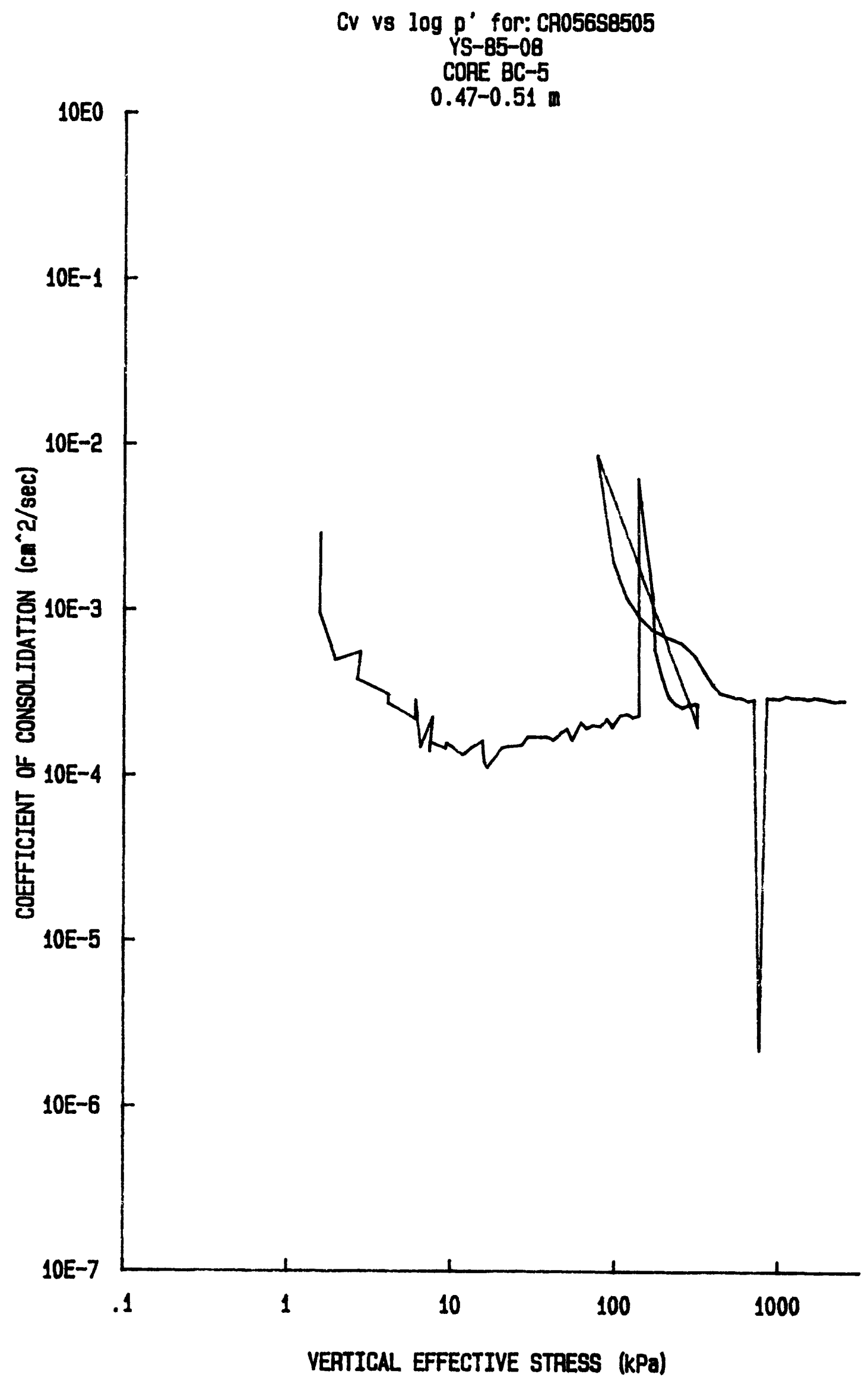




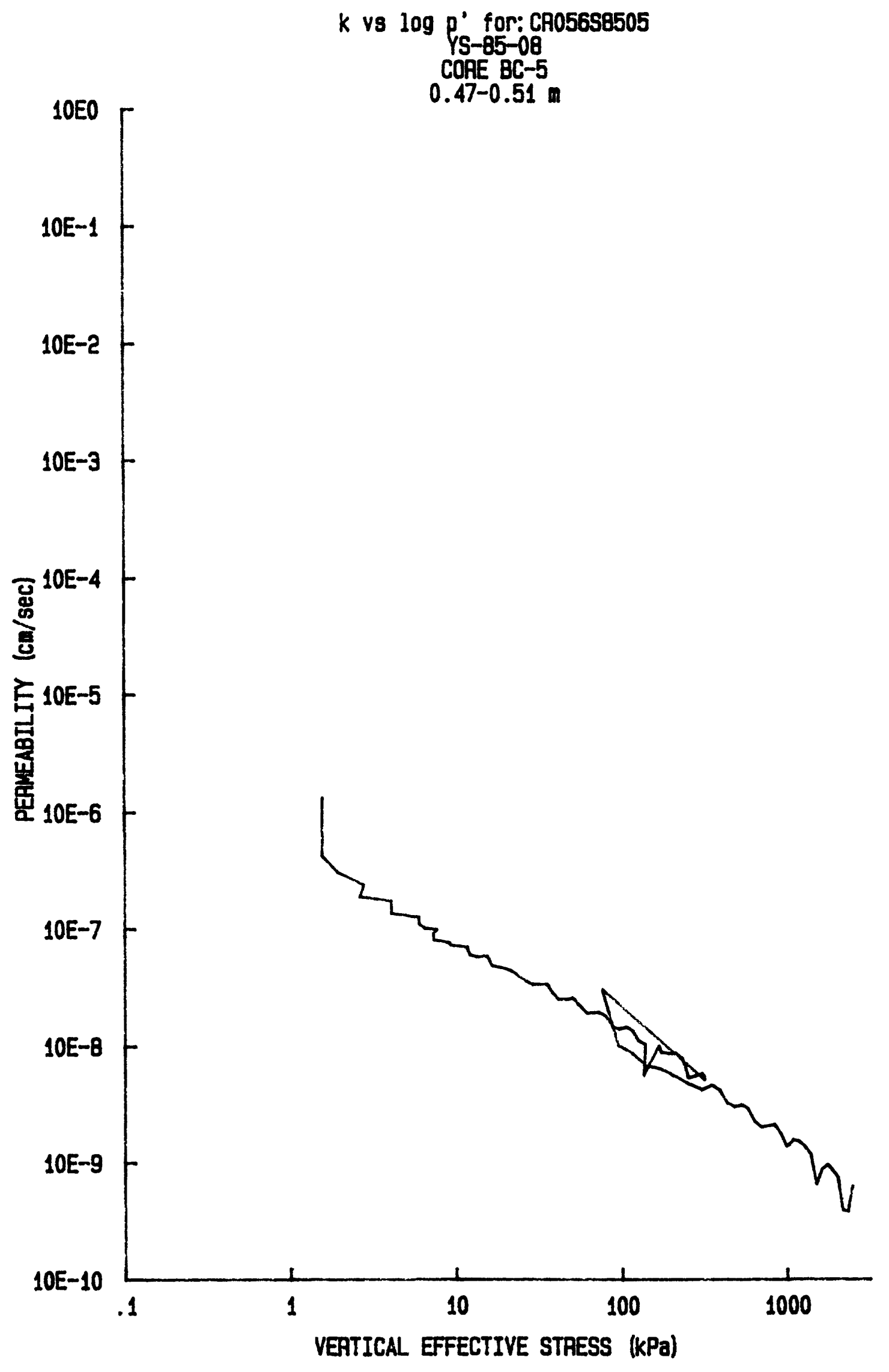




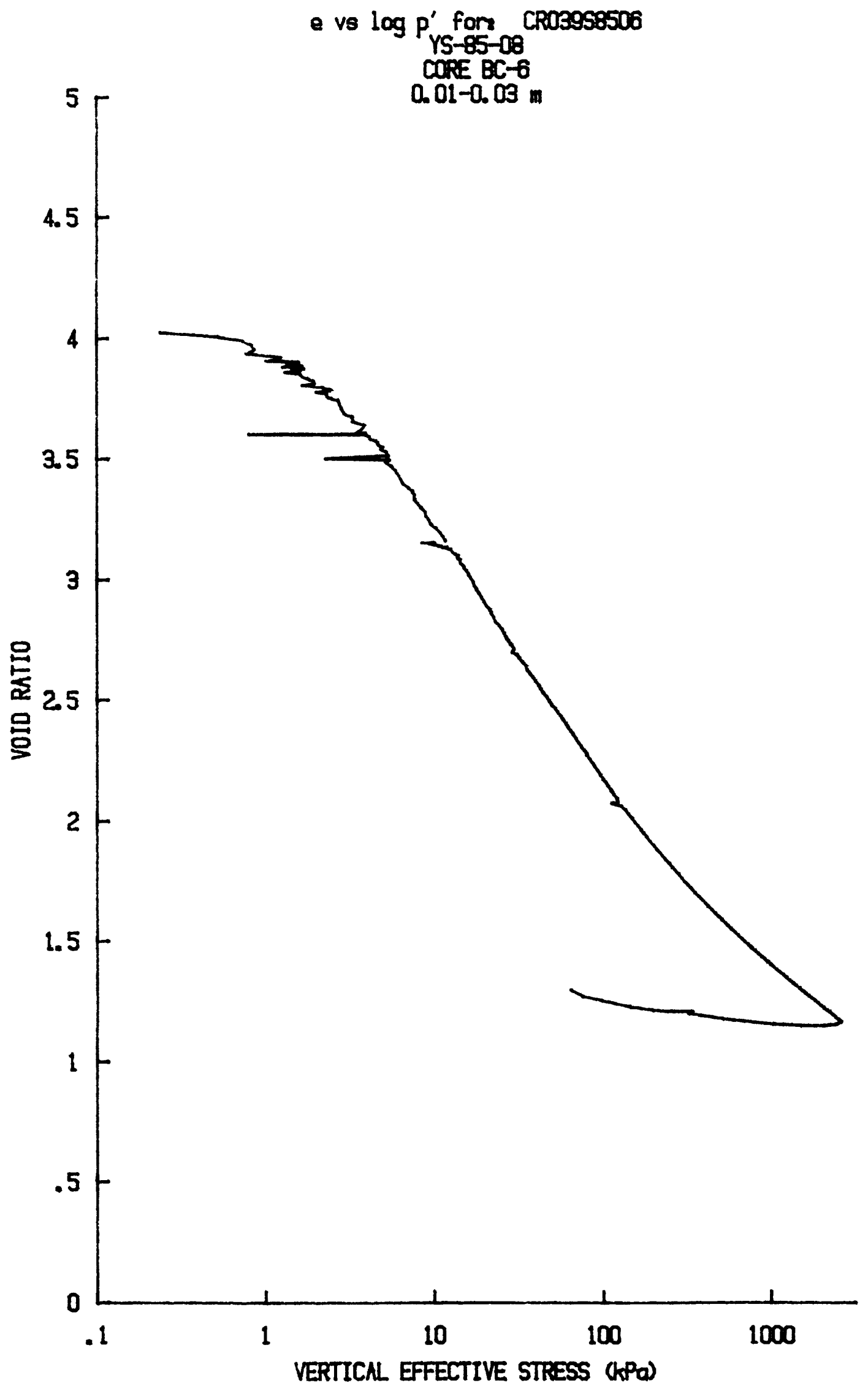




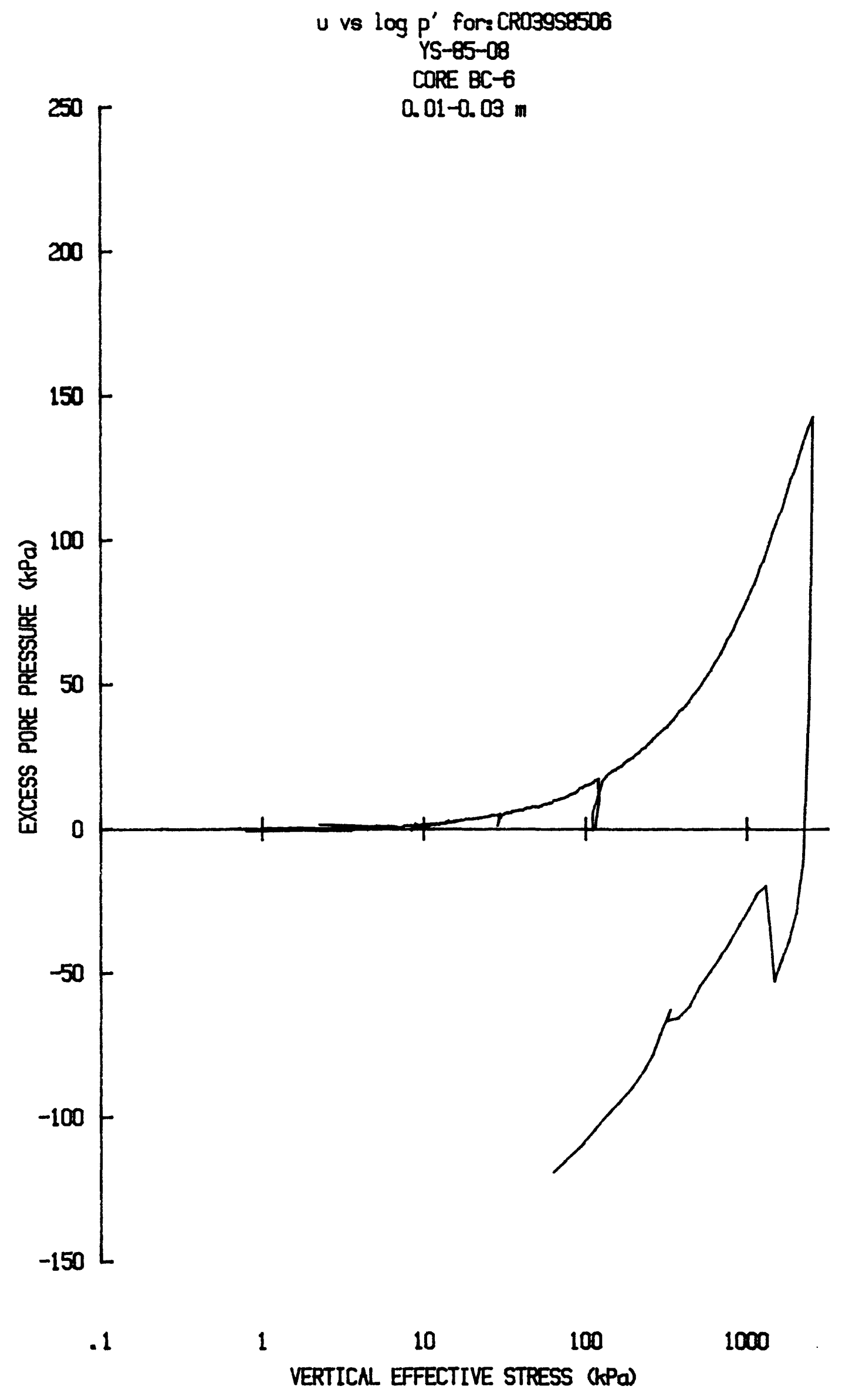




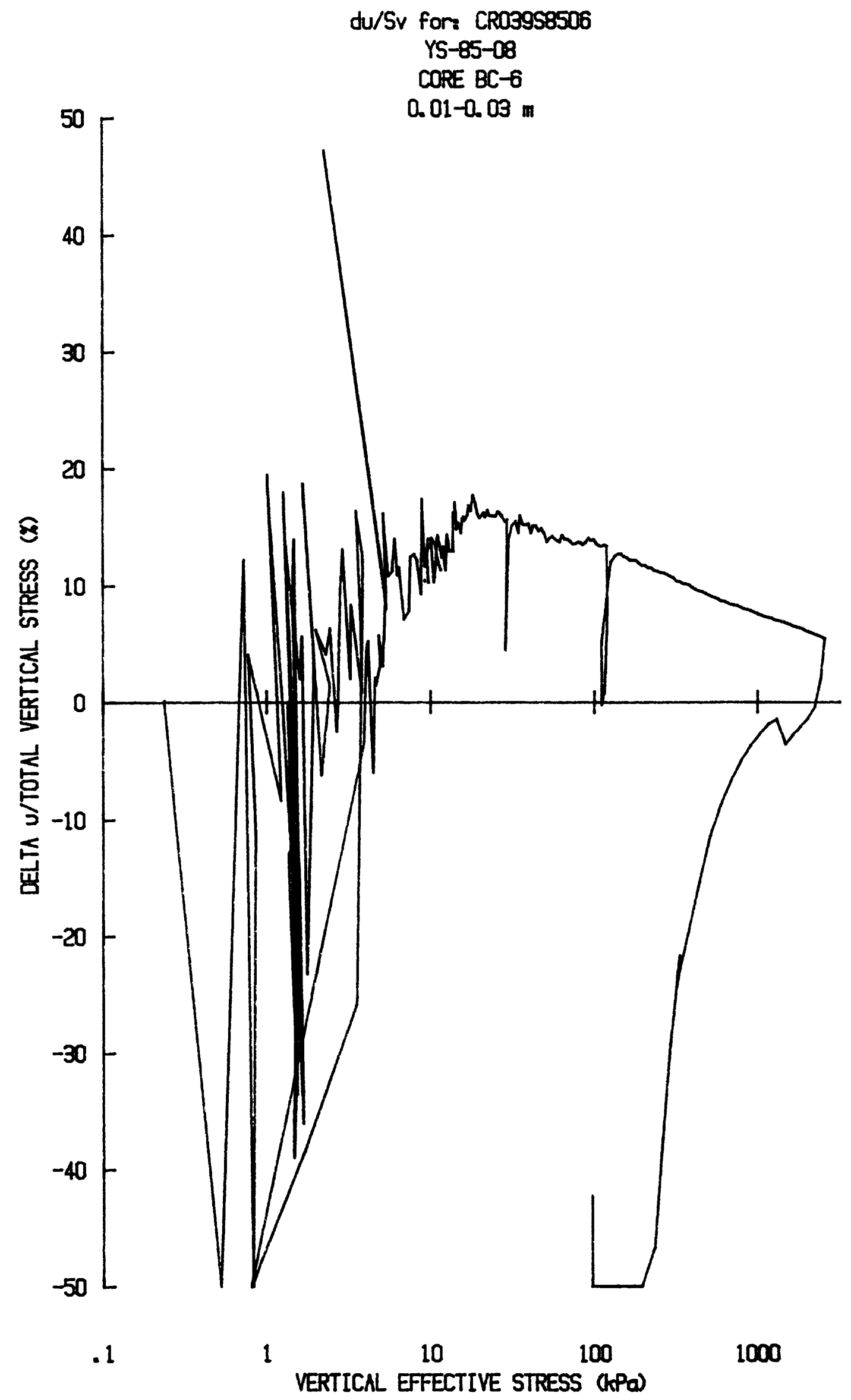




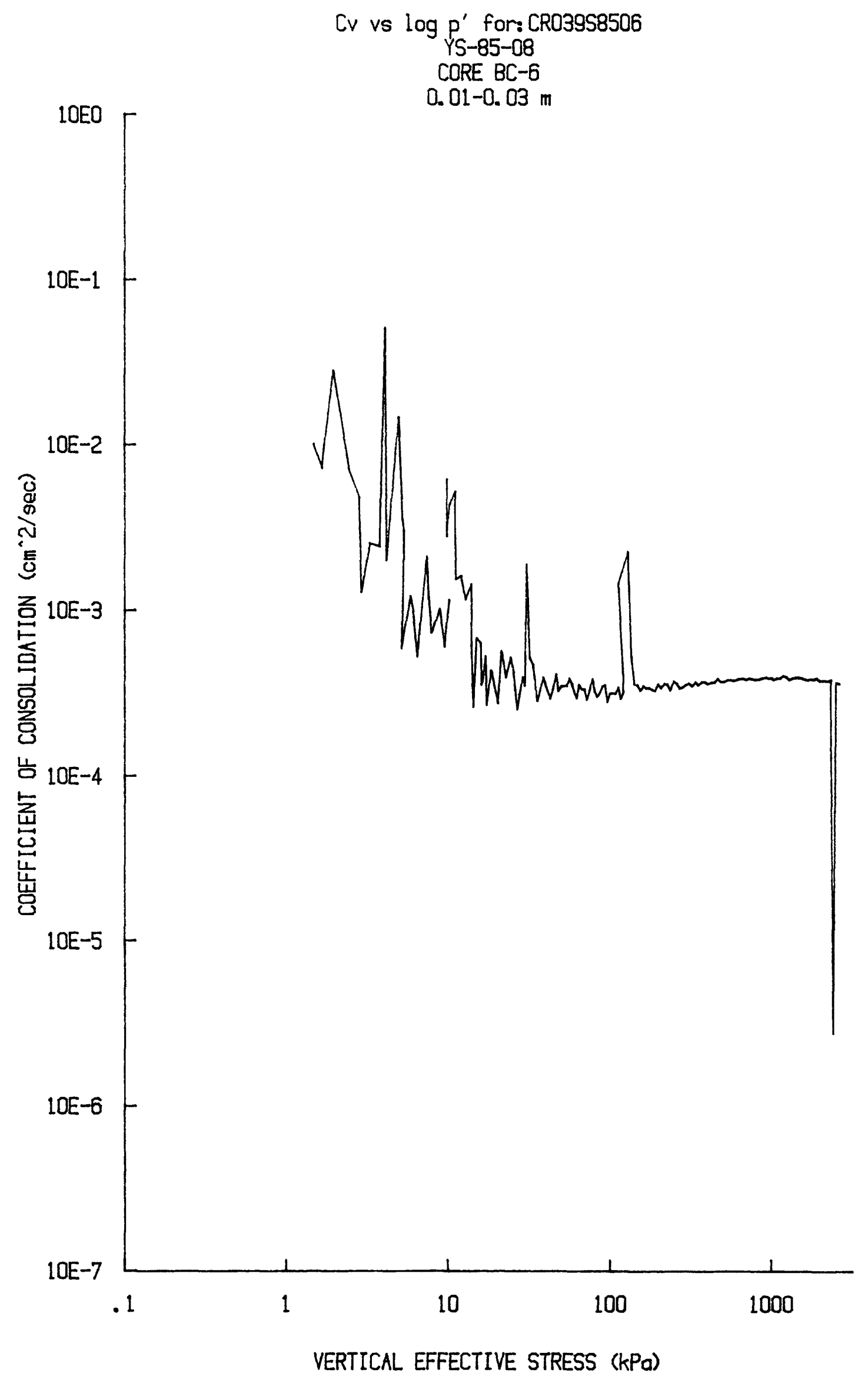




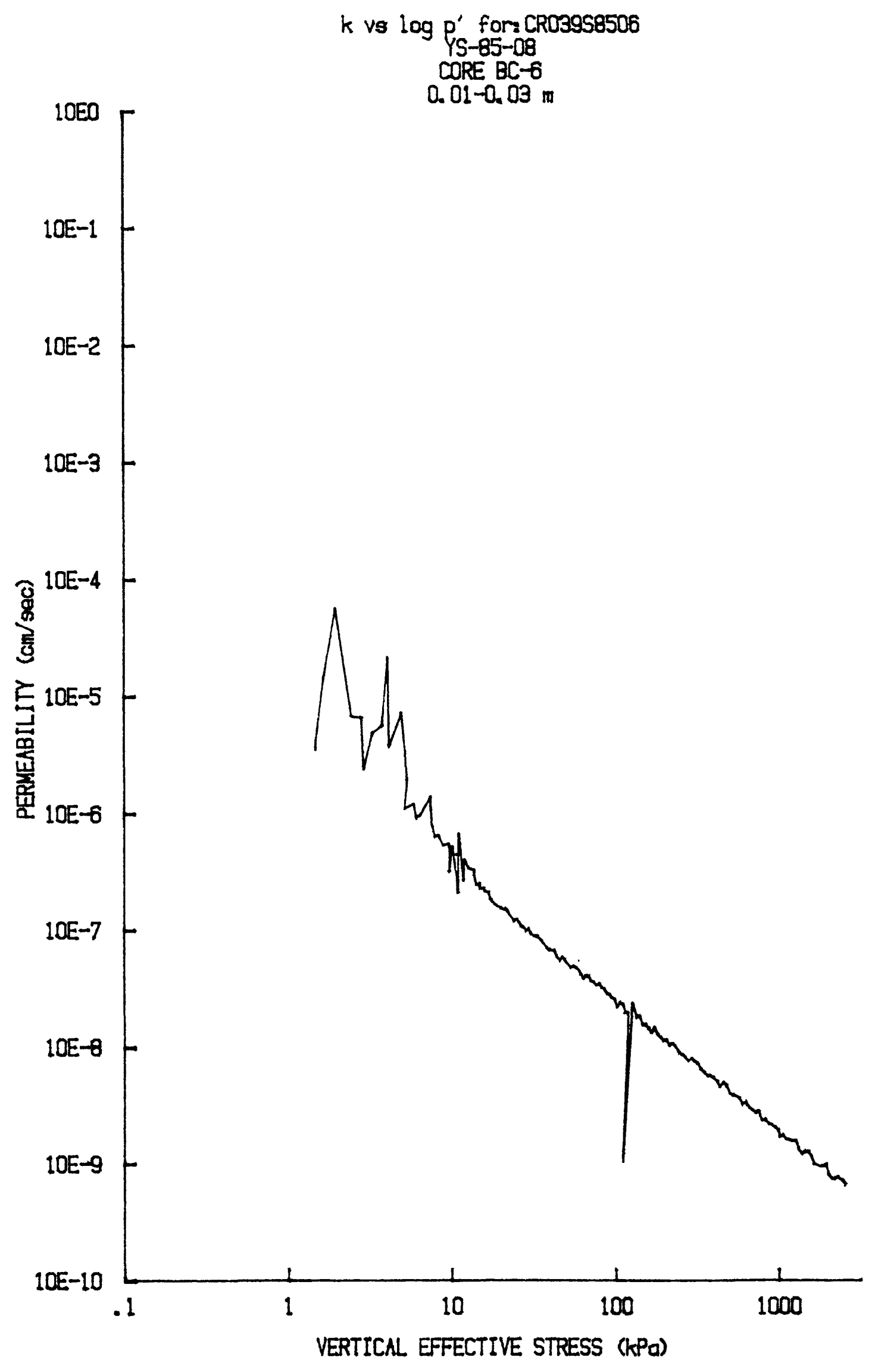




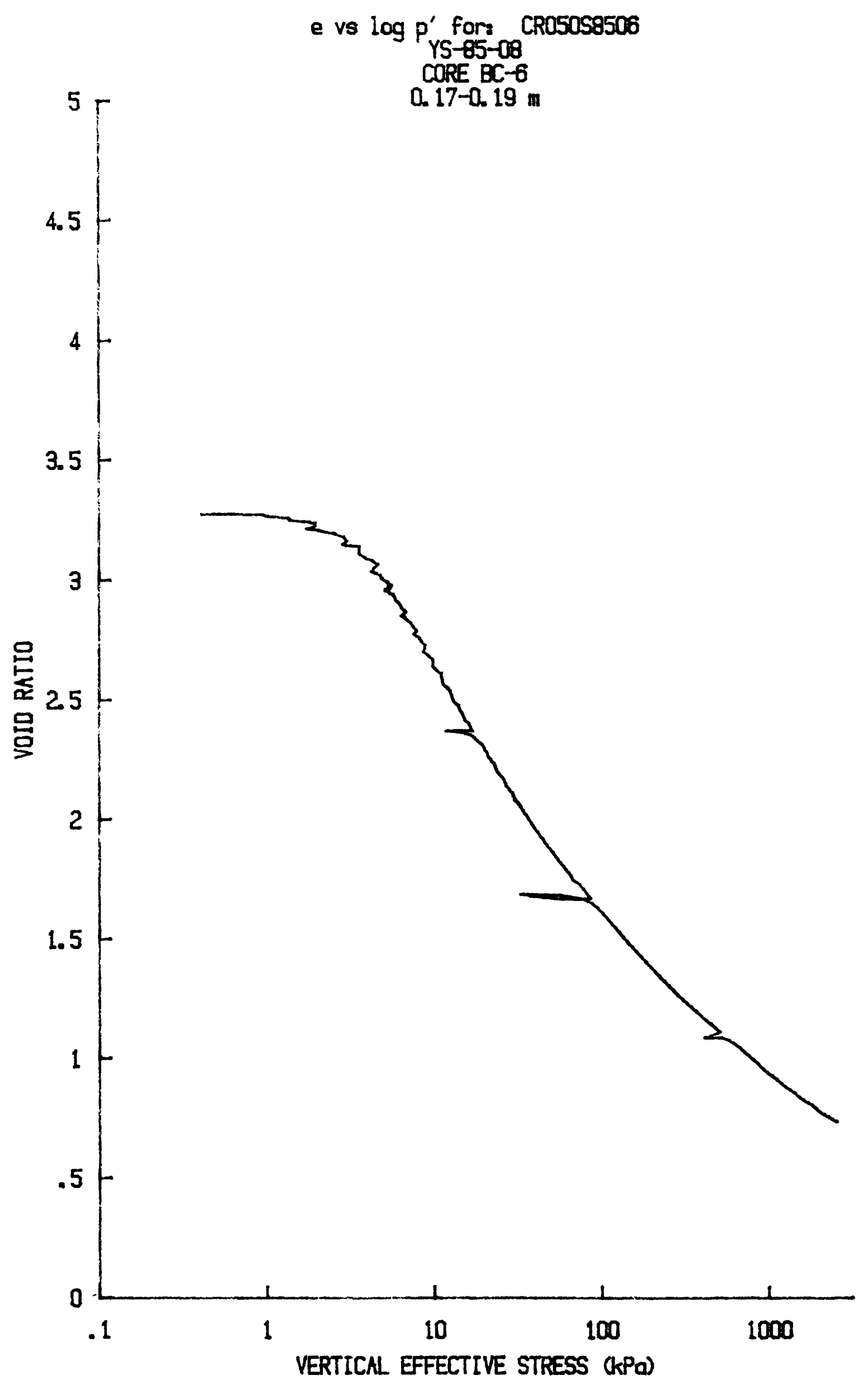




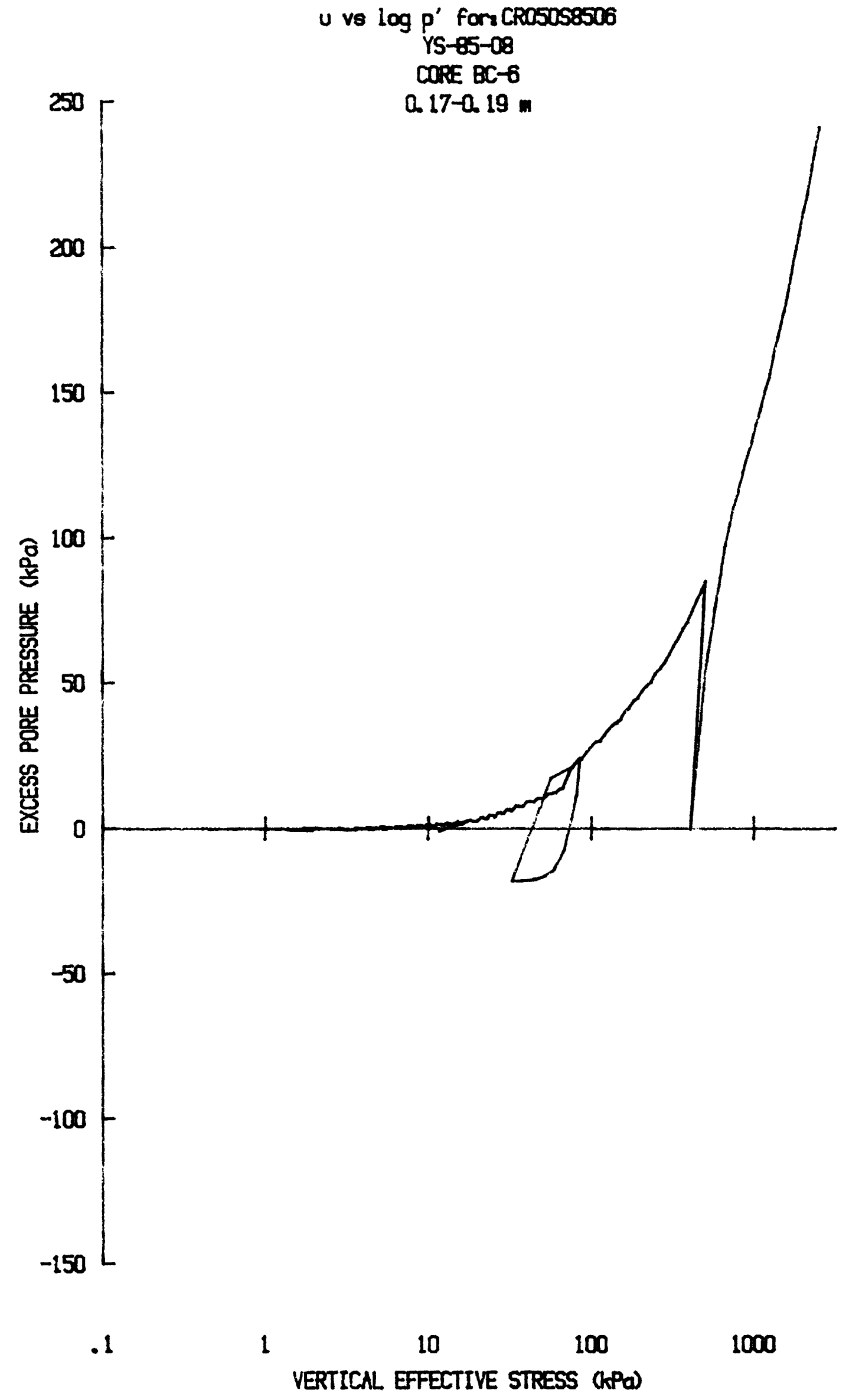




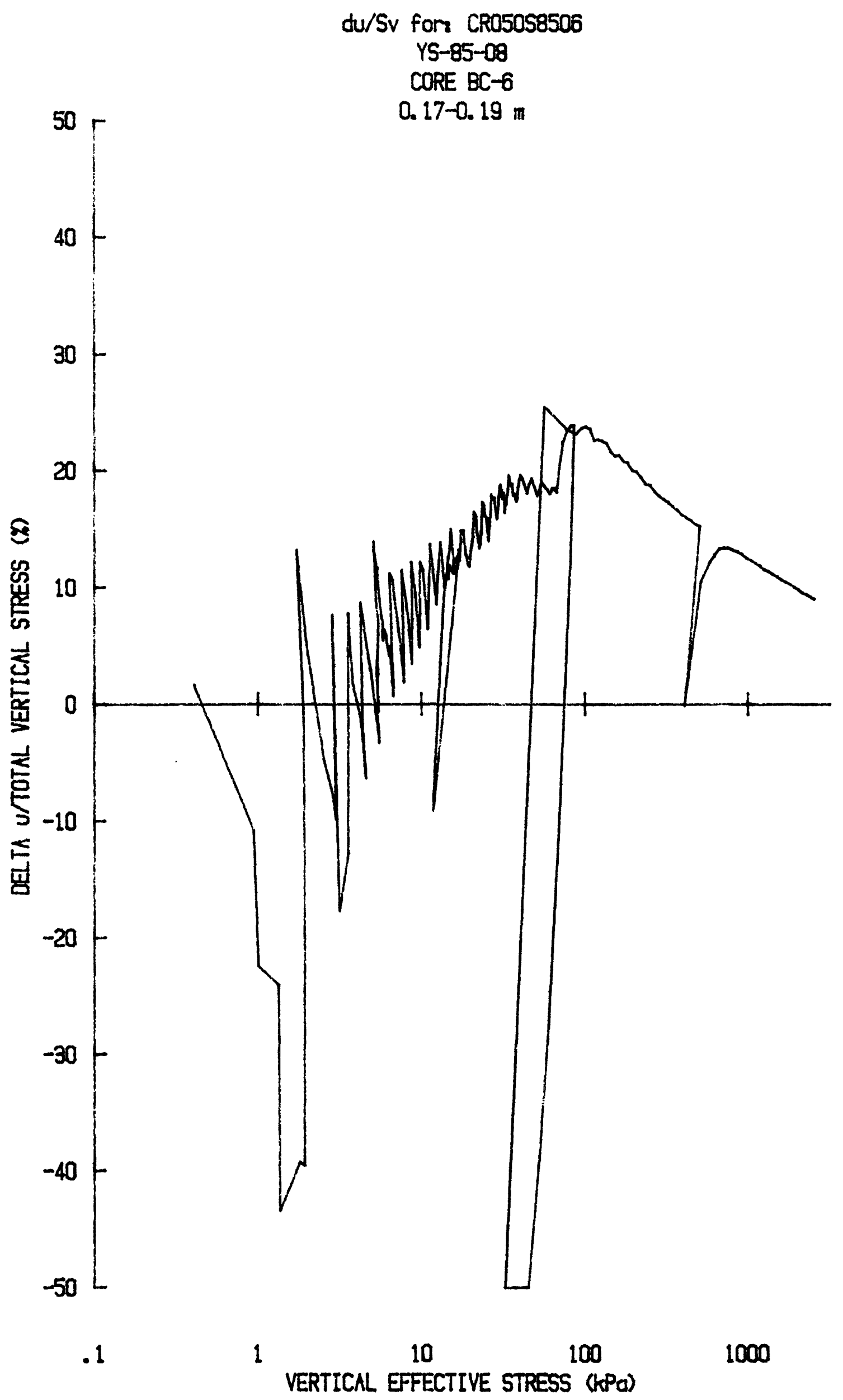




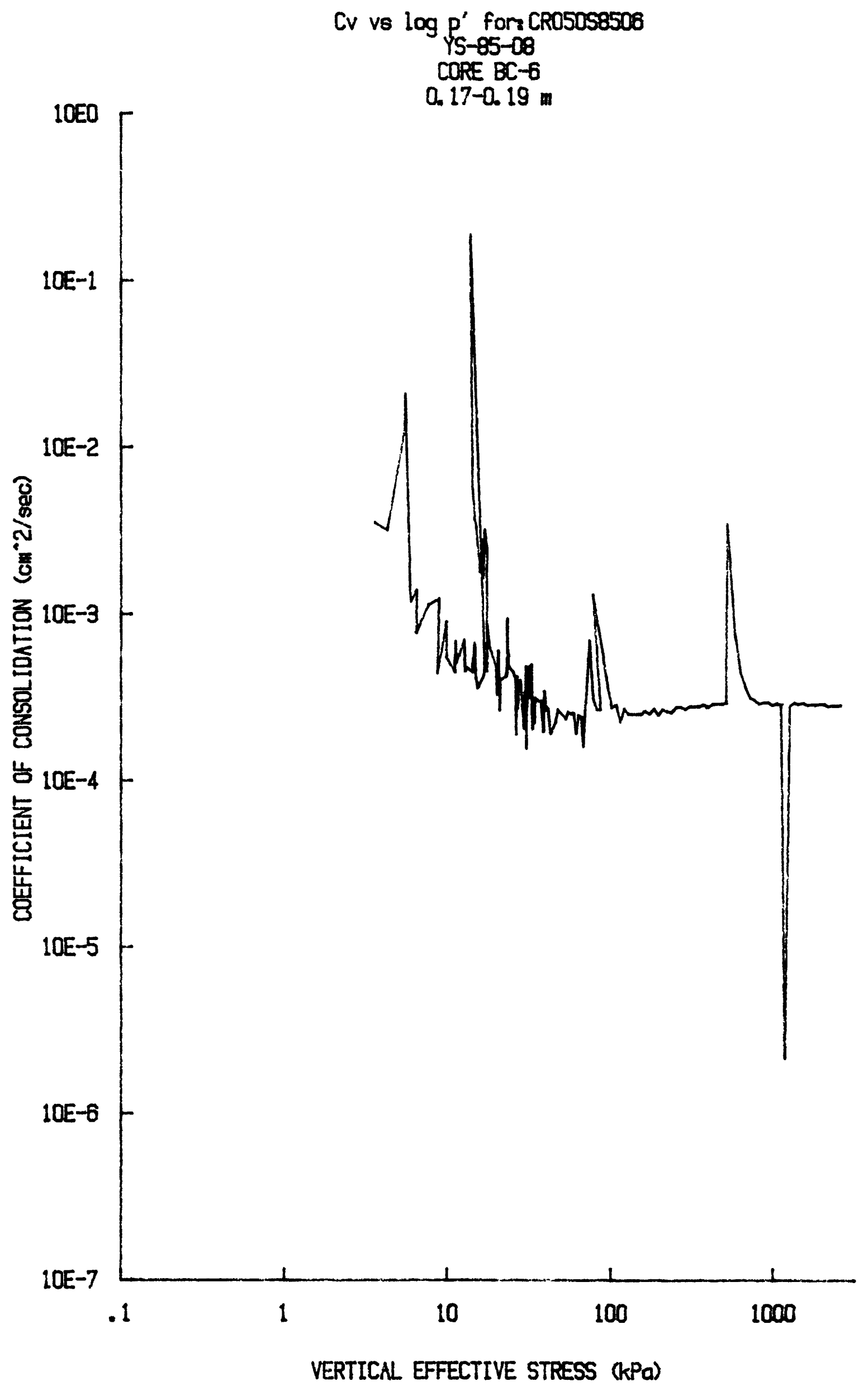




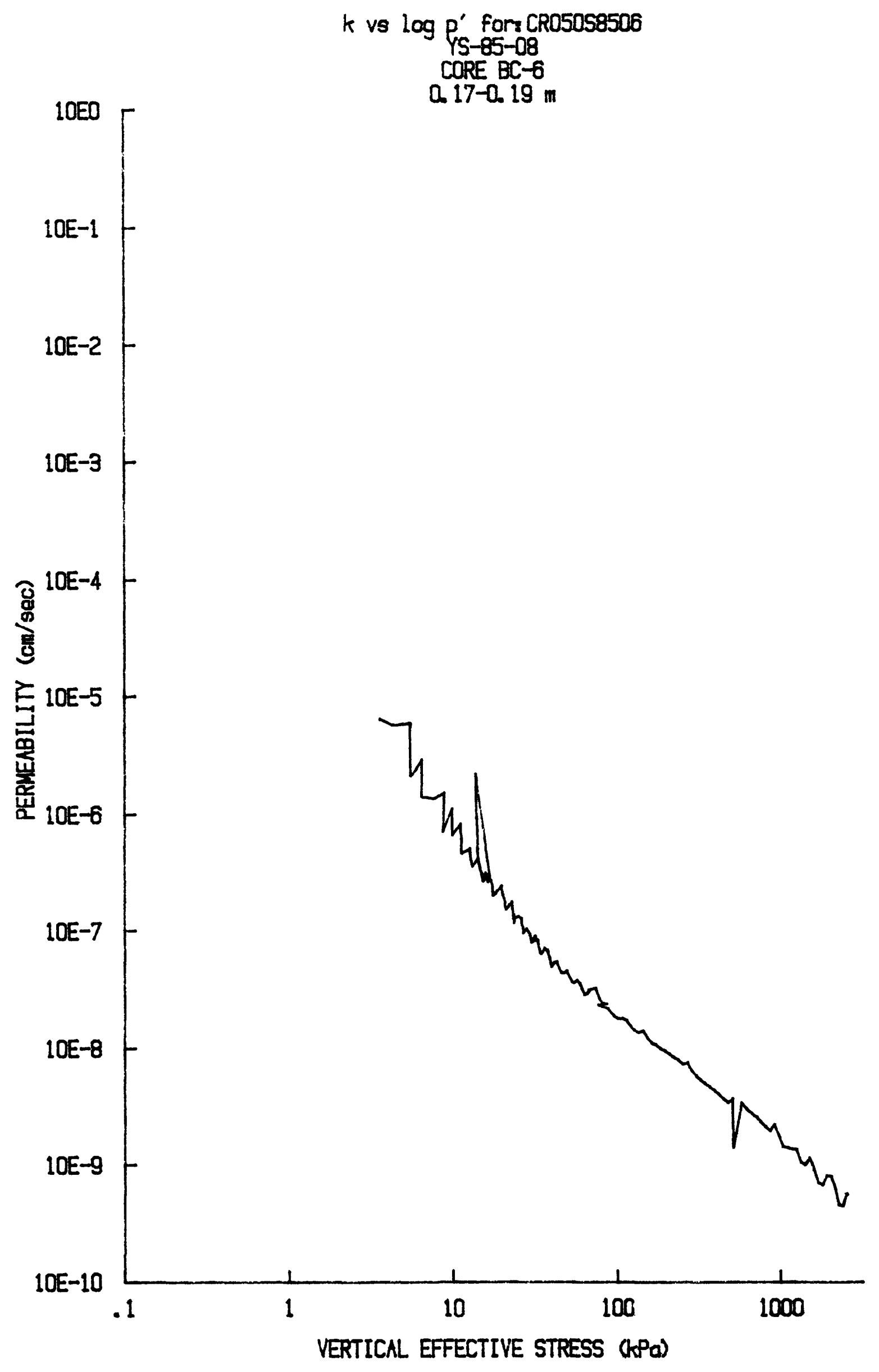




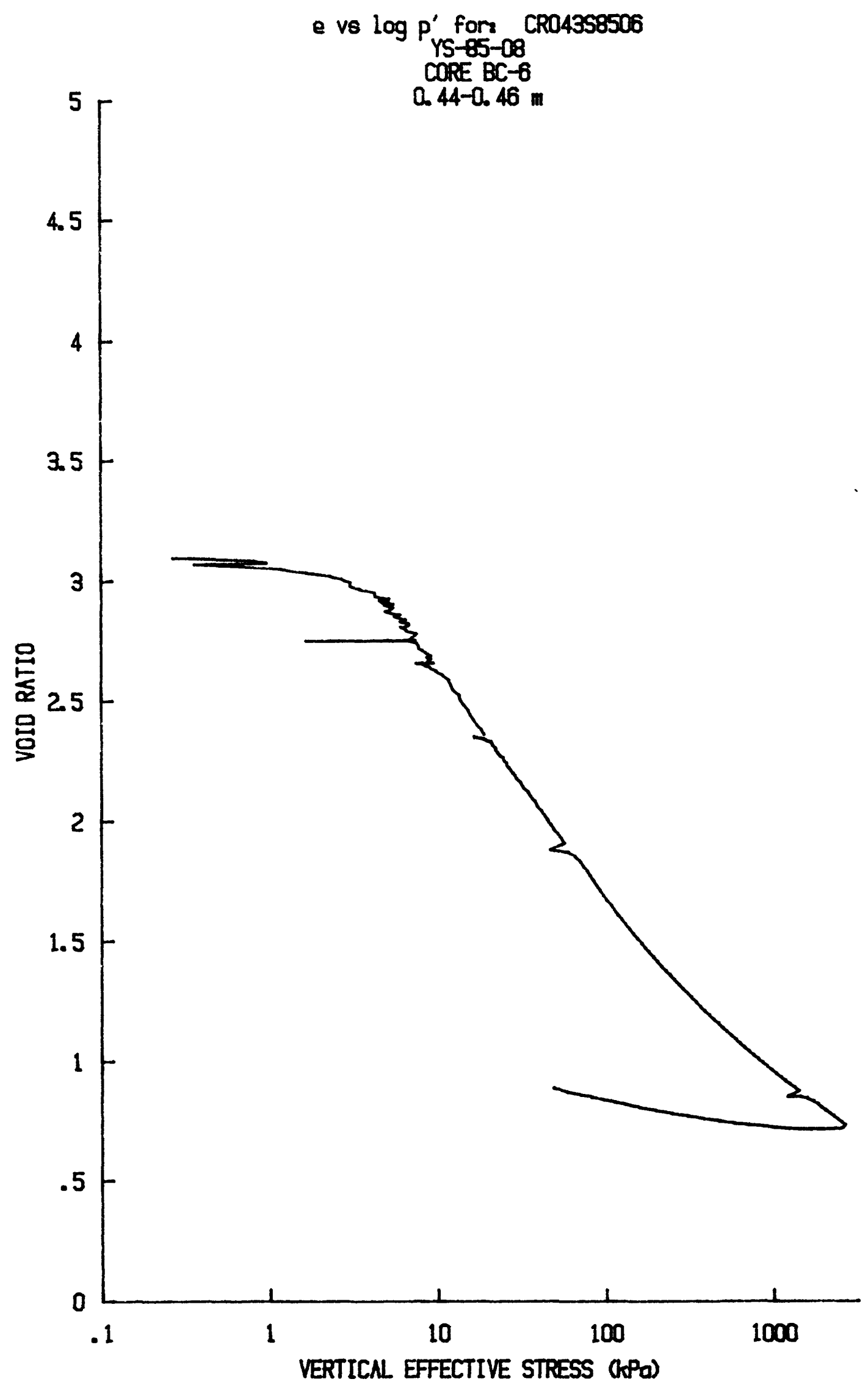




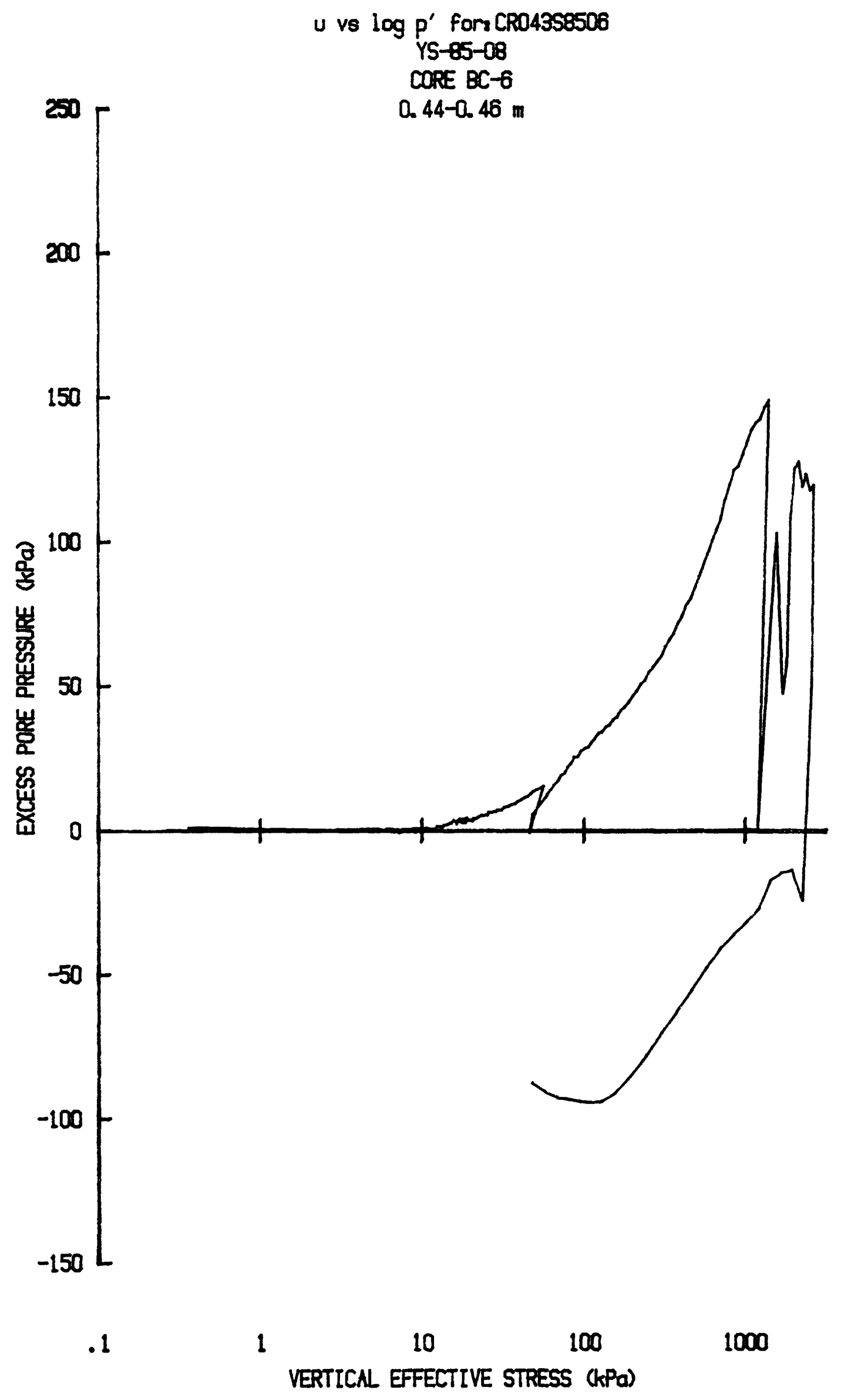




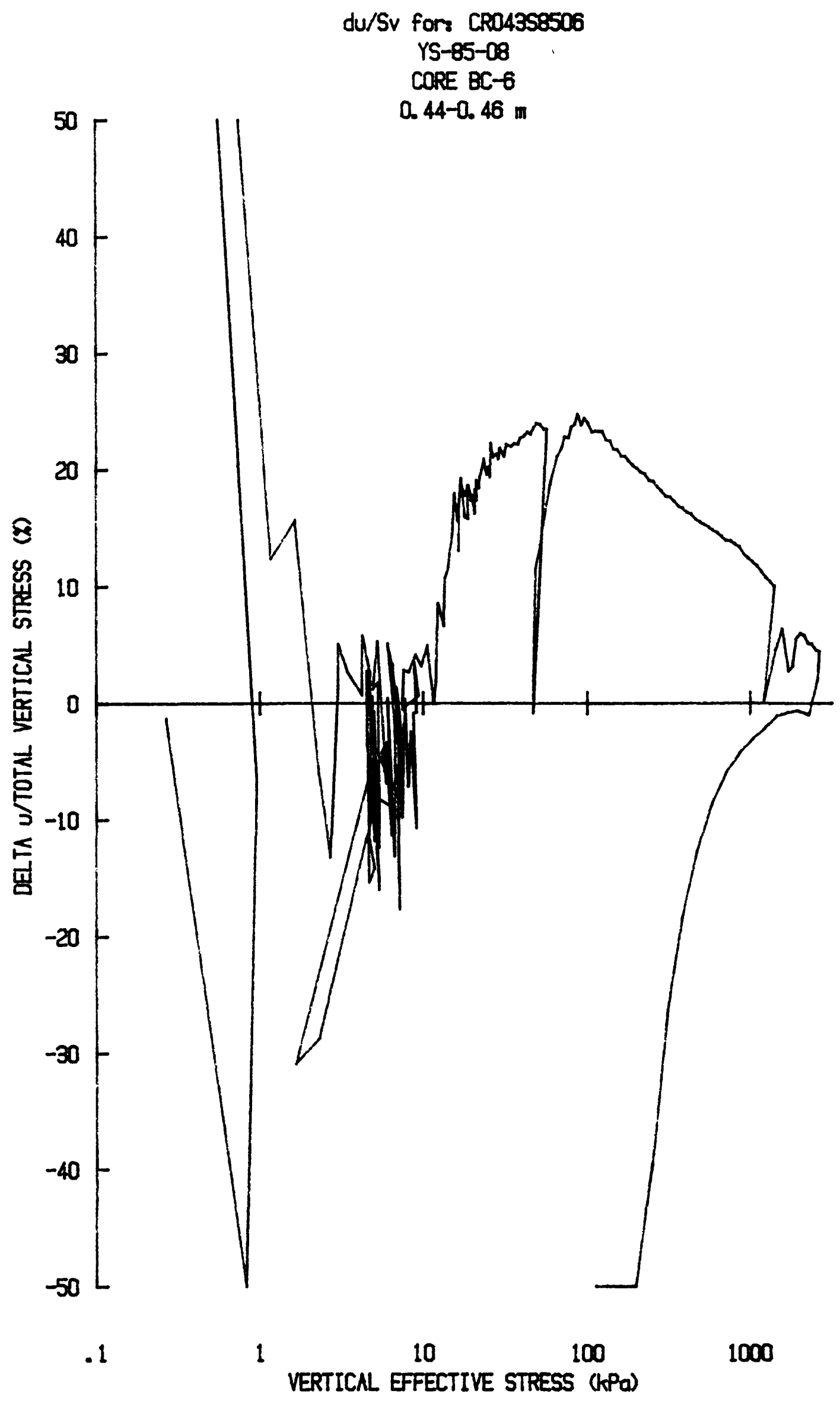




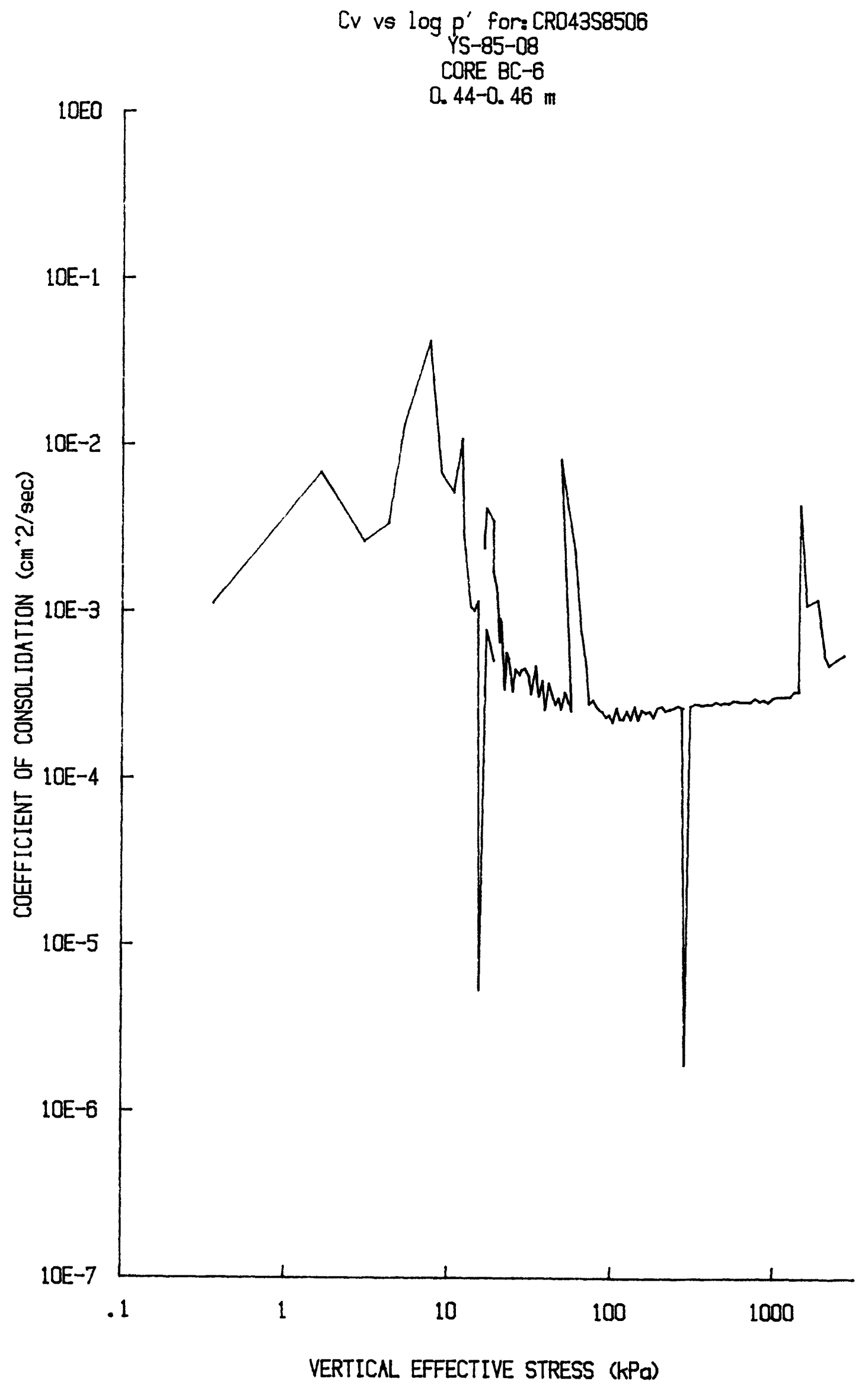




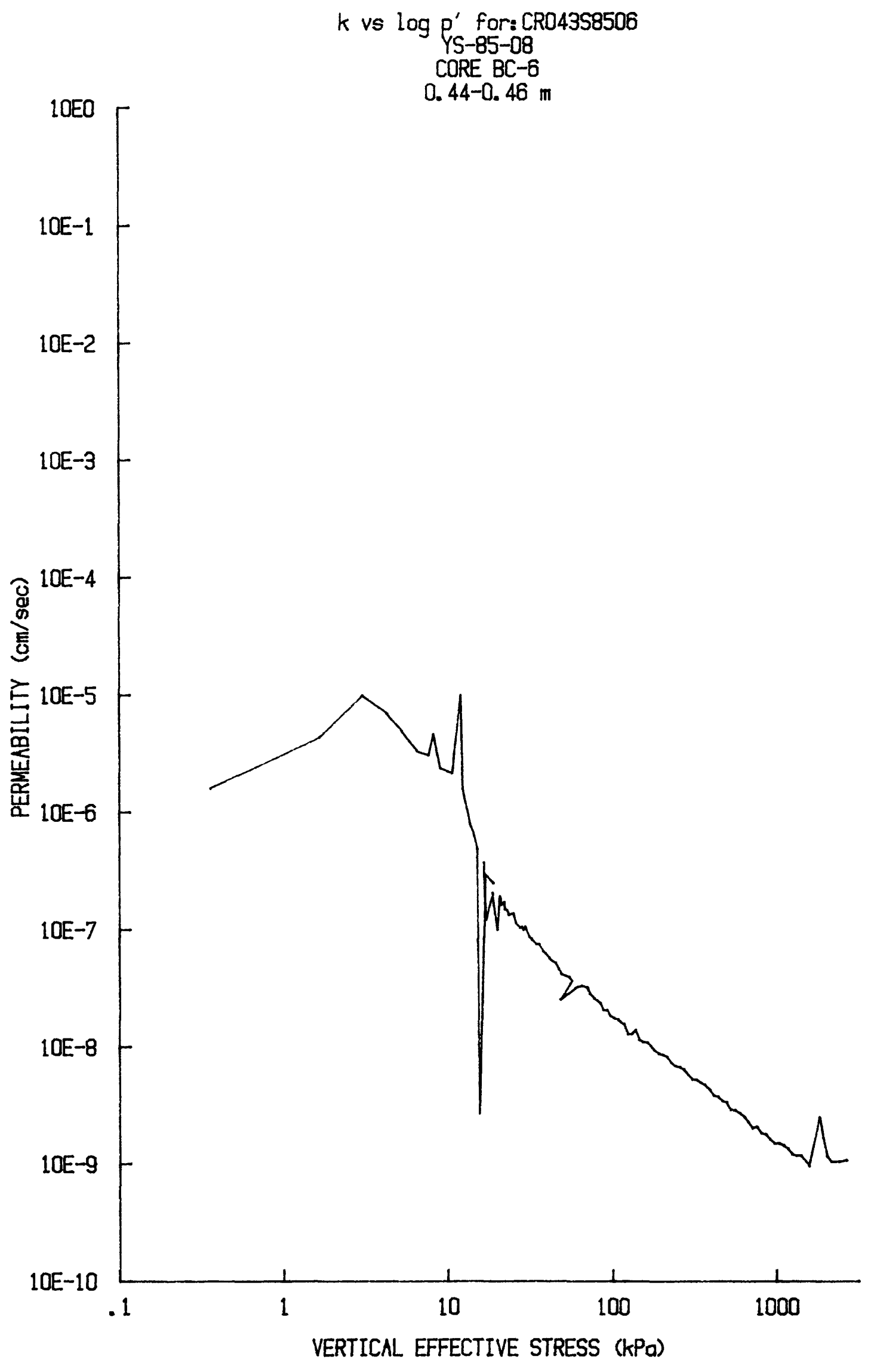




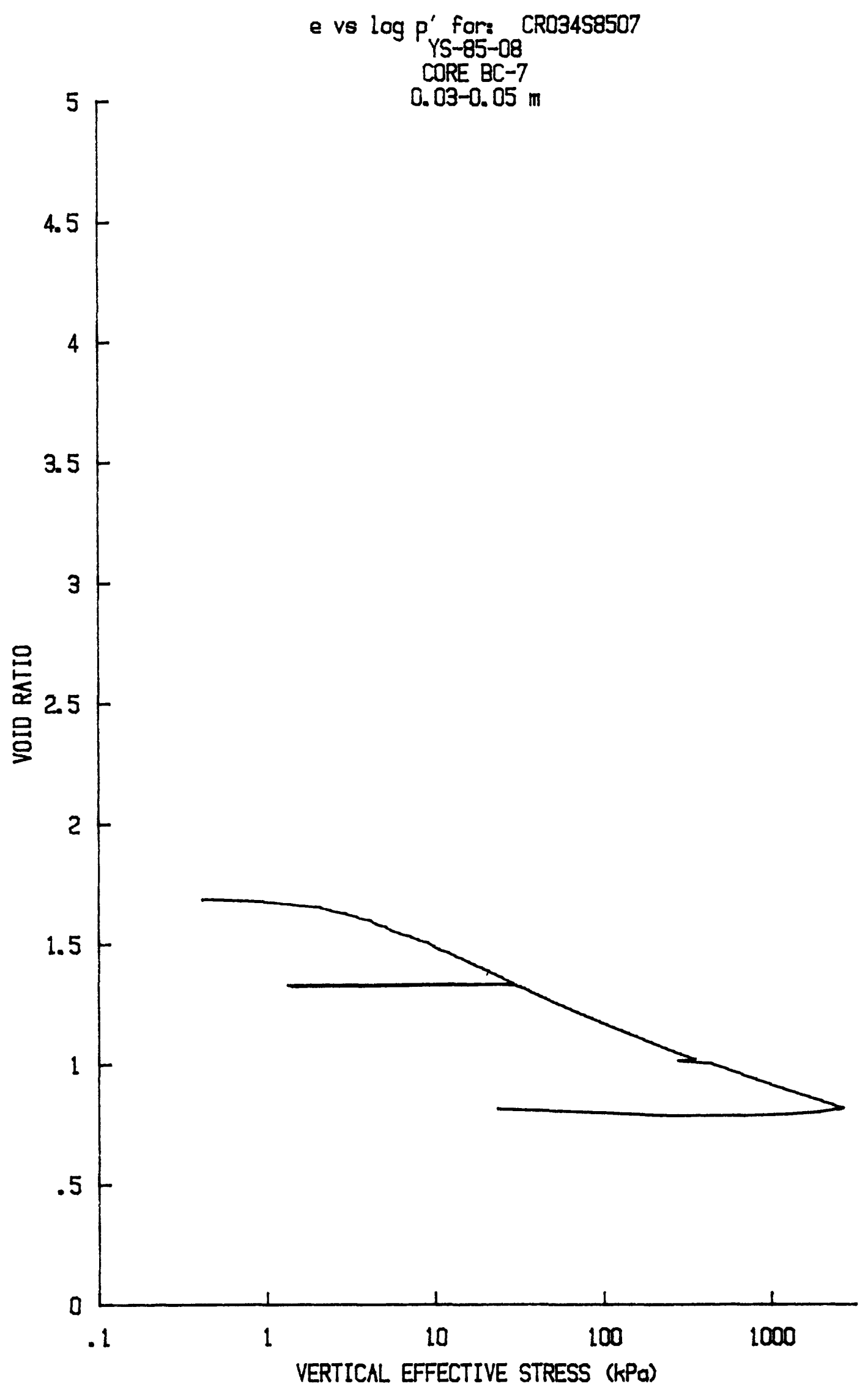




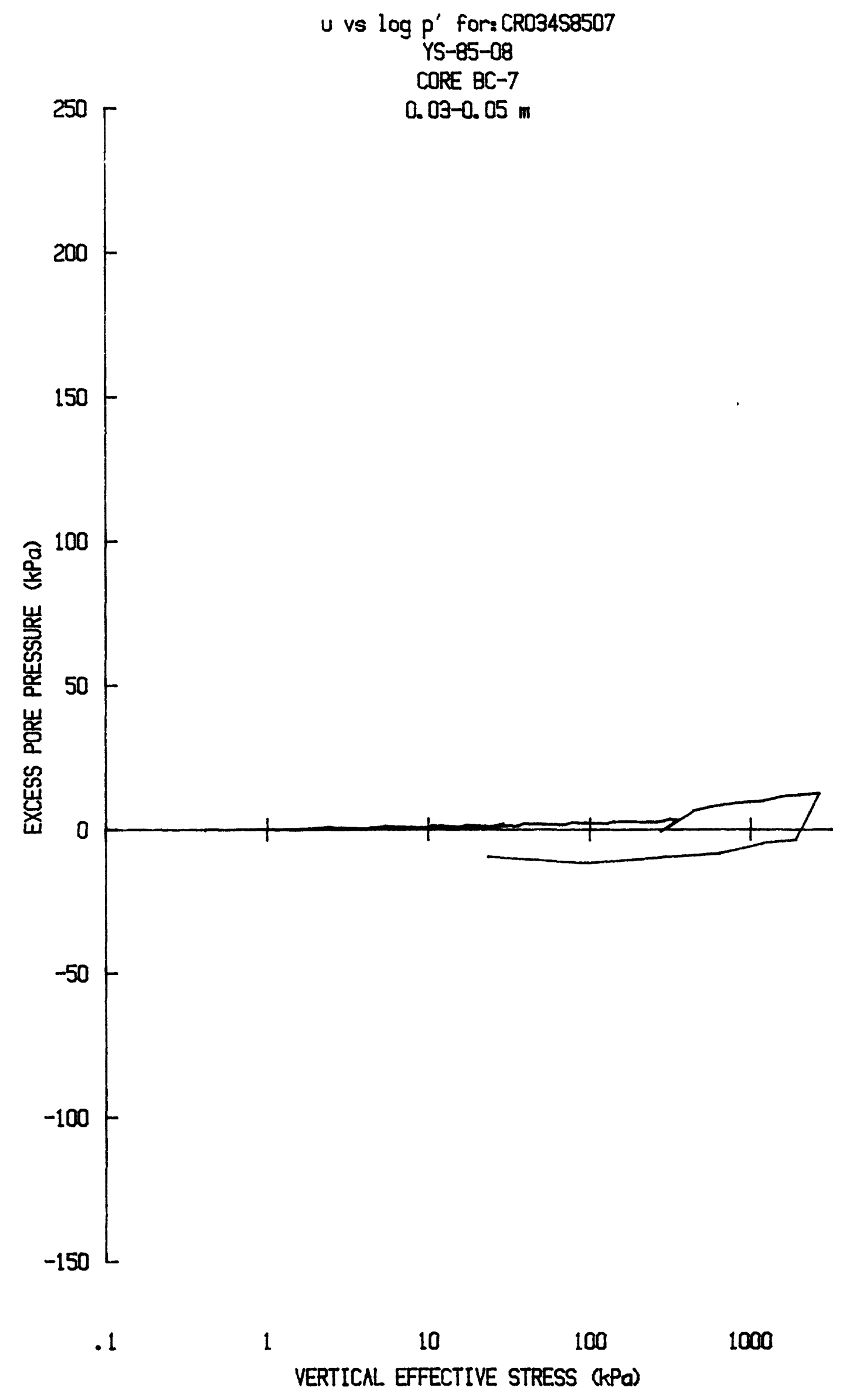




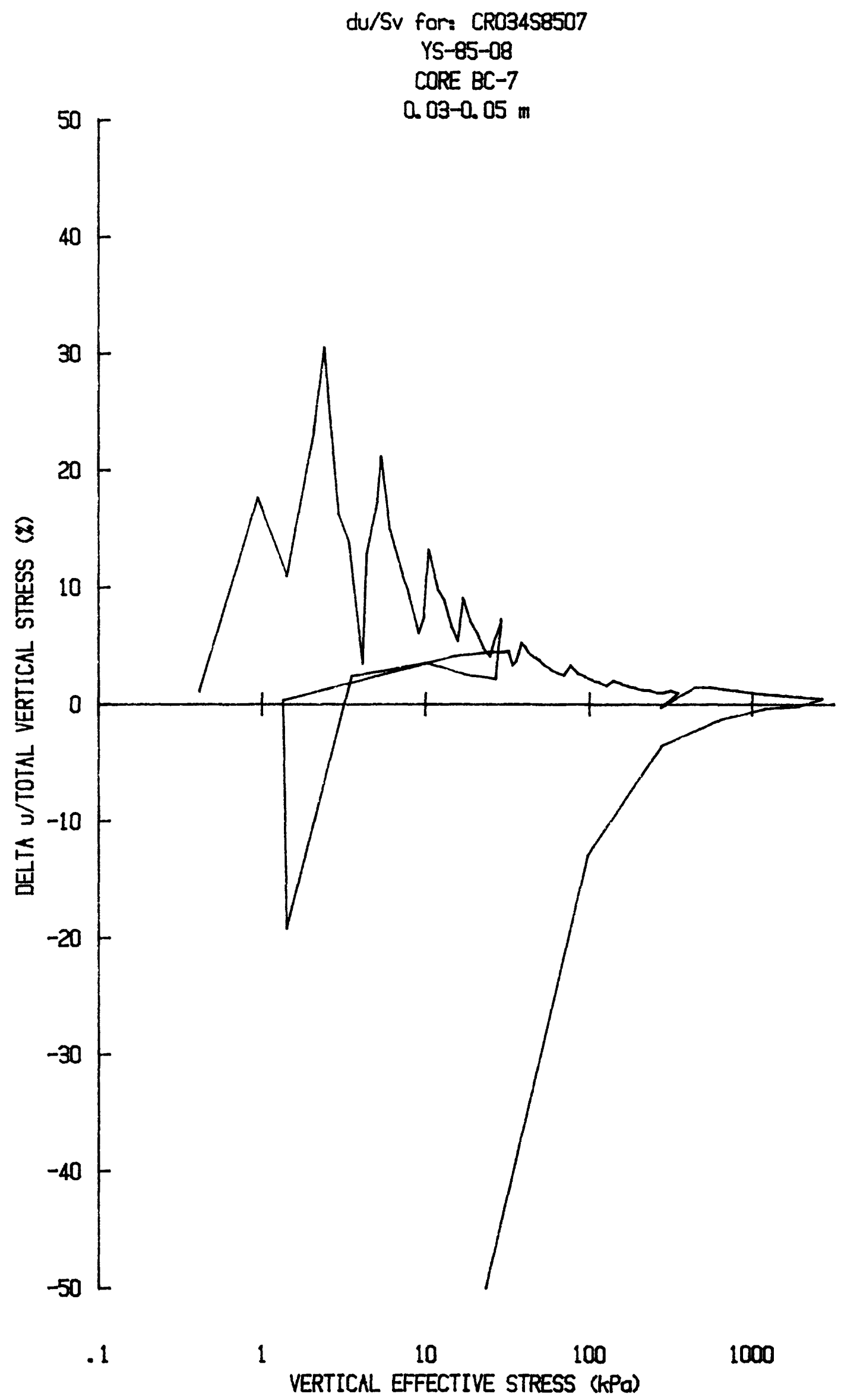




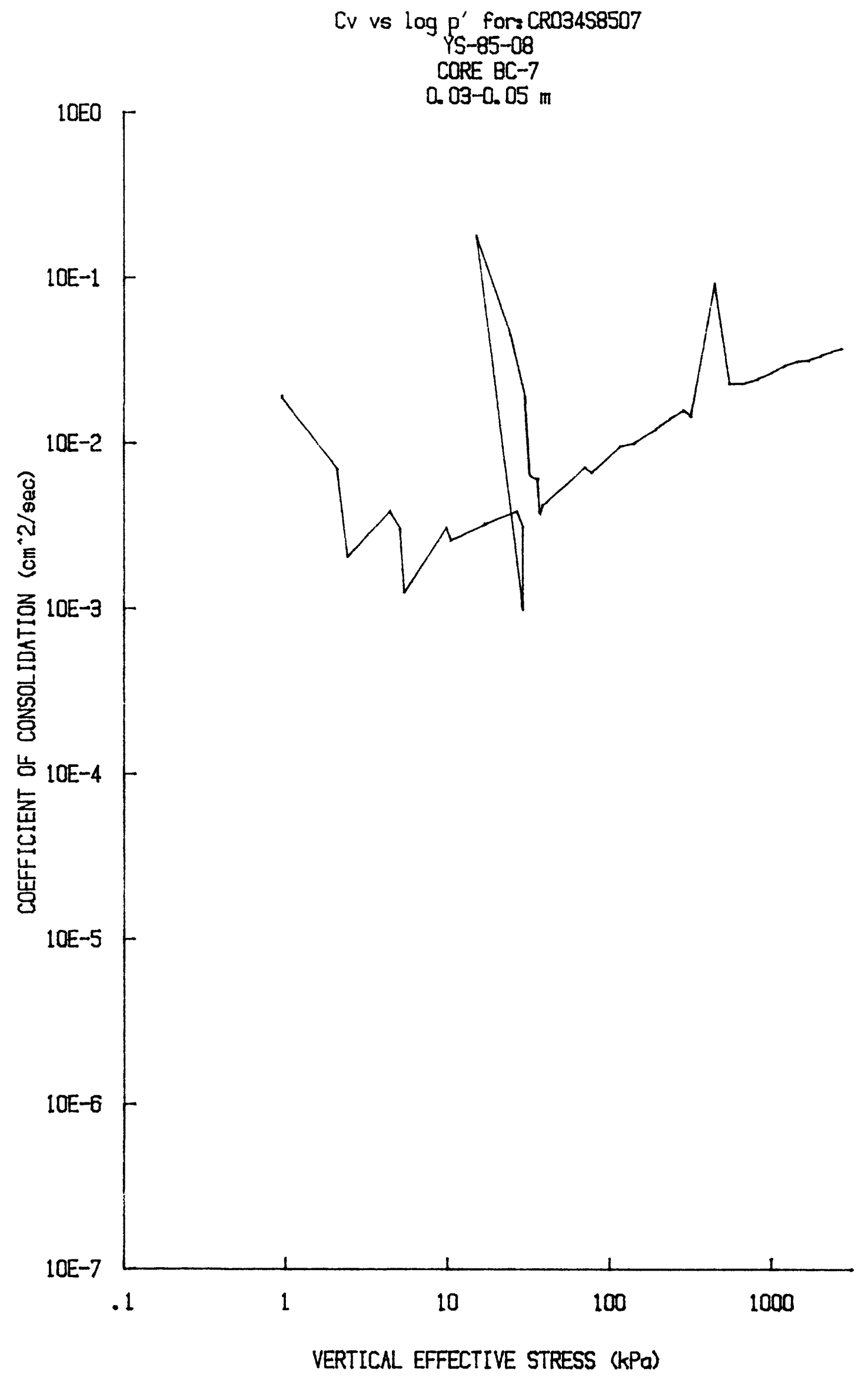




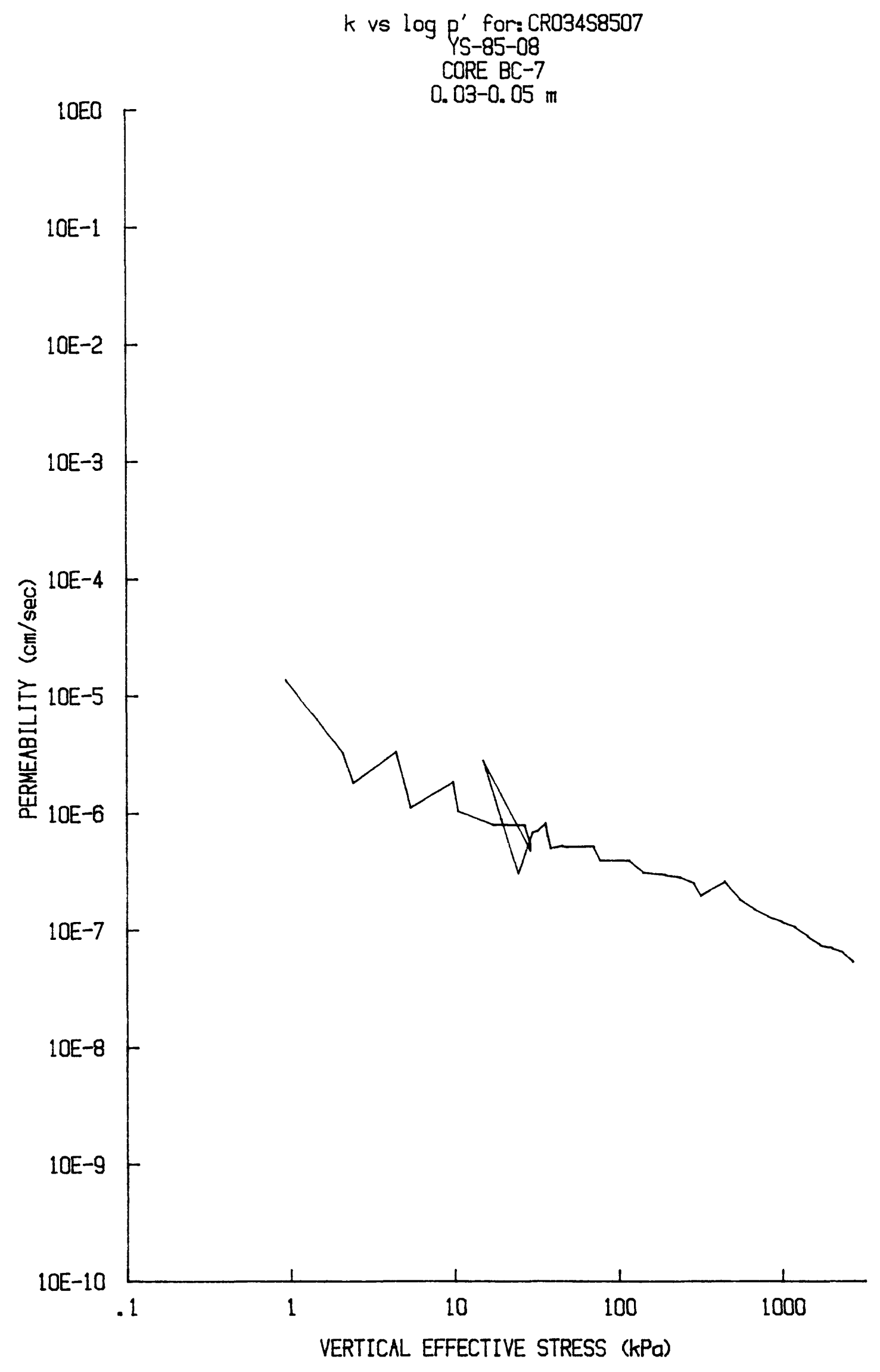




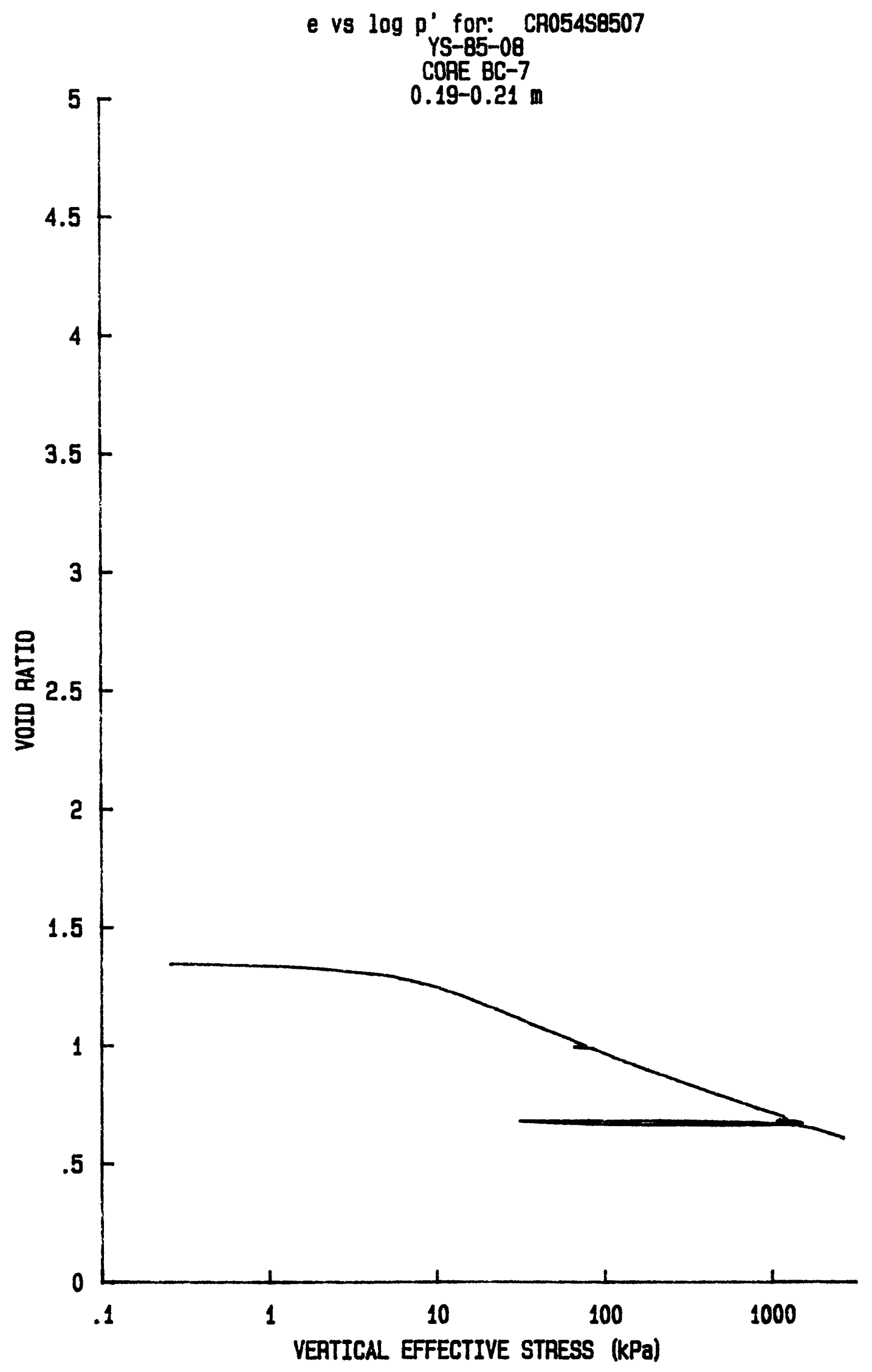




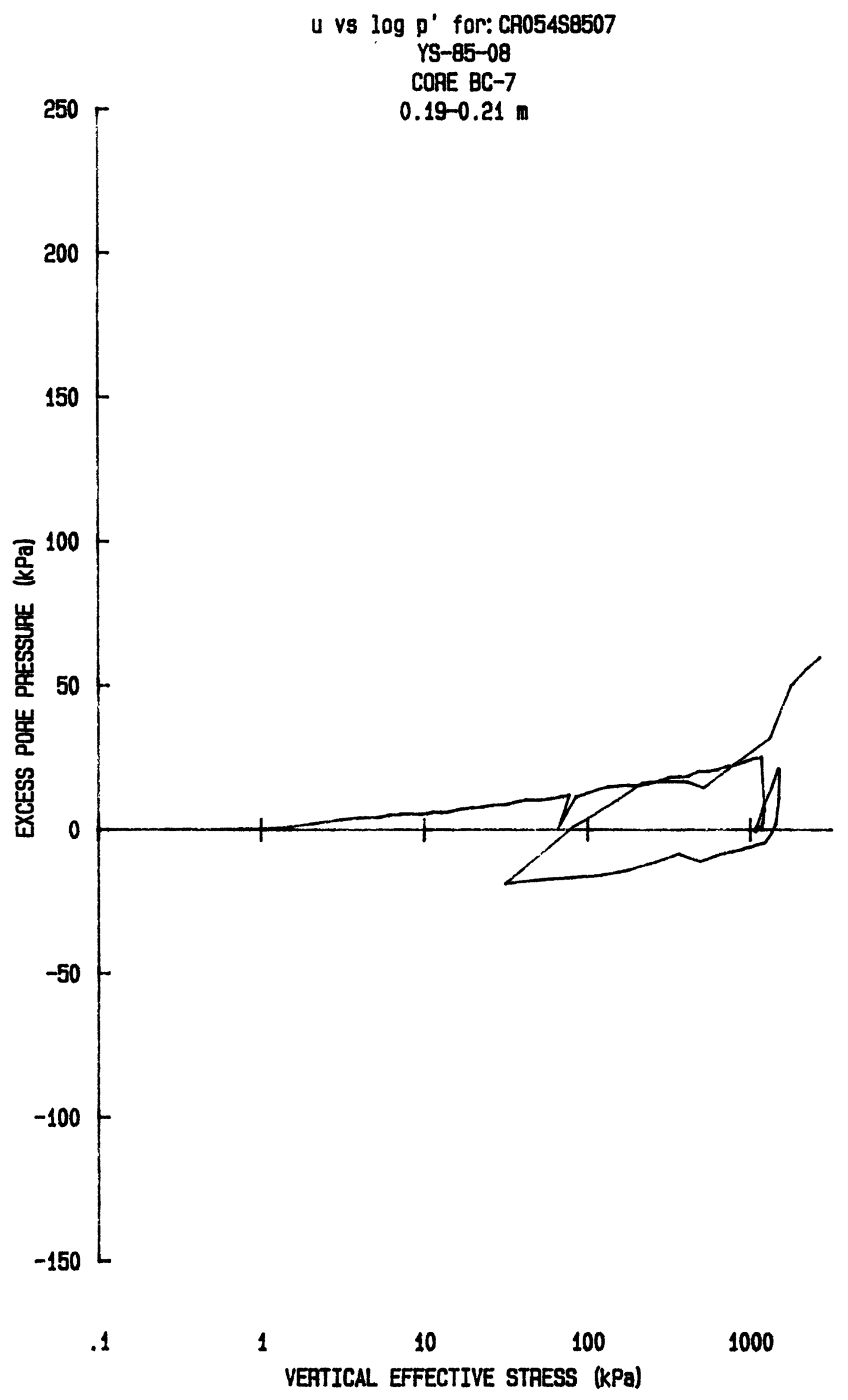




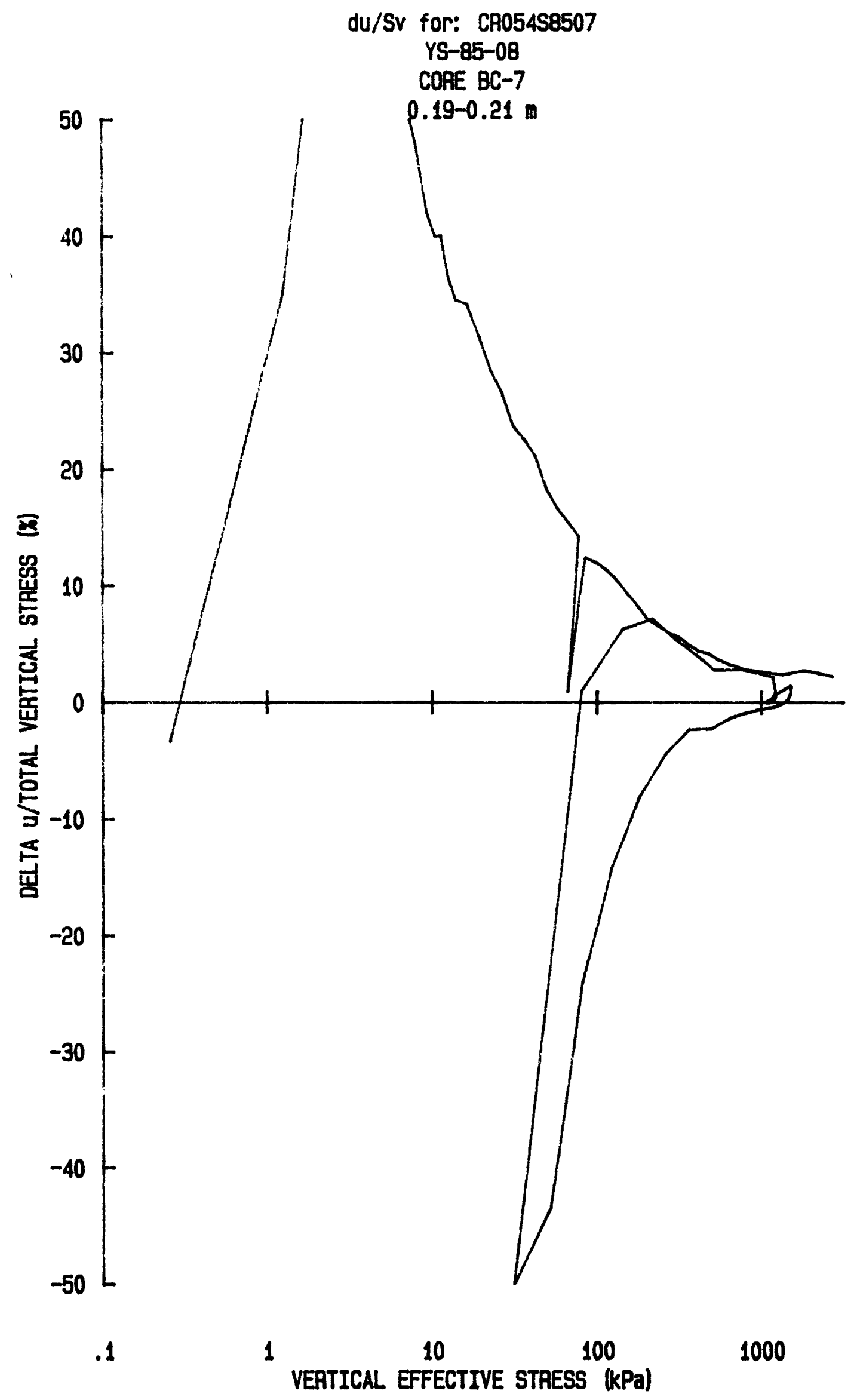




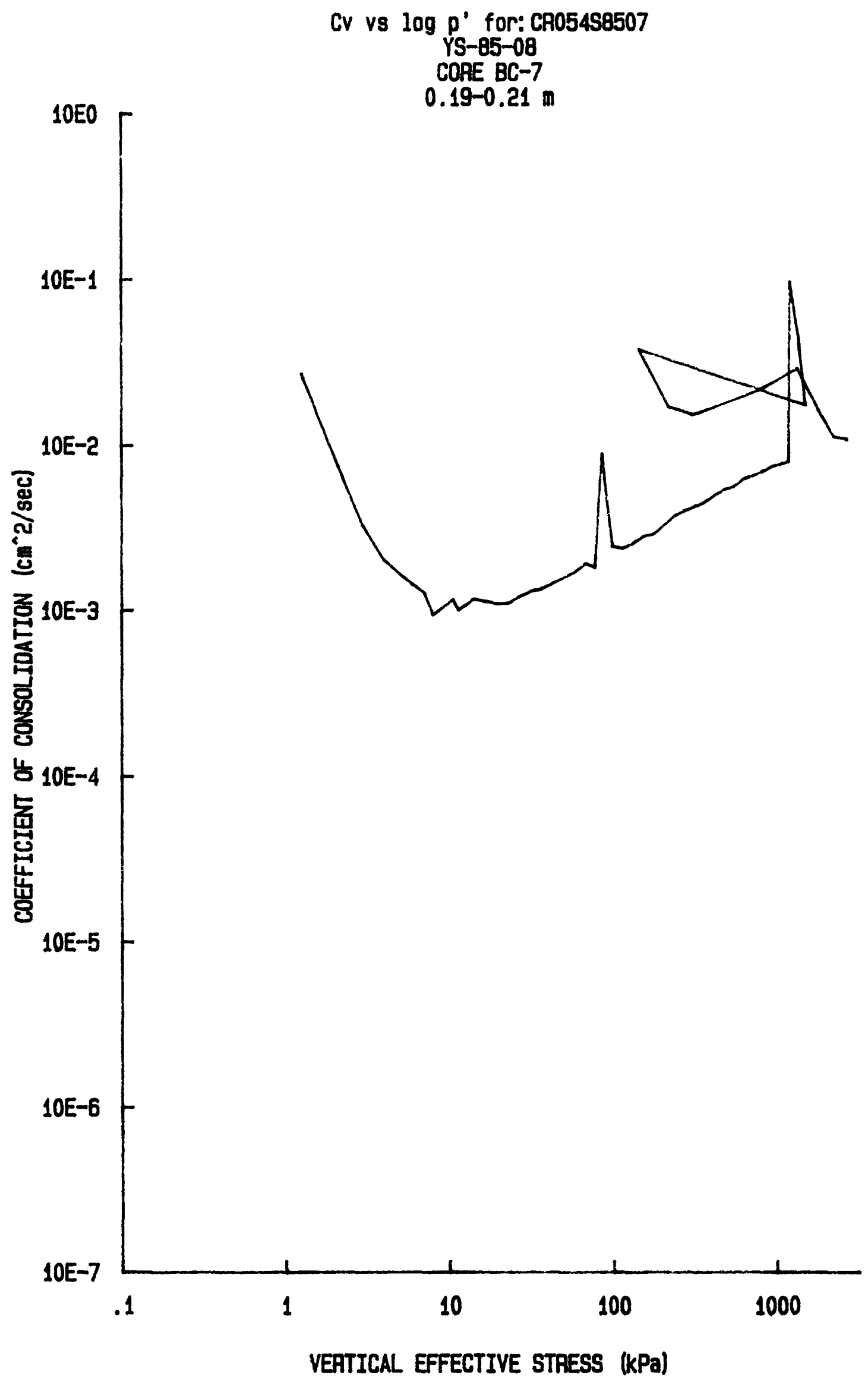




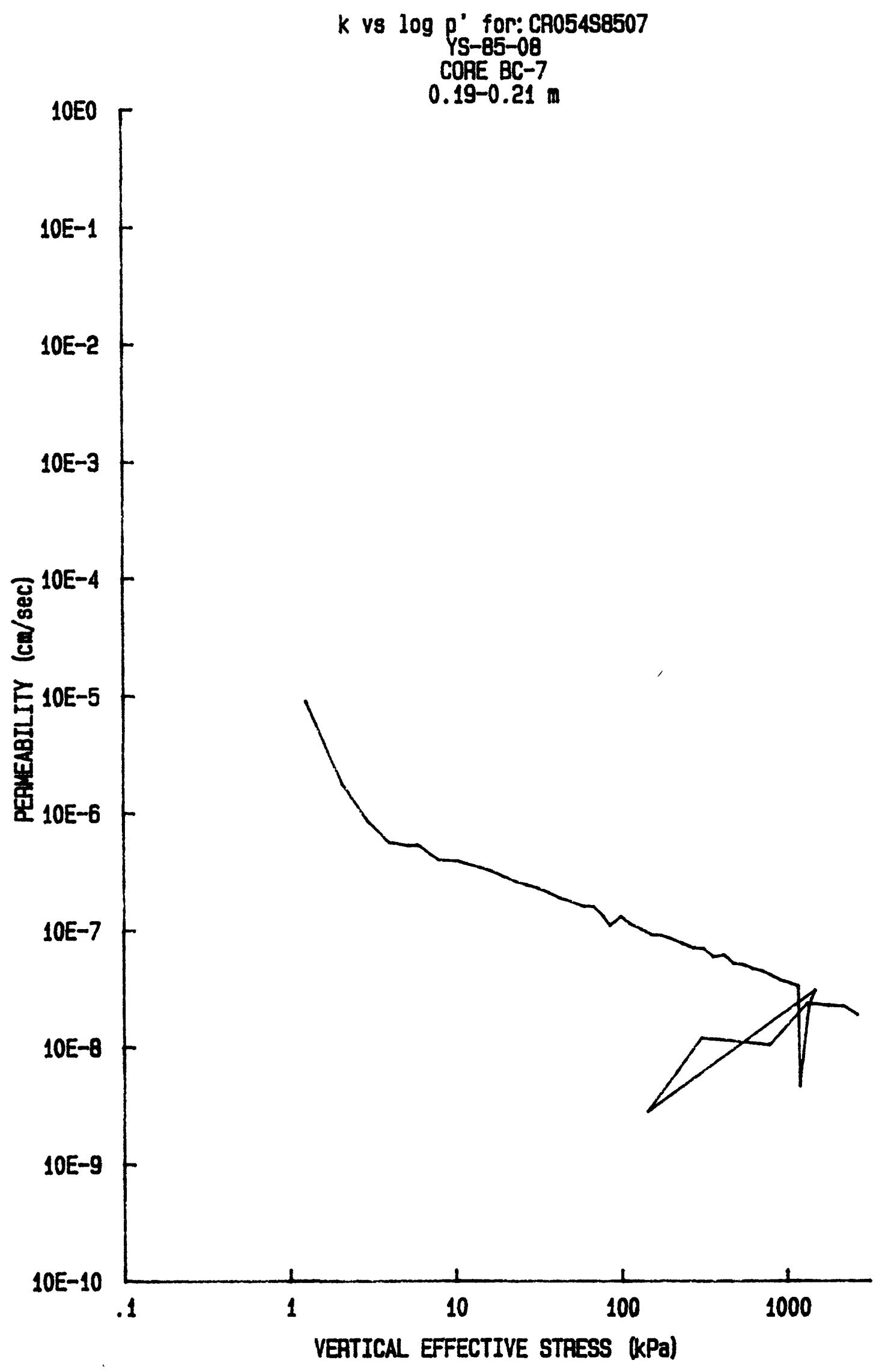




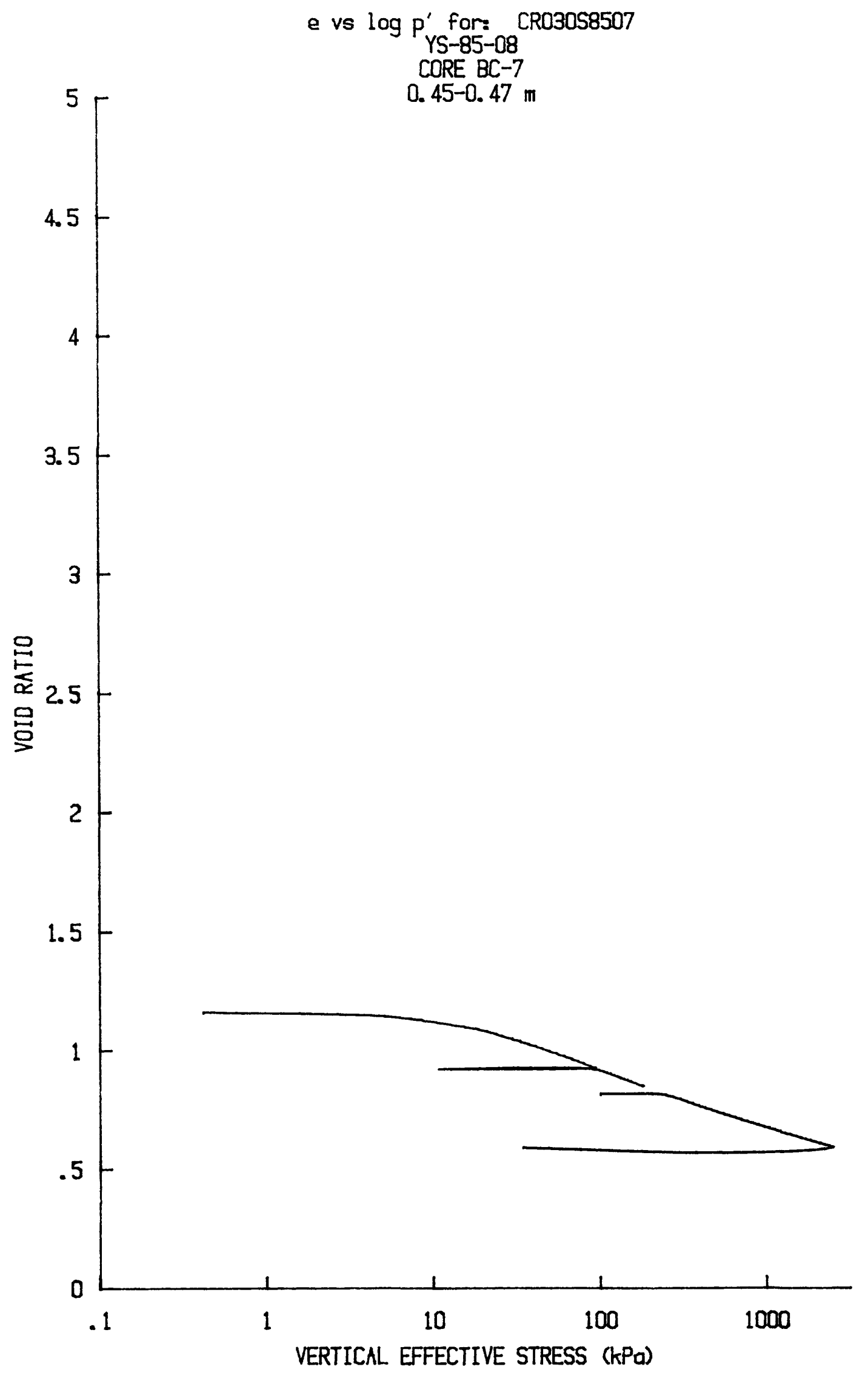




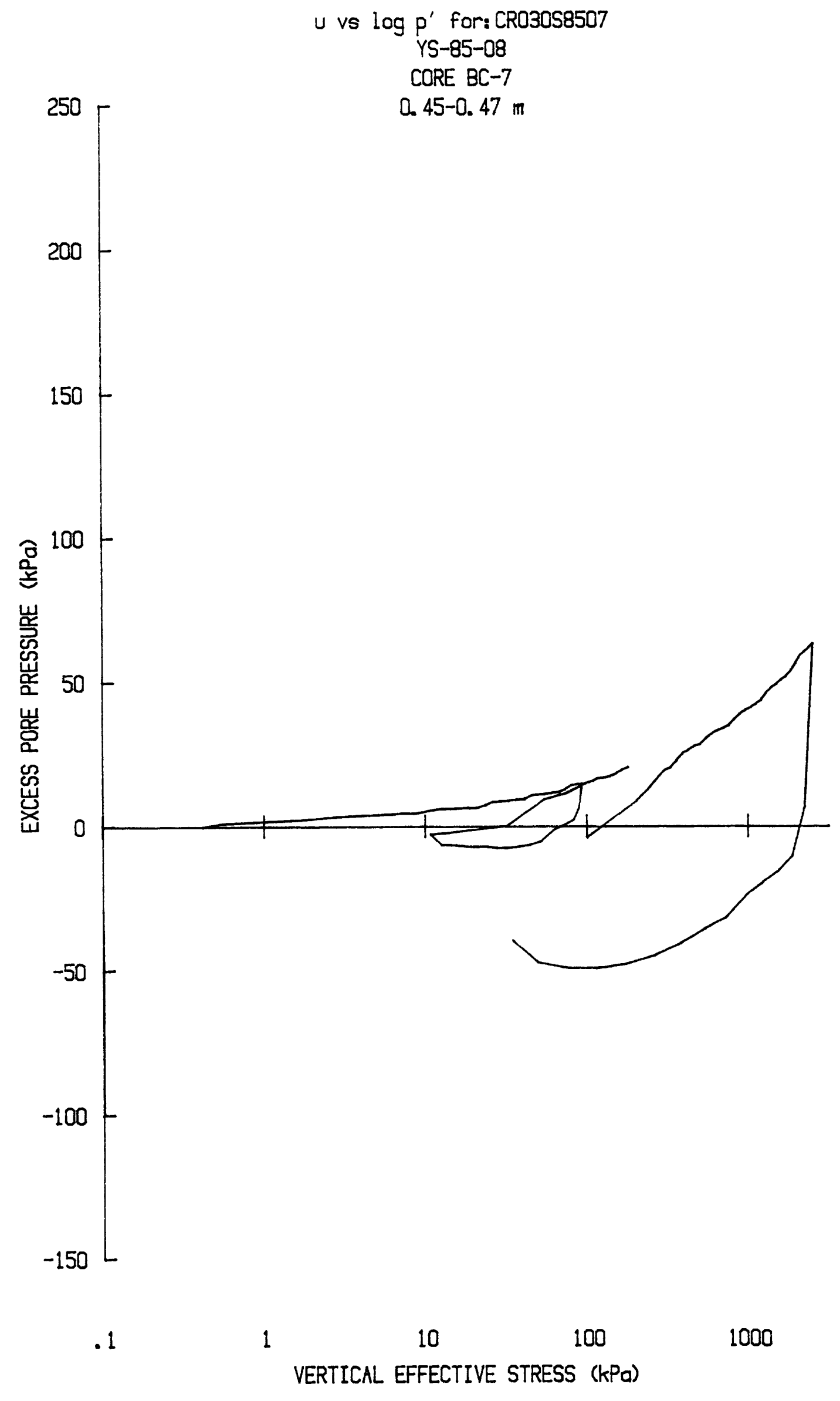




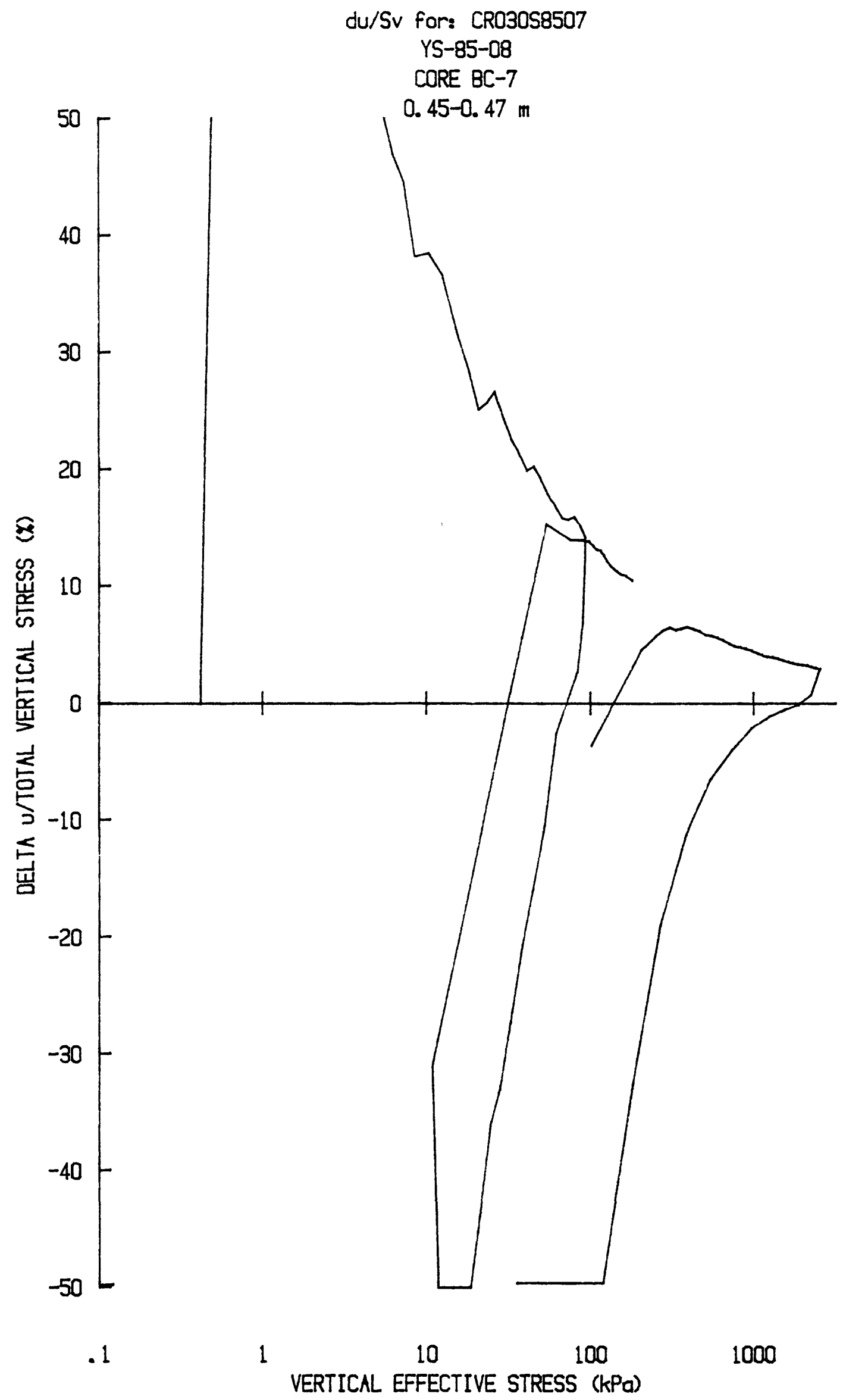




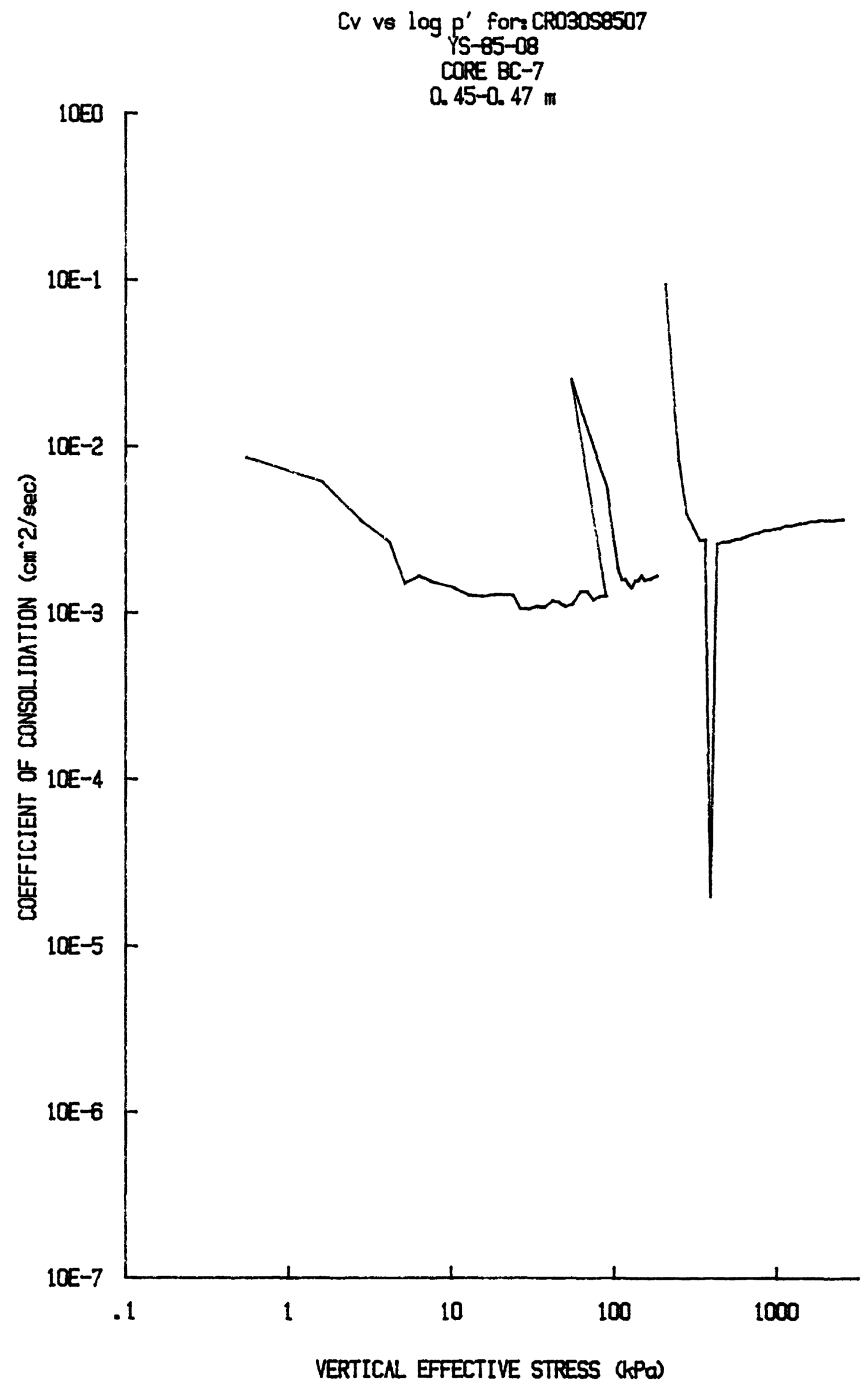




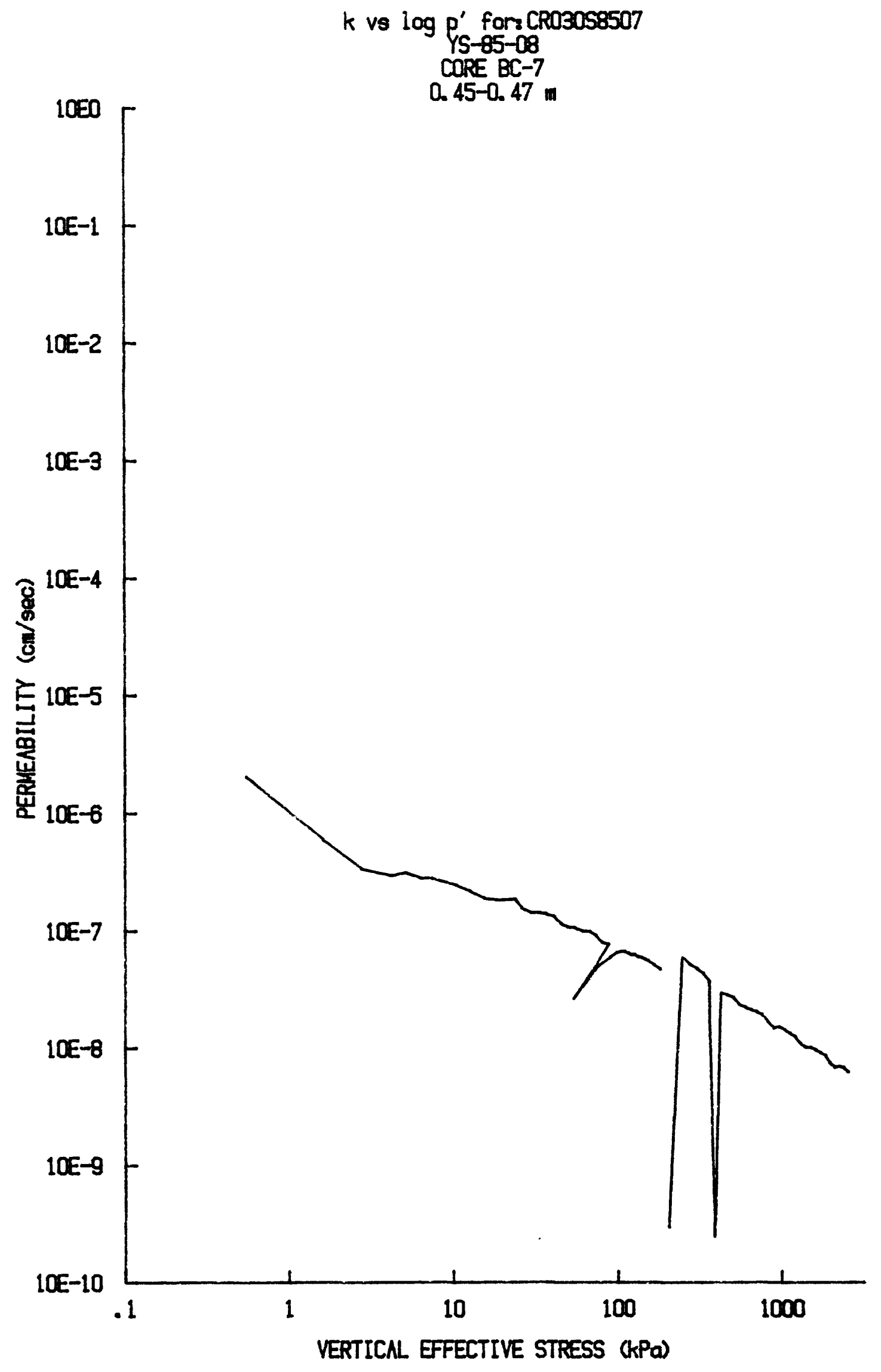




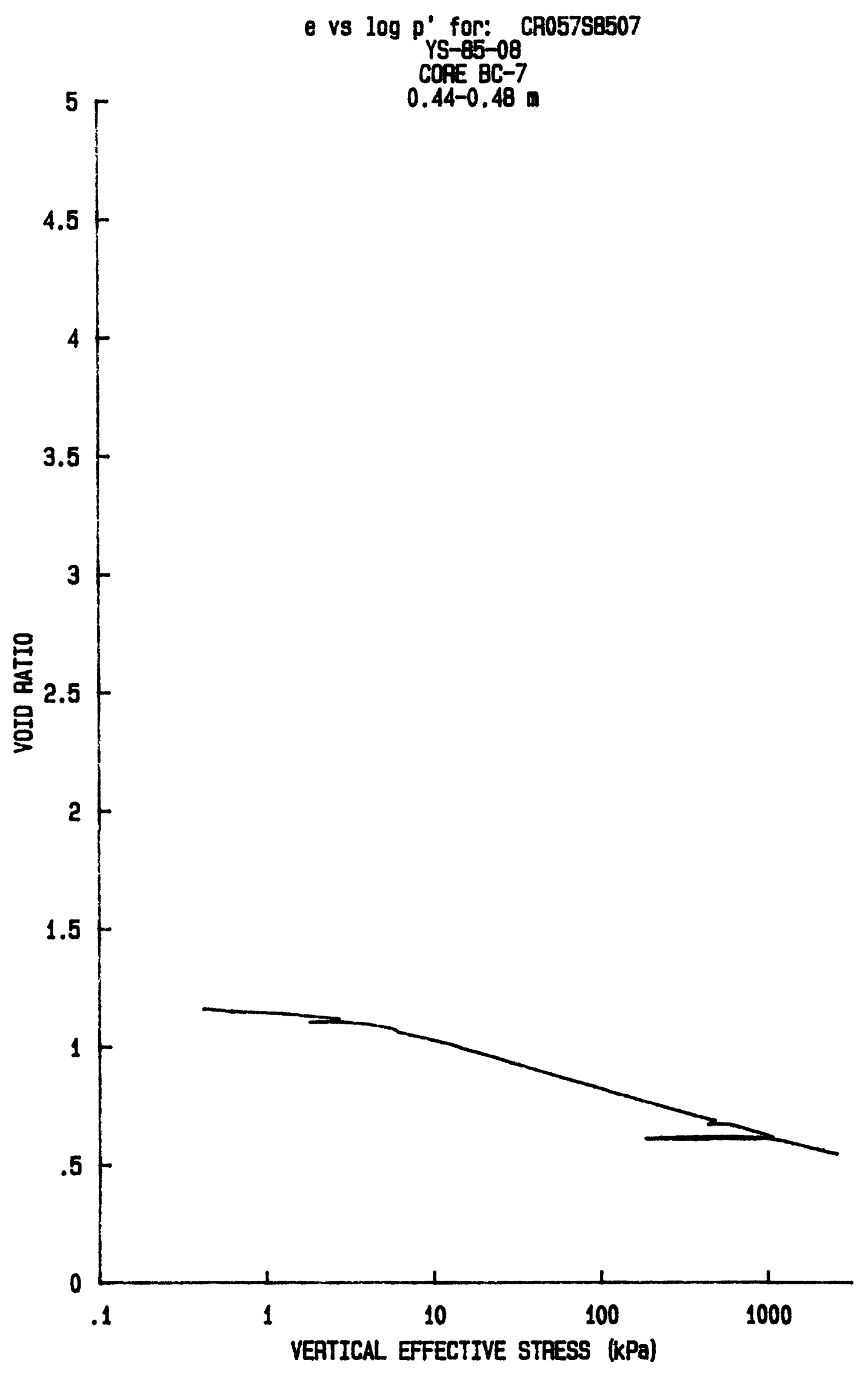




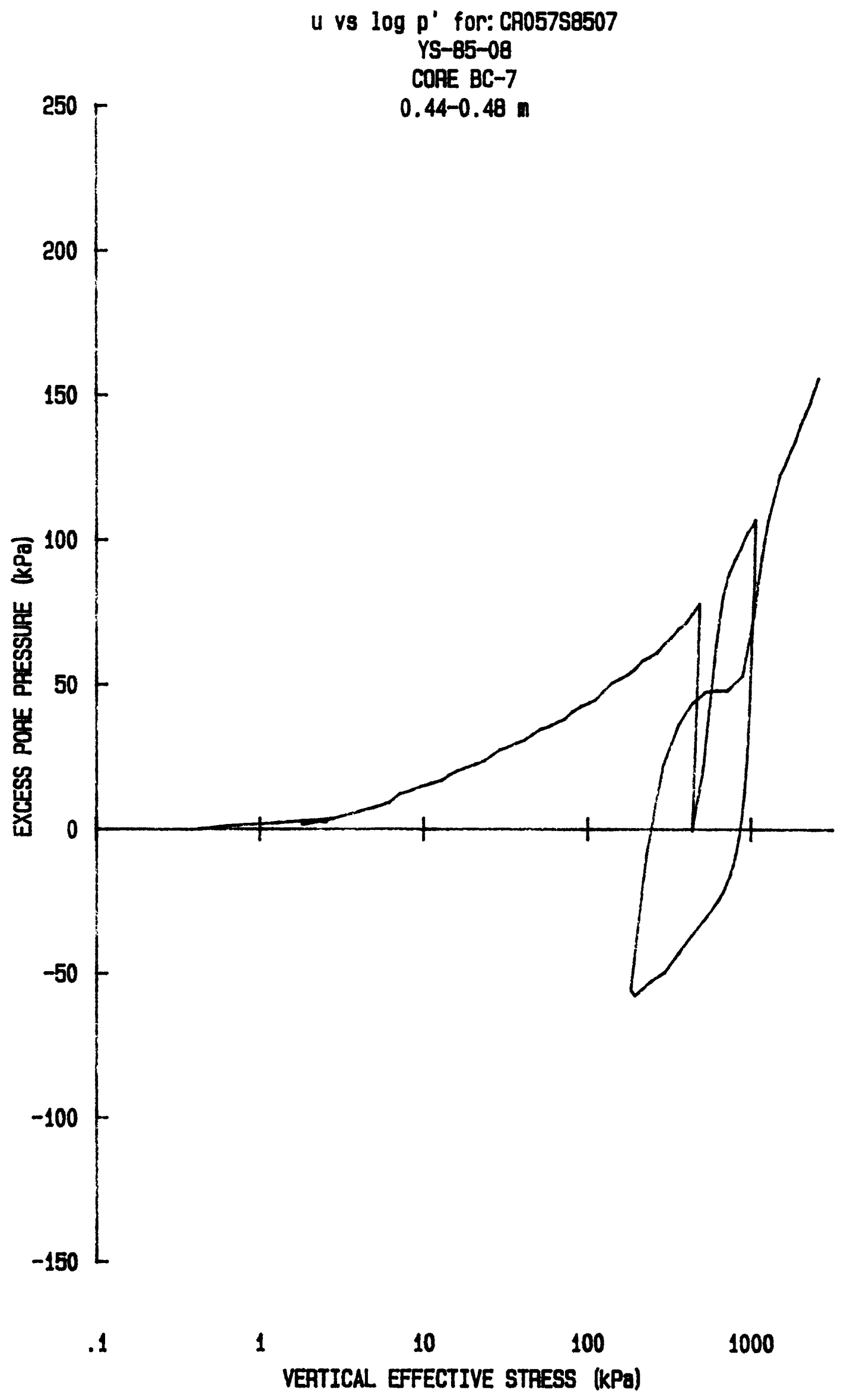




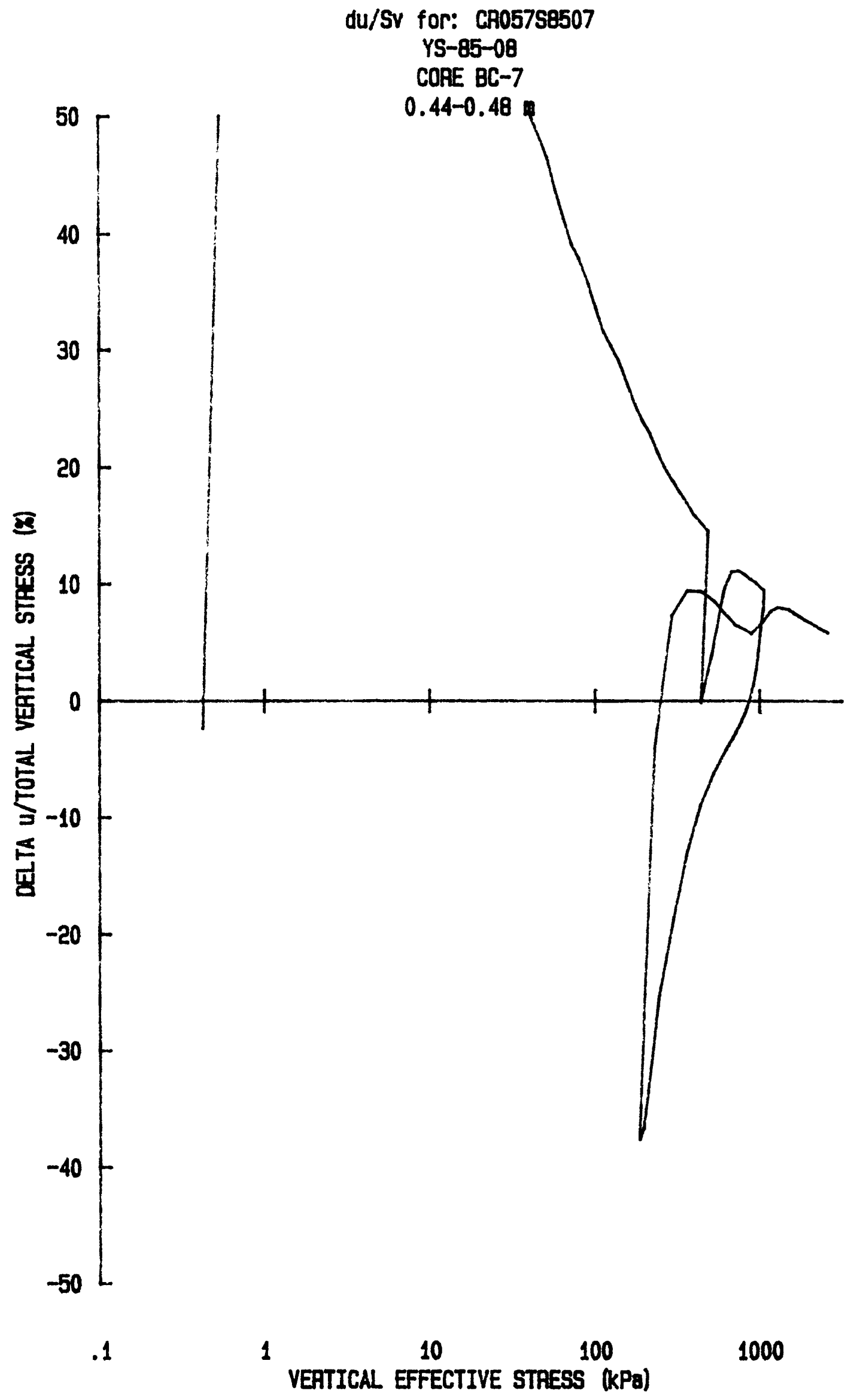




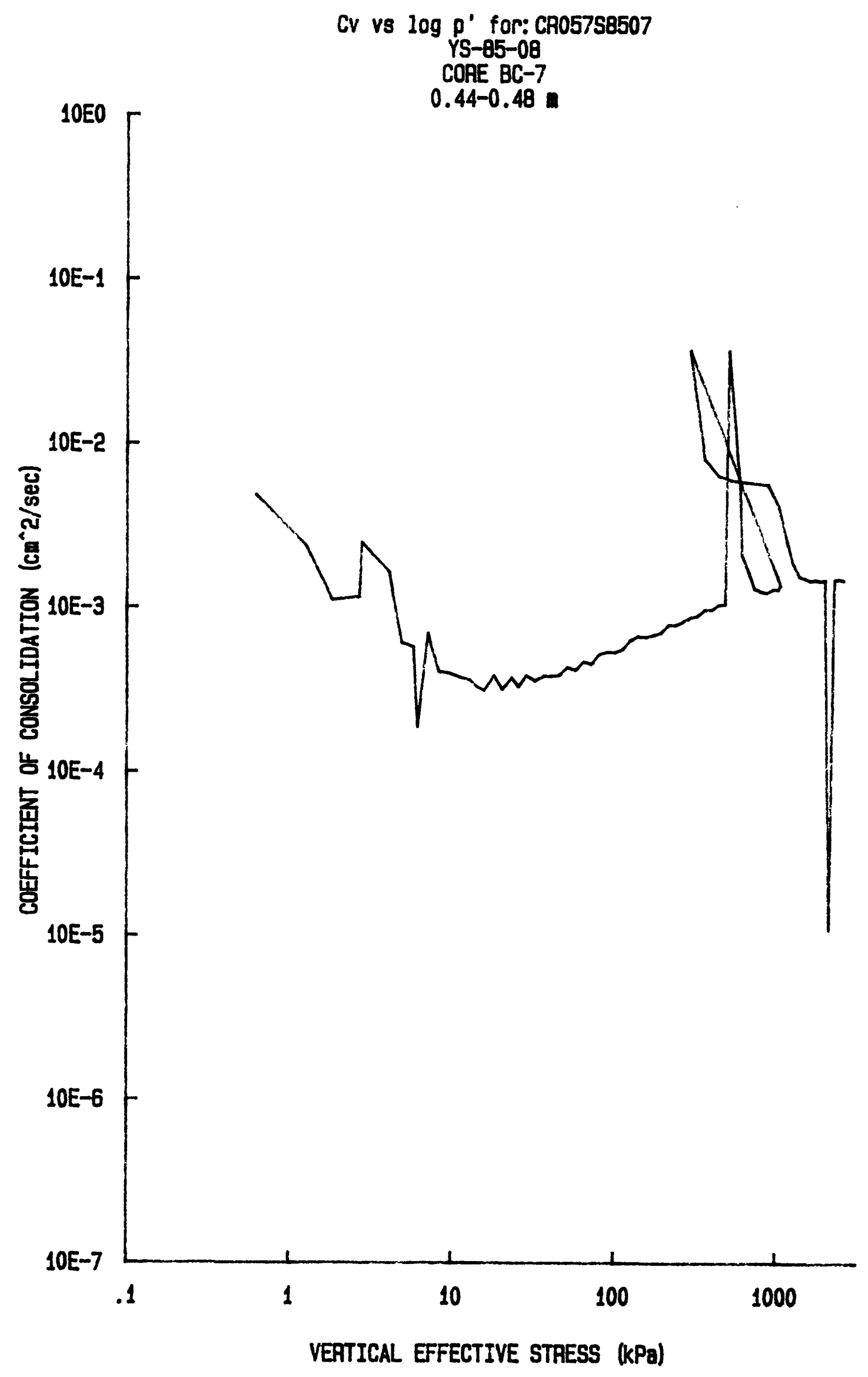




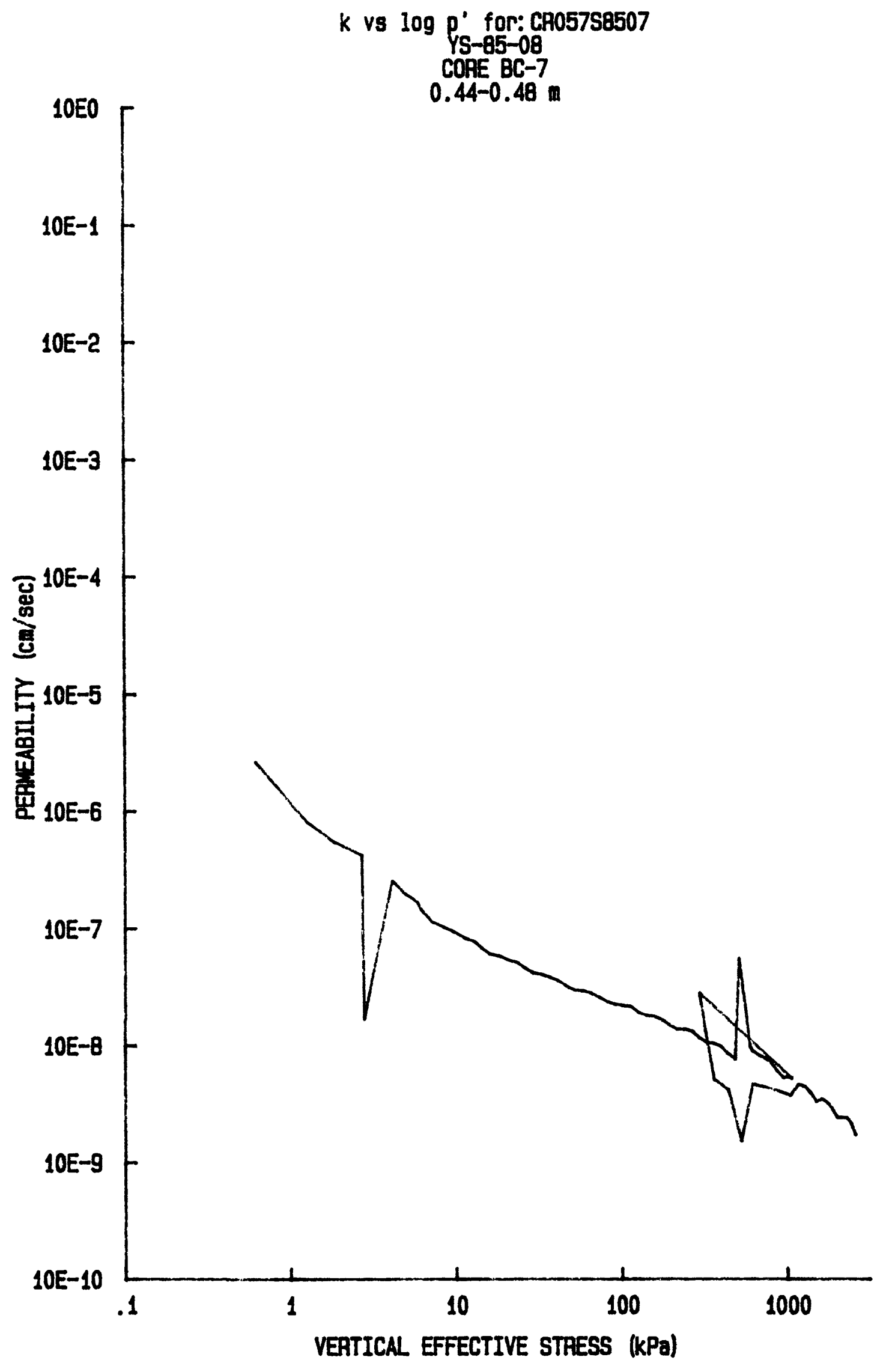




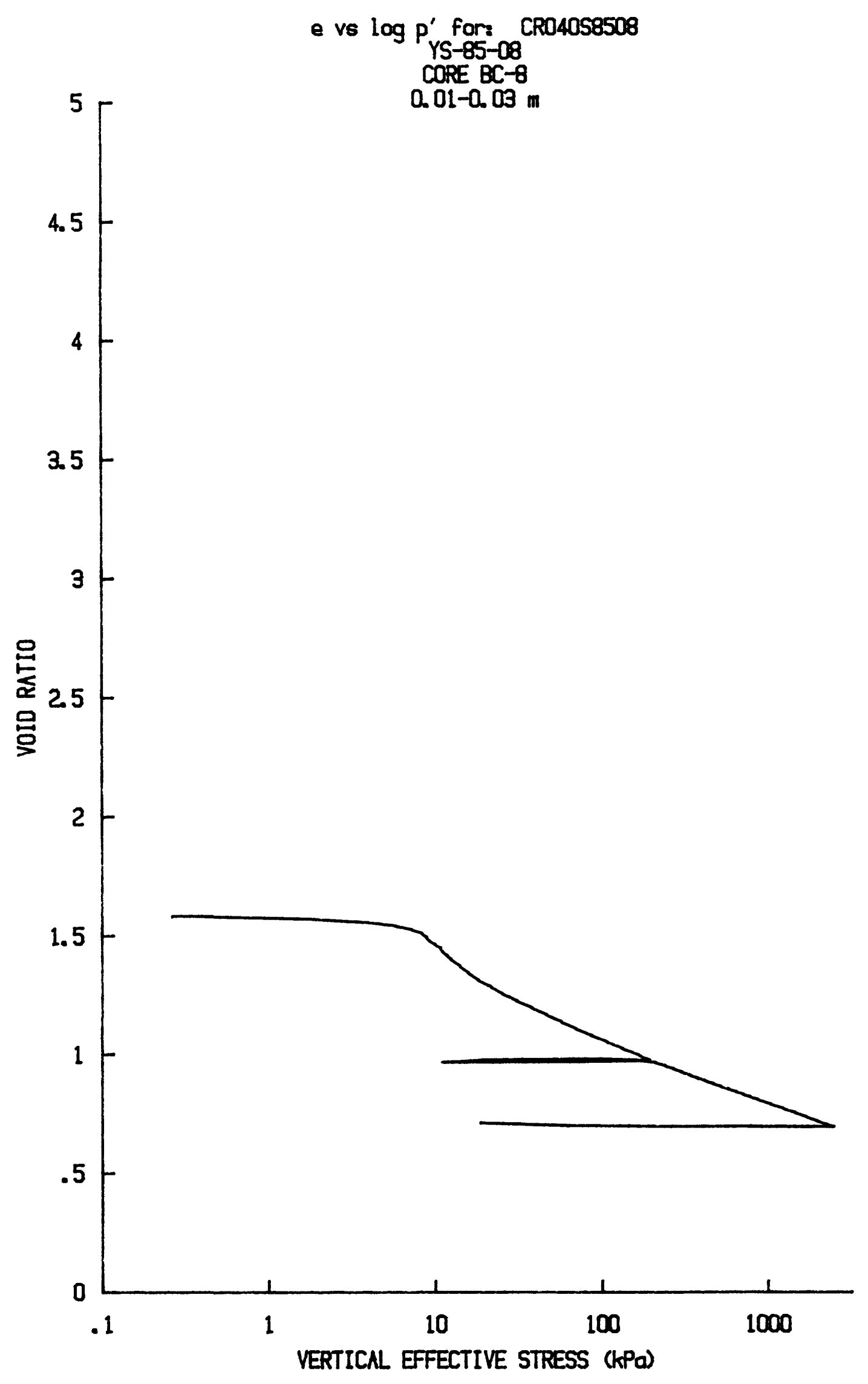




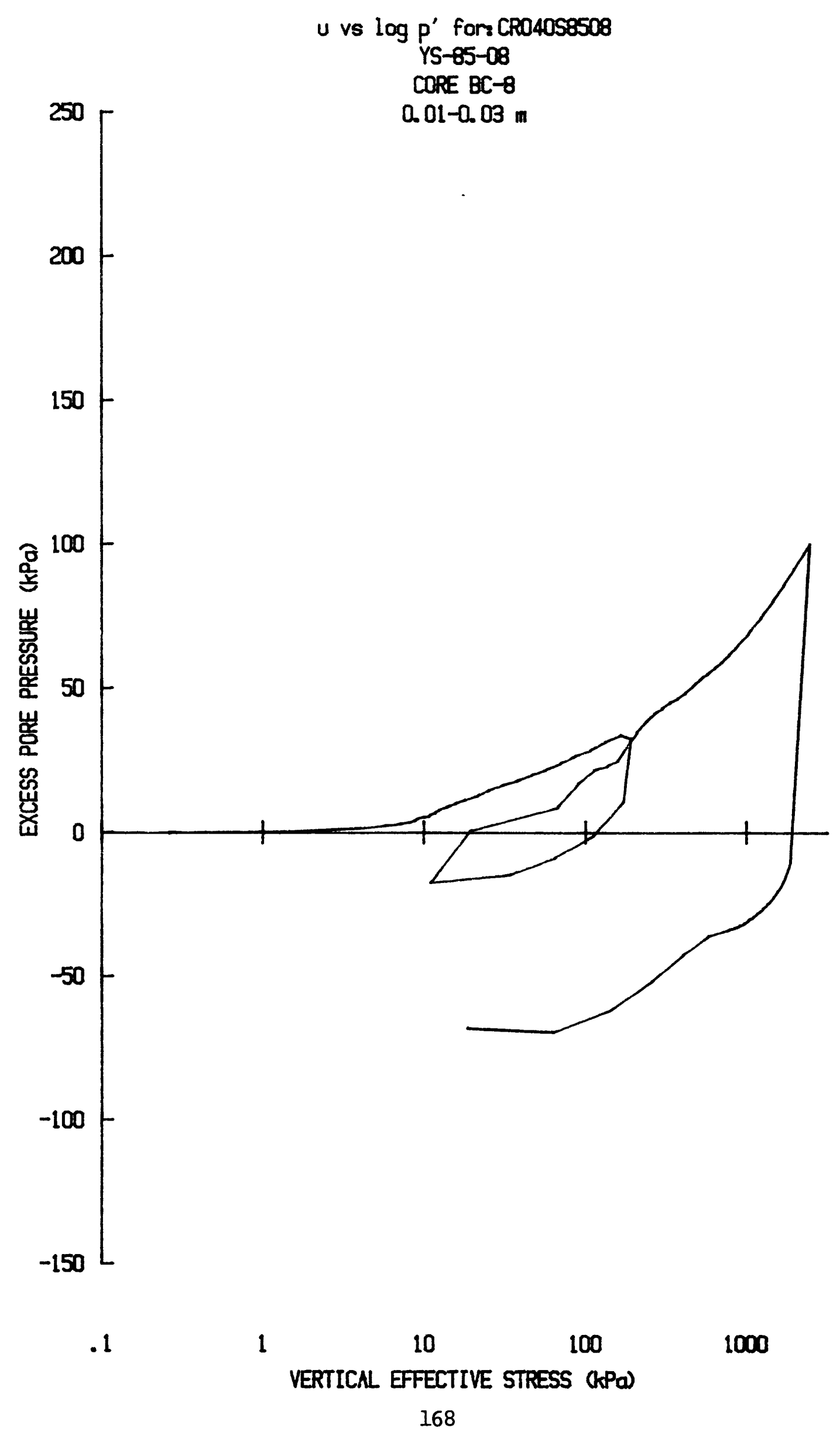




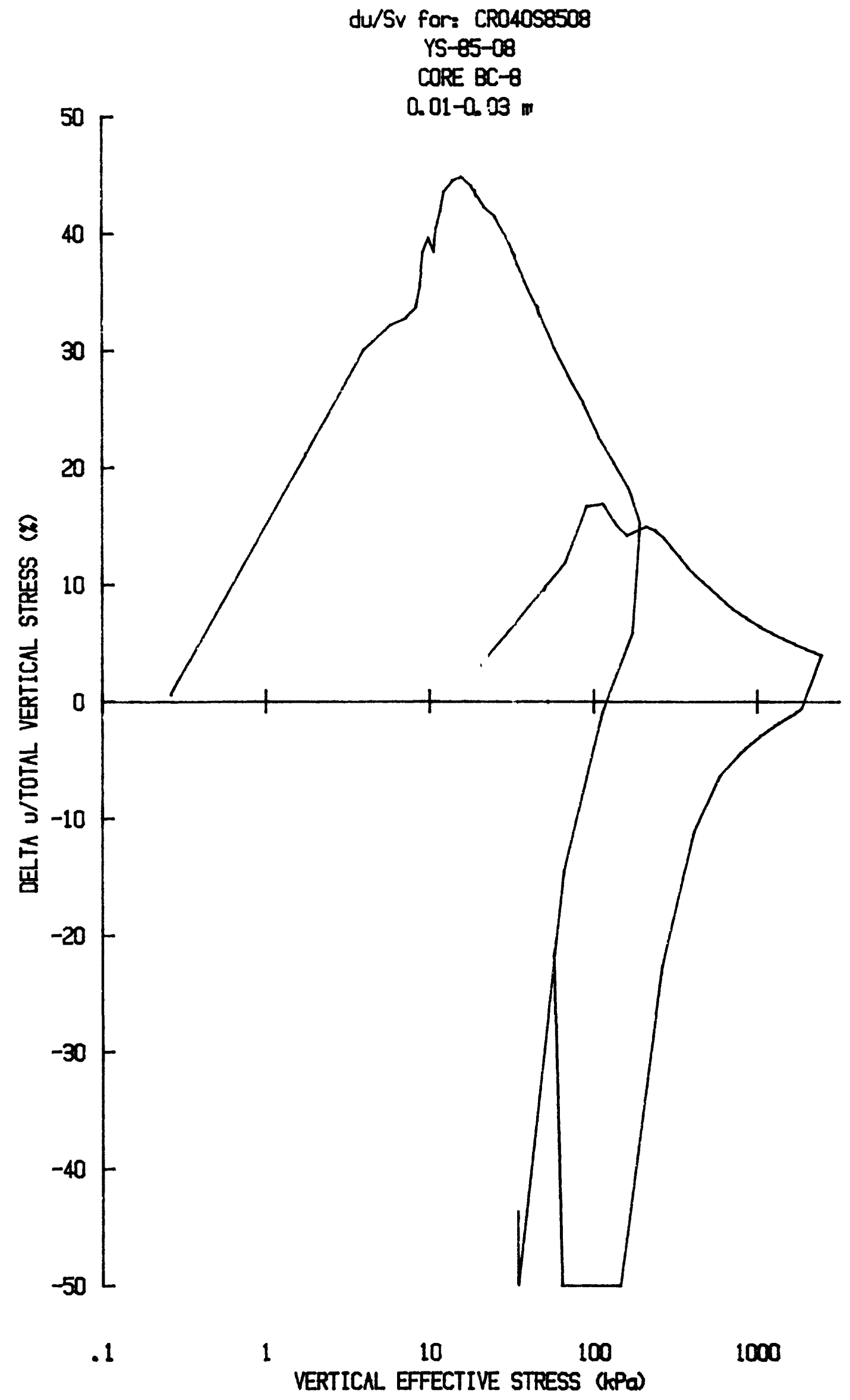




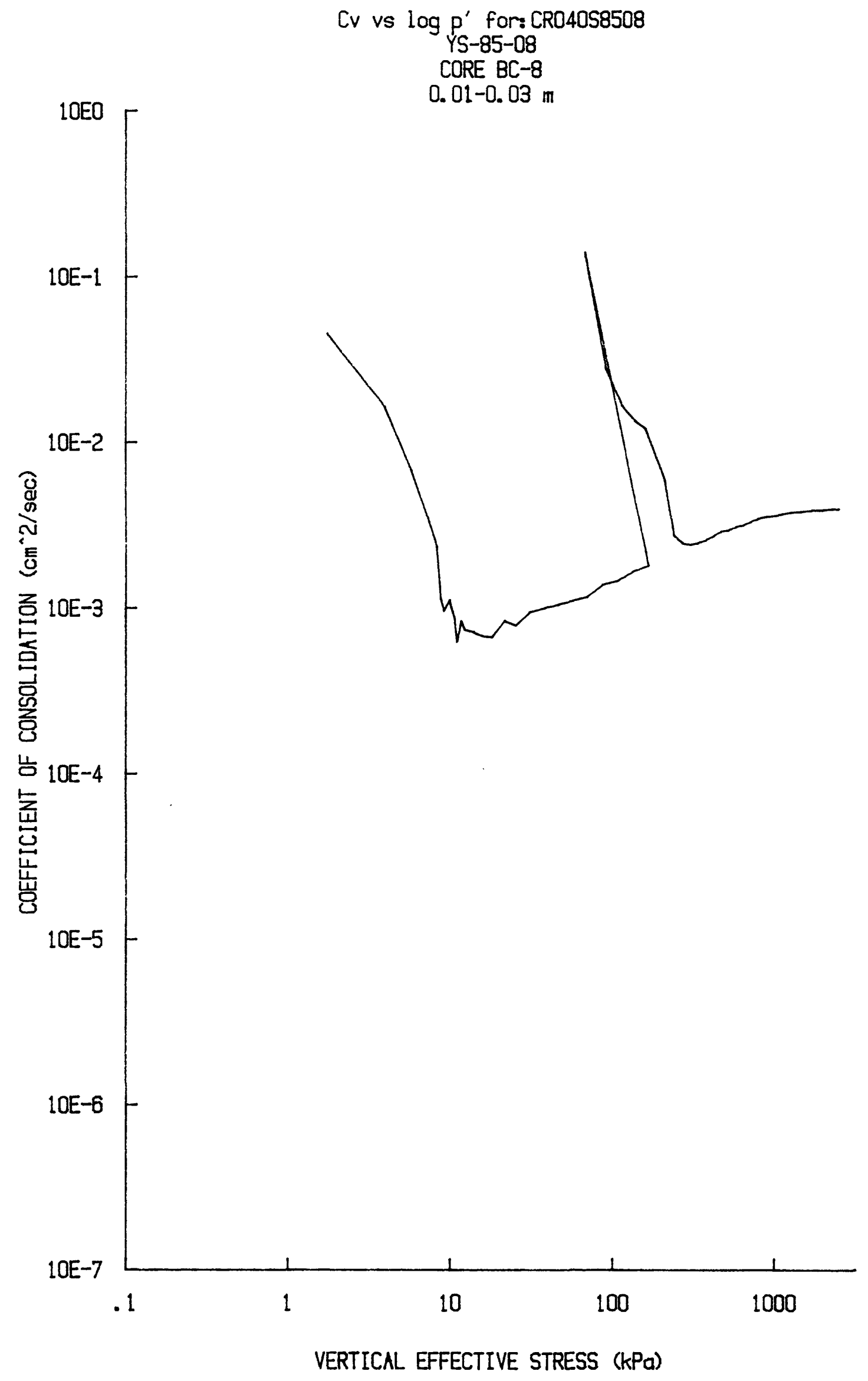




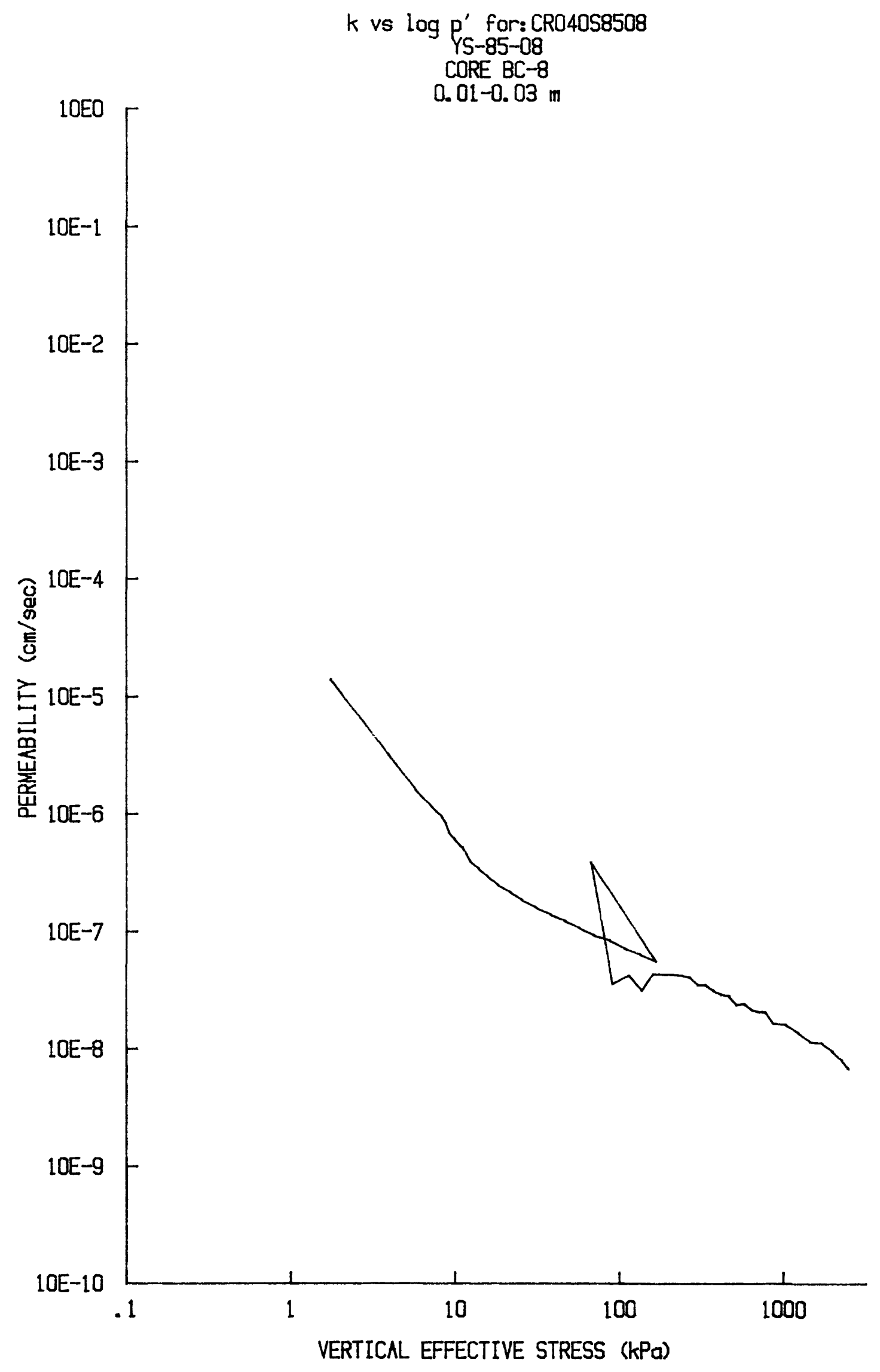




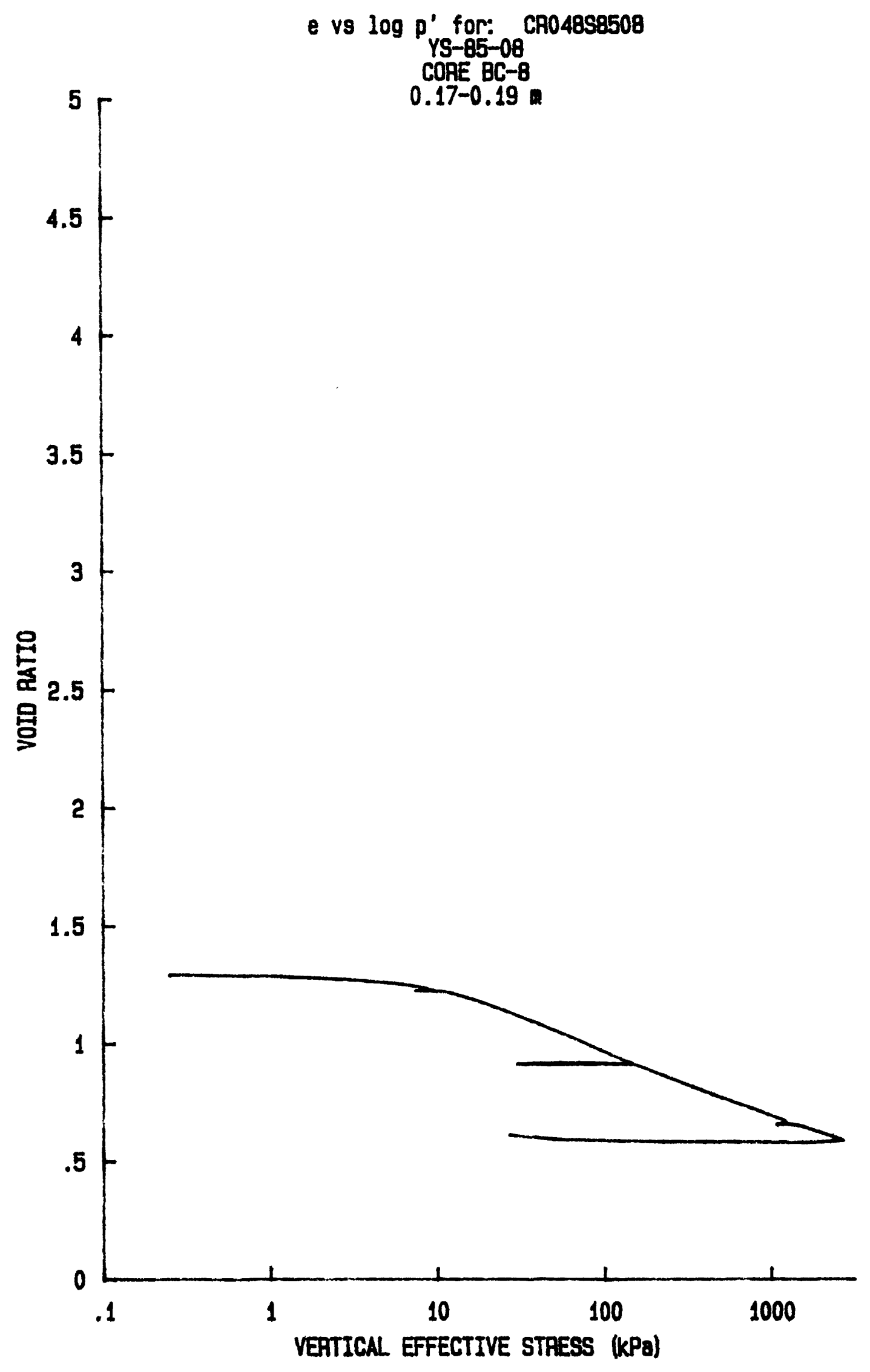




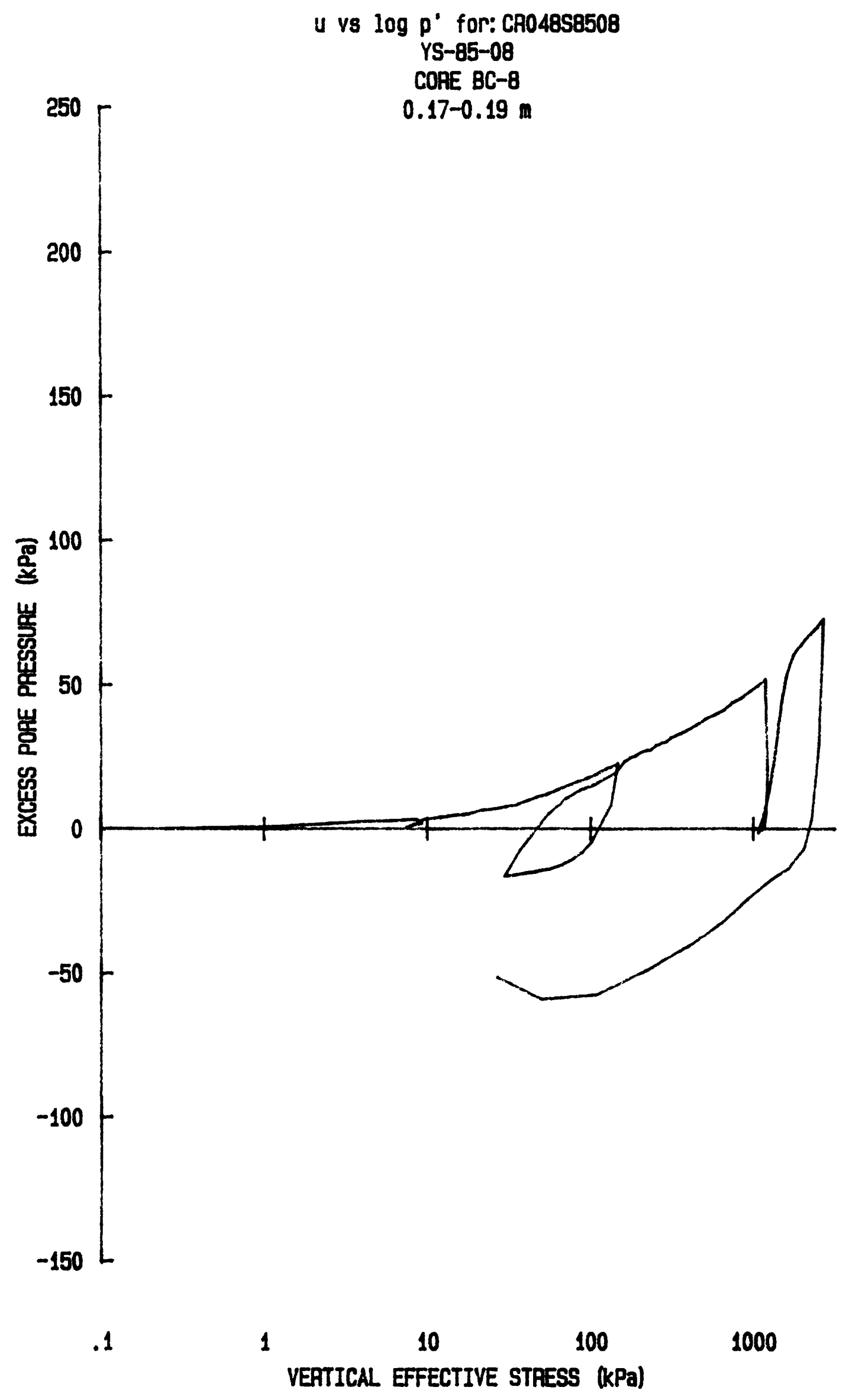




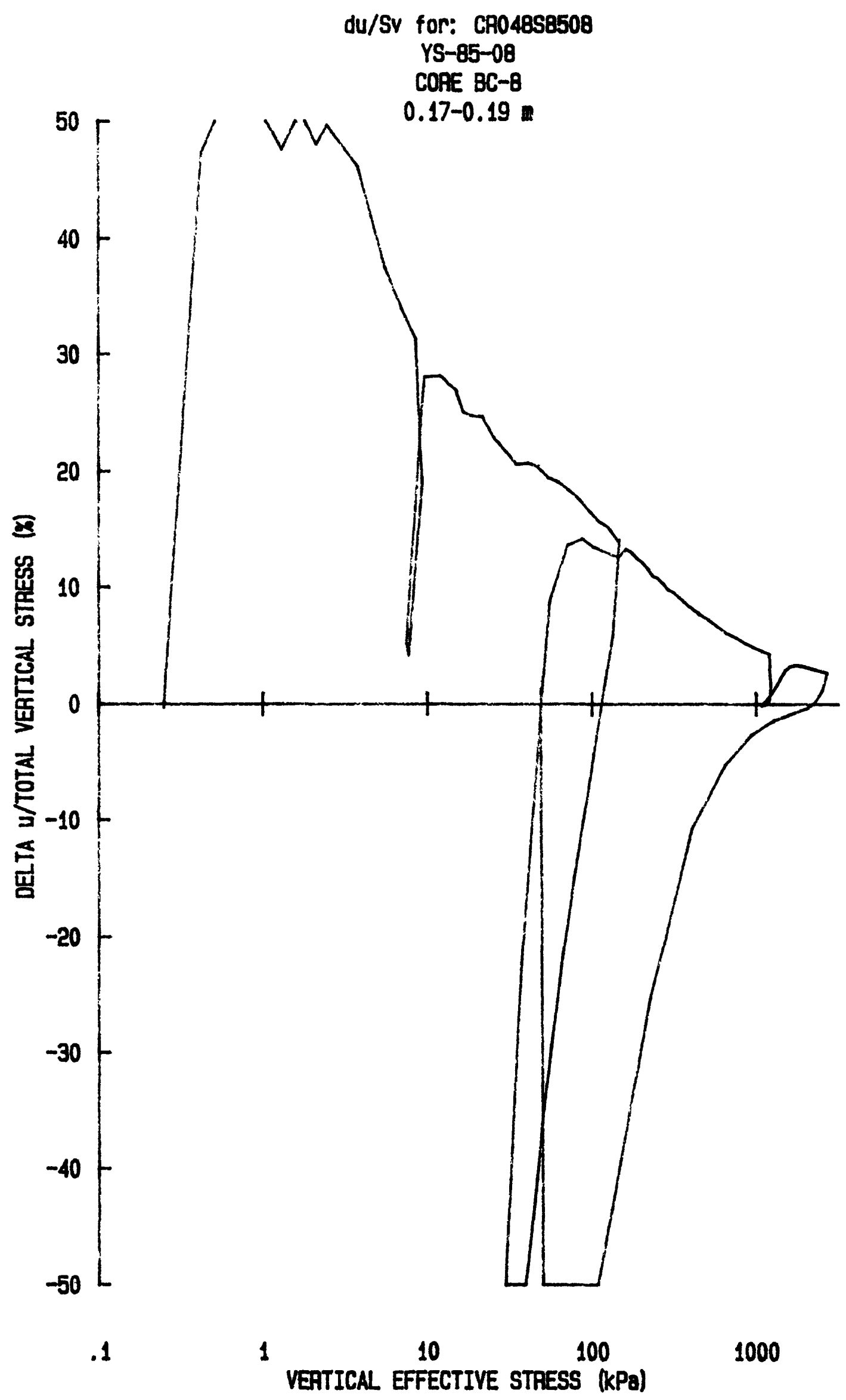




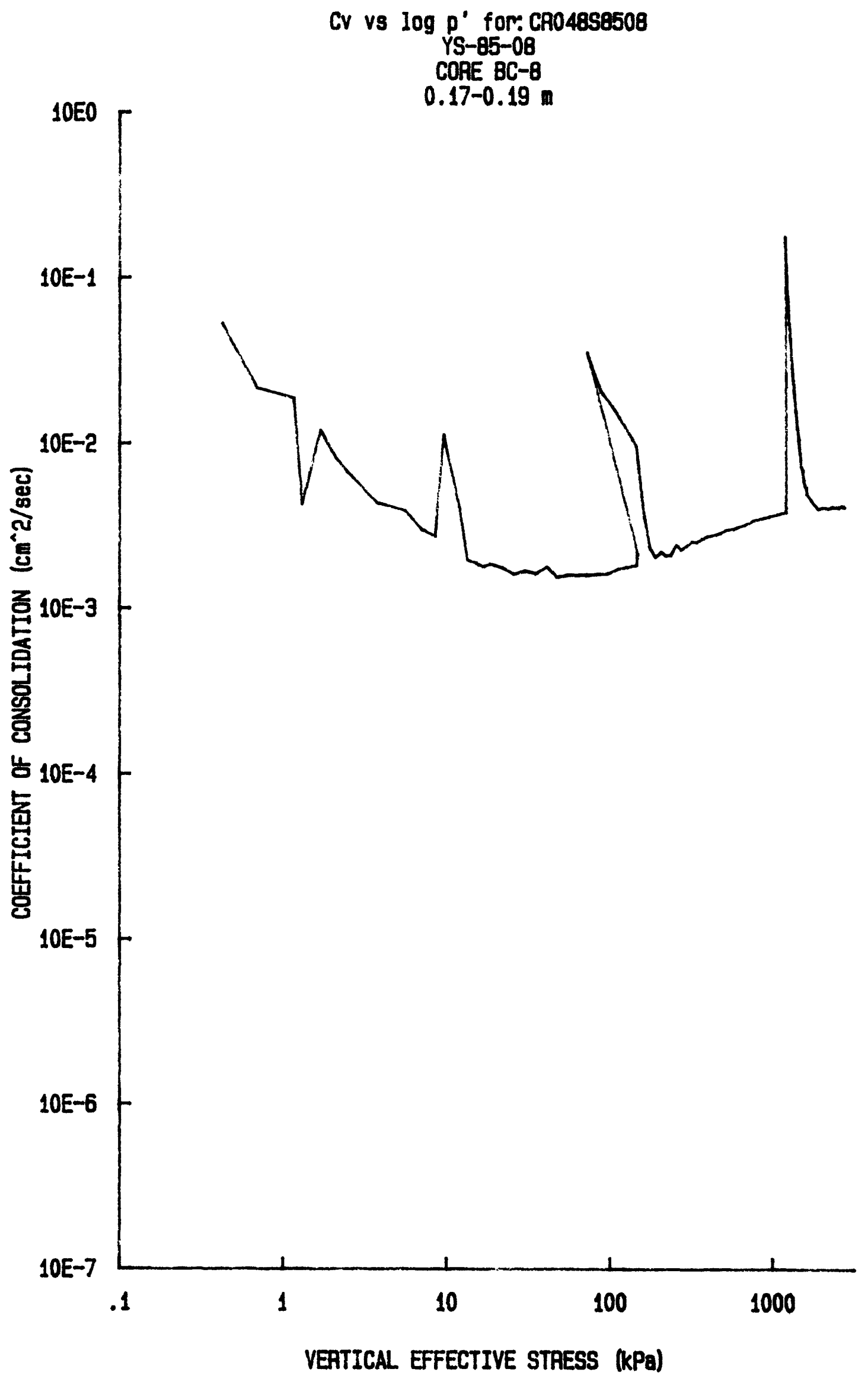




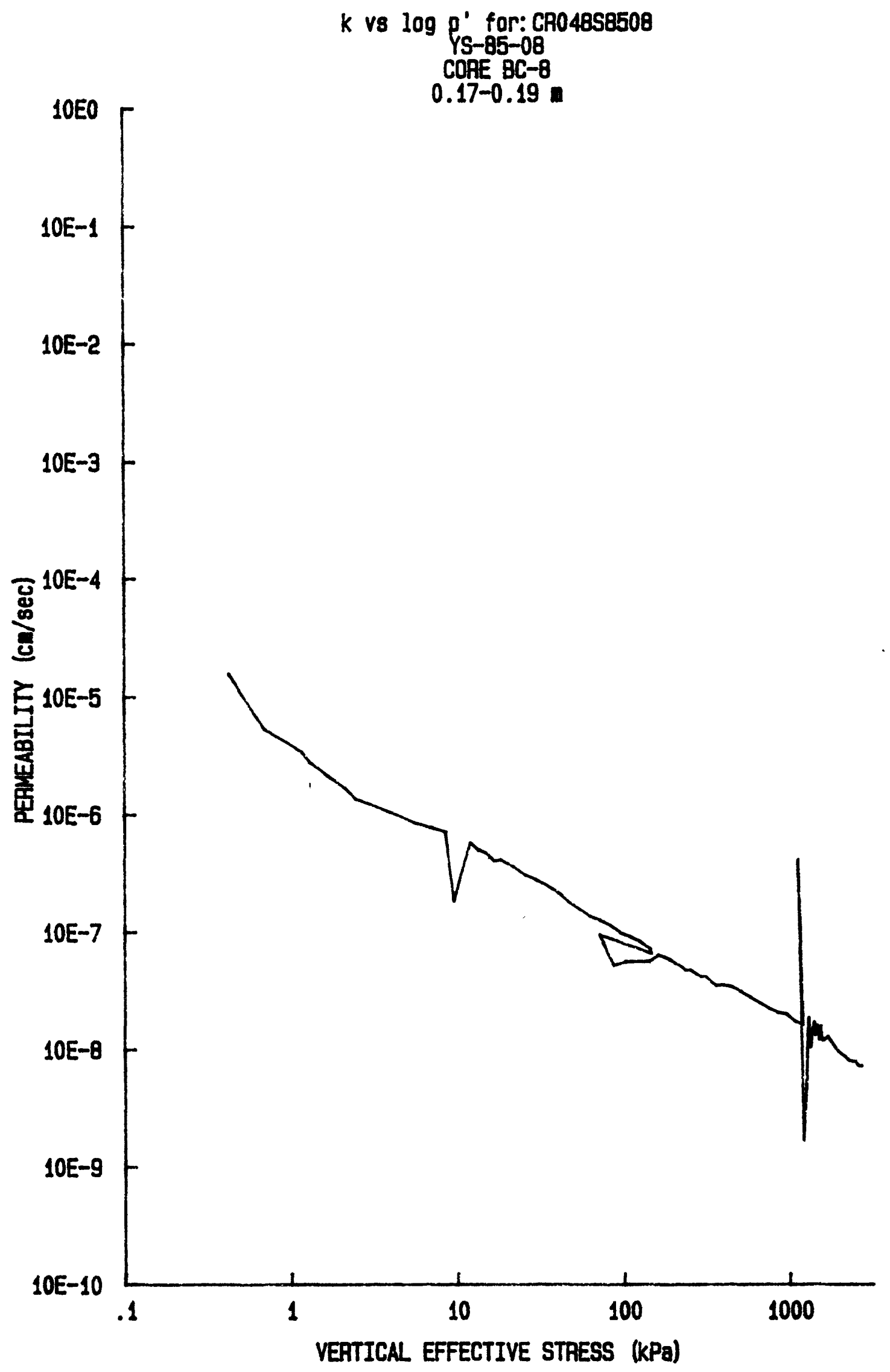




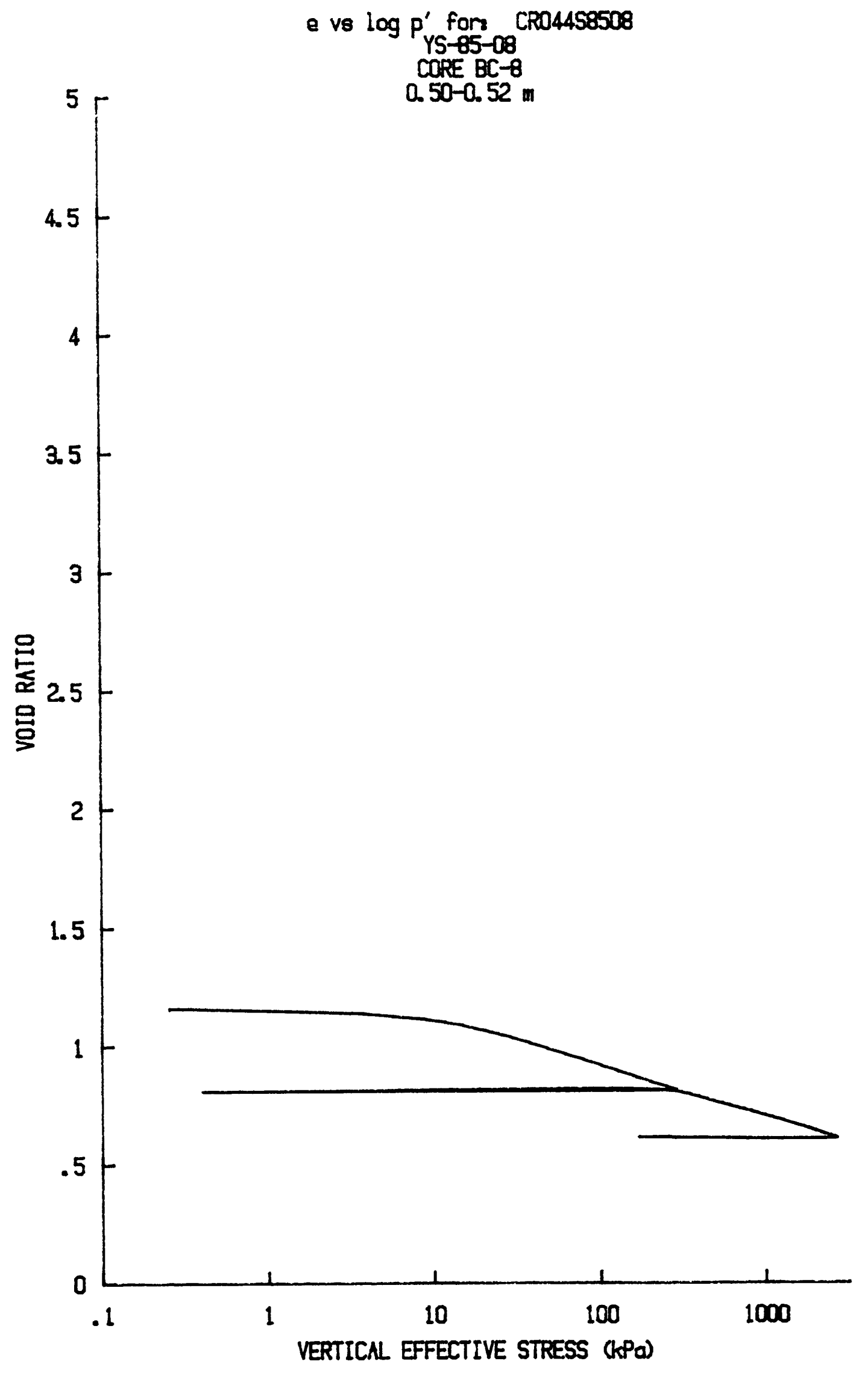




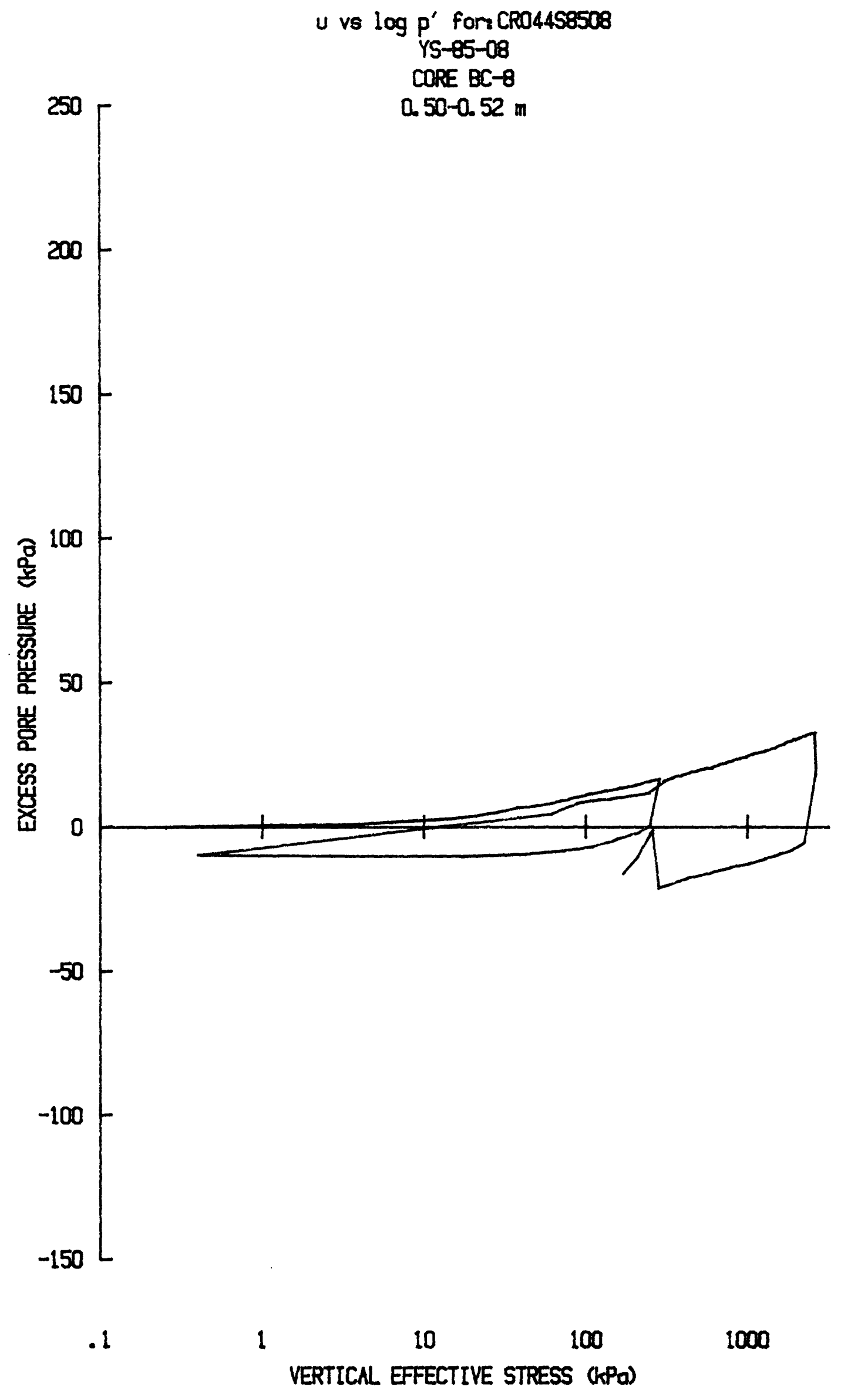




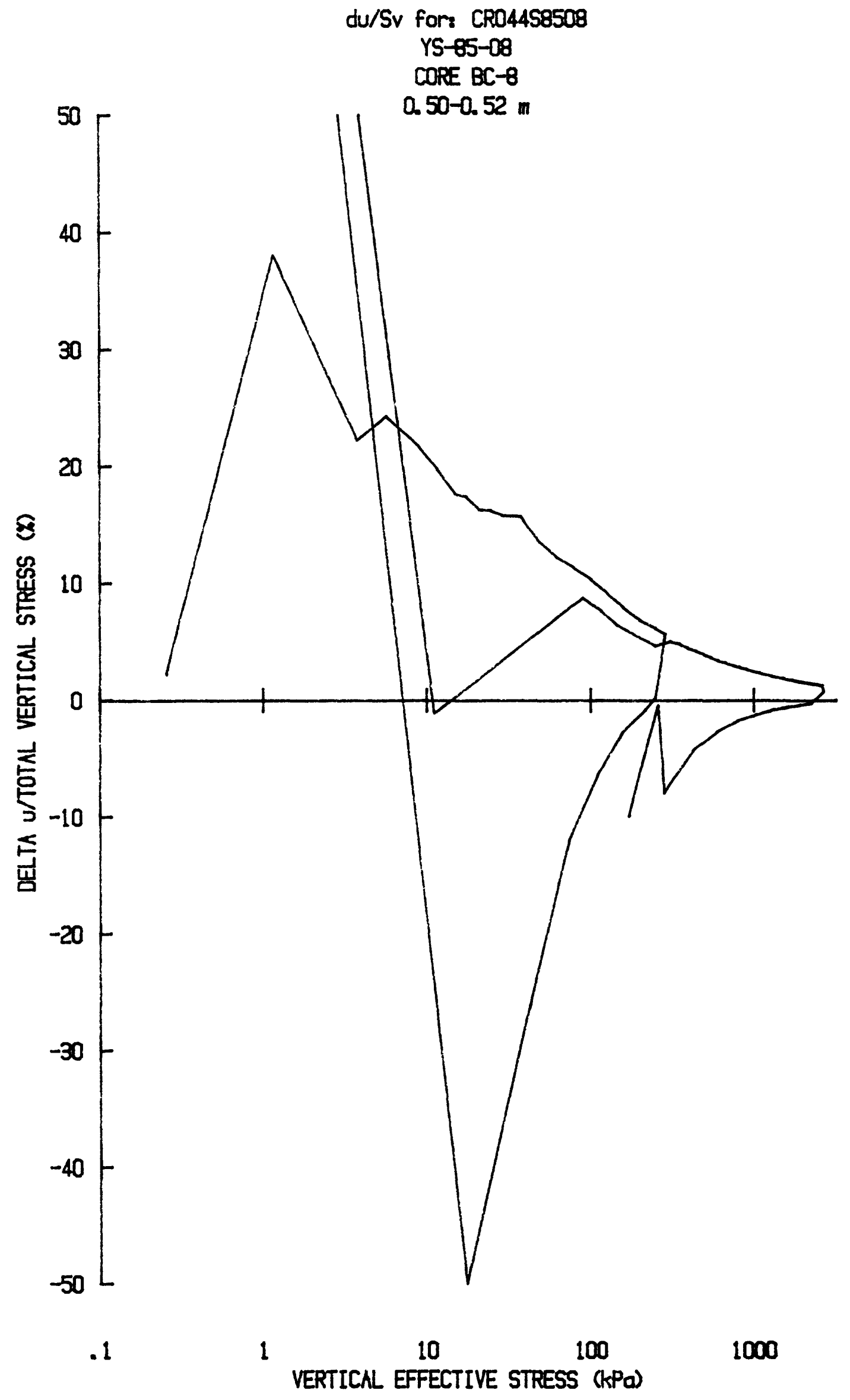




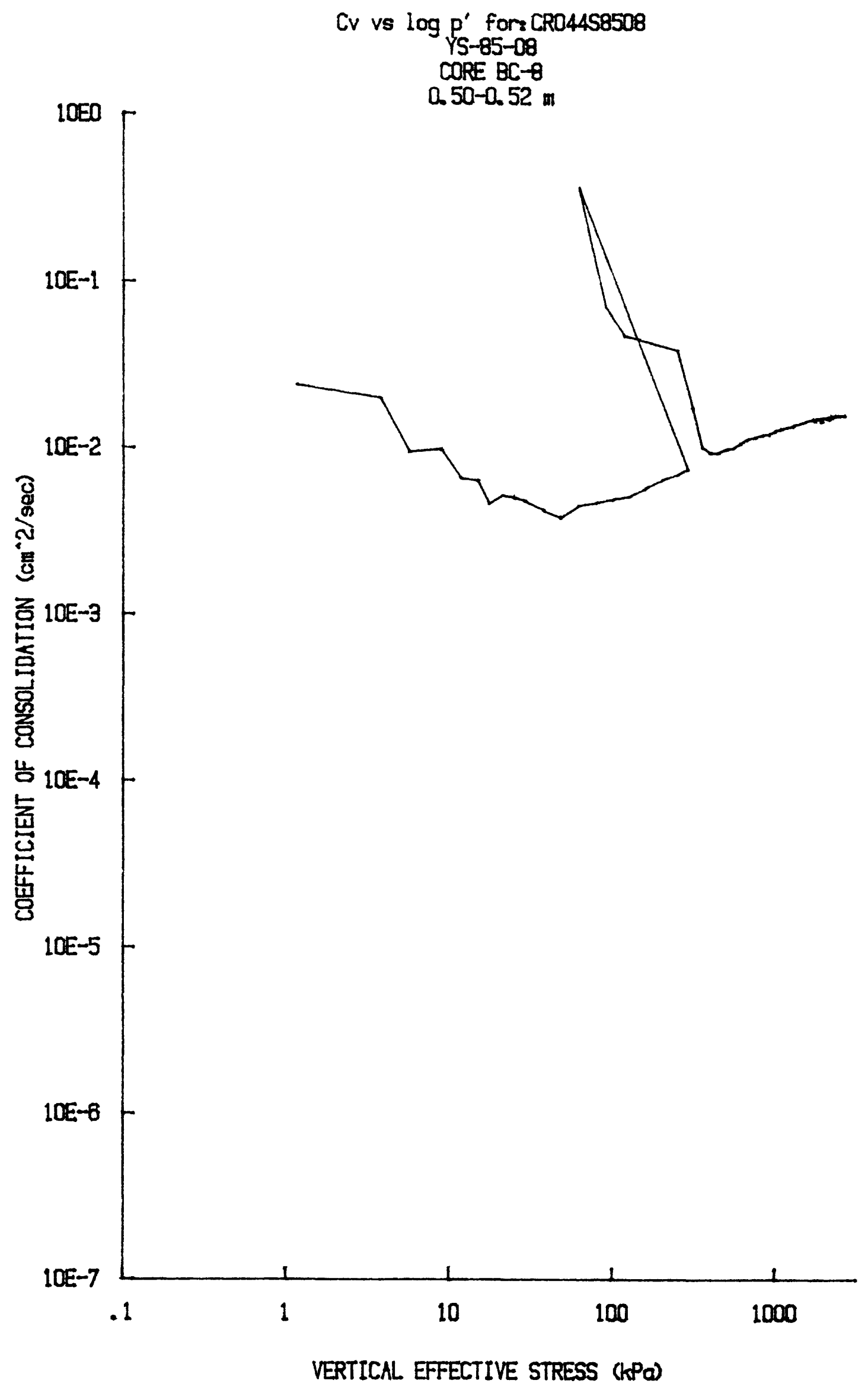




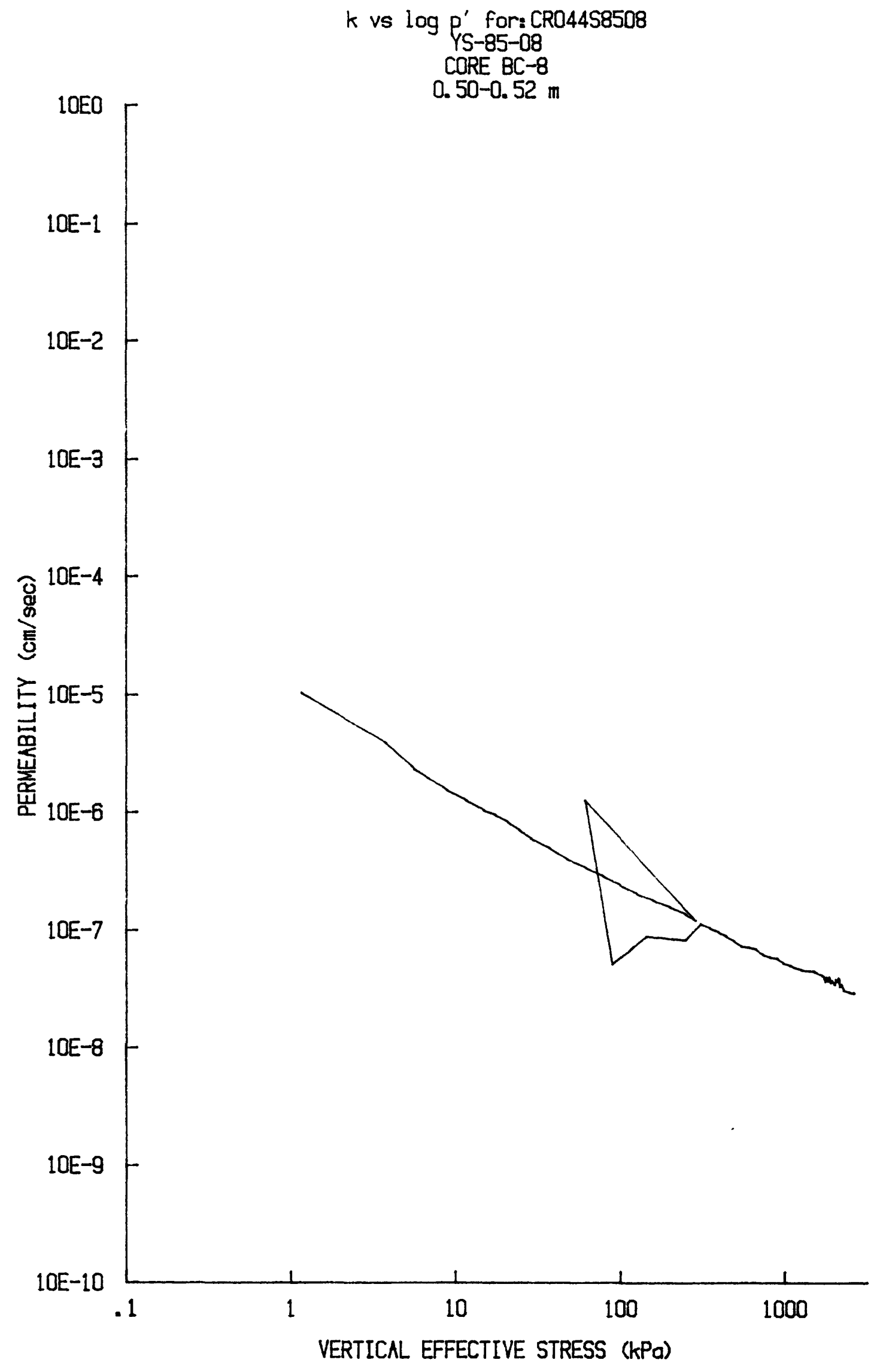




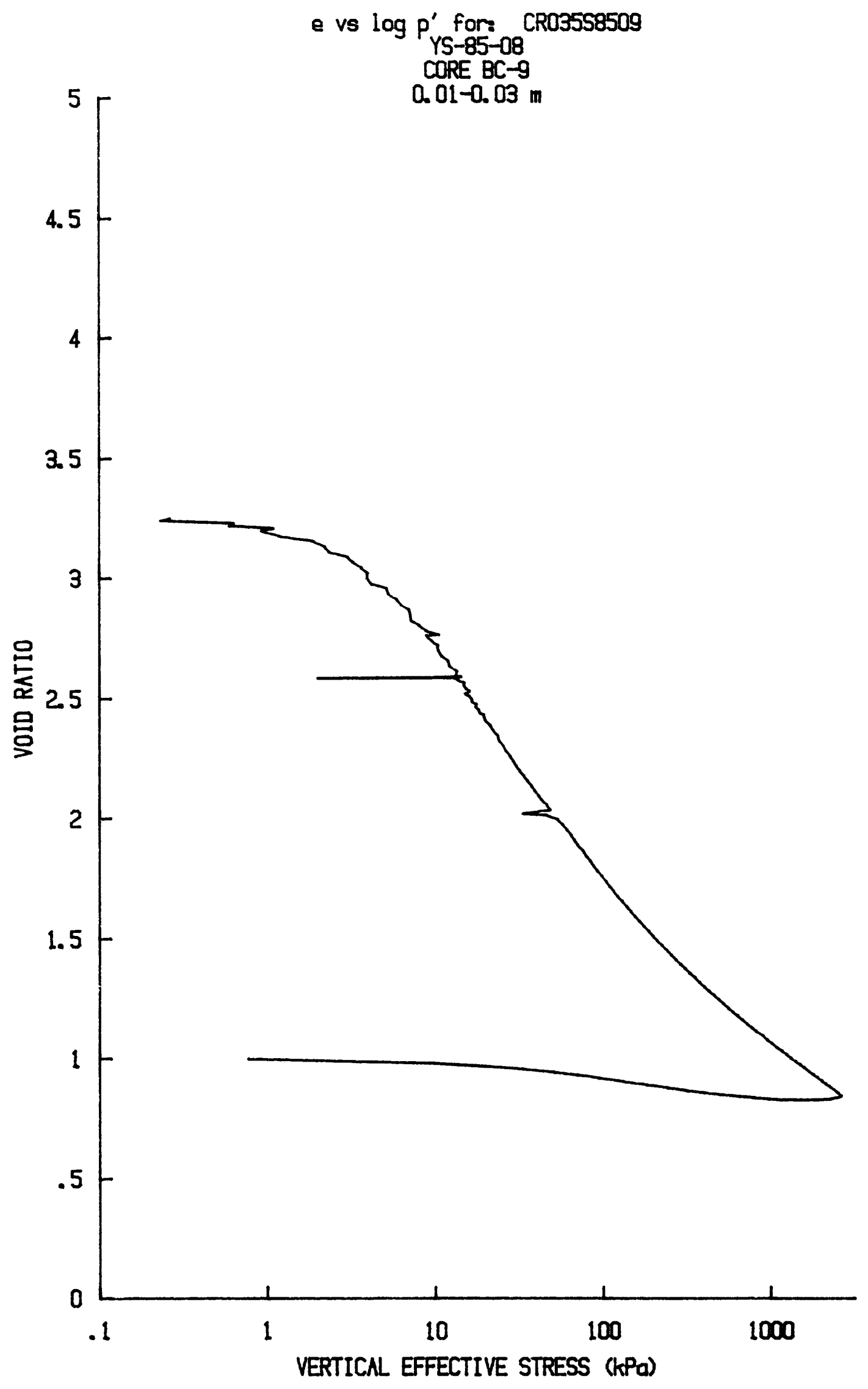




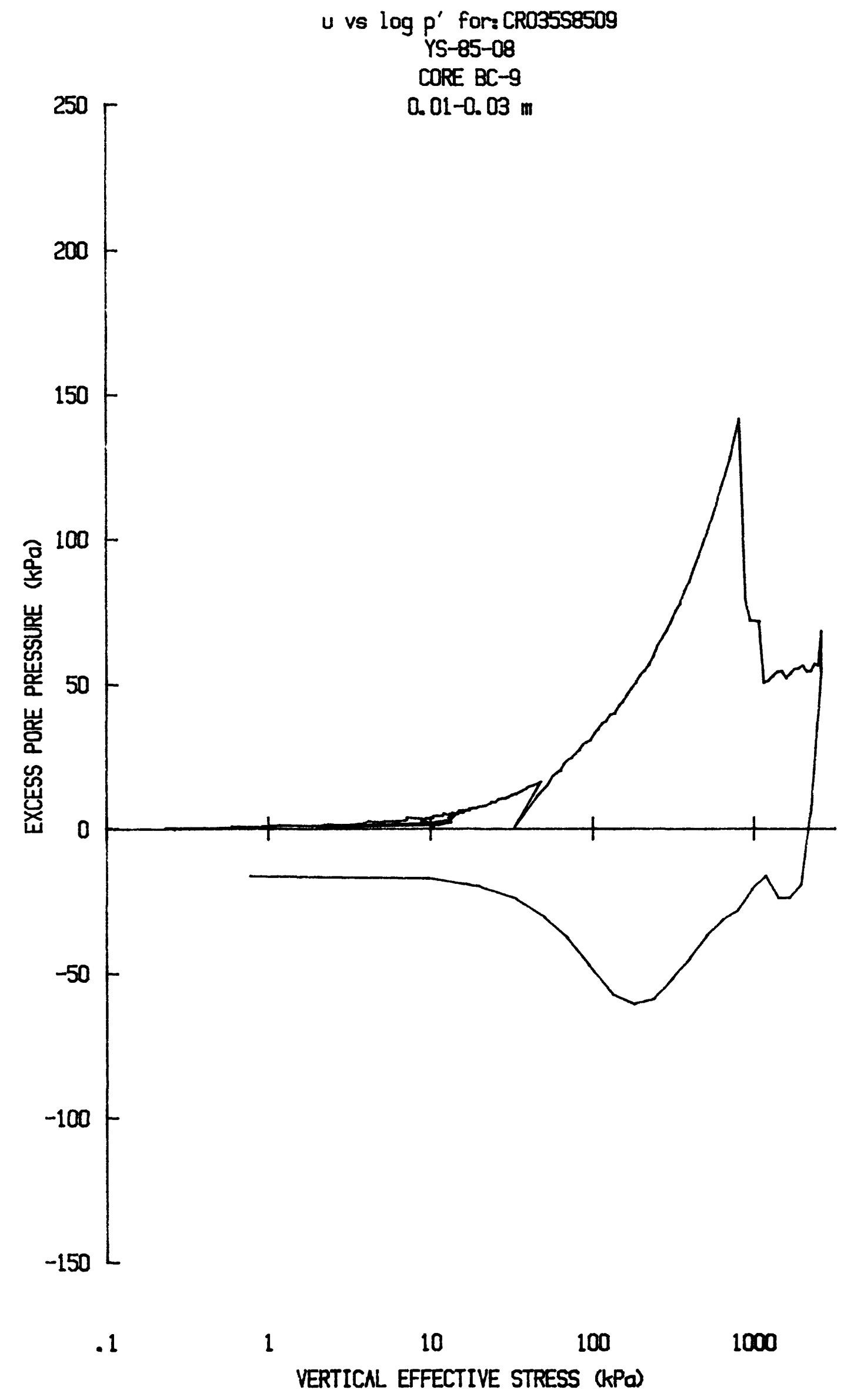




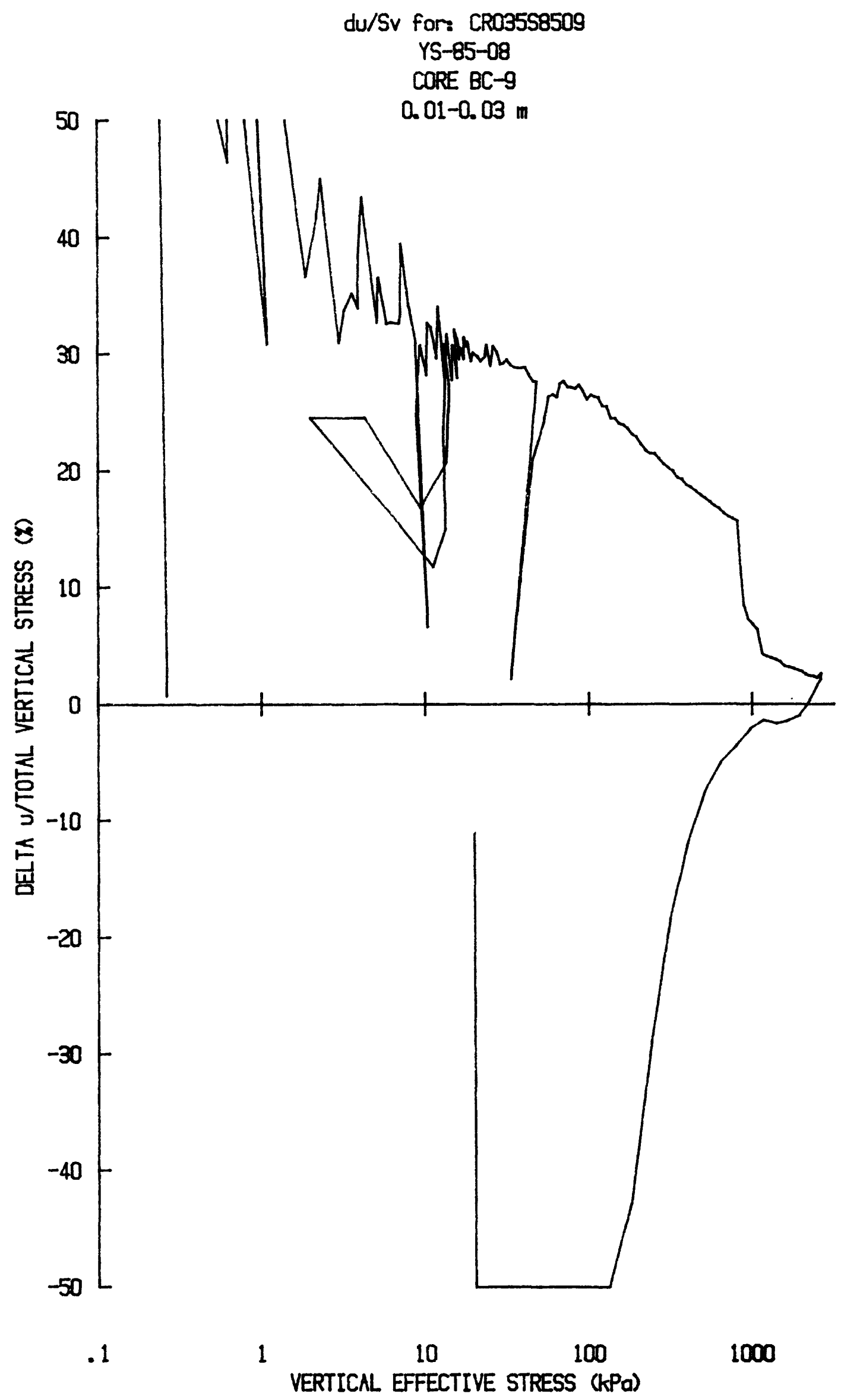




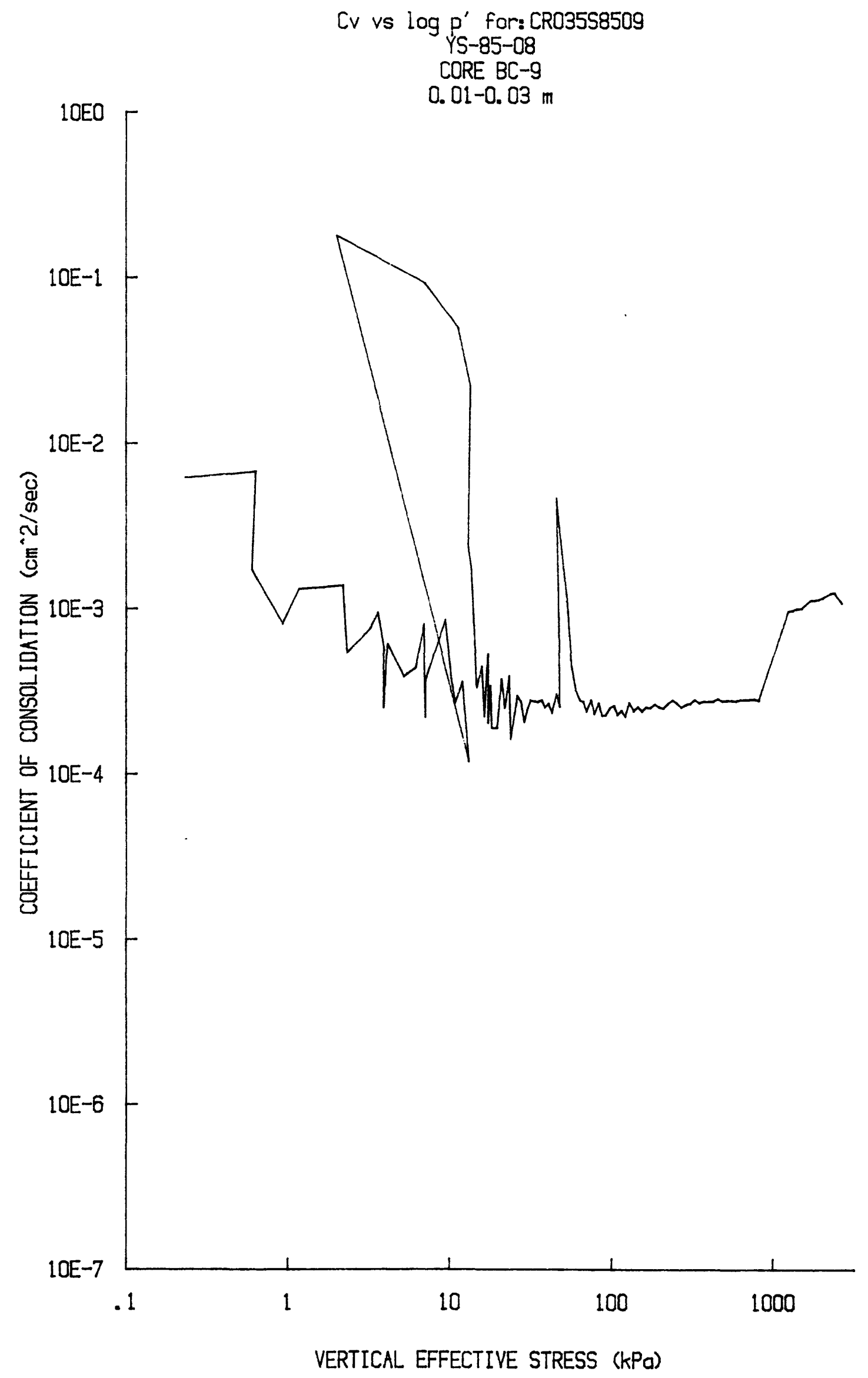




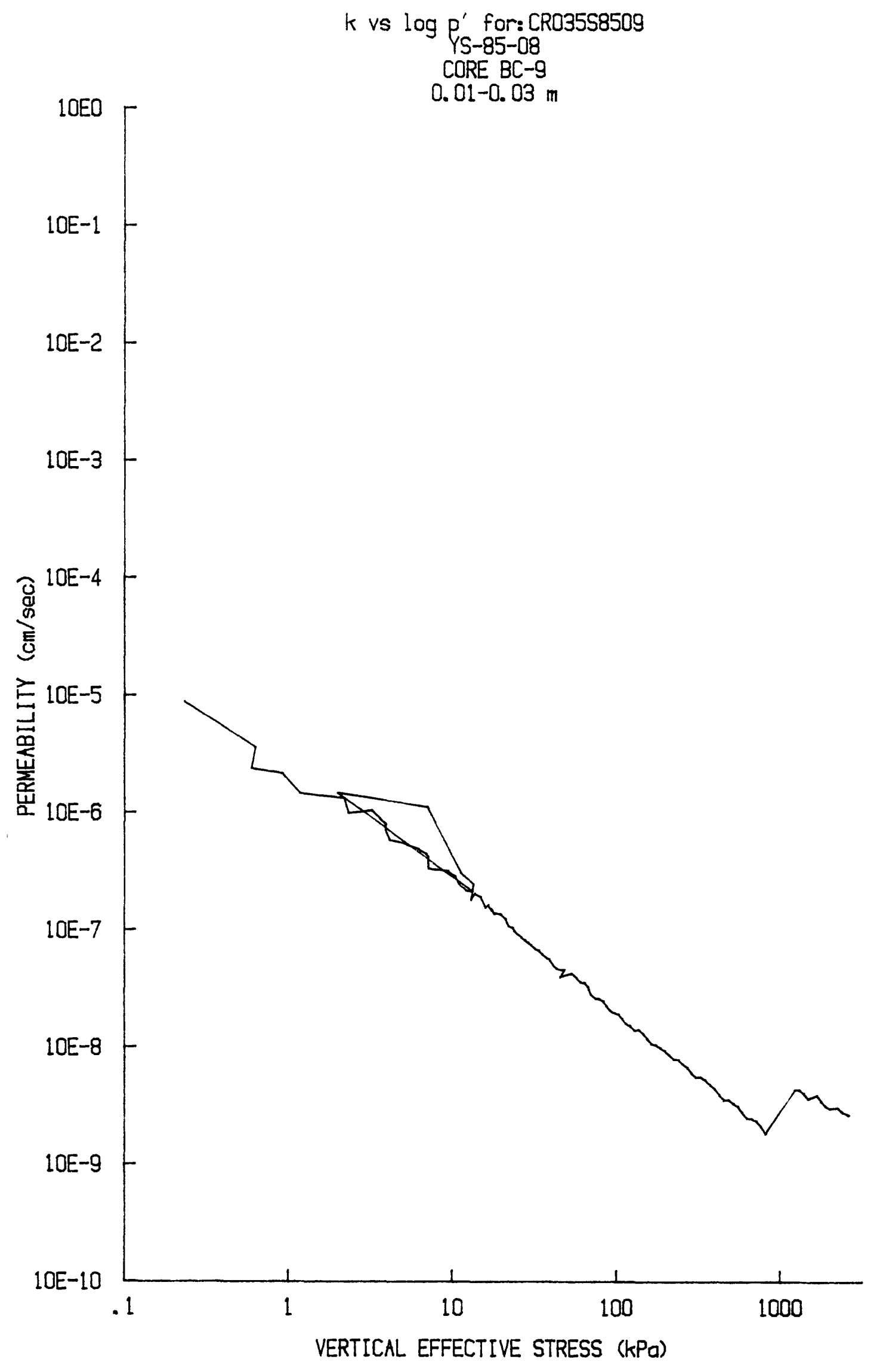




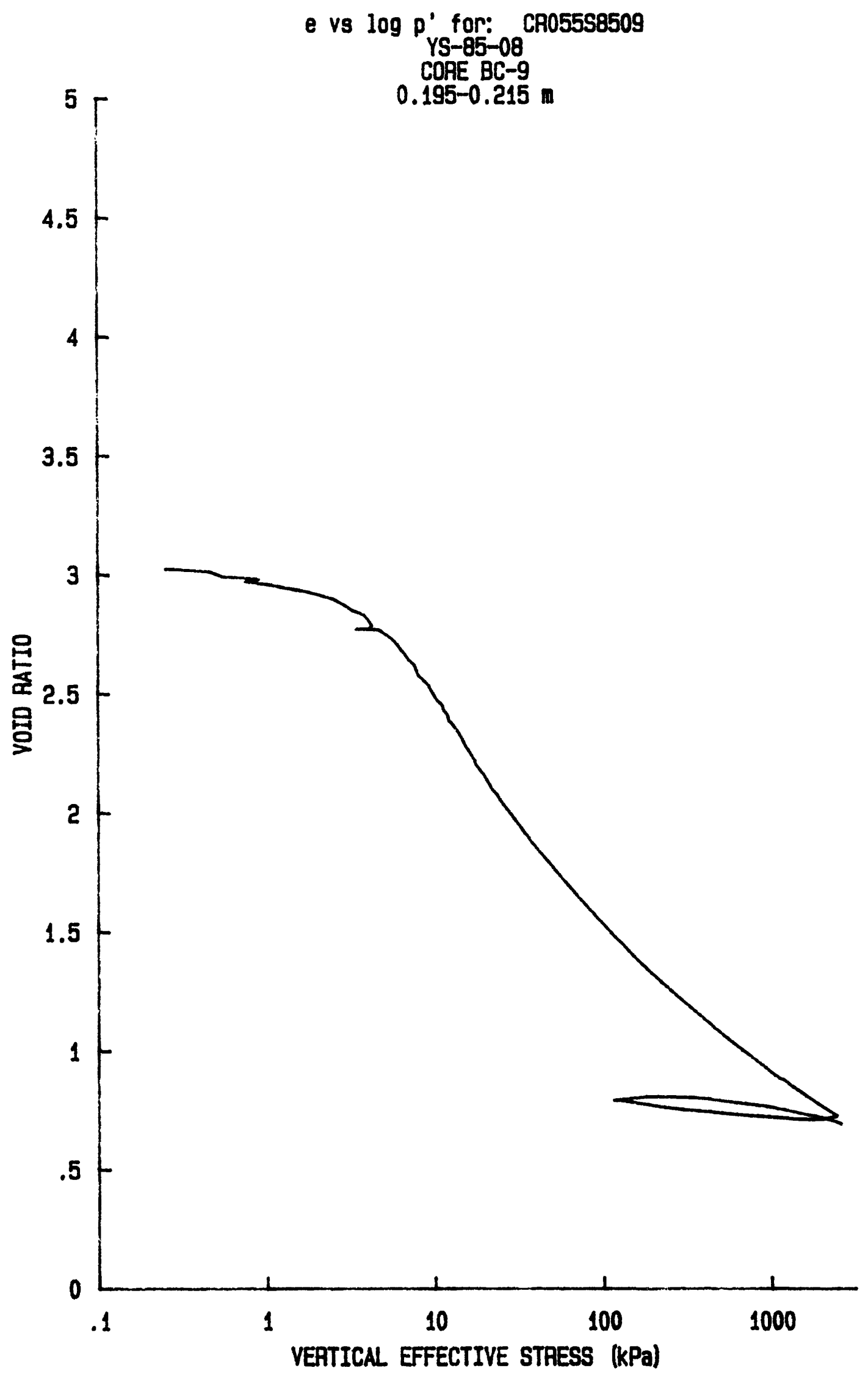




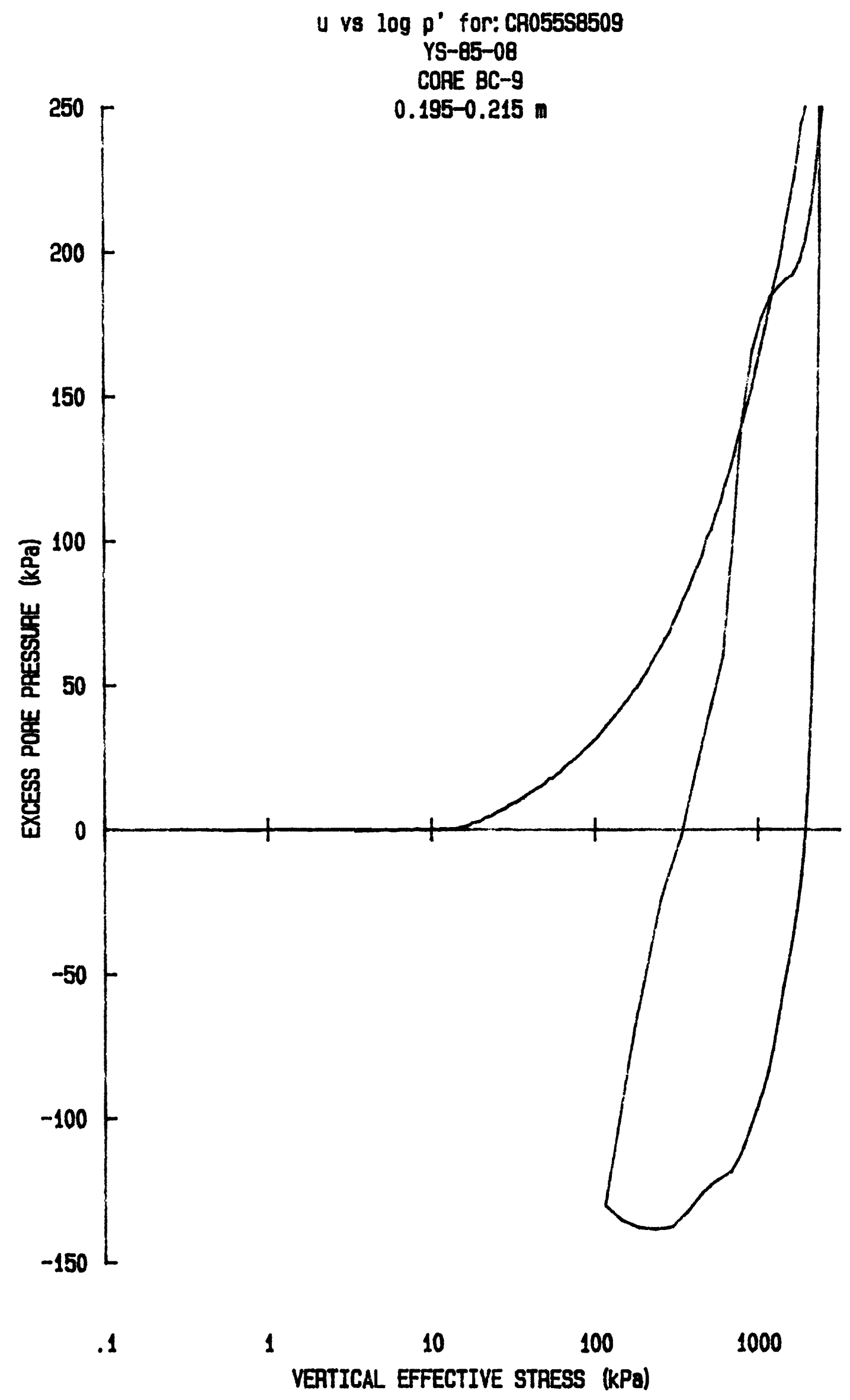




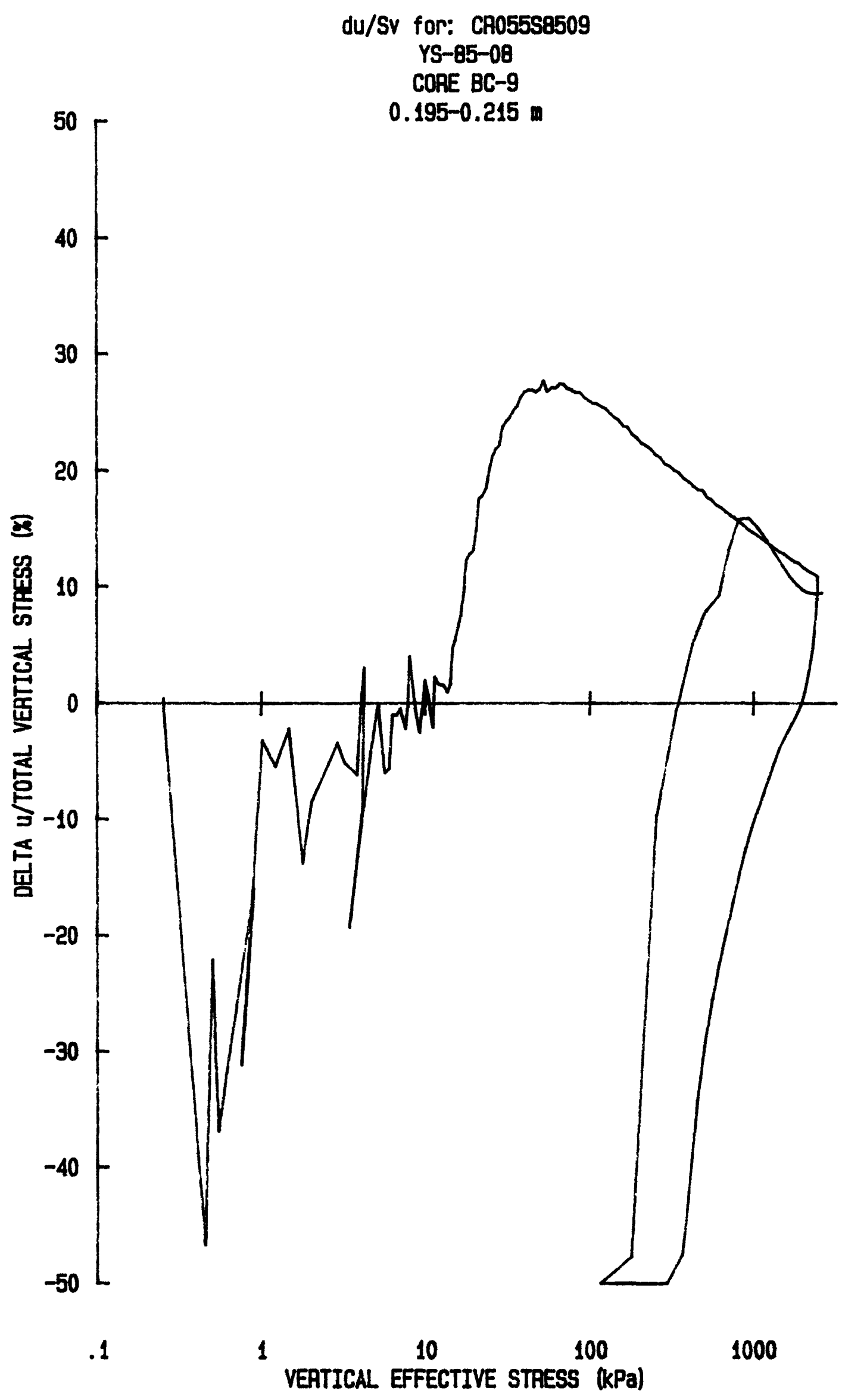




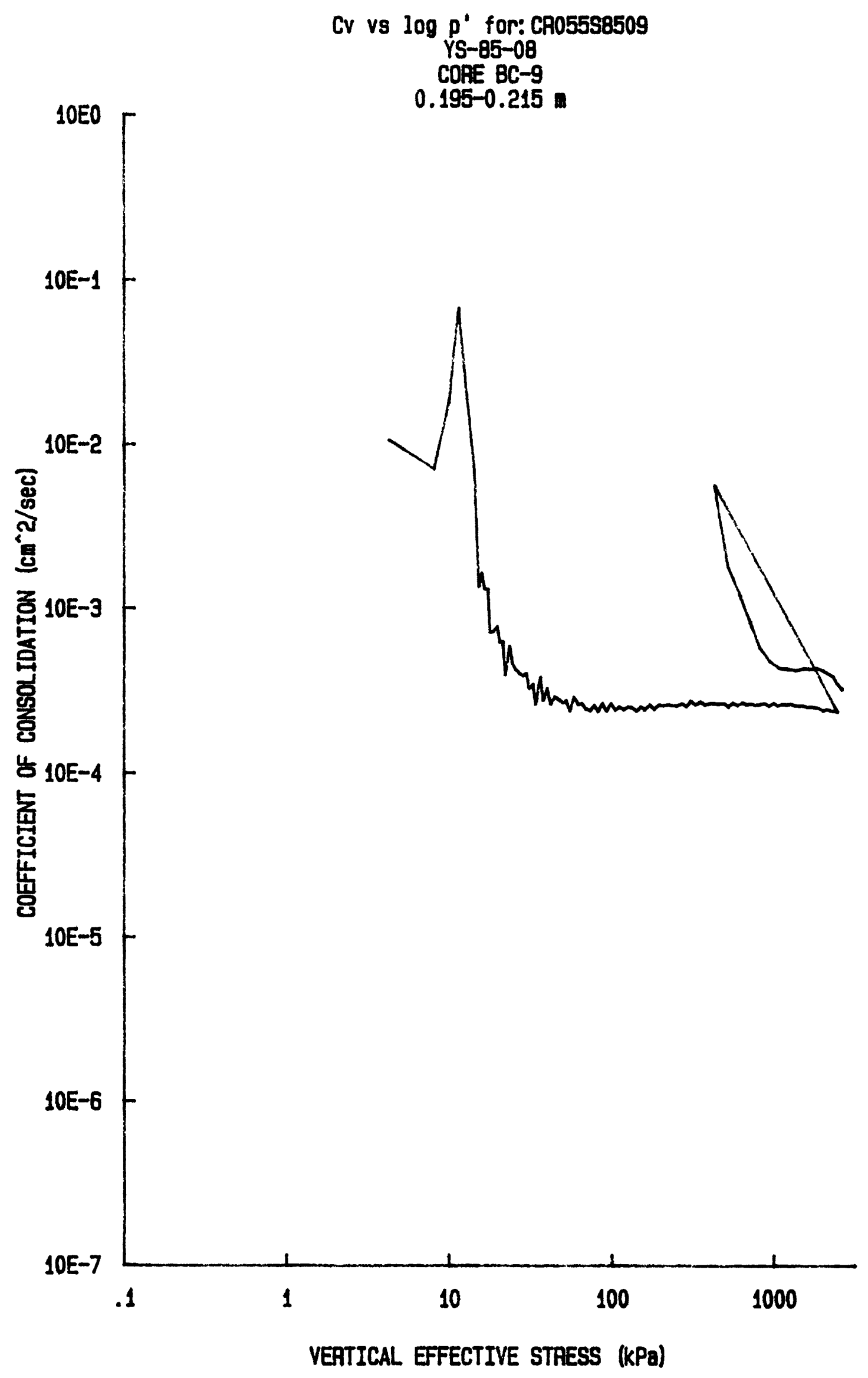




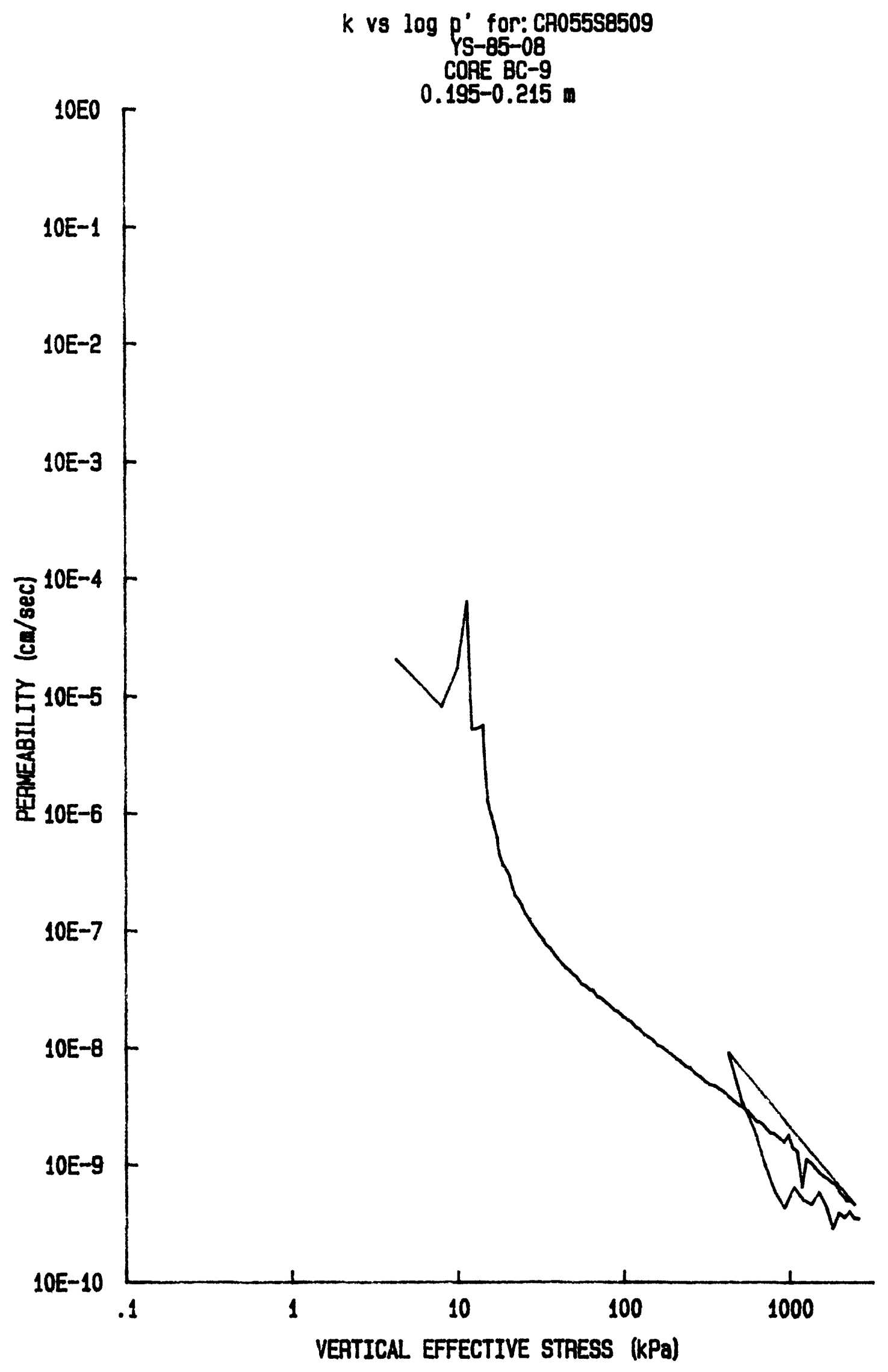




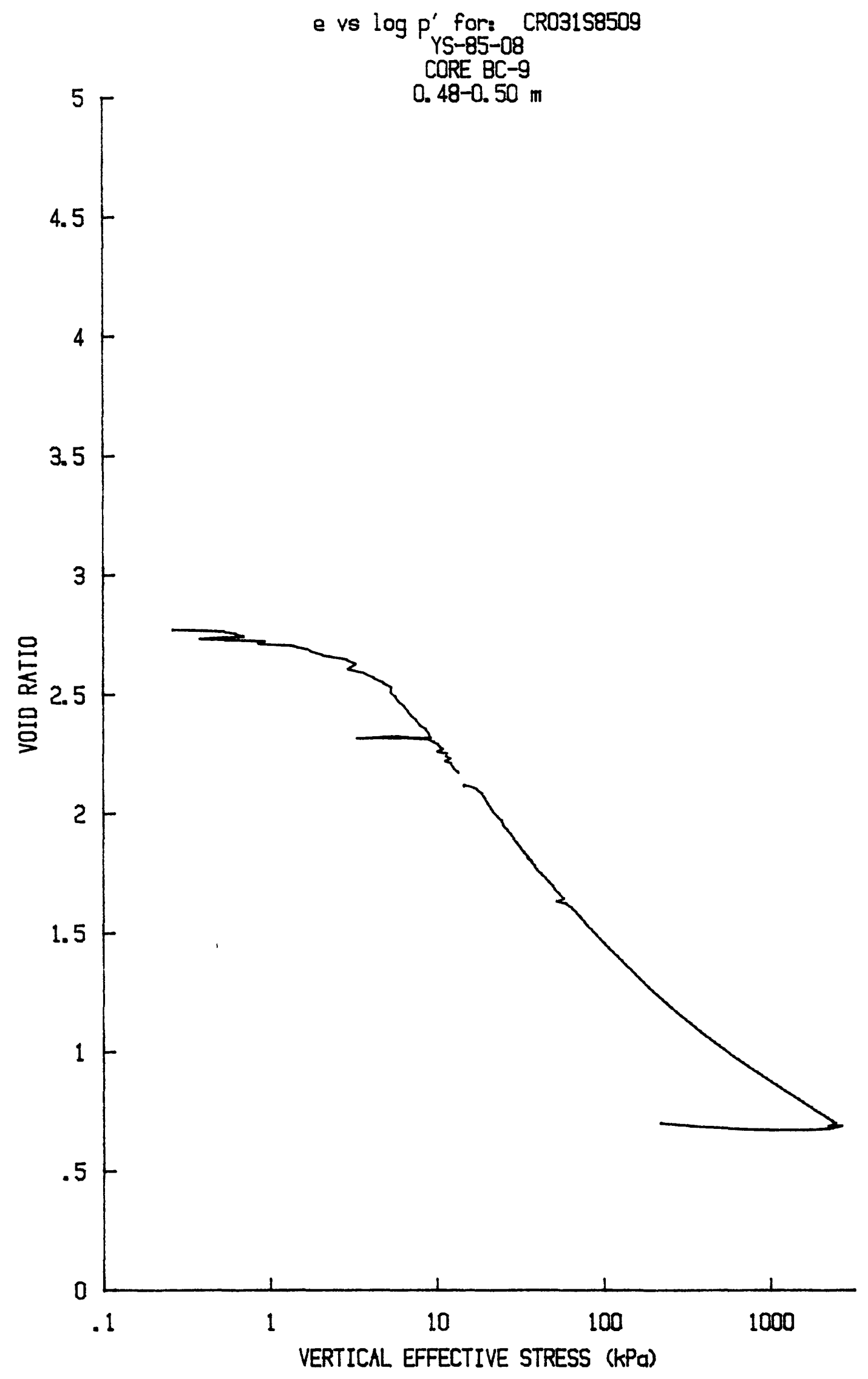




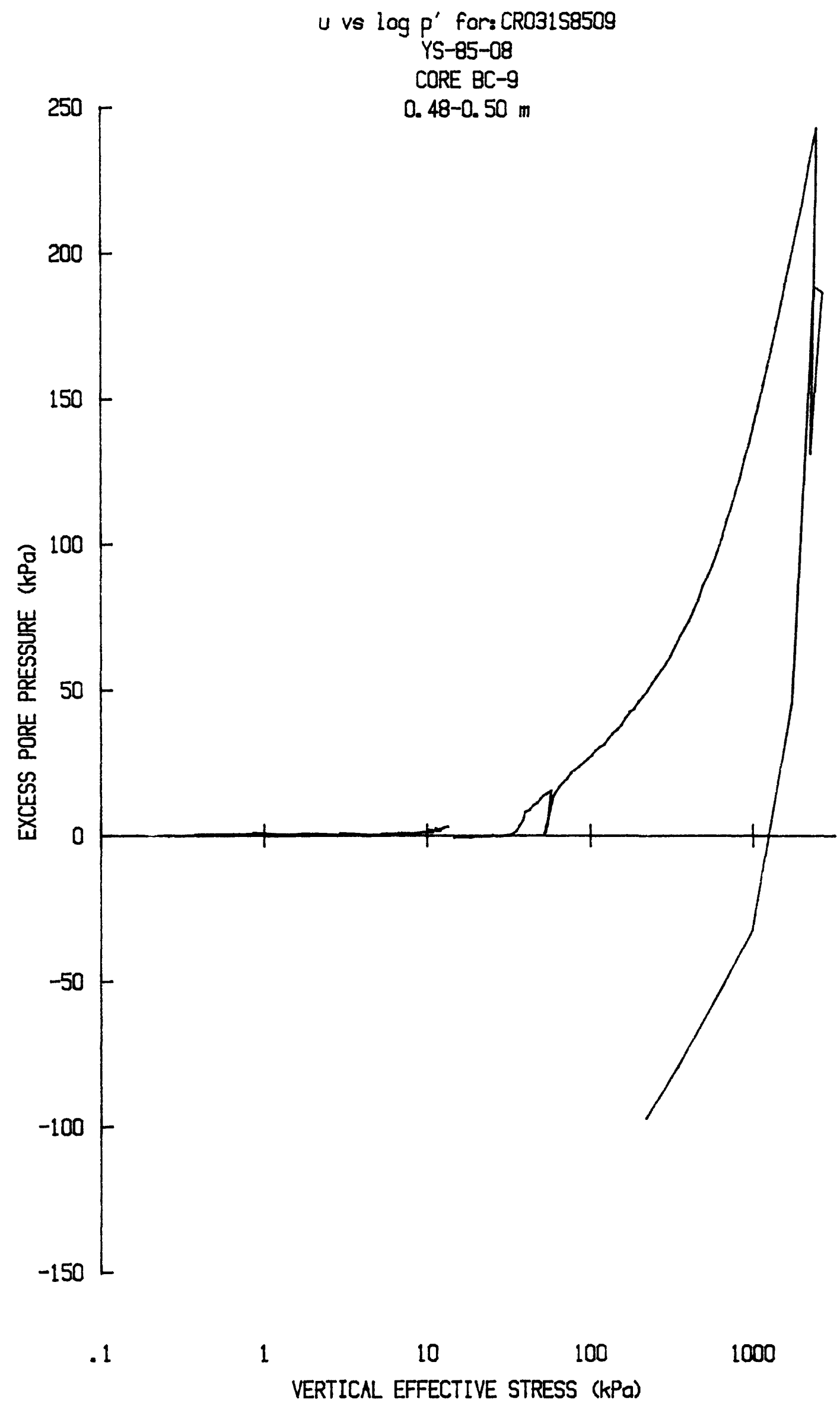




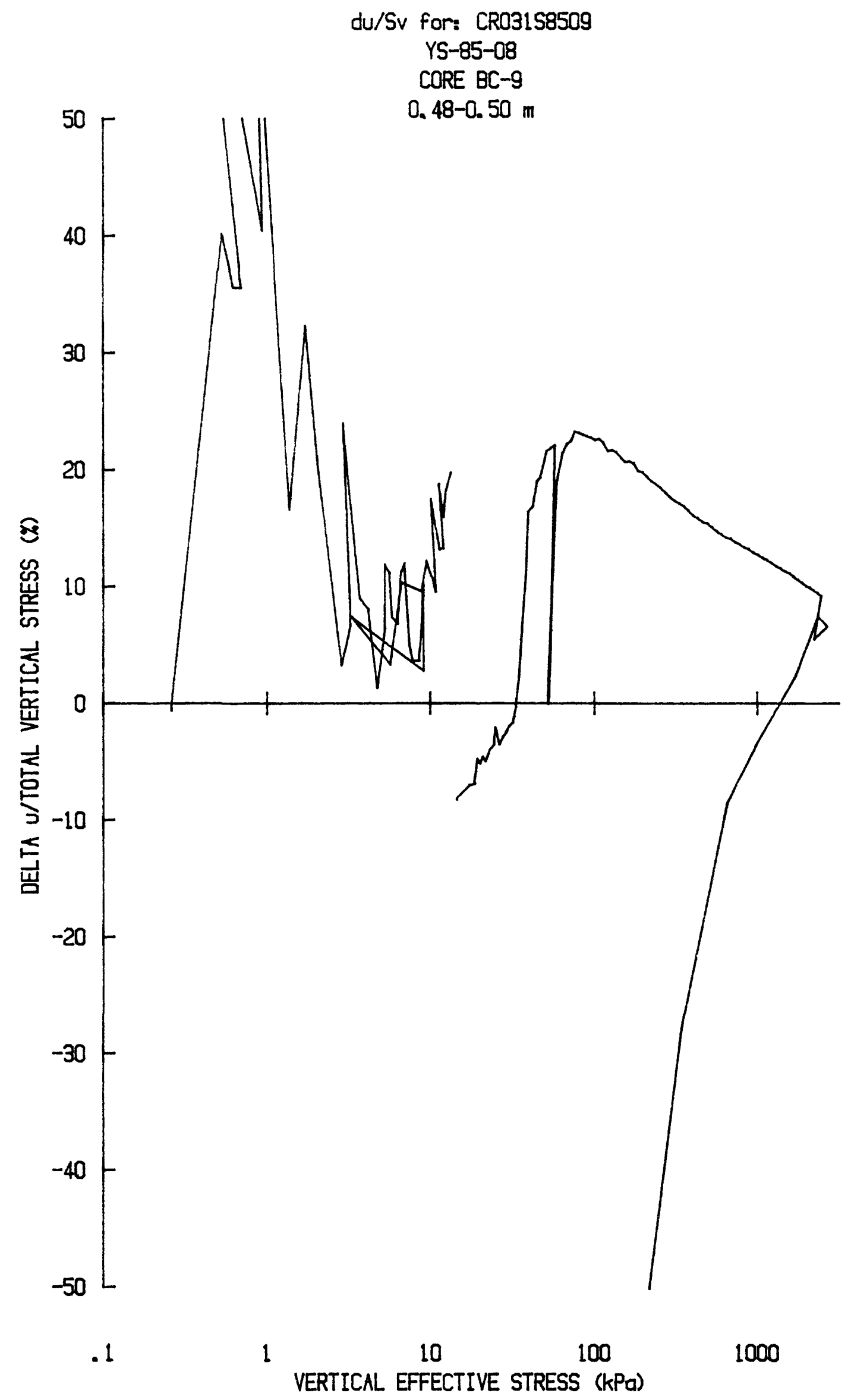




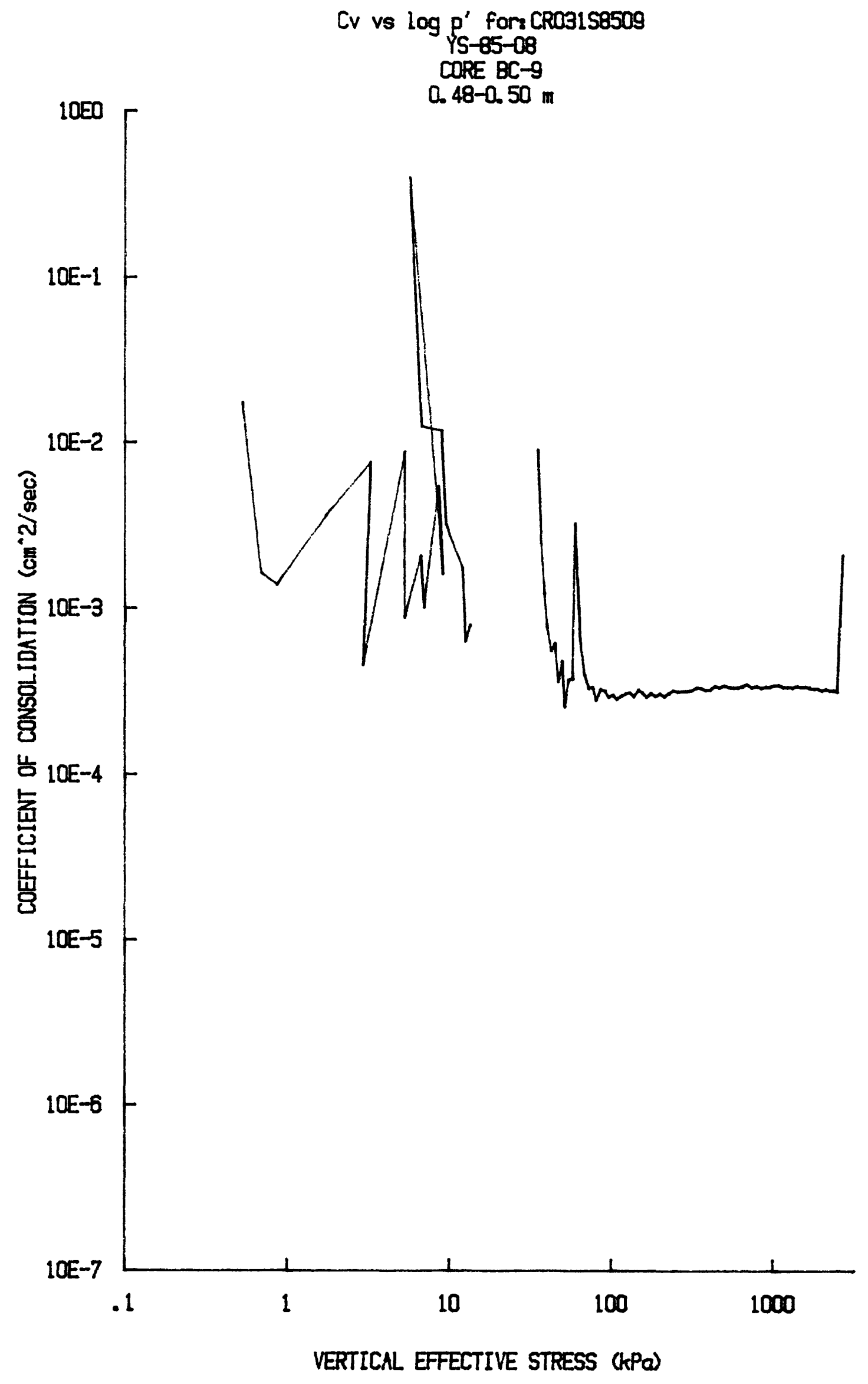




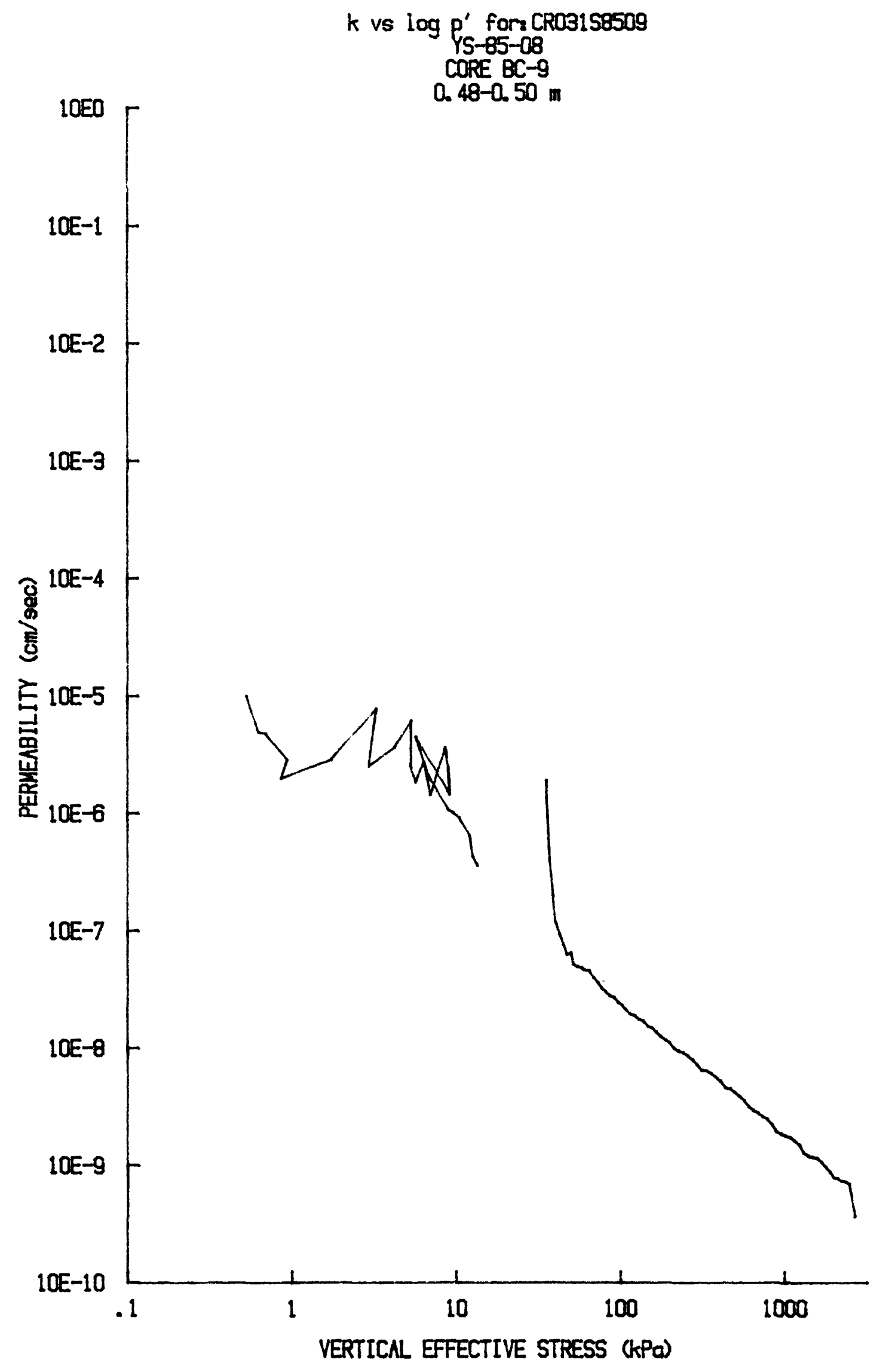




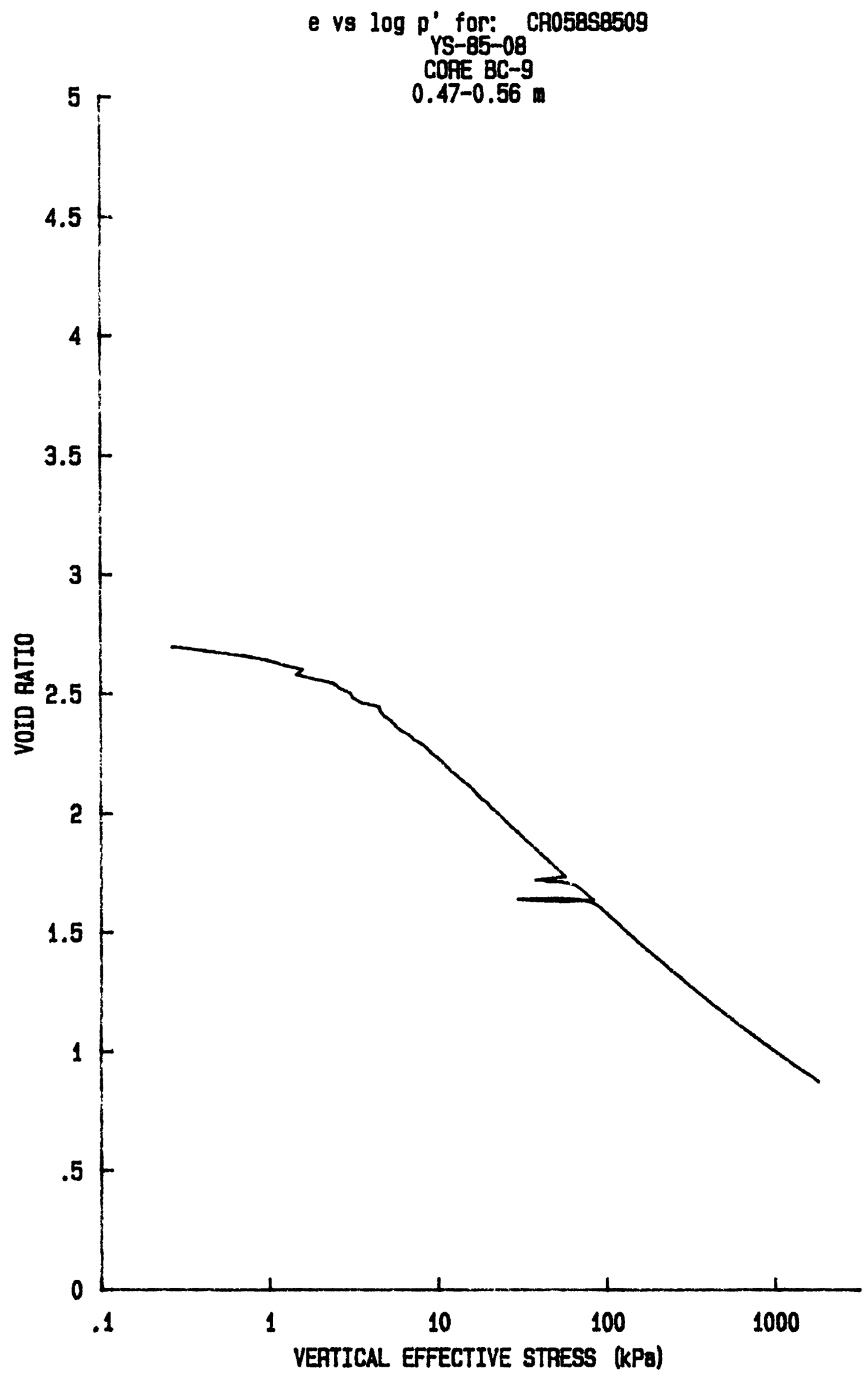




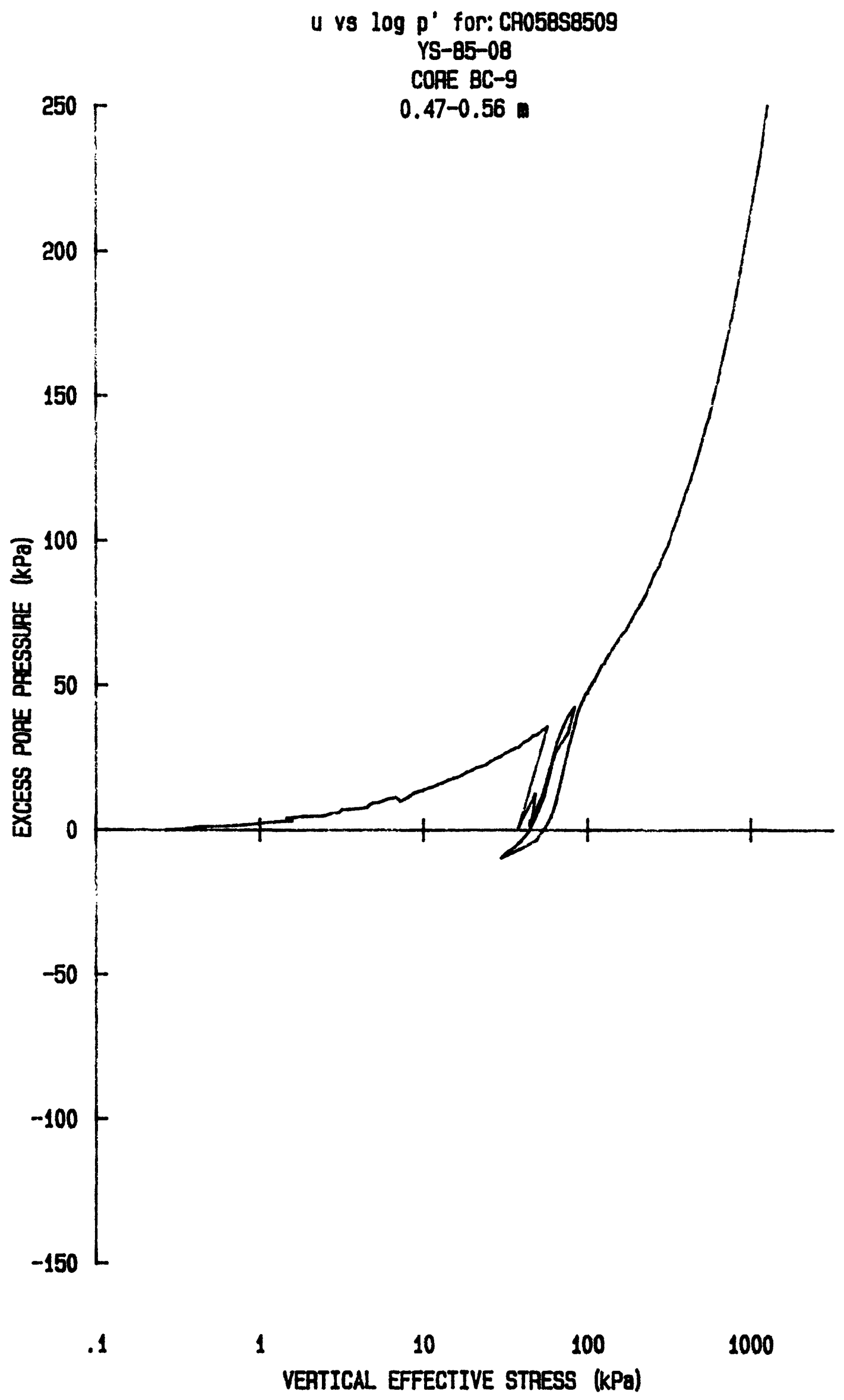




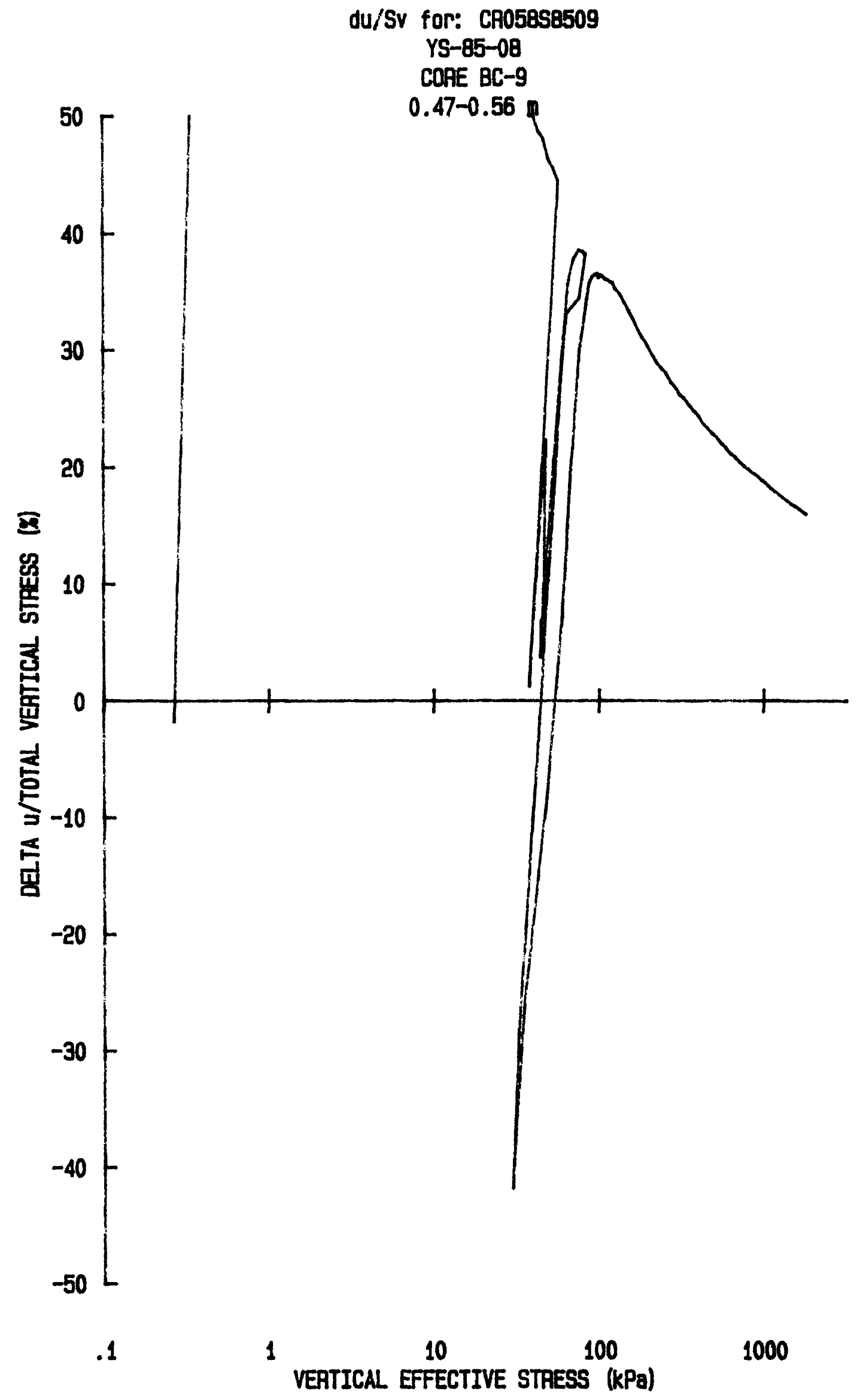




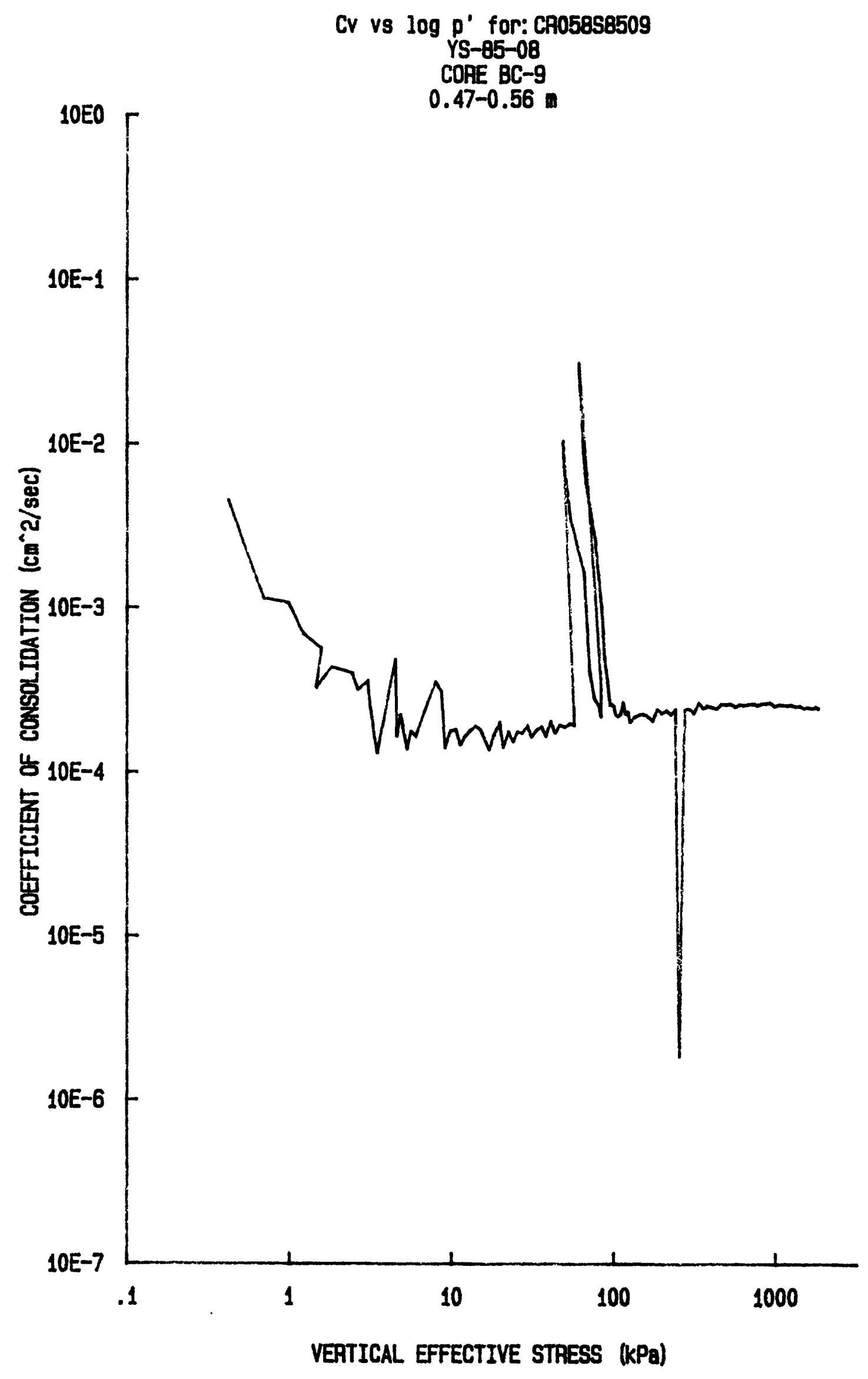




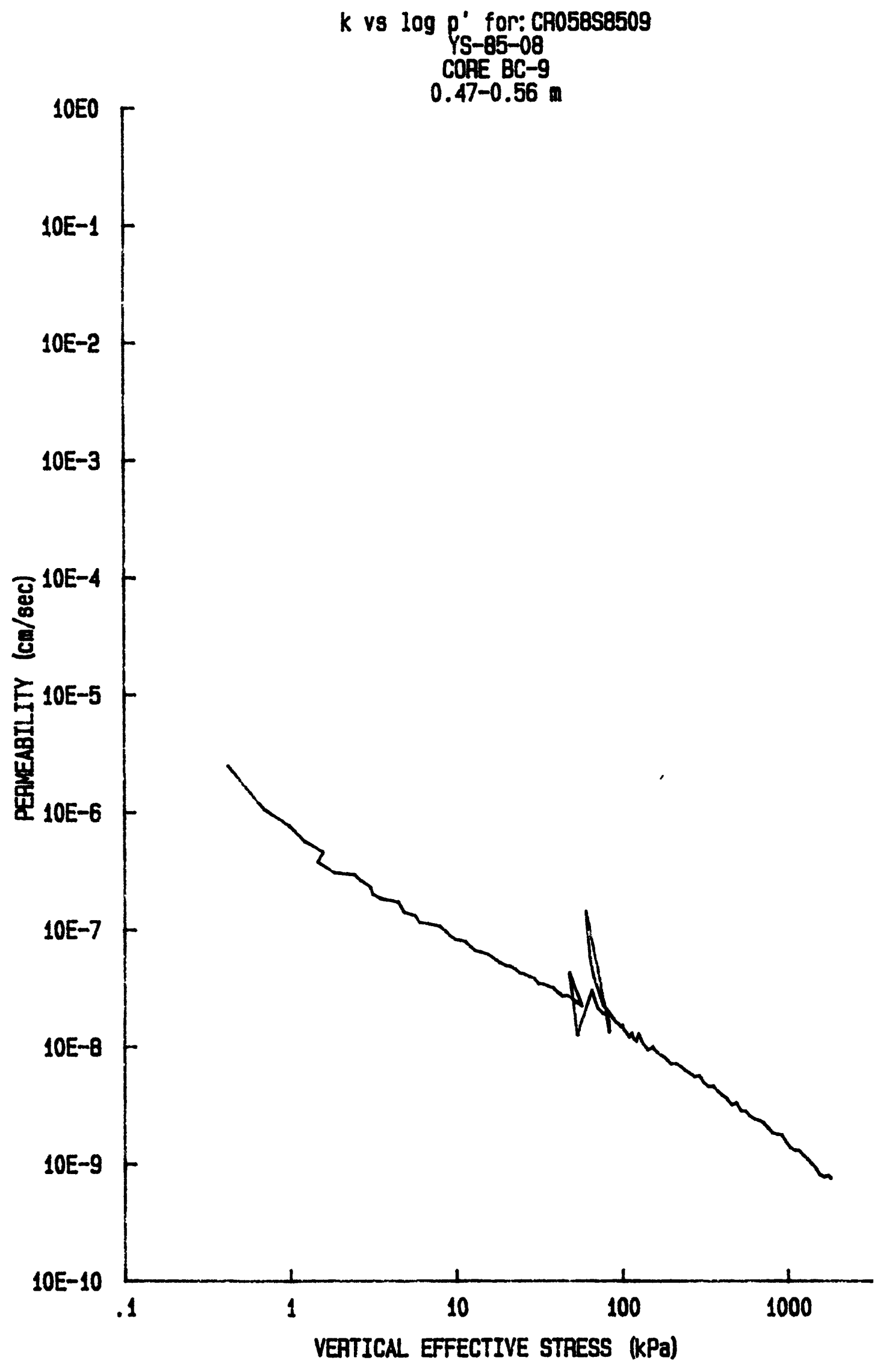




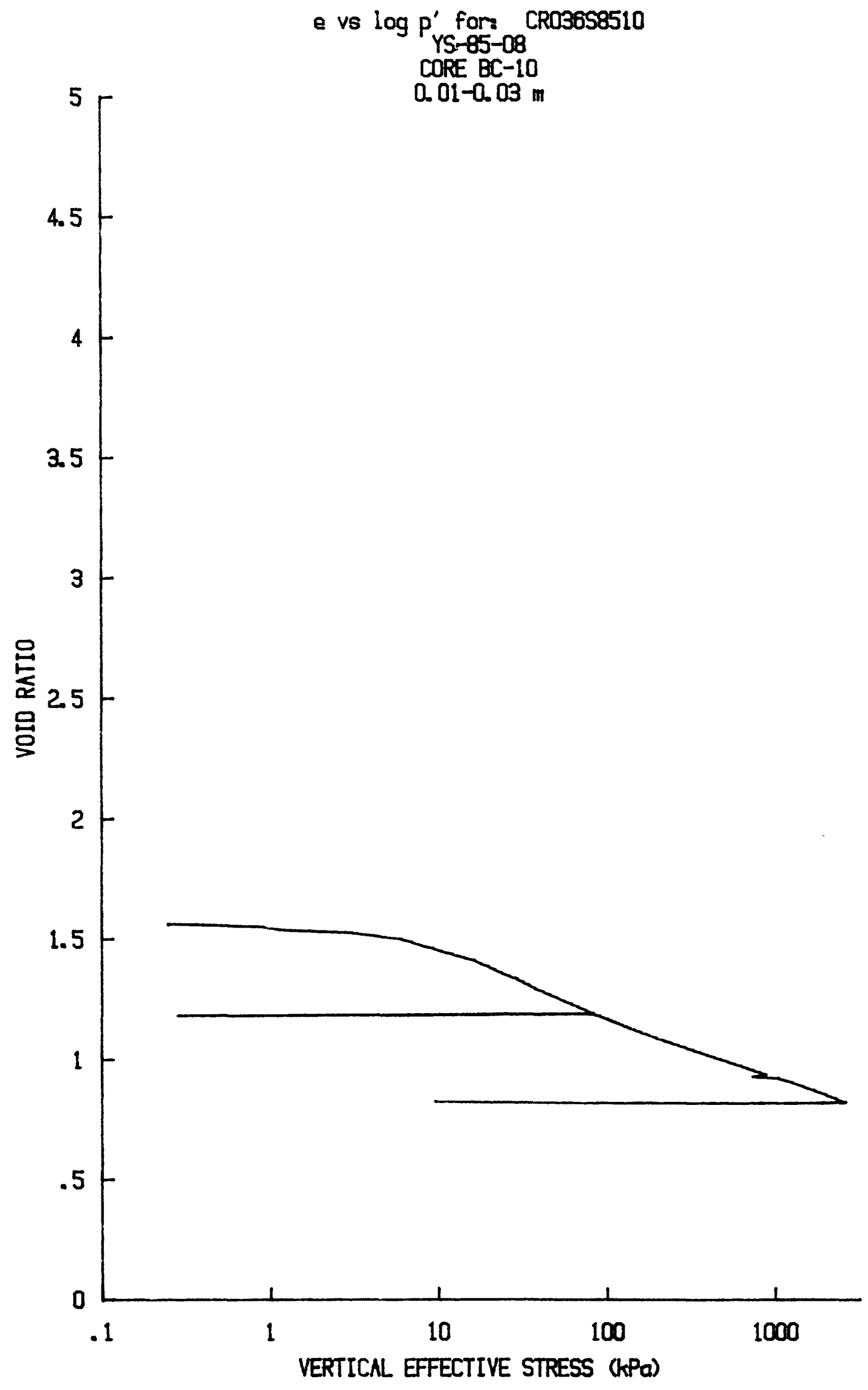




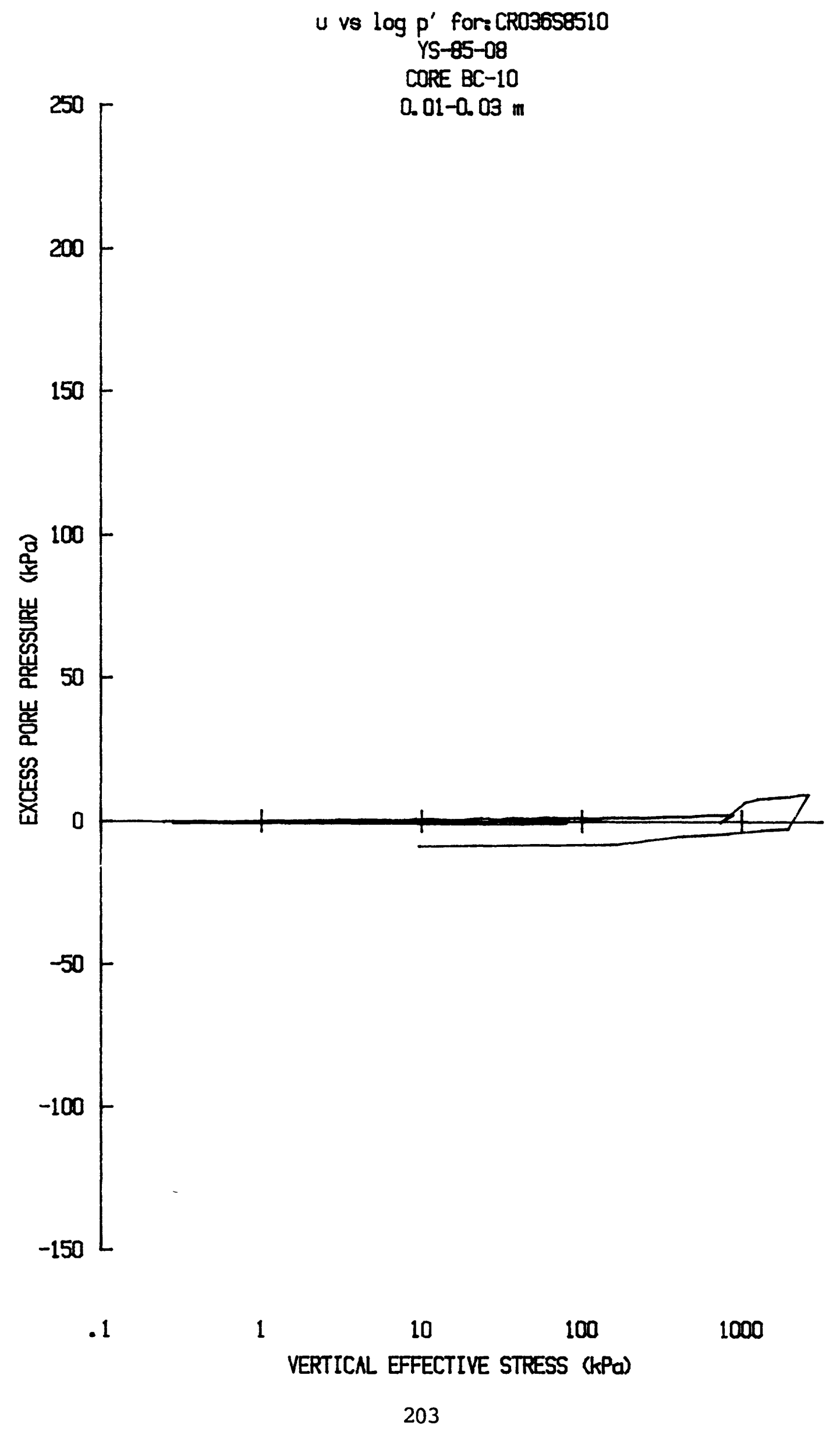




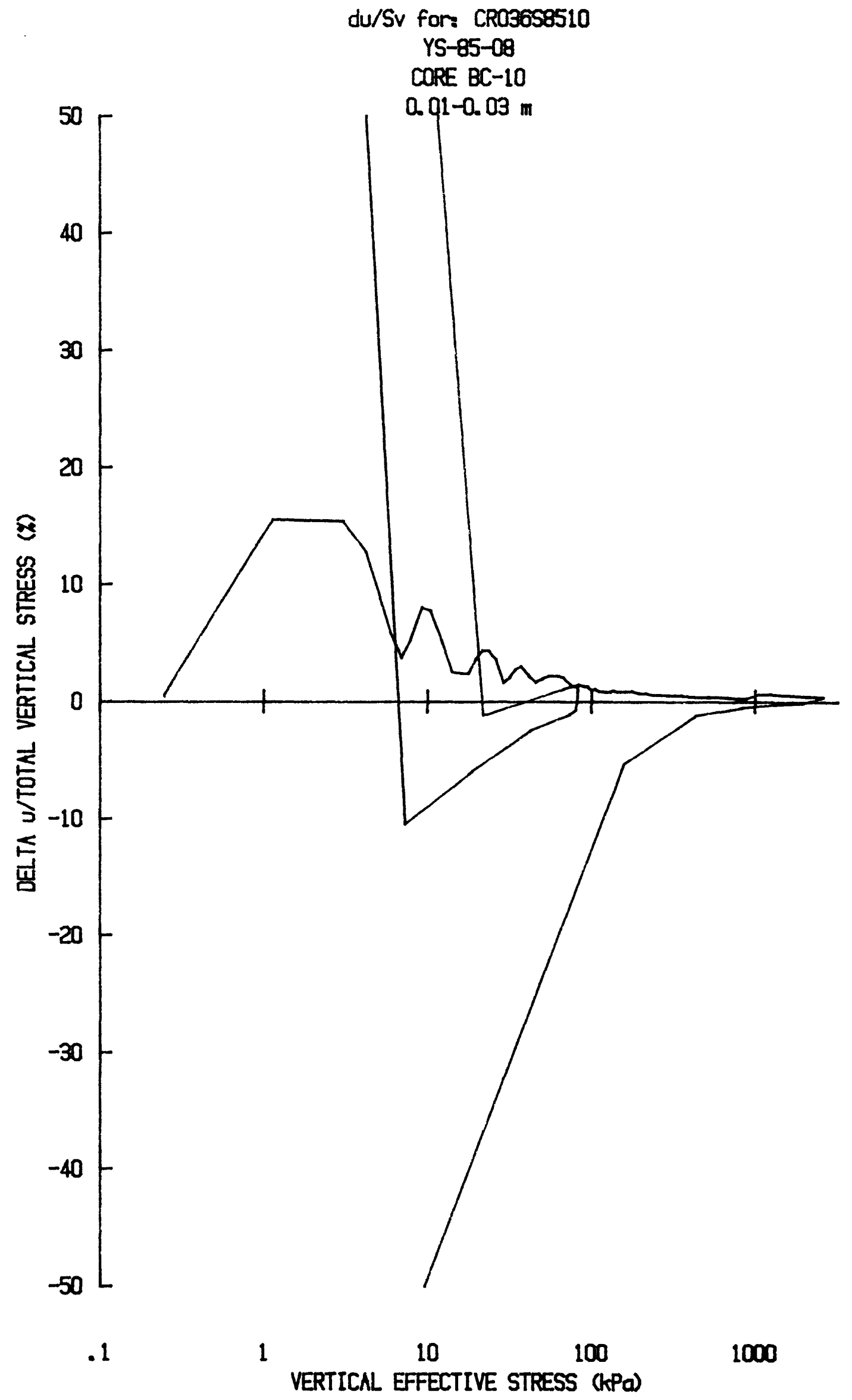




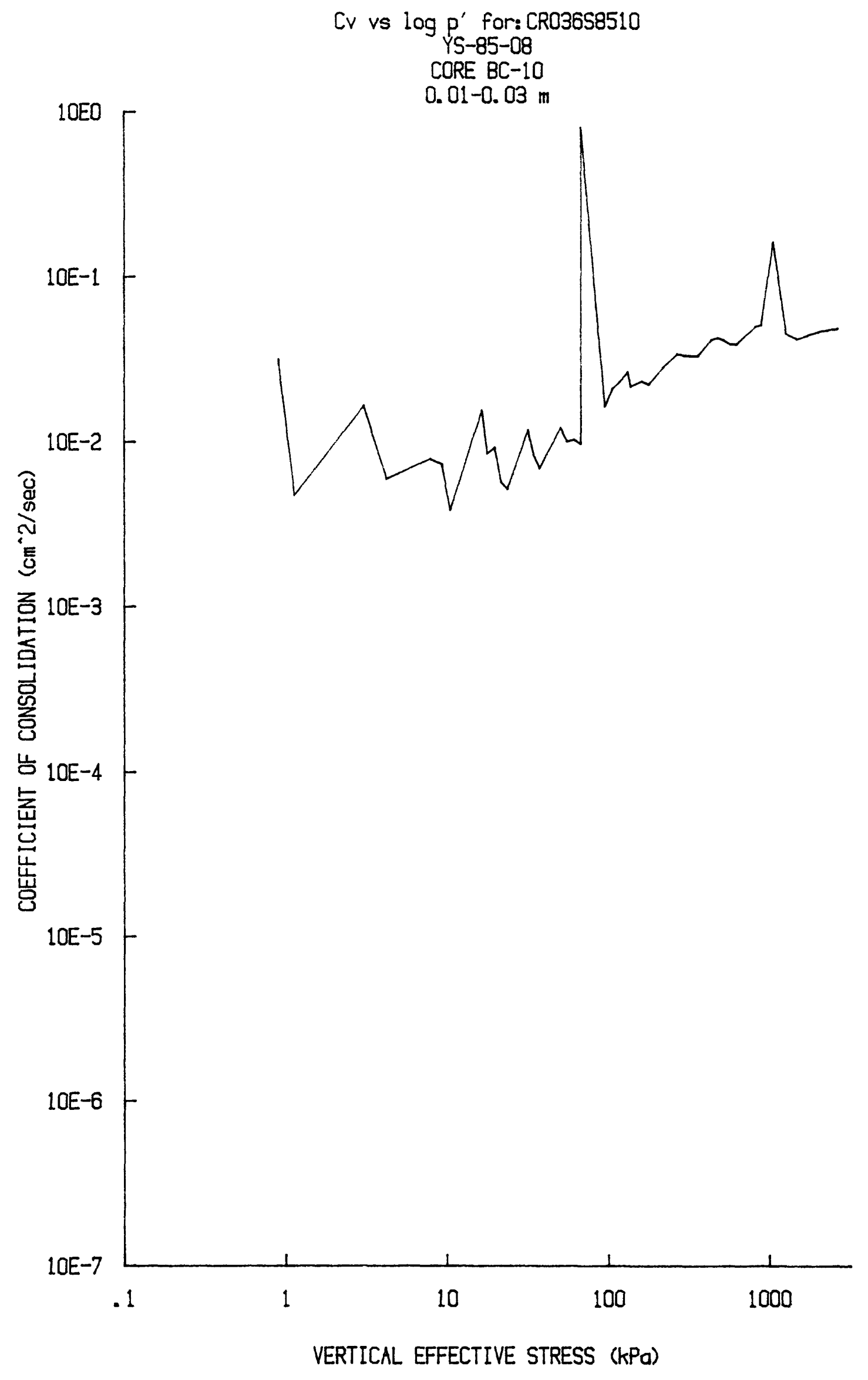




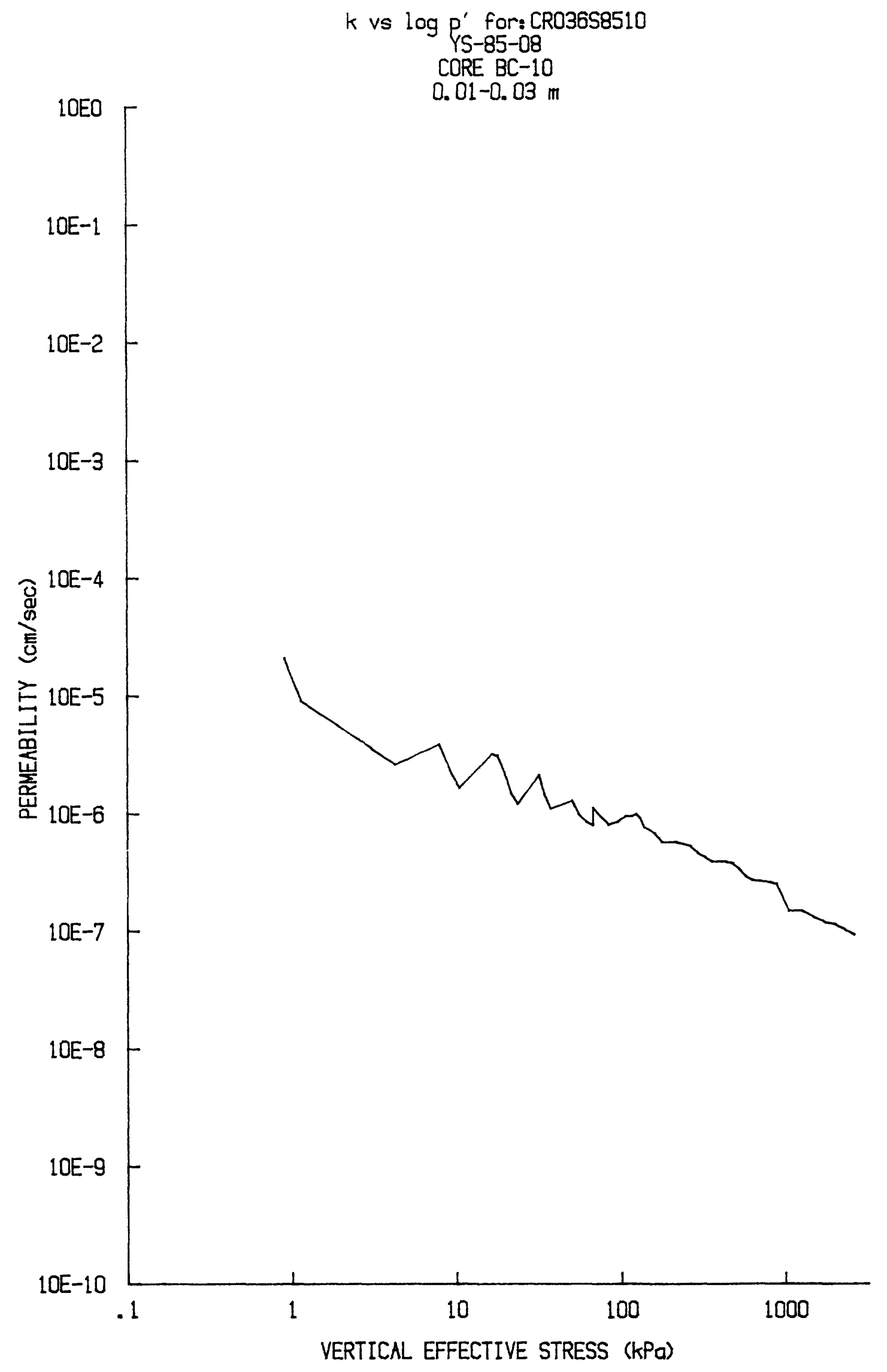




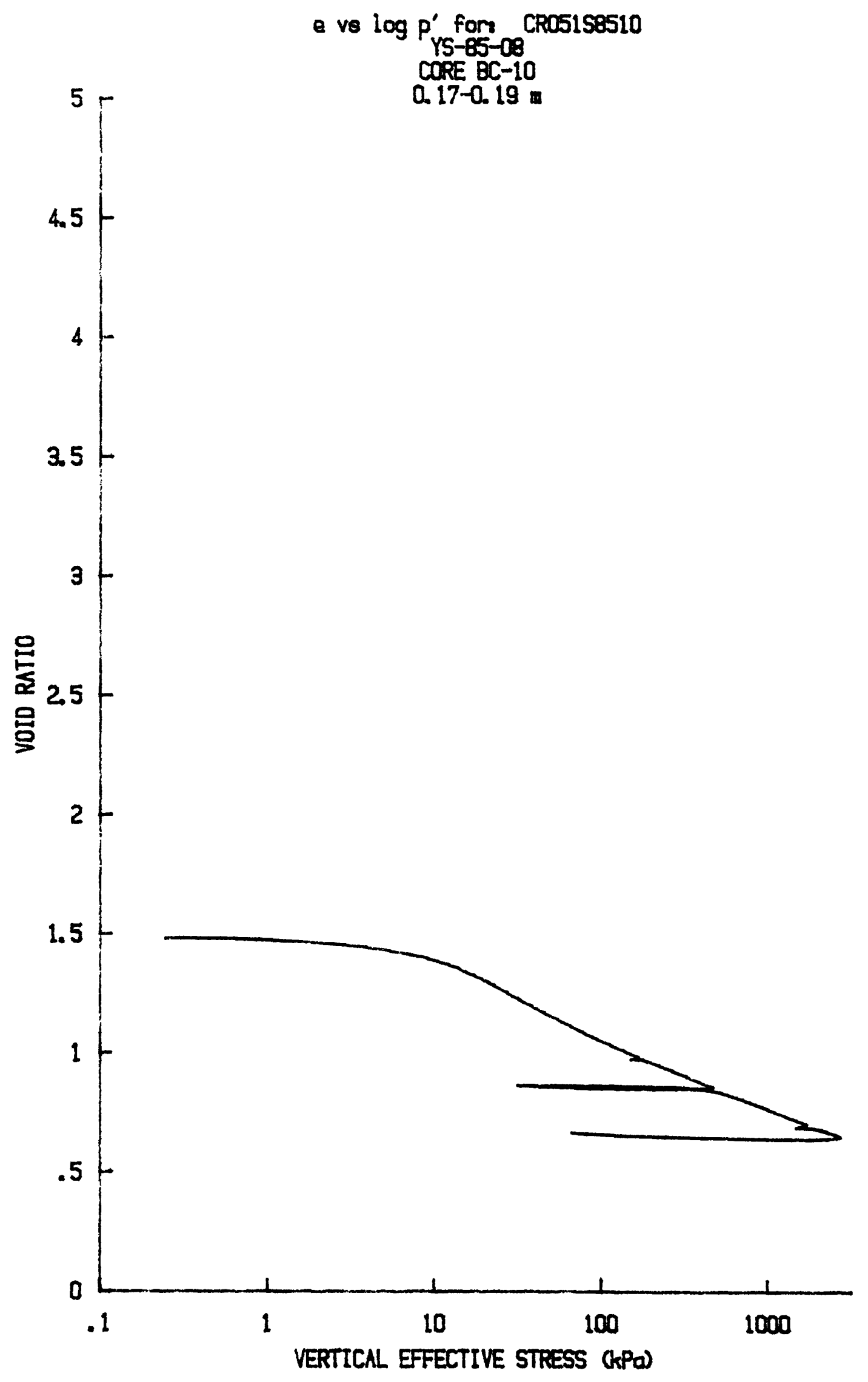




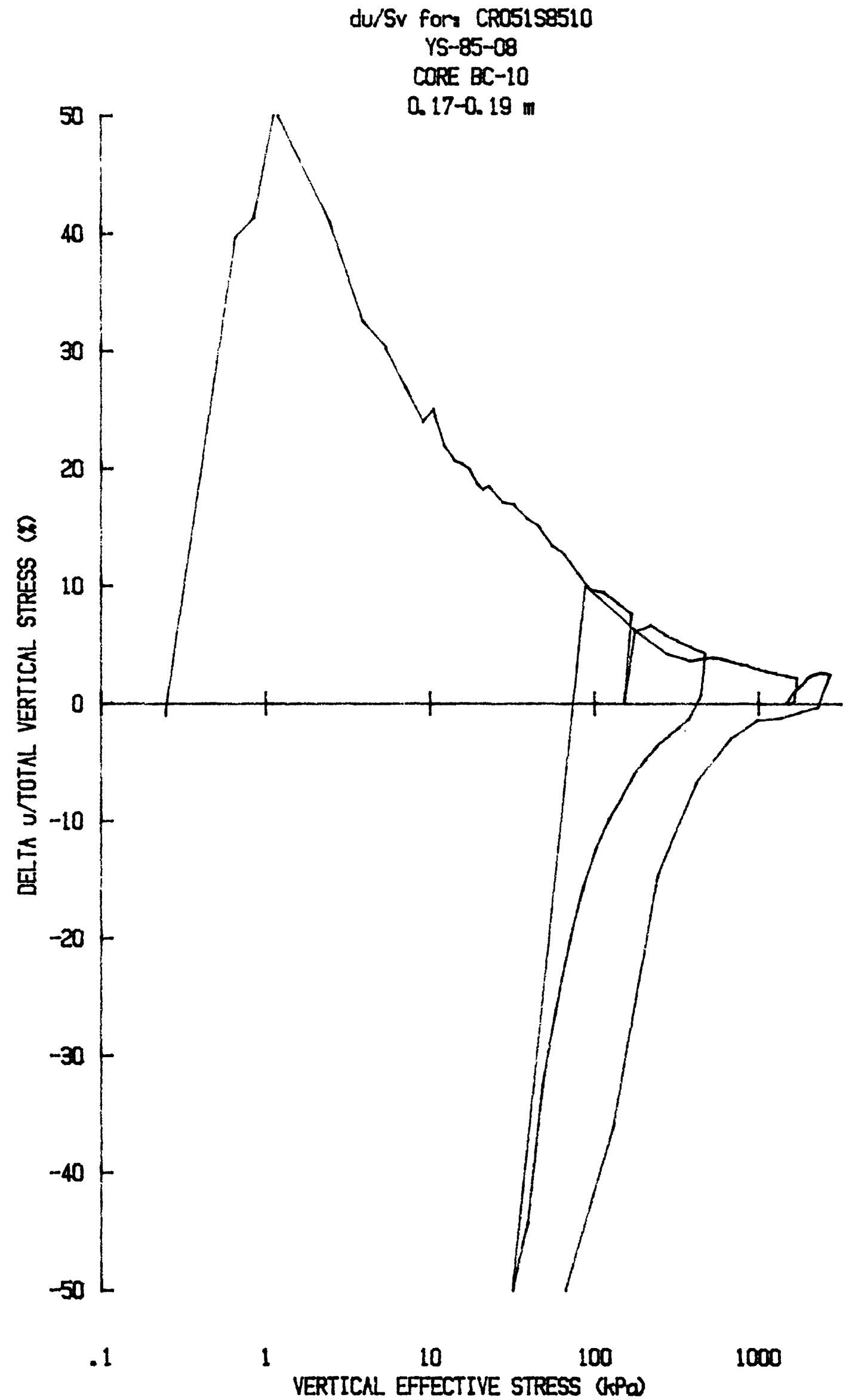




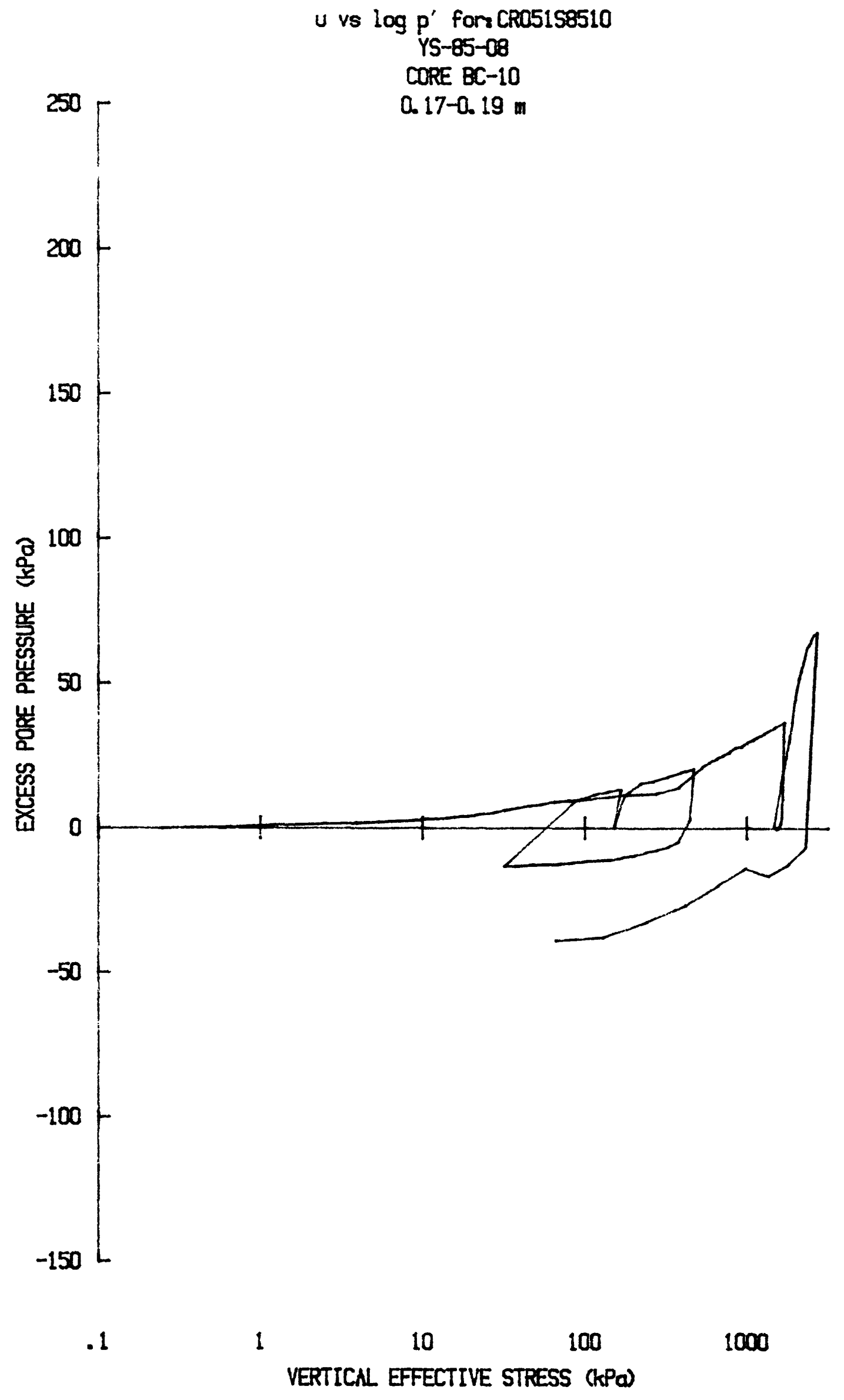




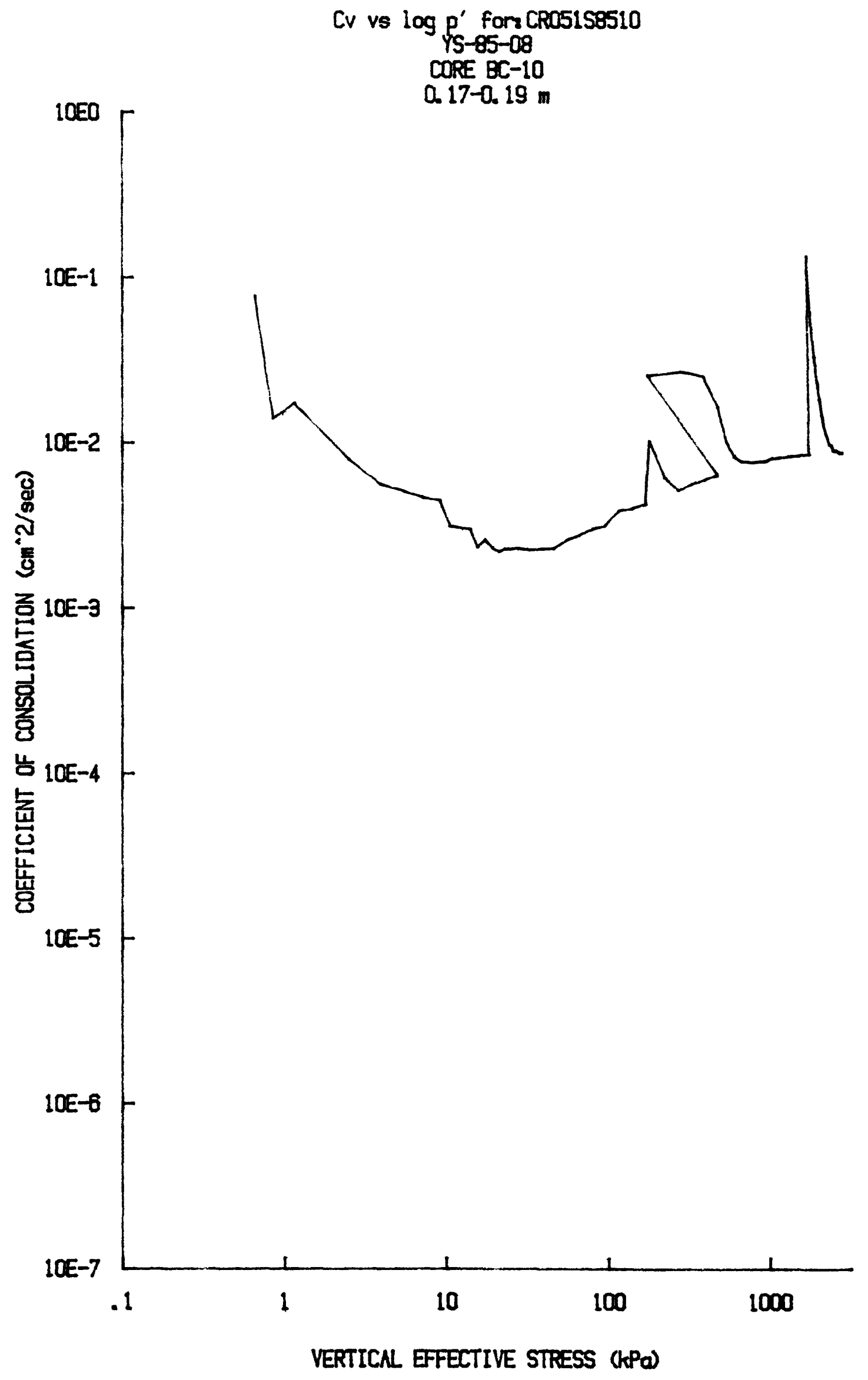




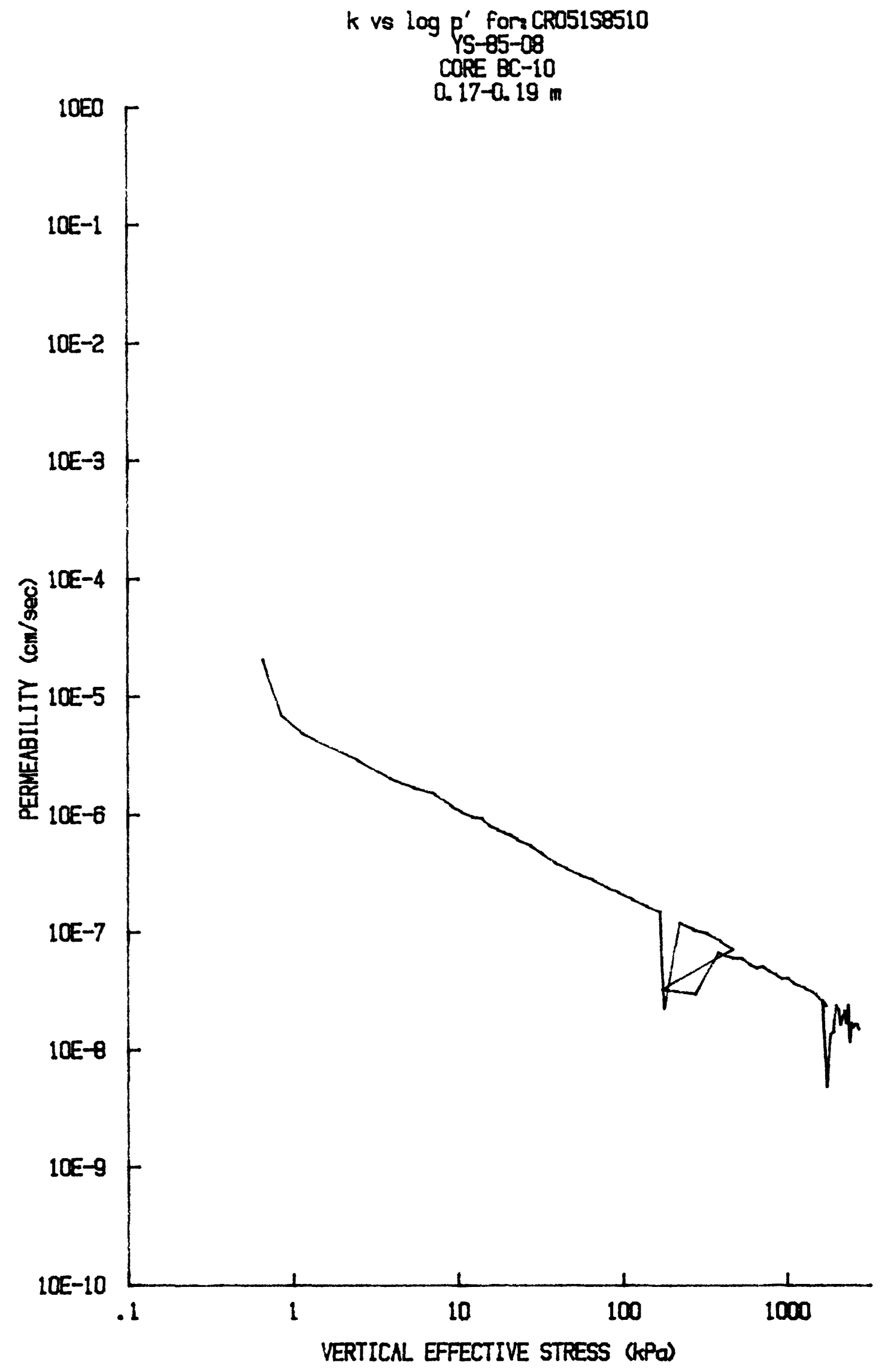




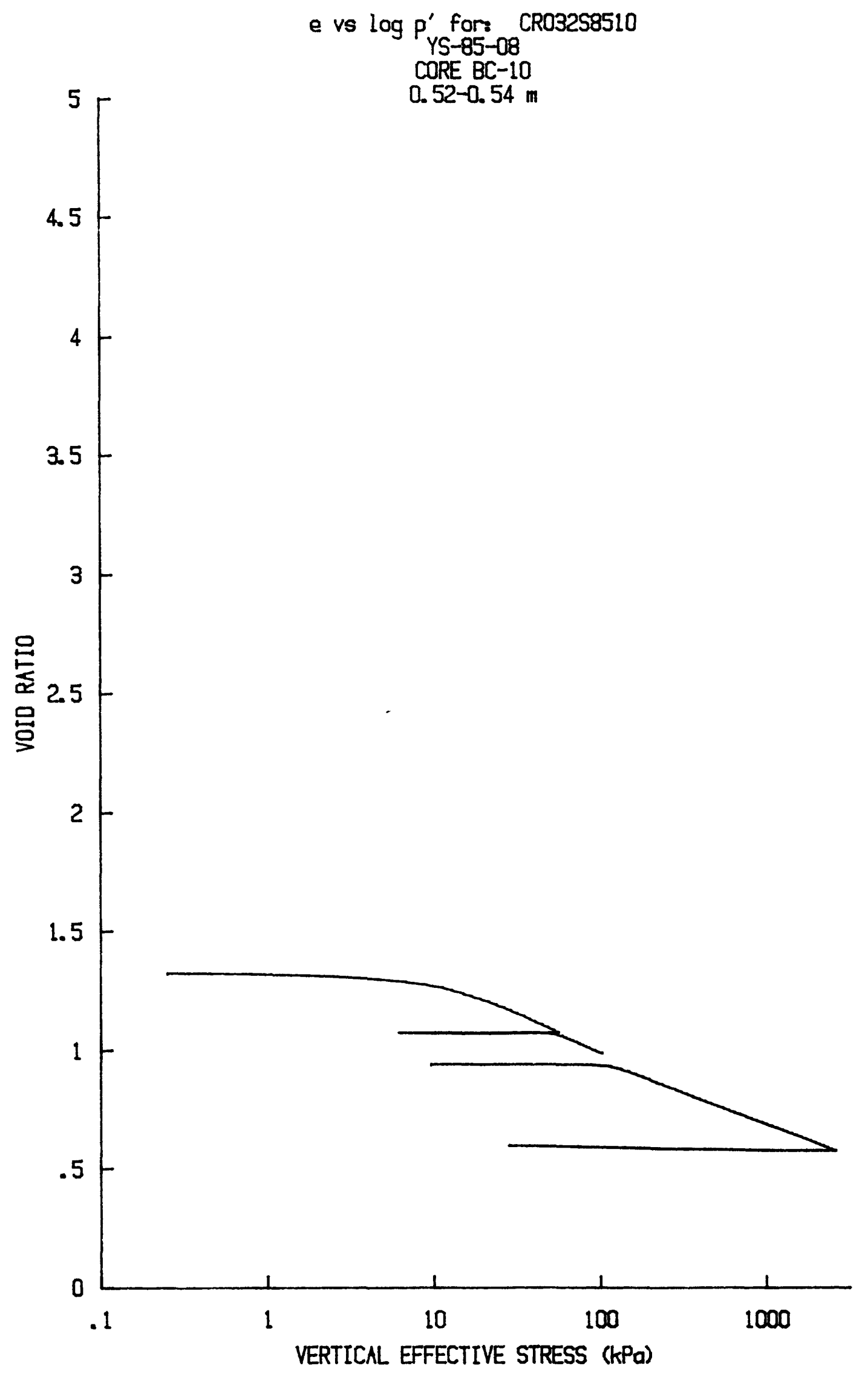




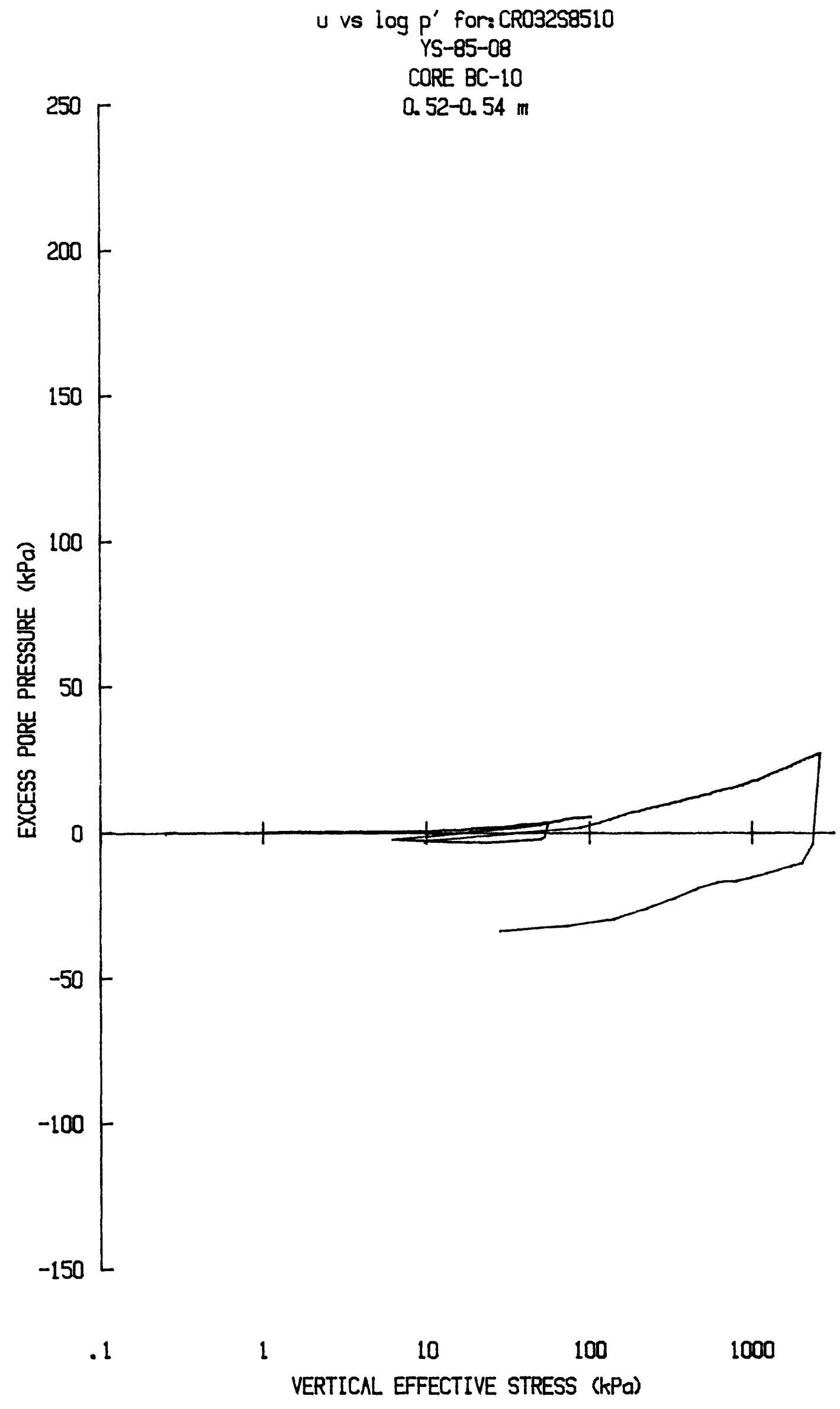




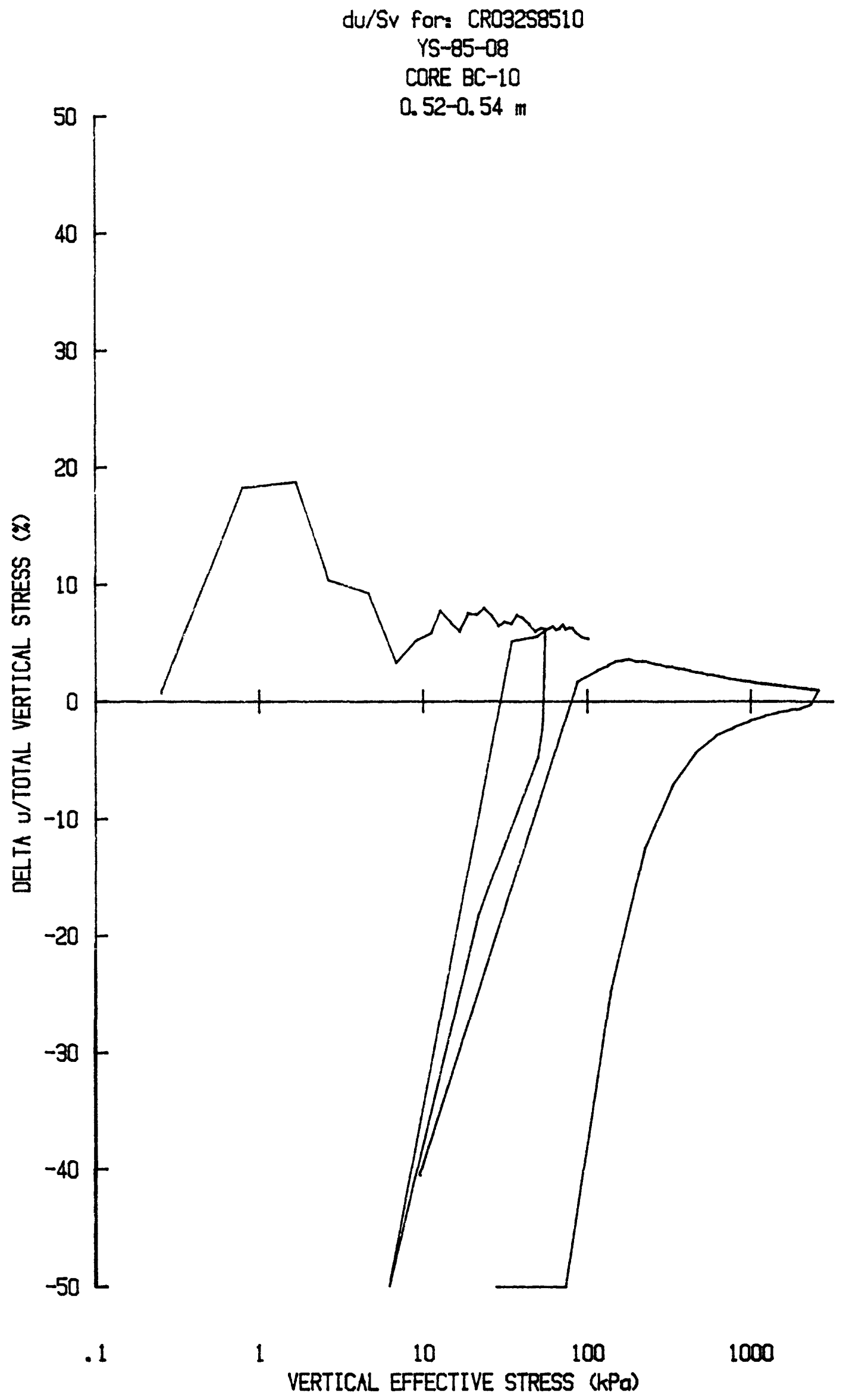




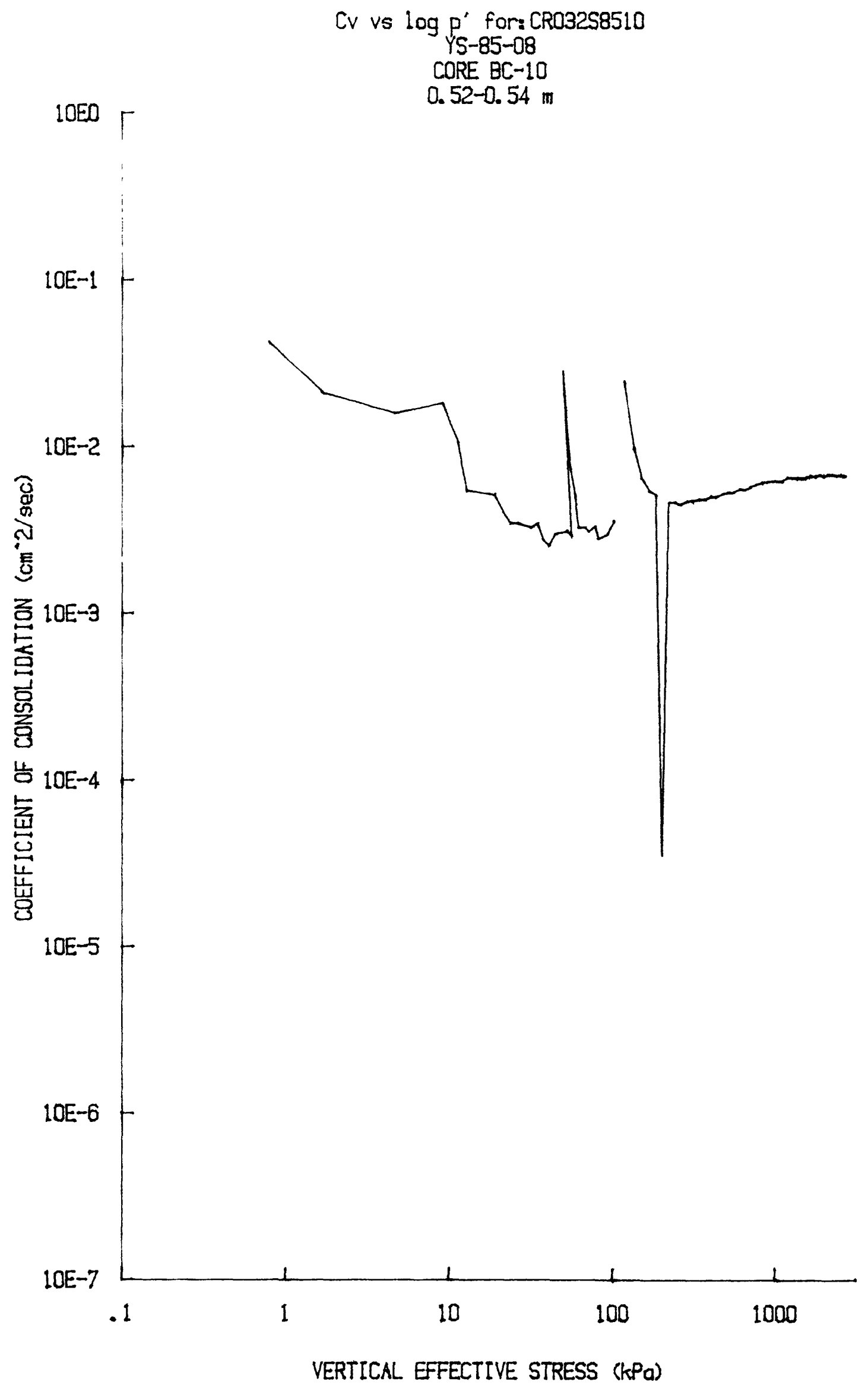




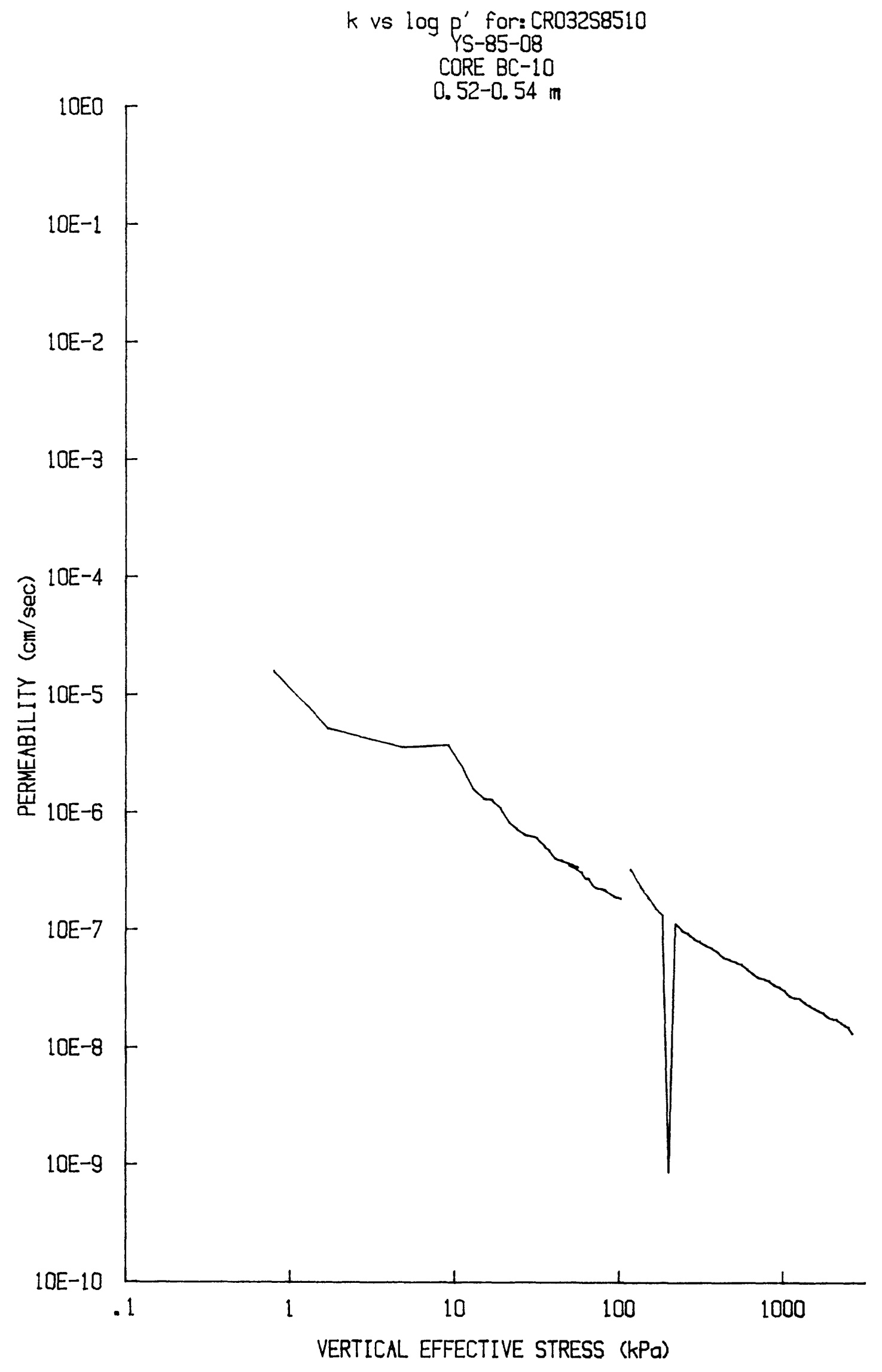




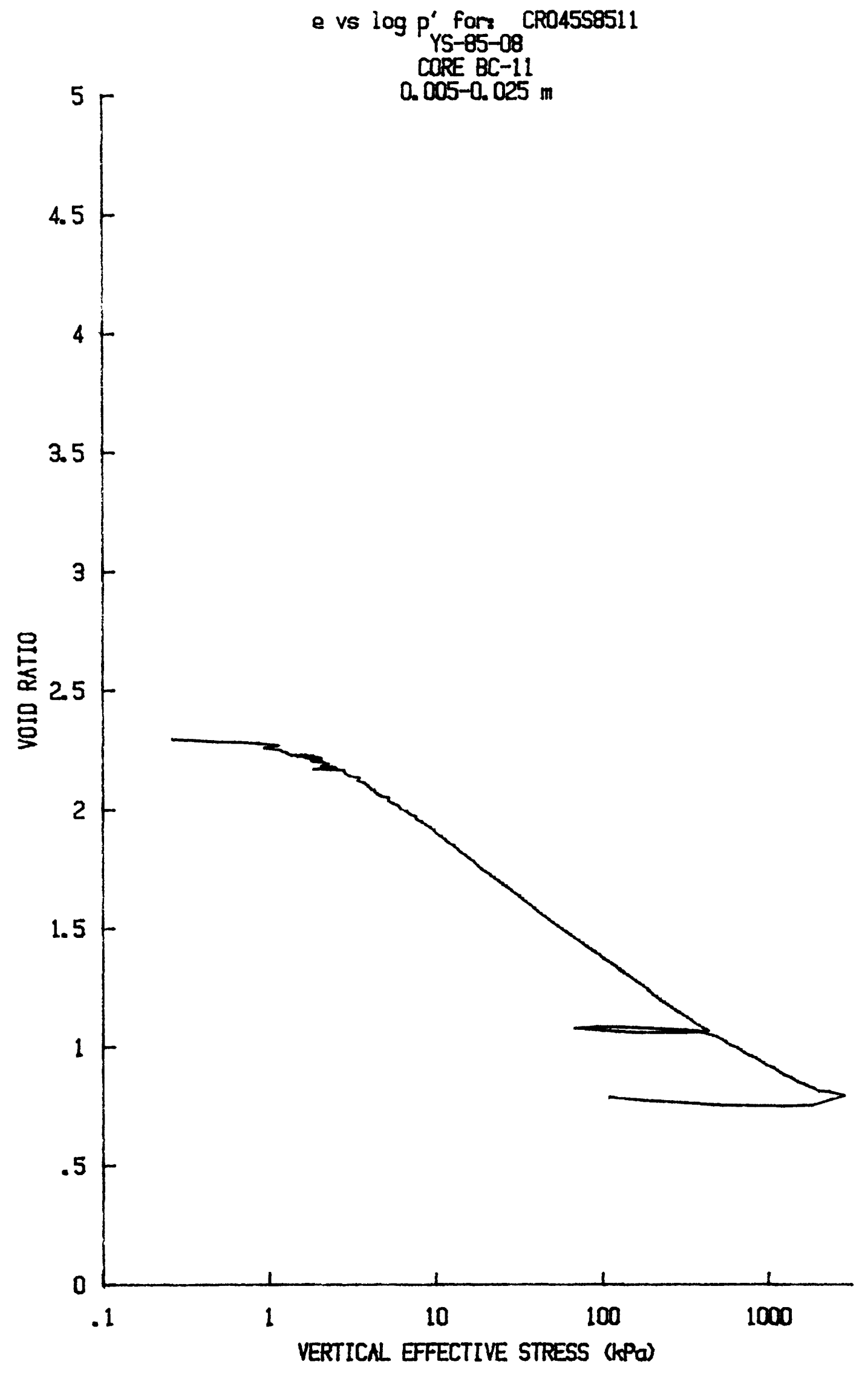




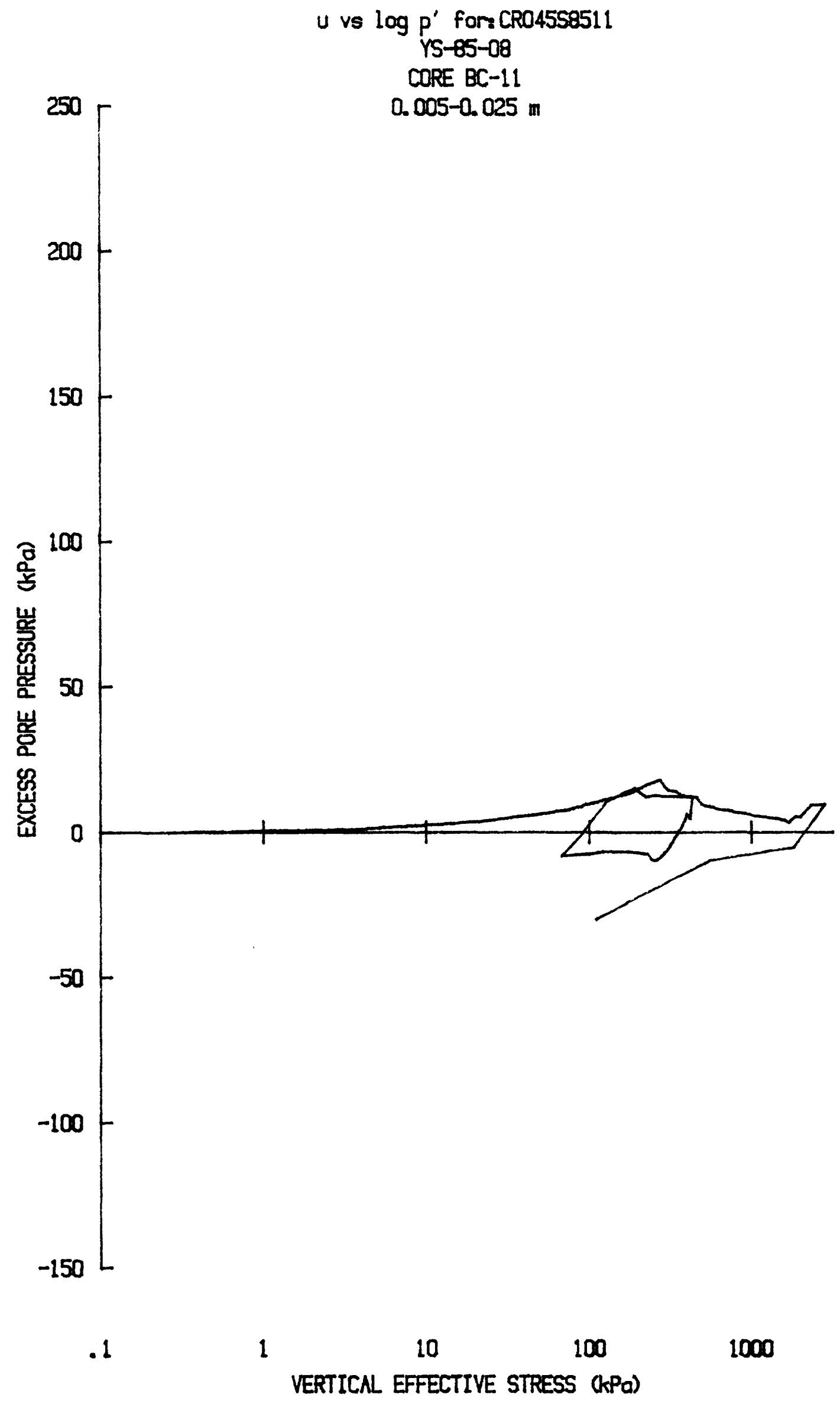




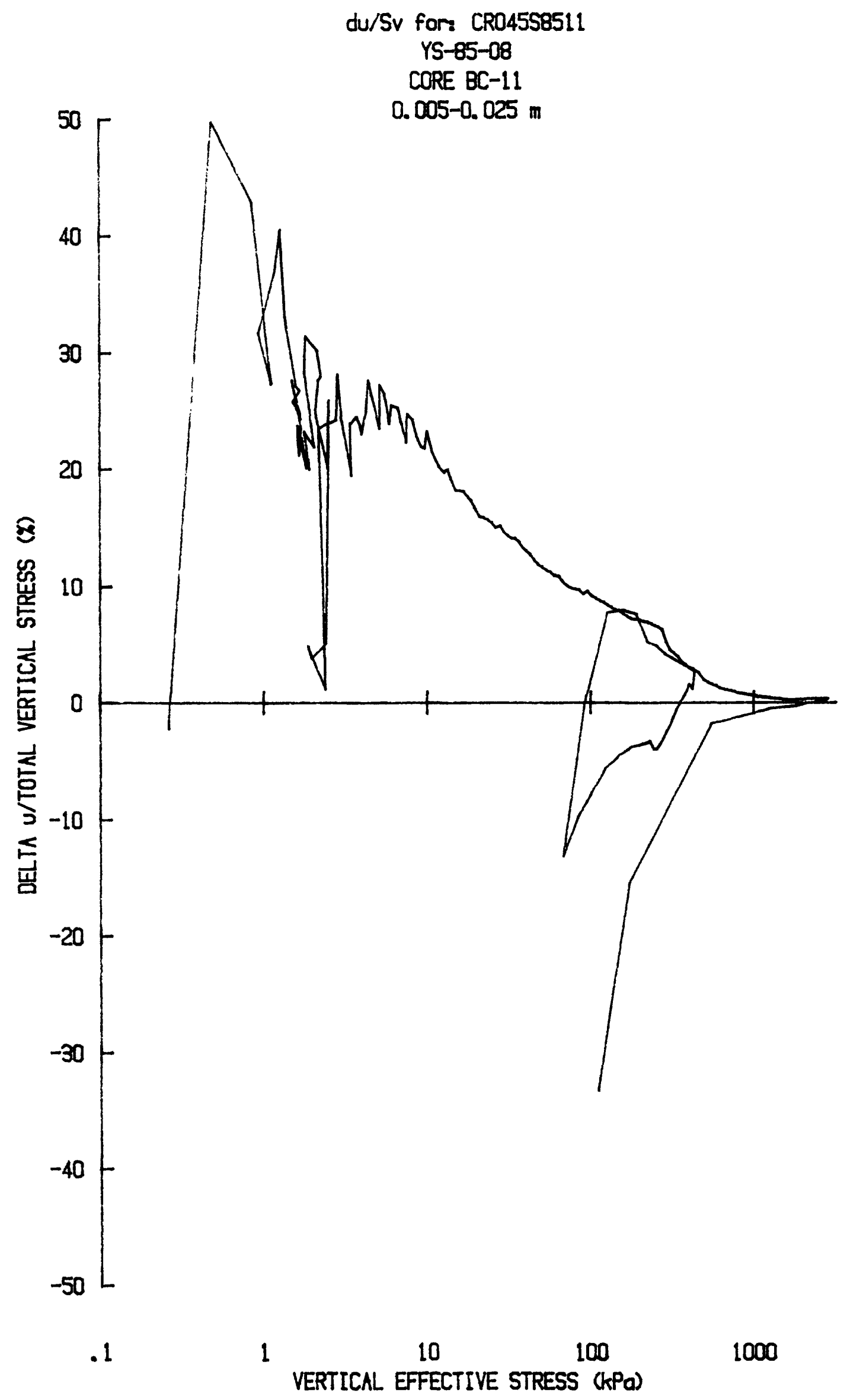




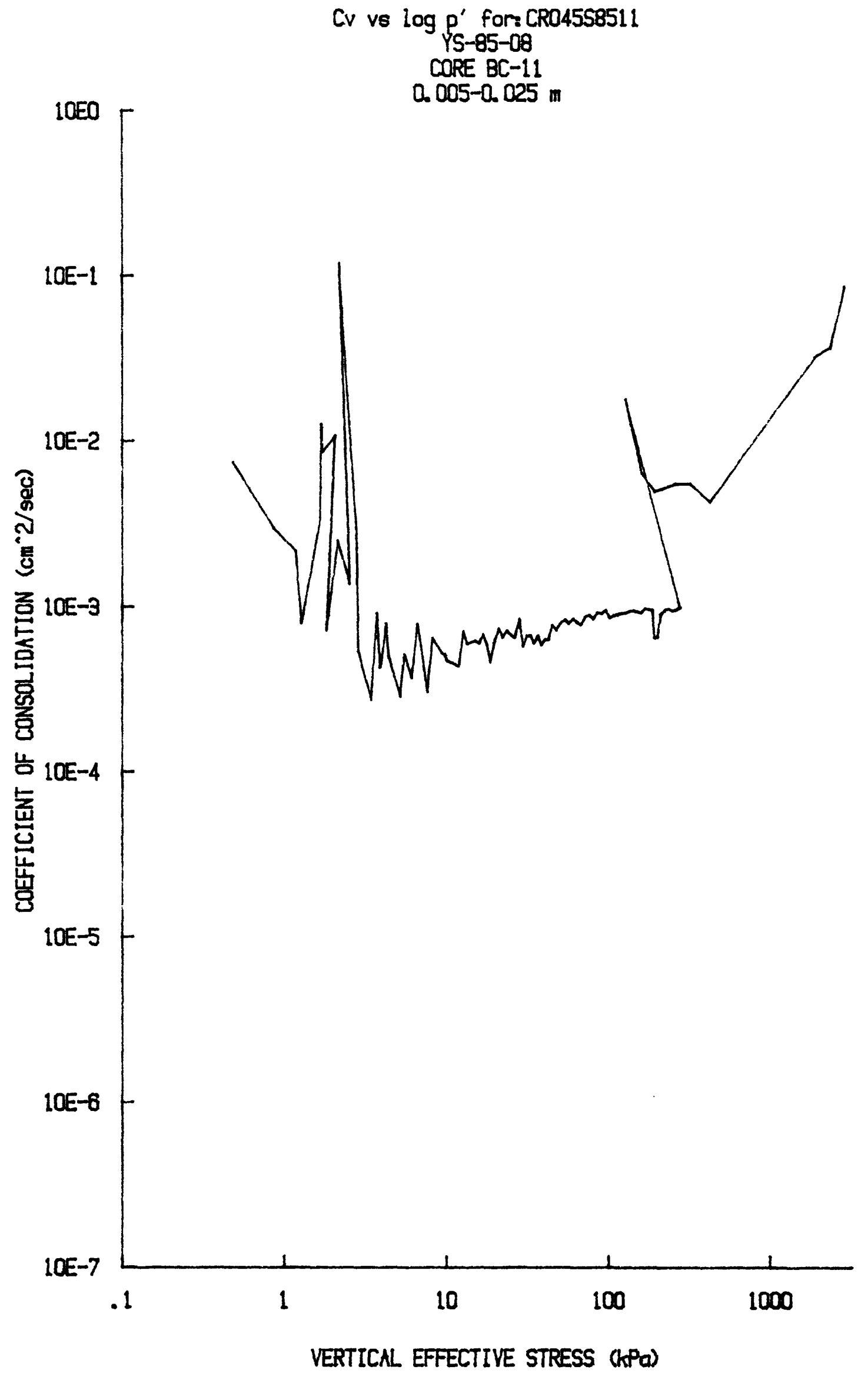




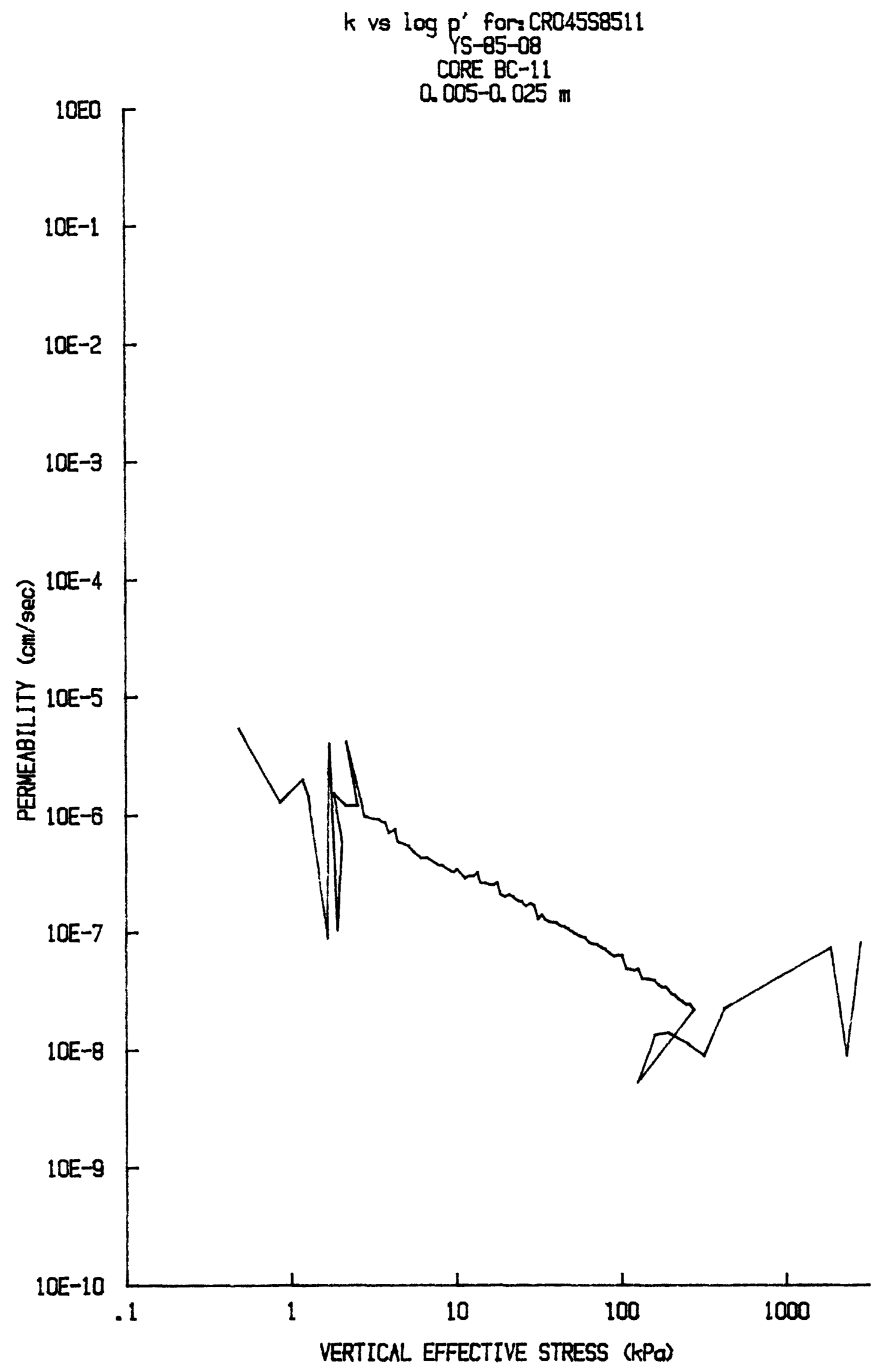




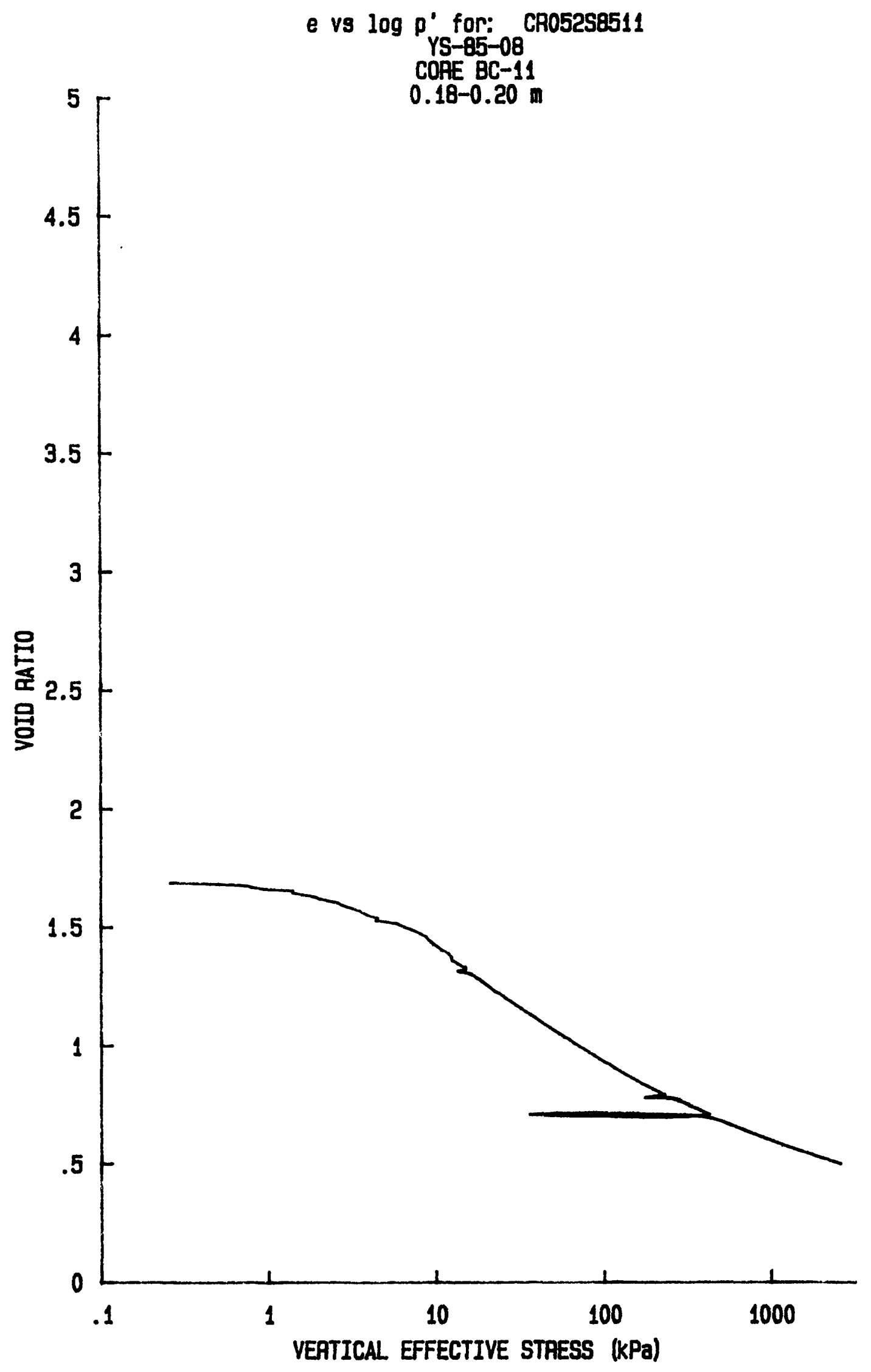




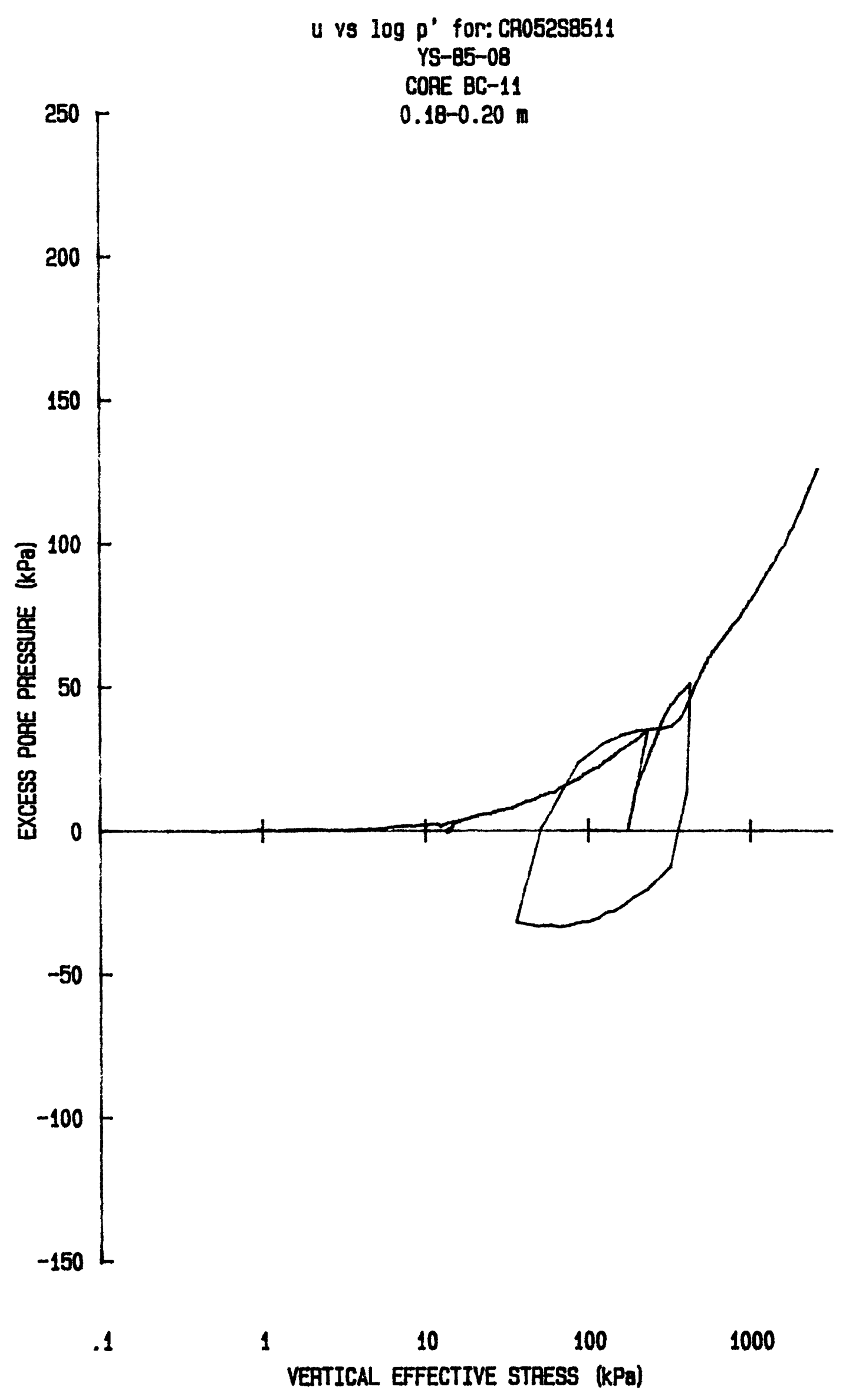




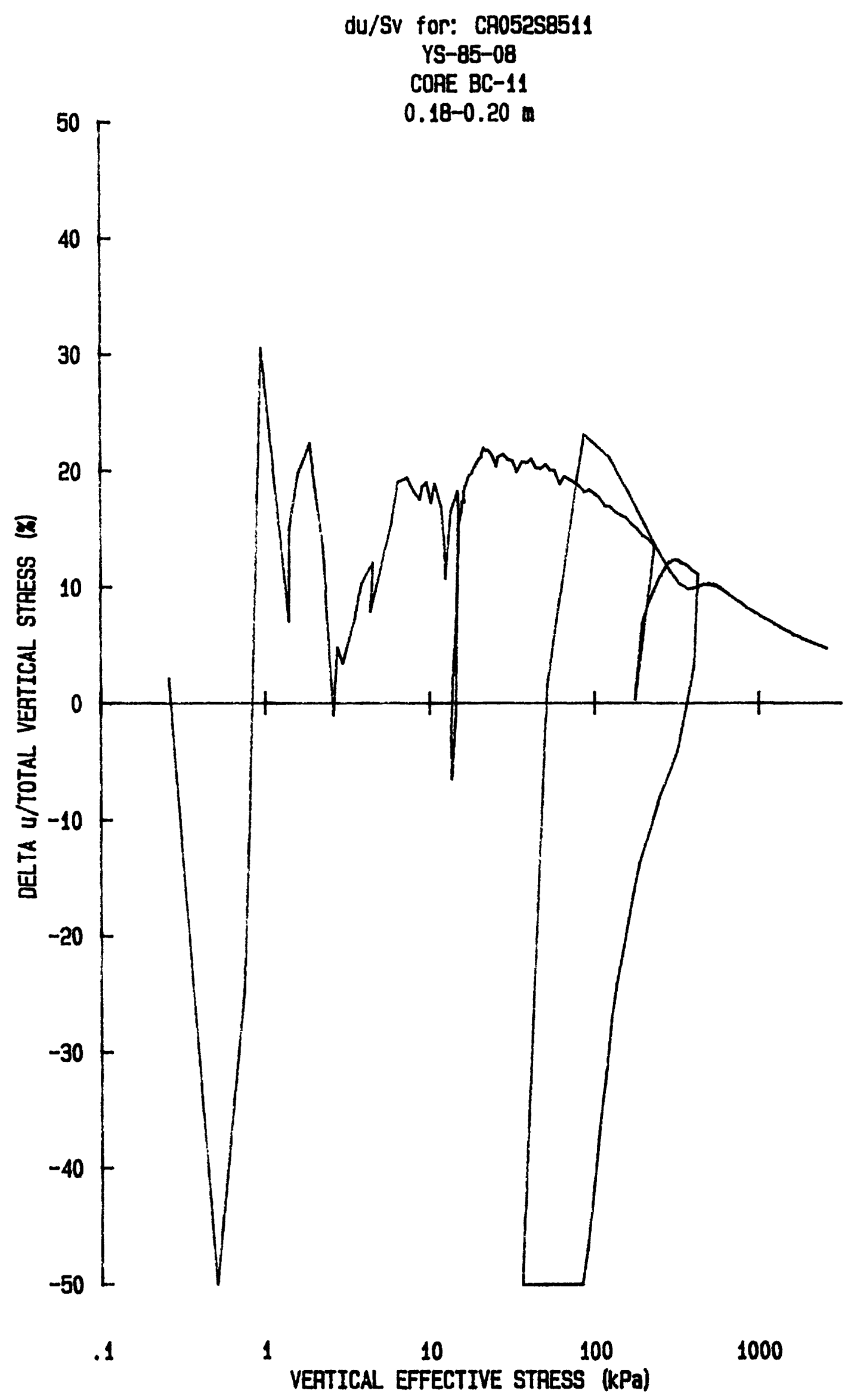




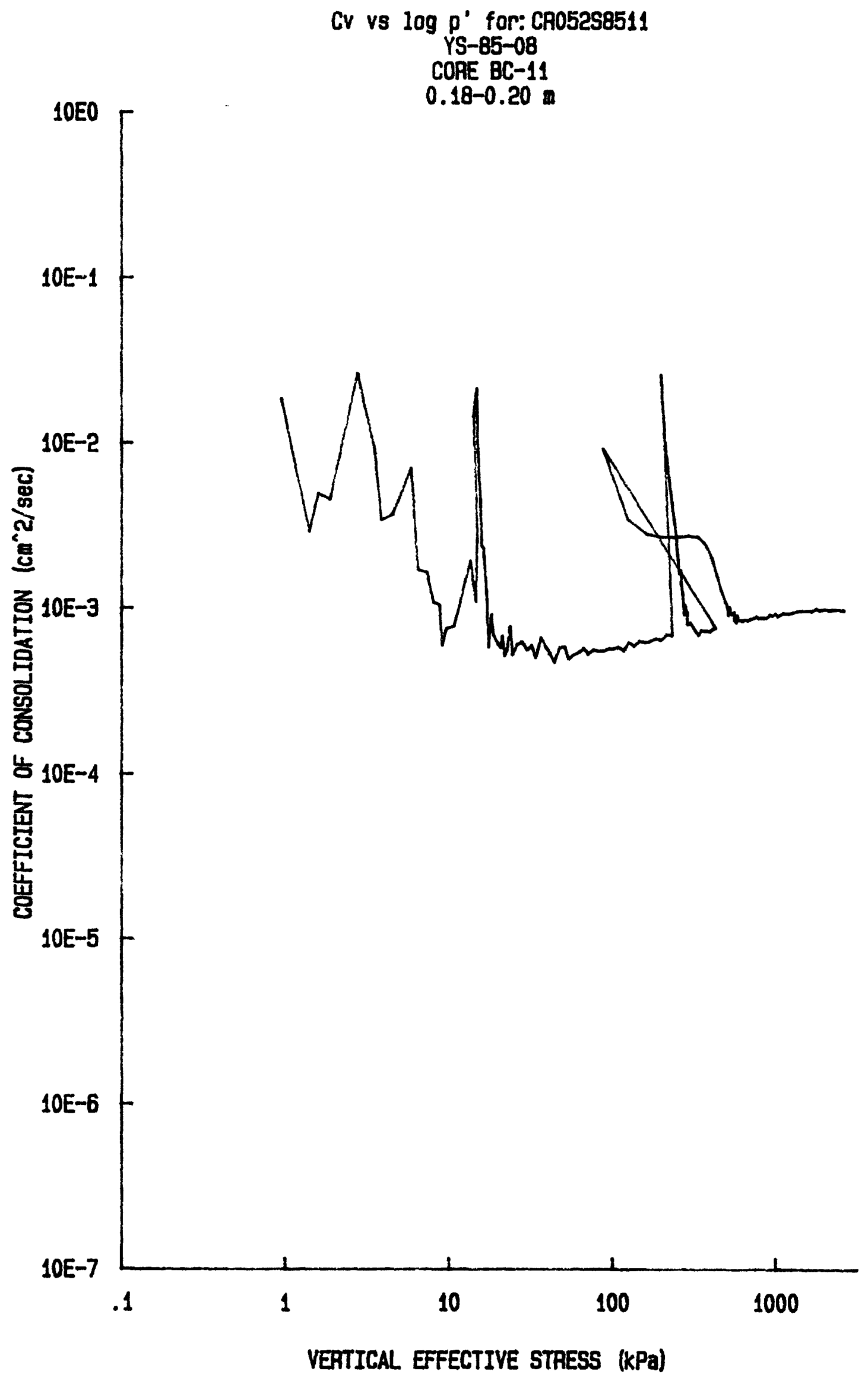




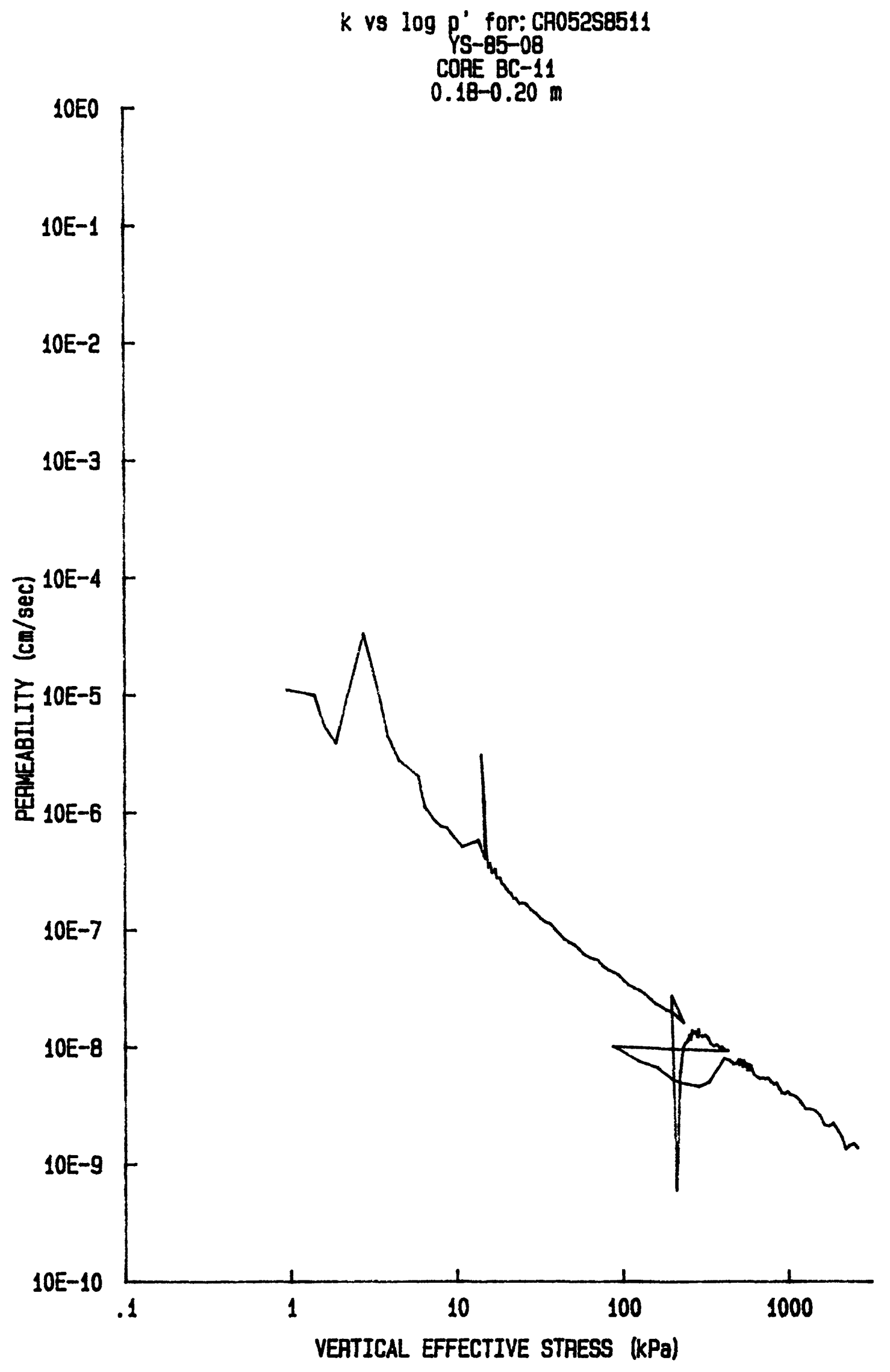




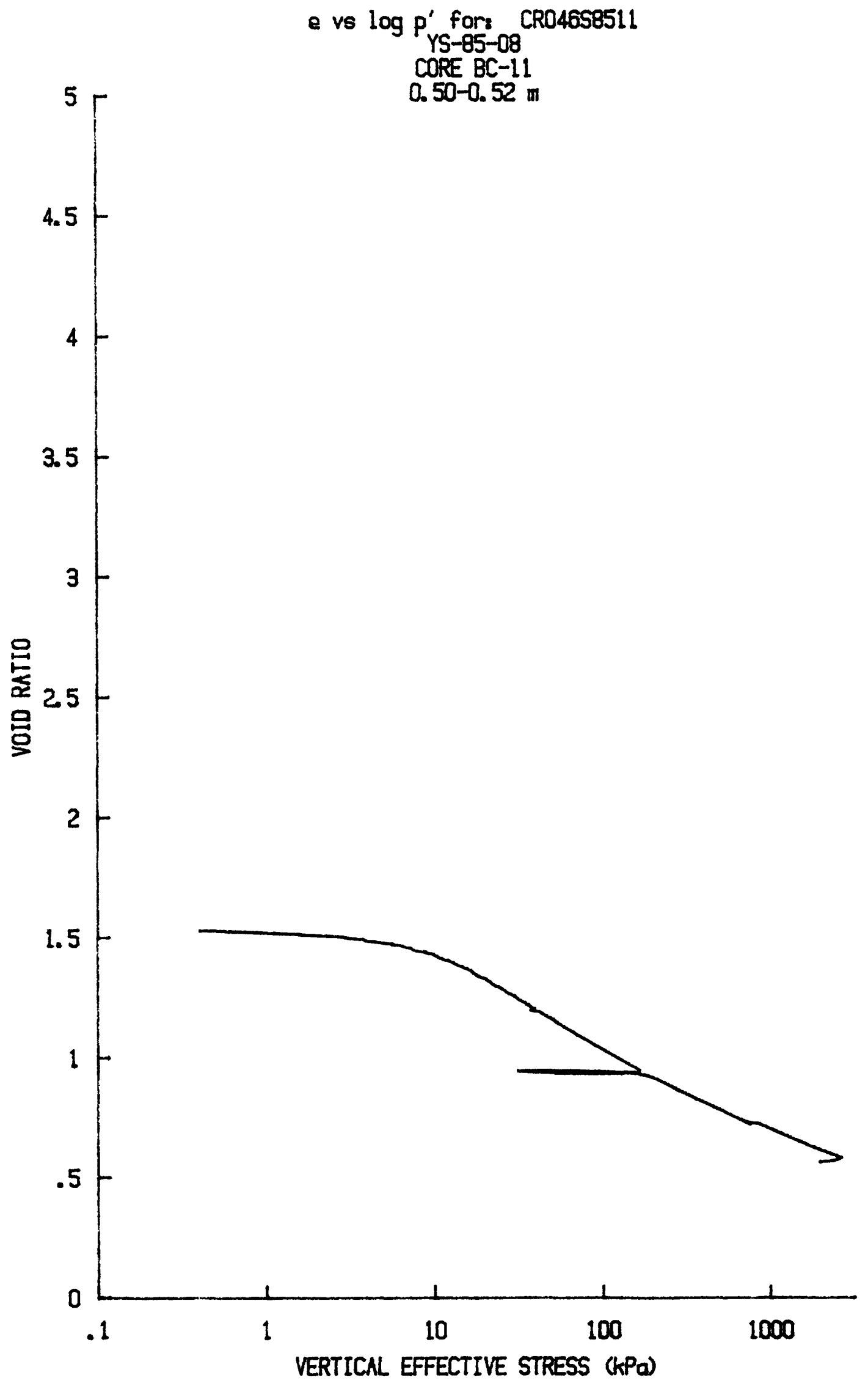




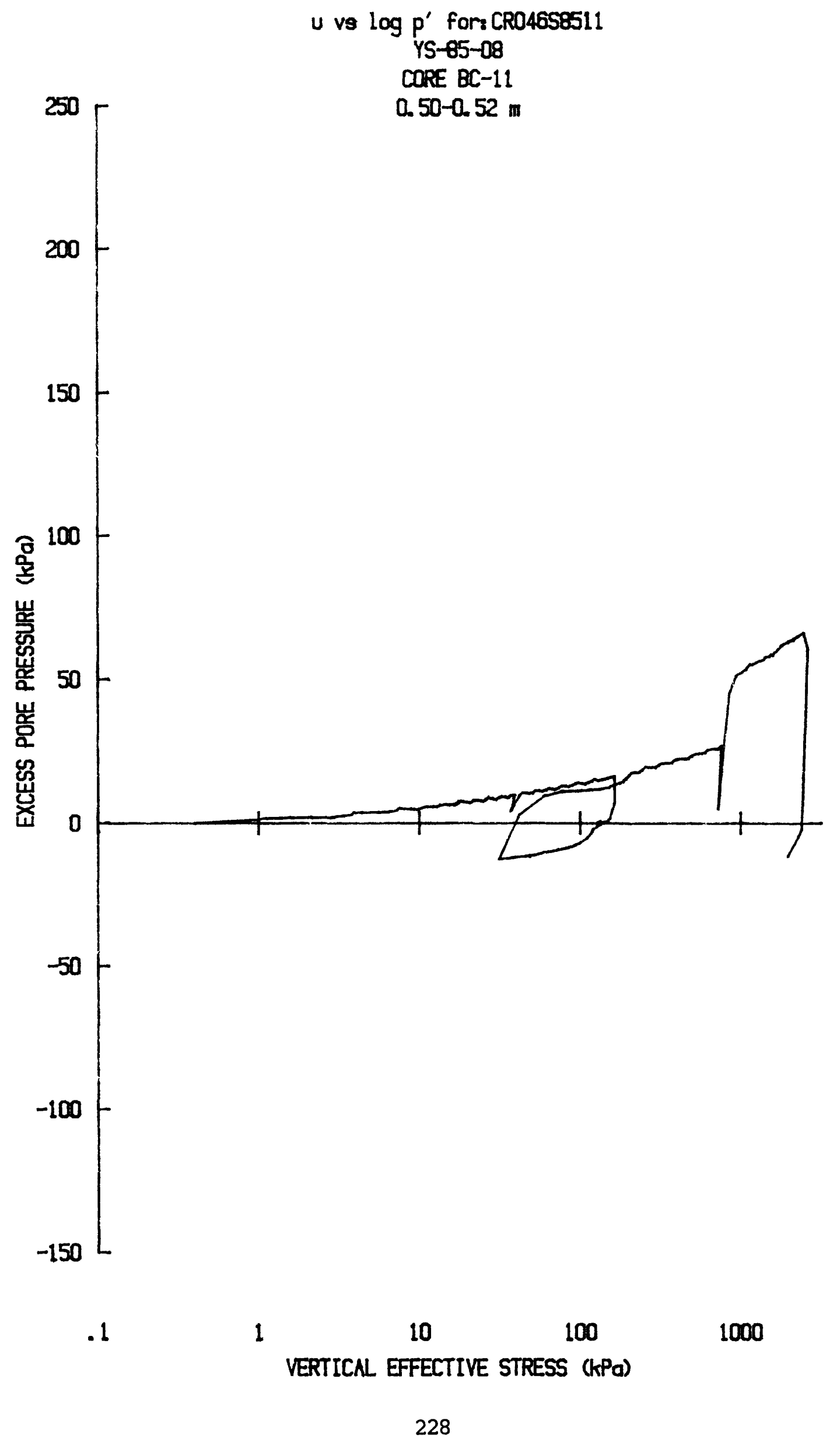




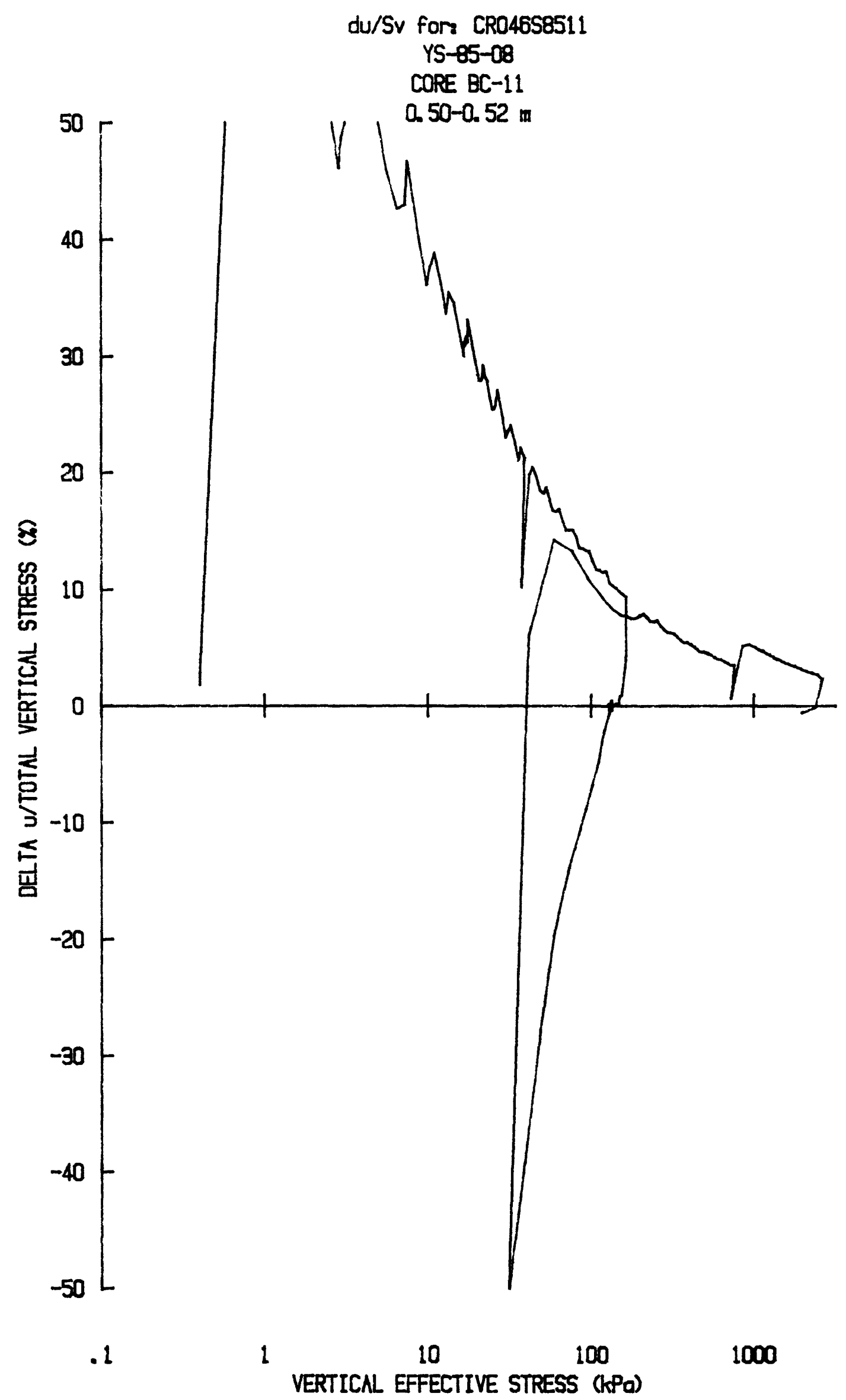




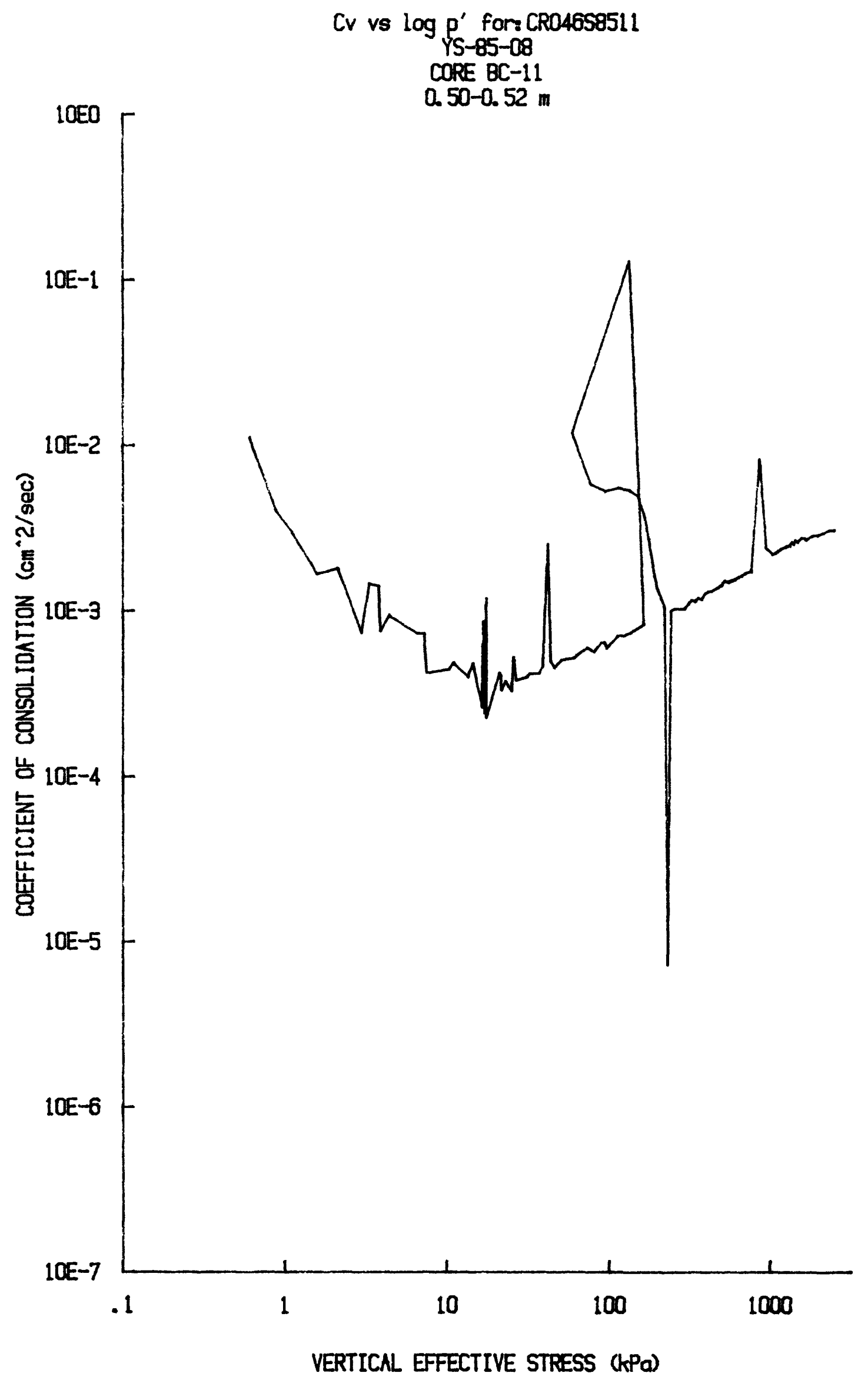




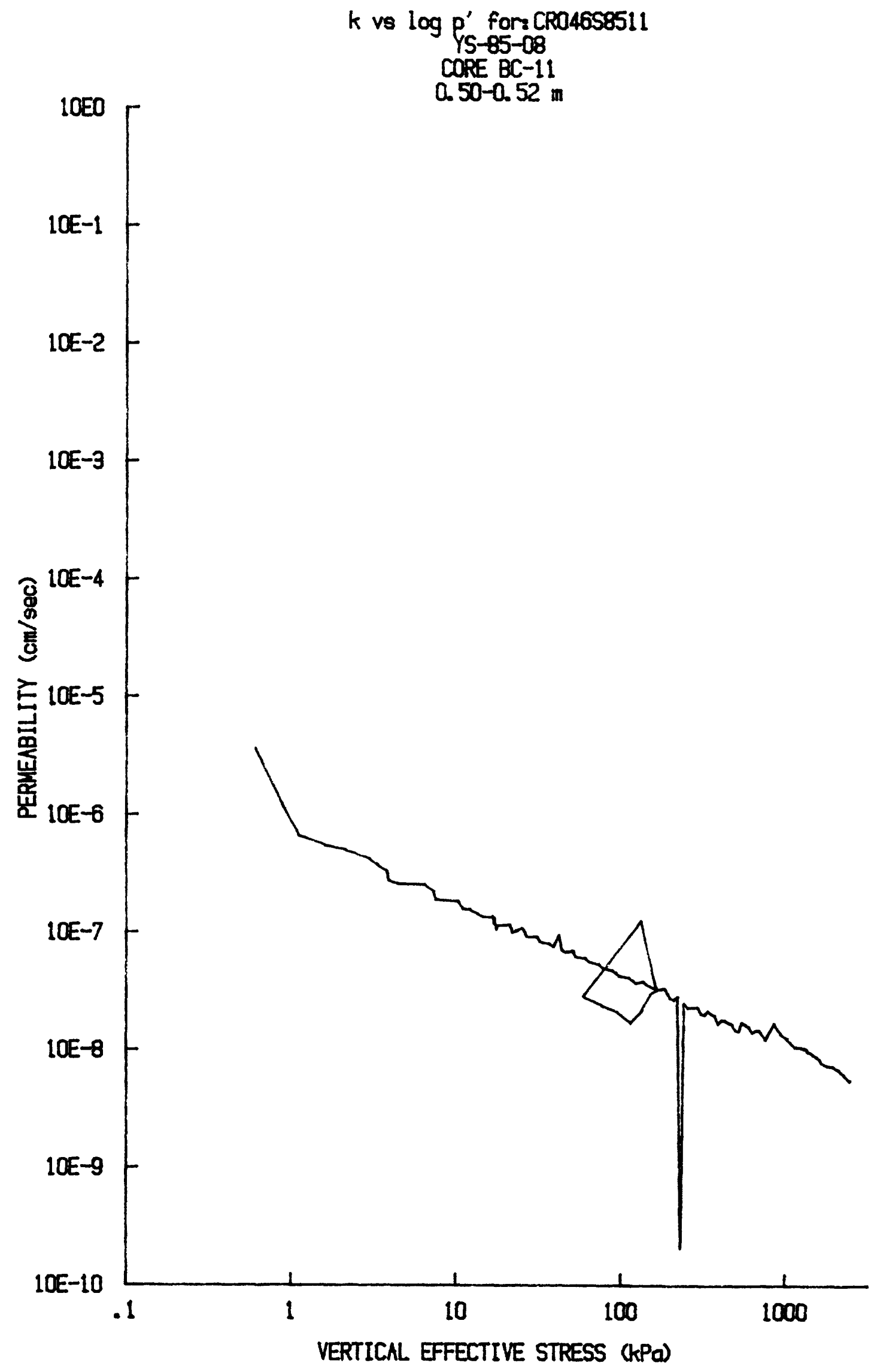




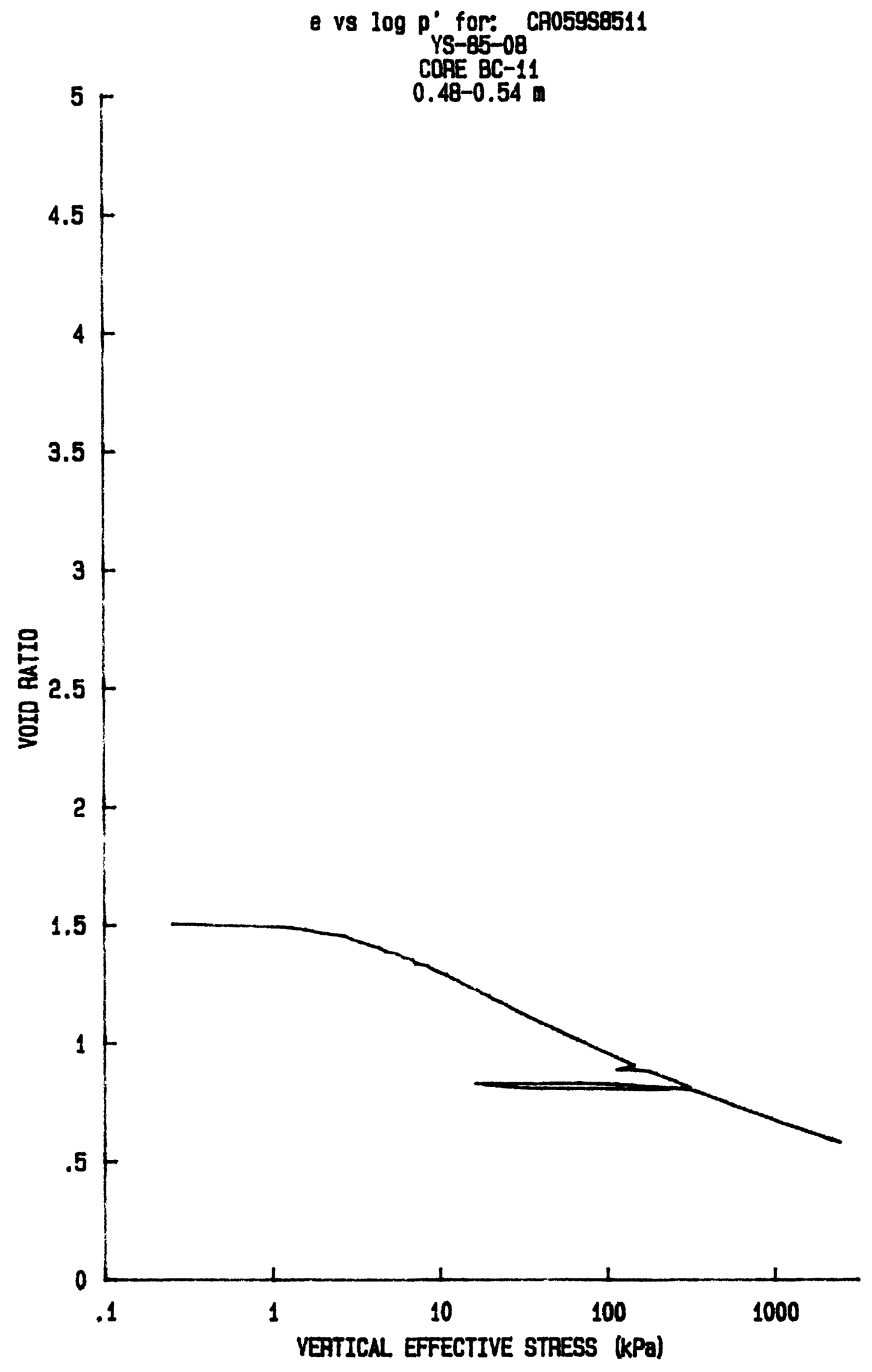




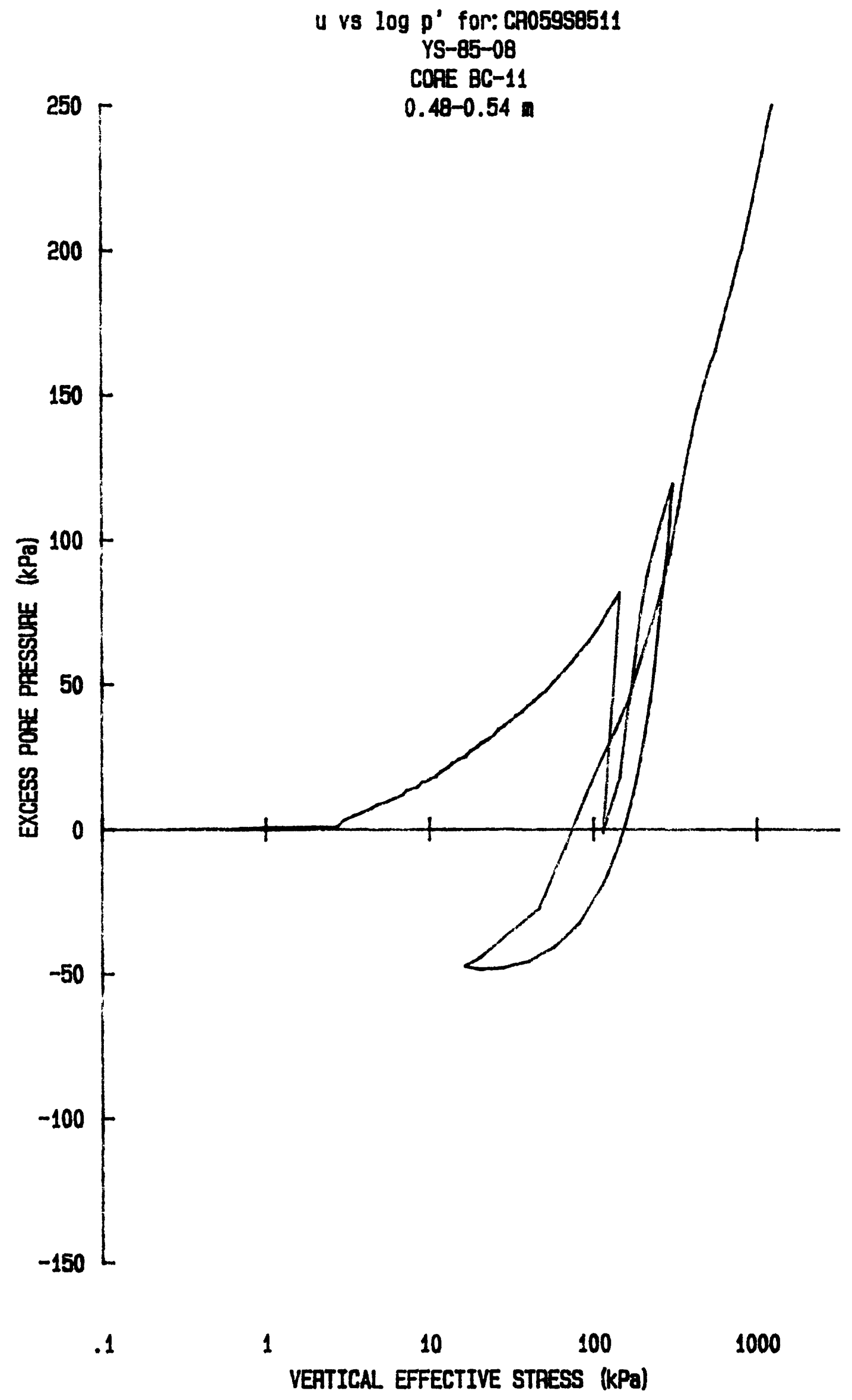




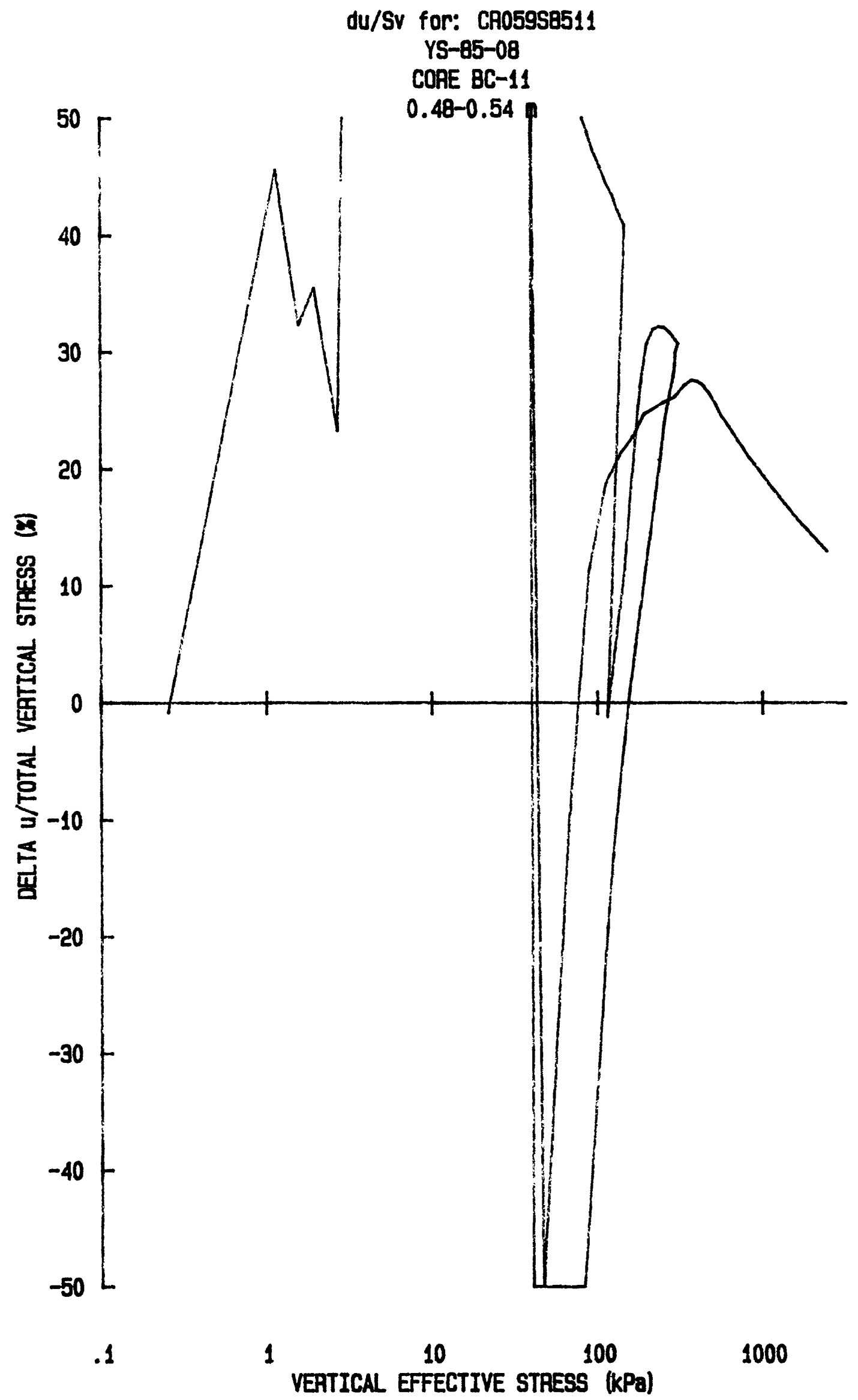




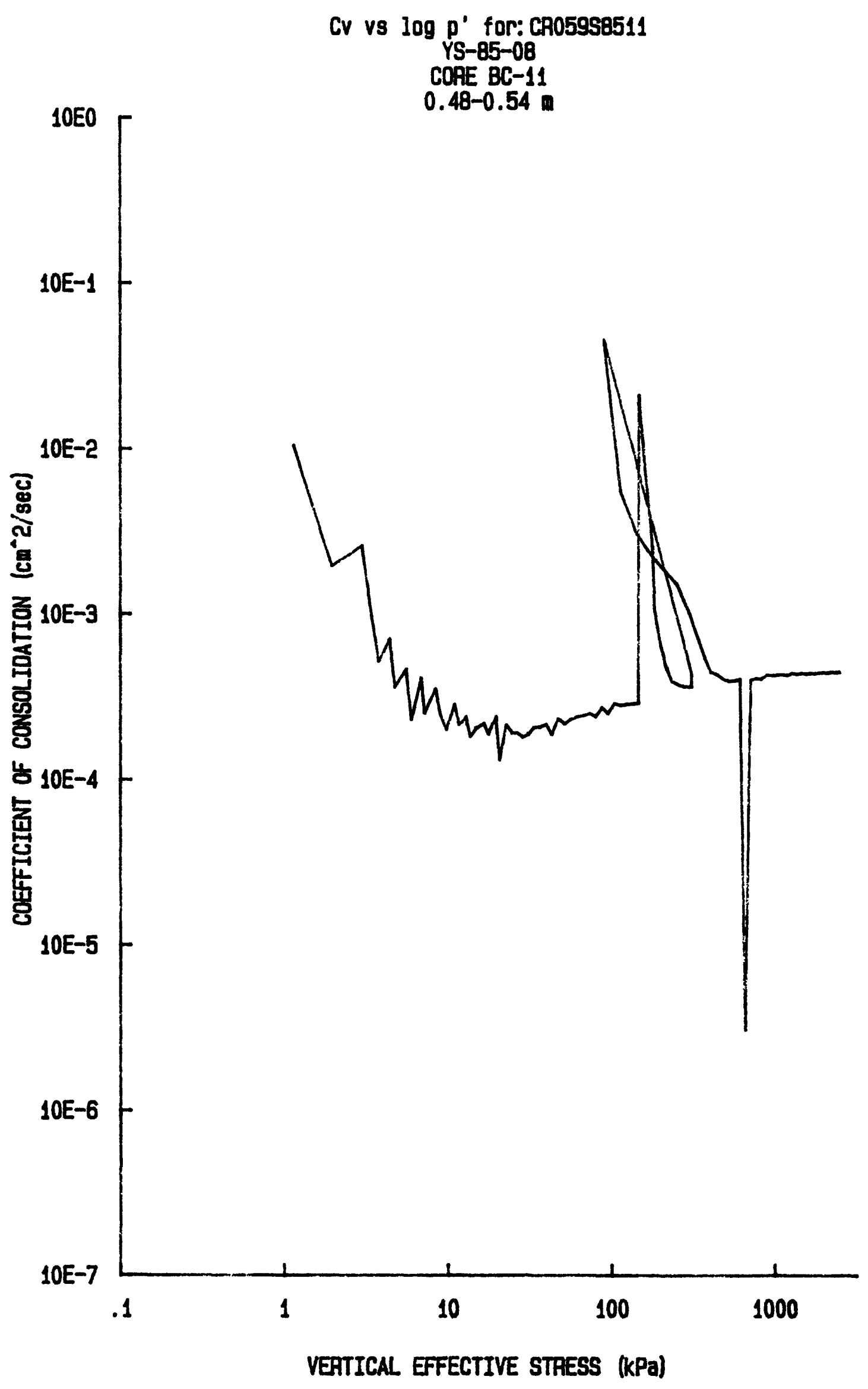




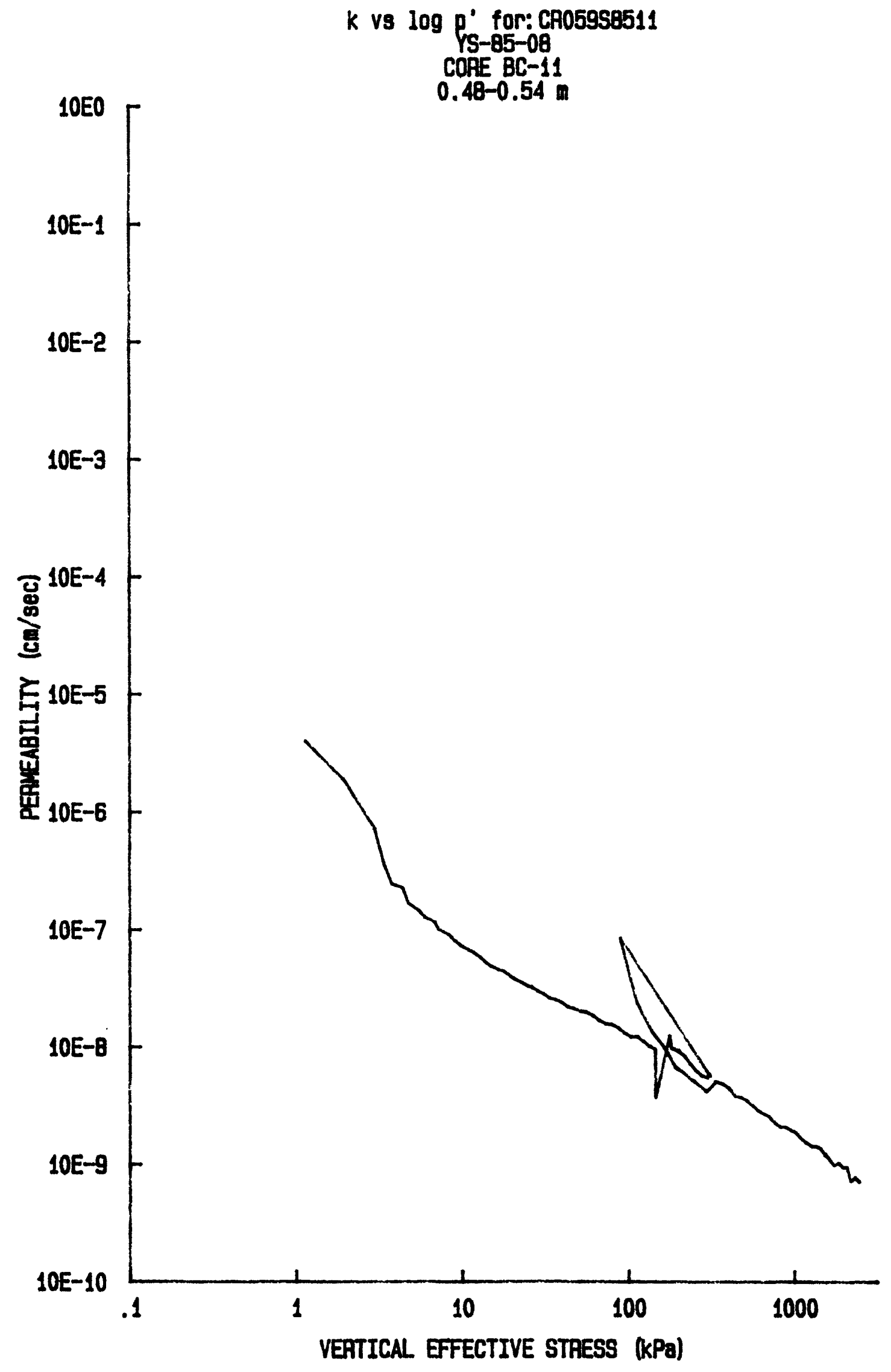




\section{Appendix D}

Results of Consolidated-Isotropic-Undrained Triaxial Tests

tabular data

unedited individual test plots

unedited multiple test plots 
TABULAR DATA 


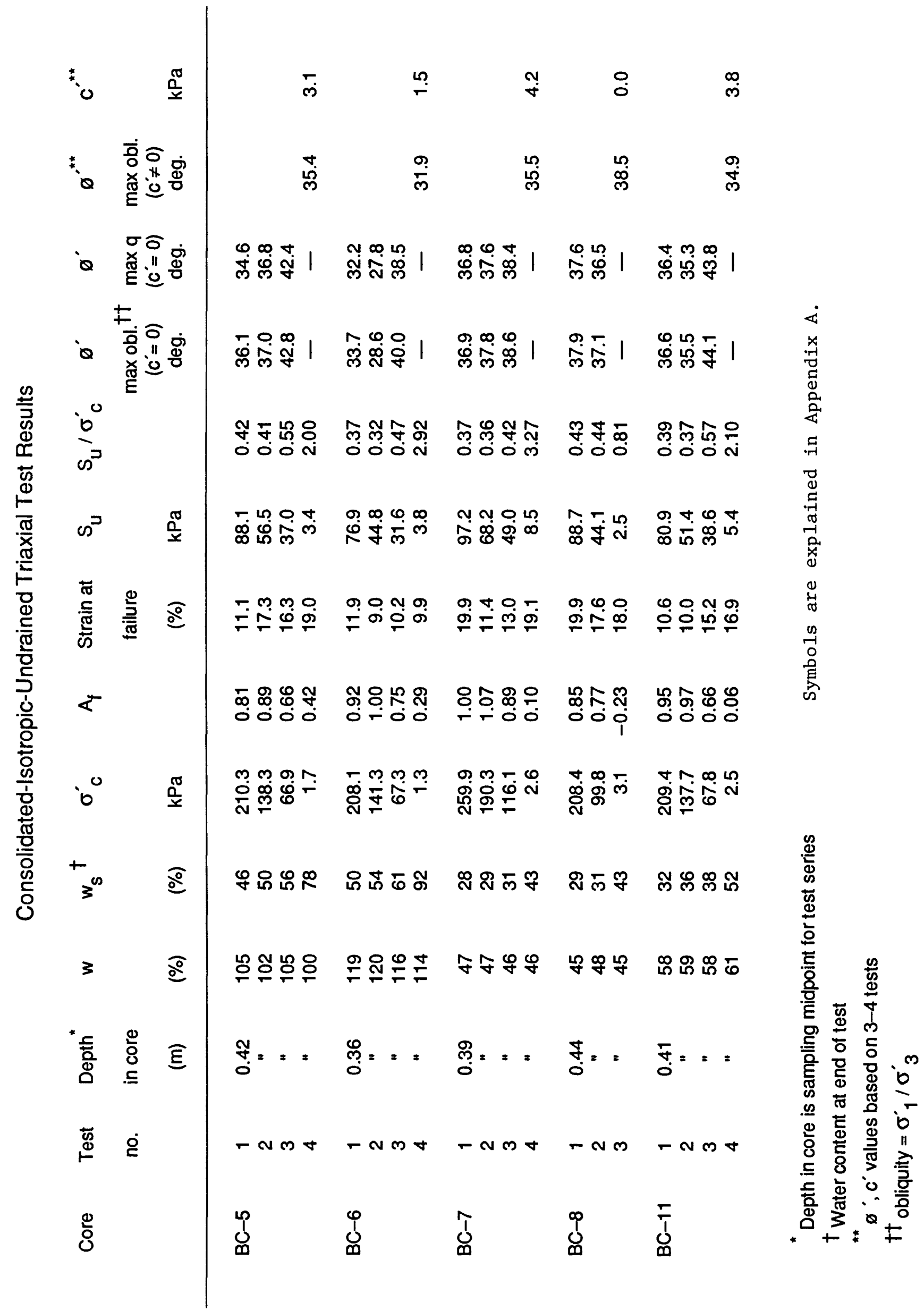


INDIVIDUAL TEST PLOTS 

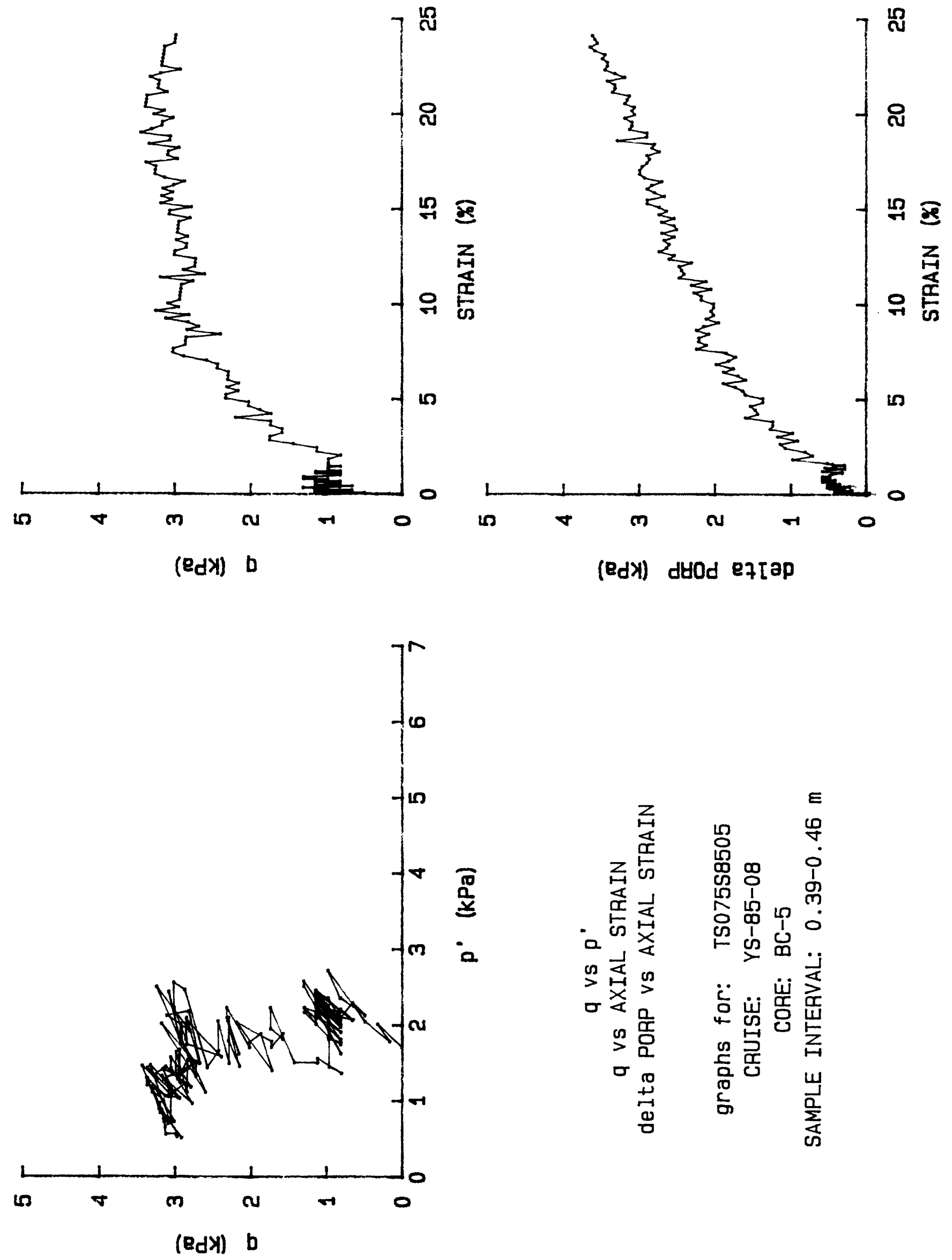

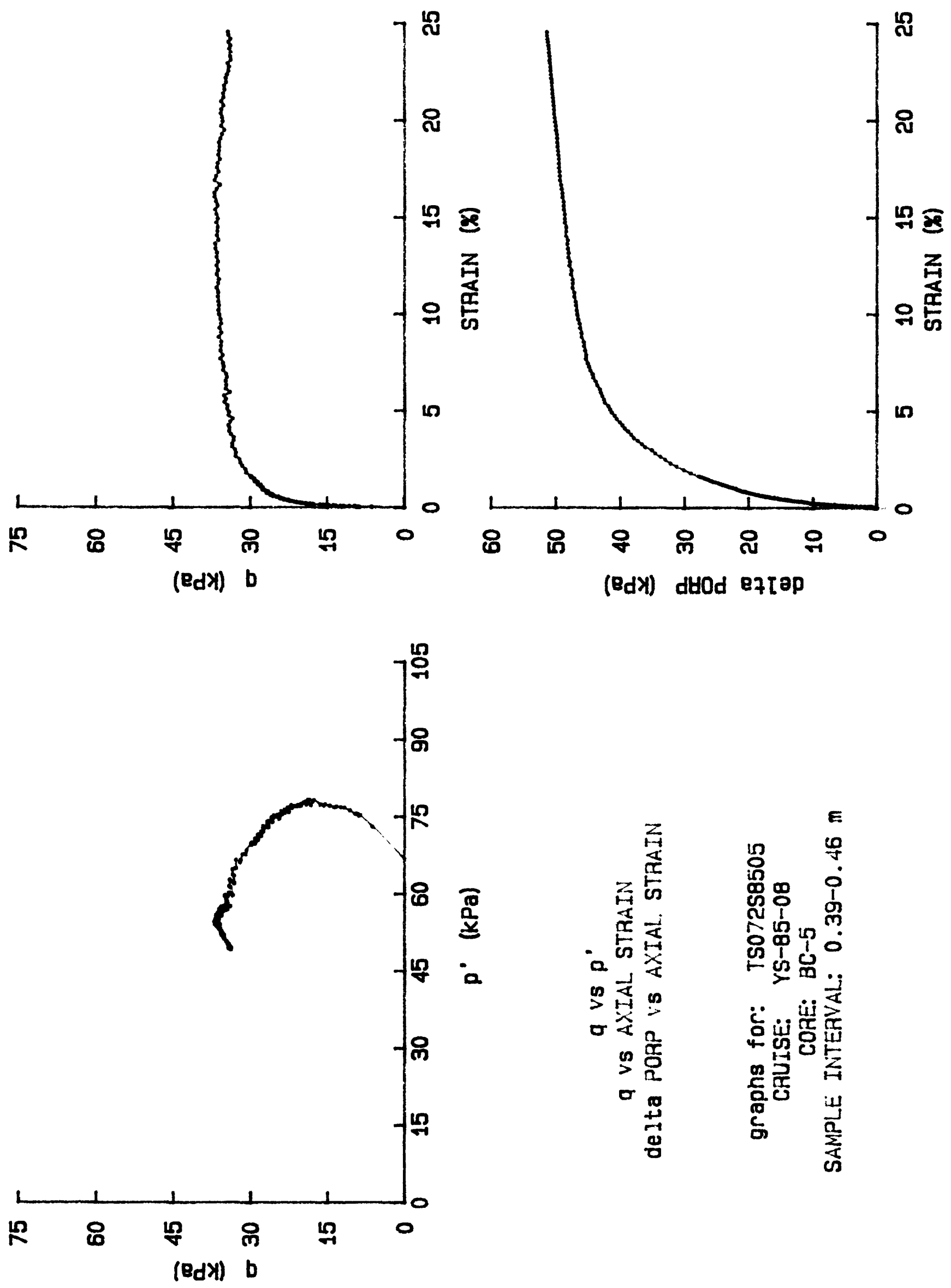

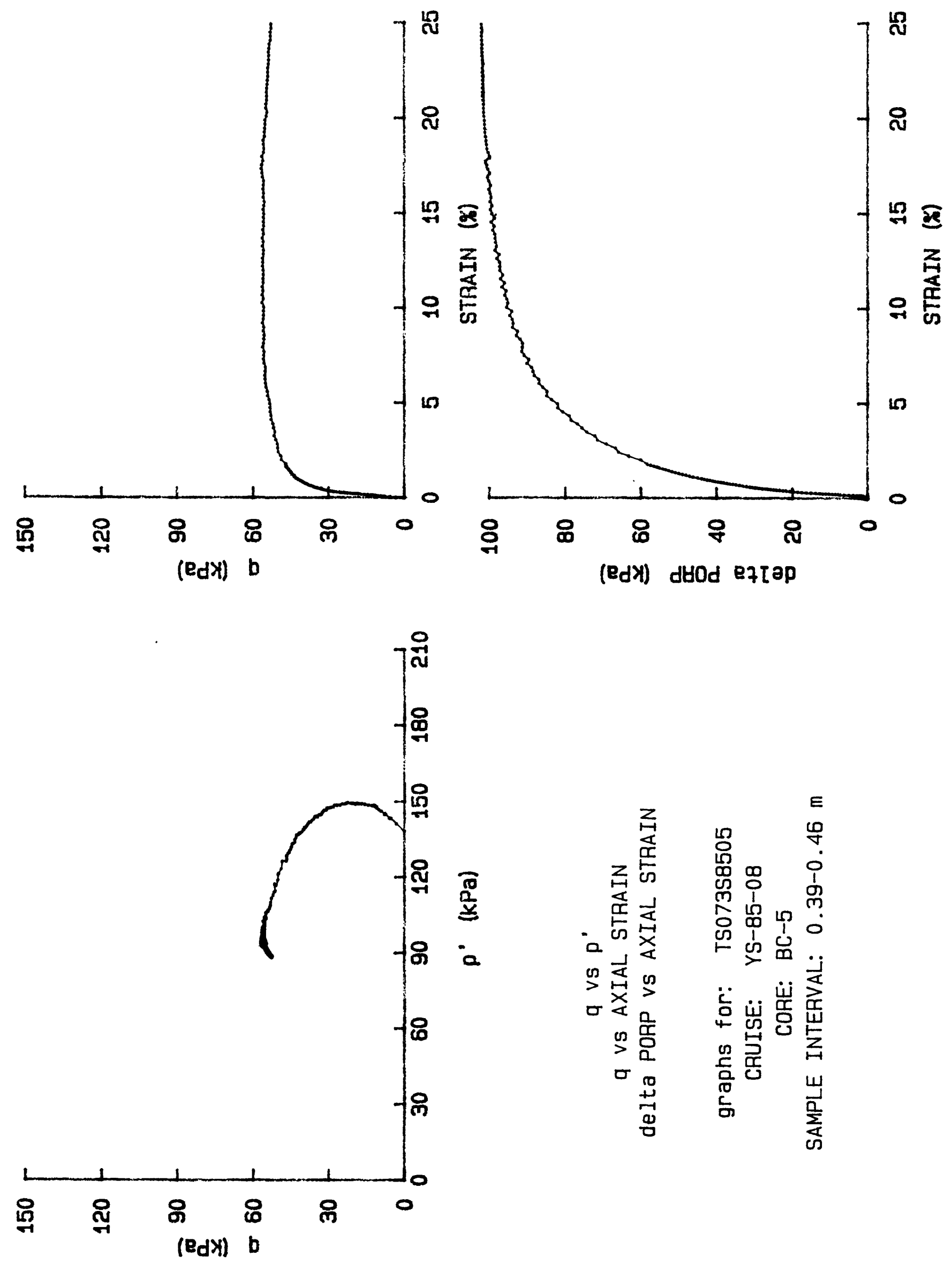

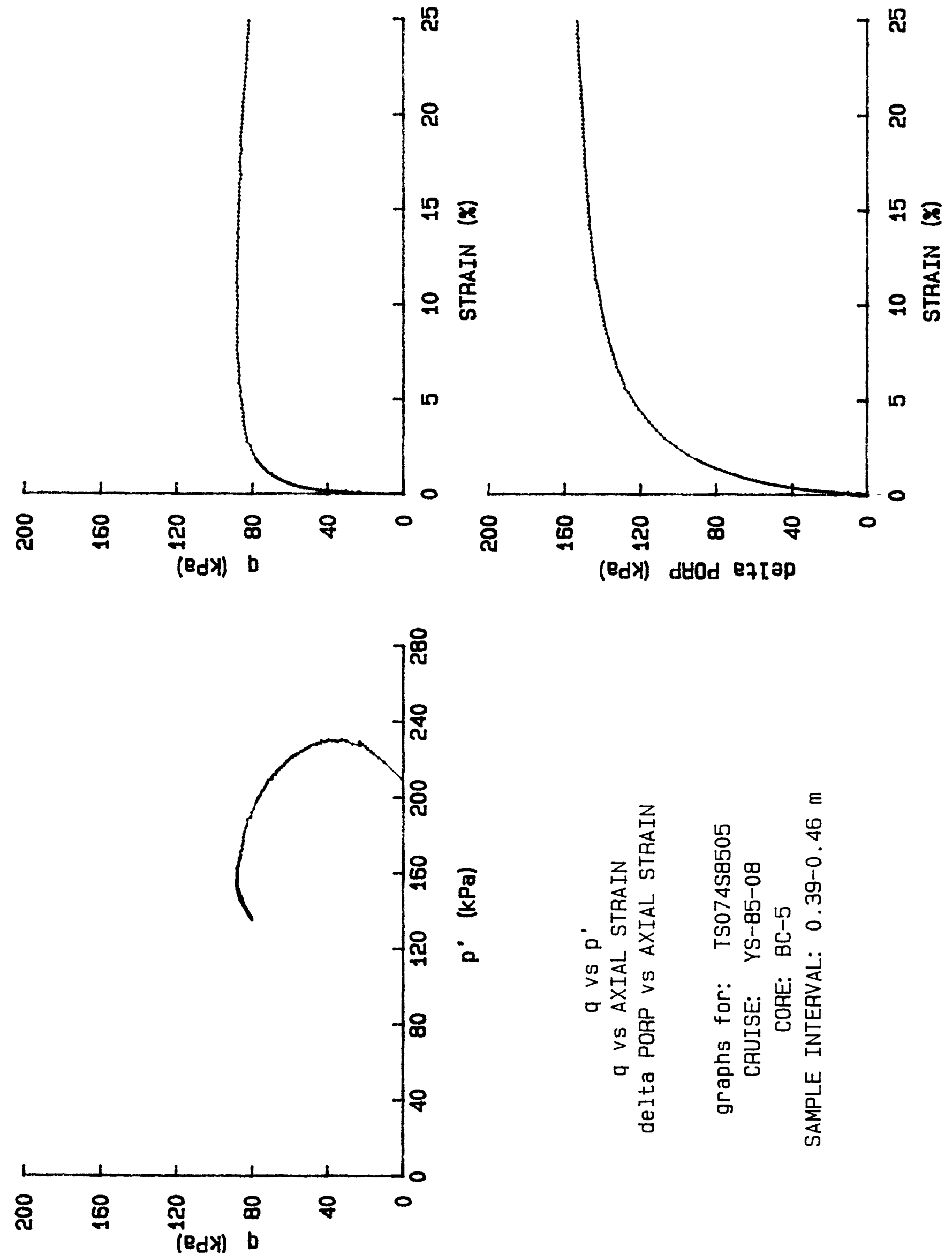

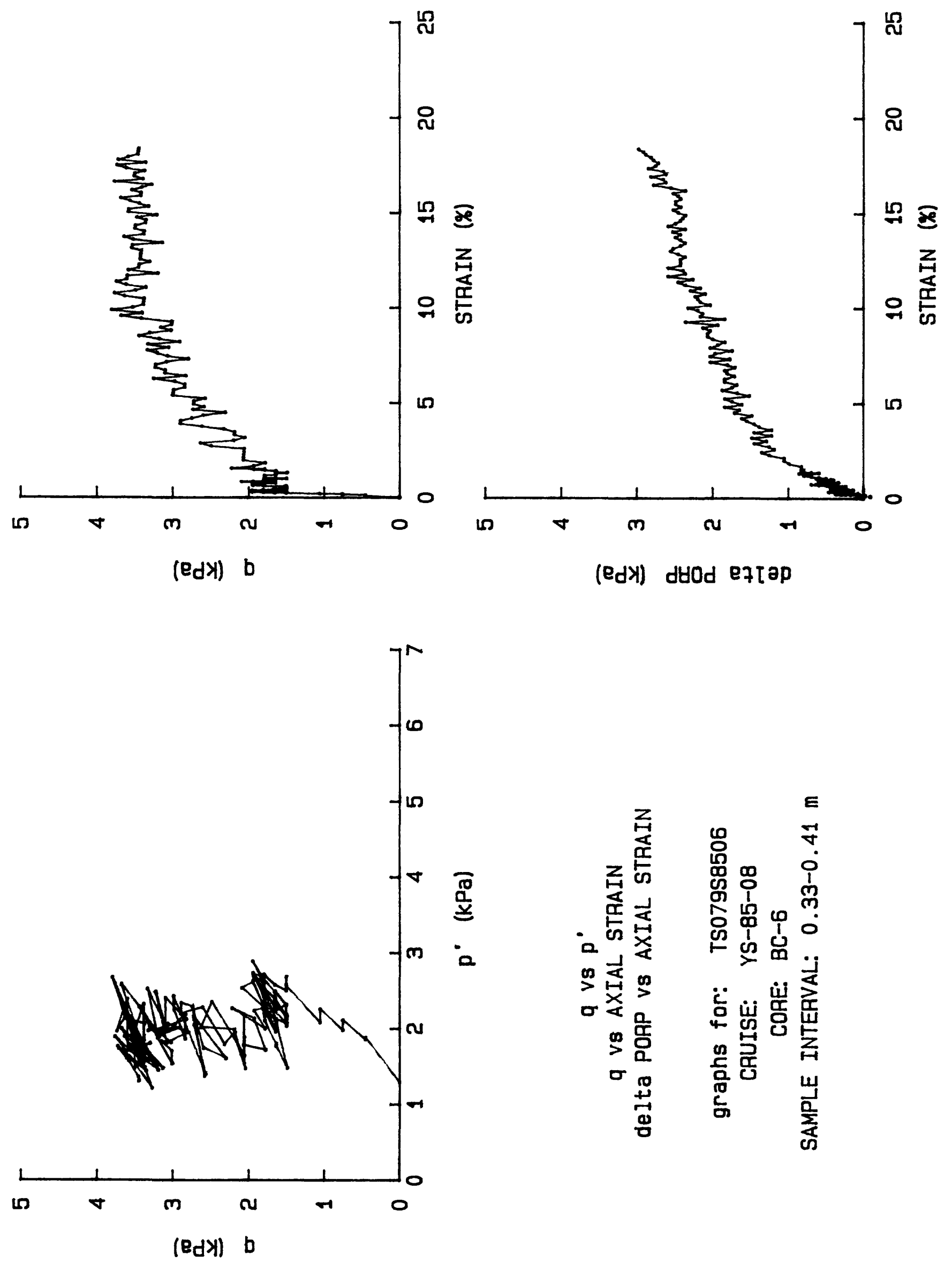


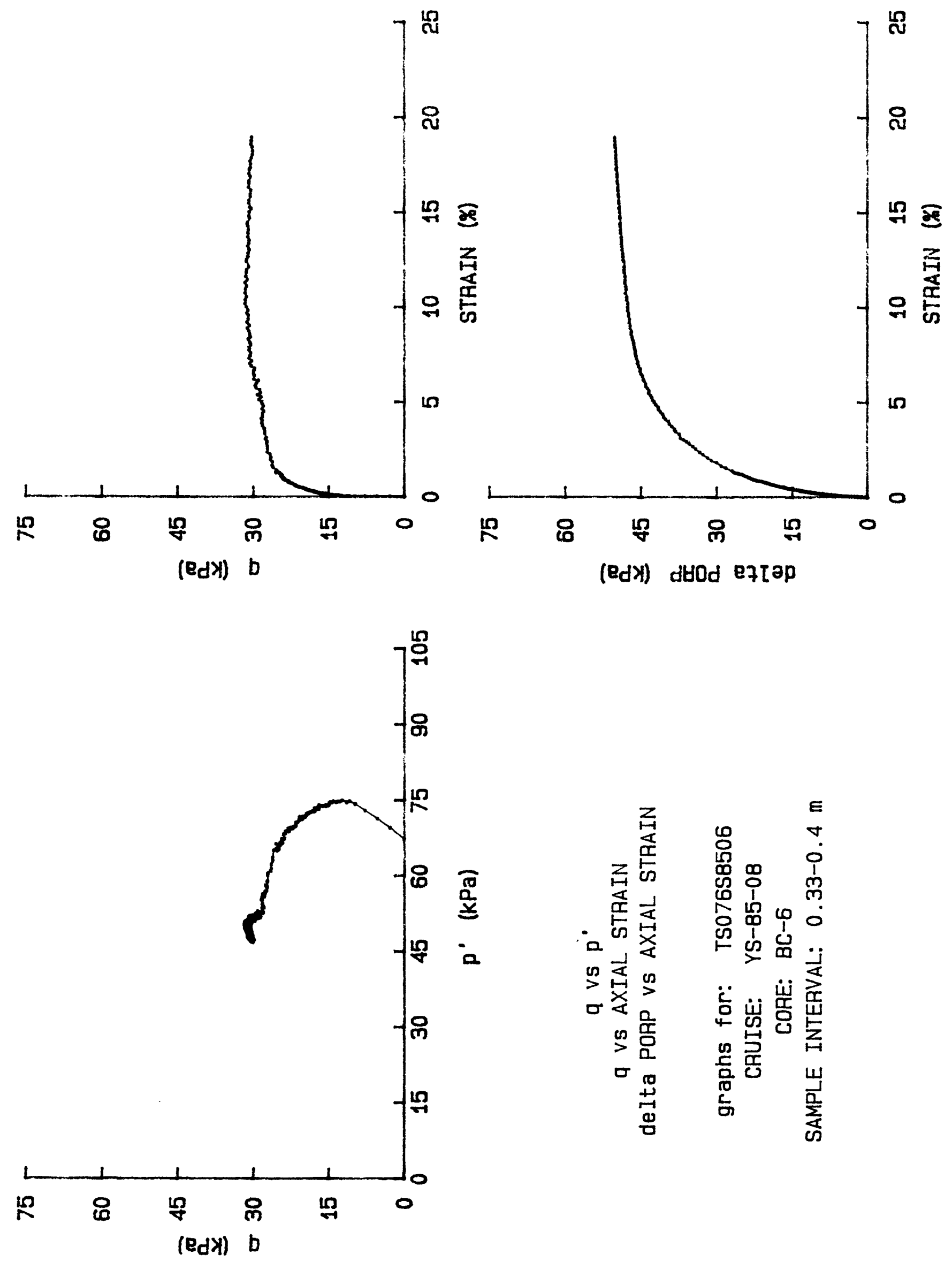



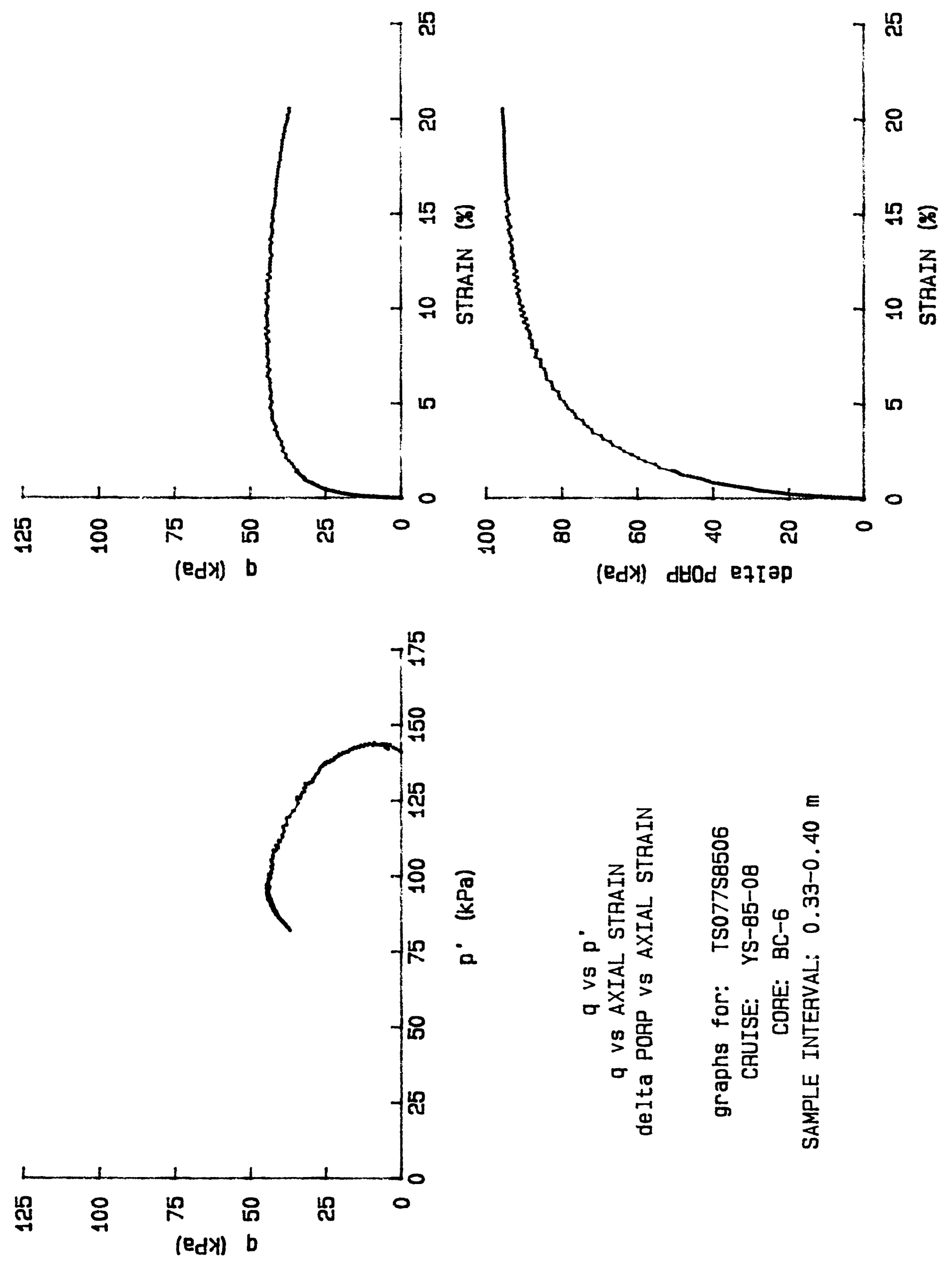

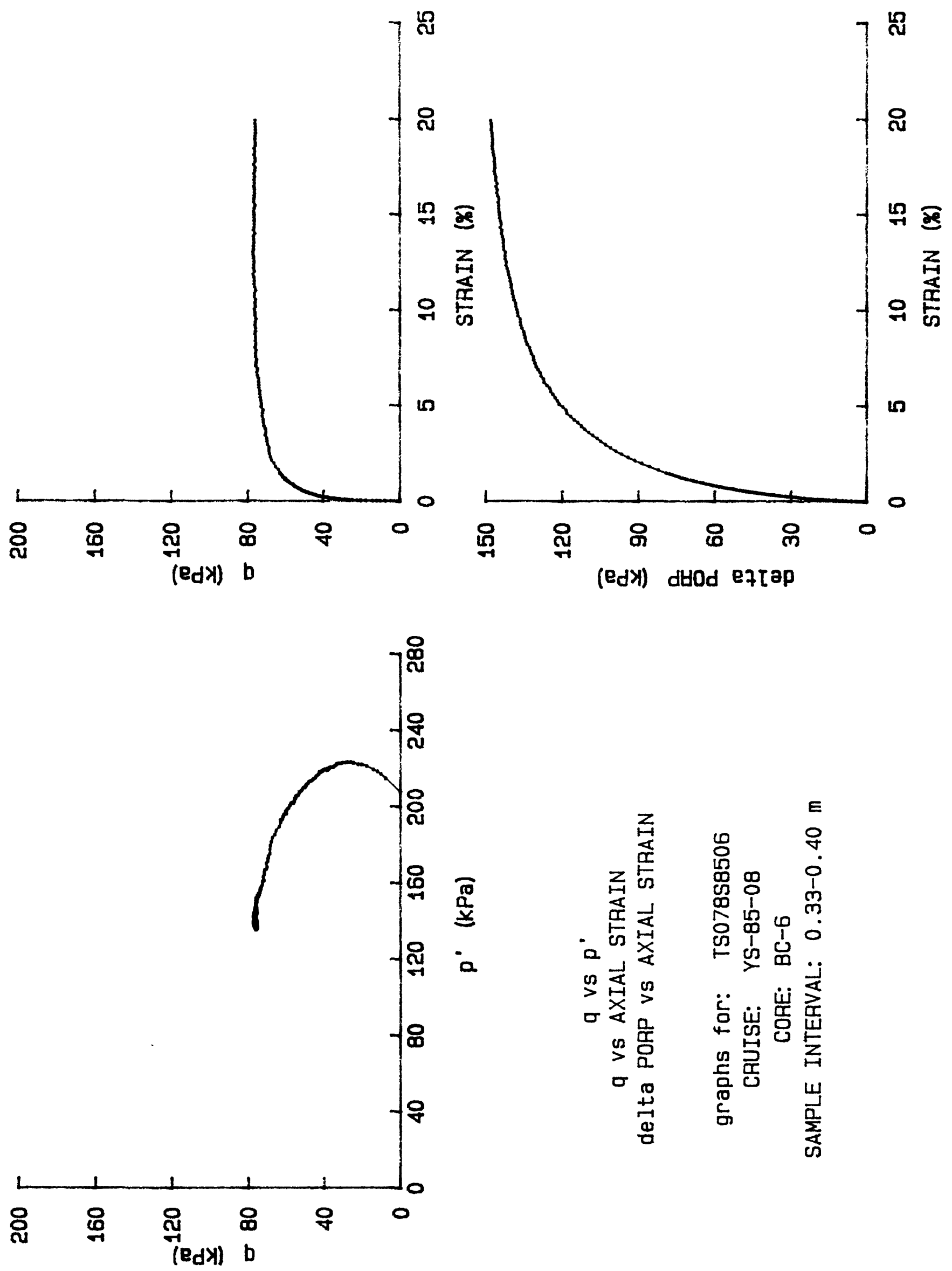

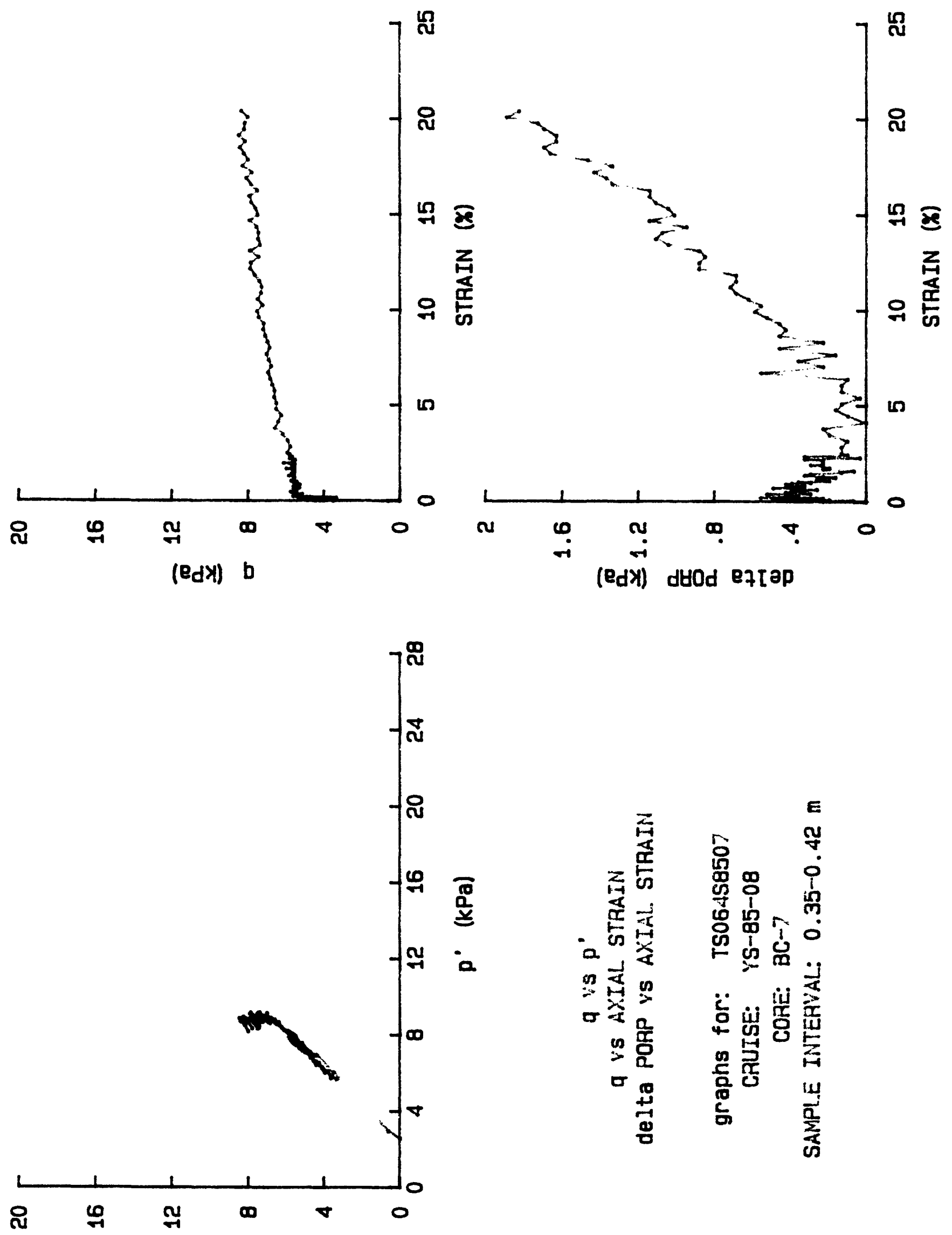

(EdY) b 

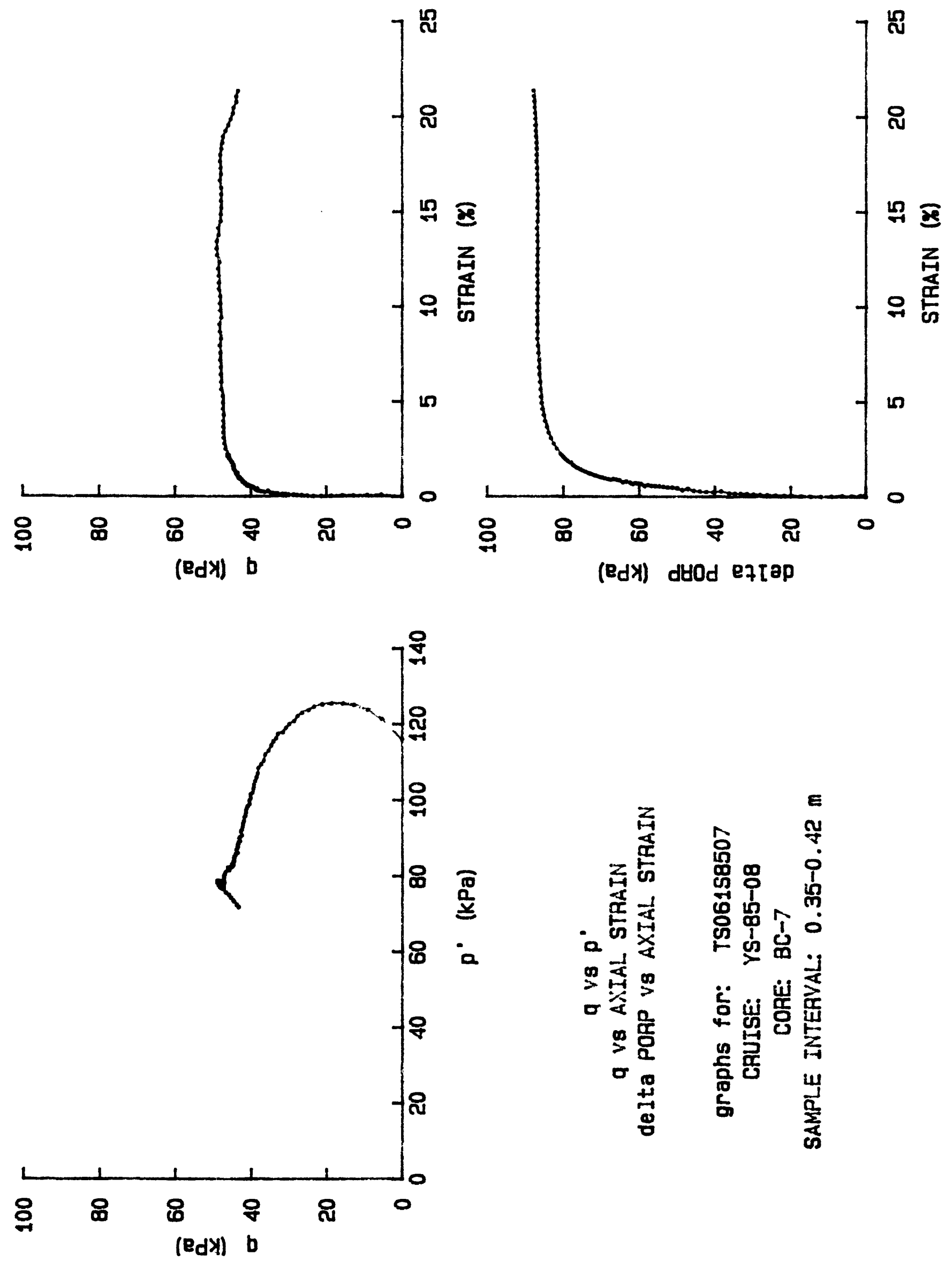

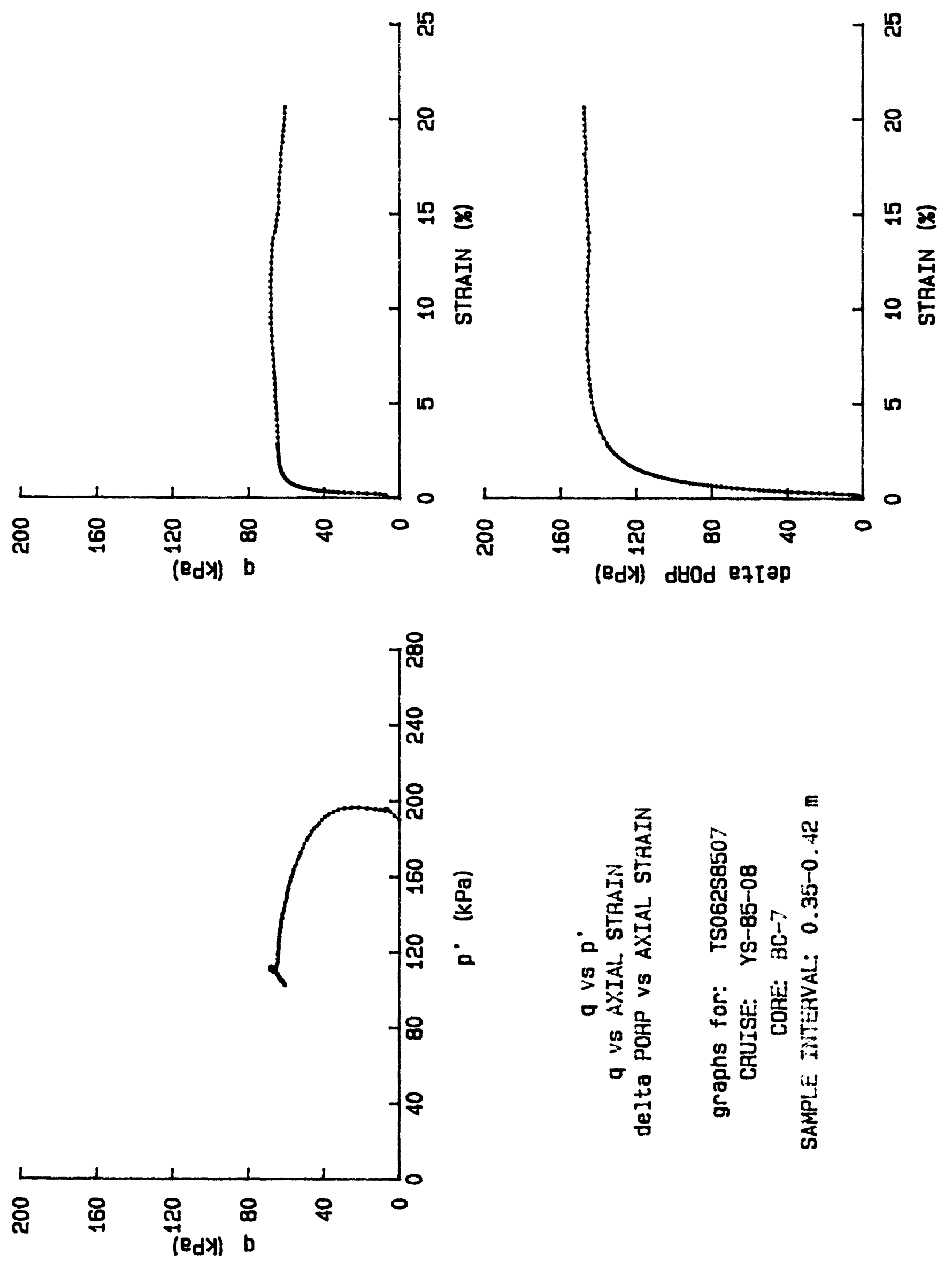


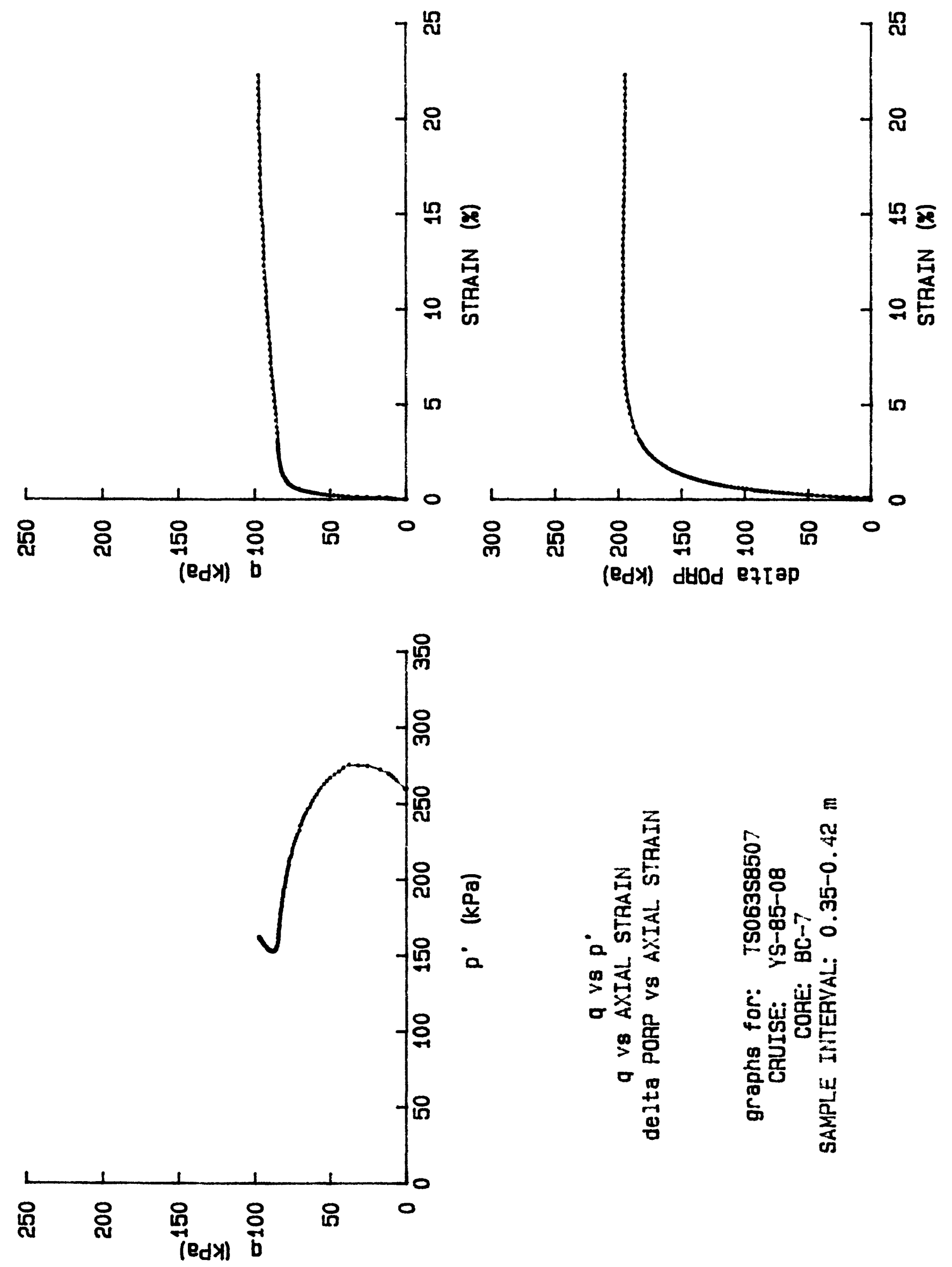



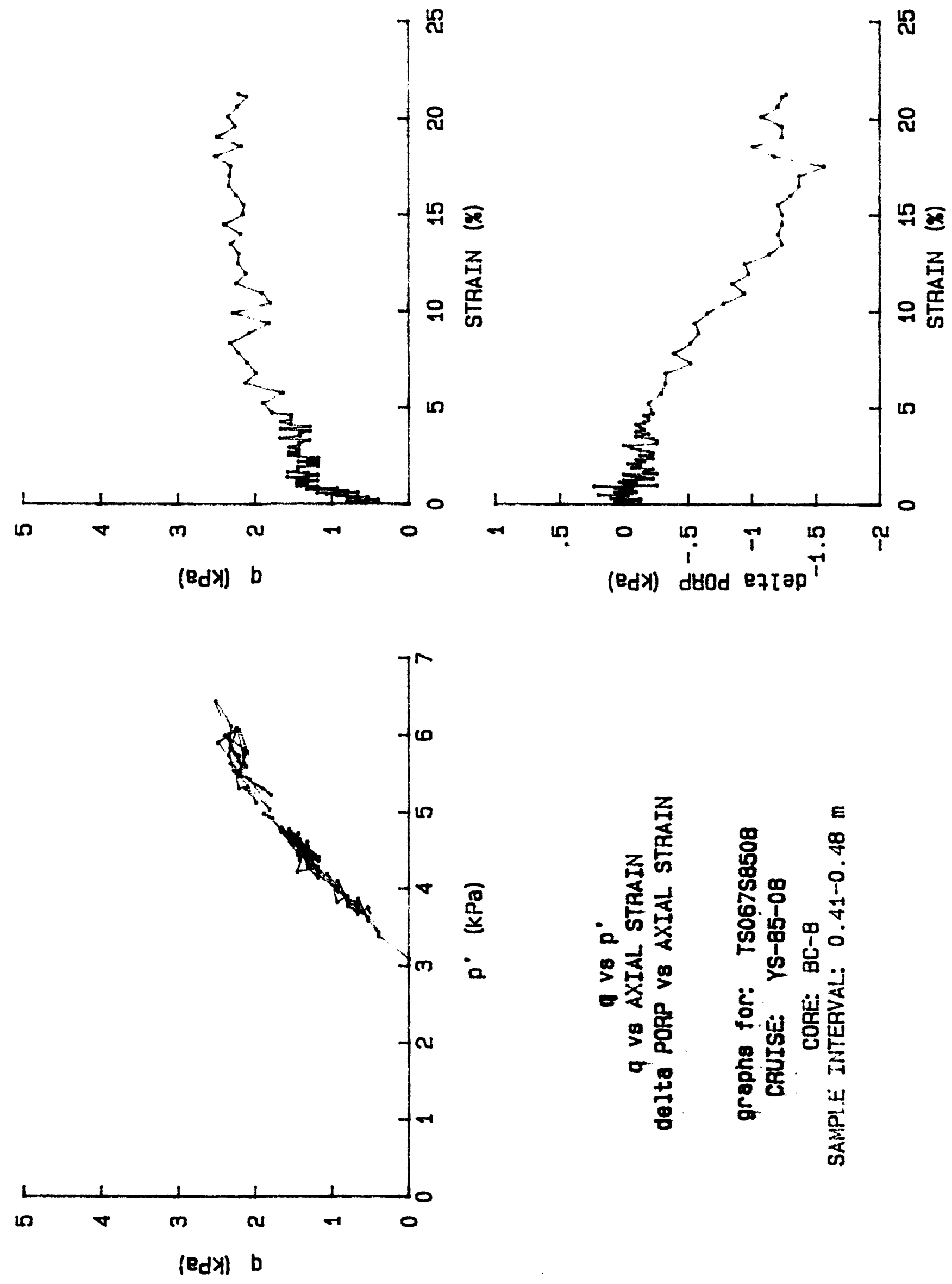


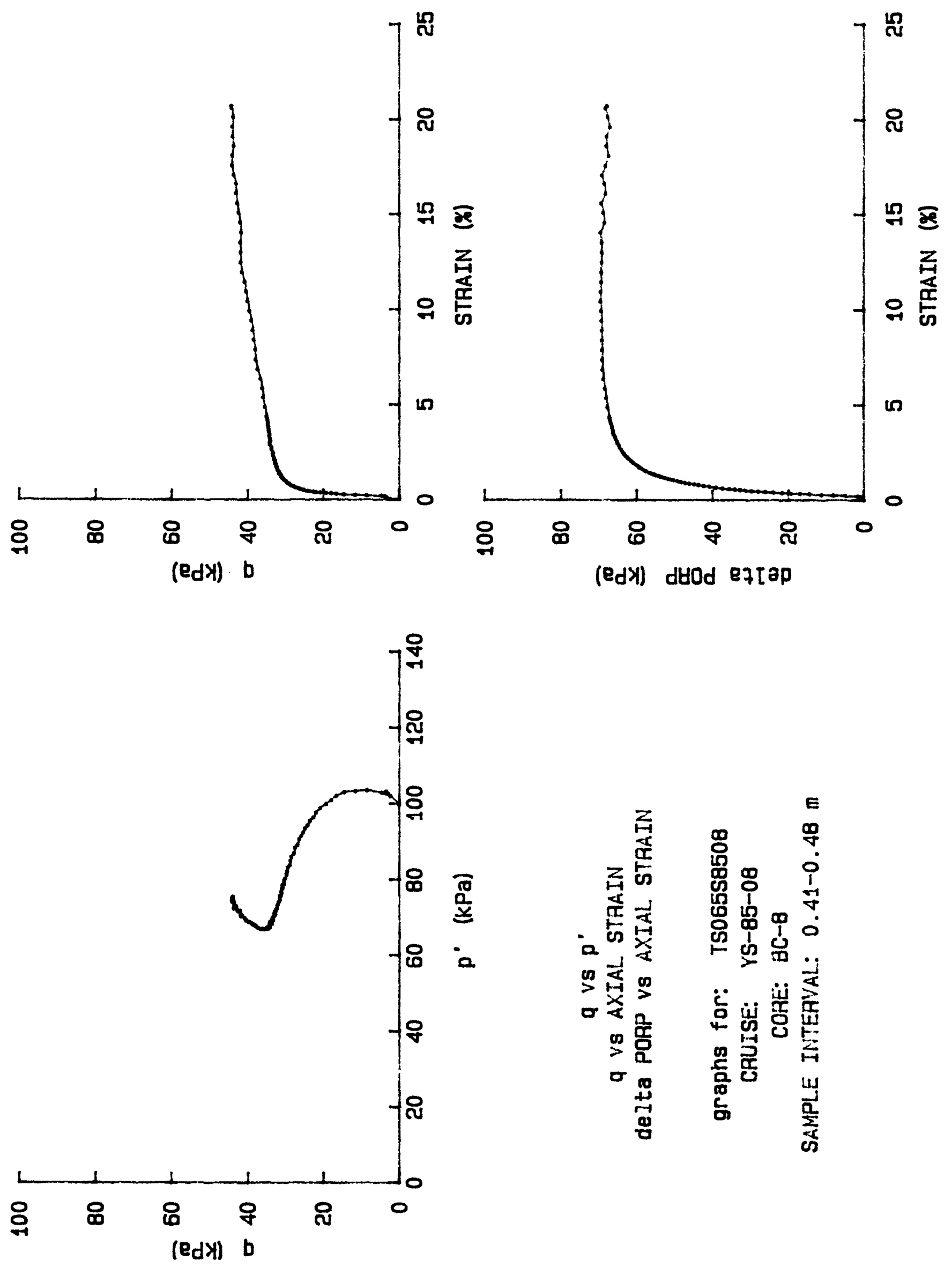




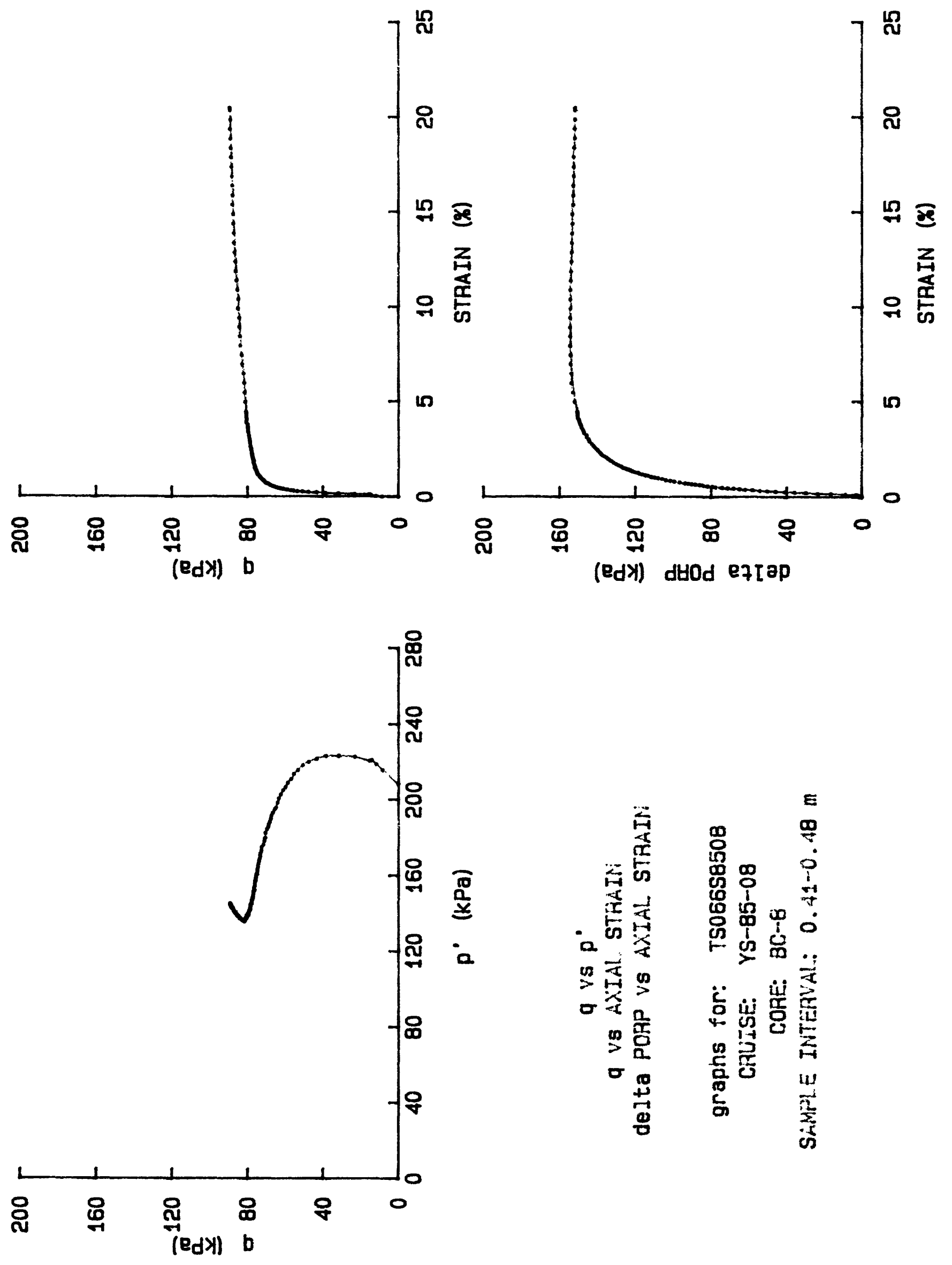



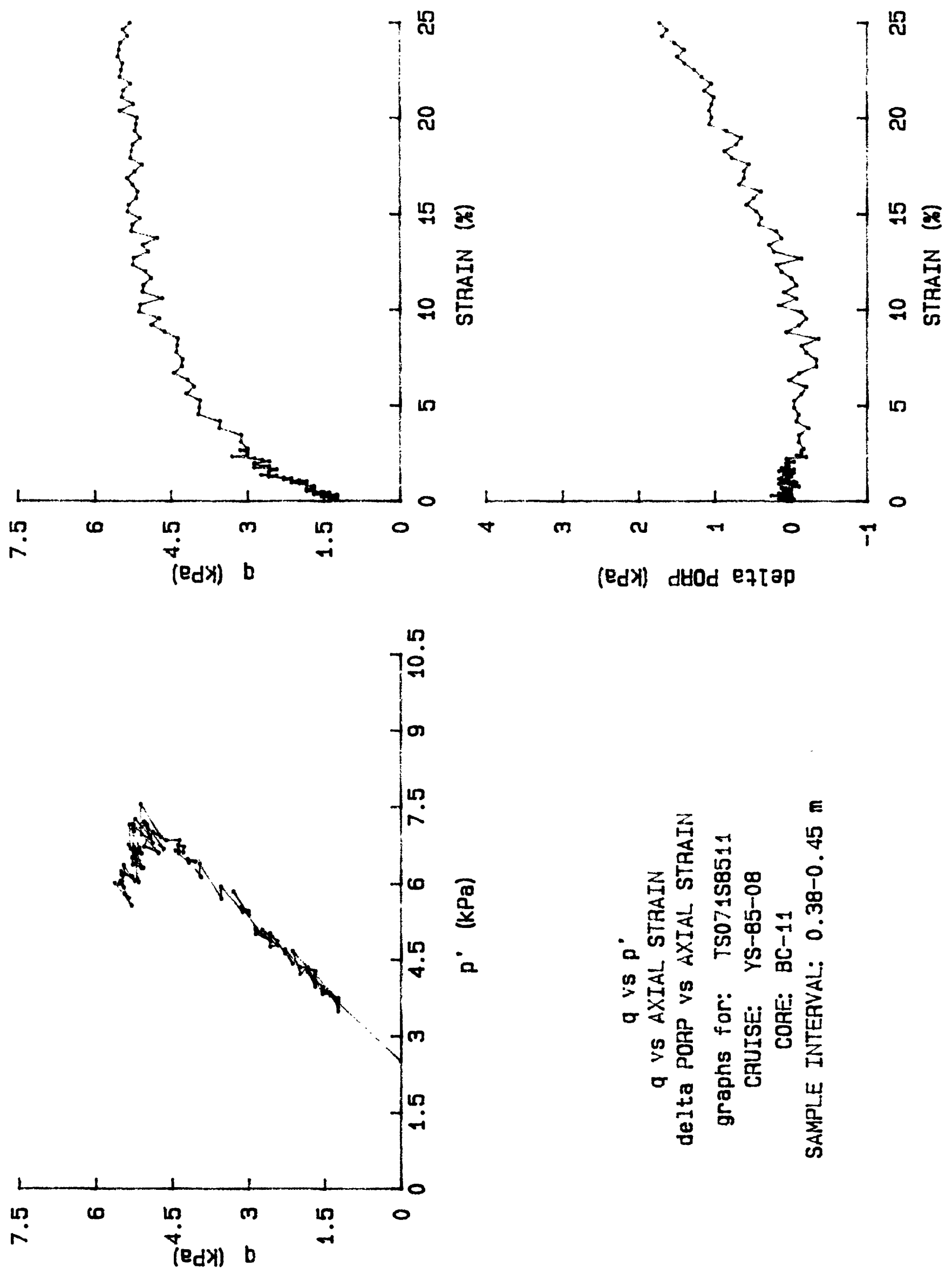

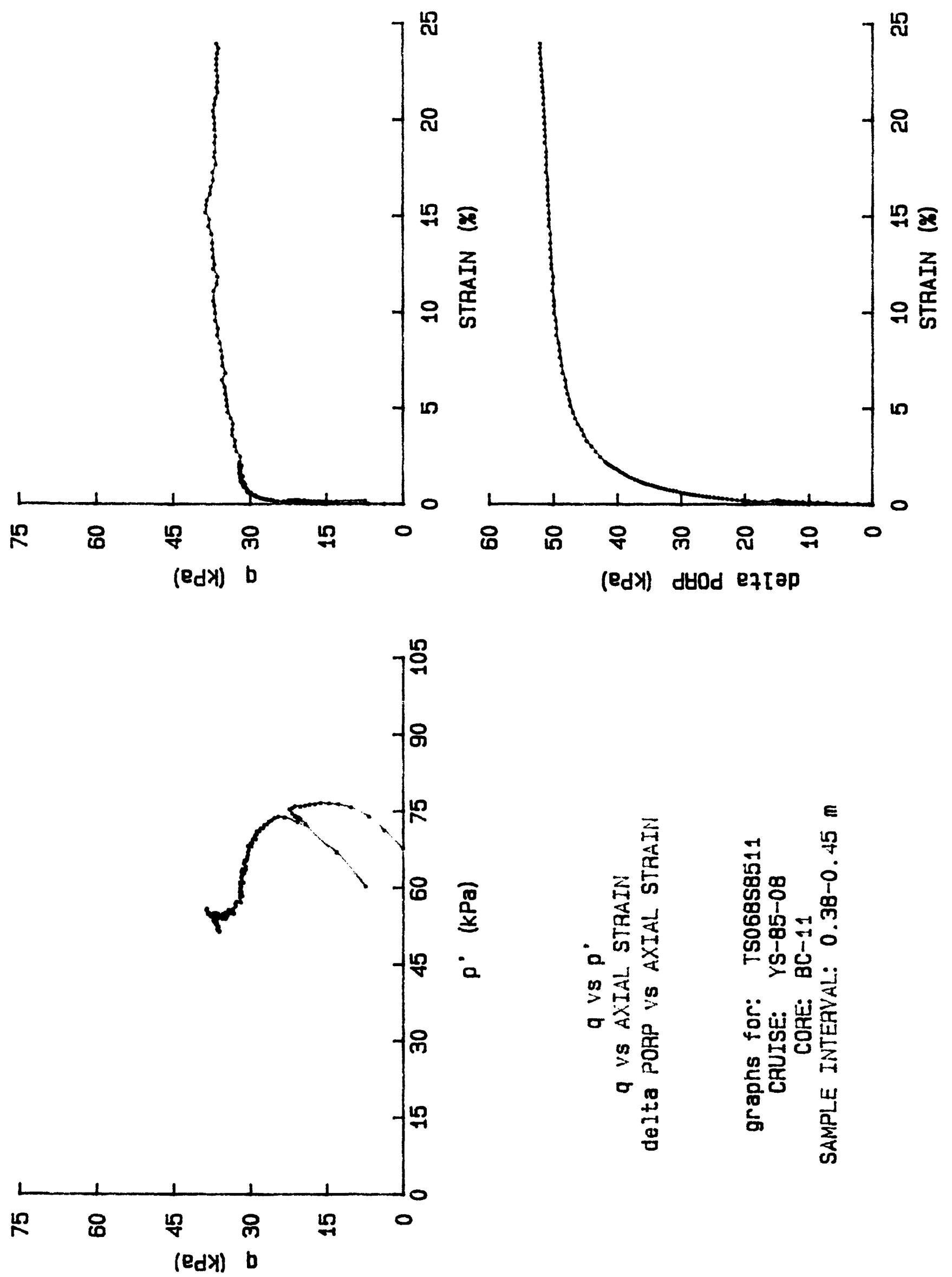

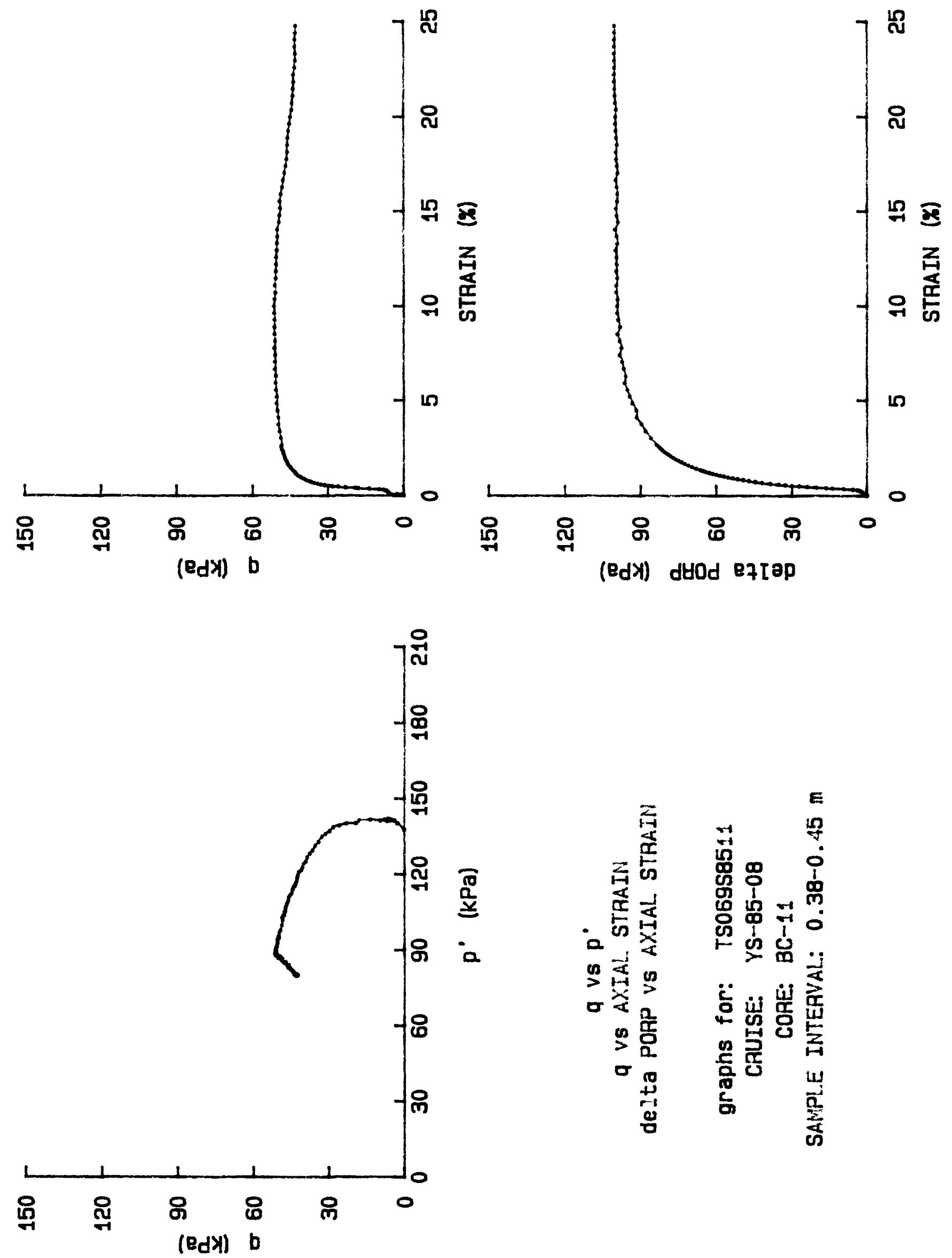

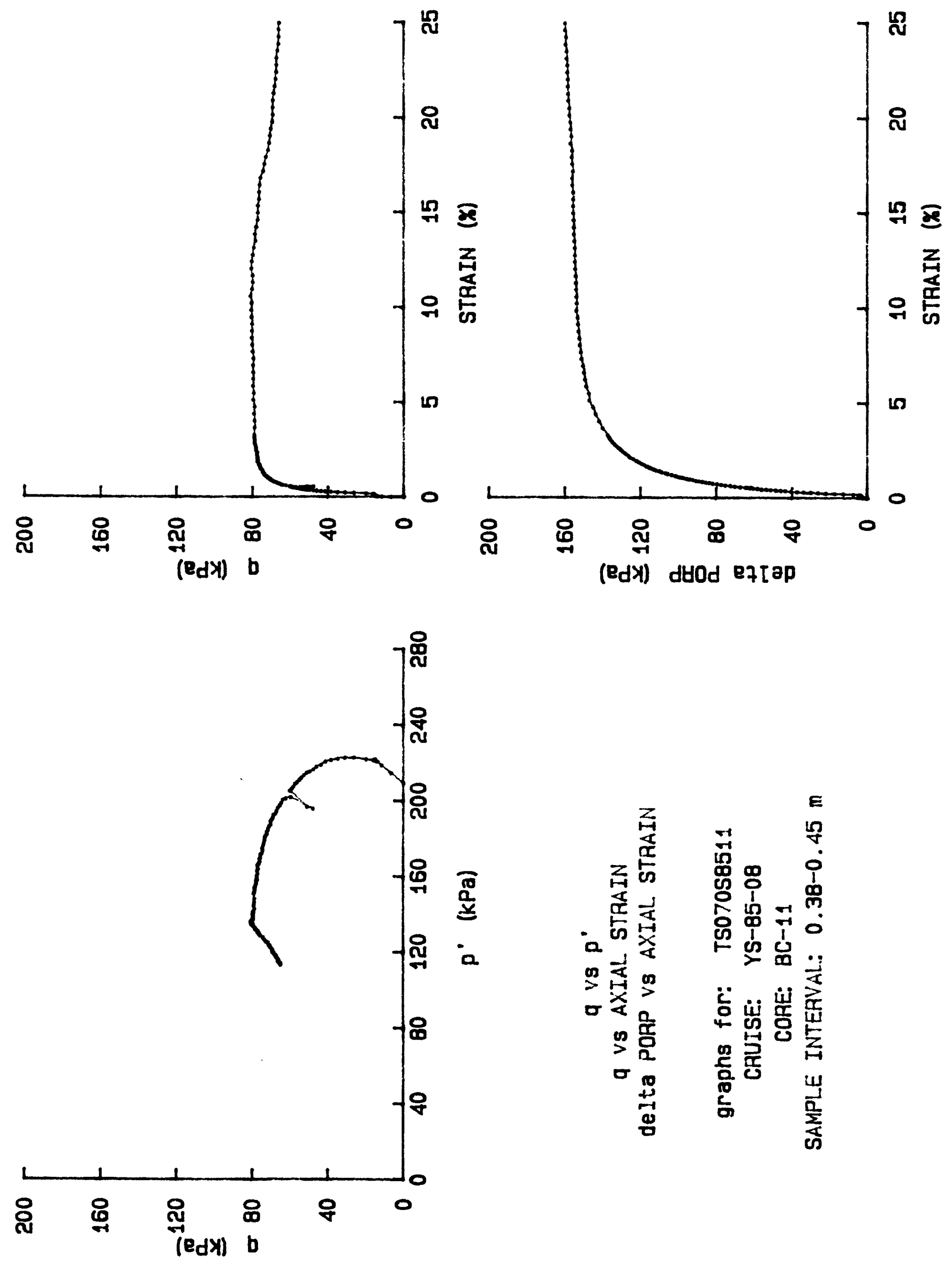
MULTIPLE TEST PLOTS 

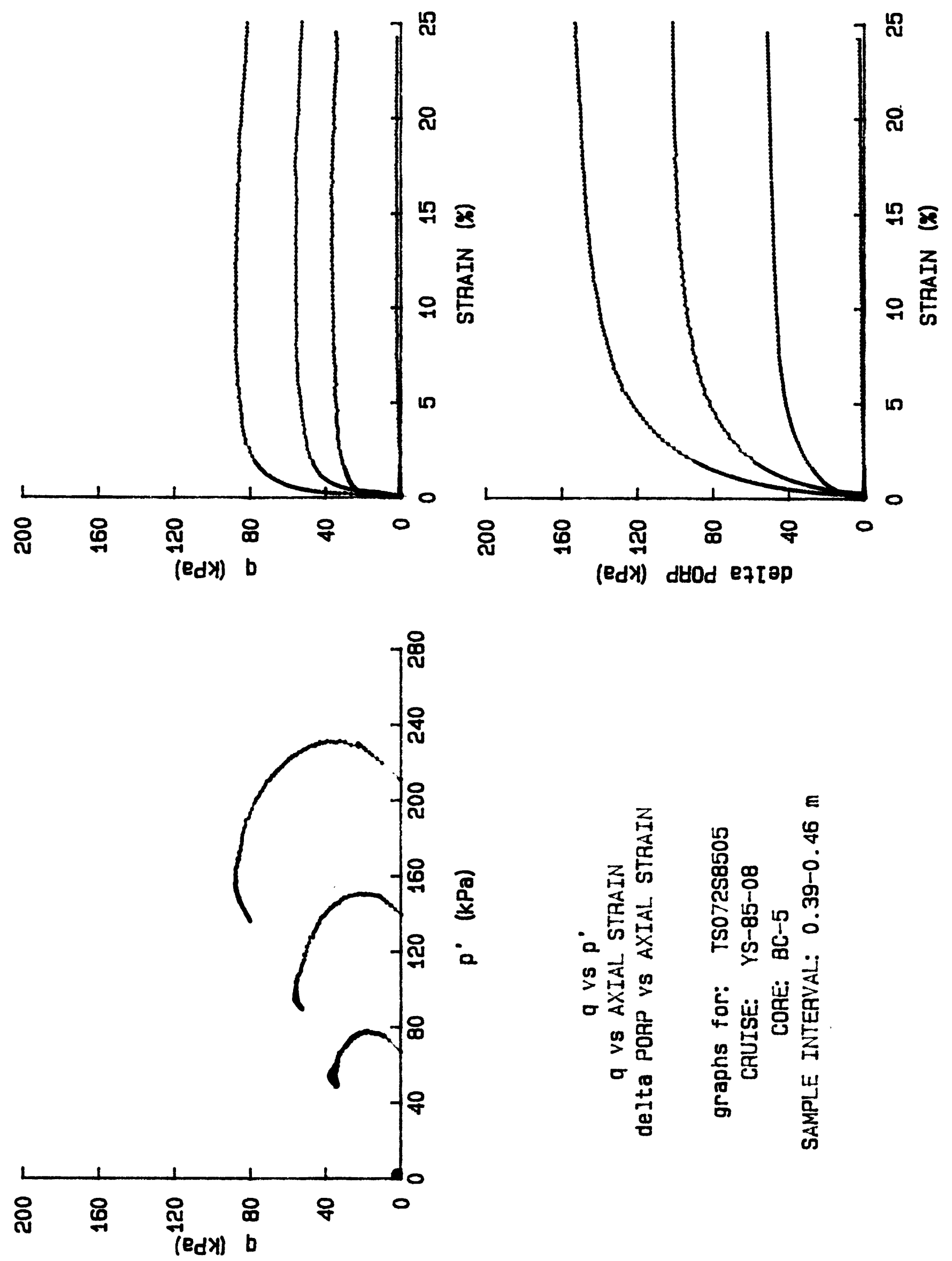


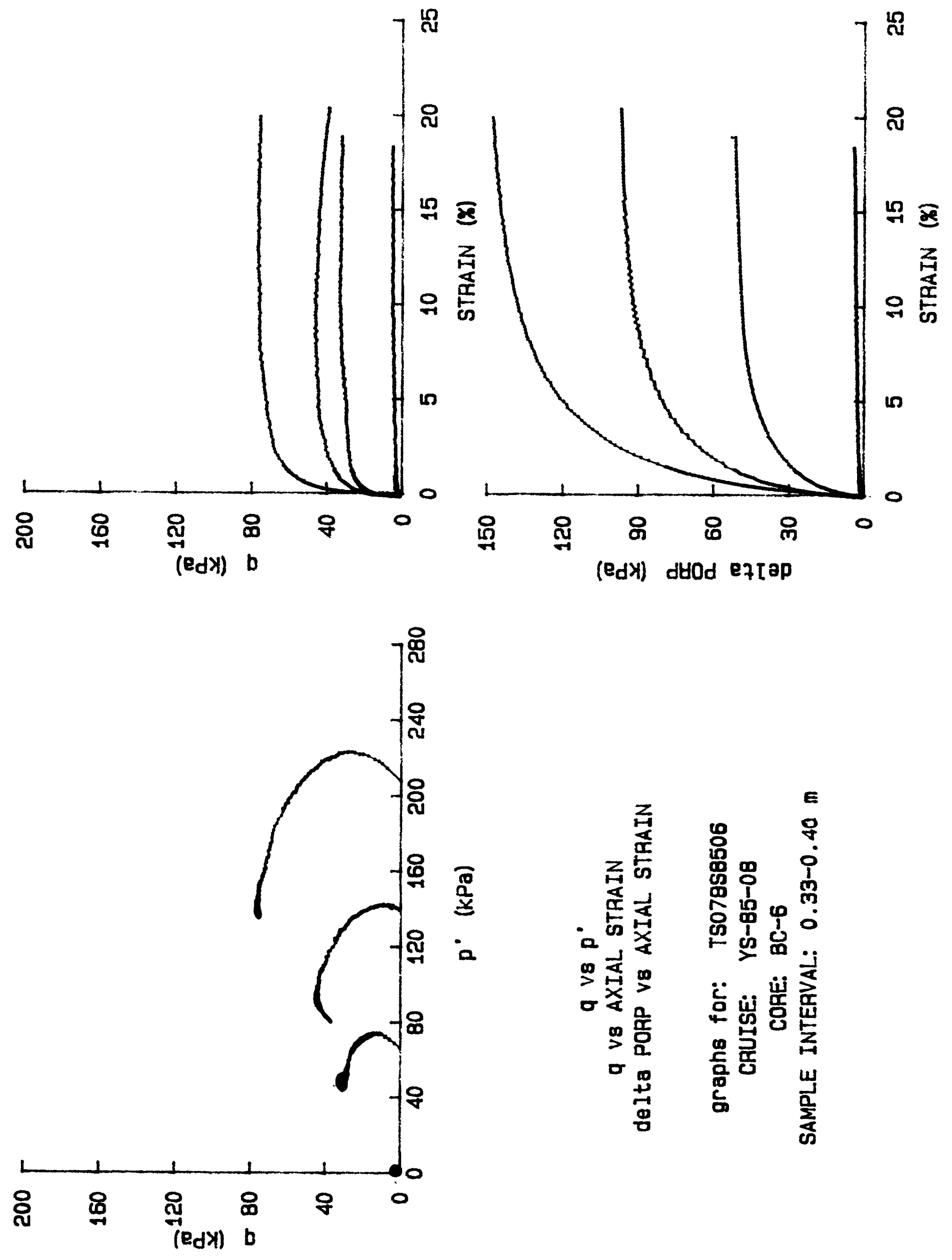



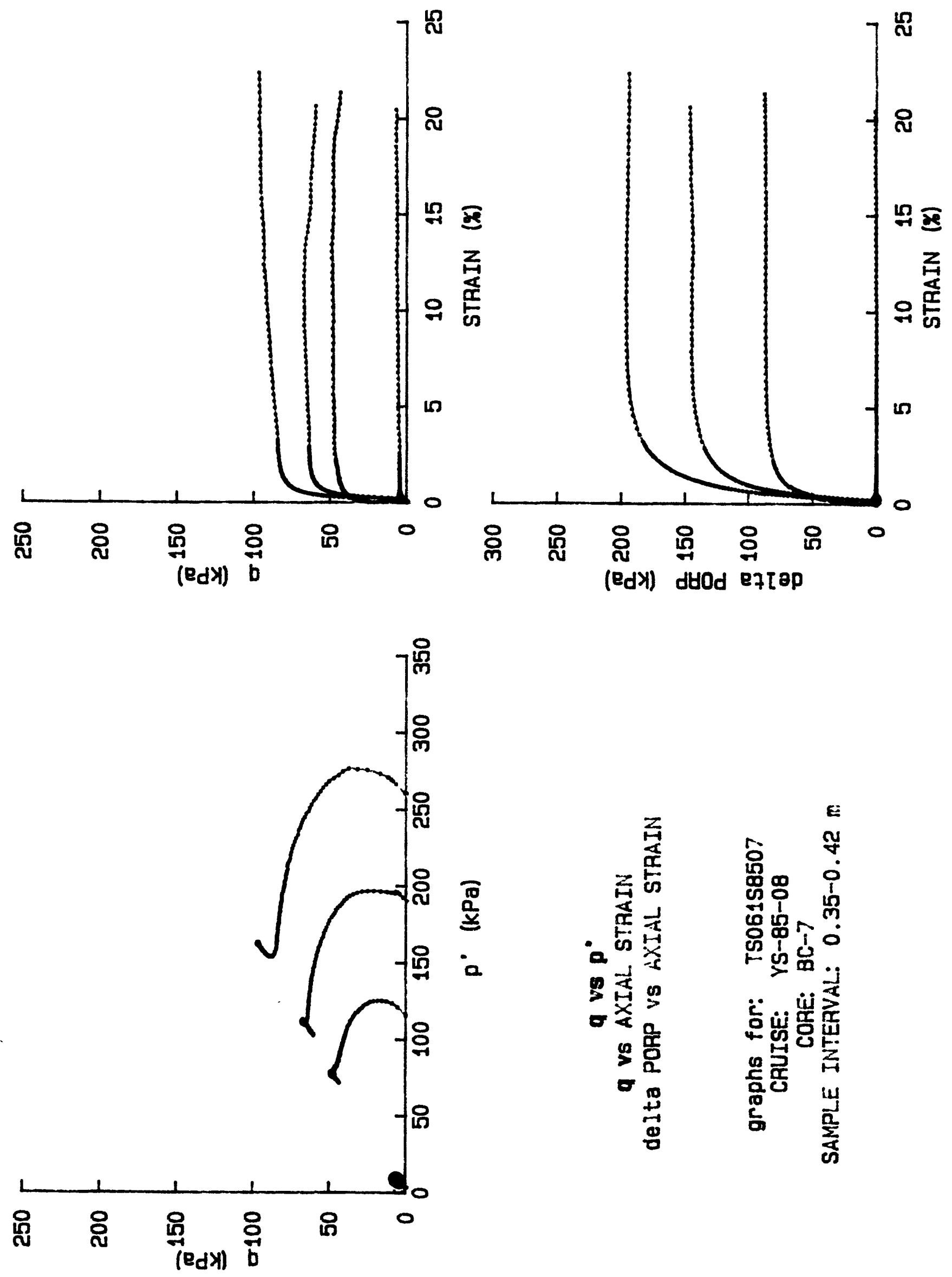

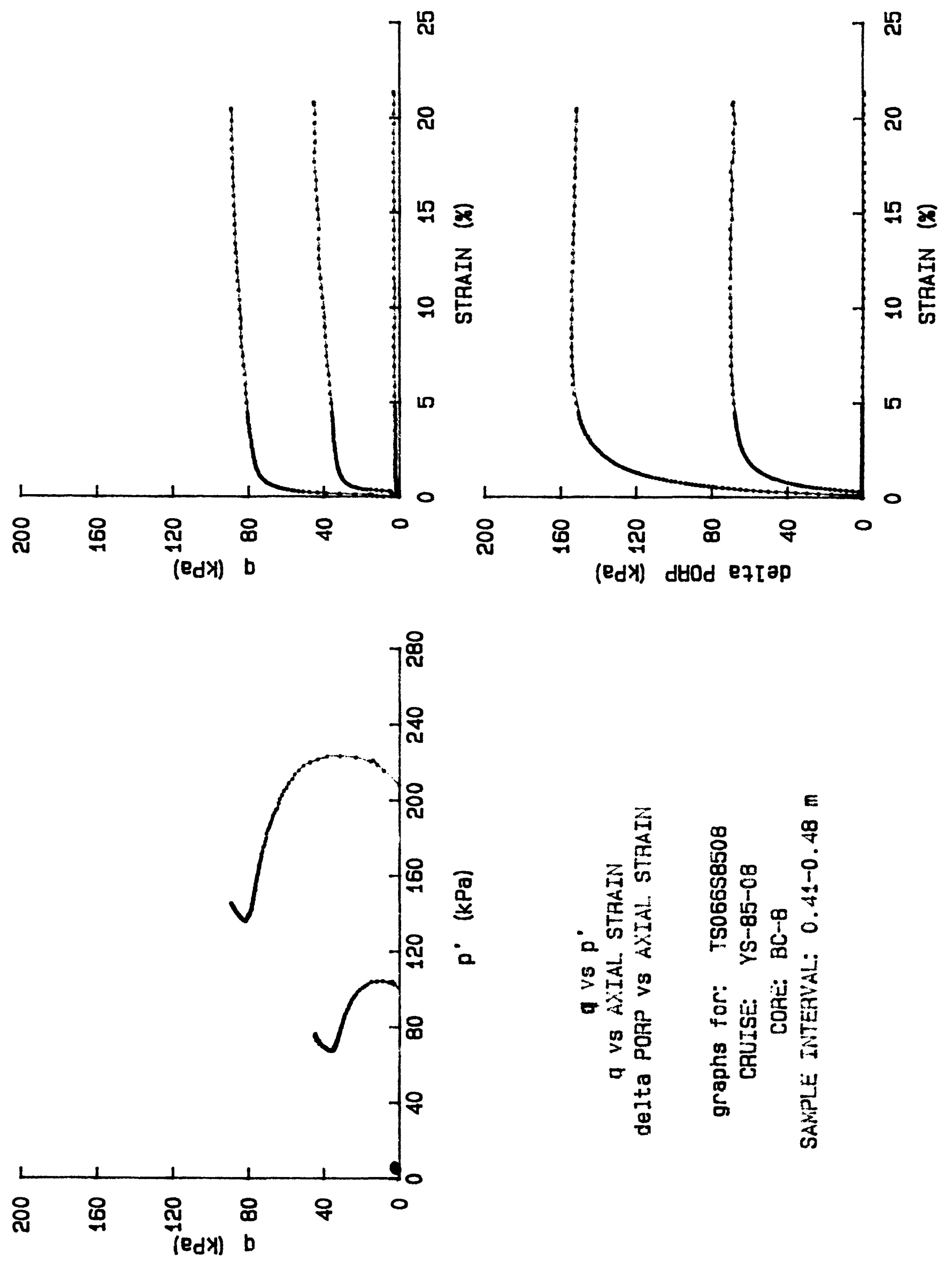

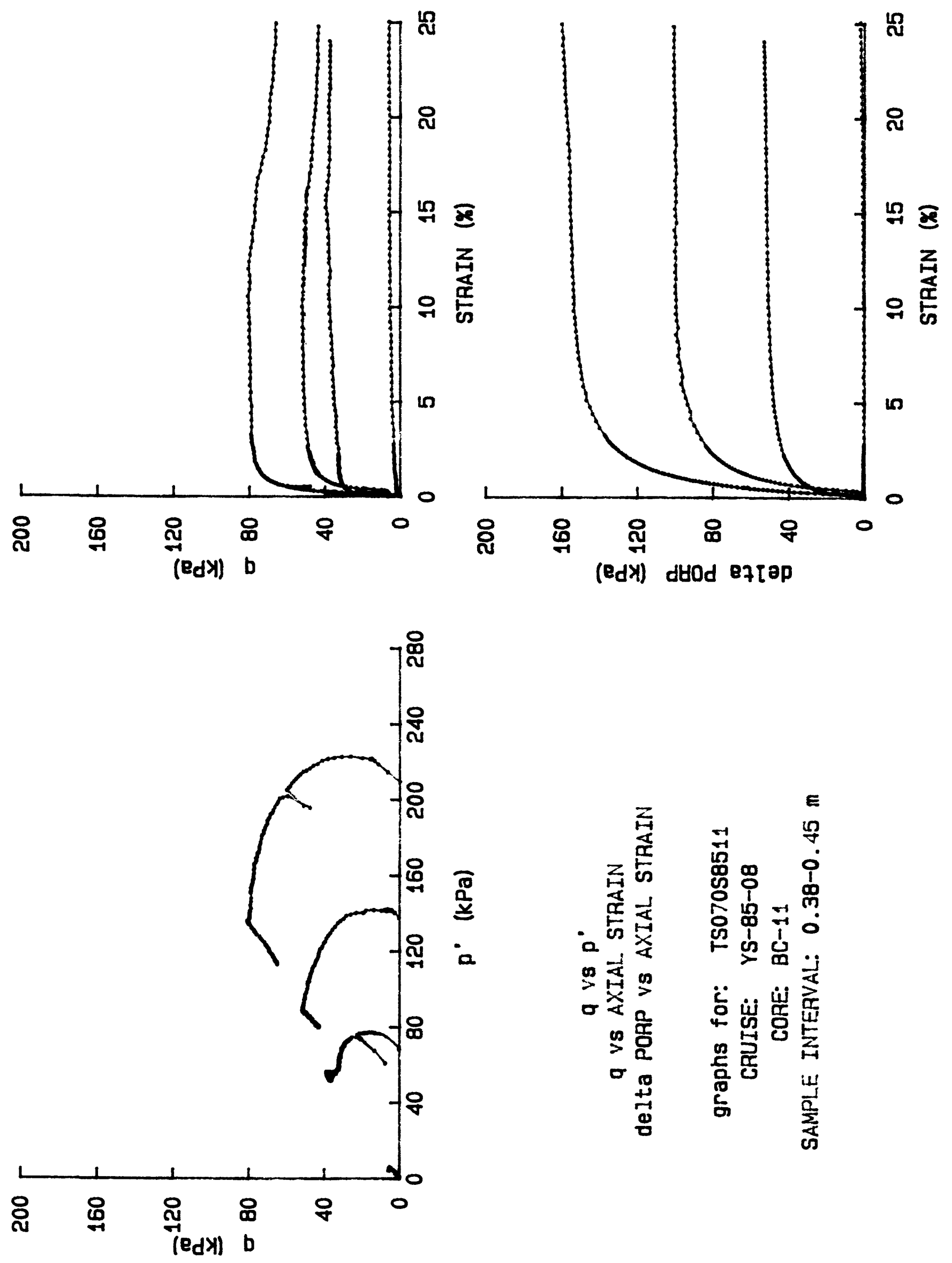